UNIVERSIDADE DE SÃO PAULO

FFCLRP - DEPARTAMENTO DE BIOLOGIA

PROGRAMA DE PÓS-GRADUAÇÃO EM ENTOMOLOGIA

\title{
"Filogenia de Leiinae (Diptera, Mycetophilidae) com uma nova proposta de classificação para a subfamília"
}

Sarah Siqueira de Oliveira

Tese apresentada à Faculdade de Filosofia, Ciências e Letras de Ribeirão Preto da USP, como parte das exigências para a obtenção do título de Doutor em Ciências, Área: Entomologia.

RIBEIRÃO PRETO - SP 


\author{
UNIVERSIDADE DE SÃO PAULO \\ FFCLRP - DEPARTAMENTO DE BIOLOGIA \\ PROGRAMA DE PÓS-GRADUAÇÃO EM ENTOMOLOGIA
}

\title{
"Filogenia de Leiinae (Diptera, Mycetophilidae) com uma nova proposta de classificação para a subfamília"
}

\author{
Sarah Siqueira de Oliveira \\ Orientador: Prof. Dr. Dalton de Souza Amorim
}

Tese apresentada à Faculdade de Filosofia, Ciências e Letras de Ribeirão Preto da USP, como parte das exigências para a obtenção do título de Doutor em Ciências, Área: Entomologia.

RIBEIRÃO PRETO - SP 


\section{FICHA CATALOGRÁFICA}

\section{Oliveira, Sarah Siqueira}

Filogenia de Leiinae (Diptera, Mycetophilidae) com uma nova proposta de classificação para a subfamília. Ribeirão Preto, 2013.

$$
\text { vii + 186p: } 332 \text { il. }
$$

Tese de Doutorado, apresentada à Faculdade de Filosofia, Ciências e Letras de Ribeirão Preto/USP. Área de concentração: Entomologia.

Orientador: Dr. Dalton de Souza Amorim

1. Leiinae. 2. Mycetophilidae. 3. Diptera. 4. Sistemática. 5. Chave de Identificação. 
Aos meus pais 


\section{SUMÁRIO}

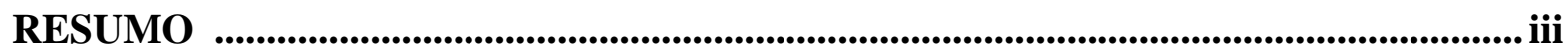

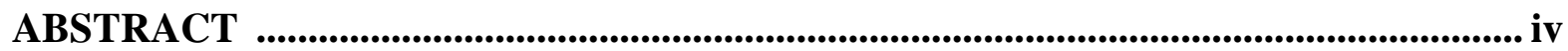

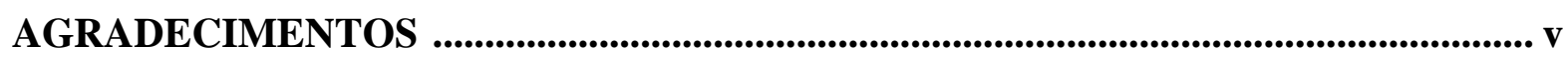

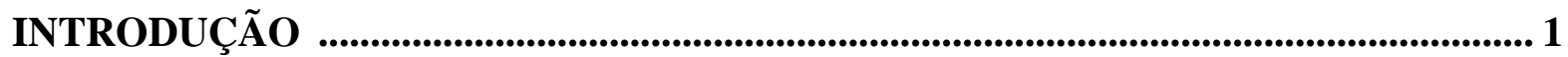

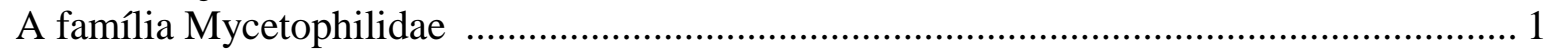

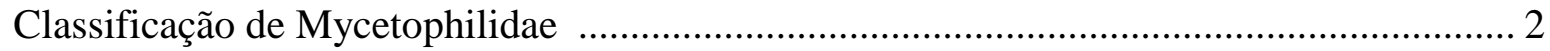

Classificação de Mycetophilidae e delimitação de Allactoneurinae e Leiinae ..................... 7

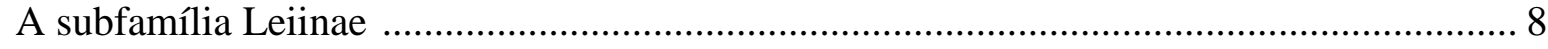

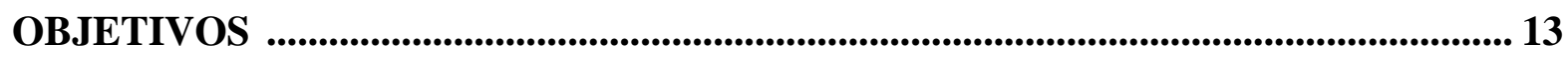

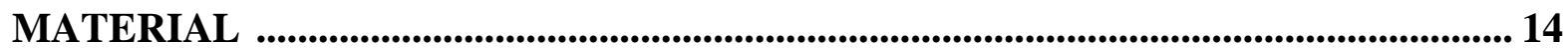

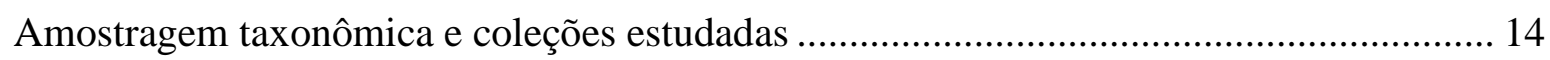

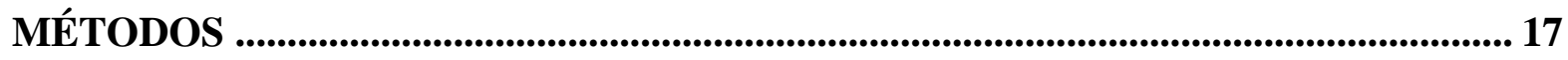

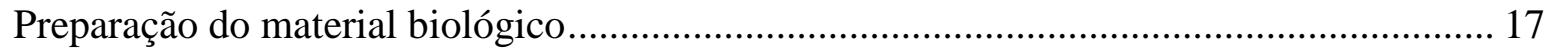

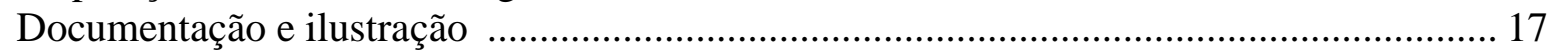

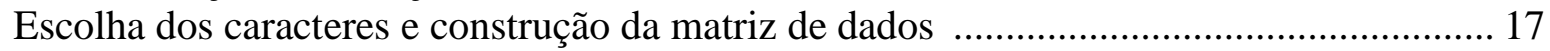

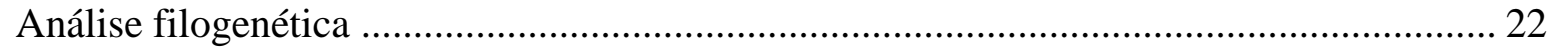

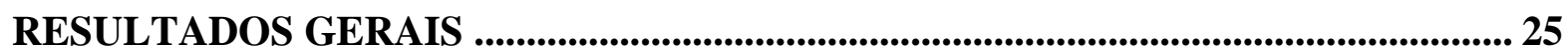

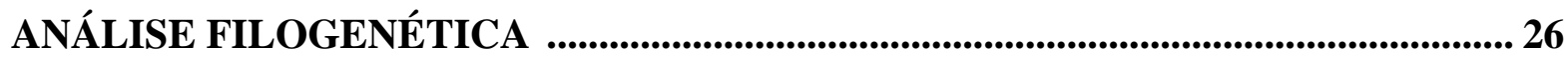

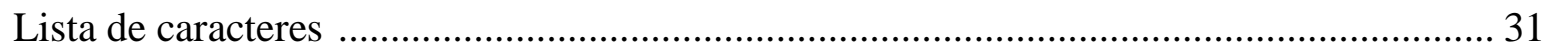

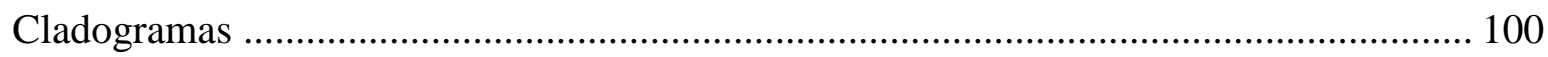

Leiinae como grupo monofilético e seus principais clados …........................................ 114

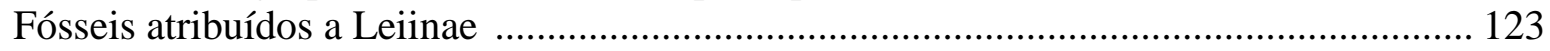

Docosia, Ectrepesthoneura, Novakia e Tetragoneura como membros de Gnoristinae .... 123

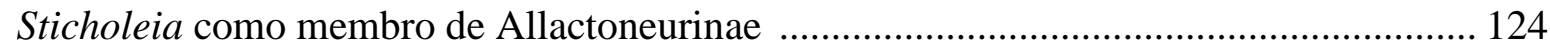

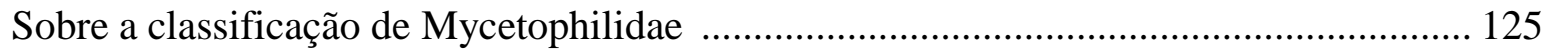

Chave de identificação para Leiinae e Allactoneurinae ................................................. 127

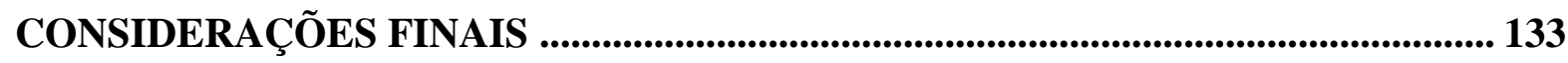

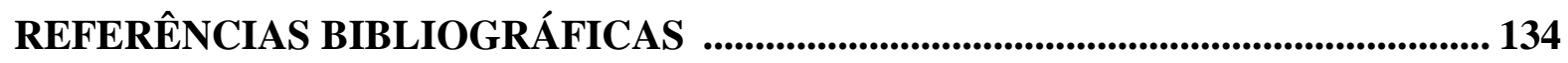

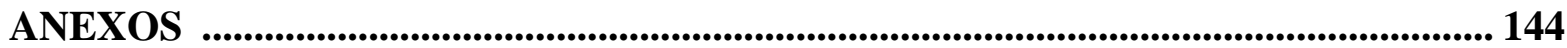

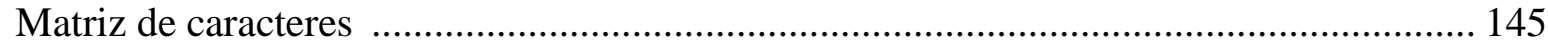

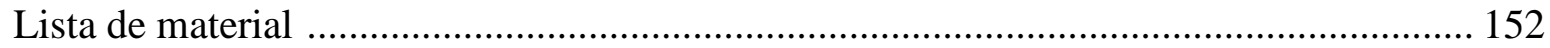

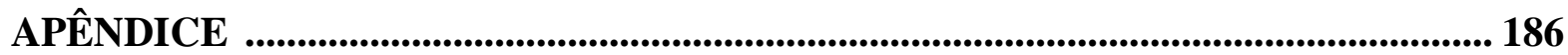


A família Mycetophilidae é a segunda mais especiosa da subordem Bibionomorpha (Diptera), abrangendo 233 gêneros e cerca de 4.500 espécies descritas de todas as regiões biogeográficas. A monofilia de Bibionomorpha e de Mycetophilidae é bem corroborada na literatura. A família de modo geral tem sido dividida nas subfamílias Sciophilinae, Gnoristinae, Mycomyiinae, Leiinae, Manotinae, Allactoneurinae, Mycetophilinae. Atualmente, uma das subfamílias que tem recebido menos atenção na literatura é Leiinae e o entendimento das relações entre seus gêneros é ainda incipiente. Essa subfamília compreende um grupo de gêneros caracterizados principalmente por um deslocamento da base do setor radial (Rs) em direção ao ápice da asa, resultando em uma $\mathrm{R}_{1}$ curta, mas há inúmeras exceções que levantam questionamentos sobre o monofiletismos do grupo e resultam em diferentes hipóteses sobre a inclusão ou não de determinados gêneros em Leiinae, como é o caso de Docosia Winnertz, Tetragoneura Winnertz, Ectepesthoneura Enderlein, Novakia Strobl, Sticholeia Søli, Aphrastomyia Coher \& Lane, entre outros. O objetivo deste trabalho foi estudar, com base em morfologia, as relações filogenéticas entre os gêneros de Leiinae, propondo limites genéricos para a subfamília. Para tanto, foram realizadas análises filogenéticas apenas com grupos viventes e com a adição de táxons fósseis. O estudo filogenético realizado indica que é possível atribuir a Leiinae um agrupamento monofilético relativamente amplo, caracterizado pela presença do mesopleurotrocantin e do mesepímero sem contato com a região ventral do tórax, terminando no mesopleurotrocantin. Os gêneros Docosia, Novakia, Ectrepesthoneura e Tetragoneura não fazem parte de Leiinae e são alocados provisoriamente em Gnoristinae. Sticholeia também não pertence à Leiinae, sendo grupo-irmão de Allactoneura e, portanto, transferido para Allactoneurinae. Leiinae passa a compreender 27 gêneros viventes. A análise realizada com fósseis não foi informativa filogeneticamente. 
The family Mycetophilidae is the second most diverse of the suborder Bibionomorpha (Diptera), with 233 genera and about 4.500 species known from all biogeographical regions. The monophyly of Bibionomorpha and Mycetophilidae is well corroborated in the literature. The family has been divided in the subfamilies Sciophilinae, Gnoristinae, Mycomyiinae, Leiinae, Manotinae, Allactoneurinae, Mycetophilinae. Currently, Leiinae is one of the subfamilies with less attention in the literature and the knowledge on the relationships between its genera is still incipient. This subfamily comprises a group of genera characterized by a displacement of the base of the radial sector (Rs) towards the wing apex, resulting in a short $R_{1}$. There are several exceptions that point in doubts the monofiletism of the group and result in different assumptions on the inclusion or not of certain genera in Leiinae, as Docosia Winnertz, Tetragoneura Winnertz, Ectepesthoneura Enderlein, Novakia Strobl, Sticholeia Søli, Aphrastomyia Coher \& Lane, among others. The aim of this study was recover the phylogenetic relationships among the Leiinae genera, based on morphology, proposing generic limits for the subfamily. Thus, phylogenetic analyzes were performed with living genera and with the addition of fossil taxa. The phylogenetic analysis indicates that Leiinae is a monophyletic group, characterized by the presence of mesopleurotrochantin and the mesepimeron not reaching the ventral region of the thorax, ending in the mesopleurotrochantin. The genera Docosia, Novakia, Ectrepesthoneura, and Tetragoneura not belongs to Leiinae and are temporalily allocated in Gnoristinae. Sticholeia is not a member of Leiinae as well being sister group of Allactoneura and thus is transferred to Allactoneurinae. Leiinae now comprises 27 living genera. The analysis performed with fossils was not phylogenetically informative. 
"A tese, o meu trabalho, no fundo não é apenas uma atividade literária, mas sim uma forma apaixonante, real, muito real, de viver a vida." (Modificado de "As palavras de Saramago: catálogo de reflexões pessoais, literárias e políticas”, Companhia das Letras, 2010).

A tese final é resultado de um esforço pessoal intenso e não seria desenvolvida em sua plenitude sem o apoio de familiares, amigos e colegas de trabalho no Brasil e no exterior.

Meus pais, Neliton e Lenira, são e sempre serão meu exemplo maior e o trabalho aqui resultante é uma das formas diárias de agradecimento por todo amor, paciência, auxílios emocional e financeiro e incentivo, essenciais para que cada dia termine com a sensação de prazer, alegria e gratidão. Mas os meus dias não seriam os mesmos sem a presença dos meus irmãos, Laura, Iara e Rodolfo, minha avó, Maria Isabel, e meu marido, Renato, que sempre me apoiaram e acompanharam, mesmo nos períodos mais distantes, tornando cada minuto mais alegre e interessante de ser vivido. Amo muito vocês!

Esse trabalho não seria possível sem o carinho, a paciência, a amizade e a orientação do professor Dr. Dalton de Souza Amorim. Com o Dalton aprendi que as piores piadas merecem uma boa risada e que as piores ideias podem resultar em boas piadas ou em excelentes trabalhos com esforço e orientação. Muito obrigada!

A tese resultante está aqui e deve muito, muitíssimo, à Maria Isabel P.A. Balbi, Bel, pessoa inestimável e muito especial, a quem venho exprimir publicamente os meus mais profundos agradecimentos e também a expressão da minha estima e do meu maior respeito. Não poderia deixar de agradecer também ao Renato S. Capellari, Renatinho, meu companheiro de viagens e visitas a instituições no Brasil e no exterior, pela convivência agradável e descontraída, por tornar as visitas mais interessantes e fazer com o tempo fora de casa não se tornasse um martírio e sim uma experiência ímpar para a vida toda. Muitíssimo obrigada!

Gostaria de agradecer aos colegas do laboratório e agregados pelo convívio, amizade, troca de experiências, momentos de descontração, cafezinhos e discussão de idéias: Danilo C. Ament, Maria Isabel P.A. Balbi, Paula R. Riccardi, Caleb C. Martins, Diego A. Fachin, Renato S. Capellari e Juliana M. Feres, Gabriela P. Ignácio, Diego S. Porto, Lucas S. Lecci, Rafael A. Moretto, Zioneth Garcia, Maria V. Urso-Guimarães, Rafaela L. Falaschi, Mateus 
H. Santos, Vera C. Silva, Guilherme C. Ribeiro, Adolfo R. Calor, Charles M.D. dos Santos, Eduardo A.B. Almeida, Nelson e Tatiana Papavero e Flávio A. Bockmann.

Agradeço aos pesquisadores de diferentes instituições que colaboraram com literatura e doação de material essenciais para o desenvolvimento deste trabalho: Eirik Rindal, Mathias Jaschhof, Olavi Kurina, Peter Kerr, Heikki Hippa, Peter Chandler, Jan Ševcík, Mitsuhiro Sasakawa, Vladimir Blagoderov e Neal Evenhuis. Àqueles que colaboram com coletas e viagens de campo: Rudolph Meyer, Brian Brown, Giar-Ann Kung, Wendy Porras, Sue Cumming. E aos curadores de todos os museus que emprestaram material necessário para o desenvolvimento deste trabalho: Erica McAlister (NHM), Christophe Daugeron (MNHN) (por intermédio de Rafaela Lopes Falaschi), Pekka Vilkamaa (FMNH), Michael Sharkey (IAvH), Cláudio B. Carvalho (DZUP).

A todos os curadores, estudantes e pesquisadores que foram muito receptivos e amáveis em todas as instituições que visitei: Orlando Tobias (MPEG), Jacqueline Recsei, Dave Britton, Dan Bickel, Shane McEvey, David McAlpine, Russel Cox, Chris Reid e Scott (AMSA, Sidney, Australia); Don Colless, David Yeates, Chris Manchester, Penny Gullan, Peter Cranston e Beth Mantle (ANIC, Canberra, Australia); Burgert Muller, Daleen Muller e Mikhail Mostovski (NMSA, Pietermaritzburg, África do Sul); Dawn Larsen e Simon Von Noort (SAMC, Cidade do Cabo, África do Sul); Ross Urban (SANC, Pretória, África do Sul); Manoel Zumbado (INBio, San José, Costa Rica); Norman Penny (CAS, Sacramento, EUA); Scott Brooks, James O'Hara, Jeff Cumming, Jeff Skevington, Bradley Sinclair, Monty Wood (CNC, Ottawa, Canadá); Peter Kerr, Chris Borkent, Martin Hauser, Alessandra Rung, Shaun Winterton, Steve Gaimari e Li Shi (CDAF, Sacramento, EUA), e, em especial, ao professor Dr. Carlos Einicker Lamas, por me receber sempre de forma tão agradável todas as vezes que visitei o MZUSP.

Aos colegas do INPA e de outras instituições brasileiras pela companhia sempre agradável e alegre em nossas viagens desbravando a Amazônia do Amazonas: José Albertino Rafael, Augusto Loureiro, Rosa e Roger Hutchings, Catarina Motta, Márcio Oliveira, Rosaly Ale-Rocha, Josenir Câmara, Valdeana Linard, Renato Machado, Edgar Alvim, Rafael Silva, Priscila Dias, Daniela Takiya, Cristiano Schwertner, Mirna Casagrande, Olaf Mielke, Monique Motta, Rodney Chavichioli, Antônio Agudelo, Ricardo Andreazze, Francisco Felipe, José Maria Vilhena, Luís, Loy, Eduardo Amat, Veracilda Ribeiro.

Gostaria de agradecer à Pós-Graduação em Entomologia e ao Departamento de Biologia da Faculdade de Filosofia, Ciências e Letras de Ribeirão Preto pela estrutura disponibilizada e aos funcionários da Universidade de São Paulo por todo apoio ao longo de 
minha passagem pela pós-graduação: Renata A. Cavallari, Vera C.C. de Lucca, Miriam Osório, Carlos Almada, Juliano O. Marquetti, César P. Brites, Denise A. Silveira, Maria Fabiana C. Tavares, Maria Inês Joaquime, Dona Cidinha, José A.T. Filho.

Sou muito grata também ao AMSA pelo "Geddes Postgraduate Awards", e em especial ao Dr. Daniel Bickel pela supervisão e apoio. Aos projetos de pesquisa que disponibilizaram material indispensável para a execução deste trabalho: Projeto Temático Biota "Limites geográficos e fatores causais de endemismo na Floresta Atlântica em Diptera" (FAPESP 2003/12.074-9); a rede temática SISBIOTA "Diptera dos estados do Mato Grosso, Mato Grosso do Sul e Rondônia: diversidade, sistemática e limites distribucionais" (SISBIOTA CNPq 563256/2010-9/ FAPESP 2010/52314-0); "Diversidade e endemismo de Diptera (Insecta) em um fragmento de Floresta Atlântica Semidecídua, em Sertãozinho, SP” (FAPESP 2009/54.497-8); PRONEX “Amazonas: diversidade de insetos ao longo de suas fronteiras" (FAPEAM/CNPq 016/2006). À FAPESP pelo auxílio concedido (processo 2008/52324-6).

$$
\begin{gathered}
\text { Português = Muito obrigada! } \\
\text { Espanhol = Gracies! } \\
\text { Inglês = Thank you! } \\
\text { Alemão = Vielen danken! } \\
\text { Africanner = Bá Dankie! } \\
\text { Zulu = Ngiyabonga! } \\
\text { Francês = Merci beaucoup! } \\
\text { Italiano = Grazie! } \\
\text { Tcheco = Děkuji! } \\
\text { Norueguês = Takk! } \\
\text { Estôniano = Aitäh! } \\
\text { Finlandês = Kiitos! } \\
\text { Japonês = Arigato! }
\end{gathered}
$$




\section{A família Mycetophilidae}

Mycetophilidae (Diptera) é a segunda mais numerosa e diversificada família da subordem Bibionomorpha, com 233 gêneros e cerca de 4.500 espécies descritas de todas as regiões biogeográficas (Pape et al., 2011). Há registros fósseis para Mycetophilidae desde o Cretáceo (Evenhuis, 1994; Amorim \& Silva, 2002). Membros da família são conhecidos de todos os continentes exceto a Antártida. Embora a maioria dos gêneros se encontre em áreas frias e temperadas (Søli et al., 2000; Rindal \& Søli, 2006), a maioria das espécies de micetofilídeos está em áreas tropicais e/ou subtropicais. Isto é, os gêneros tropicais, menos numerosos, são mais especiosos que os gêneros temperados.

$\mathrm{Na}$ região Neotropical, há 41 gêneros e cerca de 1.000 espécies conhecidas de Mycetophilidae. As espécies foram descritas principalmente por F.W. Edwards, Paul Freeman, John Lane e José Pedro Duret (Papavero, 1978; Oliveira \& Amorim, em preparação). No entanto, a riqueza da família na Região Neotropical (o que se aplica a algumas das outras) é muito maior que os dados atuais mostram. Alguns trabalhos apontam que o número de espécies conhecidas para Diptera na Região Neotropical em algumas famílias pode ser até dez vezes maior que a diversidade atualmente conhecida desses grupos (Brown, 2005). Trabalhos publicados recentemente sobre Mycetophilidae nas regiões Neotropical e Australiana (Amorim \& Oliveira, 2008; Amorim et al., 2008a,b; Oliveira \& Amorim, 2010a,b; Oliveira \& Amorim, 2011; Oliveira \& Amorim, 2012a,b) fizeram com que o número de espécies conhecidas de alguns gêneros dobrasse ou quadruplicasse, em um esforço de descrição ainda parcial.

Muitas espécies de Mycetophilidae são pequenas, mas algumas podem chegar a mais de $10 \mathrm{~mm}$ de comprimento. Geralmente apresentam coloração com uma combinação de marrom, preto e amarelo (Hutson et al., 1980). Larvas de modo geral alimentam-se de micélios, esporóforos ou hifas penetrando em material orgânico vegetal em decomposição, principalmente troncos. Os adultos são encontrados com frequência em lugares escuros, bosques úmidos, túneis e sistema radicular de árvores. Apresentam pico de atividade ao amanhecer e muitos são atraídos pela luz (Hutson et al., 1980). Representantes de muitos gêneros são frequentemente capturados em armadilhas Malaise e pitfall. Gêneros de algumas subfamílias são atraídos para armadilhas Shannon com frutas fermentadas utilizadas como 
iscas (Lane, 1959; obs. pess.). Há um caso não publicado de uma espécie de Sciophila Meigen que emergiu de galha (Valéria Cid Maia, dado não publicado).

Em um estudo sobre estratificação florestal nos Apalaches, Estados Unidos da América, foi verificada a distribuição não aleatória de diferentes espécies de Mycetophilidae em três regiões da copa de Tsuga Canadensis (L.) associadas à incidência de iluminação natural (Coots et al., 2012). Apenas indivíduos adultos foram coletados, indicando que pode haver algum tipo de comportamento migratório dentro do grupo para locais com temperatura adequada, humidade, fontes de alimentos e proteção contra inimigos naturais (Coots et al., 2012). Os micetofilídeos são comuns em florestas e a questão da continuidade entre fragmentos florestais exerce forte impacto na composição faunística da família. O ciclo de vida, em especial dos imaturos, está associado à presença de corpos de frutificação de fungos, de modo que a precipitação corresponde a um fator importante no controle populacional do grupo (Økland, 1994, 1996; Økland et al., 2005).

\section{Classificação de Mycetophilidae}

Mycetophilidae forma, juntamente com outras sete famílias recentes, os Mycetophiliformia (Hennig, 1973; Amorim \& Rindal, 2007). Há conflitos entre alguns autores acerca da filogenia do grupo (Søli, 1997a; Tozoni 1998; Rindal et al. 2009a), mas a monofilia de Bibionomorpha e de Mycetophiliformia são hipóteses bem corroboradas (Wood \& Borkent, 1989; Amorim \& Rindal, 2007). As diferentes hipóteses de relacionamento para grupo podem ser encontradas em Amorim \& Rindal (2007: 55, 69) e há poucas dúvidas de que Lygistorrhinidae seja o grupo-irmão de Mycetophilidae (figura 1).

Não há dúvidas sobre o monofiletismo de Mycetophilidae (figuras 2-4) (Søli, 1997a; Tozoni, 1998; Rindal et al., 2009a). A família inclui agrupamentos recentemente tratados como subfamílias: Sciophilinae, Gnoristinae, Mycomyiinae, Leiinae, Manotinae, Allactoneurinae e Mycetophilinae (Tozoni, 1998; Chandler, 2009; Rindal et al., 2009a; Amorim \& Oliveira, 2008; Oliveira \& Amorim, 2010a,b; Oliveira \& Amorim 2012a). As classificações de Vockeroth $(1981,2009)$ e Matile (1990) optaram por apenas duas subfamílias-Sciophilinae e Mycetophilinae, a primeira composta pelos táxons ao nível de tribo Sciophilini, Gnoristini, Mycomyini, Manotini, Allactoneurini e Leiini, e a segunda pelas tribos Mycetophiliini e Exechiini. Metanepsini, cujo posicionamento voltou a ser recentemente questionado (Ševčik \& Hippa, 2010), deve ser um clado menor dentro de Gnoristinae e mesmo seu status de tribo é questionável (Kallweit, 1998). 


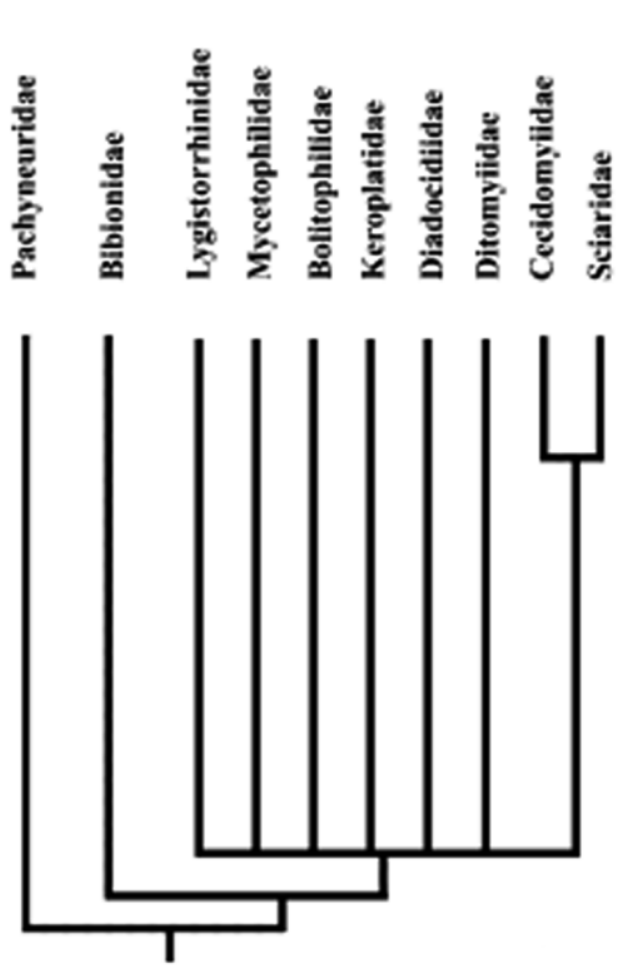

Wood \& Borkent (1989)

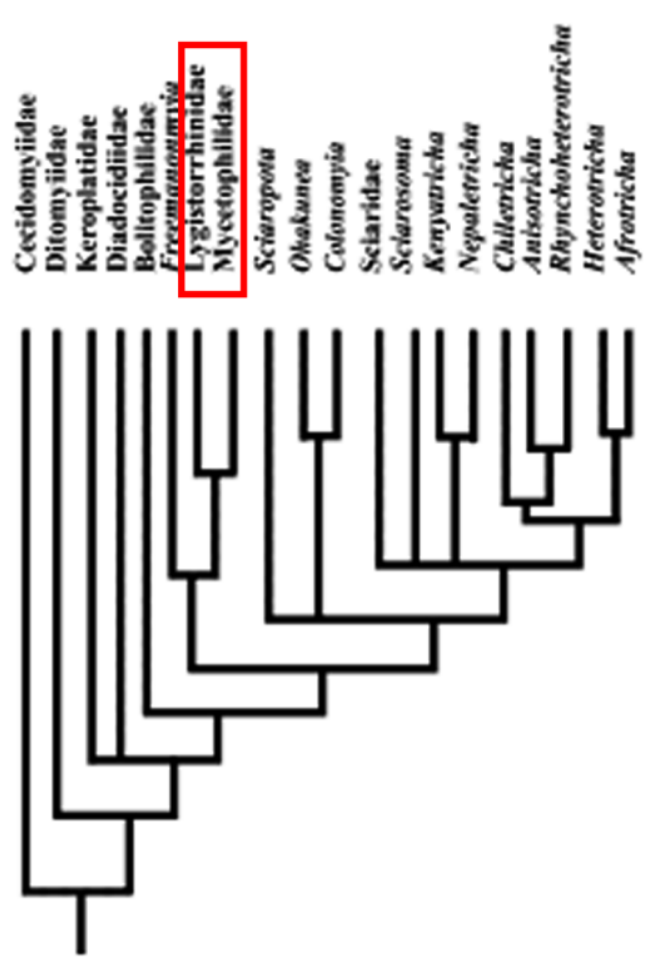

Chandler (2002)

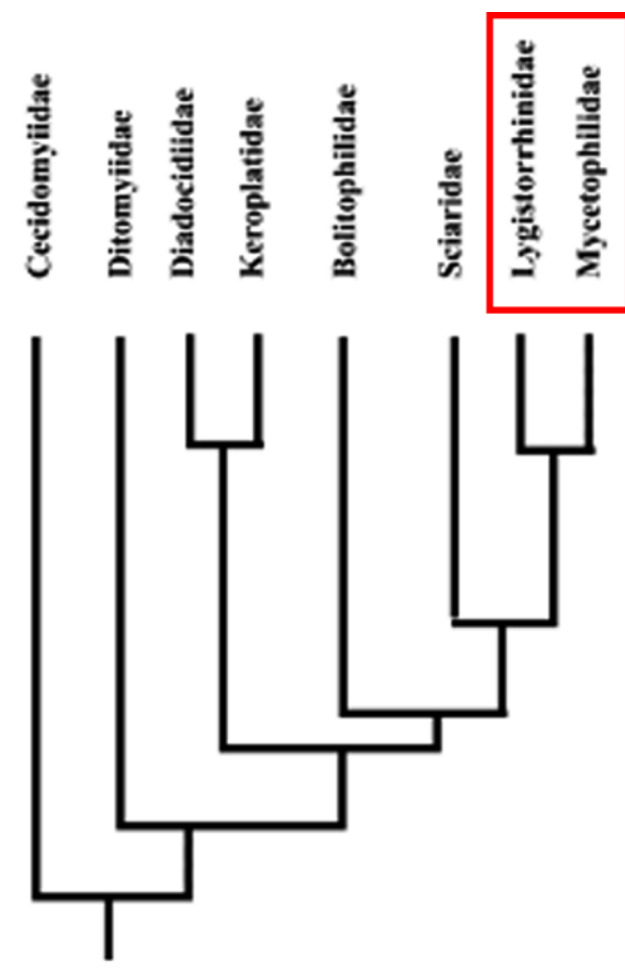

Matile (1990)

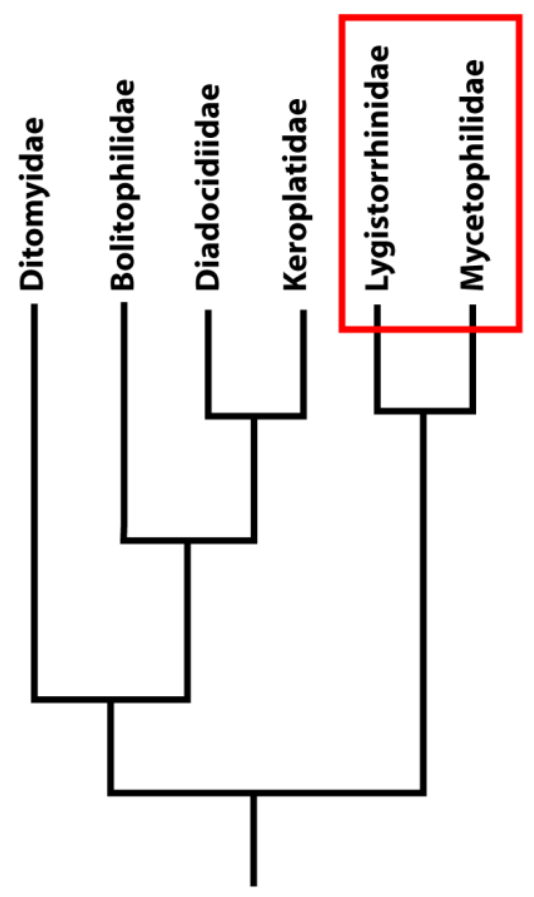

Amorim \& Rindal (2007)

Figura 1. Relações filogenéticas para Mycetophiliformia. Modificado de Amorim \& Rindal, 2007: 55, 69. 


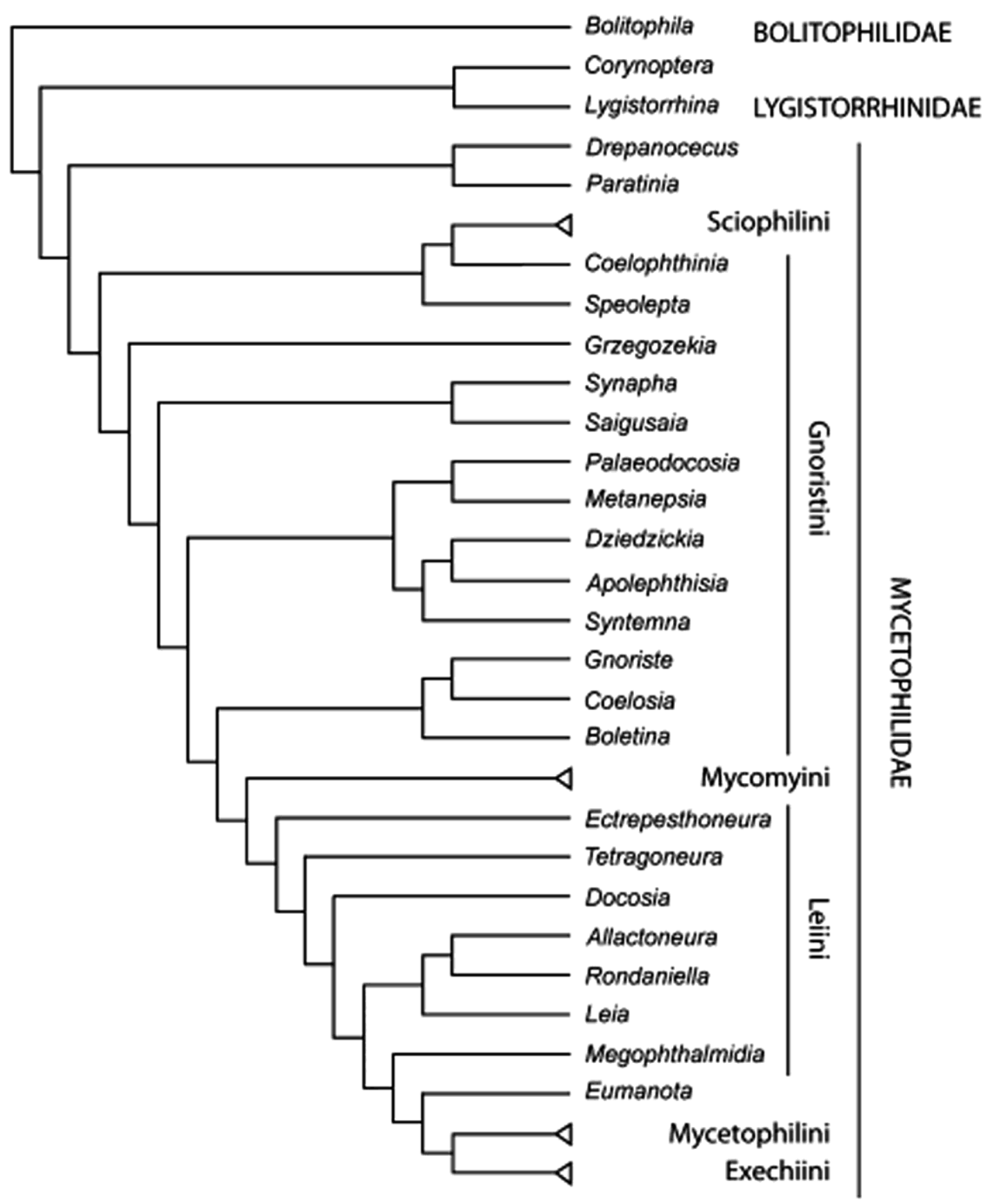

Figura 2. Relações filogenéticas para Mycetophilidae de Søli (1997a), dados morfológicos. Modificado de Rindal \& Søli, 2009a: 525.

A maior parte da evidência filogenética morfológica (figura 2-3) (Søli, 1997a; Tozoni, 1998) e molecular (figura 4) (Rindal et al., 2009a) indica que Sciophilinae sensu Matile, seja parafilético, de maneira que se aceita aqui a classificação com sete subfamílias, propostas anteriormente por Edwards (1925), Tuomikoski (1966), Hening (1973) e Väisänen (1984). O uso de distintas subfamílias para esses clados evita induzir a falsa ideia de que Sciophilinae s.l. seja monofilético e permite, mesmo aceitando que a definição das 
subfamílias ainda possa sofrer ajustes, expressar melhor o conhecimento sobre as relações entre os grupos de Mycetophilidae.

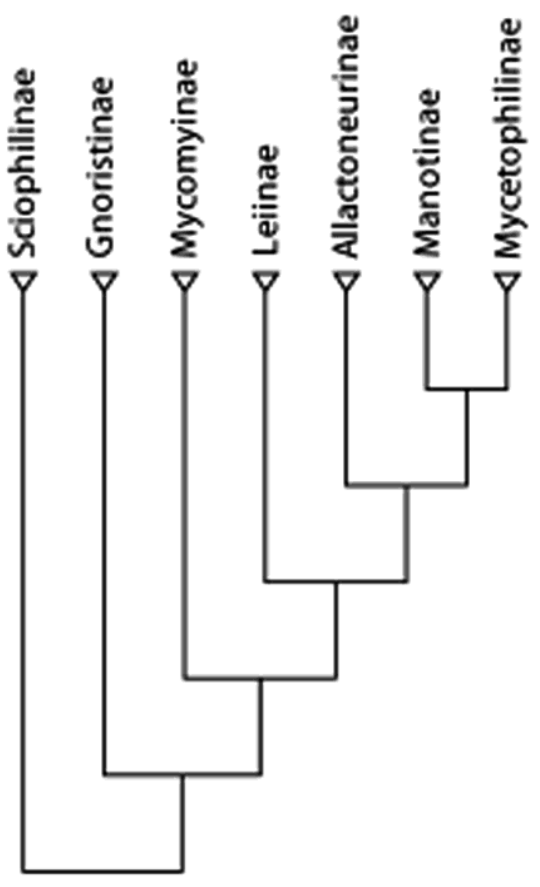

Figura 3. Relações filogenéticas para Mycetophilidae de Tozoni (1998), dados morfológicos. Modificado de Rindal \& Søli, 2009a: 526.

Quase todas as subfamílias de Mycetophilidae apresentam ampla distribuição no mundo. Allactoneurinae, com um único gênero, está ausente na região Neotropical. Manotinae, caracterizada por espécies com uma série de reduções na venação alar, é representada por um único gênero na região Neotropical, embora alguns gêneros sejam endêmicos da Região Oriental—um estudo filogenético de Manotinae foi realizado por Hippa et al. (2004) (figura 5). Sciophilinae s.s. de modo geral inclui gêneros com cerdas na membrana alar e mediotergito pubescente. Uma proposta de relações filogenéticas para a subfamília pode ser encontrada em Borkent \& Wheeler (no prelo). Os Gnoristinae são bastante diversos nas regiões Neártica e Paleártica, mas a subfamília é pobre na Região Neotropical em termos de gênero (quatro) e em termos de espécies. A filogenia do grupo está sendo estudada atualmente por Christopher Borkent (com. pess.). Os Mycomyiinae compreendem gêneros nos quais as microtríquias formam arranjos regulares nas tíbias, contendo um número pequeno de gêneros, cada um com uma grande quantidade de espécies. Coher (1950, 1952) realizou um amplo estudo de Mycomya Rondani, propondo vários subgêneros. Não há filogenias propostas sobre a subfamília como um todo. Os Mycetophilinae apresentam as microtríquias da asa arranjadas em fileiras relativamente regulares. Filogenias para os gêneros da subfamília foram propostas por Rindal \& Søli 
(2006) e Rindal et al. (2007, 2009b). Por fim, os Leiinae compreendem gêneros que compartilham o deslocamento da base do setor radial (Rs) em direção ao ápice da asa, resultando em um encurtamento evidente de $\mathrm{R}_{1}$.

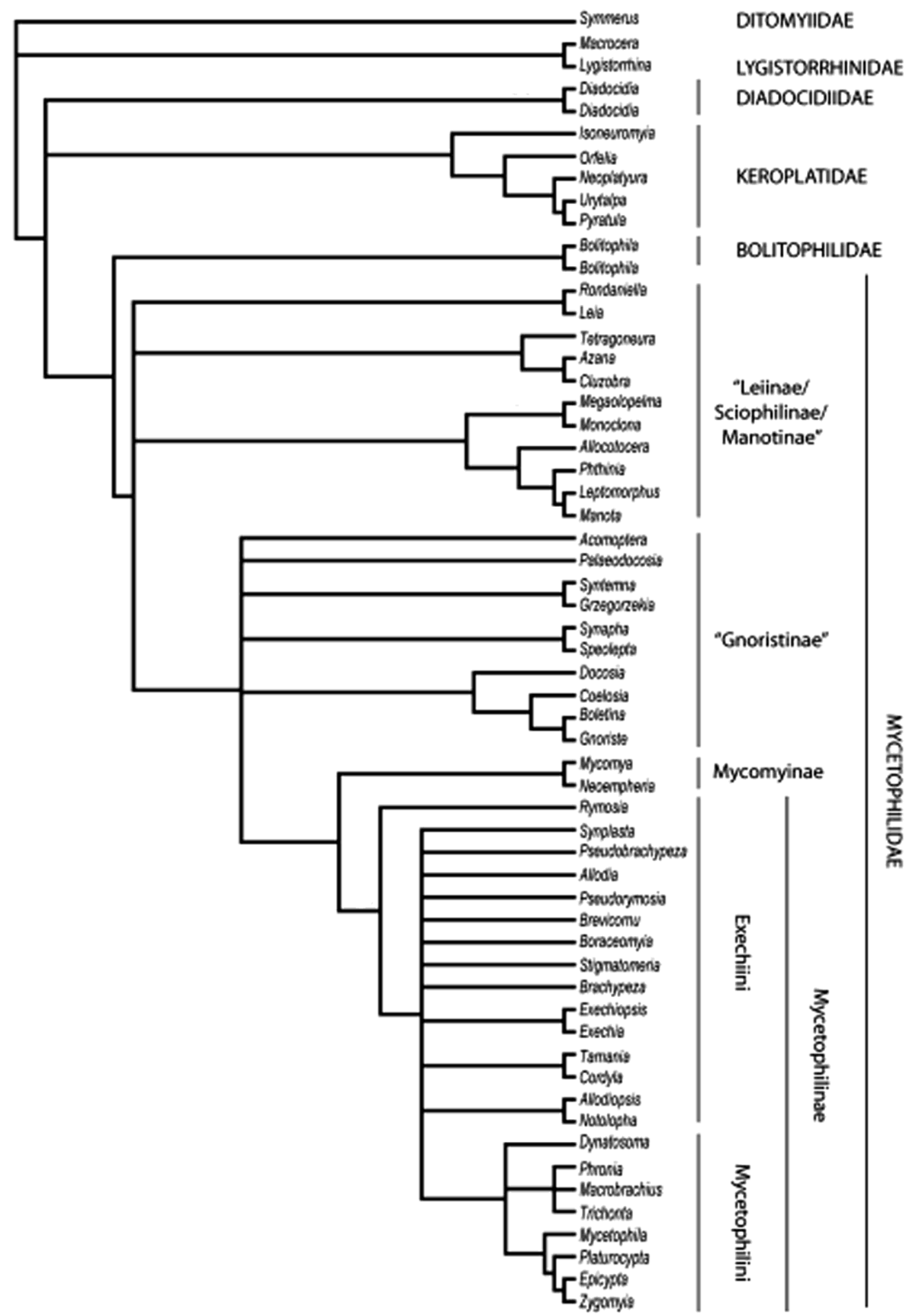

Figura 4. Relações filogenéticas para Mycetophilidae de Rindal \& Søli (2009a: 529), dados morfológicos e moleculares. 


\section{Classificação de Mycetophilidae e delimitação de Allactoneurinae e Leiinae}

Edwards (1925), em um trabalho sobre a classificação de Mycetophilidae, erigiu a subfamília Manotinae para abarcar os gêneros Allactoneura de Meijere e Manota Williston, baseado na presença de cerdas fortes nas margens anterior e posterior dos olhos e ausência de cerdas fortes no protórax (Tuomikoski, 1966). Edwards (1933a) descreveu depois o notável gênero Eumanota Edwards, que evidentemente se assemelha a Manota e seria um "elo" entre Manotinae e Leiinae, que foi posicionado em Allactoneurinae, o que, segundo Tuomikoski (1996), foi apenas um descuido no uso do nome, sendo, evidentemente, um Manotinae.

Shaw \& Shaw (1951), utilizando características torácicas, concluíram que Allactoneura é mais semelhante a Procycloneura Edwards do que a Manotinae, propondo que o gênero pertencesse a uma nova uma tribo-Allactoneurini- dentro de Sciophilinae s.l. Essa sugestão foi seguida por Hennig (1955) e Zaitzev (1981). A tribo passou a ser delimitada pela presença de uma Sc longa, terminando em C, presença de sc-r, Rs bem desenvolvida na região proximal, r-m curta, vertical, proepímero e região lateral do prosterno bem desenvolvidas. Shaw \& Shaw (1951) propuseram adicionalmente a tribo Cycloneurini para Cycloneura Marshall e Procycloneura. Segundo Tuomikoski (1966), no entanto, a amostragem restrita por eles tornava essa decisão algo prematura em relação à diversidade de Leiinae (Leiini de Edws.).

A despeito do posicionamento conflitante de Allactoneura no sistema classificatório de Mycetophilidae, o gênero é facilmente diagnosticado por diversas apomorfias. Segundo Tuomikoski (1966), o formato da cabeça e do tórax, a organização geral do escudo e as dobras longitudinais na membrana alar, lembrando a aparência de uma vespa, são diagnósticas do gênero. Além disso, a organização geral dos escleritos torácicos e a venação alar seriam semelhantes à condição encontrada em gêneros de Leiinae, como Greenomyia Brunetti e Procycloneura (Tuomikoski, 1966). Portanto, haveria fortes indícios para a inclusão de Allactoneura em Leiinae, como um representante extremamente apomórfico do grupo. Tuomikoski (1966) deixa claro, no entanto, que uma revisão de Leiinae seria necessária para elucidar as relações dentro da subfamília.

A posição de Tuomikoski (1966) foi seguida por Matile (1980) e Søli (1996). Segundo Søli (1997a), Allactoneura seria um gênero de Leiinae relacionado a Leia Meigen e Rondaniella Johannsen (figura 2). Tozoni (1998), por outro lado, defende a ideia de que Allactoneura seria relacionado a Manotinae e Mycetophilinae (figura 3). 
Manotinae, por sua vez, é tratado com uma subfamília de Mycetophilidae pela maioria dos autores (Zaitzev, 1990; Søli, 1997a, 2002; Hippa et al., 2004; Vockeroth, 2009) e suas relações filogenéticas entre seus gêneros foram elucidadas por Hippa et al. (2004). Tuomikoski (1966) descreveu dois gêneros na subfamília, Paramanota e Promanota, redefinindo-a mais acuradamente e concluindo que Manotinae é um grupo independente, proximamente relacionado a Leiinae, podendo ser seu grupo-irmão (figura 5) (Hippa et al., 2004).

Mais recentemente Søli (1996) descreveu o gênero Sticholeia e, apesar das semelhanças com Eumanota, posicionou o grupo em Leiinae. No estudo filogenético de Manotinae, realizado por Hippa et al. (2004), Allactoneura aparece como grupo-irmão de Sticholeia, sendo que Procycloneura seria grupo irmão de Manotinae (figura 5). Como seu estudo estava concentrado em Manotinae, as relações filogenéticas entre os grupos-externos têm pouca fundamentação. Ainda assim, esse fato evidencia que a discussão do monofiletismo de Leiinae - e consequentemente a delimitação genérica do grupo — é crucial para resolver os problemas de classificação de Manotinae e Allactoneurinae, particularmente, e de Mycetophilidae, de modo geral.

\section{A subfamília Leiinae}

A diversidade atual de Leiinae compreende 32 gêneros e cerca de 550 espécies, no mundo (Oliveira \& Amorim, 2012a). Na região Neotropical, estão presentes nove gêneros e aproximadamente 200 espécies, das quais 35 são encontradas em áreas da Floresta Atlântica (Papavero, 1978; Amorim \& Oliveira, em preparação; Oliveira \& Amorim, 2012a). Há 54 espécies conhecidas de fósseis, incluídas em 12 gêneros, dos quais oito são encontrados apenas em âmbar do Cretáceo (Evenhuis, 1994; Baxter \& Poinar, 1994; Blagoderov, 1998a,b, 2000; Blagoderov \& Grimaldi, 2004).

A composição do grupo começou a ser delimitada nos trabalhos de Edwards (1925), que considerava "Leiini", como foi visto, uma tribo de Sciophilinae. Os gêneros inclusos nessa tribo formariam um grupo natural por compartilhar um encurtamento de $R_{1}$, apresentando-se geralmente menor que r-m, e r-m horizontalizada, alinhada com Rs. O próprio Edwards (1925), no entanto, ressalta que, dentre os gêneros do grupo, havia exceções, como Rondaniella, Docosia Winnertz e Tetragoneura Winnertz.

Hendel (1936) elevou a tribo Leiini ao status de subfamília. Hennig (1973), no entanto, indicou claramente que a caracterização e a delimitação de Leiinae eram problemáticas. Tuomikoski (1966), seguindo nessa direção, aceita que esse agrupamento 
seria polifilético. Tozoni (1998), por sua vez, corroborou a idéia de que os Leiinae formassem um agrupamento monofilético (figura 3), indicado pela redução de $R_{5}$, base de $R s$ quase transversal, $\mathrm{R}_{4}$ ausente e sutura mediopleural incompleta, não produzida em seu quarto inferior.

Jaschhof \& Kallweit (2009) mostraram que as dúvidas acerca do monofiletismo de Leiinae estão bastante difundidas na literatura (Søli, 1997a; Søli et al., 2000; Hippa et al., 2004) e uma análise filogenética consistente da subfamília, envolvendo todos os gêneros da subfamília, seria necessária para solucionar adequadamente esse problema.

Os resultados dos vários estudos filogenéticos realizados com membros de Leiinae, mas não com o grupo todo, até o presente momento (figuras 2-5) (Søli, 1997a; Tozoni, 1998; Hippa et al., 2004; Rindal et al., 2009a), dessa maneira, são discrepantes em relação às topologias obtidas, dificultando o estabelecimento dos limites genéricos do grupo.

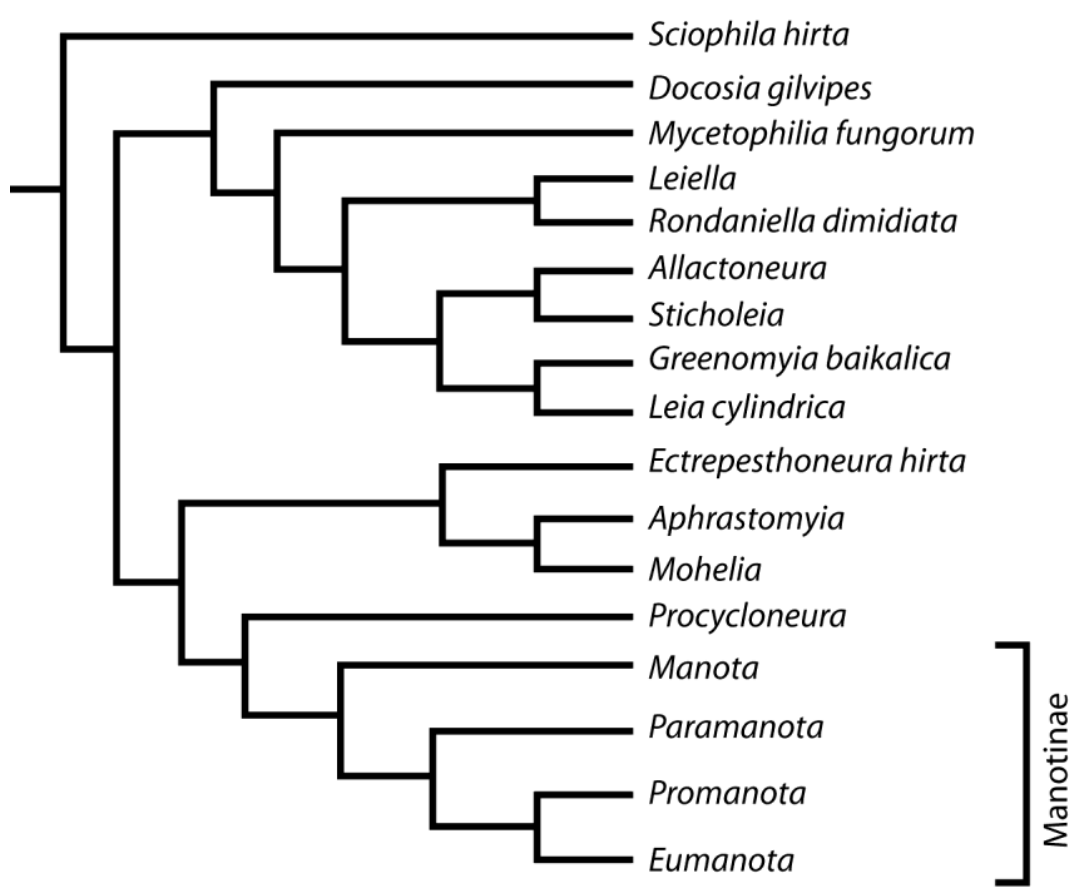

Figura 5. Relações filogenéticas para Manotinae de Hippa et al. (2004). Modificado de Hippa et al., 2004: 408, dados morfológicos.

Dentre os pontos conflitantes de delimitação do grupo, destacam-se:

(1) o posicionamento de Allactoneura em Leiinae ou em Allactoneurinae;

(2) Cycloneura e Procycloneura em "Cycloneurini";

(3) a inclusão ou não de Ectrepesthoneura Enderlein e Tetragoneura; 
(4) a inclusão de Clastobasis Skuse e Neoclastobasis Ostroverchova em "Clastobasini".

Os pontos (1) e (2) foram comentados anteriormente, de maneira que os pontos (3) e (4) precisam de alguma elucidação adicional. De forma geral, a delimitação de Leiinae, assim como de outras subfamílias de Mycetophilidae, é feita muitas vezes com o uso de caracteres plesiomórficos, gerando confusões sobre a posição de alguns gêneros. Para autores como Edwards (1925), Hackman et al. (1988), Søli (1997a) e Kurina (2004), Ectrepesthoneura e Tetragoneura pertencem a Leiinae. Por outro lado, Tuomikoski (1966) comenta que ambos os gêneros deveriam ser excluídos de Leiinae, posicionados junto a Synapha Meigen em Gnoristinae, posição seguida, por exemplo, por Väisänen (1986), Bechev (2000) e Chandler (2004).

Já os gêneros Clastobasis e Neoclastobasis foram posicionados em uma tribo independente, Clastobasini, por Ostroverchova (1970), que, em um estudo detalhado realizado por Hutson et al. (1980), é considerado como pertencente a Leiinae.

Jaschhof \& Kallweit (2009) advogam, adicionalmente, que o problema acerca da delimitação de Leiinae é mais amplo e abrange outros gêneros. Segundo esses autores, os dois caracteres levantados por Edwards (1925) para delimitar o grupo-encurtamento de $\mathrm{R}_{1}$, apresentando-se geralmente menor que qualquer extensão de r-m, e inclinação horizontal de r-m-eram sólidos o suficiente para delimitar o grupo para a diversidade de gêneros conhecidos na época de sua proposição. Atualmente, no entanto, há vários problemas e exceções. Sigmoleia Tonnoir \& Edwards, por exemplo, tem $\mathrm{R}_{1}$ mais longa que r-m e r-m não se apresenta alinhada a $\mathrm{R}_{5}$. Assim, na opinião de Jaschhof \& Kallweit (2009), gêneros como Aphrastomyia Coher \& Lane, Gracileia Matile, Mohelia Matile, Novakia Strobl e Tetragoneura deveriam ser excluídos de Leiinae. Nesses gêneros, Sc de modo geral termina em R (e não em C), uma característica relativamente típica de Gnoristinae. Entretanto, Gnoristinae é outra subfamília de Mycetophilidae que requer uma análise filogenética detalhada, de modo que sua composição e relação entre os gêneros possa ser definida de forma mais precisa (Väisänen, 1986; Søli et al., 2000; Jaschhof \& Kallweit, 2009).

Apenas um estudo filogenético minucioso de Leiinae, dessa maneira, com uma ampla amostragem taxonômica de seus gêneros e com uma amostragem de grupos-externos que validasse as inferências sobre o monofiletismo do grupo, com a inclusão de gêneros de Gnoristinae, Manotinae, Allactoneurinae e Mycetophilinae, pode solucionar a questão do 
posicionamento desses gêneros conflitantes e conferir uma classificação robusta para Leiinae.

Os gêneros de Leiinae (sensu Edwards) e Allactoneurinae conhecidos até o presente momento (incluindo fósseis), com o respectivo número de espécies e regiões biogeográficas de ocorrência, estão listados na Tabela 1. A tabela foi elaborada com base em Matile (1989), Papavero (1978), Bugledich (1999), Oliveira \& Amorim (em preparação), além de trabalhos mais recentes com descrições de novas espécies e gêneros (por exemplo, Xu et al., 2003; Kurina, 2006; Laštovka \& Ševčík, 2006; Ševčík \& Laštovka, 2008; Jaschhof \& Kallweit, 2004, 2009; Ševčík, 2010; Polevoi \& Jakovlev, 2011; Kurina \& Ševčík, 2011, 2012; Oliveira \& Amorim, 2010c, 2011, 2012a; Taber, 2011, 2012; Bechev \& Pavlova, 2012). 
Tabela 1: Número de espécies por região biogeográfica dos gêneros de Leiinae (sensu Edwards) e Allactoneurinae. Abreviações: PA, região Paleártica; NE, região Neártica; OR, região Oriental; AF, região Afrotropical; NT, região Neotropical; AU, região Australiana; ${ }^{+}$, gêneros fósseis.

\begin{tabular}{|c|c|c|c|c|c|c|c|}
\hline Gêneros & $\mathbf{P A}$ & NE & OR & $\mathbf{A F}$ & NT & $\mathbf{A U}$ & $\begin{array}{l}\text { Total de } \\
\text { espécies }\end{array}$ \\
\hline Acrodicrania Skuse & - & - & 3 & 1 & - & 4 & 8 \\
\hline Allactoneura de Meijere & 3 & - & 4 & 1 & - & 1 & 9 \\
\hline Anomalomyia Hutton & - & - & - & - & - & 14 & 14 \\
\hline Aphrastomyia Coher \& Lane & - & - & - & - & 11 & - & 11 \\
\hline Ateleia Skuse & - & - & - & - & - & 1 & 1 \\
\hline Baisepesthoneura Blagoderov $^{+}$ & 1 & - & - & - & - & - & 1 \\
\hline Caledonileia Matile & - & - & - & - & - & 1 & 1 \\
\hline Cawthronia Tonnoir \& Edwards & - & - & - & - & - & 1 & 1 \\
\hline Clastobasis Skuse & 5 & - & 3 & 5 & - & 6 & 18 \\
\hline Cycloneura Marshall & - & - & - & - & - & 2 & 2 \\
\hline Disparoleia Blagoderov \& Grimaldi ${ }^{+}$ & - & - & 1 & - & - & - & 1 \\
\hline Docosia Winnertz & 64 & 18 & 2 & - & 3 & - & 87 \\
\hline Ectrepesthoneura Enderlein & 17 & 4 & - & - & - & - & 21 \\
\hline Garretella Vockeroth & - & 1 & - & - & - & - & 1 \\
\hline Gracilileia Matile & - & - & - & - & - & 5 & 5 \\
\hline Greenomyia Brunetti & 8 & 2 & 2 & - & - & - & 12 \\
\hline Hemolia Blagoderov \& Grimaldi ${ }^{+}$ & - & - & 2 & - & - & - & 2 \\
\hline Indoleia Edwards & - & - & 1 & - & - & 1 & 2 \\
\hline 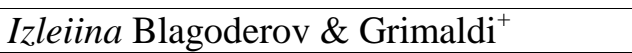 & 1 & 1 & - & - & - & - & 2 \\
\hline Lecadonileia Blagoderov \& Grimaldi $^{+}$ & - & 1 & - & - & - & - & 1 \\
\hline Leia Meigen & 45 & 19 & 21 & 20 & 62 & 1 & 168 \\
\hline Leiella Enderlein & - & - & - & - & 10 & - & 10 \\
\hline Megophthalmidia Dziedzicki & 11 & 1 & - & - & 7 & - & 19 \\
\hline Metaleia Baxter $^{+}$ & - & - & - & - & 1 & - & 1 \\
\hline Mohelia Matile & - & - & - & 1 & - & - & 1 \\
\hline Nedocosia Blagoderov \& Grimaldi $^{+}$ & 2 & 2 & - & - & - & - & 4 \\
\hline Neoclastobasis Ostroverchova & 3 & - & - & - & - & - & 3 \\
\hline Novakia Strobl & 2 & 2 & - & - & - & - & 4 \\
\hline Palaecothoracotropis Blagoderov $^{+}$ & 2 & - & - & - & - & - & 2 \\
\hline Paracycloneura Tonnoir \& Edwards & - & - & - & - & - & 3 & 3 \\
\hline Paradoxa Marshall & - & - & - & 1 & - & 1 & 2 \\
\hline Paraleia Tonnoir & - & - & - & - & 18 & 1 & 19 \\
\hline Procycloneura Edwards & - & - & - & - & 4 & - & 4 \\
\hline Protragoneura Blagoderov \& Grimaldi ${ }^{+}$ & - & - & 1 & - & - & - & 1 \\
\hline Rondaniella Johannsen & 6 & - & 3 & - & - & - & 9 \\
\hline Sigmoleia Tonnoir \& Edwards & - & - & - & - & - & 6 & 6 \\
\hline Sticholeia Søli & - & - & - & - & - & 3 & 3 \\
\hline Temaleia Blagoderov \& Grimaldi ${ }^{+}$ & - & - & 1 & - & - & - & 1 \\
\hline Tetragoneura Winnertz & 23 & 10 & - & - & 79 & 26 & 138 \\
\hline Thoracotropis Freeman & - & - & - & - & 1 & - & 1 \\
\hline Tonnwardsia Jaschhof \& Kallweit & - & - & - & - & - & 1 & 1 \\
\hline Trichoterga Tonnoir \& Edwards & - & - & - & - & - & 2 & 2 \\
\hline Waipapamyia Jaschhof \& Kallweit & - & - & - & - & - & 3 & 3 \\
\hline 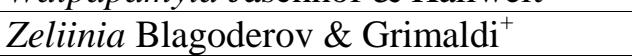 & - & 1 & 1 & - & - & - & 2 \\
\hline
\end{tabular}


Os objetivos desta tese, dessa maneira, são:

(1) fazer uma reconstrução das relações filogenéticas entre os gêneros de Leiinae s.l. com base em várias fontes de dados morfológicos;

(2) determinar a posição dos gêneros de inclusão duvidosa entre as subfamílias de Mycetophilidae;

(3) estabelecer os limites genéricos de Leiinae, propondo uma nova classificação para o grupo. 


\section{Amostragem taxonômica e coleções estudadas}

Com o objetivo de estabelecer os limites genéricos de Leiinae e estudar as relações filogenéticas entre seus gêneros, é indispensável a utilização de uma amostragem taxonômica ampla o suficiente para permitir uma abordagem adequada do problema. Foram incluídos, sempre que possível, representantes de mais de uma espécie de cada gênero, de maneira que se pudesse testar seu monofiletismo.

O grupo interno foi composto, desse modo, por 87 espécies dos 32 gêneros recentes de Leiinae: Acrodicrania (5 espécies), Anomalomyia (3), Aphrastomyia (3), Ateleia (1), Caledonileia (1), Cawthronia (1), Clastobasis (6), Cycloneura (1), Docosia (6), Ectrepesthoneura (5), Garretella (1), Gracilileia (2), Greenomyia (4), Indoleia (1), Leia (10), Leiella (3), Megophthalmidia (4), Mohelia (1), Neoclastobasis (2), Novakia (1), Paracycloneura (1), Paradoxa (2), Paraleia (4), Procycloneura (2), Rondaniella (2), Sigmoleia (2), Sticholeia (3), Tetragoneura (6), Thoracotropis (1), Tonnwardsia (1), Trichoterga (1) e Waipapamyia (1). Material de todos os gêneros, com exceção de Cawthronia, foi estudado a partir de material examinado. O gênero Cawthronia foi incluído nesta análise com o estudo da literatura (Jaschhof \& Kallweit, 2009). Sempre que necessário, foi utilizada informação adicional proveniente da literatura que corroborasse a generalidade dos estados de caráter dentro de cada gênero, o mesmo se aplicando para os grupos externos.

Com os problemas de delimitação de Leiinae na literatura, foram incluídos na análise todos os gêneros que se cogitou eventualmente pertencer à subfamília, mesmo que atualmente seja incluído em Allactoneurinae, Manotinae, Mycetophilinae ou Gnoristinae. Na execução da análise numérica, o enraizamento foi feito com Sciophilinae, já que em análises de Mycetophilidae publicadas o grupo é apontado como irmão do restante da família (figuras 2-5) (Søli, 1997a; Tozoni, 1998; Hippa et al., 2004; Rindal \& Søli, 2009a;). Os gruposexternos, assim, compreendem 20 espécies pertencentes a 18 gêneros: Tasmanina (1 espécie) e Neoallocotocera (1) (Sciophilinae); Palaeodocosia (1), Boletina (1), Dziedzickia (1), Schnusea (1), Austrosynapha (1) e Synapha (1) (Gnoristinae); Mycomya (1) e Neoempheria (1) (Mycomyinae); Mycetophila (1), Epicypta (1), Exechiopsis (1) e Rymosia (1) (Mycetophilinae); Manota (1), Eumanota (1) e Promanota (1) (Manotinae); Allactoneura (3) (Allactoneurinae). 
A matriz completa, com os grupos internos e externos, inclui 107 táxons terminais e está apresentada na Tabela 2 (seção “Anexos”).

Apesar de espécies fósseis terem sido associadas a Leiinae (Evenhuis, 1994; Baxter \& Poinar, 1994; Blagoderov, 1998a,b, 2000; Blagoderov \& Grimaldi, 2004), em especial do âmbar Cretáceo, elas não são essenciais para responder as questões principais deste trabalho. Ainda assim, foi realizada uma análise adicional com a inclusão, utilizando dados da literatura, de gêneros fósseis, apontando inicialmente a relação entre os gêneros extintos e a diversidade atual de Leiinae. Isso tem a importância de estabelecer idade mínima para vários dos grandes clados dentro da subfamília.

A informação detalhada de todos os exemplares utilizados neste estudo, incluindo os fósseis, está disponível na Tabela 2, seção “Anexos”.

Além do material recebido por empréstimo, a amostragem taxonômica utilizada neste estudo filogenético foi obtido de visitas a instituições de pesquisa no Brasil (INPA, MPEG, MZUSP) e no exterior (INBio, AMSA, ANIC, NMSA, SANC, SAMC, CNC, CDFA). Essa etapa foi essencial para o estudo de fauna de outras regiões biogeográficas e obtenção de gêneros endêmicos dessas regiões. No caso específico das coleções africanas, NMSA e SAMC, os tipos de Mycetophilidae foram fotografados e seu atual estado de conservação e dados de etiquetas documentados, de forma que a informação sobre essas coleções hoje está disponível (Oliveira \& Muller, 2012, e Oliveira, 2012, respectivamente) (seção “Apêndice”).

O material estudado pertence às seguintes coleções:

MZUSP Museu de Zoologia da Universidade de São Paulo, São Paulo, Brasil;

INPA Instituto Nacional de Pesquisas Amazônicas, Manaus, Brasil;

MPEG Museu Paraense Emílio Goeldi, Belém, Brasil;

DZUP Coleção de Entomologia Padre Jesus Santiago Moure da Universidade Federal do Paraná, Curitiba, Brasil;

LMED Laboratório de Morfologia e Evolução de Diptera, Faculdade de Filosofia, Ciências e Letras de Ribeirão Preto da Universidade de São Paulo, Ribeirão Preto, Brasil;

IAvH Instituto de Investigación de Recursos Biológicos Alexander von Humboldt, Bogotá, Colômbia;

CNC Canadian National Collection of Arachnids, Nematodes and Insects, Ottawa, Canadá; 
CDFA California Department of Food and Agriculture, Sacramento, Estados Unidos da América;

AMSA Australian Museum, Sidnei, Austrália;

ANIC Australian National Insect Collection, Camberra, Austrália;

NMSA Kwa-Zulu-Natal Museum South Africa, Pietermaritzburg, África do Sul;

SANC South African National Collection of Insects, Pretória, África do Sul;

SAMC Iziko South Africa Musuem, Cidade do Cabo, África do Sul;

NHM Natural History Museum, Londres, Reino Unido;

MNHN Muséum National d'Histoire Naturelle, Paris, França;

FMNH Finnish Museum of Natural History, Zoological Museum, University of Helsinki, Helsinque, Finlândia;

INBio Instituto Nacional de la Biodiversidad, São José, Costa Rica. 


\section{MÉTODOS}

\section{Preparação do material biológico}

A maior parte do material utilizado neste trabalho corresponde a material depositado em coleções secas. Uma pequena parte está fixada em álcool. Material-tipo foi analisado sempre que possível, mas foi dada preferência a espécimes não pertencentes às séries-tipo devido à necessidade de dissecções de asa e terminálias feminina e masculina. Uma vez que o escopo da análise é a relação entre gêneros, o fato de não estarem sendo analisados holótipos e parátipos não implica diretamente nos resultados.

Alguns machos e fêmeas de cada espécie foram dissecados e montados em lâminas permanentes, com a realização da técnica usual de diafanização com $\mathrm{KOH}$, desidratação alcoólica e montagem em bálsamo do Canadá (modificada de Walker \& Crosby, 1988; Huber \& Reis, 2011). Em alguns casos, após a diafanização, as terminálias foram montadas em lâminas temporárias com glicerina e sua visualização foi mediada pela montagem da terminália em gelatina com fenol (modificada de Zandler, 2003).

\section{Documentação e ilustração}

O habitus dos espécimes e detalhes das estruturas em lâmina e microscópio foram fotografados utilizando equipamento de captura de imagens acoplado a um microscópio estereoscópico Leica modelo MZ-16 ou a um microscópio de transmissão Leica modelo DM2500. As estruturas morfológicas foram desenhadas mediante o uso de camera lucida acoplada ao microscópio de transmissão, scanner, digitalizadas e ilustradas com o programa Adobe Illustrator 11.0. As imagens foras editadas com o programe Adobe Photoshop CS.

\section{Escolha dos caracteres e construção da matriz de dados}

O presente trabalho baseia-se exclusivamente em caracteres morfológicos de adultos machos e fêmeas. Alguns dos caracteres já foram utilizados em análises filogenéticas anteriores de Mycetophilidae (Søli, 1997a; Tozoni, 1998; Amorim \& Rindal, 2007; Rindal \& Søli, 2006; Borkent \& Wheeler, no prelo), sendo que vários são propostos aqui pela primeira vez. A terminologia morfológica adotada segue Søli (1997a), para morfologia de cabeça (figura 6) e terminália feminina (figura 10), Amorim \& Rindal (2007), para a venação alar (figura 7), e Matile (1990), para tórax e terminália masculina (figuras 8-9). 

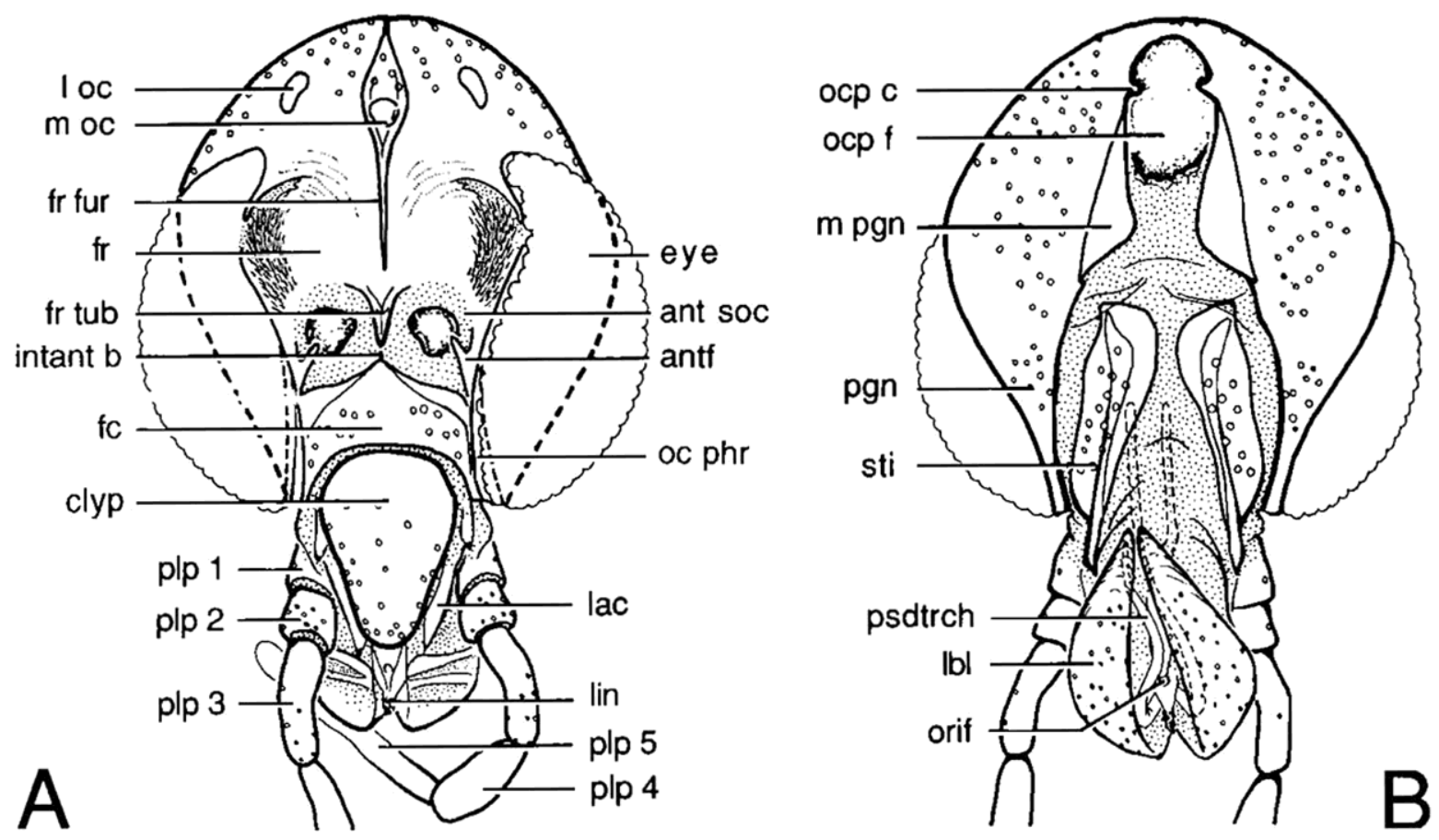

Figura 6. Cabeça de Boletina basalis Meigen (Mycetophilidae). A. Vista frontal. B. Vistal posterior. (Modificado de Søli, 1997a: 8). Abreviações: antf, antenífero; ant soc, soquete antenal; clyp, clípeo;

eye, olho; fc, face; fr, fronte; fr fur, sutura frontal; fr tub, tubérculo frontal; intant b, barra interantenal; lbl, labela; lac, lacínea; lin, língua; 1 oc, ocelo lateral; m oc, ocelo mediano; m pgn, convexidade média da pós-gena; oc phr, fragma ocelar; ocp c, côndilo ocipital; ocp f, forâmen

ocipital; orif, orifício; pal, palpômero; pgn, pós-gena; psdtrch, pseudotraquéia; sti, estipes.
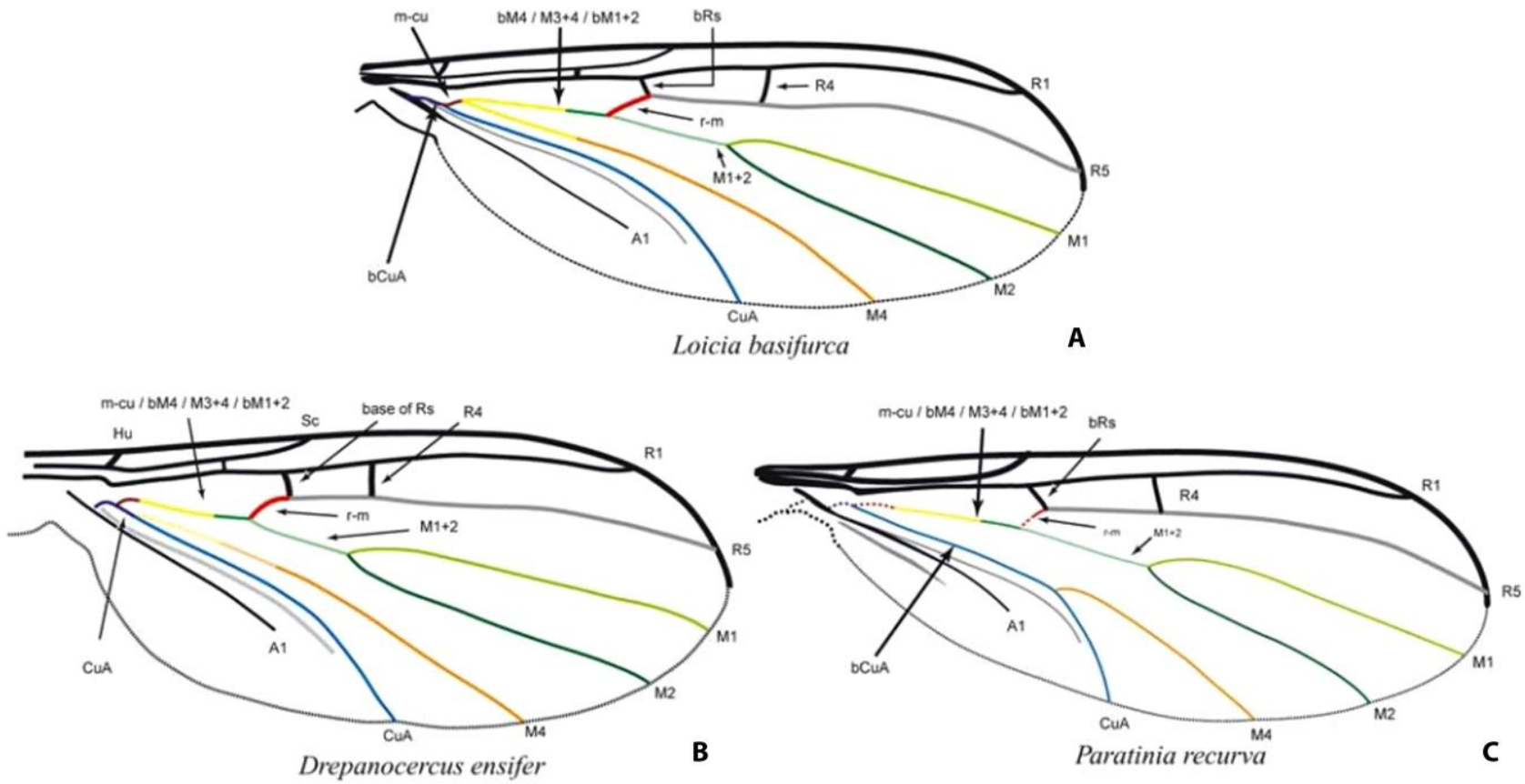

Figura 7. Estudo de homologia de venação alar em Mycetophilidae (modificado de Amorim \& Rindal, 2007: 77). A. Loicia Vockeroth (Sciophilinae); B. Drepanocercus Vockeroth (Sciophilinae); C. Paratinia Mik (Sciophilinae). 


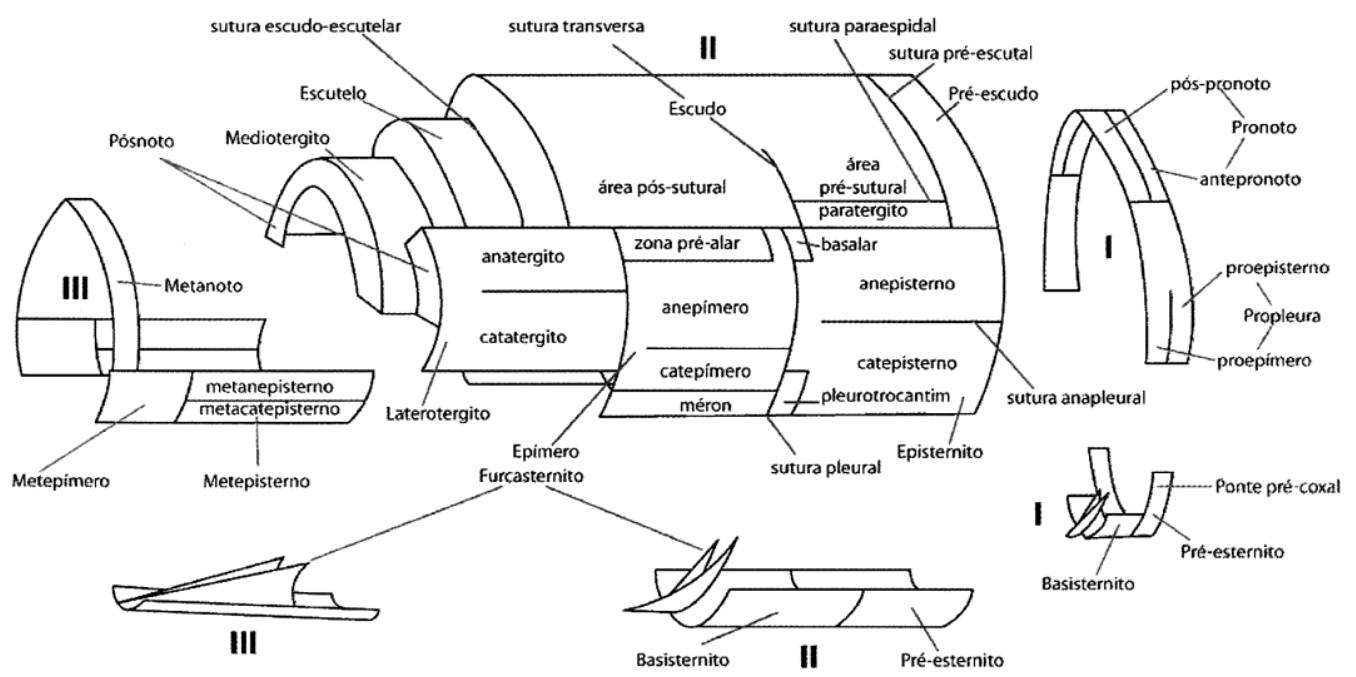

A

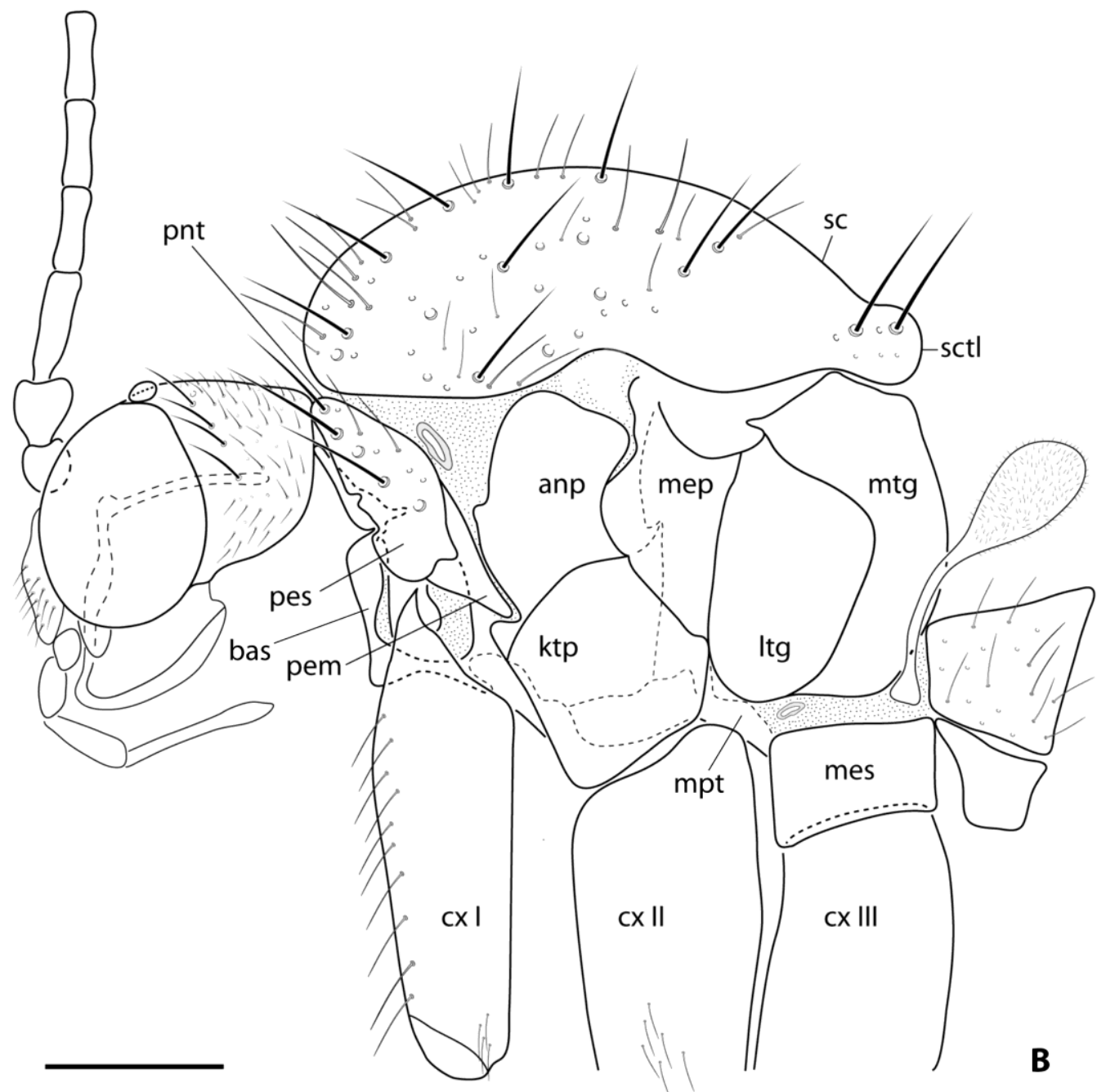

Figura 8. Organização do tórax de Diptera e Mycetophilidae. A. Plano-básico do tórax de Diptera (modificado de Matile, 1990: 40); B. Tórax de Paraleia bolivari Oliveira \& Amorim (Leiinae, Mycetophilidae), modificado de Oliveira \& Amorim (2012: 6). Escala $1 \mathrm{~mm}$. Abreviações: anp, anepisterno; bas, basisterno; cx, coxa; ktp, catepisterno; ltg; laterotergito; mes, metepistero; mep, mesepímero; mpt, mesopleurotrocantin; mtg, mediotergito; pem, proepímero; pes, proepisterno; pnt, pronoto; sc, escudo; sctl, escutelo. 

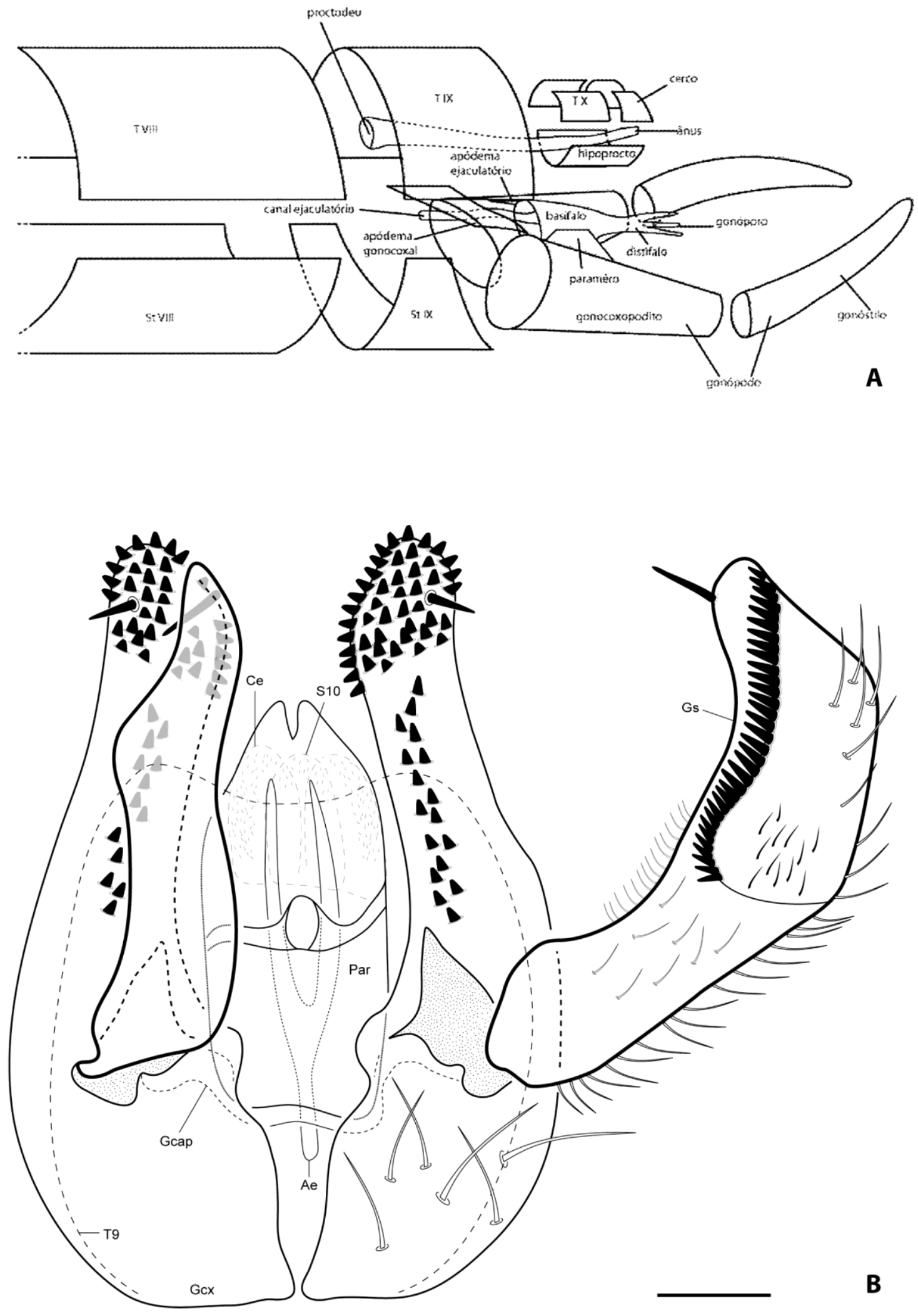

Figura 9. Organização da terminália masculina de Mycetophiloidea e Mycetophilidae. A. Planobásico do pós-abdômen de Mycetophiloidea (modificado de Matile, 1990: 68); B. Terminália masculina de Paraleia denticulata Oliveira \& Amorim (Leiinae, Mycetophilidae), modificado de Oliveira \& Amorim (2012: 14). Escala $1 \mathrm{~mm}$. Abreviações: ae, edeago; ce, cerco; gcap, apódema gonocoxal; gcx, gonocoxitoe; gs, gonóstilo; S e st, esternito; T, tergito. 

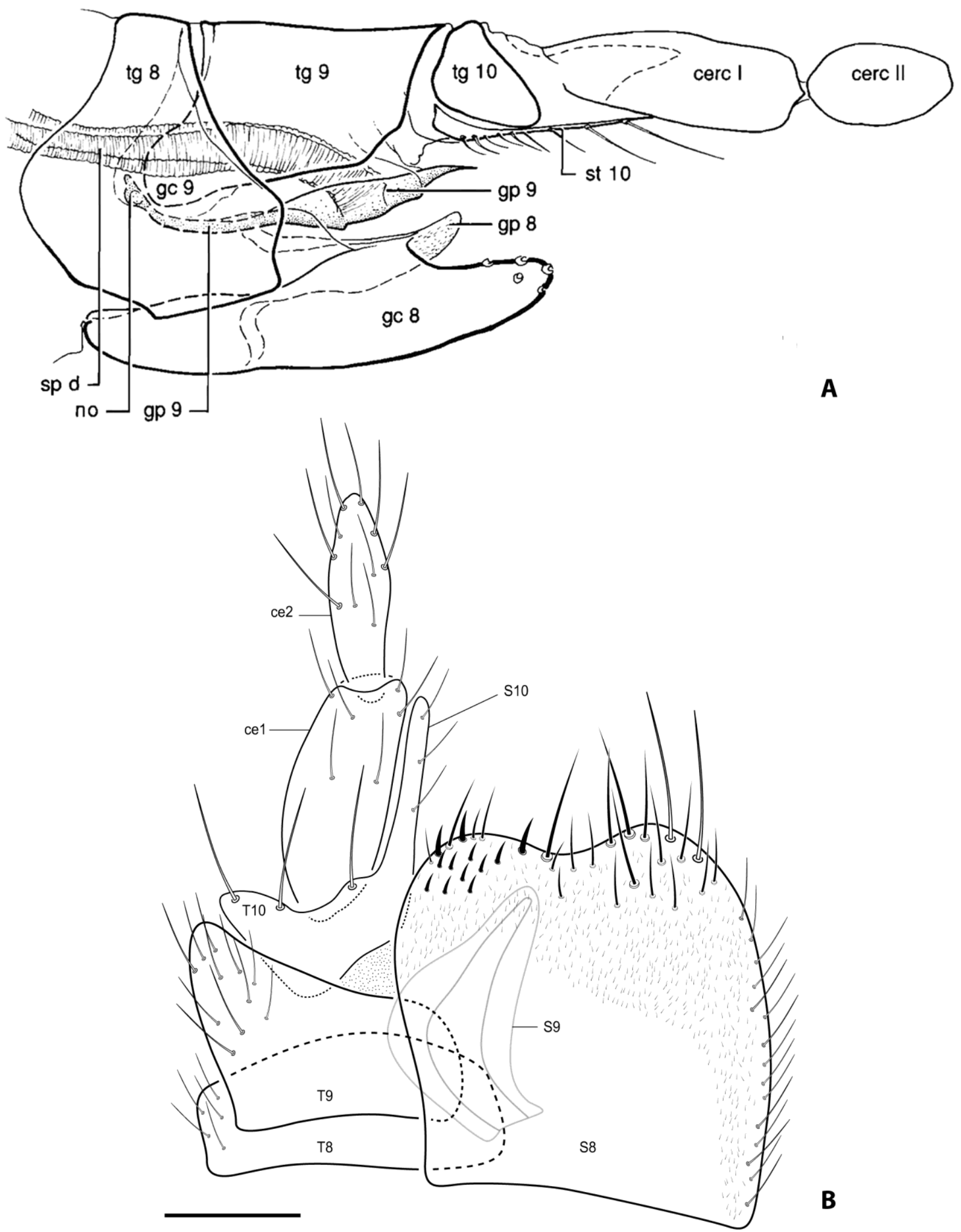

B

Figura 10. Terminália feminina de Mycetophilidae. A. Vista lateral da terminália feminina de Saigusaia Vockeroth (Gnoristinae) (modificado de Søli, 1997a: 38). B. Terminália feminina de Paraleia denticulata Oliveira \& Amorim (Leiinae, Mycetophilidae), modificado de Oliveira \& Amorim (2012: 15). Escala 1 mm. Abreviações: ce, cercômero; gc, gonocoxito; gp, gonapófise; no, noto; $\mathrm{S}$, esternito; sp d, ducto da espermateca; $\mathrm{T}$, tergito. 
Para caracteres multi-estado padrões "neomórficos" (surgimento ou desaparecimento de uma característica) e "transformacionais" (estados diferentes de uma mesma característica) não foram unidos, evitando a construção de "quimeras" (Sereno, 2007). Dessa forma, alguns caracteres foram codificados como ausente ou presente, causando interdependência em alguns casos. No entanto, optou-se por mantê-los separado como uma tentativa de extrair informações filogenéticas pertinentes das diferenças morfológicas observadas (Lee \& Bryant, 1999; Strong \& Lipscomb, 1999), mesmo havendo críticas a este tipo de codificação (Platnick et al., 1991; Maddison, 1993). Estados não observados e dados não aplicáveis foram codificados respectivamente como "?" e “-”.

No total, foram levantados 135 caracteres, referentes à morfologia de cabeça (39 caracteres), tórax (43), asa (44), terminálias masculina (8) e feminina (1). A matriz final de dados, construída com o software WinClada (versão Asado 1.89; Nixon, 1999-2004), elenca 107 táxons terminais e 135 caracteres morfológicos e está apresentada está apresentada na Tabela 2 (seção "Anexos”). A matriz final, com a inclusão dos táxons fósseis, elenca 120 táxons terminais e os mesmos 135 caracteres morfológicos (Tabela 2) (seção “Anexos").

\section{Análise filogenética}

O critério utilizado para a inferência das filogenias foi a parcimônia de Fitch (1971), que trata todos os caracteres com pesos iguais e como não ordenados, de modo a não impor quaisquer premissas sobre as transformações entre os estados. A análise de parcimônia foi implementada no programa TNT (Tree Analysis Using New Technologies-Willi Hennig Society Edition, Goloboff et al., 2008). As topologias no TNT foram obtidas através da ferramenta New Technology Search (Goloboff, 1999; Goloboff et al., 2008; Nixon, 1999), que é recomendada para matrizes com mais de 100 táxons terminais. Segundo Goloboff (1999) e Nixon (com. pess.), as novas tecnologias devem ser utilizadas em conjunto, sendo que Drifting e Ratchet são muito semelhantes e o melhor método para conjunto de dados complexos é o Ratchet (Nixon, 1999).

Os parâmetros que se seguem foram utilizados para as análises com grupos viventes e fósseis: Max. trees 10000; Random seed 0; Random addition sequences 200; Sectorial search (sect: slack7); Ratchet 200 interações; Tree fusing 5 ciclos.

O enraizamento das filogenias seguiu o método de comparação com grupos-externos, como revisto por Nixon \& Carpenter (1993). As árvores de consenso estrito, com distribuição dos caracteres sobre a filogenia, foram obtidas por meio do software WinClada (versão Asado 1.89; Nixon, 1999-2004) e editadas no Adobe Illustrator 10.0. A distribuição 
dos caracteres no cladograma foi plotada por meio da otimização ACCTRAN (Accelerated transformation), no qual as mudanças são atribuídas ao longo dos ramos o mais próximo à raiz possível, favorecendo reversões.

Estimativas de robustez ou grau de confiabilidade das hipóteses de monofiletismo podem ser inferidas com base no cálculo das chamadas medidas de suporte, como bootstrap e jackknife. Há controvérsias na literatura sobre a utilização ou não desses índices como medidas de robustez real de hipóteses filogenéticas, uma vez que seriam calculados por meio de manipulação estatística da base de dados original (Siddall, 2002; Santos \& Falaschi, 2007), razão pela qual elas não foram utilizadas no presente estudo.

Já o suporte dos ramos ou suporte de Bremer (Bremer, 1988, 1994) não lida com manipulações na base de dados original, mas com a diferença de comprimento entre as árvores mais parcimoniosas que contém o clado de interesse e aquelas que não o contém, ou seja, com o número de passos extras necessários para que um ramo presente no consenso colapse. O suporte dos ramos é reduzido quando há alternativas igualmente parcimoniosas de agrupamento ou otimização de caracteres (Kitching et al., 1998). O índice mede a estabilidade das árvores mais parcimoniosas em termos de suporte de resolução, não em termos de grau de homoplasia dos dados (Kitching et al., 1998), uma diferença significativa das práticas de pesagem implícita (Goloboff, 1993).

Os valores de suporte de Bremer, que indicam os passos extras necessários para colapsar o ramo foram calculados com o TNT utilizando árvores subótimas com 1-20 passos extras com TBR (Tree Bissection Reconnection). A árvore final foi editada no Adobe Illustrator 10.0.

Embora a árvore de consenso estrito com pesos iguais tenha sido o cladograma utilizado para a discussão que se segue, foram realizadas análises com pesagem implícita com o intuito de explorar os dados e verificar o comportamento dos clados frente a pesos diferentes para os caracteres, como uma tentativa de entender melhor o papel das homoplasias na análise.

$\mathrm{Na}$ pesagem implícita, os caracteres menos homoplásticos entre topologias conflitantes recebem um peso maior de acordo com a constante de concavidade $(\mathrm{k})$ e o melhor valor de $\mathrm{k}$ deve ser escolhido empiricamente (Goloboff, 1993). As análises de parcimônia foram realizadas no TNT, com os mesmos parâmetros utilizados para as análises com e sem grupos fósseis, mas apenas com os grupos viventes. Foram utilizados valores de k entre $1-10,15,20$ e 25 . As implicações dos cladogramas obtidos com os diferentes valores 
de k serão discutidas na seção "Análise filogenética / Leiinae como grupo monofilético e seus principais clados".

O nomeamento dos clados ao longo do cladograma foi feito com base no sistema de classificação filogenética por sequenciação, com o artifício do grupo ${ }^{+}$e grupo (Amorim, 1997, 2002). 
A execução de uma análise filogenética de um grupo amplo de Mycetophilidae, como Leiinae, envolve levantamento bibliográfico e eventuais alterações nomenclaturais, conhecimento da biodiversidade do grupo, revisões a nível genérico e amostragem ampla o suficiente para que os objetivos iniciais sejam atingidos com confiança.

A verificação da diversidade de espécies dos gêneros envolvidos acabou por resultar na proposição de novos nomes para três casos de homonímia dentro do grupo (Oliveira \& Amorim, 2010c). Docosia garretti Oliveira \& Amorim foi proposto para Docosia setosa Garrett, 1925; Leia walkeri Oliveira \& Amorim para Leia bimaculata (Walker, 1848); Tetragoneura sasakawai Oliveira \& Amorim para Tetragoneura tibialis Sasakawa, 1961 (Oliveira \& Amorim, 2010c) (seção "Apêndice”).

O estudo de diversidade de Leiinae, focado principalmente na região Neotropical, resultou na descrição de sete novas espécies, sendo uma em Docosia —D. adusta Oliveira \& Amorim—, e seis em Paraleia - P. bolivari Oliveira \& Amorim, P. denticulata Oliveira \& Amorim, P. fumosa Oliveira \& Amorim, Oliveira \& Amorim, P. tonnoiri Oliveira \& Amorim, P. nidorosa Oliveira \& Amorim e P. sharkeyi Oliveira \& Amorim (Oliveira \& Amorim 2011 e 2012a, respectivamente) (seção “Apêndice”).

O gênero Thoracotropis, conhecido apenas pela espécie-tipo Thoracotropis cypriformis, foi redescrito (Oliveira et al., 2012), viabilizando sua inclusão no estudo filogenético. Como não foram encontrados exemplares adicionais do gênero até agora para enriquecer o conhecimento do grupo e a descrição de Freeman (1951) é bastante sucinta, a redescrição detalhada do holótipo, incluindo fotos e ilustrações, supriu essa lacuna do conhecimento e favorece futuras identificações de material do gênero (seção "Apêndice"). 
Não há estudos filogenéticos publicados para a subfamília Leiinae. As discussões filogenéticas disponíveis correspondem a estudos mais amplos, em que há alguma amostragem de gêneros da subfamília, ou a estudos de subgrupos de Leiinae.

A lista de caracteres abaixo é baseada em características de morfologia externa de adultos machos e fêmeas, como cabeça, tórax, asa e terminálias masculina e feminina. Foram calculados os índices de consistência (IC) e retenção (IR) e o número de transformações de cada caráter no cladograma resultante. Estes índices são válidos apenas para a análise sem a inclusão dos fósseis. Em alguns caracteres, há uma indicação em asterisco (*), significando que este estado de caráter é particular para os táxons fósseis.

Habitus, cabeça, tórax, asa e terminálias masculina e feminina de cada gênero estudado estão disponíveis nas figuras 11-300. Os gêneros conhecidos apenas de fósseis estão apresentados nas figuras 301-325. A escala padrão é $1 \mathrm{~mm}$. Sempre que a escala significar um valor diferente o mesmo está indicado na legenda.

As pranchas estão organizadas em subfamílias, de Leiinae a Sciophilinae. Dentro de cada subfamília os táxons estão apresentados de acordo com o cladograma obtido (figura 326). 


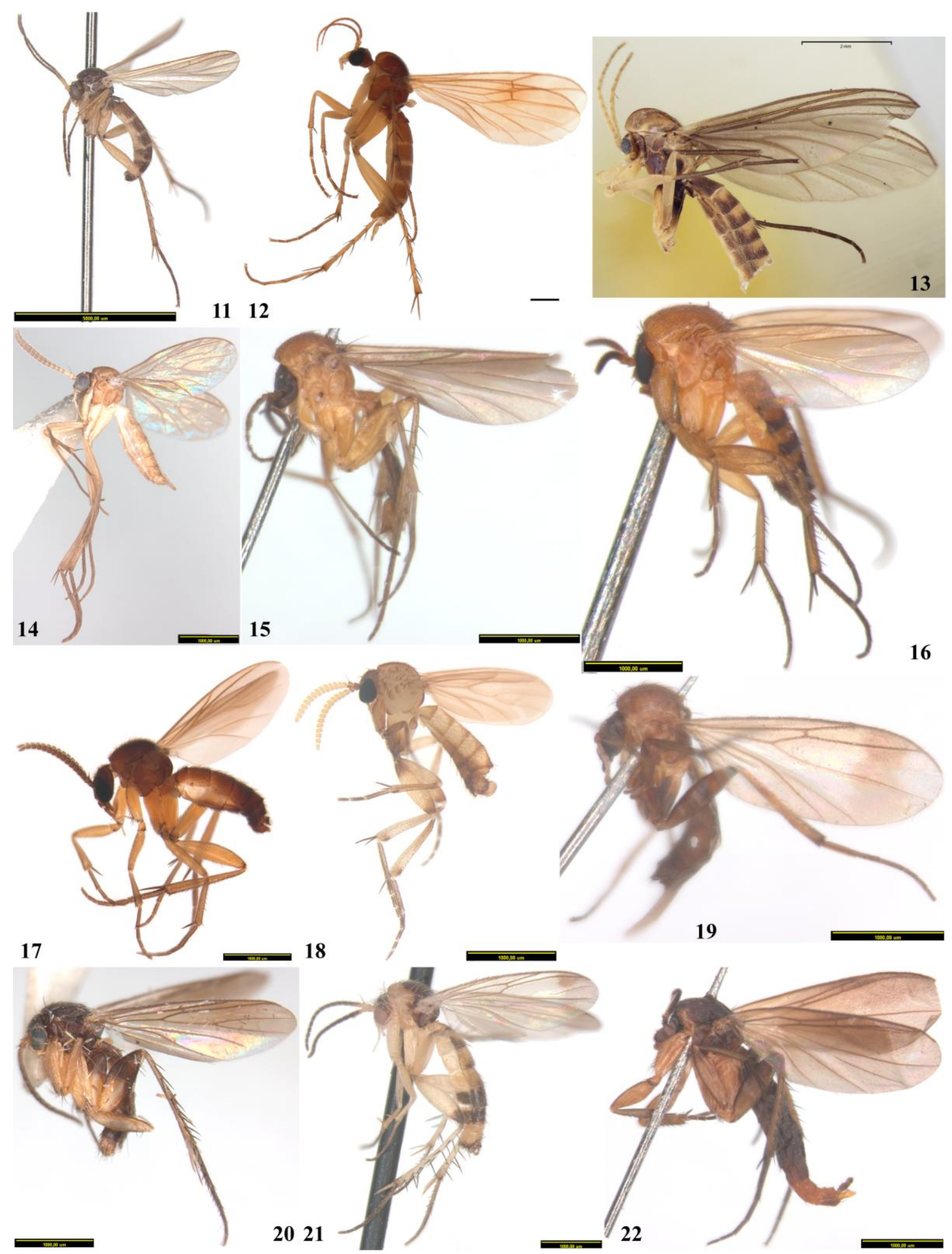

Figuras 11-22. Habitus de Mycetophilidae, vista lateral. 11. Garretella shermani (Garrett), $\hat{\jmath}$ (ANIC). Escala 5mm. 12. Paraleia fumosa Oliveira \& Amorim, parátipo 9 (modificado de Oliveira $\&$ Amorim, 2012: 5). 13. Thoracotropis cypriformis Freeman, holótipo $\widehat{\partial}$ (modificado de Oliveira et al., 2012: 460). Escala 2mm. 14. Gracilileia redunda Matile, $\widehat{\jmath}(\mathrm{MNHN})$. 15. Trichoterga monticola Tonnoir \& Edwards, $\widehat{\partial}$ (ANIC). 16. Megophthalmidia divergens Edwards, $\widehat{\partial}$ (MZUSP). 17. Mohelia nigricauda Matile, $\widehat{\partial}$ (NMSA). 18. Aphrastomyia shannoni Lane, $\widehat{\partial}$ (INPA). 19. Paracycloneura apicalis Tonnoir \& Edwards, + (ANIC). 20. Indoleia bisetosa (Edwards), $\widehat{\jmath}$ (AMSA). 21. Rondaniella dimidiata (Meigen), ô (CNC). 22. Waipapamyia elongata Jaschhof \& Kallweit, + (ANIC). 


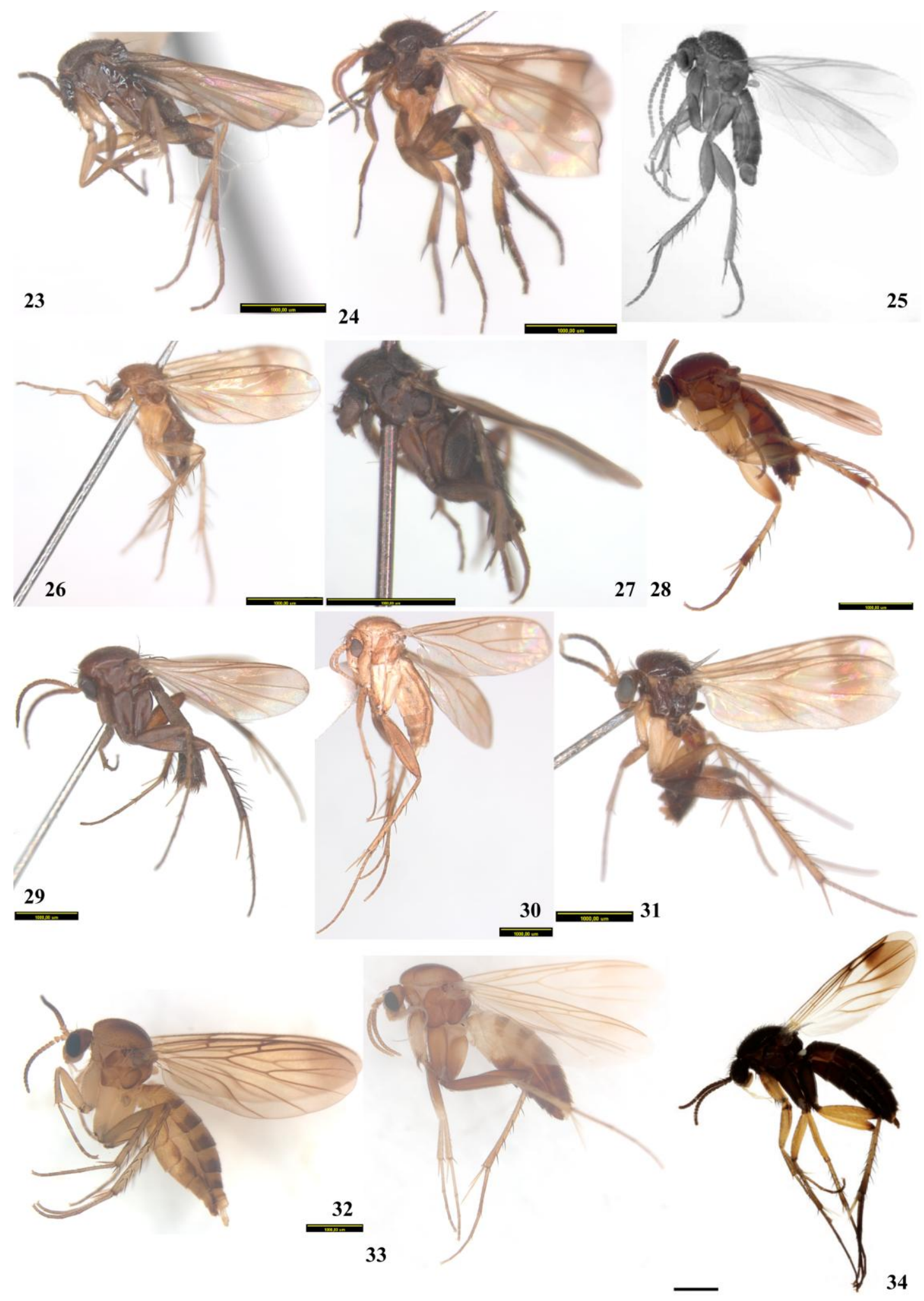

Figuras 23-34. Habitus de Mycetophilidae, vista lateral. 23. Paradoxa fusca Marshall, $\overbrace{}^{\Uparrow}$ (ANIC). 24. Sigmoleia melanoxantha Tonnoir \& Edwards, $\widehat{\partial}$ (ANIC). 25. Cawthronia nigra Tonnoir, $\widehat{\partial}$ (modificado de Jaschhof \& Kallweit, 2009: 9). 26. Cycloneura flava Marshall, o (ANIC). 27.

Tonnwardsia aberrans (Tonnoir), $\widehat{o}$ (ANIC). 28. Procycloneura paranensis Edwards, $q$ (MZUSP). 29. Leiella ochreocalcar Enderlein, $\partial^{\lambda}$ (MZUSP). 30. Anomalomyia nasuta Matile, ${ }_{+}(\mathrm{MNHN}) .31$. Ateleia spadicithorax Skuse, $q$ (ANIC). 32. Acrodicrania africana Edwards, + (SAMC). 33. Neoclastobasis draskovtisae Matile, ( (LMED). 34. Greenomyia mongolica Laštovka \& Matile, 우 (modificado de Kurina et al., 2011: 35). 

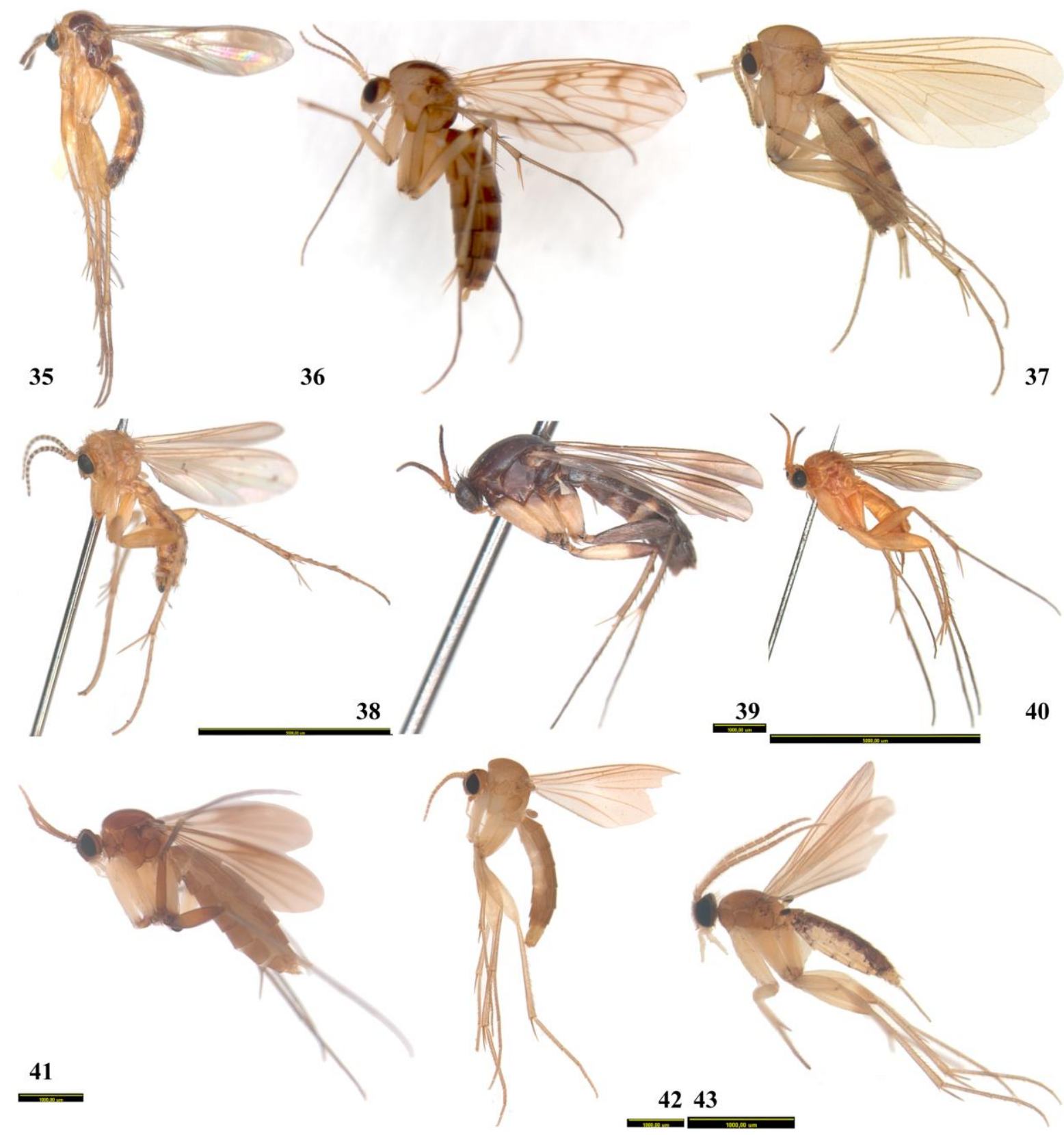

40
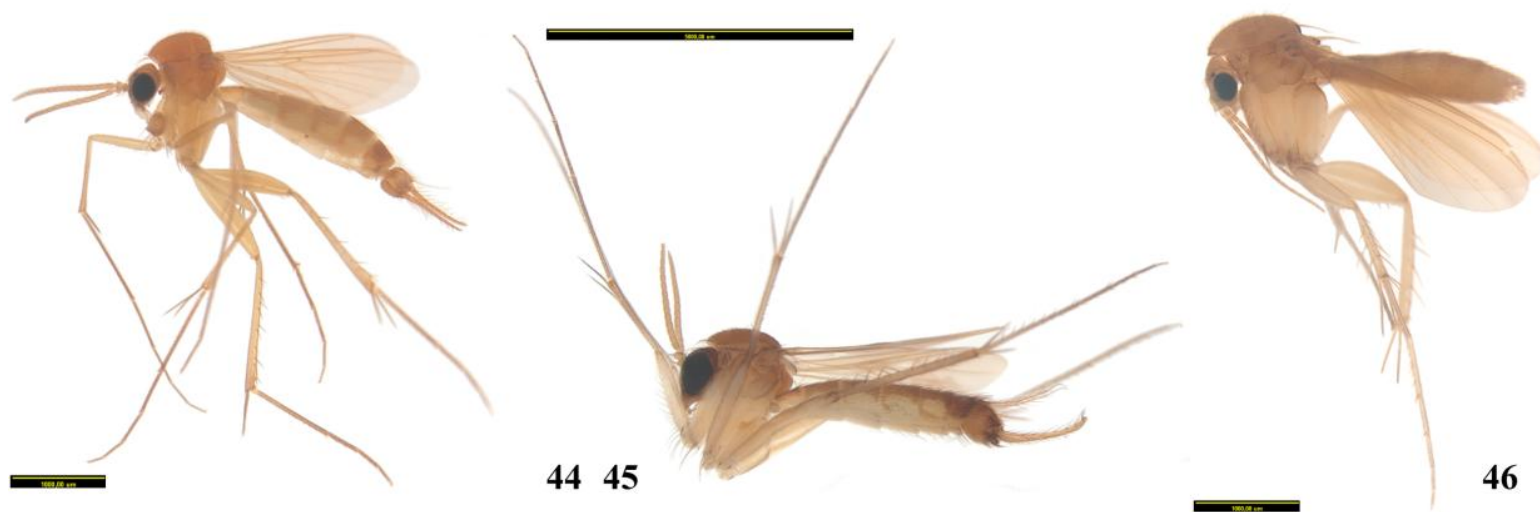

Figuras 35-46. Habitus de Mycetophilidae, vista lateral. 35. Leia andirai Lane, $\widehat{\partial}$ (MZUSP). 36. L. winthemi Lehmann, $ᄋ$ (LMED). 37. Clastobasis alternans (Winnertz), $q$ (LMED). 38. C. tryoni Skuse, $\widehat{\partial}$ (ANIC). Escala 5mm. 39. Allactoneura cincta de Meijere, ( $(\mathrm{CNC})$. 40. Sticholeia cheesmanae Søli, ô (ANIC). Escala 5mm. 41. Eumanota sp.,, (AMSA). 42. Promanota malaisei

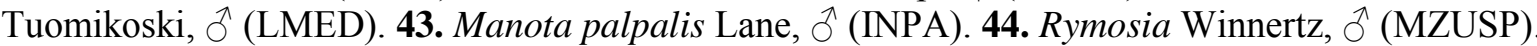
45. Exechiopsis Tuomikoski, ठ̊ (INPA). Escala 5mm. 46. Epicypta Winnertz, $ð$ (MZUSP). 


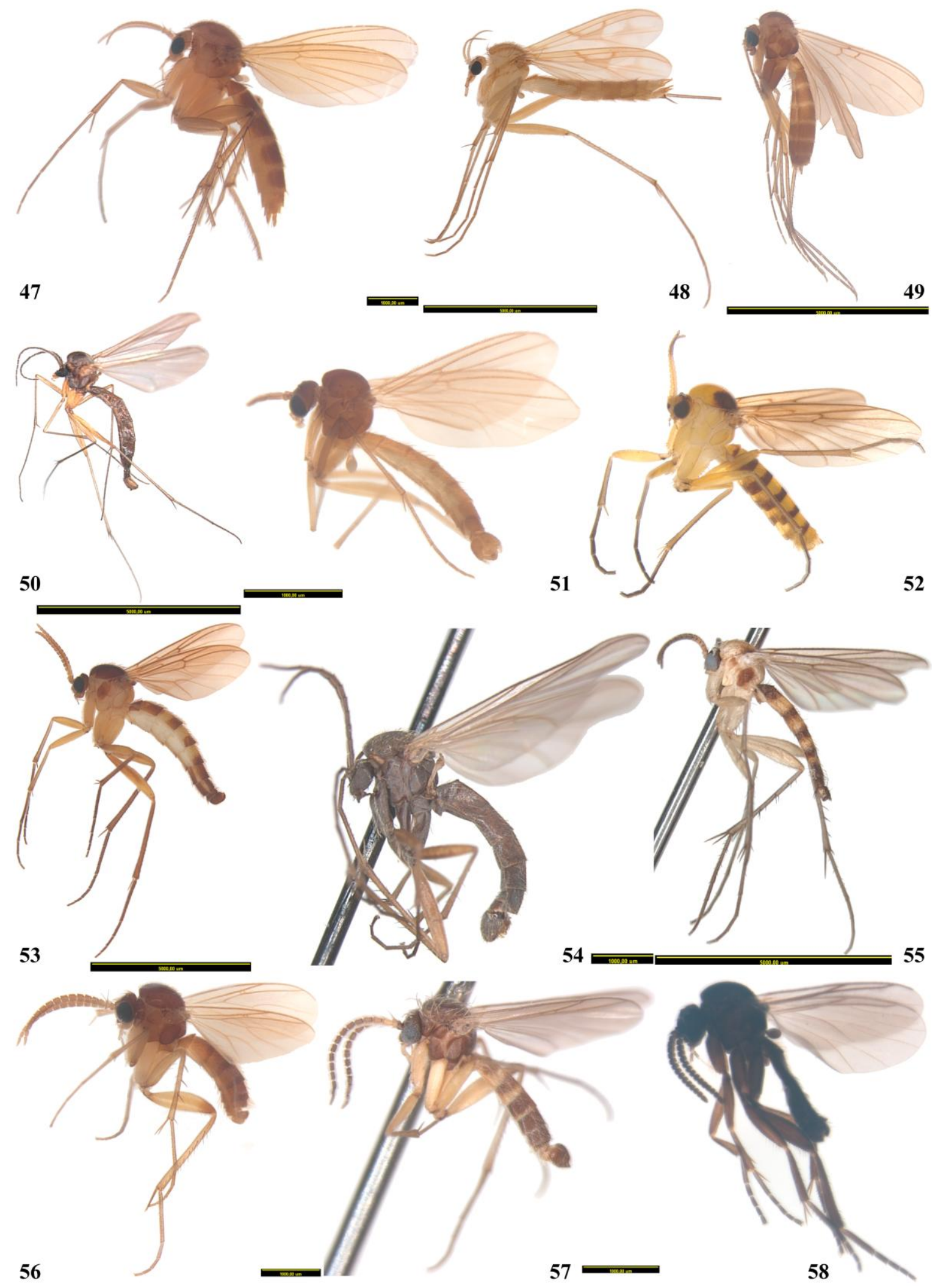

Figuras 47-58. Habitus de Mycetophilidae, vista lateral. 47. Mycetophila Meigen, Neoempheria Osten-Sacken, $\widehat{O}$ (LMED). Escala 5mm. 49. Mycomya Rondani, $q$ (MZUSP). Escala $5 \mathrm{~mm}$. 50. Synapha Meigen, $\sigma^{\uparrow}$ (AMSA). Escala $5 \mathrm{~mm}$. 51. Austrosynapha hirta Tonnoir, ô (ANIC). 52. Dziedzickia medea Lane, $q$ (MZUSP). 53. Schnusea caiabii Lane \& Coher, ô (MZUSP). Escala $5 \mathrm{~mm}$. 54. Boletina obscura Johannsen, ô (CNC). 55. Palaeodocosia vittata (Coquillett), ô (CNC). Escala 5mm. 56. Tetragoneura borgmeieri Edwards, $\widehat{\partial}$ (MZUSP). 57. Ectrepesthoneura laffooni Chandler, ô (CNC). 58. Novakia miloi Kerr, ô (LMED). 


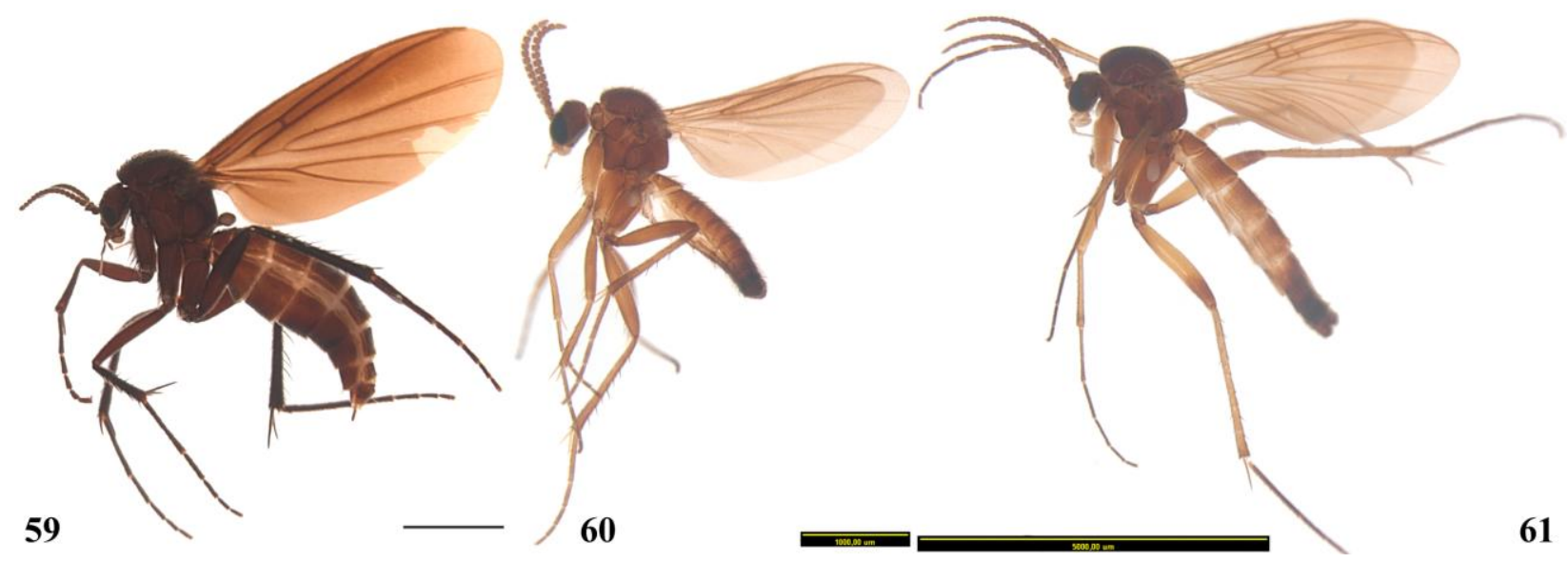

Figuras 59-61. Habitus de Mycetophilidae, vista lateral. 59. Docosia adusta Oliveira \& Amorim, $ᄋ$ (modificado de Oliveira \& Amorim, 2011: 690). 60. Neoallocotocera fusca Tonnoir, ô (ANIC). 61. Tasmanina gracilis Tonnoir, $\widehat{\jmath}$ (ANIC). Escala $5 \mathrm{~mm}$.

\section{Lista de caracteres}

\section{CABEÇA}

\section{Posição da cabeça em relação ao tórax:}

(0) vértex alinhado em relação à altura do escudo (figuras 12, 17-18, 32-34, 95-98);

(1) encaixada sob a margem anterior do escudo (figuras 13, 15, 19, 26-27, 44-47, 93, 99).

Número de passos: 5; IC: 20; IR: 50.

Segundo Tozoni (1998), em Mycetophilinae há um encaixe da cápsula cefálica sob a parte anterior do tórax, particularmente sob o escudo, e este caráter é uma sinapomorfia da subfamília. Porém, neste estudo, esta característica mostrou-se presente também em Thoracotropis, Trichoterga, Paracycloneura e no clado (Cycloneura+Tonnwardsia).

\section{Forâmen magno em relação à cabeça:}

(0) centralizado (figuras 11-14, 33-34, 40-43, 48-61);

(1) deslocado dorsalmente (figuras 13-32, 35-38, 96-98).

Número de passos: 2; IC: 50; IR: 98.

Segundo Hippa et al. (2004), a condição derivada deste caráter está presente em Allactoneura, Sticholeia, Leia, Aphrastomyia, Rondaniella, Leiella, Greenomyia, Mohelia, Ectrepesthoneura e Docosia. Esses autores de modo geral utilizaram, no entanto, apenas uma espécie de cada gênero. No presente estudo, no qual foi utilizada uma amostragem mais ampla, a condição por eles observada não se mostrou característica de todos esses gêneros. A 
condição apomórfica está presente apenas em Leiinae, no clado Thoracotropis $^{+}$, com uma reversão em (Neoclastobasis+Greenomyia).

\section{Formato da cabeça:}

(0) arredondada (figuras 11, 32-34, 56, 58);

(1) ovoide (figuras 17, 31, 96-98, 123).

Número de passos: 5; IC: 20; IR: 87.

O formato da cabeça foi utilizado como característica de valor filogenético por Søli (1997a) e Borkent \& Wheeler (no prelo), através de medidas comparativas de comprimento e largura. No presente trabalho, optou-se por utilizar o formato geral da cabeça, que é uma maneira mais clara de especificar a variabilidade morfológica observada. A condição apomórfica está presente em Mycomyinae, Mycetophilinae e, dentro de Leiinae, em Megophthalmidia ${ }^{++}$, com reversão em Anomalomyia ${ }^{*}$ (exceto em Ateleia).

\section{Cerdas ventrais na pós-gena:}

(0) curtas (figuras 64-65);

(1) 2 ou 3 cerdas de tamanho diferenciado, mais longas que as demais (figuras 109, 114$115)$;

(2) longas (figuras 63, 75, 120).

Número de passos: 5; IC: 40; IR: 92.

Esta característica ainda não havia sido utilizada em análises filogenéticas de Mycetophilidae. O estado (1) está presente (Procycloneura+Leiella) e no clado Anomalomyia*, com uma reversão em Caledonileia. O estado (2) é sinapomórfico para o clado (Manotinae (Sticholeia+Allactoneura)), com uma reversão em Promanota. A origem, assim, dos estados (1) e (2) é independente.

\section{Arranjo das cerdas pós-oculares:}

(0) aleatório (figuras 78-83);

(1) linear até a margem dorsal dos olhos (figuras 65, 80, 106);

(2) linear por toda a extensão látero-dorsal da cabeça (figuras 63 e 75).

Número de passos: 7; IC: 28; IR: 89.

Hippa et al. (2004) utilizaram a presença e ausência do arranjo linear de cerdas por toda a extensão látero-dorsal da cabeça em sua filogenia de Manotinae. Aqui é utilizado um segundo estado. O estado (1) está presente em Mycetophilinae, Promanota, Leiella e 
Anomalomyia*, com uma reversão em Caledonileia. Já o estado (2) é característico de Manotinae $^{+}$e Procycloneura. Hippa et al. (2004) indicam que em Promanota malaisei as cerdas têm arranjo linear em toda a extensão látero-dorsal da cabeça, mas no material estudado e em fotos recebidas fica evidente que Promanota possui o estado (1).

\section{Face posterior da cabeça:}

(0) não deprimida (figuras 64-65, 97-103);

(1) deprimida (figuras 39, 41, 43, 63).

Número de passos: 2; IC: 50; IR: 80.

A condição apomórfica deste caráter é uma sinapormorfia de $\mathrm{Manotinae}^{+}$, com uma reversão em Sticholeia. Na filogenia de Tozoni (1998), essa característica é apomórfica para Manotinae, também presente em Sticholeia e Allactoneura (com Sticholeia dentro de Leiinae). Tanto a codificação quanto o posicionamento de Tozoni (1999) para Sticholeia, no entanto, não foram corroborados pelo presente estudo. Os espécimes de Sticholeia analisados não apresentam a depressão na face posterior da cabeça (figuras 40 e 75) e o gênero não aparece como Leiinae, mas como grupo-irmão de Allactoneura, proximamente relacionado à Manotinae (figuras 326 e 328C). Tozoni (1998) utilizou apenas dados de literatura para sua codificação de Sticholeia e não há menção do caráter na descrição do gênero e das espécies conhecidas (Søli, 1996). Søli (1996) ilustra a cabeça de Sticholeia cheesmanae (figura 75), mas não é possível fazer tal inferência a partir da imagem.

\section{Formato da face posterior da cabeça:}

(0) retangular (figuras 12, 33-34, 114, 141-142);

(1) triangular (figuras 64-65, 96-98);

(2) como uma faixa estreita (figuras $28,39,43,63,120$ );

(3) proeminente medianamente (figuras 41 e 122).

Número de passos: 7; IC: 42; IR: 90.

Esta característica foi utilizada por Søli (1997a) e Hippa et al. (2004) como "convexidade média da pós-gena: presente ou reduzida". Como essa codificação mostrou-se pouco clara, optou-se por uma nova codificação dos estados. A condição retangular mostrouse plesiomórfica para a família. A condição triangular está presente em alguns Gnoristinae, Mycomyinae, Mycetophilinae, Promanota e em Thoracotropis ${ }^{+}$-ou seja, é plesiomórfica neste nível — com mudança em (Neoclastobasis+Greenomyia) e modificação para uma faixa estreita em Procycloneura. A face posterior da cabeça como uma faixa estreita é apomórfico 
para (Sticholeia+Allactoneura) e também está presente em Manota e Procycloneura. Já a condição proeminente medianamente é autapomórfico para Eumanota.

A redução da região dorsal da pós-gena em Allactoneura e Procycloneura não seria nova, a possibilidade de relacionamento entre os dois gêneros já tendo sido levantada na literatura (Shaw \& Shaw, 1951). De fato, há semelhança morfológica geral entre ambos, como pode ser visualizado nas figuras 63 e 28, respectivamente. Na análise de Hippa et al. (2004), Procycloneura é considerado grupo irmão de Manotinae. Essa hipótese, entretanto, não é corroborada neste estudo. Apesar das semelhanças na cápsula cefálica, há características de tórax e asa suficientes para sustentar o posicionamento de Procycloneura em Leiinae.

\section{Número de ocelos:}

(0) três (figuras 67, 73, 77-83);

(1) dois (figura 71);

$(2 *)$ zero.

Número de passos: 7; IC: 14; IR: 53.

A presença de três ocelos é característica plesiomórfica para Mycetophilidae (Vockeroth, 1981; Tozoni, 1998). A perda do ocelo mediano é vista, por exemplo, em alguns gêneros de Mycetophilidae e em alguns de Keroplatidae (Amorim \& Rindal, 2007) e é bem mais comum que a redução do ocelo mediano (Matile, 1990). A perda do ocelo mediano é apomórfica para Mycomyinae e Mycetophilinae e também está presente em Sticholeia, em duas espécies de Aphrastomyia, Indoleia, uma espécie de Anomalomyia e em Caledonileia.

\section{Ocelo mediano:}

(0) pouco menor ou do mesmo tamanho dos laterais (figuras 67, 77-83);

(1) extremamente reduzido (figuras 69-70).

Número de passos: 1; IC: 100; IR: 100.

Este caráter é novo e permite compreender melhor a questão da evolução dos ocelos, pois complementa a informação que emerge do caráter anterior. Nesta análise, aparece como uma sinapomorfia de Leiella.

\section{Disposição dos ocelos:}

(0) arranjo triangular (figuras 67, 77-80);

(1) arranjo linear (figuras 71 e 83). 
Número de passos: 12; IC: 8; IR: 77.

Segundo Tozoni (1998), a condição apomórfica deste caráter está presente no planobásico de Mycetophilidae. Porém, no estudo aqui realizado, o arranjo triangular mostrou-se plesiomórfico para a família e a condição linear surgiu várias vezes dentro da família, com destaque, dentro de Leiinae, para os clados (Garretella+Paraleia) e Anomalomyia*, com reversões em (Neoclastobasis+Greenomyia) e Leia ventralis.

\section{Cerdas interocelares:}

(0) muitas (figuras 78-79);

(1) poucas (figuras 82-83);

(2) nenhuma (figura 71).

Número de passos: 13; IC: 15; IR: 66.

Este é um caráter novo no estudo de Mycetophilidae. O estado (1) mostrou-se plesiomórfico para Leiinae e há várias mudanças paralelas dentro da subfamília, como a presença do estado (2) em (Garretella+Paraleia), Aphrastomyia e Procycloneura.

\section{Disposição dos ocelos laterais em relação à margem dos olhos:}

(0) distância maior que seu próprio diâmetro (figuras 77-80);

(1) distância menor que seu próprio diâmetro (figuras 81-83).

Número de passos: 12; IC: 8; IR: 76.

Aparentemente, a condição plesiomórfica passa para a apomórfica com grande plasticidade dentro da evolução da família, conforme observado por Hippa et al. (2004). O mesmo foi observado neste estudo e o estado derivado mostrou-se plesiomórfico para Leiinae.

\section{Cerda pós-ocelar em frente aos ocelos laterais:}

(0) ausente (figuras 77-80);

(1) presente (figuras 69 e 73 ).

Número de passos: 2; IC: 50; IR: 91.

Este é um caráter novo, apomórfico para os clados $(($ Cycloneura + Tonnwardsia $)($ Procycloneura + Leiella $))$ e (Neoclastobasis + Greenomyia $)$.

\section{Sutura frontal entre ocelo mediano e a base das antenas:}

(0) presente (figuras 67, 71, 73); 
(1) ausente (figura 84).

Número de passos: 8; IC: 12; IR: 58.

Este caráter é aqui proposto pela primeira vez para o entendimento das relações filogenéticas de Mycetophilidae. A presença da sutura é plesiomófico para Leiinae, com perdas independentes em (Garretella+Paraleia), Indoleia e Paradoxa paradoxa.

\section{Comprimento da antena em relação à cabeça e ao tórax (nos machos):}

(0) mais longa (figuras 11, 13, 43, 46, 54 e 57);

(1) menos ou tão longa (figuras 16-18, 40 e 45).

Número de passos: 20; IC: 5; IR: 47.

Este caráter é proposto pela primeira vez. A antena mais longa que cabeça e tórax é plesiomófica para Leiinae e o estado apomórfico surgiu ao menos duas vezes dentro do grupo, em Megophthalmidia ${ }^{+}$e Waipapamyia ${ }^{+}$.

\section{Formato do escapo e pedicelo:}

(0) arredondados e aproximadamente do mesmo tamanho (figura 72);

(1) escapo arredondado e pedicelo distintamente alongado na base (figuras 69-70);

(2) escapo distintamente alongado na base e pedicelo arredondado.

Número de passos: 9; IC: 22; IR: 84.

Caráter novo, o escapo e pedicelo arredondados e do mesmo tamanho é uma característica presente no plano-básico de Leiinae. A condição de escapo arredondado e pedicelo alongado é apomórfico na subfamília em Thoracotropis, (Mohelia+Aphrastomyia) e Indoleia ${ }^{+}$, com reversões em Waipapamyia e Paradoxa. O escapo alongado e pedicelo arredondado é autoapomórfico para Promanota.

\section{Densas cerdas na superfície anterior do escapo e pedicelo:}

(0) ausentes (figuras 64-66 e 72);

(1) presentes (figuras 62-63).

Número de passos: 13; IC: 7; IR: 53.

Este é um caráter novo. O estado (0) é plesiomórfico para Leiinae, sendo que o estado apomórfico surgiu várias vezes dentro do grupo, como em Indoleia, Waipapamyia, Procycloneura, Ateleia ${ }^{+}$e Neoclastobasis. 


\section{Longa cerda apico-posterior no pedicelo:}

(0) ausente (figuras 12, 37, 52-54);

(1) presente (figuras 64-66).

Número de passos: 9; IC: 11; IR: 77.

Este caráter é aqui proposto pela primeira vez para o entendimento das relações filogenéticas de Mycetophilidae. A presença de uma cerda posterior apical longa no pedicelo é apomórfico para Leiinae, com reversões em Paraleia, Megophthalmidia, (Procycloneura+Leiella) e Clastobasis sp.

\section{Comprimento da cerda em relação à altura do escapo:}

(0) menos ou igual a $2 x$ (figuras 21 e 64);

(1) mais de $2 x$ (figuras 31 e 66).

Número de passos: 6; IC: 16; IR: 76.

Conforme comentado anteriormente, a presença de uma longa cerda apico-posterior no pedicelo é apomórfico para Leiinae e o comprimento desta cerda não ultrapassa duas vezes o comprimento do escapo. Cerdas mais longas que isso surgiram várias vezes dentro do grupo, como em Gracilileia, Aphrastomyia shannoni e Paracycloneura ${ }^{+}$, com reversão em Rondaniella.

\section{Morfologia dos flagelômeros antenais:}

(0) cilíndricos (figuras 11, 43, 54 e 57);

(1) achatados lateralmente (figuras 18, 64, 98).

Número de passos: 1; IC: 100; IR: 100.

Os flagelômeros antenais em Mycetophilidae são cilíndricos e geralmente em número de 14 (Vockeroth, 1981; Tozoni, 1998). A variação da morfologia dos flagelômeros antenais foi relatada por Tozoni (1998), Hippa et al. (2004) e Borkent \& Wheeler (no prelo). No presente estudo, essa mudança mostrou-se sinapomórfica para Aphrastomyia.

\section{Flagelômeros antenais cilíndricos:}

(0) tão largos quanto longos (figuras 17 e 97);

(1) mais largos que longos (figuras 16 e 96);

(2) mais longos que largos (figuras 11 e 54).

Número de passos: 15; IC: 13; IR: 69. 
Este caráter, novo, mostra que a presença de flagelômeros antenais mais longos que largos é plesiomórfica em Leiinae, compatível com a presença de antenas com flagelômeros alongados em outras subfamílias. A presença de flagelômeros mais largos que longos é sinapomórfica para Megophthalmidia, havendo várias modificações independentes dentro de Leiinae para a condição de flagelômeros tão largos quanto longos.

\section{Primeiro flagelômero antenal:}

(0) do mesmo comprimento que os demais (figuras 11, 13, 18);

(1) mais longo que os demais (figuras 14 e 31 ).

Número de passos: 5; IC: 20; IR: 69.

Este caráter foi utilizado por Tozoni (1998) e Amorim \& Rindal (2007). De acordo com Amorim \& Rindal (2007), a condição de flagelômeros antenais todos do mesmo tamanho é plesiomórfica em Diptera. Em Leiinae, o estado apomórfico está presente em Gracilileia, Paracycloneura, (Ateleia+Acrodicrania) e Greenomyia.

\section{Um par de cerdas mais longas que as demais no último flagelômero antenal:}

(0) ausente (figuras 18, 32-33, 64);

(1) presente (figura 87).

Número de passos: 3; IC: 33; IR: 60.

Este caráter, proposto pela primeira vez, é sinapomórfico para o clado Waipapamyia $^{+}$, com reversões em (Paradoxa+Sigmoleia) e em Leiella.

\section{Fronte:}

(0) nua (figuras 80 e 83);

(1) parcialmente pubescente (figuras 77, 81-82);

(2) completamente pubescente (figuras 76, 78-79);

(3) apenas com uma cerda lateral à margen do olho, próxima à base das antenas.

Número de passos: 18; IC: 16; IR: 61.

A pubescência da fronte foi utilizada por Søli (1997a). Em Leiinae, a condição plesiomórfica é a fronte nua. A condição parcialmente pubescente está presente em Trichoterga, (Mohelia+Aphrastomyia), Megophthalmidia nigra, Paradoxa, Cycloneura ${ }^{+}$, Caledonileia e (Greenomyia cephala+G. joculator). A condição completamente pubescente é apomórfica para (Indoleia+Rondaniella), Sigmoleia e Cawthronia. A presença de apenas uma cerda lateral nas margens dos olhos é sinapomórfica para Allactoneura. 


\section{Face:}

(0) pubescente (figuras 68, 75-83);

(1) nua (figuras 62-63).

Número de passos: 3; IC: 33; IR: 60.

Caráter novo, em Leiinae a condição plesiomórfica é a presença de cerdas na face, havendo surgimentos independentes da condição apomórfica em Gracilileia e Indoleia, além de Allactoneurinae.

\section{Formato da face:}

(0) ovoide (figura 83);

(1) aproximadamente retangular com margem dorsal triangular (figura 80);

(2) retangular estreita (figura 85);

(3) quadrada (figura 68);

(4) retangular larga (figura 62);

(5) retangular alongada (figura 86);

(6) arredondada dorsalmente, mais larga e côncava ventralmente;

(7*) triangular (figura 316).

Número de passos: 12; IC: 50; IR: 88.

Este caráter é aqui proposto pela primeira. Em Leiinae, o estado (1) é plesiomórfico. O estado (2) é sinapomórfico para Thoracotropis ${ }^{+}$, com reversão em Megophthalmidia ${ }^{+}$e Waipapamyia $^{+}$. O estado (0) é apomórfico para Paracycloneura e o estado (3) para Procycloneura. Em relação às outras subfamílias de Mycetophilidae, o estado (6) é sinapomórfico para Mycomyinae, o estado (3) para Manotinae, o estado (4) para (Sticholeia+Allactoneura) e o estado (5) é autoapomórfico para Promanota.

\section{Relação entre face e clípeo:}

(0) face tão larga quanto o clípeo (figura 80);

(1) face mais larga que o clípeo (figura 68);

(2) face mais estreita que o clípeo (figuras 85-86).

Número de passos: 12; IC: 16; IR: 78.

Este caráter foi utilizado por Hippa et al. (2004) e Borkent \& Wheeler (no prelo) e é bastante plástico. Em Leiinae, o estado (1) corresponde à condição plesiomórfica. O estado (0) é apomórfico para Garretella, Gracilileia, Paracycloneura, Rondaniella, Leiella e Caledonileia ${ }^{+}$. O estado (2) é apomórfico para Paraleia e Indoleia. 


\section{Clípeo:}

(0) pubescente (figuras $62,68,75-83,85-87$ );

(1) nu (figuras 88-89).

Número de passos: 1; IC: 100; IR: 100.

Este caráter foi utilizado por Søli (1997a) e Hippa et al. (2004). A ausência de cerdas no clípeo é uma sinapomorfia de (Megophthalmidia (Aphrastomyia+Mohelia)).

\section{Desenvolvimento do clípeo em relação à face:}

(0) mais desenvolvido (figuras 62 e 74);

(1) tanto quanto (figuras $72,77,83$ );

(2) menos desenvolvido (figuras $68,78,80,86$ ).

Número de passos: 12; IC: 16; IR: 44.

Este caráter, proposto pela primeira vez, mostra o clípeo menos desenvolvido que a face como a condição no plano-básico de Leiinae. O clípeo tão desenvolvido quanto a face é apomórfico para Thoracotropis e Waipapamyia ${ }^{+}$, com reversão em (Procycloneura+Leiella). O clípeo menos desenvolvido que a face é apomórfico para Paracycloneura e Paradoxa.

\section{Clípeo:}

(0) não projetado além da margem ventral da cabeça (figuras 63, 68, 72);

(1) projetado além da margem ventral da cabeça (figuras 30, 114-115).

Número de passos: 8; IC: 12; IR: 70.

Este caráter é aqui proposto pela primeira. Em Leiinae, o estado (0) é a condição no plano-básico da subfamília e o estado (1) tem diversas origens independentes, como em (Garretella+Paraleia), Sigmoleia, Tonnwardsia, Leiella, Anomalomyia e (Neoclastobasis+Greenomyia).

\section{Margens do clípeo:}

(0) arredondadas (figura 74);

(1) anguladas (figura 90).

Número de passos: 4; IC: 25; IR: 81.

Caráter novo e em Leiinae a condição apomórfica está presente apenas em Gracilileia.

\section{Formato do clípeo:}

(0) ovoide (figuras 62 e 74); 
(1) retangular (figura 77);

(2) triangular (figura 89);

(3) quadrado (figura 72).

Número de passos: 9; IC: 33; IR: 76.

Proposto pela primeira vez, em Leiinae o estado (1) é apomórfico para Gracilileia e Paradoxa, e o estado (2), para (Mohelia+Aphrastomyia).

\section{Saliência anterior do clípeo:}

(0) ausente (figuras 62 e 74);

(1) presente (figuras 57, 59, 137-138).

Número de passos: 2; IC: 50; IR: 95.

Este é um caráter novo, com dois surgimentos independentes em Mycetophilidae, um em Docosia $^{+}$e outro em Paraleia.

\section{Labro bem desenvolvido e alongado, mais longo que o clípeo:}

(0) ausente;

(1) presente (figuras 64-65, 88-89).

Número de passos: 1; IC: 100; IR: 100.

Este é um caráter novo, sinapomórfico para (Megophthalmidia (Mohelia+Aphrastomyia)).

\section{Organização das peças bucais:}

(0) como uma labela curta (figuras 75-83);

(1) alongadas como uma probóscide levemente alongada (figuras 17 e 97);

(2) alongados como uma probóscide longa (figuras 64-65).

Número de passos: 2; IC: 100; IR: 100.

Este caráter foi utilizado por Tozoni (1998) e, neste estudo, algum alongamento da probóscide é sinapomórfico para (Megophthalmidia (Mohelia+Aphrastomyia)). A probóscide longa é apomórfica dentro de Aphrastomyia, como em Aphrastomyia cramptoni.

\section{Peças bucais:}

(0) bem desenvolvidas (figuras 64-66);

(1) reduzidas (figuras 76 e 78).

Número de passos: 3; IC: 33; IR: 33. 
Tozoni (1998) utilizou uma codificação parecida, referenciando-se à fusão das labelas 1 e 2. Este caráter é redefinido aqui, com uma redução das peças bucais, em Leiinae, sendo apomórfica para Thoracotropis, Sigmoleia e Caledonileia, conforme discutido por Matile (1993) e Oliveira et al. (2012).

\section{Número de palpômeros (sem considerar o palpígero):}

(0) quatro (figura 83);

(1) dois (figuras 76 e 78);

$(2 *)$ três.

Número de passos: 3; IC: 33; IR: 33.

Vockeroth (1981) comenta que o estado mais geral em relação ao número de palpômeros em Mycetophilidae é o de quatro palpômeros (considerando o palpígero como não sendo um artículo). A variação do número de palpômeros na família é bastante comum. Em Gnoristinae, há exemplos de modificações em Dziedzickia Johannsen e Metanepsia Edwards (Tozoni, 1998; Oliveira, 2009). A presença de apenas dois palpômeros maxilares é apomórfica para Thoracotropis, Sigmoleia e Caledonileia, conforme discutido por Matile (1993) e Oliveira et al. (2012).

\section{Terceiro palpômero labial:}

(0) arredondado (figura 83);

(1) levemente alongado (figura 77);

(2) muito mais longo que os demais (figuras 66 e 90).

Número de passos: 10; IC: 20; IR: 66.

Este caráter foi utilizado por Amorim \& Rindal (2007). O alongamento do terceiro palpômero labial é uma condição do plano básico de Leiinae. A presença de um palpômero extremamente alongado é sinapomórfico para Gracilileia e o terceiro palpômero arredondado está presente em Megophthalmidia ${ }^{+}$, Paracycloneura e Waipapamyia ${ }^{+}$, com reversões em (Cycloneura+Tonnwardsia) e Leiella.

\section{Comprimento do último palpômero labial $\left(5^{\circ}\right)$ em relação ao penúltimo $\left(4^{\circ}\right)$ :}

(0) aproximadamente 1,5x (figuras 79, 81-82, 126);

(1) maior que $1,5 \mathrm{x}$ (figuras 74 e 91 );

(2) do mesmo comprimento (figuras 77 e 80);

(3) extremamente longo, muito mais longo que os demais (figura 68); 
(4) menor (figuras 40 e 77).

Número de passos: 25; IC: 16; IR: 36.

Søli (1997a), Tozoni (1998), Hippa et al. (2004) e Amorim \& Rindal (2007) utilizaram este caráter com algumas variações nos estados observados. No presente estudo, o estado (3) é autoapomórfico para Eumanota e o estado (4) é sinapomórfico para Sticholeia.
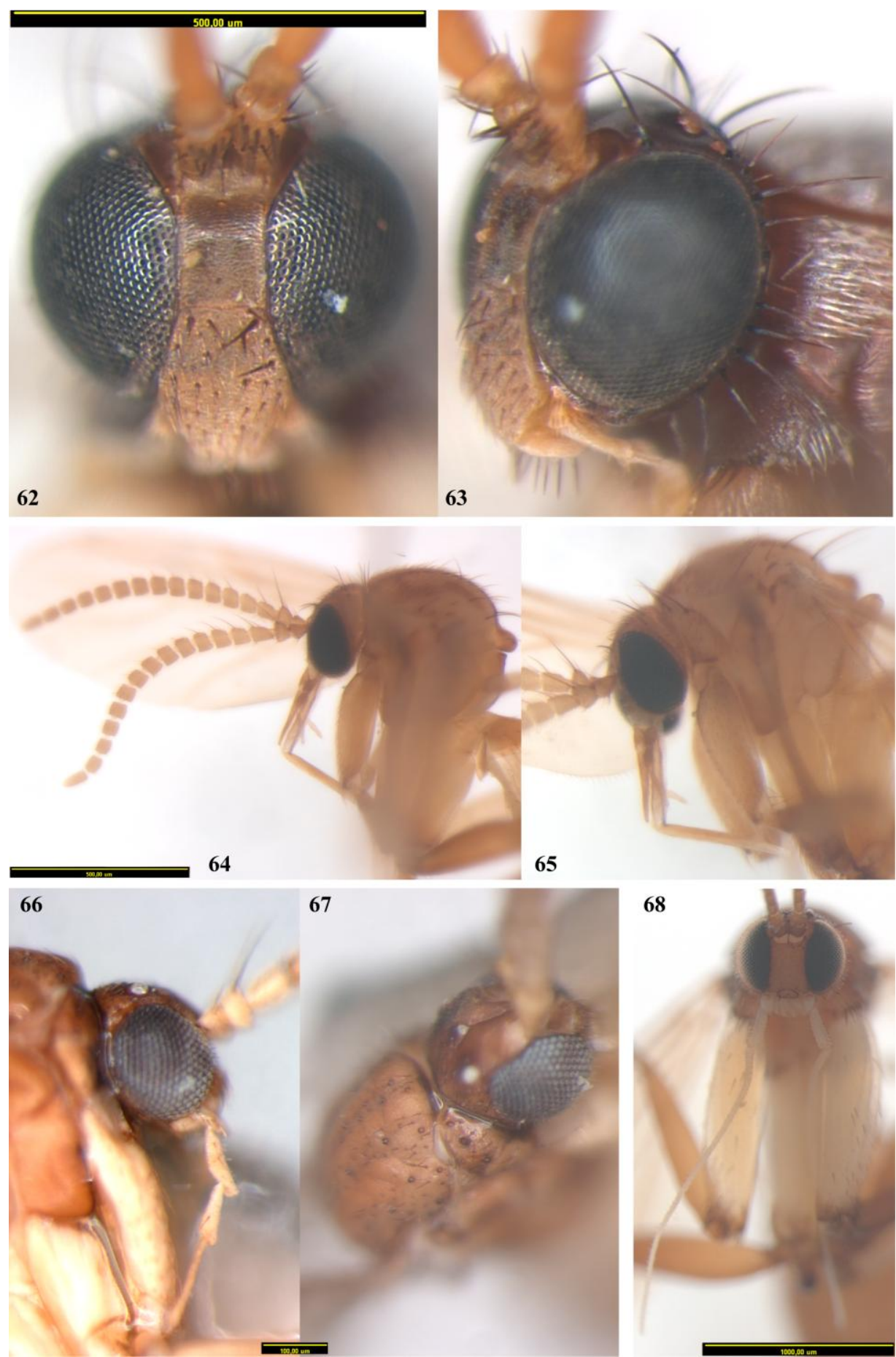

Figuras 62-68. Cabeça e tórax de Mycetophilidae. 62-63. Allactoneura arguentosquamosa Enderlein, $\widehat{\jmath}$ (NMSA). Escala $0,5 \mathrm{~mm}$. 62. Vista frontal. 63. Vista lateral. 64-65. Aphrastomyia cramptoni Coher \& Lane, $\widehat{\partial}$ (MZUSP). Escala $0,5 \mathrm{~mm}$. Vista lateral. 66-67. Gracilileia redunda, $\widehat{\partial}$ (MNHN). 66. Vista lateral. 67. Vista dorsal. 68. Eumanota, ${ }_{+}$(AMSA). 


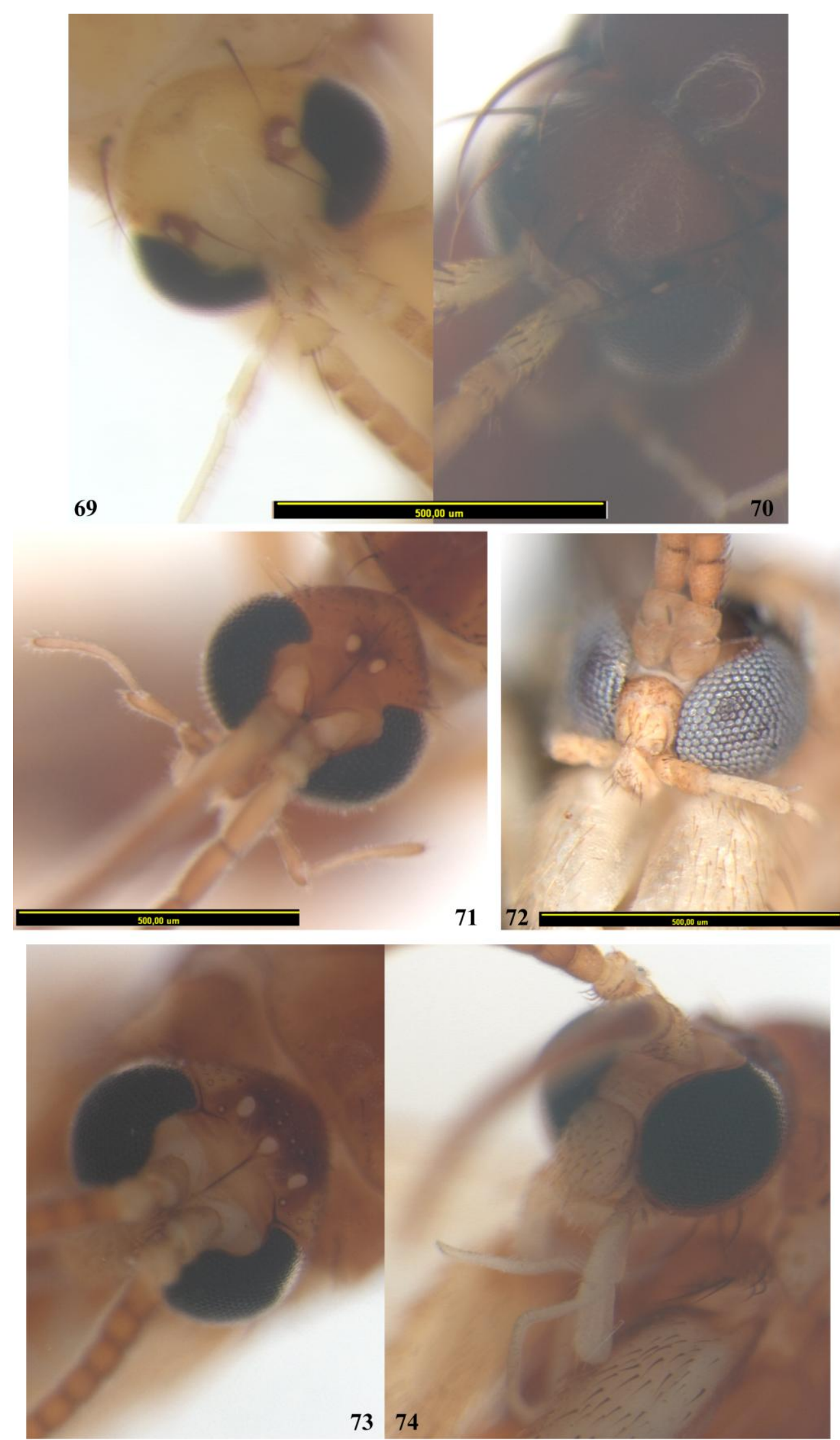

Figuras 69-74. Cabeça de Mycetophilidae. 69. Leiella unicincta Edwards, $q$ (INPA). Escala 0,5mm. 70. Leiella ochreocalcar, ô (MZUSP). Escala 0,5mm. 71. Mycomya, ô (MZUSP). Escala 0,5mm. 72. Palaeodocosia vittata, $\widehat{\partial}(\mathrm{CNC})$. Escala $0,5 \mathrm{~mm}$. 73-74. Neoclastobasis draskovitsae, $\widehat{\partial}$ (LMED). 73. Vista dorsal. 74. Vista frontal. 

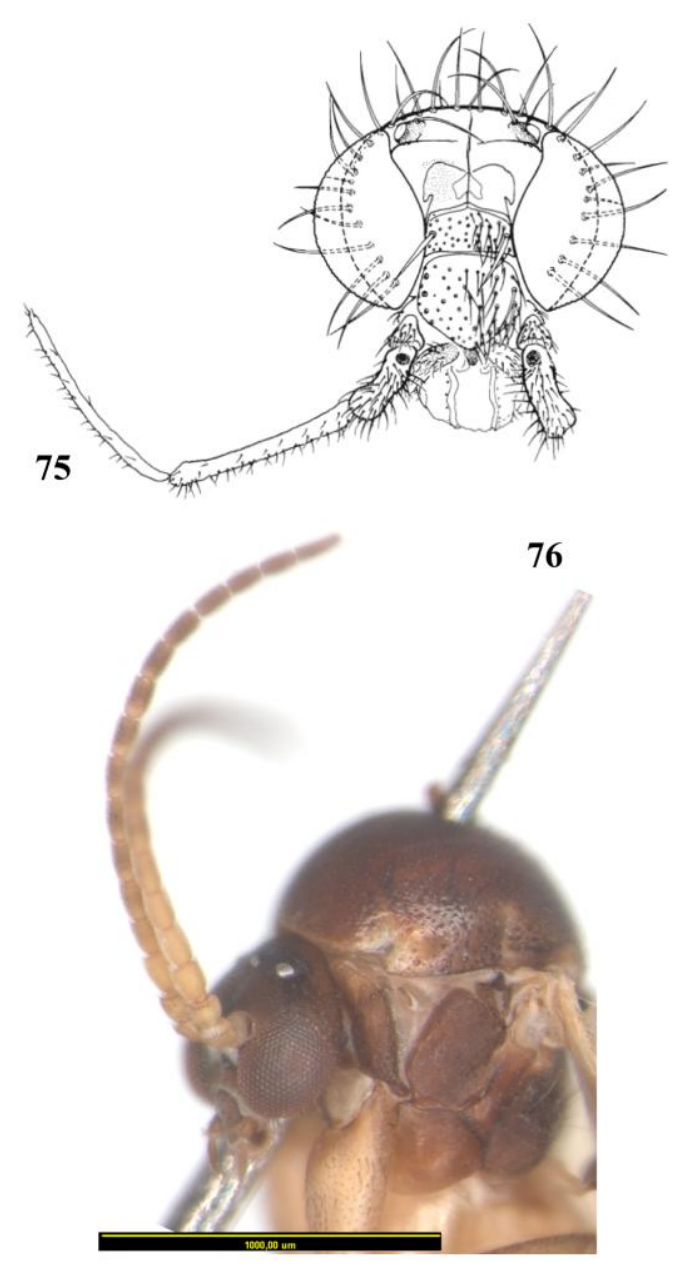
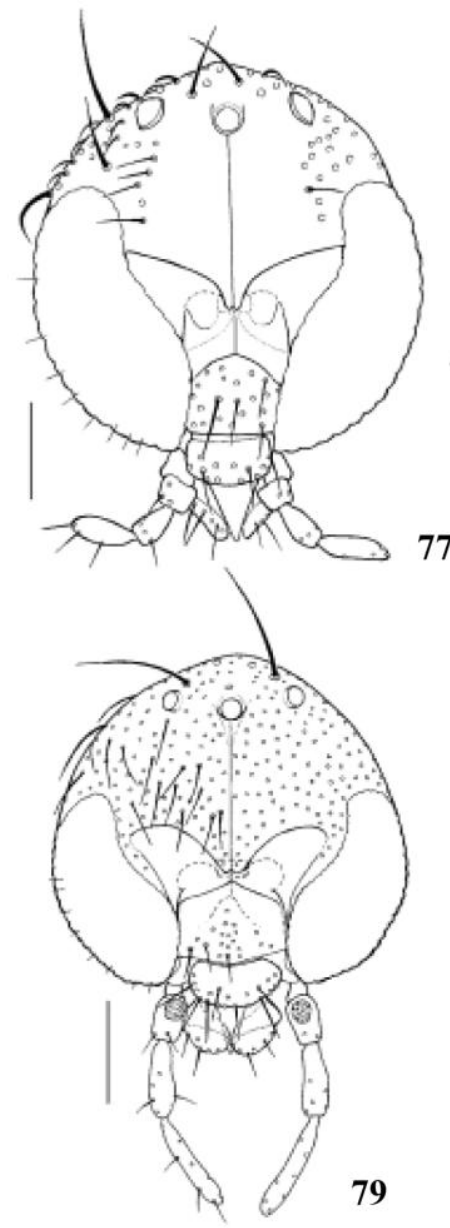

77
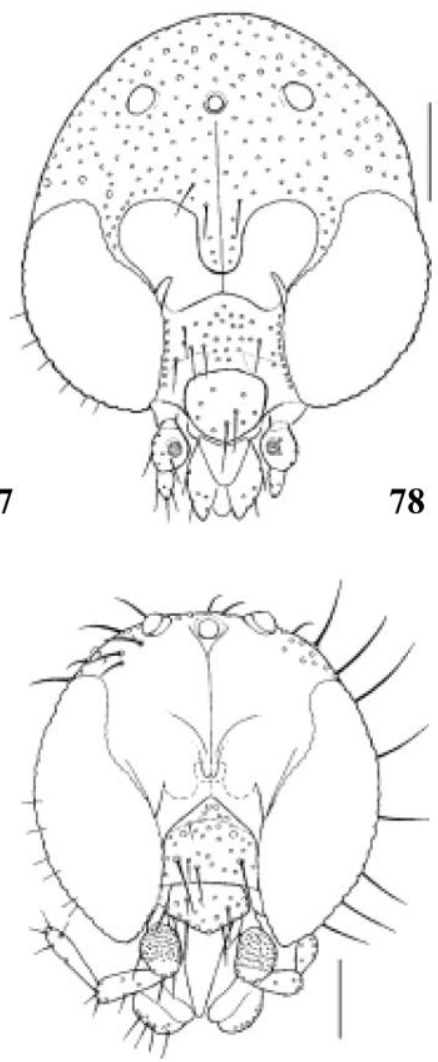

80

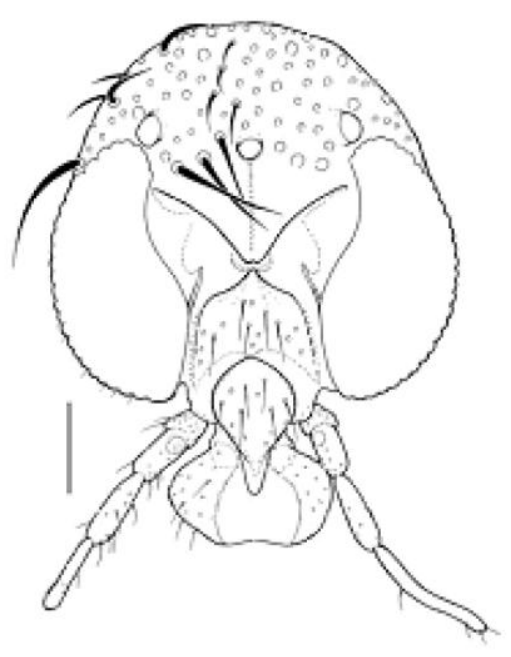

81

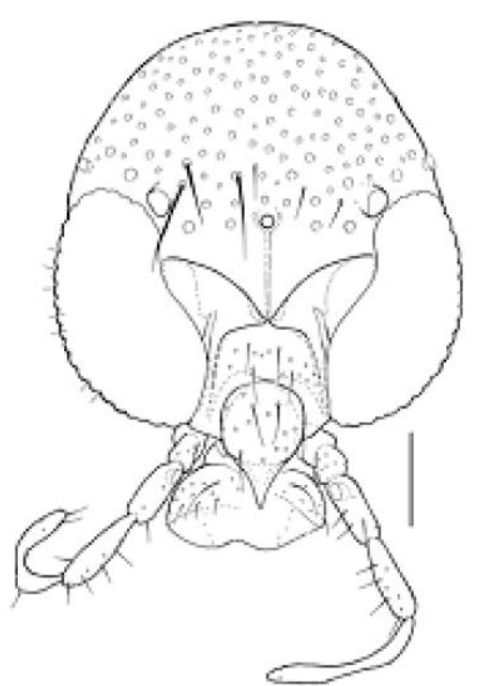

82

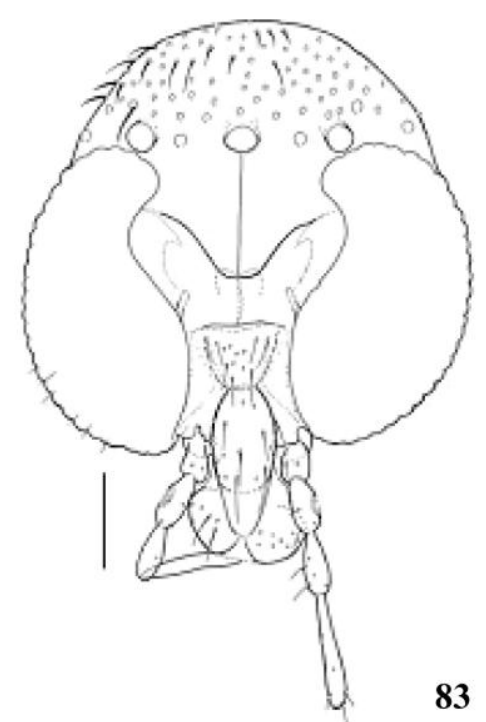

Figuras 75-83. Cabeça de Mycetophilidae. 75. Sticholeia cheesmanae (modificado de Søli, 1996: 3). 76. Sigmoleia melanoxantha, ơ (MNHN). 77. Paradoxa fusca (modificado de Jaschhof \& Kallweit, 2009: 14). 78. Sigmoleia peterjohnsi Jaschhof \& Kallweit (modificado de Jaschhof \& Kallweit, 2009: 14). 79. Cawthronia nigra (modificado de Jaschhof \& Kallweit, 2009: 14). 80. Waipapamyia dentata

Jaschhof \& Kallweit (modificado de Jaschhof \& Kallweit, 2009: 14). 81. Cycloneura Marshall (modificado de Jaschhof \& Kallweit, 2009: 14). 82. Tonnwardsia Jaschhof \& Kallweit (modificado de Jaschhof \& Kallweit, 2009: 14). 83. Paracycloneura apicalis (modificado de Jaschhof \& Kallweit, 2009: 14). 

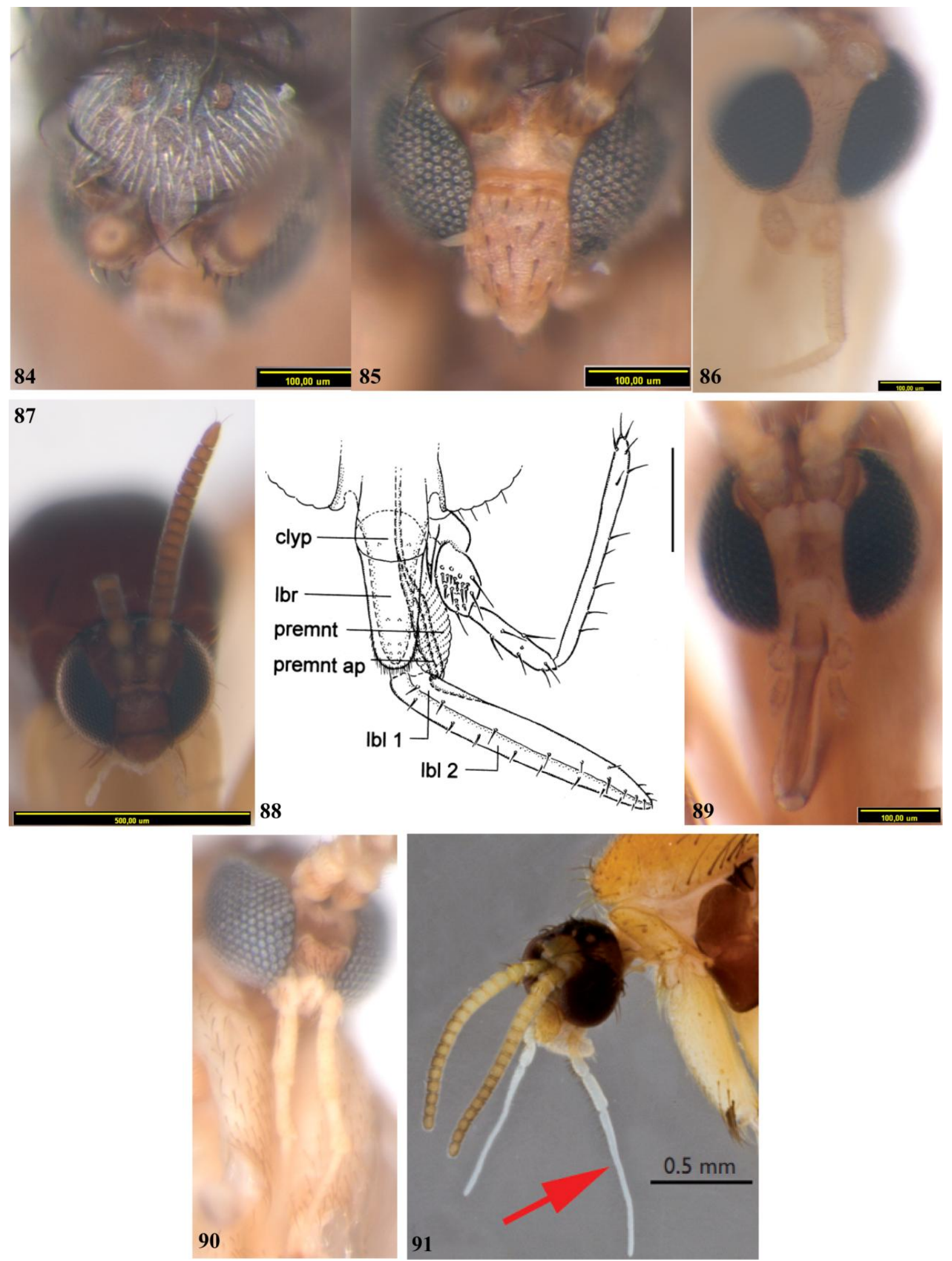

Figuras 84-91. Cabeça e peças bucais de Mycetophilidae. 84-85. Indoleia bisetosa, , (AMSA). 84. Vista dorsal. 85. Vista frontal. 86. Promanota malaisei, ô (LMED). 87. Procycloneura Edwards, $q$ (IAvH). Escala 0,5mm. 88. Aphrastomyia longirostris Jaschhof \& Kallweit (modificado de Jaschhof \& Kallweit, 2004: 109). Escala 0,1 mm. 89. Aphrastomyia cramptoni, $\widehat{\partial}$ (MZUSP). Escala 0,1mm. 90. Gracilileia redunda, $\widehat{\partial}$ (ANIC). 91. Greenomyia stackelbergi Zaitzev, q (modificado de Kurina et al., 2011: 36). 


\section{TÓRAX}

\section{Organização geral do tórax:}

(0) não deprimido dorso-ventralmente (figuras 8B, 11-14, 42, 49-55);

(1) moderadamente deprimido dorso-ventralmente (figuras 16-22, 44-45);

(2) fortemente deprimido dorso-ventralmente (figuras 28-29).

Número de passos: 8; IC: 25; IR: 81.

Segundo Tozoni (1998), Allactoneurinae, Manotinae e Mycetophilinae apresentam o tórax fortemente deprimido dorso-ventralmente e esta modificação se refletiria no formato geral do corpo, especialmente no mediotergito. Essa característica também está presente em Cycloneura, Procycloneura, Acrodicrania, Leiella e, em menor grau, em Sticholeia (Tozoni, 1998). No presente estudo, em Mycetophilinae, (Rymosia+Exechiopsis) apresentam o estado (1). Em Manotinae, Promanota o estado (0). Assim, há ressalvas em relação à generalidade dos resultados de Tozoni (1998) para este caráter. Em Leiinae, o estado (0) é plesiomórfico, como esperado, sendo que o estado (1) é apomórfico para Megophthalmidia ${ }^{++}$e o estado (2) para (Procycloneura+Leiella).

\section{Organização geral do escudo:}

(0) superfície dorsal côncava (figuras 134-137);

(1) projetado dorso-anteriormente (figuras $8 \mathrm{~B}, 12-13,93$ );

(2) levemente achatado dorso-ventralmente (figuras 99-104, 122, 124, 127-128);

(3) projetado dorso-medianamente (figuras 76 e 105);

(4) achatado dorso-ventralmente, superfície dorsal aproximadamente reta (figuras 28, 39-40, $108,120-121)$.

Número de passos: 11; IC: 36; IR: 75.

Esse caráter é aqui proposto pela primeira vez e tenta analisar conjuntamente as modificações observadas no formato dorsal do escudo. A superfície dorsal côncava é a condição do plano básico de Mycetophilidae. O escudo com a região anterior projetada dorso-anteriormente está presente em Paraleia e Thoracotropis, aquisições independentes. $\mathrm{O}$ escudo levemente achatado é uma característica de Mycetophilinae (com reversão em Rymosia), Manotinae (com reversão em Promanota), Paracycloneura ${ }^{+}$(com reversão em Anomalomyia*). A projeção dorso-mediana é sinapomórfica para Sigmoleia e o achatamento dorso-ventral é homoplástico entre Procycloneura e (Sticholeia+Allactoneura). Esse último estado está relacionado às semelhanças já comentadas entre Procycloneura e Allactoneura 
(Shaw \& Shaw, 1951), mas que aparecem como não homólogas na topologia aqui encontradas.

\section{Margem posterior do escudo:}

(0) sem cerdas de comprimento diferenciado (figura 144);

(1) duas longas cerdas nas laterais;

(2) quatro longas cerdas, duas laterais e duas centrais (figura 145);

(3) duas longas cerdas centrais;

(4) seis longas cerdas, quatro laterais e duas centrais.

Número de passos: 7; IC: 57; IR: 78.

Este caráter é aqui proposto pela primeira vez para o entendimento das relações filogenéticas de Mycetophilidae. O estado (2) é a condição plesiomórfica para Leiinae, com quatro cerdas posteriores no escudo, de onde se derivam diversas outras condições. Esse estado é encontrado também em Tasmanina, Neoallocotocera, Tetragoneura, Austrosynapha e Dziedzickia, indicando que possivelmente essa é a condição plesiomórfica para Mycetophilidae como um todo. O estado (1), com a redução das duas cerdas centrais, é apomórfico para Paracycloneura e Paradoxa, como surgimentos independentes, e o estado (3), com as perdas das duas cerdas laterais, é autoapomórfico para Sigmoleia. O estado (4) é sinapomórfico para Mycomyinae, com um ganho de duas cerdas laterais, e o estado (0) é apomórfico típico de Manotinae, com a perda da diferenciação em tamanho dessas cerdas em relação às demais cerdas do escudo.

\section{Quetotaxia do escudo:}

(0) densamente pubescente, cerdas longas e robustas por toda a superfície (figura 57);

(1) somente cerdas acrosticais, intra-alares, supra-alares e dorso-centrais (figuras 67 e 143);

(2) somente cerdas pequenas de igual tamanho, com exceção da algumas cerdas marginais mais longas (figuras 16, 96, 108-109).

Número de passos: 7; IC: 28; IR: 88.

A condição desse caráter em Leiinae (0) é condição compartilhada com Sciophilinae e alguns Gnoristinae, sendo plesiomórfica na família, com cerdas robustas amplamente distribuídas no escudo. A restrição das cerdas maiores às acrosticais e dorso-centrais é um estado (1) apomórfico com origens independentes em Thoracotropis, Gracilileia, Trichoterga e Clastobasis loici. Tozoni (1998) observou cerdas uniformes em Allactoneura e Manotinae, sendo que ela propôs que em Leiella haveria redução das cerdas longas (estado 
(2)), uma condição que seria diferente daquela encontrada em Allactoneurinae e Manotinae. O reexame dessa característica neste estudo indica que, de fato, a condição observada em Leiella é semelhante à de Allactoneurinae, Manotinae e Mycetophilinae. Esse estado é de fato, apomórfico para Megophthalmidia ${ }^{++}$, com reversão em Anomalomyia* .

\section{Cerdas escutelares:}

(0) apenas cerdas de igual tamanho (figura 144);

(1) além das cerdas curtas, duas longas e fortes (figura 145);

(2) além das curtas, quatro longas e fortes (figura 143);

(3) além das curtas, seis longas e fortes;

$\left(4^{*}\right)$ ausentes.

Número de passos: 18; IC: 16; IR: 61.

A presença de cerdas diferenciadas no escutelo pertence ao plano-básico de Mycetophilidae (Vockeroth, 1981). O uso da quetotaxia do escutelo como um caráter adicional para o entendimento das relações dentro da família, no entanto, é feito aqui pela primeira vez. Em Leiinae, o estado (2), com quatro cerdas escutelares, é a condição plesiomórfica, compartilhada também por Tasmanina e alguns dos Gnoristinae. O estado (1), com uma redução para duas cerdas escutelares fortes, surge diversas vezes, sendo apomórfico em Thoracotropis, Trichoterga, Aphrastomyia, Paracycloneura e (Paradoxa+Sigmoleia). O estado (3), com a adição de duas outras cerdas escutelares fortes, é apomórfico para Megophthalmidia crassicornis e Neoclastobasis kamijoi. Em Leia e Clastobasis, o estado (1) surge diversas vezes.

\section{Formato do escutelo:}

(0) ovoide, margens anterior e posterior paralelas (figuras 143-145);

(1) aproximadamente triangular, margem posterior abaulada medianamente (figuras $126 \mathrm{e}$ 128).

Número de passos: 3; IC: 33; IR: 60.

Este caráter é aqui proposto pela primeira e é sinapomórfico para Mycetophilinae ${ }^{+}$, com reversões em Promanota e (Sticholeia+Allactoneura).

\section{Sutura mediana do pronoto (entre pós-pronoto e proepisterno): \\ (0) ausente (figuras 96 e 99); \\ (1) presente (figura 102).}


Número de passos: 8; IC: 12; IR: 75.

Este caráter, proposto pela primeira vez, tem o estado (0) amplamente distribuído em Mycetophilidae e é a condição plesiomórfica em Leiinae. O estado (1) apomórfico para Gracilileia, Mohelia e Paradoxa ${ }^{+}$, com reversões em Sigmoleia e (Cycloneura+Tonnwardsia).

\section{Formato do pronoto:}

(0) elíptico, ovoide (figuras 94-103);

(1) retangular estreito (figura 106);

(2) largo medianamente, com extremidades afiladas (figura 122);

(3) retangular largo (figuras 120, 121, 124);

(4) como uma "gota", extremidade anterior afilada e posterior arredondada (figuras 125126).

(5) alongado, extremidade posterior afilada (figura 109).

Número de passos: 5; IC: 100; IR: 100.

Este é um caráter novo e parece relacionado às modificações na parte anterior do tórax relacionada ao encaixe da cabeça sob a margem anterior do escudo. Em Leiinae, o estado (0) é plesiomórfico, condição também presente em Sciophilinae e Gnoristinae, dessa condição derivando-se as demais. O estado (1) é autoapomórfico para Indoleia e o estado (5) é sinapomórfico para Leiella, duas modificações independentes dentro de Leiinae. Em Mycetophilinae, o estado (4) é sinapomórfico para Exechiini, mas os Mycetophilini mantêm a condição (0). Tantos os Manotinae quanto os Allactoneurinae têm condições derivadas. O estado (3) é uma apomorfia compartilhada entre Manota, Allactoneura e Sticholeia, sendo que Eumanota e Promanota possuem o estado (2). O mais parcimonioso é que a condição elíptica tenha dado origem à condição retangular na base de (Manotinae (Sticholeia+Allactoneura)), que depois sofre em afilamento nas extremidades em Promanota ${ }^{+}$.

\section{Pubescência do pronoto:}

(0) cerdas fortes e longas, além das pequenas de igual tamanho (figuras 100, 103, 108, 110);

(1) apenas cerdas pequenas de igual tamanho (figuras 120, 122, 124);

(2) predominantemente cerdas pequenas de igual tamanho, com exceção de algumas mais longas em sua margem ventral (figura 121).

Número de passos: 3; IC: 66; IR: 83. 
Essa é a primeira vez que esse caráter é usado, proposto a partir das observações de Tuomikoski (1966) sobre as diferenças entre os Manotinae. A condição (0) é evidentemente plesiomórfica em Mycetophilidae. O estado (1) é sinapomórfico para (Manotinae)(Sticholeia+Allactoneura)), com uma reversão em Promanota e uma modificação para o estado (2) em Sticholeia.

\section{Conexão do proepímero à porção ventro-posterior do pronoto:}

(0) por uma região bastante estreita (figura 102);

(1) até sua região mediana (figura $8 \mathrm{~B}$ );

(2) em quase toda a sua extensão (figuras 106, 120-121);

(3) minimamente conectados e encoberto pelo proepisterno (figura 124).

Número de passos: 8; IC: 37; IR: 89.

Este é um caráter complexo, proposto aqui pela primeira vez. O estado (0) é plesiomórfico para a família, sendo que a maioria dos Mycetophilidae "superiores" (Leiinae, Gnoristinae, Manotinae, Allactoneurinae e Mycetophilinae) apresentam algum grau de modificação. Em Mycomyiinae, Mycomyia apresenta o estado (1) e Neoempheria, o estado (0). A maior parte dos Leiinae apresenta a condição (1), sendo que o estado apomórfico (2) está presente em Indoleia e Leiella, condição também observada em (Manotinae)(Sticholeia+Allactoneurinae)). O estado (3) é exclusivo de Manota e corresponde a uma mudança ainda mais acentuada dessa parte anterior do tórax nesse gênero.

\section{Porção ventral do proepímero:}

(0) arredondada (figura 138);

(1) afilada (figuras 106 e 108);

(2) angulada aproximadamente $90^{\circ}$ (figuras 120 e 121).

Número de passos: 9; IC: 22; IR: 79.

Um caráter novo, a condição apomórfica (2) é típica de (Manotinae)(Sticholeia+Allactoneura)). A condição (1) está presente na maior parte dos micetofilídeos superiores, aparentemente com algumas reversões em Leiinae.

\section{Formato do proepímero:}

(0) triangular (figura 8B);

(1) digitiforme (figuras 102 e 105); 
(2) retangular (figuras 120-121);

(3) aproximadamente ovóide, com extremidades afiladas (figura 106);

(4) alongado, extremidades afiladas e medianamente abaulado (figura 124).

Número de passos: 13; IC: 30; IR: 75.

Este caráter é aqui proposto pela primeira vez. O estado (0) é aparentemente é plesiomórfico para Mycetophilidae, conforme se pode inferir por um estudo da evolução do proepímero em outras famílias de Bibionomorpha, ainda que alguns gêneros de Sciophilinae e Docosia tenha a condição (1). Em Leiinae, a condição (0) é evidentemente plesiomórfica. O estado (1), assim, é uma homoplasia entre Paracycloneura, Sigmoleia e Cawthronia, bem como para o clado Clastobasis ${ }^{*}$, que tem reversões em Leia ventralis e L. spinifera. O estado (2) é exclusivo para Rondaniella sp. e o estado (3) surge independentemente em Indoleia e Leiella.

\section{Basisterno, em vista lateral, imediatamente além do proepisterno:}

(0) pouco desenvolvido, como uma faixa estreita (figuras 8B, 106, 114);

(1) bastante desenvolvido, largo, com um formato de "escudo" (figuras 120 e 122).

Número de passos: 1; IC: 100; IR: 100.

Hippa et al. (2004) indicam que o estado apomórfico deste caráter está presente em Sticholeia, Allactoneura e Eumanota. A presença de um basisterno largo é sinapomórfica para (Manotinae (Sticholeia+Allactoneura)), formando uma característica importante para definir esse clado.

\section{Cerdas no basisterno:}

(0) microtríquias e cerdas curtas esparsas (figuras 109 e 111);

(1) cerdas curtas e longas esparsas (figuras 106 e 114);

(2) densas cerdas por toda a superfície (figuras 120 e 122).

Número de passos: 8; IC: 25; IR: 75.

Este caráter foi utilizado por Hippa et al. (2004), Rindal \& Søli (2006) e Amorim \& Rindal (2007), mas codificando apenas como ausente e presente. Neste estudo, três estados de caráter foram reconhecidos. A condição plesiomórfica na família é evidentemente (0), condição verificada, inclusive, em Mycetophilinae. A condição (2) é exclusiva de (Manotinae (Sticholeia+Allactoneura)), sendo que o estado (1) tem surgimentos independentes, dentro de Leiinae, em Aphrastomyia, Indoleia, parte de Rondaniella, parte de Leiella, Caledonileia ${ }^{+}$e algumas espécies de Leia. 


\section{Cerdas no mesepímero:}

(0) ausentes (figuras 104-115);

(1) presentes (figuras 127-128).

Número de passos: 1; IC: 100; IR: 100.

Caráter utilizado por Rindal \& Søli (2006), é sinapomórfico para os Mycetophilini, em Mycetophilinae.

\section{Extremidade ventral do mesepímero:}

(0) em contato com a porção ventral do tórax (figuras 133-135);

(1) em contato com o catepisterno (figuras 125 e 128);

(2) em contato com o mesopleurotrocantin (figuras 109-110).

Número de passos: 3; IC: 66; IR: 97.

A condição em que a porção ventral do mesepímero alcança a margem ventral da pleura torácica é uma plesiomorfia evidente, sendo que a aproximação entre o catepisterno e o metepisterno em vários grupos de Mycetophiliformia impede que o mesepímero alcance a margem ventral do tórax (Shaw \& Shaw, 1951; Søli, 1997a; Amorim \& Rindal, 2007). Os Manotinae ${ }^{+}$, em seu plano-básico, são plesiomórficos para essa série de transformação e em Mycetophilinae a condição (1) é encontrada em parte de seus gêneros. A condição (2), entretanto, não é idêntica à condição (1), e é uma sinapomorfia de Leiinae, em que o mesepímero alcança o mesopleurotrocantin. Esta estrutura, presente em Mecoptera e retida em muitos grupos de Diptera, muitas vezes é pouco perceptível, inclusive em Mycetophilidae, de maneira que a condição (1) corresponde a uma pequena alteração nessa porção do tórax. Esse caráter é proposto aqui pela primeira vez e corresponde a uma condição derivada única no grupo, corroborando fortemente a hipótese de que gêneros como Sticholeia, Allactoneura, Tetragoneura, Ectrepesthoneura, Novakia e Docosia, entre alguns outros, não pertençam à subfamília.

\section{Formato do mesepímero:}

(0) alongado e mais estreito na região ventral (figuras 134-135);

(1) achatado dorsalmente e mais estreito na região ventral (figura 120);

(2) aproximadamente retangular com margem ântero-ventral obsoleta (figura 122);

(3) aproximadamente ovóide, com região mediana acinturada (figuras 125, 127-128).

Número de passos: 8; IC: 37; IR: 86. 
É a primeira vez que esse caráter é usado em estudos filogenéticos de Mycetophilidae. A condição (0) é plesiomórfica para Mycetophilidae, encontrada em alguns Leiinae, bem como em Sticholeia. Em Manotinae e Leiiella encontra-se a condição (2), e a condição (3) é sinapomórfica para Mycetophilinae. O estado (1) é apomórfico para diferentes clados em Leiinae, mas é apomórfica também para Allactoneura e Docosia.

\section{Laterotergito:}

(0) nu (figuras 8B, 99-104);

(1) pubescente (figuras 105, 117, 120-121, 140).

Número de passos: 12; IC: 8; IR: 70.

A presença de cerdas no laterotergito apresenta distribuição homoplástica, com surgimentos independentes em vários grupos de Mycetophiliformia, incluindo os Mycetophilidae, de forma que a evolução desse caráter dentro da família é pouco elucidativa e extremamente plástica (Amorim \& Rindal, 2007). Este caráter foi também utilizado por Søli (1997a), Hippa et al. (2004) e Borkent \& Wheeler (no prelo). Em Leiinae, o laterotergito nu é a condição plesiomórfica; a presença de cerdas é apomórfica para Trichoterga ${ }^{+}$, com reversões em Paracycloneura e Waipapamyia ${ }^{+}$, e reaquisição secundária em Sigmoleia e Leiella.

\section{Formato do laterotergito:}

(0) ovoide (figuras 135-136);

(1) aproximadamente retangular (figuras 8B, 113-119).

Número de passos: 5; IC: 20; IR: 90.

O formato do laterotergito foi utilizado por Søli (1997a) e Borkent \& Wheeler (no prelo), mas com variações nos estados de caráter. No presente trabalho, o laterotergito ovoide é uma característica do plano básico de Mycetophilidae preservada no plano-básico de Leiinae, sendo que a condição retangular, apomórfica, está presente em Paraleia e Caledonileia $^{++}$.

\section{Eixo maior do laterotergito em relação ao eixo dorso-ventral do tórax:}

(0) aproximadamente vertical (figuras 8B, 94-95, 132-135);

(1) inclinado (figuras 106, 109, 127).

Número de passos: 4; IC: 25; IR: 93. 
Proposto pela primeira vez, o estado (0) é a condição do plano-básico de Leiinae, sendo que o estado apomórfico possui surgimentos independentes em Indoleia $^{++} \mathrm{e}$ Mycetophilinae $^{++}$.

\section{Mesopleurotrocantin:}

(0) oculto na parte ventral da pleura (figuras 137 e 142);

(1) visível lateralmente (figuras 8B, 109-110).

Número de passos: 1; IC: 100; IR: 100.

Este caráter é aqui proposto pela primeira vez e sua condição visível lateralmente é uma condição sinapomórfica única de Leiinae, constituindo, dessa maneira, uma característica importante para a delimitação da subfamília, corroborando as posições expressas na literatura de que Allactoneura, Sticholeia, Docosia, Tetragoneura, Novakia e Ectrepesthoneura não pertecem aos Leiinae.

\section{Anepisterno e catepisterno:}

(0) tão largos ou mais estreitos que o laterotergito (figura 114);

(1) mais largos que o laterotergito (figuras 108-109).

Número de passos: 3; IC: 33; IR: 85.

Essa é a primeira vez que essa característica é utilizada no entendimento das relações filogenéticas em Mycetophilidae. A condição (0) é evidentemente plesiomórfica na família. O estado apomórfico deste caráter apresenta dois surgimentos independentes, um em Cawthronia $^{+}$e outro em (Manotinae (Sticholeia+Allactoneura)), com reversão em Promanota.

\section{Sutura ente anepisterno e catepisterno:}

(0) completa (figuras 109-102, 105, 114);

(1) incompleta (figuras 96-98, 103, 108).

Número de passos: 5; IC: 20; IR: 73.

Segundo Søli (1997a), há quatro estados para este caráter, considerando-se diferentes graus de redução da sutura anapleural. Borkent \& Wheeler (no prelo) codificaram três estados de caráter. Amorim \& Rindal (2007) optaram pela codificação presente/ausente. Como foram observadas diferenças dentro de um mesmo gênero em relação à redução da sutura, o que implicaria na codificação polimórfica, optou-se por uma simplificação desta característica como uma tentativa de obter um sinal filogenético mais livre de ruído (como 
em Amorim \& Rindal, 2007). O estado apomórfico está presente em Allactoneura e, em Leiinae, como surgimentos independentes em Megophthalmidia ${ }^{+}$, em Indoleia, Paradoxa e Procycloneura.

\section{Cerdas no anepisterno mesotorácico:}

(0) ausentes (figuras 92-104);

(1) presentes (figuras 105, 127-128).

Número de passos: 4; IC: 25; IR: 57.

Este caráter foi utilizado por Søli (1997a), Tozoni (1998), Hippa et al. (2004), Rindal \& Søli (2006), Amorim \& Rindal (2007) e Borkent \& Wheeler (no prelo). O estado apomórfico é característico de Mycetophilini, Manotinae e do gênero Sigmoleia, em Leiinae, além de sua ocorrência em Neoallocotocera.

\section{Tamanho do anepisterno em relação ao catepisterno:}

(0) menor (figuras 99-100);

(1) do mesmo tamanho (figuras 110-102);

(2) maior (figura 109).

Número de passos: 17; IC: 11; IR: 71.

Proposto pela primeira vez, em Leiinae o estado (0) é plesiomórfico, o estado (1) é apomórfico para Paraleia e Trichoterga ${ }^{+}$, com algumas reversões, e o estado (2) é apomórfico para Leiella.

\section{Formato do catepisterno:}

(0) retangular (figura 142);

(1) ovoide (figura 123);

(2) triangular (figura 124);

(3) quadrado (figuras 121 e 127).

Número de passos: 20; IC: 15; IR: 67.

Tozoni (1998) utilizou dois formatos para catepisterno, sendo que, no presente trabalho, outras condições foram codificadas. Em todos os Mycomyinae, Mycetophilinae e Sticholeia há a presença da condição apomórfica (3). O estado (2) é apomórfico para Manotinae e Allactoneurinae. O estado (1) é sinapomórfico para (Promanota+Eumanota). Em Leiinae, há uma plasticidade grande entre os estados (0) e (3). 


\section{Margem ântero-ventral do catepisterno em relação à margem póstero-ventral:}

(0) contígua, em uma linha horizontal (figuras 113-119, 127-128);

(1) projetada ventralmente, em uma linha transversal (figuras 8B, 94-98, 122-124).

Número de passos: 6; IC: 16; IR: 89.

Este caráter foi utilizado por Rindal \& Søli (2006) em combinação com o formato do catepisterno. Nesta análise, o estado (1) parece ser a condição plesiomórfica, para Mycetophilidae de onde o estado (0) apomórfico surgiu mais de uma vez, incluindo em Paracycloneura $^{+}$, com reversões em Anomalomyia minor e Acrodicrania.

\section{7. Ângulo póstero-dorsal do catepisterno:}

(0) leve reentrância em que se encaixa a região ântero-ventral do mesepímero (figuras 109 e 121);

(1) projeção angulada em que se encaixa a região ântero-ventral do mesepímero (figuras 8B, 101, 103).

Número de passos: 6; IC: 16; IR: 82.

Tozoni (1998) comenta que a reentrância no catepisterno está presente em grande parte dos Bibionomorpha, incluindo todos os grupos basais de Mycetophilidae. No presente estudo, a condição apomórfica é característica de Leiinae, com reversão em Leiella e Caledonileia, e com homoplasias em gêneros de Gnoristinae.

\section{Mediotergito:}

(0) ligeiramente abaulado na porção anterior, com aumento da altura do esclerito (figuras 8B, 94-95, 134-136);

(1) curto e reto (figura 108);

(2) curvatura acentuada, formando uma dobra e reduzindo a altura do esclerito (figuras 97 , $107,115)$;

(3) fortemente abaulado medianamente (figuras 44-45, 125-126).

Número de passos: 8; IC: 37; IR: 84.

Este caráter foi utilizado por Tozoni (1998), com alguma diferença na delimitação dos estados. O estado (0) é plesiomórfico para Mycetophilidae, sendo encontrado em outras famílias de Mycetophiliformia. O estado (1) aparece em Mycetophilinae ${ }^{+}$, com alguma variação ulterior, e em (Procycloneura+Leiella). O estado (2) é apomórfico para Megophthalmidia $^{++}$, ou seja, para a maior parte dos Leiinae, também com variação dentro do 
grupo, com surgimento também em Sticholeia. O estado (3) é apomórfico para Exechini, em Mycetophilinae.

\section{Cerdas no mediotergito:}

(0) ausentes;

(1) presentes.

Número de passos: 2; IC: 50; IR: 50.

Tozoni (1998), Rindal \& Søli (2006) e Borkent \& Wheeler (no prelo) utilizaram esse caráter em suas análises filogenéticas de Mycetophilidae. Segundo Tozoni (1998), no plano básico de Mycetophilidae, o mediotergito é nu, havendo cerdas em Sciophilinae e alguns gêneros pertencentes a outras subfamílias, inclusive Garretella. Tozoni (1998), no entanto, não tinha em mãos espécimes de Garretella. Na descrição do gênero por Vockeroth (1980), o mediotergito e o laterotergito são indicados com sendo nus, o que é confirmado na análise feita aqui. Para a amostragem aqui utilizada, as cerdas no mediotergito foram encontradas apenas nos gêneros estudados de Sciophilinae e em Mycomya.

\section{Perna I:}

(0) aproximadamente do mesmo comprimento das pernas I e II (figuras 34 e 59);

(1) aproximadamente metade do comprimento das pernas I e II (figuras 18 e 28).

Número de passos: 3; IC: 33; IR: 91.

Este caráter é aqui proposto pela primeira vez. O estado (1) é obviamente plesiomórfico em Mycetophilidae. O estado apomórfico, com a redução na extensão da perna anterior, está presente em Allactoneura e, dentro de Leiinae, nos clados Megophthalmidia $^{+}$e em Waipapamyia ${ }^{+}$.

\section{Pubescência na coxa I:}

(0) densa na região anterior (figuras 96 e 127);

(1) uniformemente distribuída por toda superfície (figura 146).

Número de passos: 12; IC: 8; IR: 77.

Caráter não utilizado previamente, o estado (1) em Leiinae é apomórfico para o clado Paracycloneura ${ }^{+}$, com reversões em algumas espécies de Clastobasis e Leia, e para Manotinae ${ }^{+}$. 
72. Uma longa e esclerotizada cerda apical na coxa II:

(0) ausente;

(1) presente.

Número de passos: 1; IC: 100; IR: 100.

Este caráter não havia sido utilizado na literatura e é uma sinapomorfia de Docosia.

\section{Coxas II e III:}

(0) sua largura é um terço de seu comprimento (figuras 35-38);

(1) sua largura é metade de seu comprimento (figuras 109, 127-128).

Número de passos: 3; IC: 33; IR: 83.

Segundo Tozoni (1998), esta característica estaria presente em Allactoneura, Manota, Leiella e Procycloneura. Nesta análise, a codificação aponta para o estado apomórfico presente em Allactoneura, em Mycetophilini (Mycetophilinae) e em Leiinae, no clado Cawthronia $^{+}$. Em Manota, as coxas II e III são pouco mais largas que a coxa I, mas sua largura não chega a ser um terço de seu comprimento.

\section{4. Ápice das coxas I e II com longas cerdas distribuídas regularmente:}

(0) ausente (figura 134);

(1) presente (figuras 109 e 146).

Número de passos: 4; IC: 25; IR: 78.

Este caráter não foi utilizado na literatura. A presença de cerdas regulares no ápice das coxas I e II é apomórfica para Mycetophilinae ${ }^{+}$e para Indoleia e Leiella, dentro de Leiinae.

\section{Achatamento ântero-posterior do fêmur I:}

(0) ausente (figuras 12, 14, 21);

(1) presente (figuras 16, 22, 26, 97-98).

Número de passos: 3; IC: 33; IR: 88.

O estado apomórfico deste caráter, utilizado pela primeira vez, apresenta duas aquisições independentes em Leiinae, uma em (Megophthalmidia (Mohelia+Aphrastomyia)) e outra em Waipapamyia ${ }^{+}$, com reversão em Leiella. 


\section{Fêmur III:}

(0) não achatado ântero-posteriormente (largura menor que 2 vezes a das regiões apicais) (figuras 11-12);

(1) achatado ântero-posteriormente (largura de 2 a 3 vezes a das regiões apicais) (figuras 19, $38,40)$;

(2) profundamente achatado (largura maior que 3 vezes a das regiões apicais) (figuras 2028).

Número de passos: 9; IC: 22; IR: 87.

Este é um caráter novo. O estado (0) é plesiomórfico para Leiinae. Em Leiinae, parece haver a passagem da condição (0) para a condição (1) em Thoracothrops $^{+}$e para o

estado (2) no clado Indoleia ${ }^{++}$, com reversão para o estado (1) em Anomalomyia*. Em Mycetophilinae ${ }^{+}$, estado (1) é apomórfico em Sticholeia e o estado (2) em Manota e em Mycetophilini.

\section{Cerdas tibiais:}

(0) irregularmente arranjadas;

(1) regularmente arranjadas (figuras 148 e 150).

Número de passos: 3; IC: 33; IR: 89.

Søli (1997a), Tozoni (1998), Hippa et al. (2004) e Rindal \& Søli (2006) utilizaram este caráter em suas análises. O arranjo linear das cerdas tibiais é considerado uma homoplasia entre Mycomyinae e Mycetophilinae (Väisänen, 1984). A amostragem taxonômica deste estudo indica que o arranjo regular das cerdas está presente, além de Mycomyinae e Mycetophilinae, também em Manotinae, Sticholeia e, em Leiinae, no clado Megophthalmidia ${ }^{+}$. A interpretação mais parcimoniosa é de uma reversão em Allactoneura.

\section{Espinhos tibiais III:}

(0) mais curtos que o diâmetro apical da tíbia (figuras 60, 148, 150);

(1) mais longos que o diâmetro apical da tíbia (figuras 11-12, 20-21, 29, 31).

Número de passos: 9; IC: 11; IR: 78.

Hippa et al. (2004) e Rindal \& Søli (2006) utilizaram este caráter em suas análises filogenéticas de Mycetophilidae. Em Leiinae, a condição apomórfica está presente em Garretella $^{+}$, Trichoterga e Indoleia ${ }^{+}$, com reversão em Paradoxa paradoxa. 


\section{Espinhos tibiais III:}

(0) irregularmente arranjados (figuras 20-21, 29, 31);

(1) regularmente arranjados (figuras 148 e 150).

Número de passos: 7; IC: 14; IR: 85.

Caráter novo. Em Leiinae o estado apomórfico está presente em Megophthalmidia ${ }^{+}$, Paracycloneura e Paradoxa ${ }^{+}$, com reversão em Paradoxa fusca.

\section{0. Órgão sensorial da tíbia III:}

(0) formado por poucas cerdas (figura 147);

(1) formado por muitas cerdas regularmente arranjadas (figuras 148-150).

Número de passos: 3; IC: 33; IR: 83.

Este é um caráter novo, presente apenas entre os Leiinae. O órgão sensorial da tíbia III é formado por muitas cerdas em um arranjo regular e está presente em (Garretella+Paraleia), Megophthalmidia ${ }^{+}$e Paradoxa paradoxa.

\section{Esporão tibial da perna III:}

(0) mais curto que o primeiro tarsômero (figura 42);

(1) tão longo quanto o primeiro tarsômero (figuras 29 e 33).

Número de passos: 3; IC: 33; IR: 83

Este caráter é pela primeira vez com esta definição. O esporão da metatibia tão longo quanto o primeiro tarsômero está presente em Allactoneura e, entre os Leiinae, no clado Cawthronia $^{+}$e em Neoclastobasis.

\section{Garras tarsais:}

(0) bífidas (figura 152-153);

(1) simples (figura 151).

Número de passos: 1; IC: 100; IR: 100.

Este caráter é novo para estudos filogenéticos de Mycetophilidae e é uma sinapomorfia de Mycomyinae. 


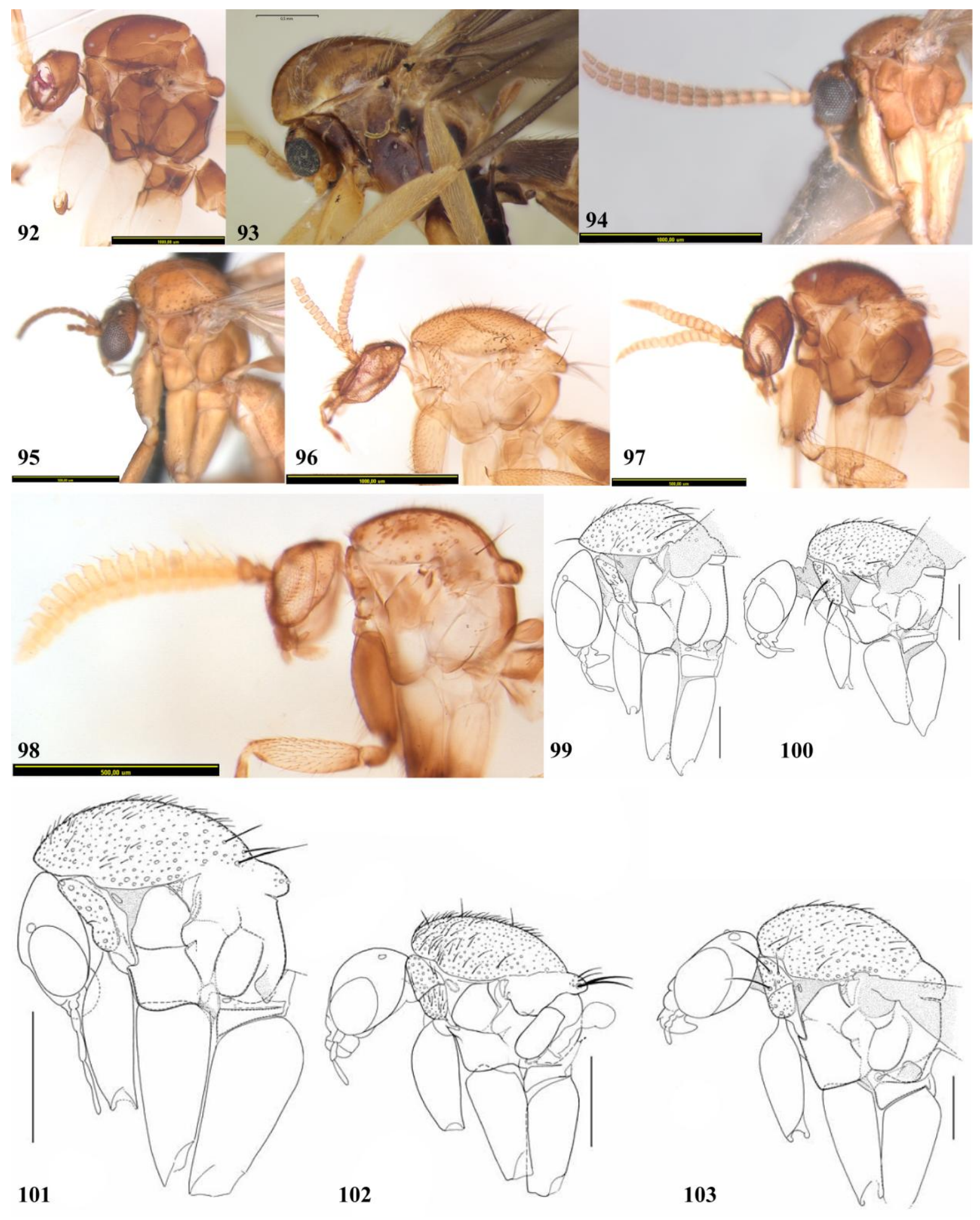

Figuras 92-103. Tórax de Mycetophilidae, vista lateral. 92. Garretella shermanni, $\partial^{\jmath}(\mathrm{CNC}) .93$. Thoracotropis cypriformis, holótipo $\widehat{\partial}$ (modificado de Oliveira et al., 2012: 460). Escala 0,5mm. 94. Gracilileia redunda, ô (MNHN). 95. Trichoterga monticola, $q$ (CNC). Escala 0,5mm. 96. Megophthalmidia divergens, $\hat{o}$ (MZUSP). 97. Mohelia nigricauda, + (SAMC). Escala 0,5mm. 98. Aphrastomyia shannoni, $\widehat{\jmath}$ (INPA). Escala $0,5 \mathrm{~mm}$. 99. Paracycloneura apicalis (modificado de Jaschhof \& Kallweit, 2009: 17). Escala 0,25mm. 100. Tonnwardsia aberrans (modificado de Jaschhof \& Kallweit, 2009: 17). Escala 0,25mm. 101. Cycloneura (modificado de Jaschhof \& Kallweit, 2009: 16). Escala 0,5mm. 102. Cawthronia nigra (modificado de Jaschhof \& Kallweit, 2009: 16). Escala 0,5mm. 103. Paradoxa fusca (modificado de Jaschhof \& Kallweit, 2009: 15).

Escala $0,25 \mathrm{~mm}$. 


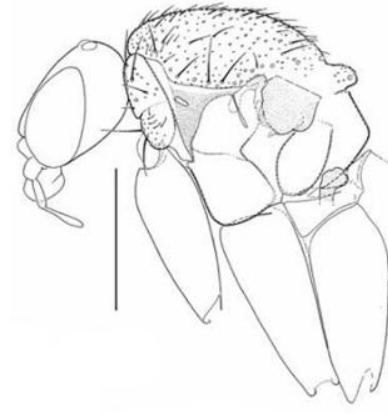

104

107

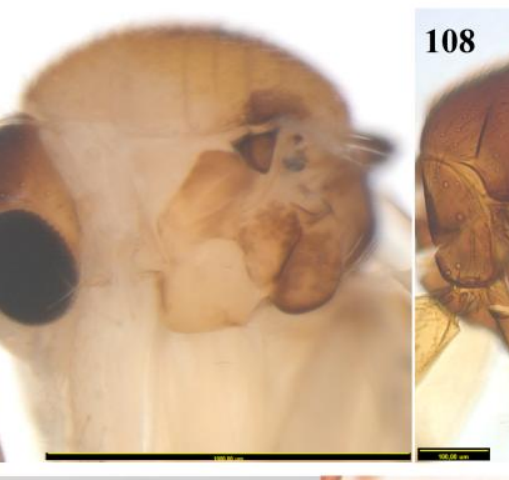

110

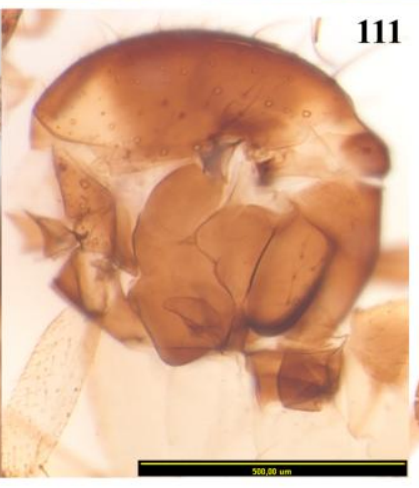

111
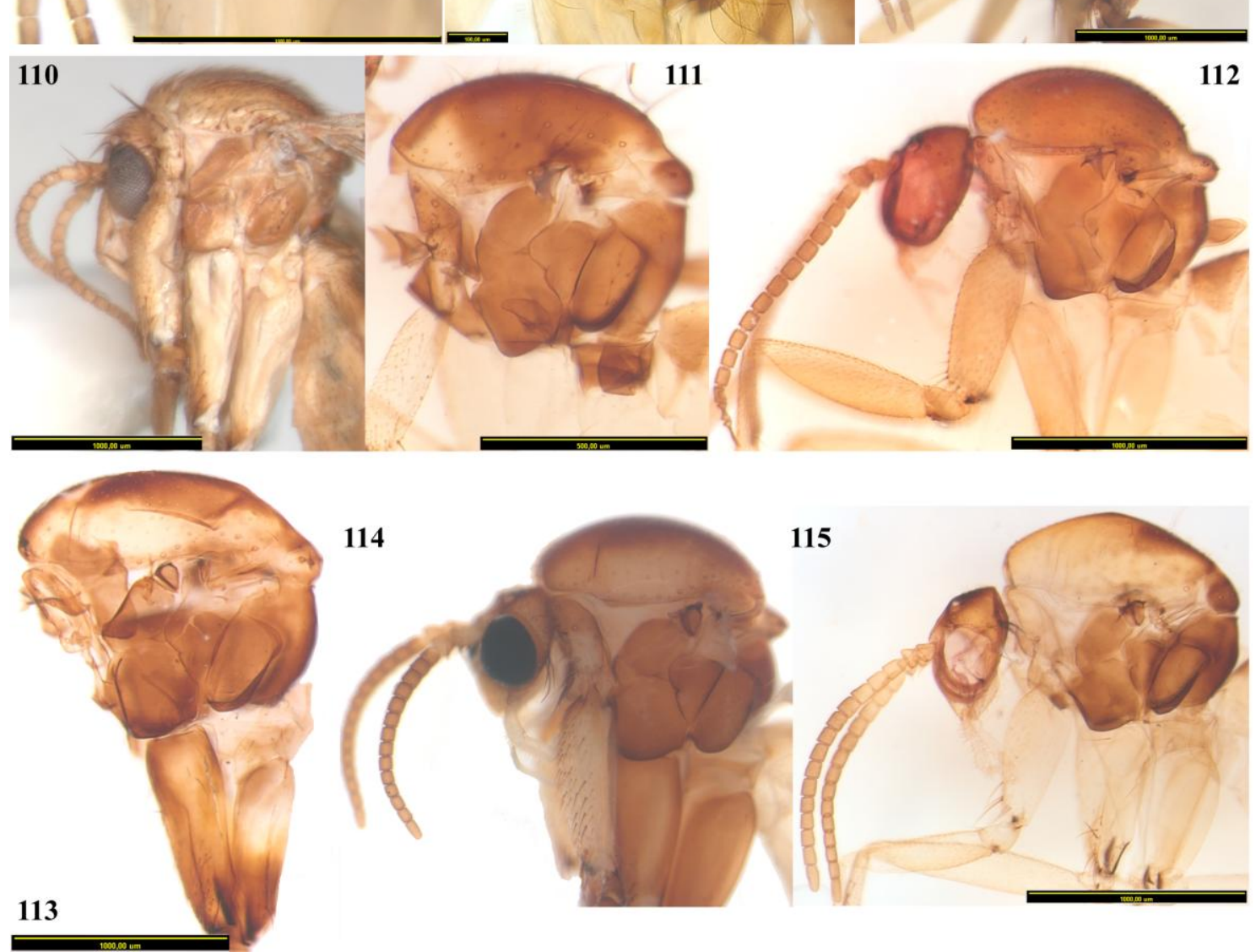

Figuras 104-115. Tórax de Mycetophilidae, vista lateral. 104. Waipapamyia dentata (modificado de Jaschhof \& Kallweit, 2009: 16). Escala 0,5mm. 105. Sigmoleia similis Jaschhof \& Kallweit (modificado de Jaschhof \& Kallweit, 2009: 16). Escala 0,5mm. 106. Indoleia bisetosa, ô (ANIC).

107. Rondaniella dimidiata, ô (LMED). 108. Procycloneura paranensis, $q$ (MZUSP). Escala

$0,1 \mathrm{~mm}$. 109. Leiella unicincta, $q$ (INPA). 110. Anomalomyia nasuta, $q$ (MNHN). 111. Ateleia spadicithorax, ô (ANIC). Escala $0,5 \mathrm{~mm}$. 112. Acrodicrania africana, $\widehat{\partial}$ (SAMC). 113. Caledonileia pusilla Matile, parátipo $\widehat{\partial}(\mathrm{MNHN})$. 114. Neoclastobasis draskovitsae, $\widehat{\partial}(\mathrm{LMED})$. 115. Greenomyia stackelbergi, ô (LMED). 


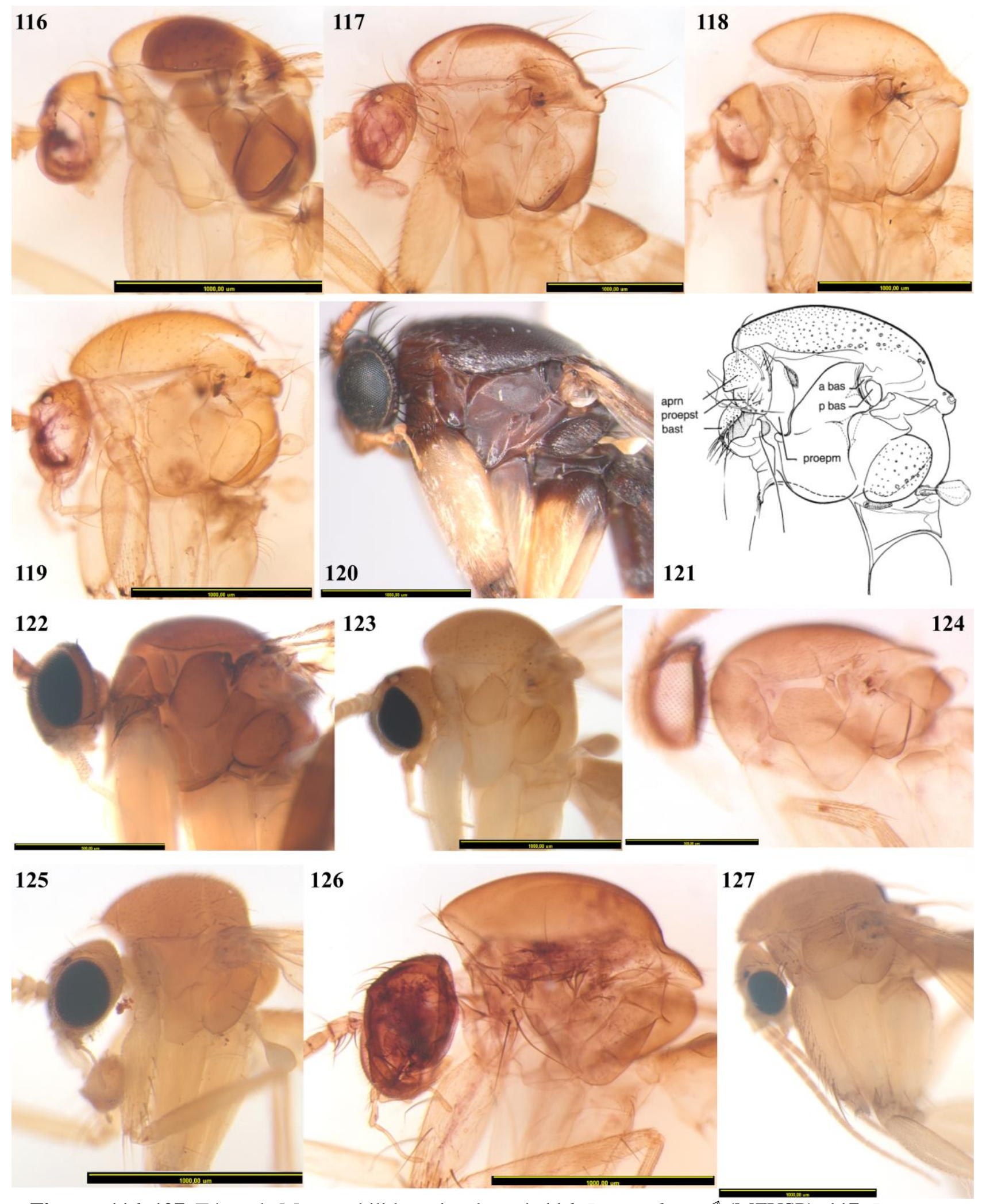

Figuras 116-127. Tórax de Mycetophilidae, vista lateral. 116. Leia andirai, ठิ (MZUSP). 117. L. winthemi, o (LMED). 118. Clastobasis alternans, q (LMED). 119. C. tryoni, q (ANIC). 120. Allactoneura papuensis Bechev, $\widehat{\partial}$ (AMSA). 121. Sticholeia cheesmanae (modificado de Søli, 1996: 3). 122. Eumanota, $q$ (AMSA). Escala $0,5 \mathrm{~mm}$. 123. Promanota malaisei, $\hat{\jmath}$ (LMED). 124. Manota palpalis, $\widehat{o}$ (INPA). Escala $0,5 \mathrm{~mm}$. 125. Rymosia, $\hat{\jmath}$ (MZUSP). 126. Exechiopsis, Epicypta, $\widehat{\widehat{\partial}}$ (MZUSP). 


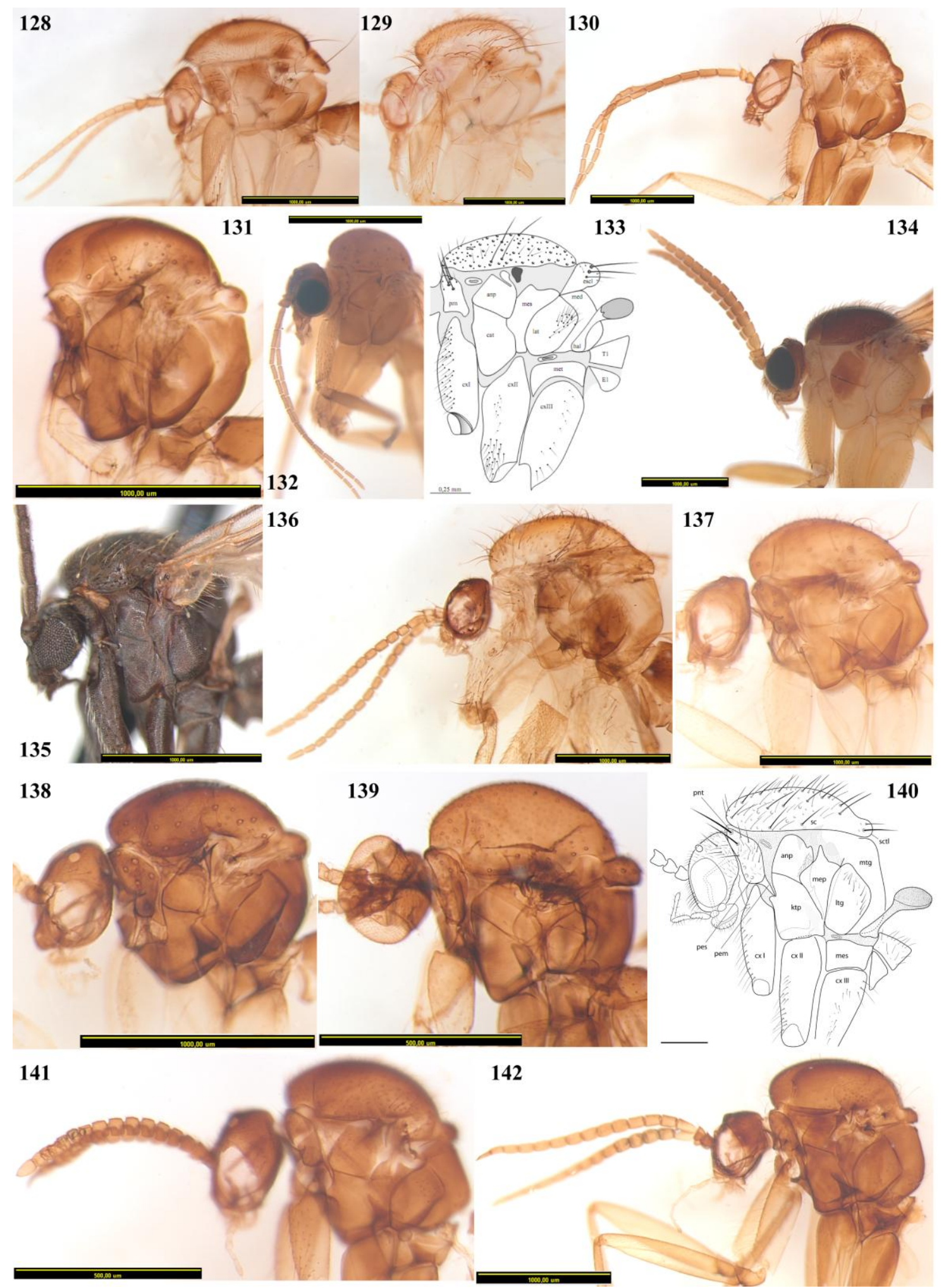

Figuras 128-142. Tórax de Mycetophilidae, vista lateral. 128. Mycetophila, $\circ$ (MZUSP). 129.

Neoempheria, $\widehat{\jmath}$ (LMED). 130. Mycomya, $\widehat{\partial}$ (MZUSP). 131. Synapha, $q$ (AMSA). 132.

Austrosynapha hirta, $\bigcirc$ (ANIC). 133. Dziedzickia variabilis Lane (modificado de Oliveira, 2009: 100). Escala 0,25mm. 134. Schnusea caiabii, đ̂ (MZUSP). 135. Boletina obscura, ô (CNC). 136. Palaeodocosia vittata, ㅇ (CNC). 137. Tetragoneura borgmeieri, ô (MZUSP). 138.

Ectrepesthoneura hirta (Winnertz), $\widehat{\jmath}$ (LMED). 139. Novakia miloi, $\widehat{\partial}$ (LMED). Escala $0,5 \mathrm{~mm} .140$. Docosia adusta, parátipo $\widehat{o}$ (modificado de Oliveira \& Amorim, 2011: 691). Escala 0,3mm. 141. Neoallocotocera fusca, ô (ANIC). Escala $0,5 \mathrm{~mm}$. 142. Tasmanina gracilis, $\widehat{\partial}$ (ANIC). 


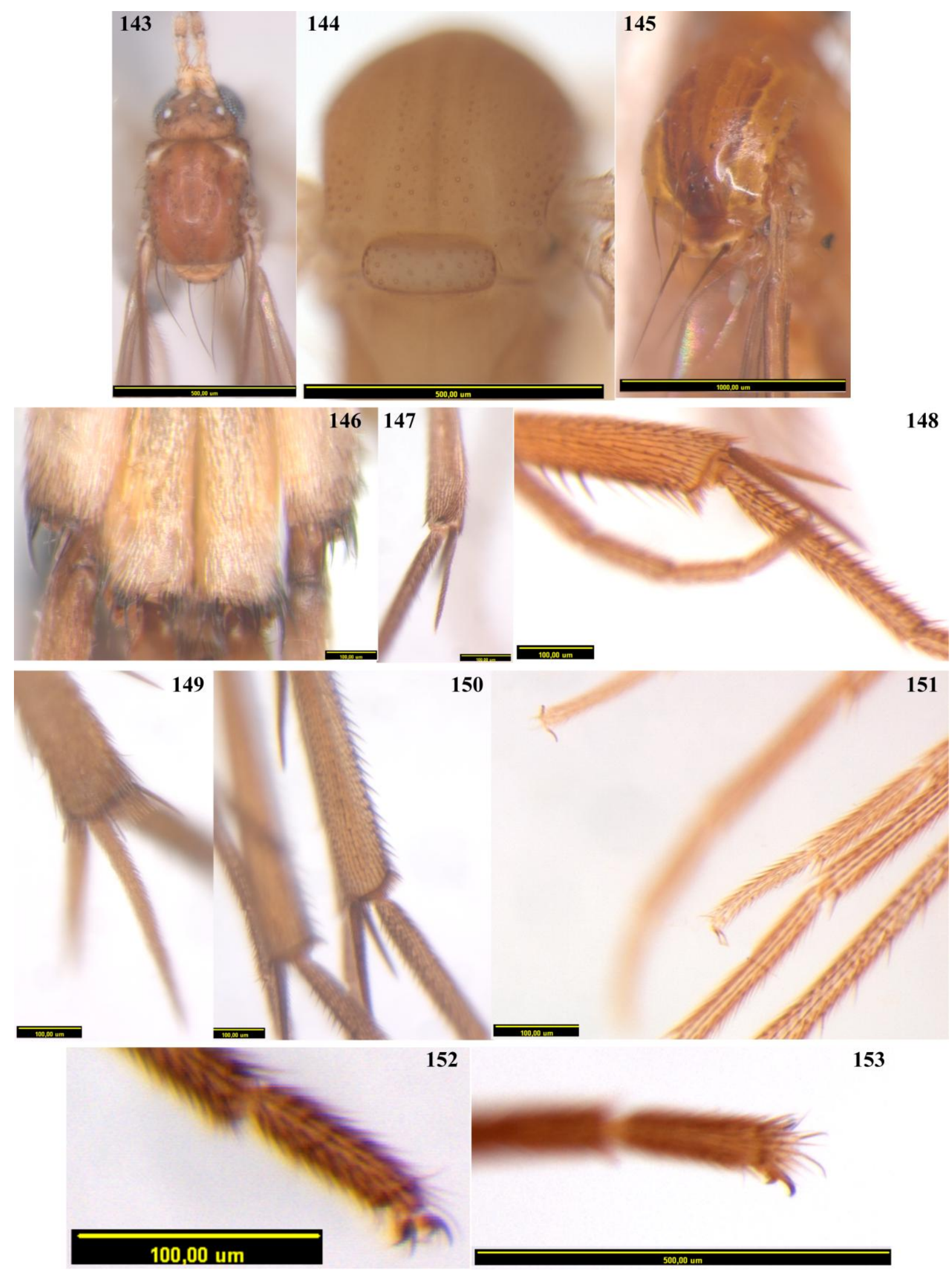

Figuras 143-153. Tórax (vista lateral) e pernas de Mycetophilidae. 143. Gracilileia redunda, ${ }^{\widehat{ }}$ (ANIC). 144. Promanota malaisei, đ̊ (LMED). 145. Sticholeia loici Søli, \& (AMSA). 146. Allactoneura papuensis, $\widehat{\partial}$ (AMSA). 147. Gracilileia redunda, $\widehat{\partial}$ (ANIC). 148. Aphrastomyia

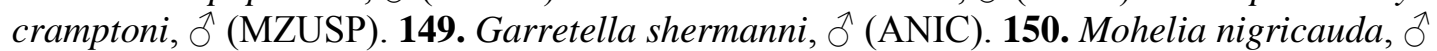
(NMSA). 151. Mycomya, $q$ (MZUSP). 152. Mohelia nigricauda, $\widehat{\partial}$ (NMSA). 153. Leia winthemi, $q$ (LMED). Escalas 143-144 e 153 0,5mm. Escalas 145-152 0,1mm. 


\section{Membrana alar:}

(0) hialina (figuras 160-161, 181,186-193);

(1) manchas como faixas transversais (figuras 155 e 174);

(2) manchas na região apical da asa (figuras 169-173, 178-180);

(3) toda membrana alar esfumaçada (figuras 172, 183, 185, 203);

(4) manchas em diferentes setores da asa e de diferentes formatos (figura 192).

Número de passos: 24; IC: 16; IR: 55.

Essa característica como caráter de relevância filogenética foi utilizado por Amorim (1993). O padrão de manchas na membrana alar em Mycetophilidae tem um padrão complexo, encontradas em praticamente todos as subfamílias. Entre os gêneros aqui representados, há manchas em uma espécie de Docosia e em Neoempheria. Entre os Manotinae $^{+}$, parece ter havido uma reversão em Manota e em Promanota. Entre os Leiinae, ocorre aquisição de manchas dentro de Paraleia e em Paracycloneura ${ }^{+}$, com algumas reversões dentro do grupo. O único caso de membrana toda esfumaçada (3) em Leiinae é de Leiella ochreocalcar.

\section{Disposição das asas:}

(0) expandidas, membrana alar distendida (figuras 11-38);

(1) dobradas longitudinalmente, membrana alar dobrada como um leque (figura 39).

Número de passos: 1; IC: 100; IR: 100.

Presente na literatura apenas na forma de descrição esta é a primeira vez que essa característica é vista como uma sinapomorfia de Allactoneura.

\section{Macrotríquias na membrana alar:}

(0) dispersas por toda a superfície (figuras 204-205);

(1) esparsas pela região anal da asa (figuras 165, 168, 171);

(2) ausentes (figuras 154-163).

Número de passos: 7; IC: 28; IR: 37.

Tozoni (1998), Rindal \& Søli (2006), Amorim \& Rindal (2007) e Borkent \& Wheeler (no prelo) utilizaram este caráter como presença e ausência de macrotríquias, sendo que Søli (1997a) codificou de forma um pouco diferente. Neste presente, a ausência de macrotríquias é plesiomórfica para Leiinae e provavelmente para Mycetophilidae, ainda que esteja presente 
em muitos gêneros de Sciophilinae. Em Manotinae, apenas Eumanota tem macrotríquias esparsas pela região anal da asa. Entre os Leiinae, o aparecimento dessas cerdas é uma sinapomorfia para o clado Waipapamyia ${ }^{+}$, com reversões em Paradoxa fusca, Cycloneura ${ }^{++}$, havendo reaparecimento em Procycloneura paranensis.

\section{Microtríquias na membrana alar:}

(0) irregularmente arranjadas (figuras 154-163);

(1) parcialmente arranjadas em fileiras regulares (figura 187);

(2) arranjadas em fileiras regulares distintas (figuras 188-191).

Número de passos: 3; IC: 66; IR: 80.

Tozoni (1998), Rindal \& Søli (2006) e Borkent \& Wheeler (no prelo) utilizaram este caráter em suas análises filogenéticas de Mycetophilidae. A passagem do estado (0) para o estado (2) é sinapomórfico para Mycetophilinae ${ }^{+}$, com reversão em (Sticholeia+Allactoneura), sendo que a passagem para o estado (1) é sinapomórfico para (Eumanota+Promanota). Isso significa que, em conformidade com a topologia obtida aqui, a falta de alinhamento das microtríquias na membrana em (Sticholeia+Allactoneura) é resultante de perda.

\section{Costal (C):}

(0) terminando pouco além de $\mathrm{R}_{5}$ (figuras 163-164, 170);

(1) terminando em $\mathrm{R}_{5}$ (figuras 171-172, 176-182);

(2) terminando muito além de $\mathrm{R}_{5}$, próximo ao ápice da asa (figuras 157-162, 165-168).

Número de passos: 14; IC: 14; IR: 80.

Este caráter foi utilizado por Tozoni (1998), Hippa et al. (2004), Rindal \& Søli (2006) e Amorim \& Rindal (2007). A extensão de C além de $\mathrm{R}_{5}$ é uma característica plesiomórfica em Bibionomorpha, sendo que sua extensão até $\mathrm{M}_{1}$ ou alcançando apenas $\mathrm{R}_{5}$ é uma condição apomórfica (Amorim, 1993; Amorim \& Rindal, 2007). Em Leiinae, o grande alongamento de $\mathrm{C}$ além de $\mathrm{R}_{5}$ (2), também presente em Manotinae e Novakia+ , é apomórfico para Thoracotropis ${ }^{+}$, com várias reversões.

\section{Subcostal (Sc):}

(0) completa, terminando em C (figuras 154-155, 163-164, 173-180);

(1) incompleta, livre e reta (figuras 158, 162, 166-167, 169-171);

(2) incompleta, livre e inclinada, direcionada a R (figuras 159-161). 
Número de passos: 13; IC: 15; IR: 77.

Este caráter foi utilizado por Søli (1997a), Tozoni (1998), Hippa et al. (2004), Amorim \& Rindal (2007) e Borkent \& Wheeler (no prelo). Segundo Amorim \& Rindal (2007), a interpretação a respeito da extensão da Sc é equivocada, sendo que há referências a "Sc terminando em C" e "Sc terminando em $\mathrm{R}_{1}$ ". Sc terminando em C é uma condição plesiomórfica, ao passo que $\mathrm{Sc}$ terminando em $\mathrm{R}_{1}$ corresponde, na verdade, a uma $\mathrm{Sc}$ incompleta com sc-r presente. A análise por parcimônia indica a distribuição esparsa da condição plesiomórfica, fazendo com que a condição de Sc livre seja vista como sinapomórfica para todos os Mycetophilidae menos Sciophilinae, havendo inúmeras reversões. A hipótese de reaquisição múltipla de estruturas perdidas, ainda que evidentemente possível, muitas vezes parece pouco aceitável. Neste caso, a subamostragem dos grupos que são plesiomórficos para esse caráter pode ter implicado na inversão da evolução dos estados.

\section{Sc:}

(0) nua (figuras 159-161, 174-176);

(1) pubescente (figuras 163-164, 172, 183).

Número de passos: 10; IC: 10; IR: 50.

Este caráter foi utilizado por Søli (1997a), Hippa et al. (2004) e Amorim \& Rindal (2007). No estudo de Søli (1997a) e Hippa et al. (2004), há uma separação entre cerdas na superfície ventral e dorsal e em Amorim \& Rindal (2007) há a restrição a presença de macrotríquias apenas na metade distal de Sc. Por causa da plasticidade do caráter, novamente a subamostragem de grupos-externos pode ter invertido o sentido das mudanças. $\mathrm{Na}$ análise numérica, o estado de Sc nua aparece como plesiomórfico em Leiinae. O estado apomórfico, Sc pubescente, aparece diversas vezes, como em (Indoleia+Rondaniella), Leiella, Neoclastobasis, (Clastobasis sp.+ Leia amapaensis).

\section{Veia sc-r:}

(0) presente (figuras 154-155, 174-177);

(1) ausente (figuras 163-164, 172-173).

Número de passos: 17; IC: 5; IR: 64.

Este caráter foi utilizado por Tozoni (1998), Hippa et al. (2004) e Borkent \&Wheeler (no prelo). A veia sc-r é bastante pequena já no plano-básico de Diptera, tendo sido perdida diversas vezes, em diferentes clados (Amorim \& Rindal, 2007). A plasticidade na evolução 
dessa veia e a dificuldade de observação podem gerar falsas interpretações (Matile, 1990; Amorim \& Rindal, 2007). Em acordo com a discussão no caráter 93, "Sc terminando em R" implica na presença de sc-r. A análise numérica indica a perda da veia próximo à base da evolução da família, com diversas reaquisições, o que parece pouco crível, mas é a interpretação numérica mais parcimoniosa para a amostragem feita aqui. Na base do grupo Thoracotropis $^{+}$a veia está ausente, com uma reaquisição em Ateleia* ${ }^{*}$

\section{Setor radial da asa:}

(0) com cerdas dispersas regularmente (figuras 154-182);

(1) densamente coberto por cerdas (figura 183).

Número de passos: 1; IC: 100; IR: 100.

Este caráter não utilizado antes na literatura e é uma sinapomorfia de Allactoneura.

\section{Região da asa em que $R_{1}$ alcança $C$ :}

(0) no terço apical da asa (figuras 154-156);

(1) no terço medial da asa (figuras 164-173);

(2) no terço basal da asa (figura 187).

Número de passos: 6; IC: 33; IR: 83.

Søli (1997a) utilizou apenas dois estados para esta característica, $\mathrm{R}_{1}$ alcançando C na metade apical da asa ou na metade basal. Como esta característica relaciona-se à característica erigida por Edwards (1925) para delimitar a subfamília Leiinae, o encurtamento de $\mathrm{R}_{1}$, optou-se por um caráter multiestado a fim de abranger a variabilidade morfológica observada. No presente estudo $R_{1}$ alcançando $C$ no terço apical da asa é plesiomórfica para Leiinae, condição vista em outras famílias de Bibionomorpha. A presença de uma $\mathrm{R}_{1}$ "mais curta”, alcançando C no terço medial da asa, está presente em Gracilileia ${ }^{+}$, com uma reversão apenas em Indoleia. A presença de uma $\mathrm{R}_{1}$ muito curta é autoapomórfica para Manota. $\mathrm{O}$ gênero Sticholeia também apresenta uma redução da extensão de $\mathrm{R}_{1}$, que alcança C no terço medial da asa, razão utilizada por Søli (1996) posicionar em Leiinae. O clado Docosia ${ }^{+}$também possui a $\mathrm{R}_{1}$ alcançando $\mathrm{C}$ no terço medial da asa.

\section{Comprimento de $\mathbf{R}_{1}$ em relação a r-m:}

(0) mais de 3 vezes (figuras 167, 194-195, 198-199);

(1) de 1 a 3 vezes (figuras 156, 163-164, 168);

(2) mais curta (figuras 154-155, 173-175); 
(3) tão longa quanto (figuras 157, 161, 172).

Número de passos: 21; IC: 14; IR: 66.

Assim como no caráter 92, esta característica relaciona-se àquela erigida por Edwards (1925) para delimitar a subfamília Leiinae, o encurtamento de $\mathrm{R}_{1}$. Tozoni (1998) e Hippa et al. (2004) utilizaram como estados "longa" e "curta", mas no presente estudo optou-se por uma relação do comprimento de $\mathrm{R}_{1}$ e de $\mathrm{r}-\mathrm{m}$ para representar as variações morfológicas observadas. Segundo Tozoni (1998), na maioria dos gêneros de Gnoristinae, Mycomyinae e Sciophilinae, $\mathrm{R}_{1}$ é bastante longa, alcançando a margem da asa em uma posição bem distal. Essa seria a condição plesiomórfica de $\mathrm{R}_{1}$, também encontrada em famílias próximas a Mycetophilidae, como Ditomyiidae, Keroplatidae e Bolitophilidae (Amorim, 1993). Reduções na extensão de $\mathrm{R}_{1}$ também são conhecidas em Sciophilinae, Gnoristinae, Manotinae e Leiinae (Tozoni, 1998). O estado apomórfico deste caráter em Leiinae, no entanto, está relacionado ao deslocamento para uma posição apical da origem de Rs, não a uma redução na extensão de $\mathrm{R}_{1}$, de maneira que este caráter não duplica o anterior. A condição plesiomórfica (0) é típica de Sciophilinae, Mycomyiinae e Gnoristinae. Essa condição também está presente em Mycetophilinae, sendo que Manotinae tem as condições (1) e (2). Entre os Leiinae, o estado (0) aparece em Trichoterga e Sigmoleia. Por otimização, a condição (1) aparece no plano-básico da subfamília, tornando o estado em Trichoterga e Sigmoleia uma reversão. O estado (2) é apomórfico para Garretella $^{+}$e Waipapamyia $^{++}$, com algumas reversões. O estado (3) é uma condição que surge diversas vezes, como em, Gracilileia, Mohelia ${ }^{+}$, Leiella ochreocalcar, Anomalomyia guttata, Clastobasis sp. e C. alternans.

\section{Forma de $R_{1}$ :}

(0) levemente oblíqua ou horizontal (figuras 154, 156, 163);

(1) curvada em direção à margem da asa (figuras 159-161);

(2) transversal (figuras 155, 157, 166-171);

$\left(3^{*}\right)$ acompanhando a curvatura da asa (figura 307).

Número de passos: 11; IC: 18; IR: 80.

Este caráter é utilizado aqui pela primeira vez. Em Leiinae, o estado (0) é plesiomórfico. O estado (1) é sinapomórfico para Megophthalmidia ${ }^{+}$. O estado (2) surge em Gracilileia $^{+}$, com reversões em Indoleia, Leiella ochreocalcar e em Anomalomyia* (exceto Greenomyia mongolica ${ }^{+}$, Leia stigmatica, L. arsona e L. fascipennis), uma plasticidade que 
indica que outras mudanças (como extensão) de $\mathrm{R}_{1}$ podem implicar em uma mudança paralela de sua forma.

\section{Origem do primeiro setor de Rs:}

(0) no terço basal da asa (figuras 158 e 168);

(1) no terço medial da asa (figuras 169-173).

Número de passos: 9; IC: 11; IR: 42.

Segundo Amorim \& Rindal (2007), a origem do primeiro setor de Rs entre os terço basal e medial da asa é a condição plesiomórfica para Diptera. Tozoni (1998) indica que a condição apomórfica (1) é compartilhada basicamente pelos Leiinae, mas no presente há reversões em Trichoterga e Cawthronia.

\section{Setor basal de Rs:}

(0) oblíquo (figuras 164, 166-167, 184);

(1) praticamente transversal/vertical (figuras 154-163).

Número de passos: 17; IC: 5; IR: 61.

Utilizado pela primeira vez em um estudo filogenético de Mycetophilidae, o estado (1) é característico de Leiinae, com reversões em Rondaniella dimidiata, Paradoxa ${ }^{++}$(exceto Cycloneura $^{+}$), Neoclatobasis, Greenomyia mongolica ${ }^{+}$e várias vezes em Clastobasis .

\section{7. $\mathbf{R}_{\mathbf{4}}$ :}

(0) ausente (figuras 154-164);

(1) presente (figuras 165, 192-193).

Número de passos: 3; IC: 33; IR: 84.

Este caráter foi utilizado por Søli (1997a), Tozoni (1998) e Borkent \& Wheeler (no prelo). A perda de $\mathrm{R}_{4}$ é bastante comum em Mycetophilidae. Em Sciophilinae e Gnoristinae, o uso dessa característica requer cautela, pois os dois estados do caráter podem ser encontrados dentro de um mesmo gênero, como em Speolepta e Dziedzickia (Tozoni, 1998). Em Leiinae, o único gênero que possui $\mathrm{R}_{4}$ é Waipapamyia. A posição isolada desse gênero dentro da topologia de Leiinae sugere que $\mathrm{R}_{4}$ nesse caso é realmente um neomorfismo.

\section{Ponto em que $R_{5}$ alcança margem da asa:}

(0) próximo ao ápice da asa (figuras 154-156);

(1) em uma posição anterior (figuras 159-162). 
Número de passos: 10; IC: 10; IR: 74.

Hippa et al. (2004) codificaram os estados desse caráter como comprimento de $\mathrm{R}_{5}$, "longa" e "curta". Em Leiinae, o estado (0) é plesiomórfico para a subfamília, sendo que a redução na extensão de $\mathrm{R}_{5}$, o estado (1), é apomórfico para Gracilileia ${ }^{+}$, com reversões em Indoleia, Anomalomyia, Ateleia ${ }^{+}$e Caledonileia. Há homoplasias com gêneros das outras subfamílias.

\section{Forma de $\mathbf{R}_{5}$ próximo ao ápice:}

(0) acompanhando a curvatura da asa (figuras 154, 156, 203);

(1) aproximadamente reta de sua origem até a margem da asa (figuras 155, 157, 200-201);

(2) aproximadamente reta com região dorsal curvada dorsalmente (figura 202);

(3) aproximadamente reta com região dorsal curvada ventralmente (figuras 164 e 171).

Número de passos: 14; IC: 21; IR: 72.

Segundo Tozoni (1998), a curvatura de $\mathrm{R}_{5}$ acompanhando a curvatura da asa é encontrada dentro e fora de Mycetophilidae, mas há variações de formato na família. No presente trabalho, o estado (0) é plesiomórfico para Leiinae. O estado (1) é apomórfico para Paraleia, Gracilileia, Trichoterga, espécies neotropicais de Megophthalmidia, Mohelia ${ }^{+}$, Paracycloneura, Sigmoleia, Cycloneura ${ }^{+}$e Greenomyia. O estado (3) é apomórfico para Rondaniella e Procycloneura. O estado (2) é exclusivo para Novakia.

\section{Posição de r-m:}

(0) longitudinal (figuras 154 e 169);

(1) oblíqua (figuras 160-161, 165);

(2) transversal (figuras 164, 167, 178);

(3) curvada medianamente (figuras 179-182);

(4) angulada $90^{\circ}$ medianamente, porção ventral nua e menos esclerotizada (figura 183).

Número de passos: 24; IC: 16; IR: 68.

Este caráter foi utilizado por Tozoni (1998) e Amorim \& Rindal (2007). A mudança de uma condição transversa de r-m para uma condição oblíqua é sinapomórfica para Mycetophiliformia (Amorim \& Rindal, 2007). Ainda que homoplástica dentro de Mycetophilidae, este é um caráter interessante ao definir pequenos grupos dentro da família (Tozoni, 1998). A condição (1) é evidentemente plesiomórfica, presente no plano-básico de Leiinae, com inúmeras variações dentro do grupo. O estado (4) é sinapomórfico para Allactoneurinae. 
101. Comprimento de r-m em relação ao primeiro setor de Rs:

(0) menor que 2 vezes (figuras 164, 167, 198-199);

(1) de 2 a 4 vezes (figuras 155, 159, 162-163);

(2) maior que 4 vezes (figura 154, 156-157);

(3) do mesmo comprimento (figuras 190-191);

(4) menor (figura 192).

Número de passos: 27; IC: 14; IR: 53.

Amorim \& Rindal (2007) utilizaram o comprimento de r-m como caráter, mas comparando com a distância entre C-Sc. No presente estudo, optou-se por uma comparação com o comprimento de Rs. Nesta análise, a condição (1) é a do plano-básico de Mycetophilidae. Há grande variação entre os gêneros nas várias subfamílias, correspondendo a casos de encurtamento ou alongamento de r-m. O alongamento de r-m para o estado (2) é uma apomorfia de Leiinae, com diversos eventos de redução.

\section{Transversal r-m:}

(0) nua (figuras 196-199);

(1) pubescente (figuras 157-163).

Número de passos: 3; IC: 33; IR: 66.

Este caráter, usado pela primeira vez, tem a condição pubescente em todos os Leiinae, havendo ausência de pubescência em Gnoristinae e Mycomyiinae.

\section{Forquilha medial:}

(0) presente (figuras 154-161);

(1) ausente (figuras 162, 169-170).

Número de passos: 2; IC: 50; IR: 50.

Tozoni (1998) utilizou este caráter em sua análise filogenética de Mycetophilidae associado às características do caráter 106. Segundo Tozoni (1998), a relação entre o comprimento de $\mathrm{M}_{1+2}$ e a forquilha medial apresenta uma série de variações dentro de Mycetophilidae. Só é possível estabelecer essa comparação quando existe a forquilha, de maneira que, no presente trabalho, optou-se pela separação dessas características, o que também foi feito por Amorim \& Rindal (2007) e Borkent \& Wheeler (no prelo). Em Leiinae, a forquilha medial está ausente apenas em Paracycloneura e (Cycloneura+Tonnwardsia). 
104. $M_{1+2}$ :

(0) nua (figuras 155, 160-161;

(1) pubescente (figuras 154, 166, 178).

Número de passos: 10; IC: 10; IR: 78.

Este caráter foi utilizado por Amorim \& Rindal (2007) e Borkent \& Wheeler (no prelo). Em Leiinae, o estado apomórfico está presente em Garretella, Gracilileia, Megophthalmidia crassicornis e Paracycloneura ${ }^{+}$, com reversões em Paradoxa paradoxa e Procycloneura.

\section{5. $M_{1+2}$ :}

(0) esclerotizada (figuras 154-163);

(1) obsoleta, completamente não esclerotizada (figuras 171 e 187).

Número de passos: 8; IC: 12; IR: 56.

Esta característica foi utilizada por Tozoni (1998), Rindal \& Søli (2006) e Amorim \& Rindal (2007). Em Leiinae, o estado apomórfico está presente apenas em Procycloneura.

\section{Extensão de $M_{1+2}$ em relação ao comprimento da forquilha medial:}

(0) um terço (figuras 158 e 165);

(1) do mesmo comprimento (figuras 164 e 167);

(2) metade (figuras 154-156);

(3) mais longa;

(4) um quinto (figuras 166 e 171);

(5) um quarto (figuras 177, 179-180);

(6) extremamente reduzida (figuras 184-185).

Número de passos: 29; IC: 20; IR: 66.

Conforme comentado na discussão do caráter 103, Tozoni (1998) e Borkent \& Wheeler (no prelo) utilizaram relações entre o comprimento de $\mathrm{M}_{1+2}$ e o comprimento da forquilha medial. O estado (2) é a condição no plano-básico de Leiinae. O estado (0) está presente em Paraleia fulvescens, Trichoterga, Waipapamyia, Caledonileia, Greenomyia mongolica e várias vezes em Clastobasis ${ }^{*}$. O estado (1) está presente em Megophthalmidia divergens, (Indoleia+Rondaniella), Sigmoleia melanoxantha e (Anomalomyia guttata+A. minor). O estado (3) está presente em Sigmoleia peterjohnsi. O estado (4) em Paradoxa fusca e Procycloneura. O estado (5) em Neoclastobasis, (Greenomyia cephala+G. joculator) e várias vezes em Clastobasis ${ }^{*}$. 


\section{7. $M_{1}$ :}

(0) completa (figuras 154-157);

(1) obsoleta basalmente (figuras 164, 171-172, 174);

(2) ausente (figuras 162, 169-170).

Número de passos: 12; IC: 16; IR: 58.

Este caráter foi utilizado por Tozoni (1998) e Borkent \& Wheeler (no prelo). O estado (0) é evidentemente plesomórfico e as condições (1) e (2) são independentes. A interrupção basal de $\mathrm{M}_{1}$ é relativamente comum em Mycetophilidae (Tozoni, 1998). Em Leiinae, o estado (1) é apomórfico para Rondaniella, Paradoxa paradoxa, (Procycloneura+Leiella) e Ateleia. O estado (2) é apomórfico para Paracycloneura e (Cycloneura+Tonnwardsia).

\section{8. $M_{1}$ :}

(0) nua (figuras 158, 196-197):

(1) pubescente (figuras 154, 159-160).

Número de passos: 4; IC: 25; IR: 57.

Este caráter foi utilizado por Rindal \& Søli (2006), Amorim \& Rindal (2007) e Borkent \& Wheeler (no prelo). O estado (1) é característico de Leiinae, com exceção de Thichoterga.

\section{Sinuosidade de $M_{1}$ :}

(0) ausente (figuras 154-157);

(1) presente (figuras 188-189).

Número de passos: 1; IC: 100; IR: 100.

Segundo Tozoni (1998), o gênero Sigmoleia apresenta forte sinuosidade. Porém, apenas Sigmoleia malanoxantha (figura 167) apresenta tal característica. A sinuosidade descrita neste caráter é uma sinuosidade leve, na porção medial de $\mathrm{M}_{1}$ e é sinapomórfica para Exechiini, em Mycetophilinae.

\section{0. $\mathrm{M}_{2}$ :}

(0) completa (figuras 154-155);

(1) obsoleta basalmente (figuras 165 e 186);

(2) ausente (figuras 162, 169-170).

Número de passos: 13; IC: 15; IR: 42. 
Este caráter foi utilizado por Tozoni (1998) e está presente também em alguns grupos de Sciophilinae e Gnoristinae. Em Leiinae, o estado (1) está presente em Waipapamyia, Paradoxa fusca, Procycloneura e Greenomyia mongolica. O estado (2) está presente em Paracycloneura e (Cycloneura+Tonnwardsia).

\section{1. $\mathbf{M}_{2}$ :}

(0) nua (figuras 158, 196-197);

(1) pubescente (figuras 154, 157, 159-160).

Número de passos: 6; IC: 16; IR: 54.

Este caráter foi utilizado por Borkent \& Wheeler (no prelo). A pubescência de $\mathrm{M}_{2}$ é característica de todos os Leiinae, com exceção de Trichoterga.

\section{2. Ápice de $M_{2}$ :}

(0) completo, atingindo a margem da asa (figuras 154-155);

(1) incompleto, não atingindo a margem da asa (figuras 174, 176-177, 184).

Número de passos: 6; IC: 16; IR: 50.

Em um número importante de gêneros de Mycetophilidae, as veias são incompletas apicalmente, não atingindo a margem da asa (Tozoni, 1998). Em Leiinae o estado (1) está presente em Ateleia, Caledonileia, Neoclastobasis, Clastobasis stylata e Leia spinifera ${ }^{+}$.

\section{3. $M_{1}$ e $M_{2}$ :}

(0) paralelas (figuras 154, 158, 160);

(1) divergentes (figuras 155, 165, 167);

(2) convergentes (figuras 179 e 182).

Número de passos: 23; IC: 8; IR: 60.

Utilizado pela primeira vez, os estados (0) e (1) são recorrentes em Leiinae e o estado (2) é apomórfico para Clastobasis stylata, C. vicina, C. alternans, Leia bivittata, L. andirai e L. opima.

\section{Extensão do primeiro setor de CuA (da base da asa até o início da forquilha cubital):}

(0) no máximo um terço do comprimento da forquilha cubital (figuras 175, 198-199);

(1) aproximadamente tão longa quanto a forquilha cubital (figuras 156, 193, 200);

(2) metade do comprimento da forquilha cubital (figuras 154, 159-160); 
(3) muito reduzido (figuras 164-166, 172);

(4) mais longo que o comprimento da forquilha cubital (figuras 157-158);

(5) ausente (figuras 171, 183, 185-186, 201);

(6*) até a margem da asa (figuras 313 e 315$)$.

Número de passos: 35; IC: 14; IR: 53.

Este caráter foi utilizado por Tozoni (1998), mas aqui foram codificados mais estados. Segundo Tozoni (1998), há variações consideráveis dentro de Mycetophilidae, sendo que a mais comum é a redução da forquilha, com um alongamento da base de CuA. Em Leiinae, os estados (0), (1), (2) e (3) são recorrentes. O estado (4) é apomórfico para Gracilileia redunda e Trichoterga. O estado (5) é apomórfico para Procycloneura.

\section{Primeiro setor de CuA:}

(0) nu (figuras 155, 161, 196-199);

(1) pubescente (figuras 154, 156, 160).

Número de passos: 10; IC: 10; IR: 62.

Este caráter foi utilizado por Borkent \& Wheeler (no prelo). A maior parte dos Leiinae tem cerdas no primeiro setor de $\mathrm{CuA}$, com algumas perdas secundárias, como em Paraleia, Trichoterga, Aphrastomyia, Paracycloneura, Rondaniella, Waipapamyia e (Cycloneura+Tonnwardsia).

\section{Ponto de bifurcação de $\mathrm{CuA}+\mathrm{M}_{4}$ em relação ao ápice de Sc:}

(0) junto ao ápice de Sc (figuras 155 e 173);

(1) mais distalmente que o ápice de Sc (figuras 157-162, 179-180);

(2) mais basalmente que o ápice de Sc (figuras 154, 163-165, 181-182).

Número de passos: 22; IC: 9; IR: 62.

Este caráter não foi codificado desta maneira antes. Seria esperado que fosse uma característica distintiva entre Leia e Clastobasis. Em Leiinae, os três estados são recorrentes, inclusive dentro de Clastobasis $^{*}$, reforçando a ideia de que a separação entre os dois gêneros é artificial, ainda que fosse necessária uma amostragem mais ampla ao nível de espécie para inferências mais definitivas.

117. $\mathrm{M}_{4}$ :

(0) completa (figuras 156-161);

(1) obsoleta basalmente (figuras 163-166). 
Número de passos: 14; IC: 7; IR: 74.

Tozoni (1998) comenta que $\mathrm{M}_{4}$ obsoleta é bastante comum em Mycetophilidae. Em Leiinae, o estado plesiomórfico é encontrado em Paraleia, Mohelia, Megophthalmidia, Greenomyia, Anomalomyia e Sigmoleia. O estado apomórfico ocorre inúmeras vezes, presente em Garretella, Paracycloneura ${ }^{+}$, com reversão em Sigmoleia, Anomalomyia, Greenomyia mongolica ${ }^{+}$, Leia stigmatica, L. winthemi e L. spinifera.

\section{8. $M_{4}$ :}

(0) nua (figuras 158, 162, 194-197);

(1) pubescente (figuras 154-156, 159).

Número de passos: 5; IC: 20; IR: 50.

Este caráter foi utilizado por Søli (1997a) e Borkent \& Wheeler (no prelo). A condição plesiomórfica é evidentemente $\mathrm{M}_{4}$ pubescente, com diversas perdas independentes, como, dentro de Leiinae, em Trichoterga e Paracycloneura.

\section{9. Ápice de $M_{4}$ :}

(0) completo, atingindo a margem da asa (figuras 154-161);

(1) incompleto, não atingindo a margem da asa (figuras 176-177).

Número de passos: 5; IC: 20; IR: 55.

$\mathrm{M}_{4}$ não alcançando a margem da asa é uma característica evidentemente apomórfica. A maior parte dos gêneros nas várias subfamílias é plesiomórfica, condição do plano-básico de Leiinae. O estado (1) está presente em Rondaniella sp., Caledonileia, algumas espécies de Leia e Clastobasis e em Neoclastobasis. Em Allactoneurinae, Sticholeia tem a condição apomórfica.

\section{Formato do segundo setor de $\mathrm{CuA}$ :}

(0) como uma curva em direção à margem da asa (figuras 156-161);

(1) com uma depressão mediana leve (figuras 155, 165, 176-177);

(2) com uma depressão mediana profunda curva (figuras 166, 168-175);

(3) com uma depressão mediana profunda angulada (figura 167);

(4) reta (figuras 190-191).

Número de passos: 17; IC: 23; IR: 74.

Essa característica ainda não havia sido utilizada em um estudo filogenético de Mycetophilidae. A condição (4) está presente em Manota e em Mycetophilinae, sendo que 
Allactoneura e Sticholeia possuem condições sucessivamente apomórficas (estados (1) e (2), respectivamente). O plano-básico de Leiinae tem o estado (0). O estado (1) é encontrado como aquisições independentes em Paraleia e em algumas espécies do clado Indoleia ${ }^{++}$. O estado (2) é apomórfico para Indoleia ${ }^{++}$, com algumas reversões, e o estado (3) é exclusivo de Sigmoleia.

\section{1. $\mathrm{A}_{1}$ :}

(0) incompleta, terminando no terço medial da asa (figuras 158, 172, 188-189);

(1) incompleta, terminando no terço basal da asa (figuras 154-155, 162, 168).

Número de passos: 9; IC: 11; IR: 33.

Esta característica foi utilizada por Tozoni (1998) e Amorim \& Rindal (2007). Segundo Tozoni (1998), $\mathrm{A}_{1}$ incompleta seria uma sinapomorfia de Mycetophilidae. O estado (1) é amplamente distribuído em Leiinae, com alguns casos de reversão dentro do grupo.

\section{A :}

(0) livre (figuras 154-155, 162, 168);

(1) fundida distalmente à CuA (figuras 167, 169, 171).

Número de passos: 3; IC: 33; IR: 66.

Segundo Tozoni (1998), esta modificação ímpar seria exclusiva de Cycloneura, Procycloneura e Sigmoleia. No presente estudo, foi possível verificar que a fusão de $\mathrm{A}_{1}$ distalmente a CuA também é compartilhada por Paradoxa e que os gêneros Cawthronia, Townwardsia e Leiella, no entanto, que pertencem ao mesmo clado obtido aqui, são plesiomórficos para esse caráter. Porém, nesses gêneros $A_{1}$ termina muitíssimo próxima à $\mathrm{CuA}$, mas sem fundir-se totalmente à $\mathrm{CuA}$.

\section{3. $\mathrm{A}_{1}$ :}

(0) nua (figuras 155 e 162);

(1) pubescente (figuras 154, 166, 168).

Número de passos: 6; IC: 16; IR: 85.

Este caráter foi utilizado por Amorim \& Rindal (2007). A condição pubescente de $\mathrm{A}_{1}$ é amplamente distribuída em Mycetophilidae e evidentemente plesiomórfica. Em Leiinae, igualmente, a condição pubescente é amplamente distribuída, havendo alguns casos de perdas secundárias, como em Paraleia, Trichoterga, Megophthalmidia ${ }^{+}$, Paracycloneura e (Indoleia+Rondaniella). 


\section{Posição de $A_{1}$ em relação a CuA:}

(0) convergente (figuras 169 e 171);

(1) divergente (figuras 165, 168, 174-175);

(2) paralela (figuras 158, 176-178).

Número de passos: 14; IC: 14; IR: 69.

Este caráter foi utilizado por Tozoni (1998) apenas com as condições convergente e divergente, sendo a condição apomórfica exclusiva de Cawthronia. Em Leiinae, o estado divergente, além de Cawthronia, mostrou-se presente em Thoracotropis, Gracilileia, (Indoleia+Rondaniella), Waipapamyia, Leiella, Anomalomyia, Ateleia ${ }^{+}$e Clastobasis ${ }^{*}$. O estado (2) é apomórfico para (Garretella+Paraleia), Trichoterga, Megophthalmidia ${ }^{+}$, Paracycloneura, Tonnwardsia, Sigmoleia e Caledonileia ${ }^{+}$.

125. Dobra alar próxima à margem e acompanhando a curvatura da asa em sua região anal:

(0) ausente (figuras 157-163);

(1) presente (figuras 187-191).

Número de passos: 2; IC: 50; IR: 75.

Esta característica ainda não havia sido utilizada. A condição apomórfico é encontrada em Manota e nos Mycetophilinae.

126. Dobras alares entre os setores radial/medial, medial/cubital e cubital/anal da asa:

(0) ausentes (figuras 157-163);

(1) presentes (figura 183).

Número de passos: 1; IC: 100; IR: 100.

Essa característica, utilizada primeira vez em um contexto filogenético, é uma sinapomorfia de Allactoneura. 

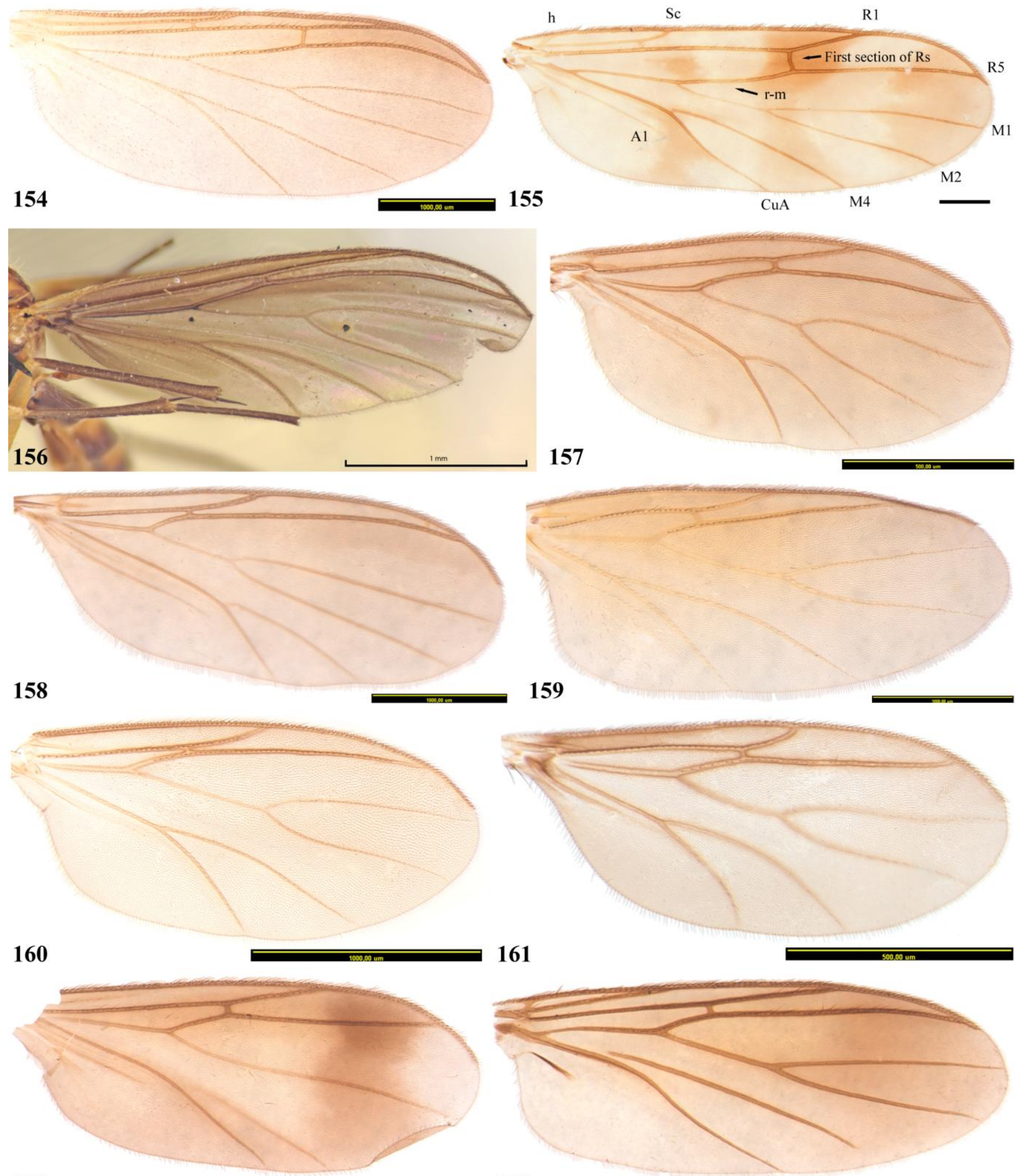

162

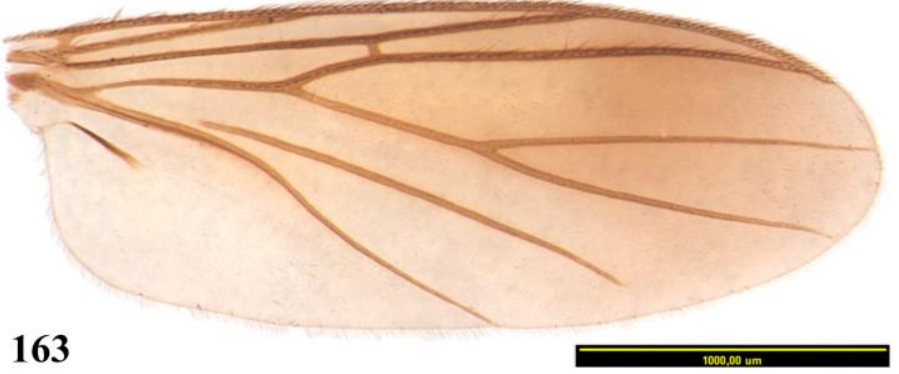

Figuras 154-163. Asas de Mycetophilidae. 154. Garretella shermani, $ð$ (ANIC). Escala $0,1 \mathrm{~mm}$. 155. Paraleia bolivari Oliveira \& Amorim, parátipo $\widehat{\jmath}$ (modificado de Oliveira \& Amorim, 2012: 7).

Escala 0,5mm. 156. Thoracotropis cypriformis, holótipo ô (modificado de Oliveira et al., 2012: 460). 157. Gracilileia redunda, $\widehat{\partial}(\mathrm{MNHN})$. Escala $0,5 \mathrm{~mm}$. 158. Trichoterga monticola, $\widehat{\partial}$ (ANIC).

159. Megophthalmidia divergens, $\widehat{\partial}$ (MZUSP). 160. Mohelia nigricauda, $\widehat{\partial}$ (NMSA). 161. Aphrastomyia shannoni, $\widehat{\partial}$ (INPA). Escala 0,5mm. 162. Paracycloneura apicalis, ㅇ (ANIC). 163. Indoleia bisetosa, o (AMSA). 

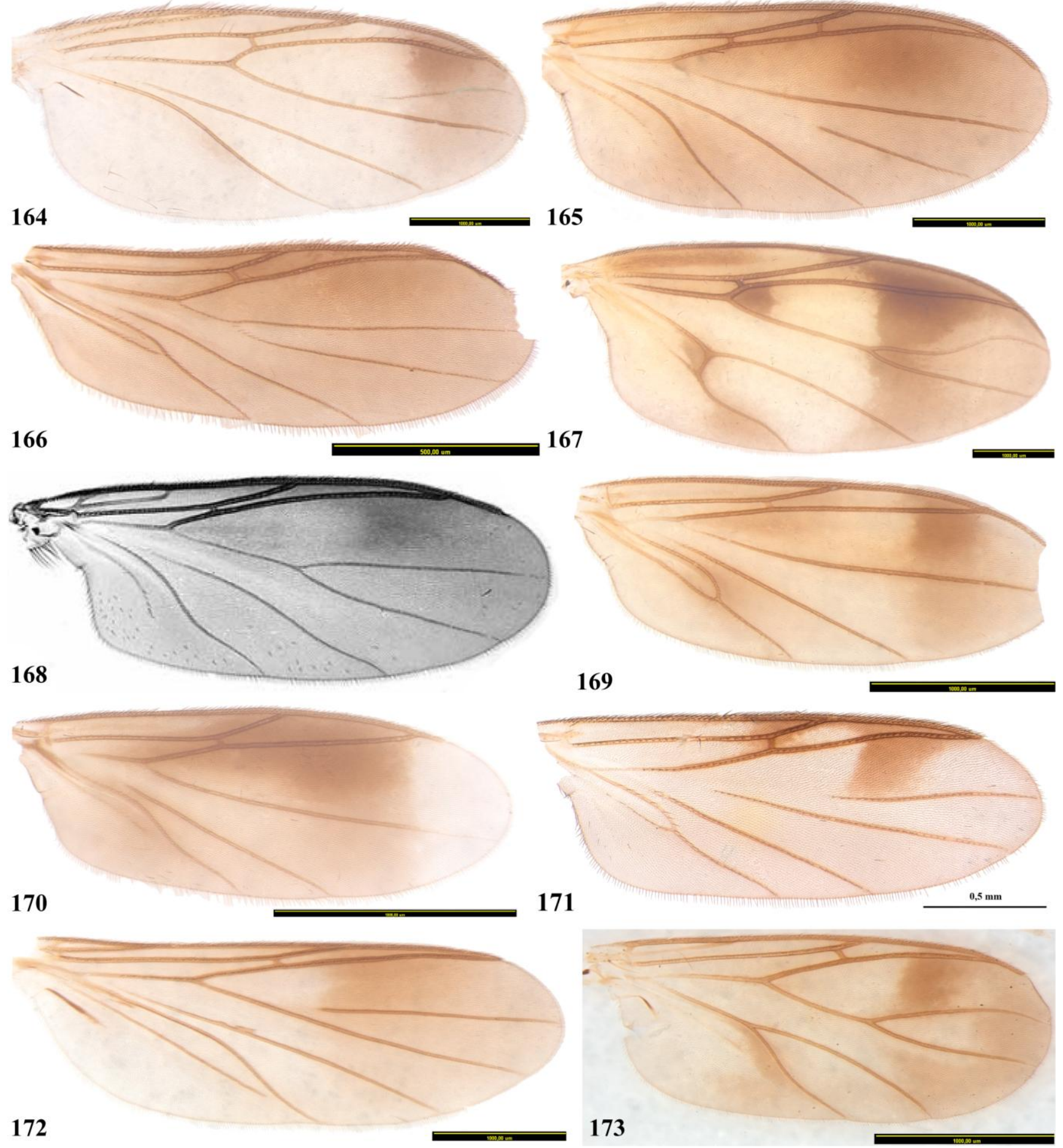

Figuras 164-173. Asas de Mycetophilidae. 164. Rondaniella dimidiata, § (CNC). 165.

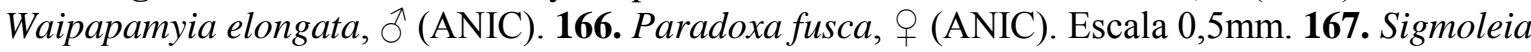
melanoxantha, $q$ (ANIC). 168. Cawthronia nigra (modificado de Jaschhof \& Kallweit, 2009: 13).

169. Cycloneura flava, ơ (ANIC). 170. Tonnwardsia aberrans, $q$ (ANIC). 171. Procycloneura paranensis, $\widehat{\partial}$ (MZUSP). Escala $0,5 \mathrm{~mm}$. 172. Leiella ochreocalcar, $\widehat{\partial}$ (MZUSP). 173. Anomalomyia minor (Marshall), $\widehat{o}$ (ANIC). 

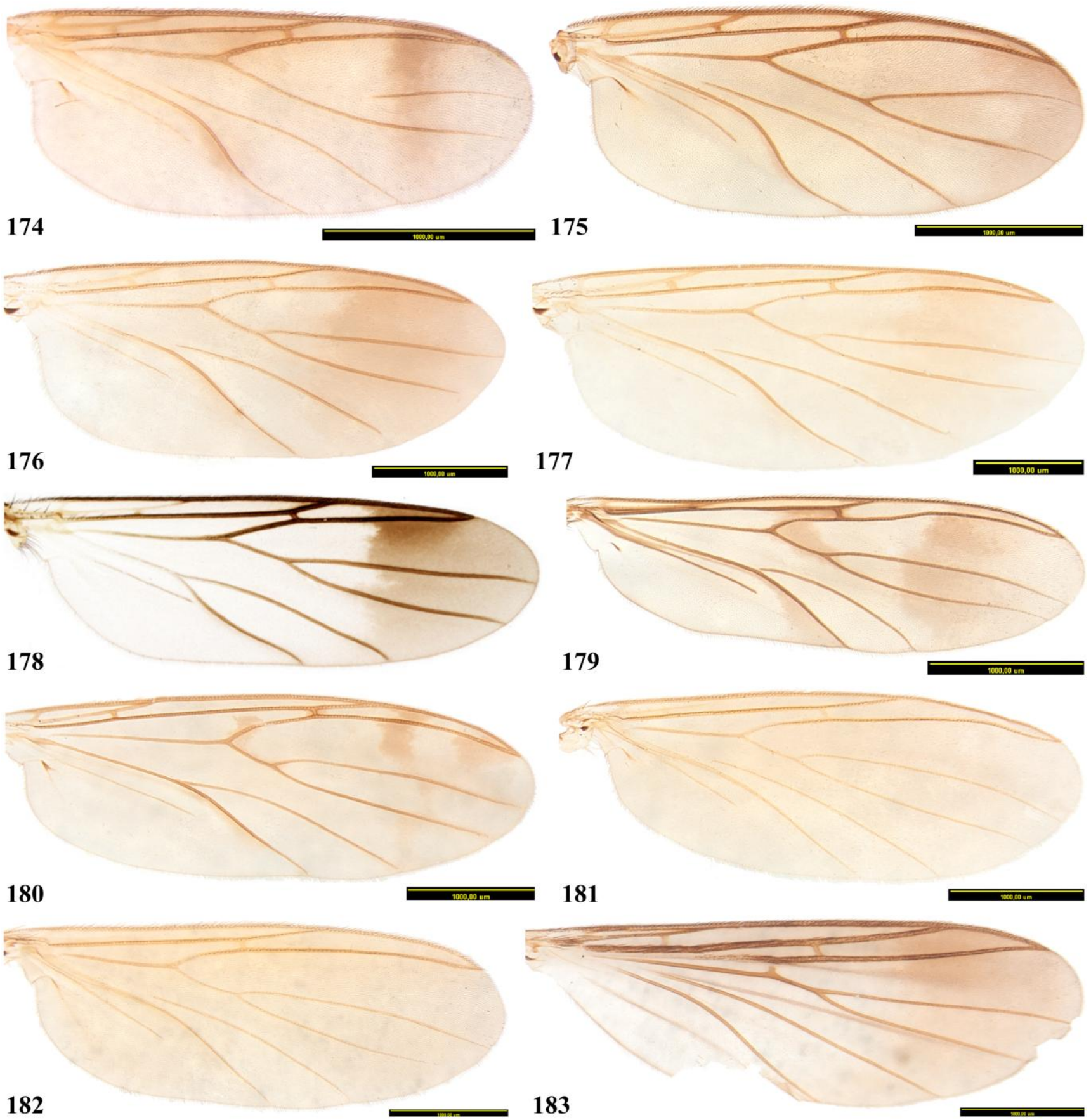

Figuras 174-183. Asas de Mycetophilidae. 174. Ateleia spadicithorax, đ̊ (ANIC). 175.

Acrodicrania africana, ô (SAMC). 176. Caledonileia pusilla, parátipo $\widehat{\jmath}$ (MNHN). 177.

Neoclastobasis draskovitsae, $q$ (LMED). 178. Greenomyia mongolica, $q$ (modificado de Kurina et al., 2011: 37). 179. Leia andirai, $\widehat{\jmath}$ (MZUSP). 180. L. winthemi, đ̊ (LMED). 181. Clastobasis alternans, $\widehat{\partial}$ (LMED). 182. C. tryoni, $\widehat{\partial}$ (ANIC). 183. Allactoneura arguentosquamosa, $\widehat{\partial}$ (NMSA). 

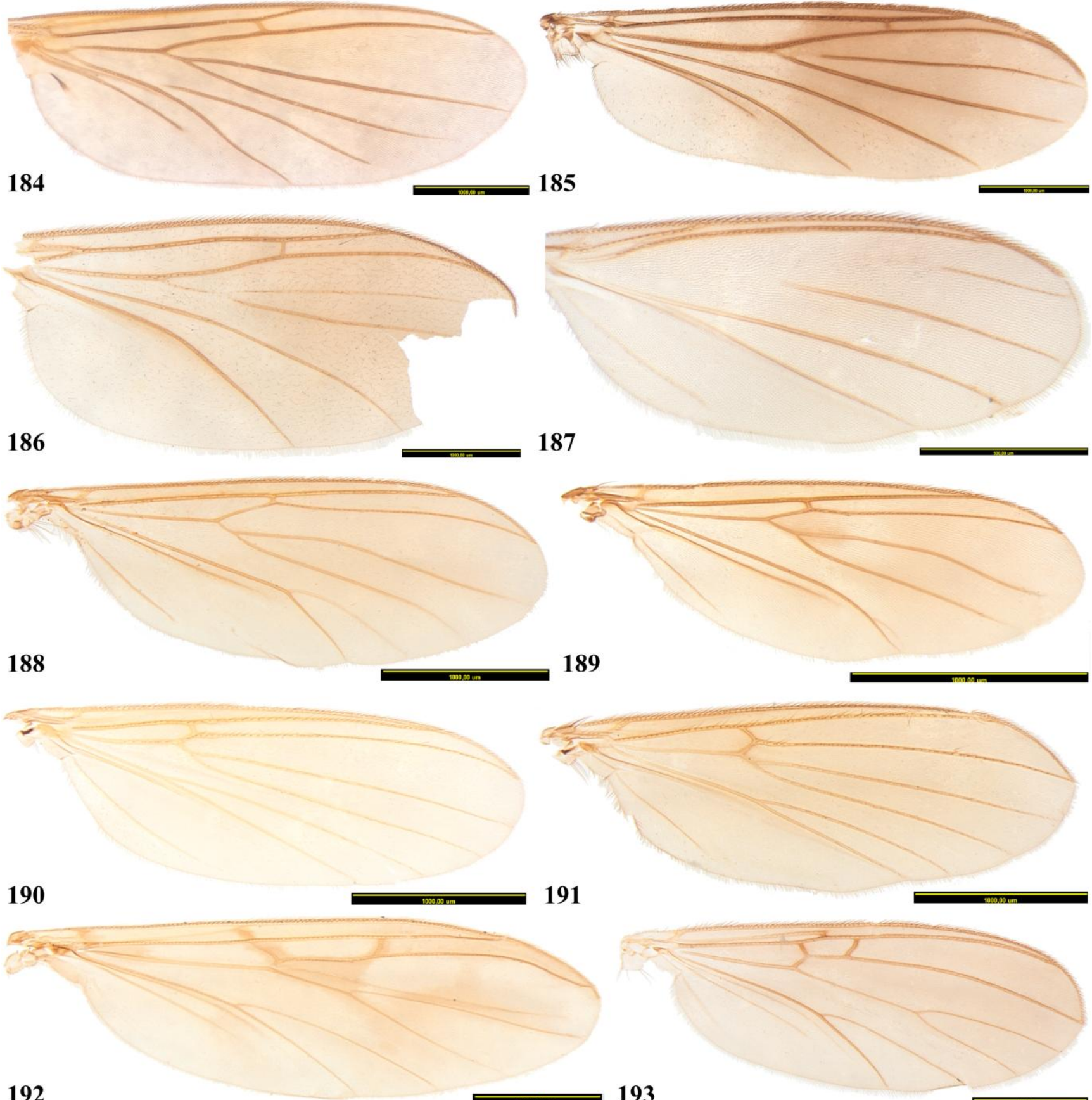

192

193

Figuras 184-193. Asas de Mycetophilidae. 184. Sticholeia cheesmanae, đึ (ANIC). 185. Eumanota, $\uparrow$ (AMSA). 186. Promanota malaisei, đ̋ (LMED). 187. Manota palpalis, ở (INPA). Escala $0,5 \mathrm{~mm}$.

188. Rymosia, o (MZUSP). 189. Exechiopsis, ㅇ (INPA). 190. Epicypta, ㅇ (MZUSP). 191.

Mycetophila, ơ (MZUSP). 192. Neoempheria, đ̋ (LMED). 193. Mycomya, $q$ (MZUSP). 


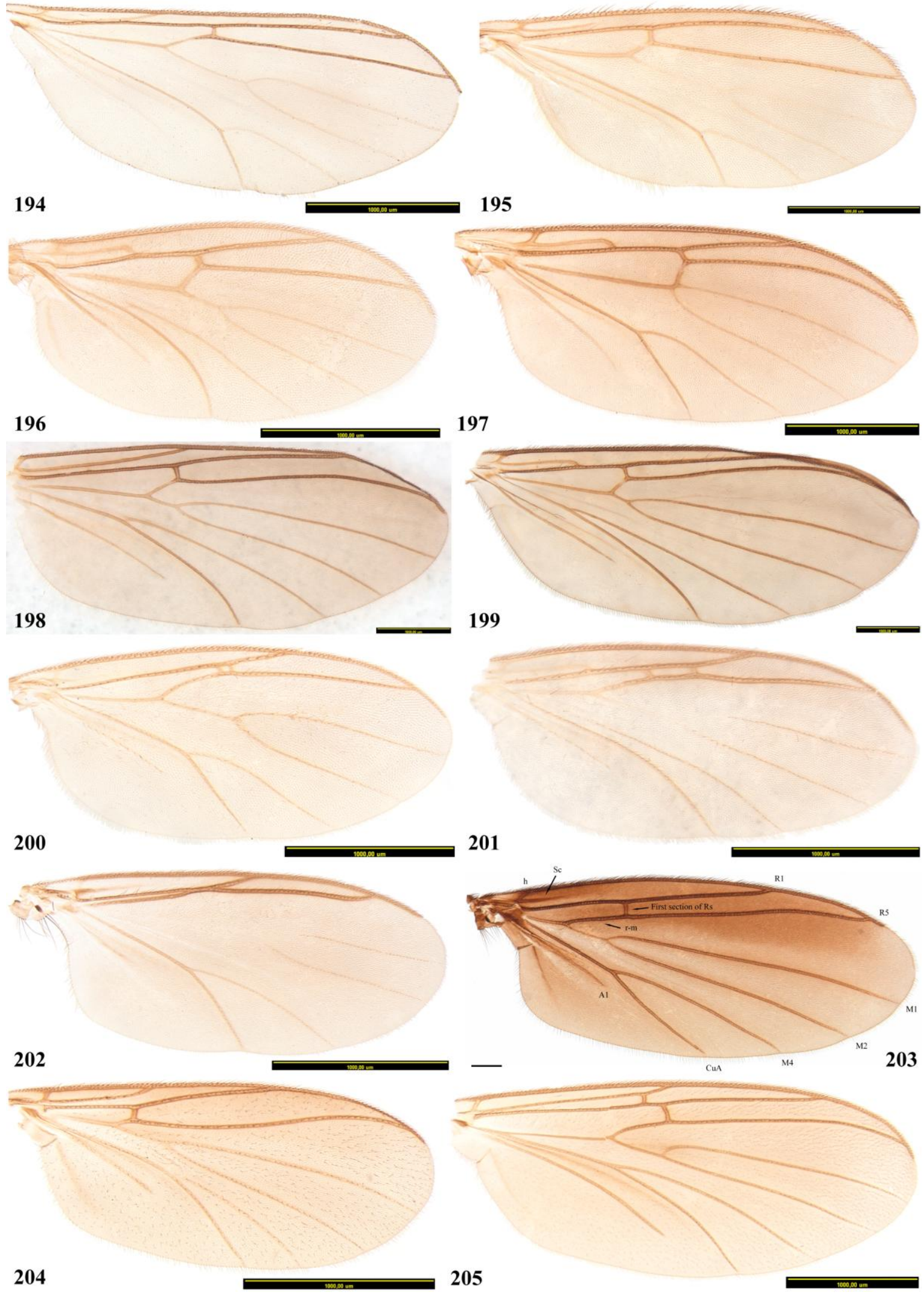

Figuras 194-205. Asas de Mycetophilidae. 194. Synapha, ô (AMSA). 195. Austrosynapha hirta, $\widehat{\jmath}$ (ANIC). 196. Dziedzickia medea, đ̊ (MZUSP). 197. Schnusea caiabii, đ̊ (MZUSP). 198. Boletina obscura, $\widehat{\partial}(\mathrm{CNC})$. 199. Palaeodocosia vittata, + $(\mathrm{CNC})$. 200. Tetragoneura borgmeieri, $\hat{\sigma}$ (MZUSP). 201. Ectrepesthoneura laffooni, $\widehat{\jmath}(\mathrm{CNC})$. 202. Novakia miloi, $q$ (LMED). 203. Docosia adusta, parátipo $q$ (modificado de Oliveira \& Amorim, 2011: 692). Escala 0,3mm. 204. Neoallocotocera fusca, $\hat{\partial}$ (ANIC). 205. Tasmanina gracilis, $\widehat{\partial}$ (ANIC). 


\section{TERMINÁLIA MASCULINA}

\section{Posição da terminália masculina em relação ao abdômen:}

(0) alinhada (figuras 21, 25, 42-43);

(1) flexionada (figuras 17-18, 255B);

(2) duplamente flexionada (figura 255A).

Número de passos: 2; IC: 100; IR: 100.

Este caráter é pela primeira vez utilizado para o entendimento das relações filogenéticas em Mycetophilidae. A flexão dorsal da terminália masculina é sinapomórfica para (Megophthalmidia (Mohelia+Aphrastomyia)). Há uma condição ainda mais modificada (estado (2)) em Megophthalmidia crassicornis.

\section{Organização geral do gonóstilo:}

(0) simples (figuras 9B, 221, 233, 245-246);

(1) bífido (figuras 206-207);

(2) bem desenvolvido, ornamentado, com regiões diferenciadas (figuras 209, 213C, 214 215, 216B, 217C).

Número de passos: 12; IC: 16; IR: 81.

Amorim \& Rindal (2007) observaram sete estados de caráter para a organização geral do gonóstilo. Um refinamento desta característica poderia ter sido feito, mas, de modo geral, corresponde a características de pequenos grupos, fora do escopo deste trabalho. A condição simples, digitiforme, é evidentemente plesiomórfica em Mycetophilidae, encontrada em grande número de gêneros em Sciophilinae, Gnoristinae, Mycomyinae e Mycetophilinae. Em Leiinae, os casos de gonóstilos digitiformes são secundários, havendo gonóstilos bífidos, por exemplo, em Garretella, Thoracotropis e Clastobasis ${ }^{*}$, sendo que ornamentações mais complexas são encontradas em Gracilileia $^{+}$, com algumas reversões em Procycloneura (estado (0)) e Clastobasis ${ }^{*}$ (estados (0) e (1)).

\section{Cerdas modificadas em espinhos no gonóstilo:}

(0) ausentes (figuras 206-207);

(1) presentes (figuras 9B, 213C, 218B, 224-225, 246).

Número de passos: 12; IC: 8; IR: 73.

Søli (1997b) e Borkent \& Wheeler (no prelo) utilizaram a presença de espinhos no gonóstilo em seus estudos filogenéticos de Mycetophilidae. Em Leiinae, o estado (1) é 
apomórfico para Paraleia, Trichoterga e Paracycloneura ${ }^{+}$, com reversões em Cawthronia, Procycloneura similis e em Clastobasis ${ }^{*}$ (exceto Leia ventralis).

\section{Relação altura do gonóstilo/altura do gonocoxito (sem considerar as projeções dorsais do gonocoxito):}

(0) gonóstilo mais curto que altura do gonocoxito (figuras 206-207, 219A);

(1) gonóstilo tão longo quanto o gonocoxito (figuras 224, 227, 233);

(2) gonóstilo mais longo que o gonocoxito (figuras 9B, 237-238).

Número de passos: 13; IC: 15; IR: 45.

Amorim \& Rindal (2007) trabalharam com uma relação entre o gonocoxito e suas projeções maiores, mas não o gonóstilo. No presente trabalho, a extensão do gonóstilo é comparada com o gonocoxito. O gonóstilo é mais curto que o gonocoxito no plano-básico de Mycetophilidae e em boa parte das subfamílias. Há surgimentos independentes, em Leiinae, de gonóstilos alongados, como em Gracilileia, Procycloneura paranensis, Neoclastobasis e algumas espécies de Clastobasis ${ }^{*}$, os casos mais modificados sendo os de Paraleia e Gracilileia redunda.

\section{Cercos:}

(0) membranosos (figuras 207-208, 210, 233);

(1) com estruturas esclerotizadas (figuras 247 e $252 \mathrm{~A}-\mathrm{B}$ ).

Número de passos: 2; IC: 50; IR: 83.

Este caráter é pela primeira vez, sendo que a presença de estruturas esclerotizadas nos cercos é apomórfica para Boletina e Docosia.

\section{Cercos:}

(0) simples (figuras 207-208, 210);

(1) bilobados (figuras 233 e 246).

Número de passos: 2; IC: 50; IR: 66.

Caráter usado pela primeira vez, a presença de cercos bilobados é apomórfica para Schnusea e Allactoneura. Em Schnusea, no entanto, o formato dos cercos não é igual (figura 246), reforçando a ideia de que tenham origens independentes.

\section{Espinhos regularmente arranjados nos cercos:}

(0) ausentes (figuras 207-208, 210); 
(1) presentes (figuras 247 e $252 \mathrm{~A}-\mathrm{B}$ ).

Número de passos: 3; IC: 33; IR: 71.

Este novo caráter tem sua condição apomórfica em Boletina, Ectrepesthoneura laffooni e Docosia.

134. Cercos extremamente alongados, tão longos quanto as projeções apico-laterais dos gonocoxitos:

(0) ausentes (figuras 207-208, 210, 233);

(1) presentes (figura 234A).

Número de passos: 1; IC: 100; IR: 100.

Amorim \& Rindal (2007) codificaram as condições dos cercos como normalmente desenvolvidos e lobulares, reduzidos ou ausentes, e bem desenvolvidos. Em virtude da dificuldade de codificar cercos de forma muito distintas, optou-se por ressaltar a condição presente em Sticholeia, muito singular em Mycetophilidae. Portanto, exclusiva do gênero. 

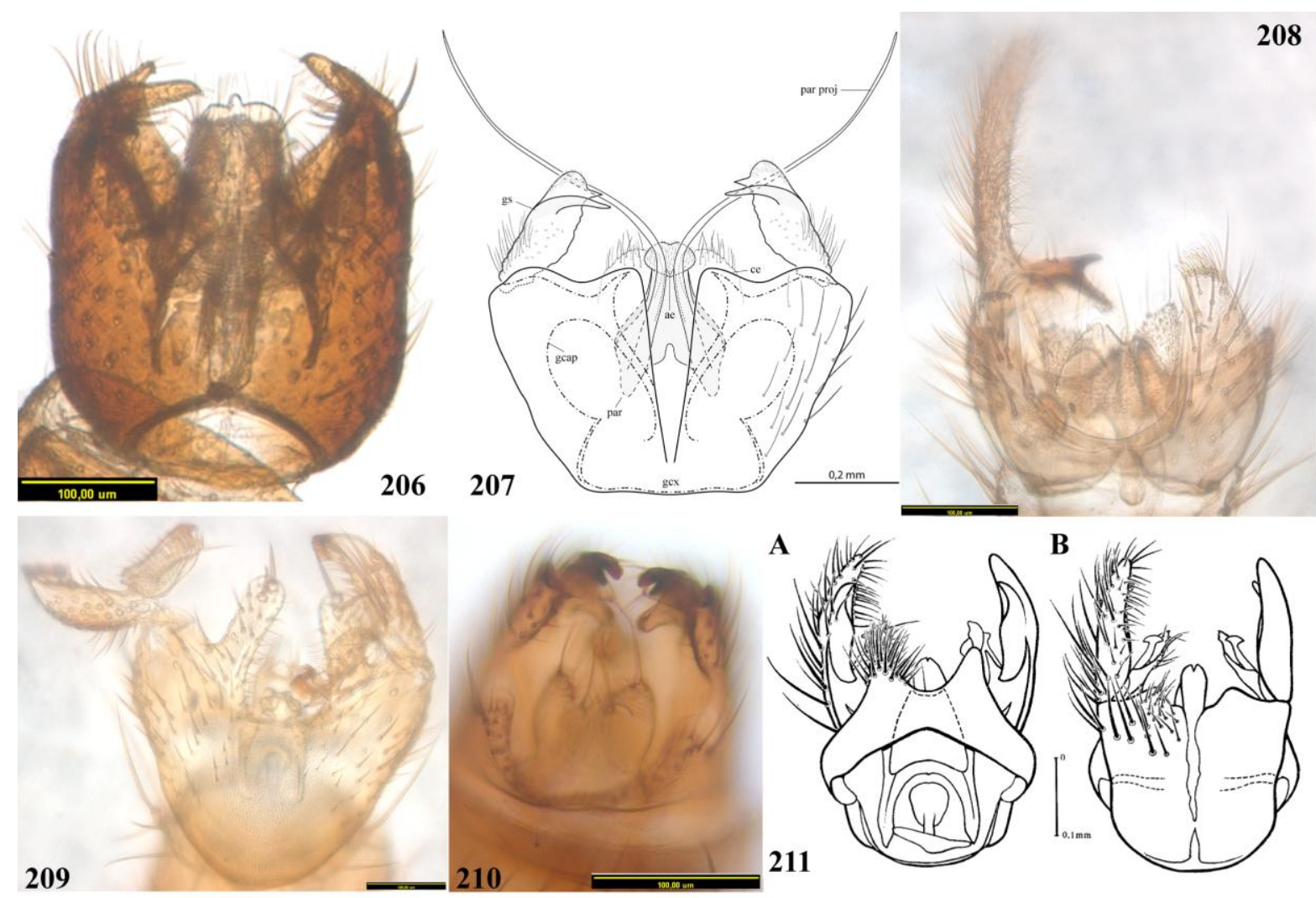

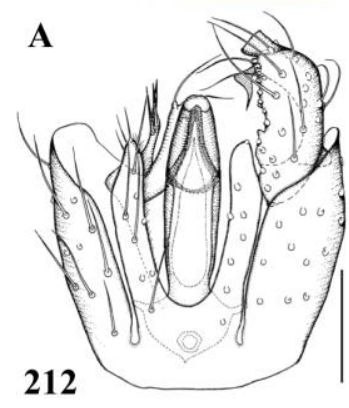

214

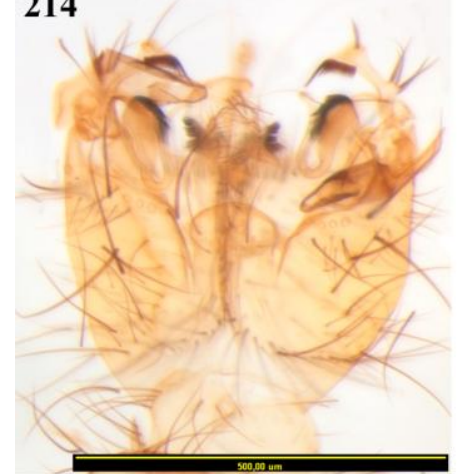

B

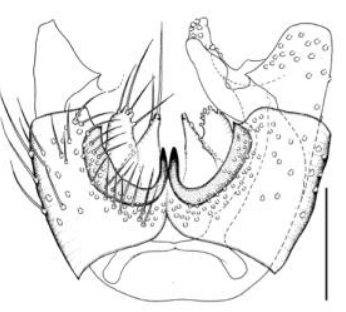

$\mathbf{A}$

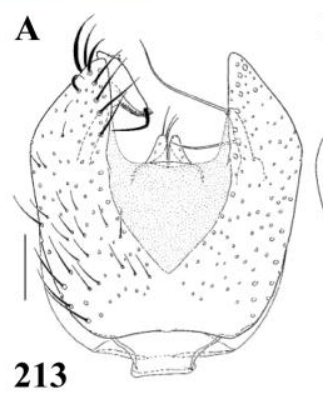

B
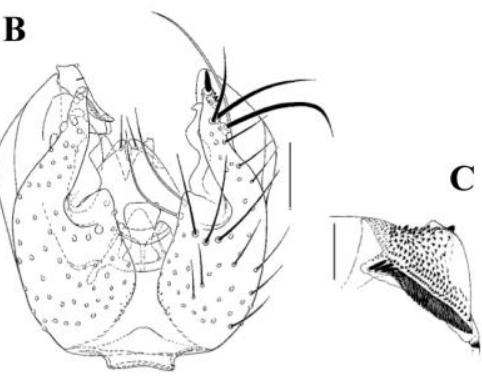

C

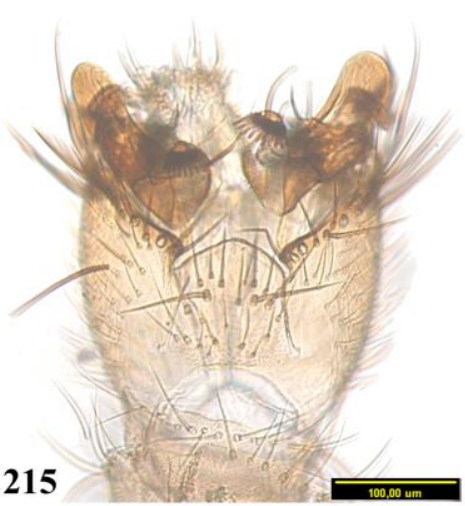

$\mathbf{A}$
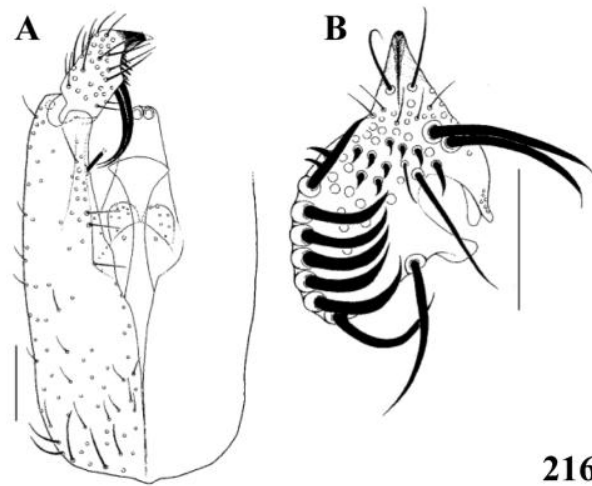

216

Figuras 206-216. Terminálias masculinas de Mycetophilidae. 206. Garretella shermani (ANIC). Vista ventral. 207. Thoracotropis cypriformis, holótipo (modificado de Oliveira et al., 2012: 461). Vista ventral. Escala 0,2mm. 208. Gracilileia redunda (ANIC). Vista dorsal. 209. Trichoterga monticola (CNC). Vista ventral. 210. Megophthalmidia divergens (MZUSP). Vista dorsal. 211. Mohelia nigricauda (modificado de Matile, 1978: 271). A. Vista dorsal. B. Vista ventral. 212. Aphrastomyia longirostris (modificado de Jaschhof \& Kallweit, 2004: 114). A. Vista dorsal. B. Vista ventral. 213. Paracycloneura apicalis (modificado de Jaschhof \& Kallweit, 2009: 25). A. Vista dorsal. B. Vista ventral. C. Gonóstilo. 214. Indoleia bisetosa (ANIC). Vista ventral. Escala 0,5 mm.

215. Rondaniella dimidiata (CNC). Vista ventral. 216. Waipapamyia elongata (modificado de Jaschhof \& Kallweit, 2009: 35). A. Vistra ventral. B. Gonóstilo. Escalas (exceto 207 e 214) 0,1mm. 

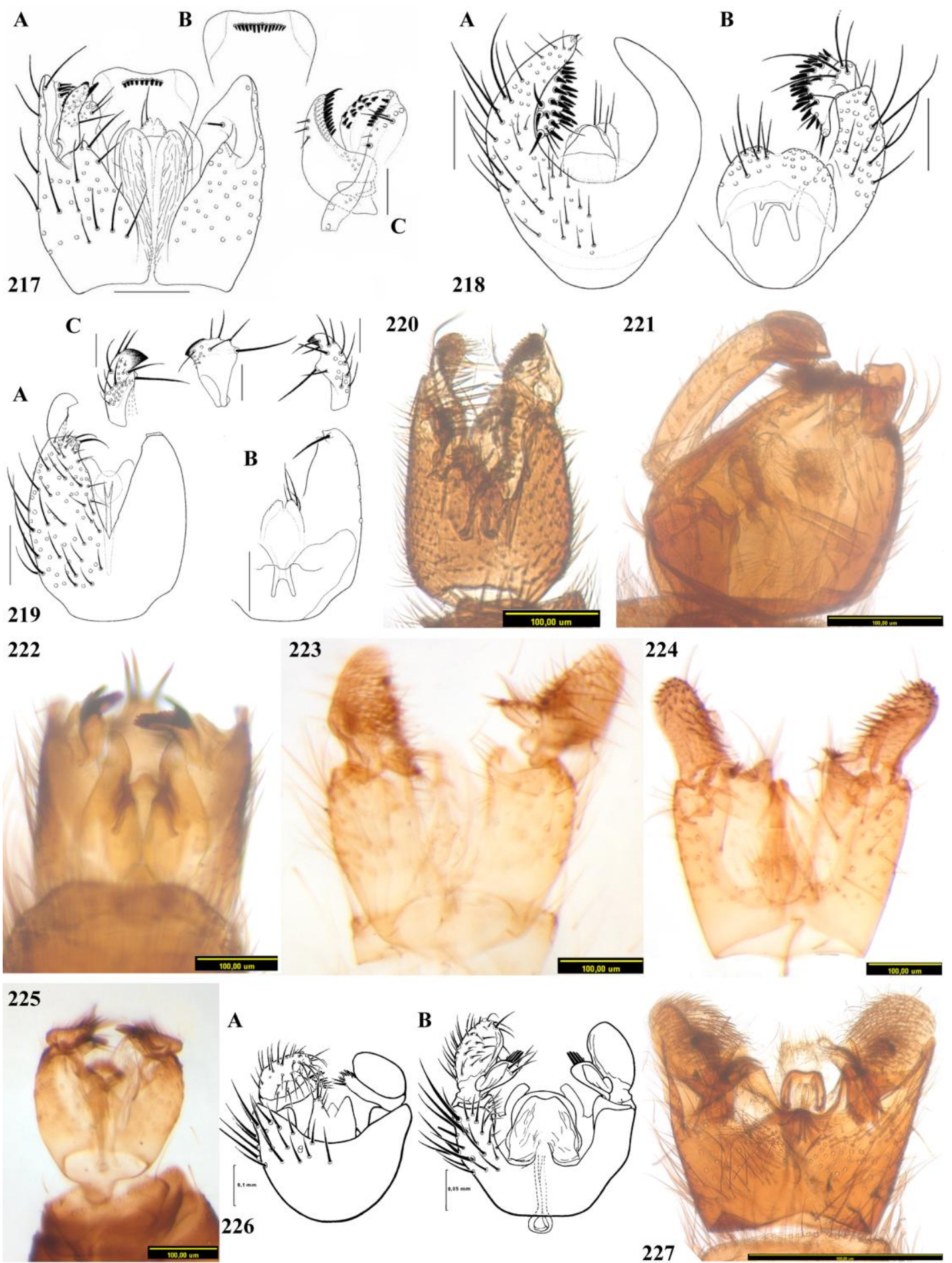

Figuras 217-227. Terminálias masculinas de Mycetophilidae. 217. Paradoxa fusca (modificado de Jaschhof \& Kallweit, 2009: 20). A. Vista ventral. B. Vista ventral do T9. C. Gonóstilo. Escala $0,1 \mathrm{~mm}$. 218. Sigmoleia melanoxantha (modificado de Jaschhof \& Kallweit, 2009: 21). A. Vista ventral. B. Vista dorsal. Escala 0,1mm. 219. Cawthronia nigra (modificado de Jaschhof \& Kallweit, 2009: 30). A. Vista ventral. B. Vista dorsal. Escala A-B 0,1mm. C. Gonóstilo em vistas ventral, medial e dorsal, respectivamente. Escala $0,05 \mathrm{~mm}$. 220. Cycloneura flava (ANIC). Vista ventral. Escala 0,1mm. 221. Procycloneura paranensis (NHM). Vista lateral. Escala 0,1 $\mathrm{mm}$. 222. Leiella unicincta (MZUSP). Vista ventral. Escala $0,1 \mathrm{~mm}$. 223. Anomalomyia guttata (Hutton) (ANIC). Vista ventral. Escala 0,1mm. 224. Ateleia spadicithorax (ANIC). Vista dorsal. Escala 0,1mm. 225. Acrodicrania africana (SAMC). Vista ventral. Escala $0,1 \mathrm{~mm}$. 226. Caledonileia pusilla (modificado de Matile, 1993: 180). A. Vista dorsal. Escala 0,1 mm. B. Vista ventral. Escala 0,05mm. 227. Neoclastobasis draskovitsae (LMED). Vista ventral. Escala $0,5 \mathrm{~mm}$. 
228
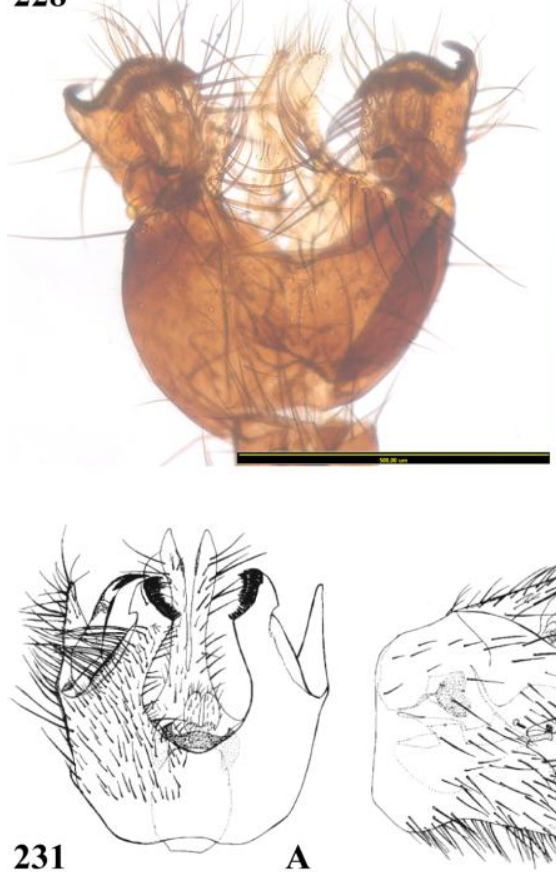

A
229

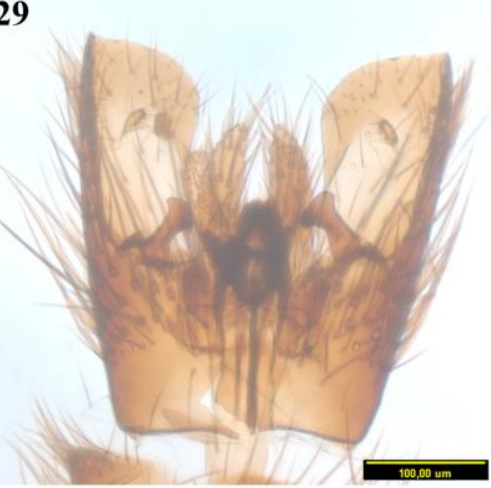

230

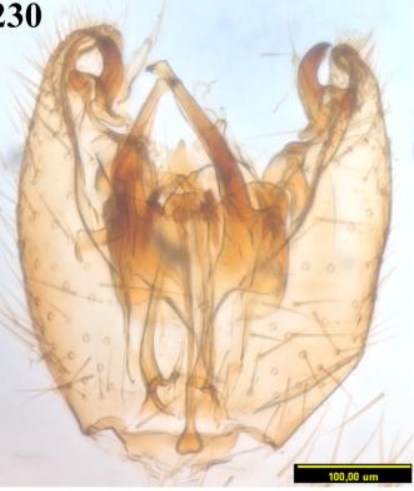

232

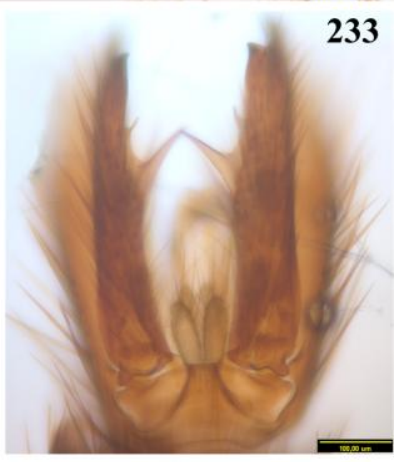

C

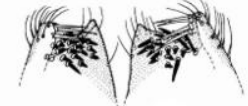

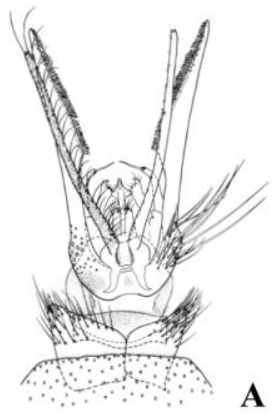

A

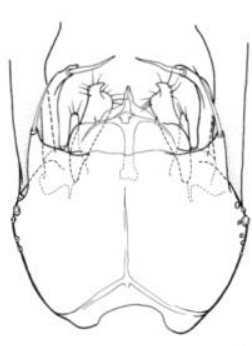

B

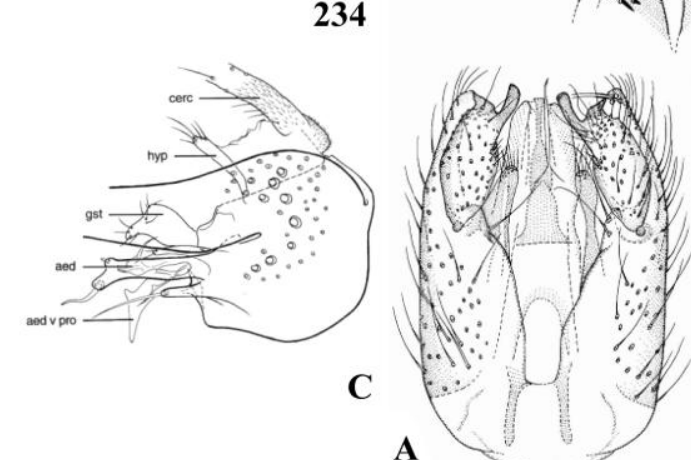

A

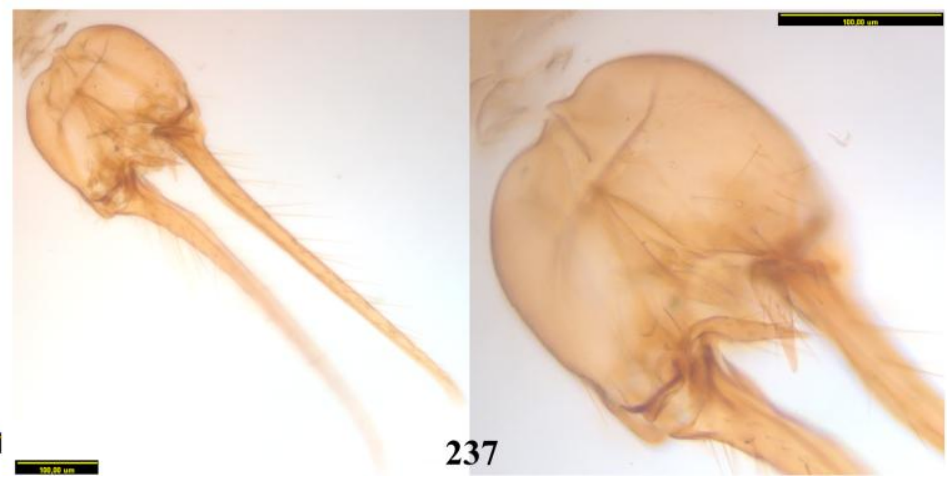

236

Figuras 228-237. Terminálias masculinas de Mycetophilidae. 228. Greenomyia stackelbergi (LMED). Vista ventral. Escala 0,5mm. 229. Leia andirai (MZUSP). Vista dorsal. Escala 0,1mm. 230. L. winthemi (LMED). Vista dorsal. Escala $0,1 \mathrm{~mm}$. 231. Clastobasis alternans (modificado de Chandler, 2001: 222). 232. C. tryoni (ANIC). Vista ventral. Escala 0,1mm. 233. Allactoneura arguentosquamosa (NMSA). Vista dorsal. Escala $0,1 \mathrm{~mm}$. 234. Sticholeia cheesmanae (modificado de Søli, 1996: 5). A. Vista dorsal. B. Vista ventral. C. Vista lateral. 235. Promanota malaisei (modificado de Hippa et al., 2004: 417). A. Vista dorsal, com remoção do T9 e estruturas associadas.

B. T9 com estruturas associadas. C. Porção ápico-ventral dos gonocoxitos em vista dorsal. Escala $0,1 \mathrm{~mm}$. 236. Manota palpalis (INPA). Vista ventral. Escala 0,5mm. 237. Rymosia (MZUSP). Vista ventral. Escala $0,1 \mathrm{~mm}$. 

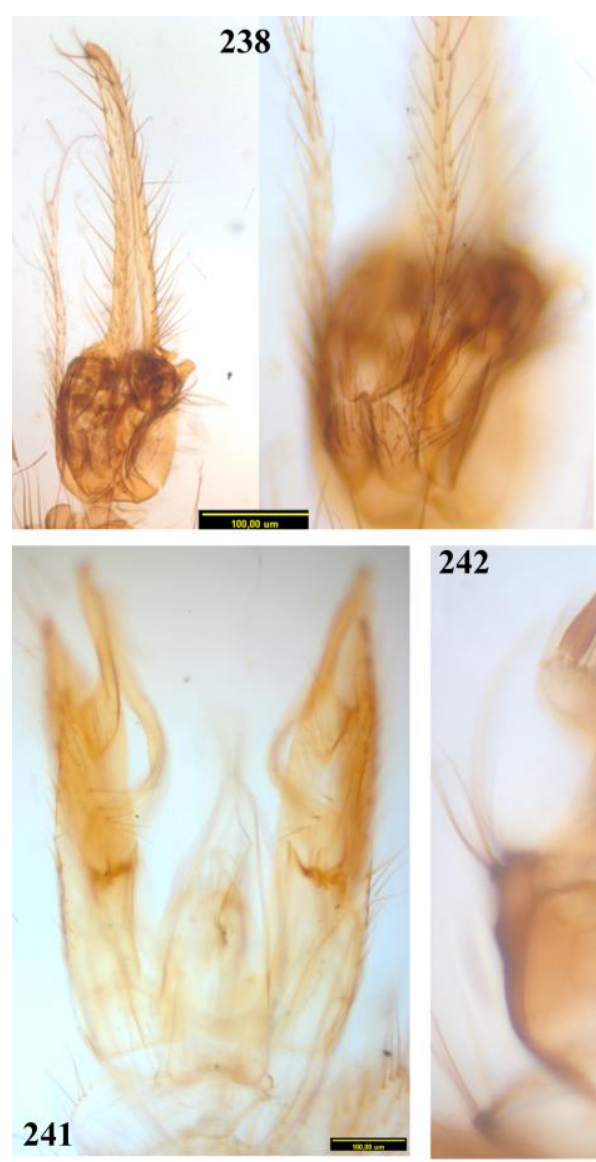

244

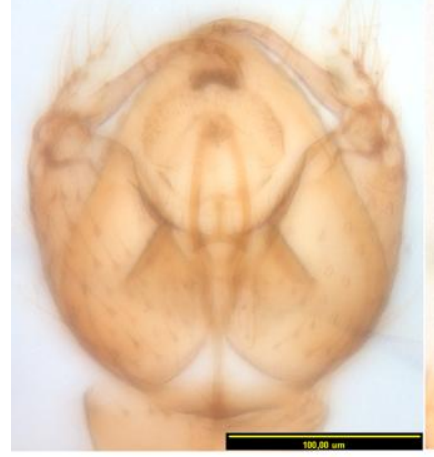

247
242

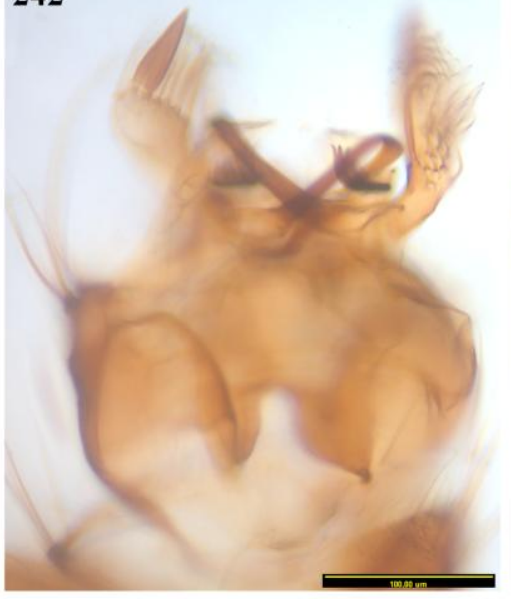

245

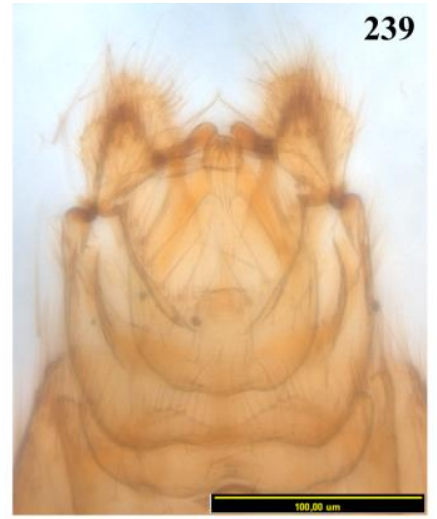

240

243

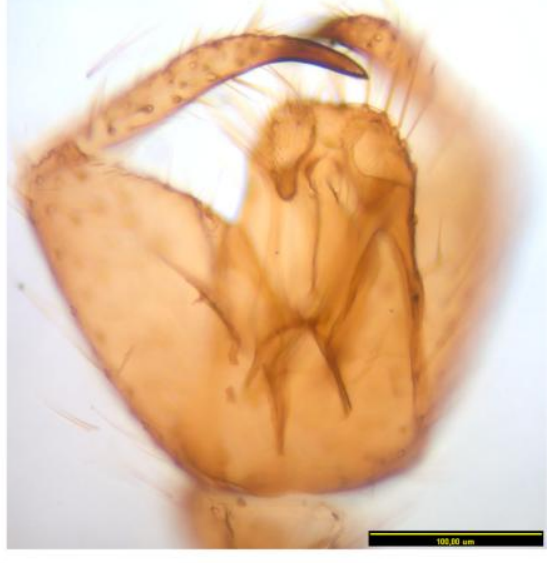

246

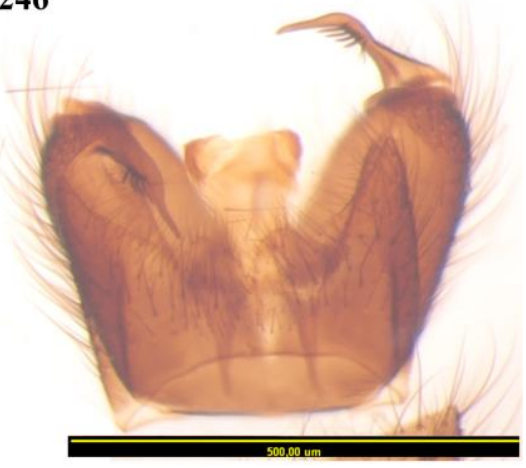

248
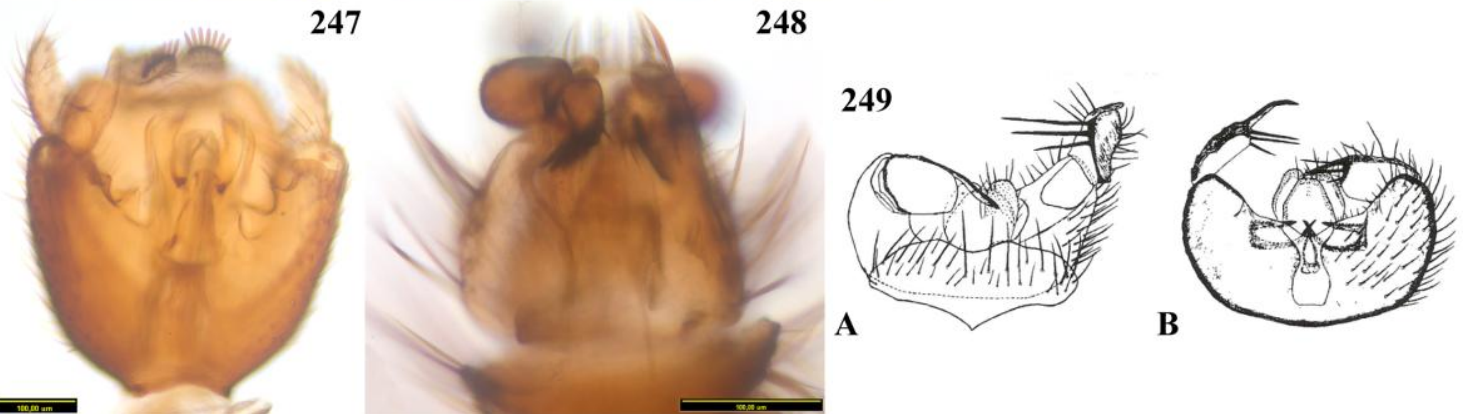

Figuras 238-249. Terminálias masculinas de Mycetophilidae. 238. Exechiopsis (MZUSP). Vista dorsal. 239. Epicypta (MZUSP). Vista dorsal. 240. Mycetophila (MZUSP). Vista dorsal. 241. Neoempheria (LMED). Vista dorsal. 242. Mycomya (MZUSP). Vista ventral. 243. Synapha (AMSA). Vista ventral. 244. Austrosynapha hirta (ANIC). Vista ventral. 245. Dziedzickia medea (MZUSP). Vista dorsal. 246. Schnusea caiabii (MZUSP). Vista dorsal. Escala 0,5mm. 247. Boletina obscura (CNC). Vista ventral. 248. Palaeodocosia vittata (CNC). Vista ventral. 249. Tetragoneura sylvatica (Curtis) (modificado de Chandler, 1980: 28). A. Vista dorsal. B. Vista ventral. Escalas (exceto 246) $0,1 \mathrm{~mm}$. 


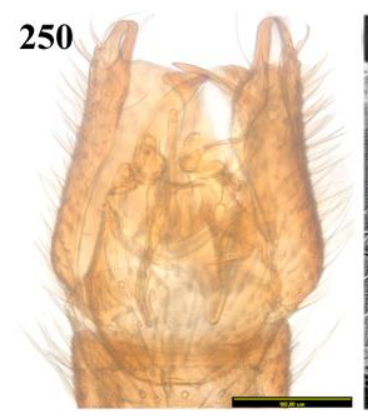

A
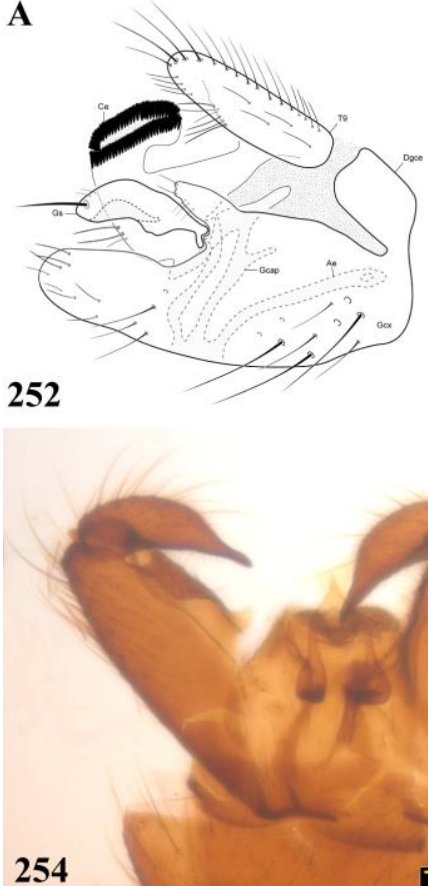

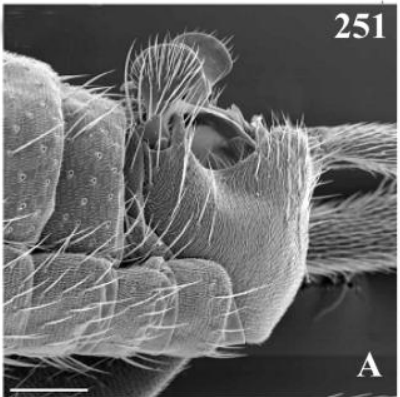

B
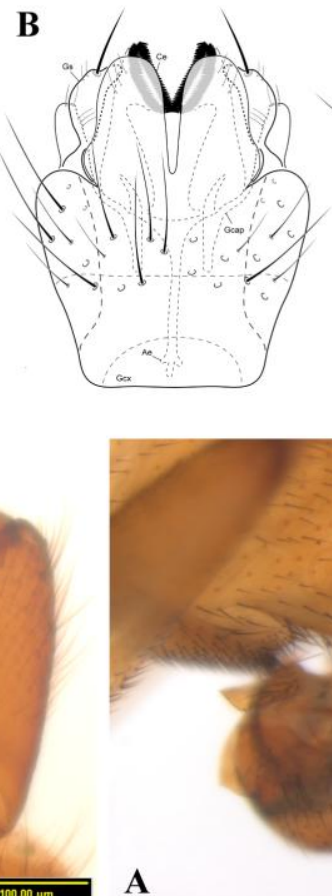

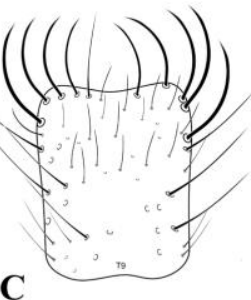

C
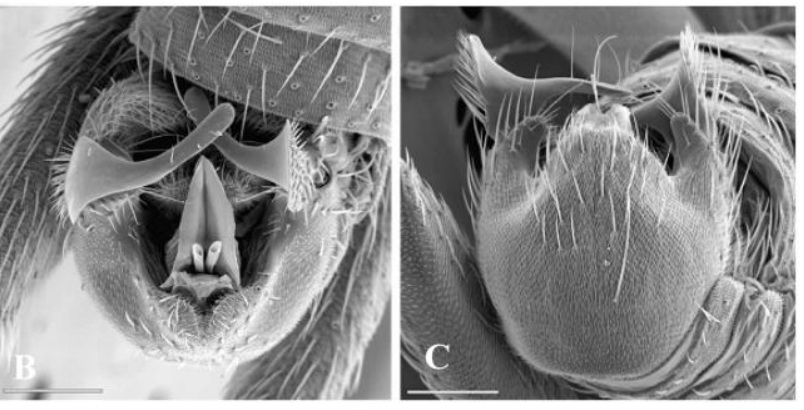

253

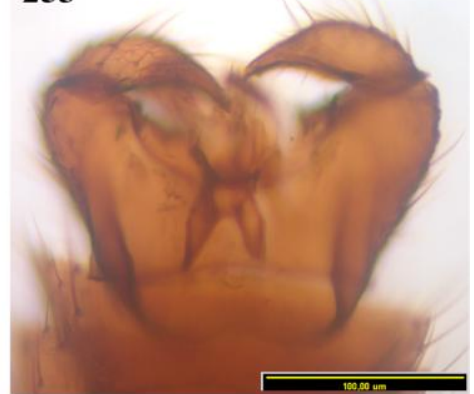

Figuras 250-255. Terminálias masculinas de Mycetophilidae. 250. Ectrepesthoneura laffooni (CNC). Vista dorsal. 251. Novakia miloi (modificado de Kerr, 2007: 30). A. Vista lateral. B. Vista terminal. C. Vista dorsal. 252. Docosia adusta (modificado de Oliveira \& Amorim, 2011: 693).

Parátipo. A. Vista lateral. B. Vista ventral, com remoção do T9. C. Vista dorsal do T9. 253. Neoallocotocera fusca (ANIC). Vista ventral. 254. Tasmanina gracilis (ANIC). Vista dorsal. 255. Megophthalmidia, vista leteral. A. M. crassicornis (LMED). B. M. occidentalis (CNC). Escalas $0,1 \mathrm{~mm}$.

\section{TERMINÁLIA FEMININA}

\section{Cercômero II:}

(0) ausente (figuras 278, 280-283A);

(1) presente (figuras 256-261).

Número de passos: 12; IC: 8; IR: 59.

Hippa et al. (2004) observaram que Promanota, Eumanota e Allactoneura possuem apenas um cercômero na terminália feminina. No presente estudo, esta condição foi observada também em Docosia, Dziedzickia, Austrosynapha, Sticholeia, Indoleia, Greenomyia stalckelbergi e na maioria das espécies de Clastobasis ${ }^{*}$. 

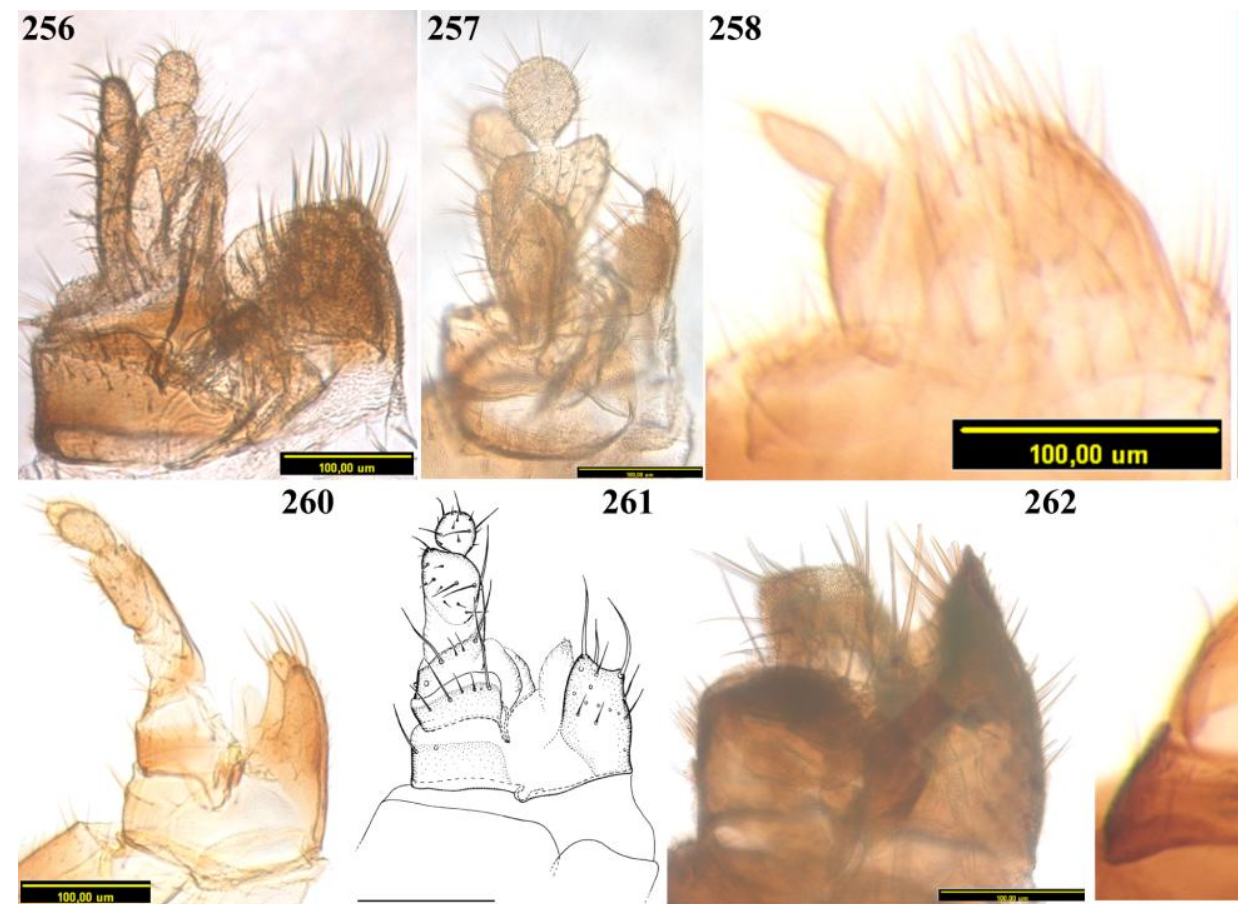

262
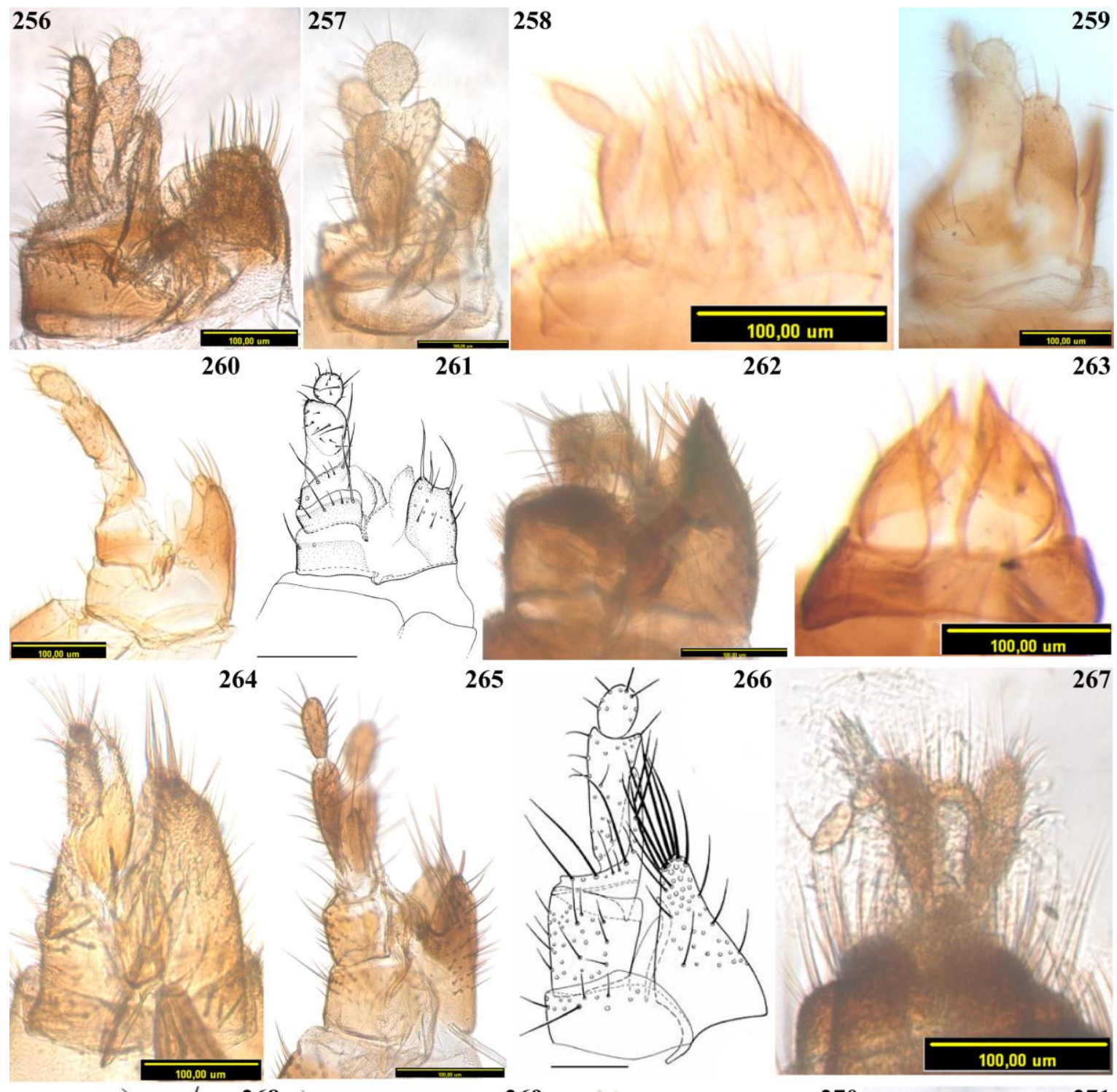

265

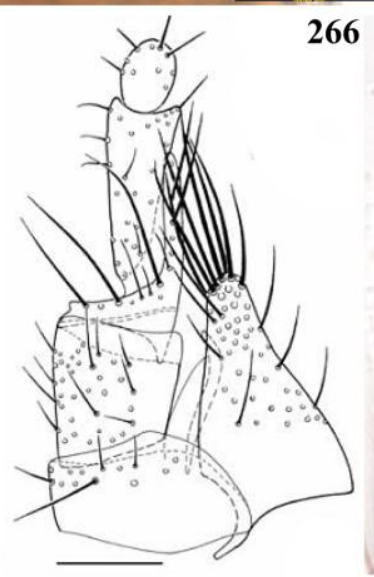

266
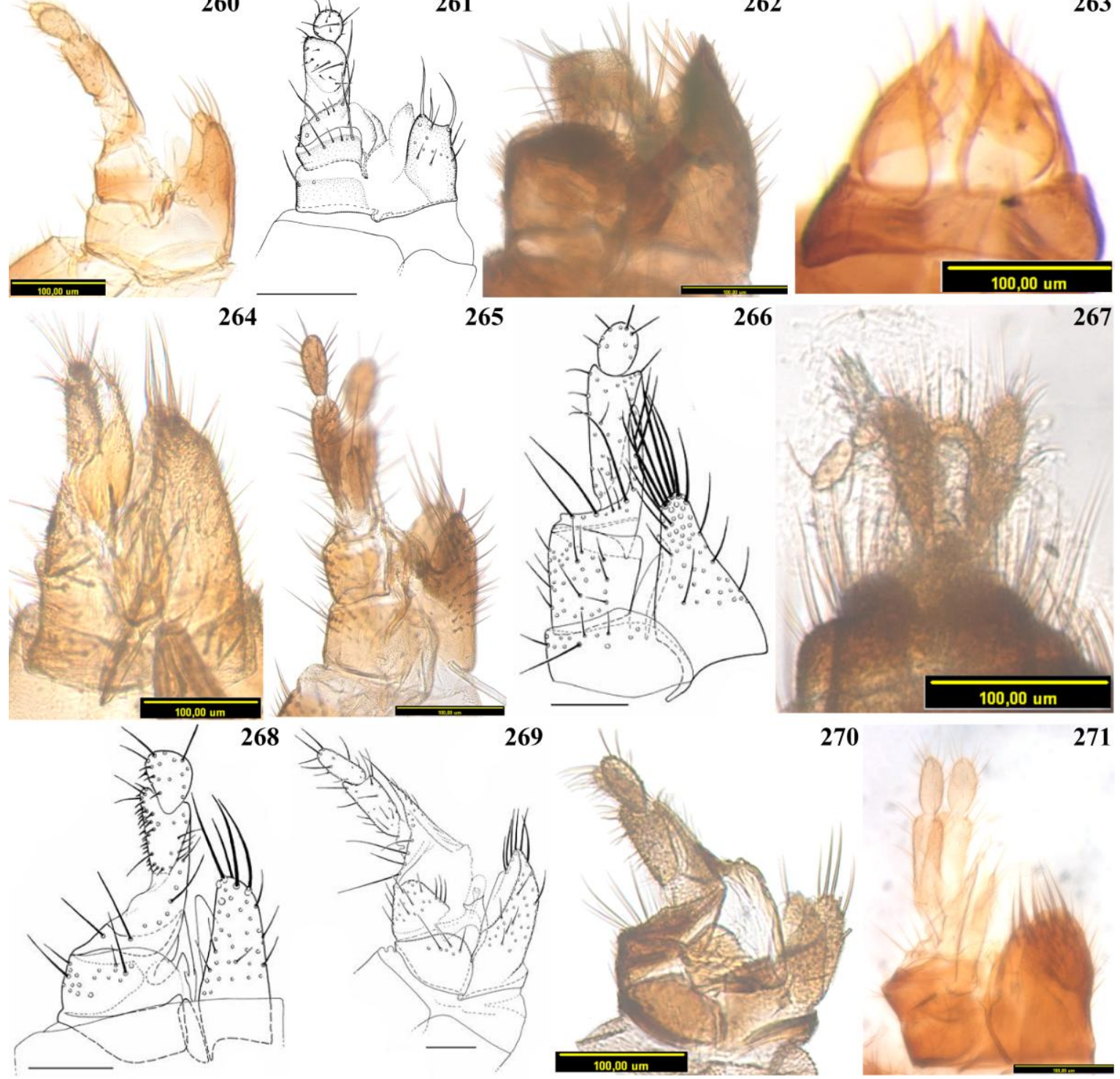

Figuras 256-271. Terminálias femininas de Mycetophilidae em vista lateral (exceto 263). 256.

Garretella shermani (ANIC). 257. Gracilileia redunda (MNHN). 258. Trichoterga monticola

(CNC). 259. Megophthalmidia nigra Freeman (CNC). 260. Mohelia nigricauda (NMSA). 261.

Aphrastomyia communis Jaschhof \& Kallweit (modificado de Jaschhof \& Kallweit, 2004: 25). Escala

0,2 mm. 262. Paracycloneura apicalis (ANIC). 263. Indoleia bisetosa (ANIC). Vista dorsal. 264.

Rondaniella dimidiata (CNC). 265. Waipapamyia elongata (ANIC). 266. Paradoxa fusca

(modificado de Jaschhof \& Kallweit, 2009: 18). 267. Sigmoleia melanoxantha (ANIC). 268.

Cawthronia nigra (modificado de Jaschhof \& Kallweit, 2009: 18). 269. Cycloneura (modificado de

Jaschhof \& Kallweit, 2009: 18). 270. Tonnwardsia aberrans (ANIC). 271. Procycloneura paranensis

(MZUSP). Escalas (exceto 261) 0,1 mm. 

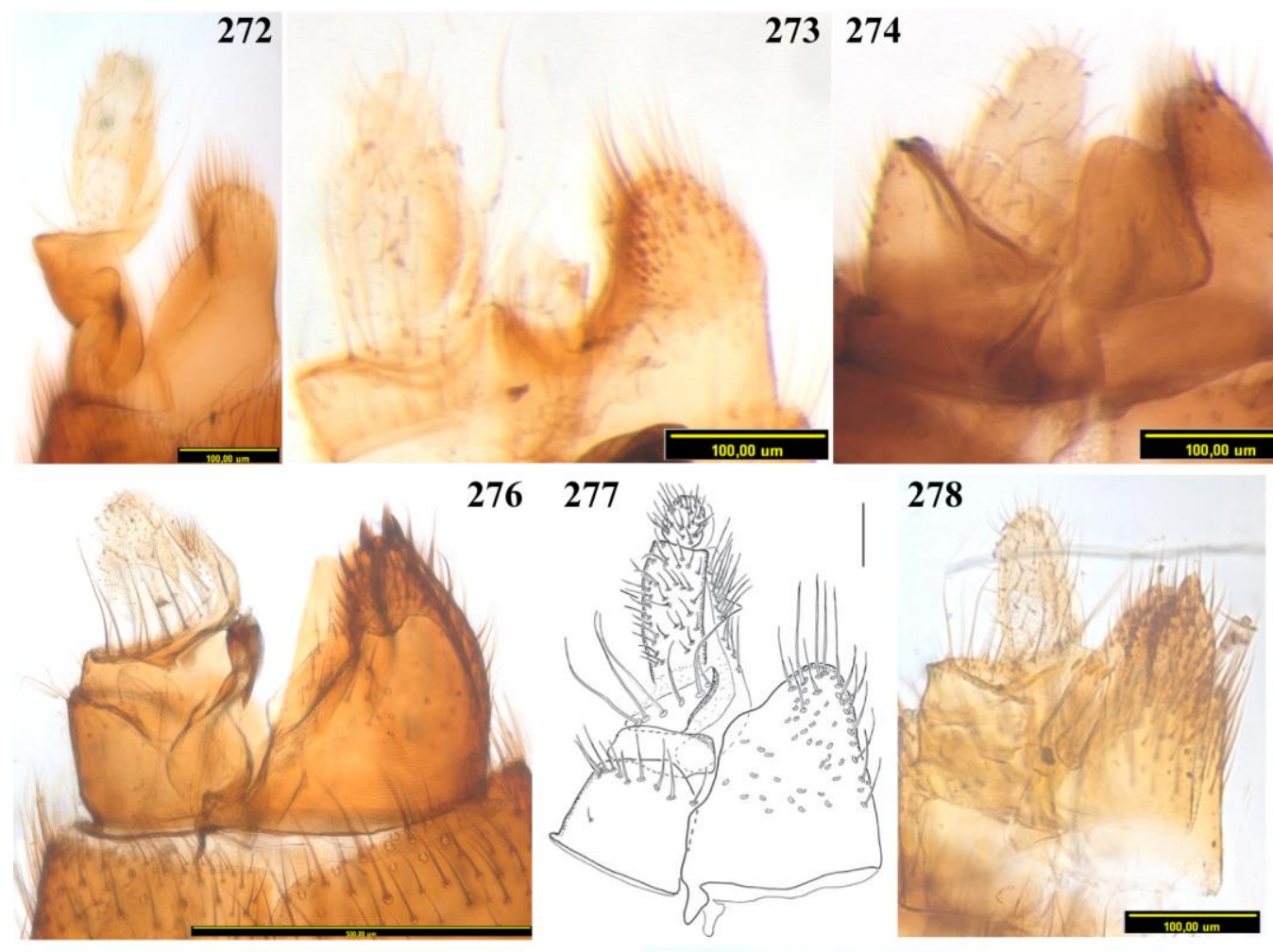

279

281

282
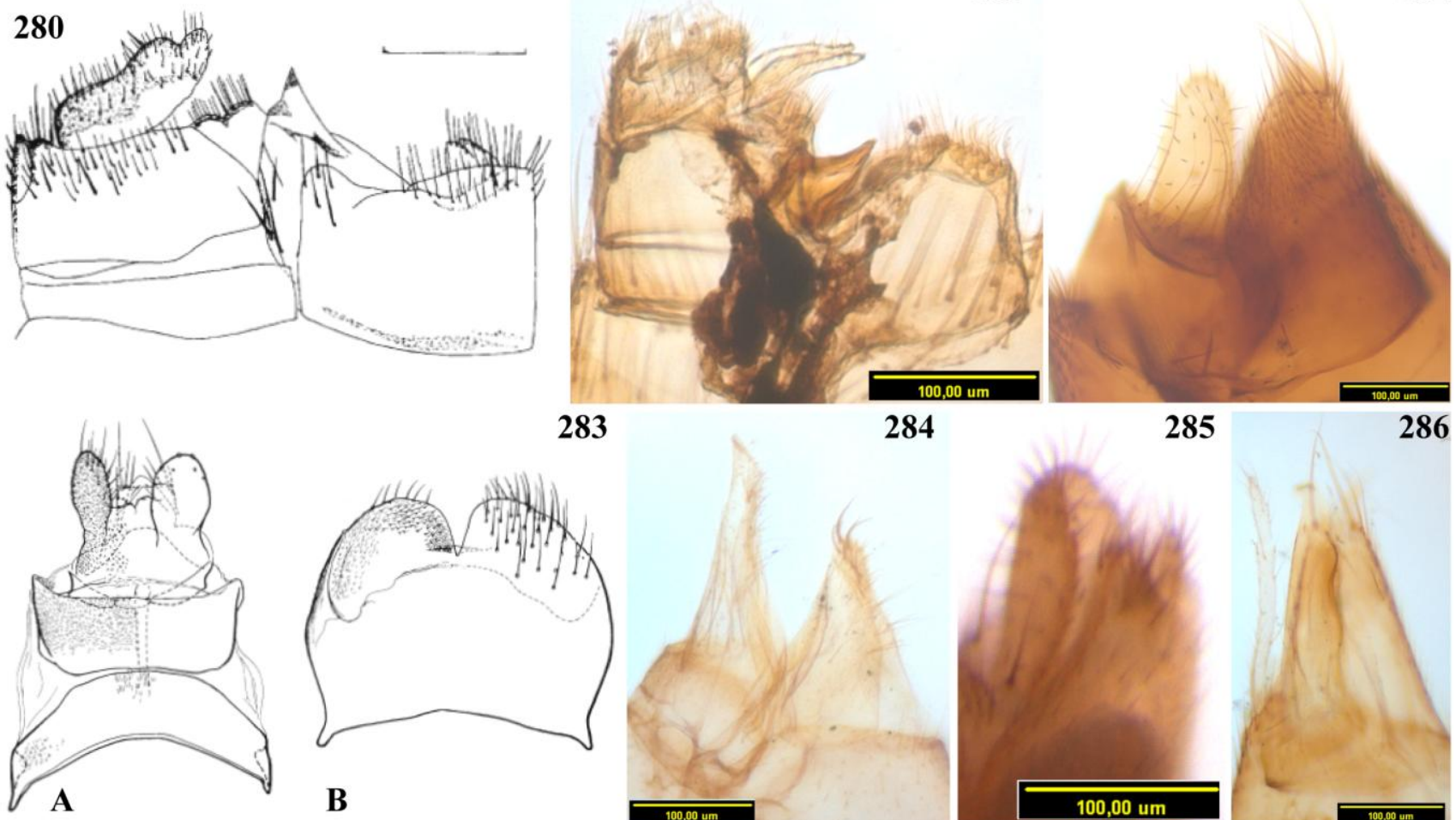

284

285

286

Figuras 272-286. Terminálias femininas de Mycetophilidae em vista lateral. 272. Leiella unicincta (INPA). 273. Anomalomyia guttata (ANIC). 274. Ateleia spadicithorax (ANIC). 275. Acrodicrania africana (SAMC). 276. Neoclastobasis draskovitsae (LMED). Escala $0,5 \mathrm{~mm}$. 277. Greenomyia mongolica (modificado de Kurina et al., 2011: 38). 278. Leia andirai (MZUSP). 279. L. winthemi (LMED). 280. Clastobasis alternans (modificado de Chandler, 2001: 223). Escala 0,2mm. 281. C. tryoni (ANIC). 282. Allactoneura cincta (CNC). 283. Sticholeia cheesmanae (modificado de Søli, 1996: 8). A. Vista dorsal, com remoção do S8. B. Vista dorsal do S8. 284. Eumanota (AMSA). 285. Manota palpalis (INPA). 286. Rymosia (MZUSP). Escalas (exceto 276 e 280) 0,1mm. 


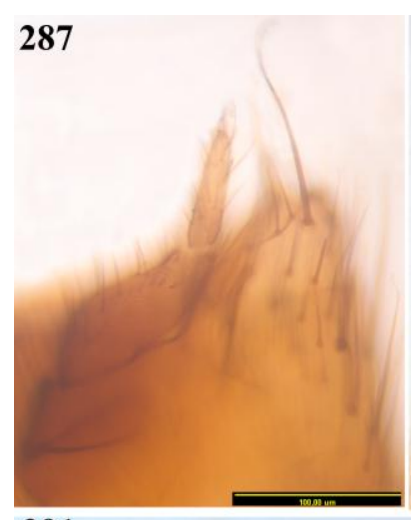

291

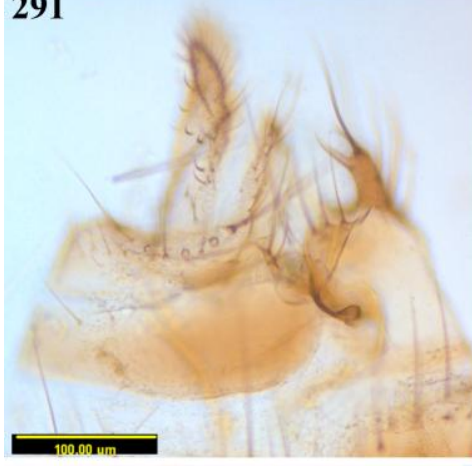

295

288

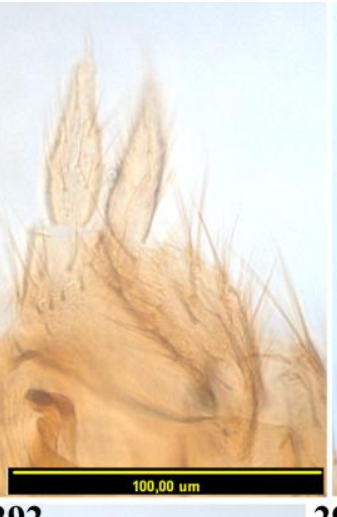

292
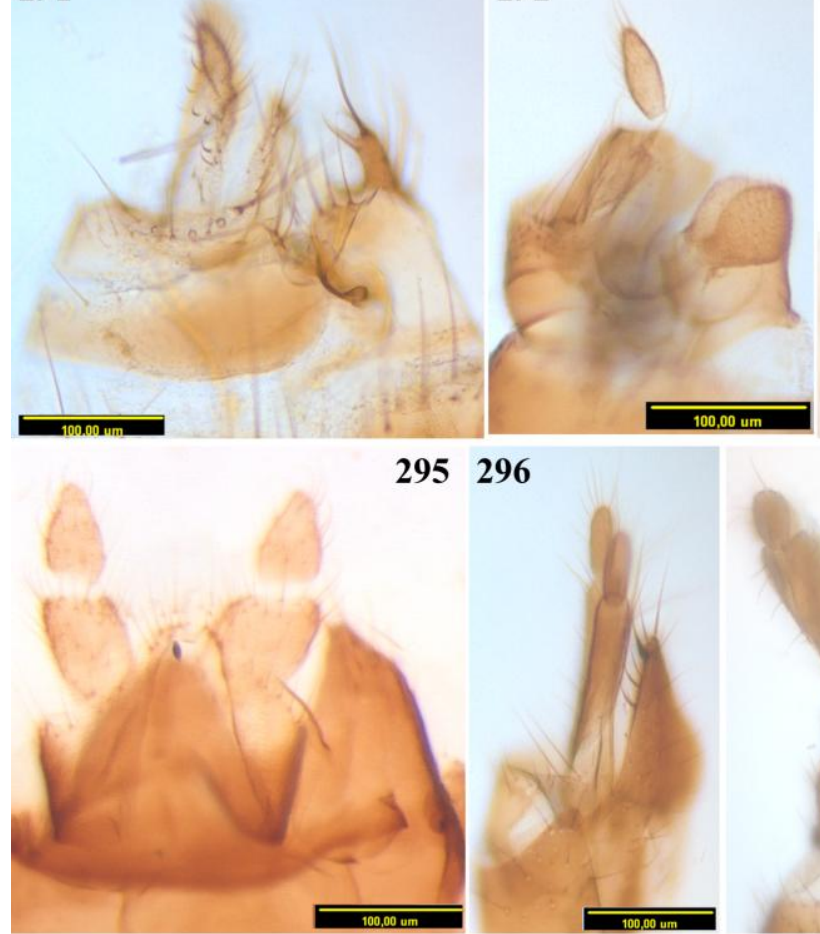

296

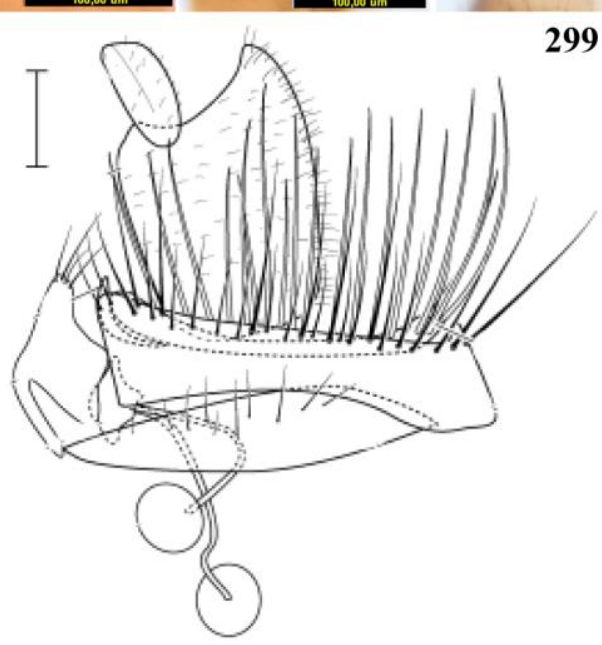

293

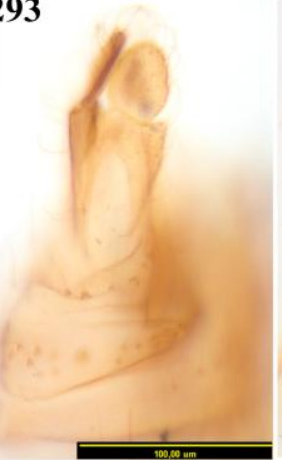

297
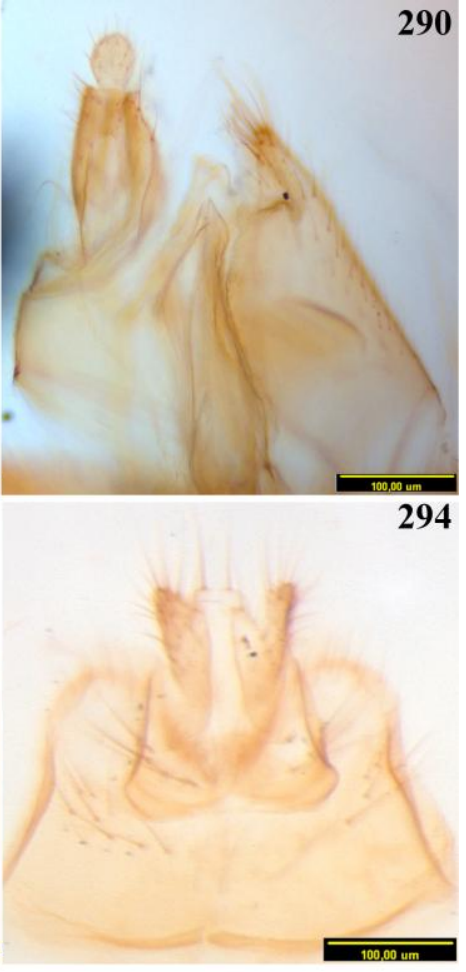

298

Figuras 287-300. Terminálias femininas de Mycetophilidae em vista lateral (exceto 294-295 e 300). 287. Exechiopsis (INPA). 288. Epicypta (MZUSP). 289. Mycetophila (MZUSP). 290. Neoempheria (LMED). 291. Mycomya (MZUSP). 292. Synapha (AMSA). 293. Austrosynapha hirta (ANIC). 294. Dziedzickia medea (MZUSP). Vista dorsal. 295. Schnusea caiabii (MZUSP). Vista dorsal. 296. Palaeodocosia vittata (CNC). 297. Tetragoneura sylvatica (CNC). 298. Ectrepesthoneura laffooni (CNC). 299. Novakia miloi (modificado de Kerr, 2007: 33). 300. Docosia adusta (modificado de Oliveira \& Amorim, 2011: 694). Vista látero-dorsal. Escalas 0,1mm. 

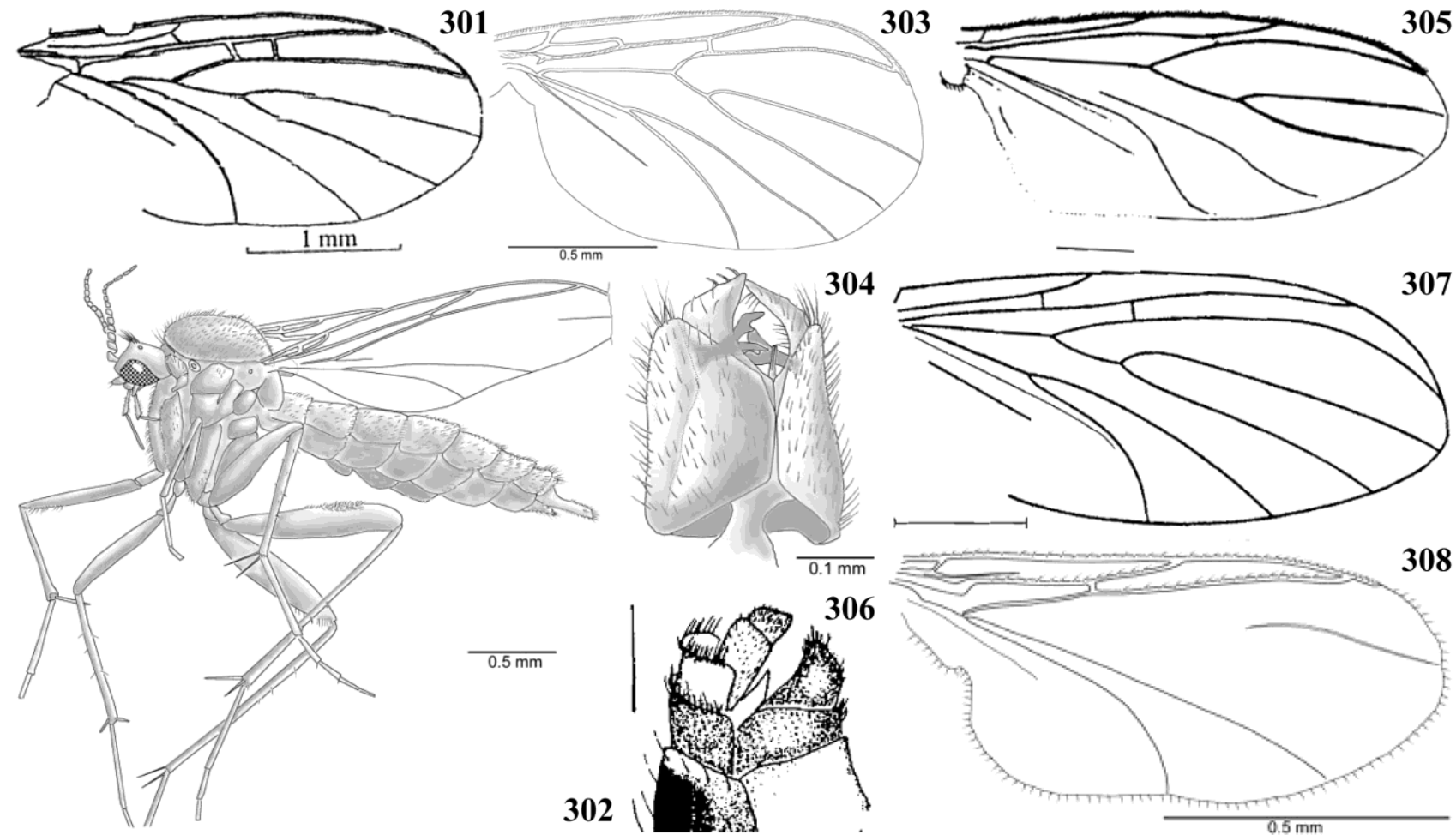

304

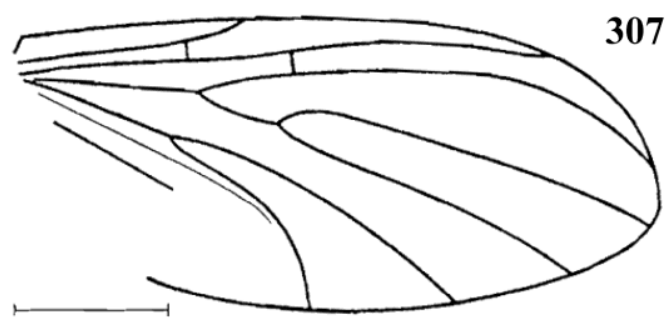

309

302
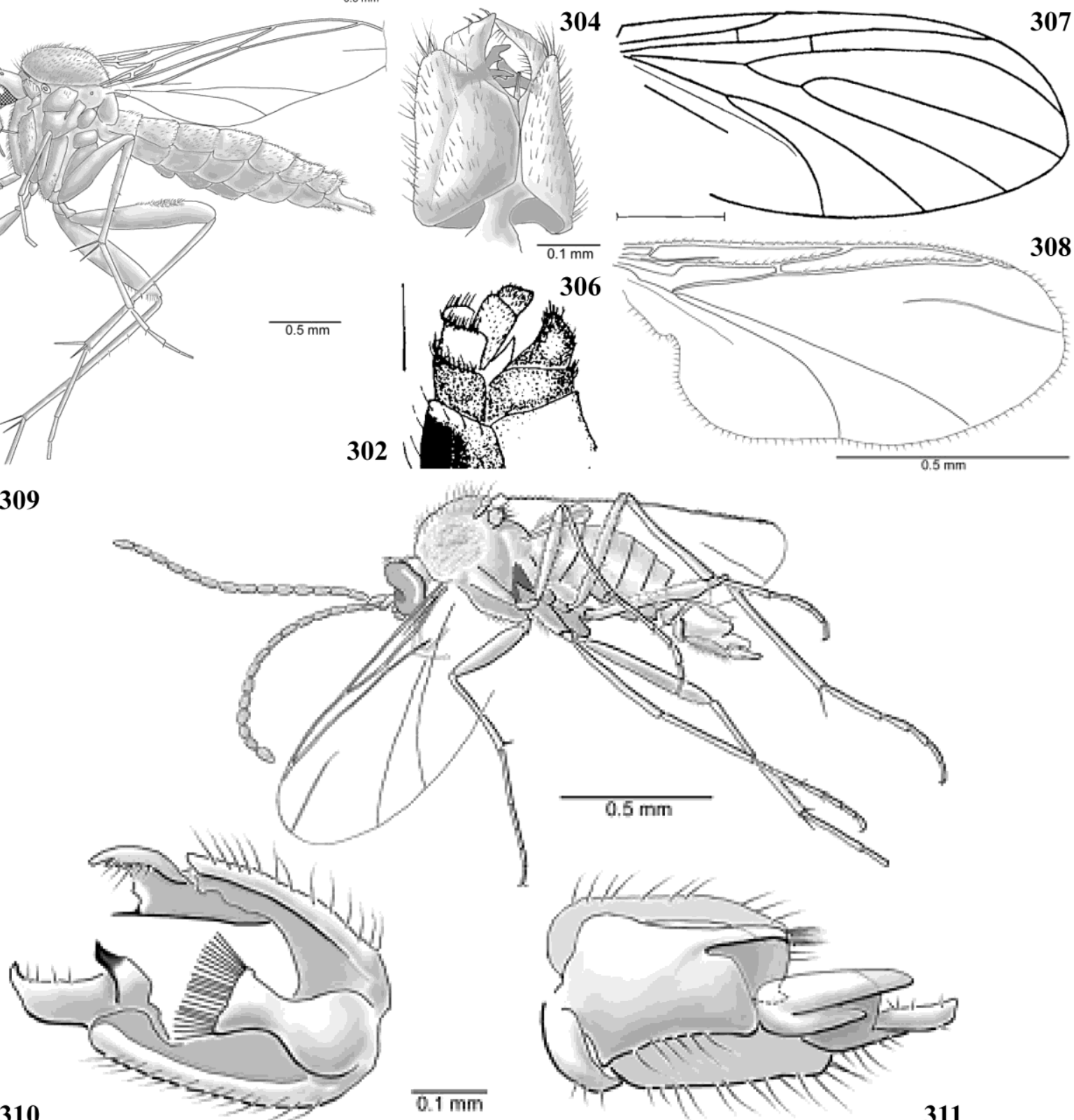

Figuras 301-311. Gêneros fósseis de Mycetophilidae. 301. Asa de Baisepesthoneura mesozoica Bladoderov (modificado de Blagoderov, 1998a: 58). 302. Habitus em vista lateral de Disparoleia cristata Blagoderov \& Grimaldi (modificado de Blagoderov \& Grimaldi, 2004: 49), 9 . Escala

0,5mm. 303-304. Hemolia matilei Blagoderov \& Grimaldi (modificado de Blagoderov \& Grimaldi,

2004: 49). 303. Asa. Escala $0,5 \mathrm{~mm}$. 304. Terminália $\widehat{\jmath}$. Escala $0,1 \mathrm{~mm}$. 305-306. Metaleia maculicoxa Baxter \& Poinar (modificado de Baxter \& Poinar, 1994:95). Escala 0,5mm. 305. Asa.

306. Terminália 9 . 307. Asa de Palaeothoracotropis dundulensis Blagoderov (modificado de

Blagoderov, 1998b: 602). 308-311. Zeliinia orientalis Blagoderov \& Grimaldi (modificado de

Blagoderov \& Grimaldi, 2004: 44). 308. Asa. Escala 0,5mm. 309. Habitus em vista lateral, §̋. Escala

$0,5 \mathrm{~mm}$. 310-311. Terminália $\widehat{\jmath}$ em vistas dorsal e lateral, respectivamente. Escala $0,1 \mathrm{~mm}$. 


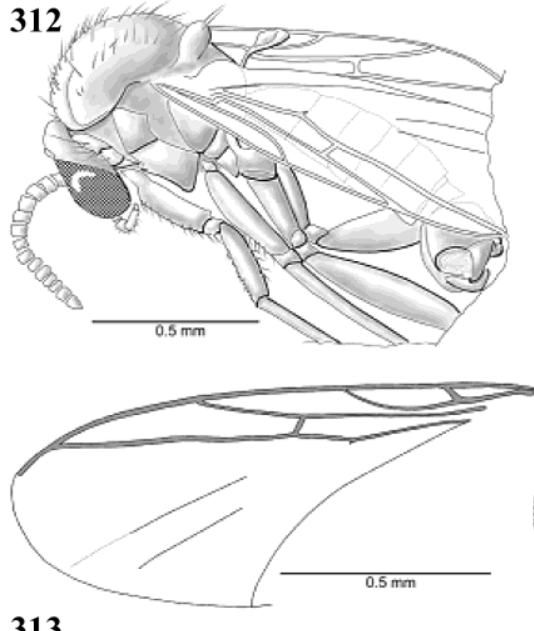

313

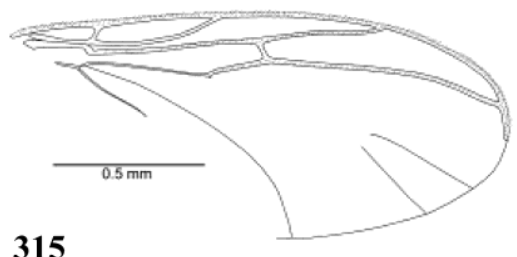

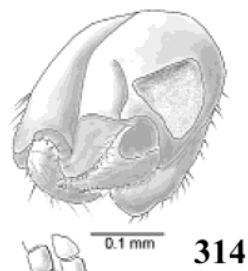

314
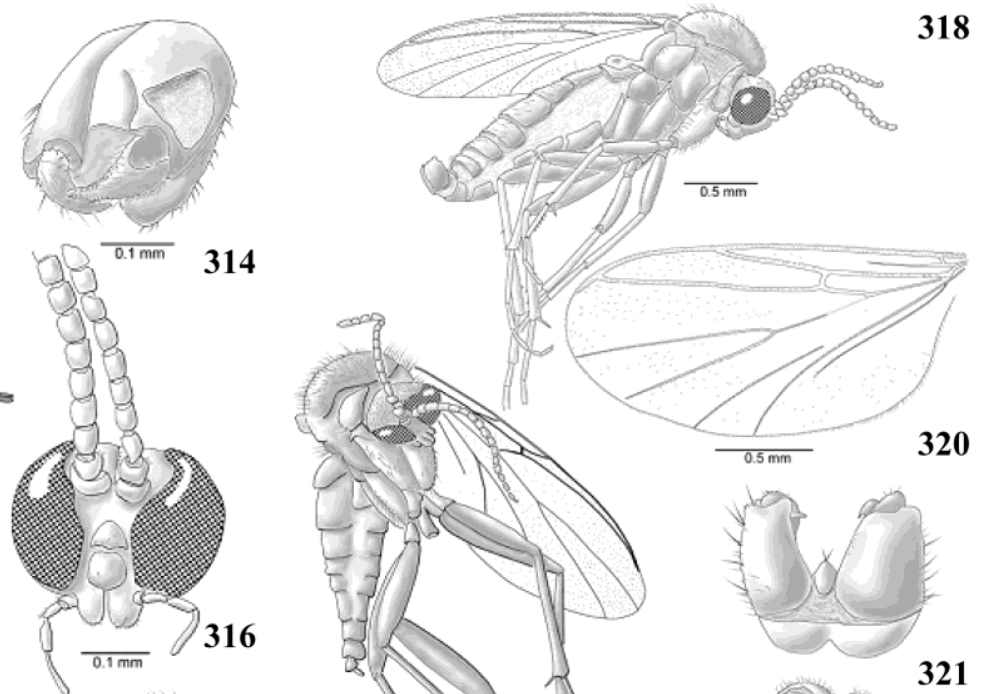

319
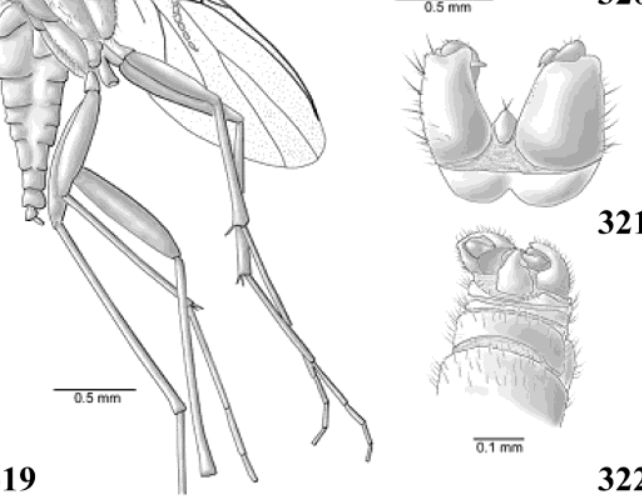

321

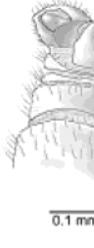

323

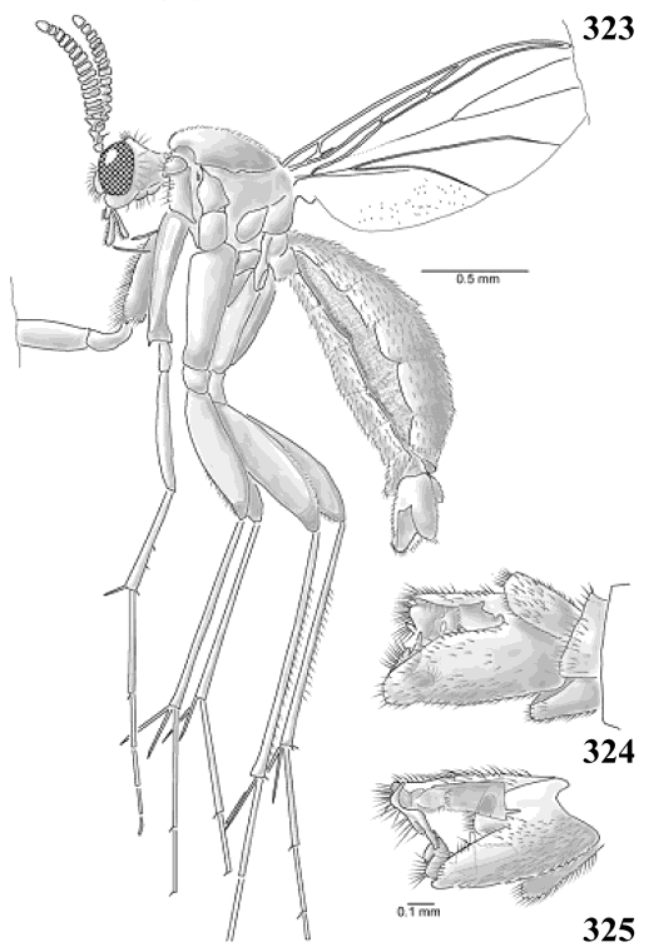

Figuras 312-325. Gêneros fósseis de Mycetophilidae. 312-314. Izleiina mirifica Blagoderov \& Grimaldi (modificado de Blagoderov \& Grimaldi, 2004: 42). 312. Habitus em vista lateral, $\widehat{O}$. Escala $0,5 \mathrm{~mm}$. 313. Asa. Escala $0,5 \mathrm{~mm}$. 314. Terminalia $\widehat{\jmath}$. Escala $0,1 \mathrm{~mm}$. 315-317. I. spinotibialis Blagoderov \& Grimaldi (modificado de Blagoderov \& Grimaldi, 2004: 42). 315. Asa. Escala 0,5mm. 316. Cabeça em vista frontal. Escala $0,1 \mathrm{~mm}$. 317. Terminália ${ }^{\top}$. Escala $0,1 \mathrm{~mm}$. 318. Habitus de Temaleia birmitica Blagoderov \& Grimaldi (modificado de Blagoderov \& Grimaldi, 2004: 46), $\widehat{\jmath}$. Escala 0,5mm. 319-322. Lecadonileia parvistyla Blagoderov \& Grimaldi (modificado de Blagoderov \& Grimaldi, 2004: 46). 319. Habitus em vista lateral, §̋. Escala 0,5mm. 320. Asa. Escala 0,5mm.

321-322. Terminália $\widehat{o}$ em vistas ventral e dorsal, respectivamente. Escala 0,1mm. 323-325. Protragoneura platycera Blagoderov \& Grimaldi (modificado de Blagoderov \& Grimaldi, 2004: 50). 323. Habitus em vista lateral, $ð$. Escala $0,5 \mathrm{~mm}$. 324-325. Terminália $\widehat{\jmath}$ em vistas látero-dorsal e látero-ventral, respectivamente. Escala $0,1 \mathrm{~mm}$. 


\section{Cladogramas}

Este é o primeiro estudo de relações filogenéticas em Leiinae com uma amostragem praticamente completa de seus gêneros. Ainda que certo número de caracteres tenha um índice de consistência baixo devido a sua grande plasticidade, o número total de caracteres em relação ao número de táxons terminais permite responder com muita robustez ao centro do problema abordado, de delimitação de um clado correspondente aos Leiinae. Por outro lado, com o andamento da análise, foi possível perceber que, de fato, a solução completa da posição dos clados menores que eram incluídos em Leiinae, em particular Tetragoneura e gêneros relacionados, depende de uma reconstrução filogenética de Mycetophilidae como um todo. Nesta análise, isso demandaria uma amostragem taxonômica muito maior de Sciophilinae e Gnoristinae, o que está além do escopo estabelecido para este trabalho.

Para que houvesse ao menos alguma informação retirada dos fósseis, para benefício do conhecimento da evolução de Leiinae, os caracteres utilizados para as análises apenas com grupos recentes foi também utilizada com a inclusão de fósseis como terminais.

A análise apenas com os grupos recentes resultou em 99 árvores mais parcimoniosas (AMPs), com 1083 passos. O consenso estrito (figura 326) possui 1119 passos, IC: 20 e IR: 74. A análise incluindo os fósseis resultou em 96 AMPs com 1196 passos. O consenso estrito (figura 327) possui 1659 passos, IC: 14 e IR: 61.

A fim de facilitar a visualização, o cladograma de consenso estrito resultante da análise com grupos viventes, com indicação dos caracteres, foi dividido de acordo com os grandes clados recuperados (figura 328A-H).

O cladograma com os índices de Bremer está apresentado na figura 329. Alguns dos cladogramas obtidos com pesagem implícita estão apresentados nas figuras 330-332. 


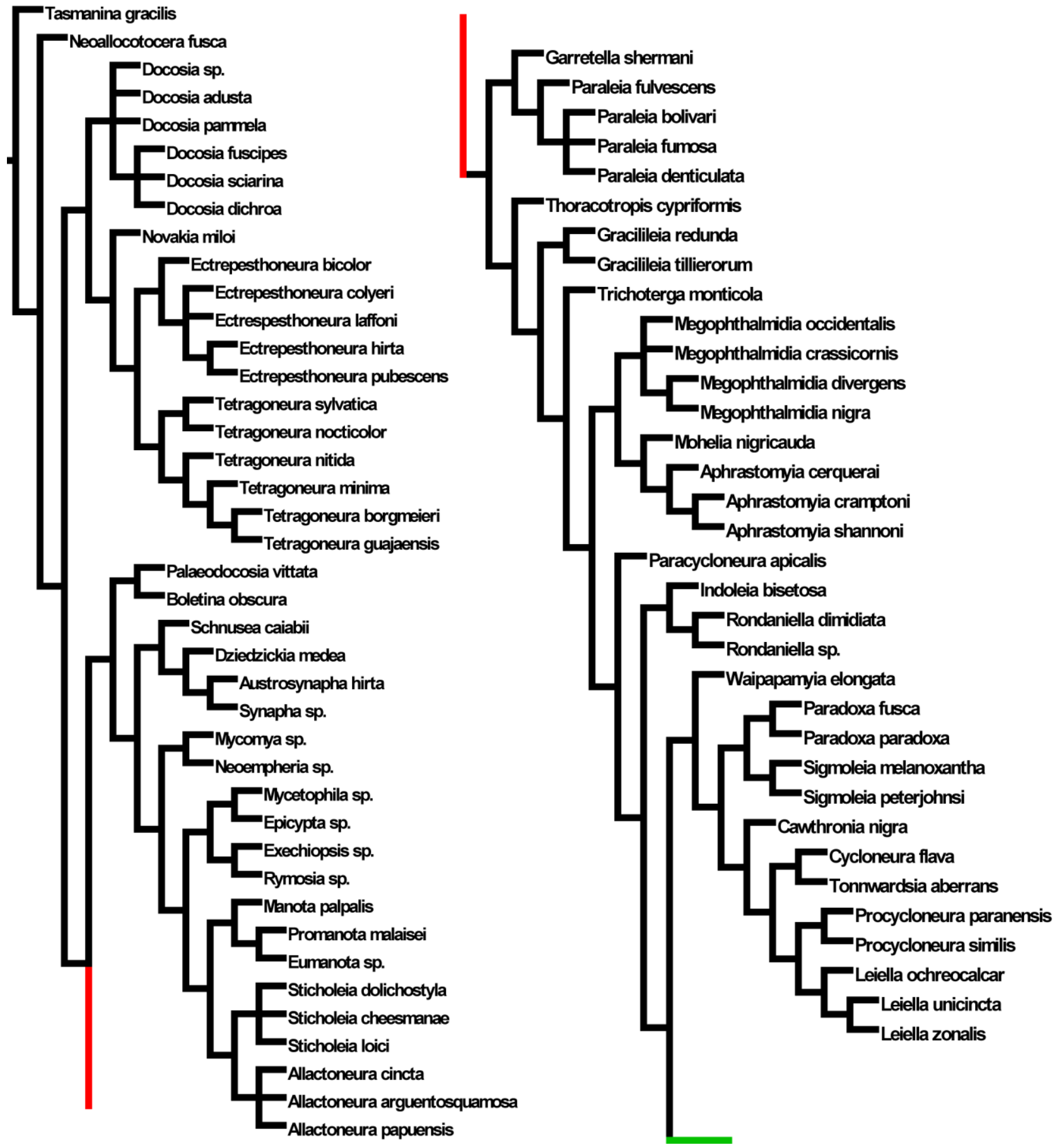

Figura 326. Cladograma de consenso estrito para a análise com grupos viventes. 


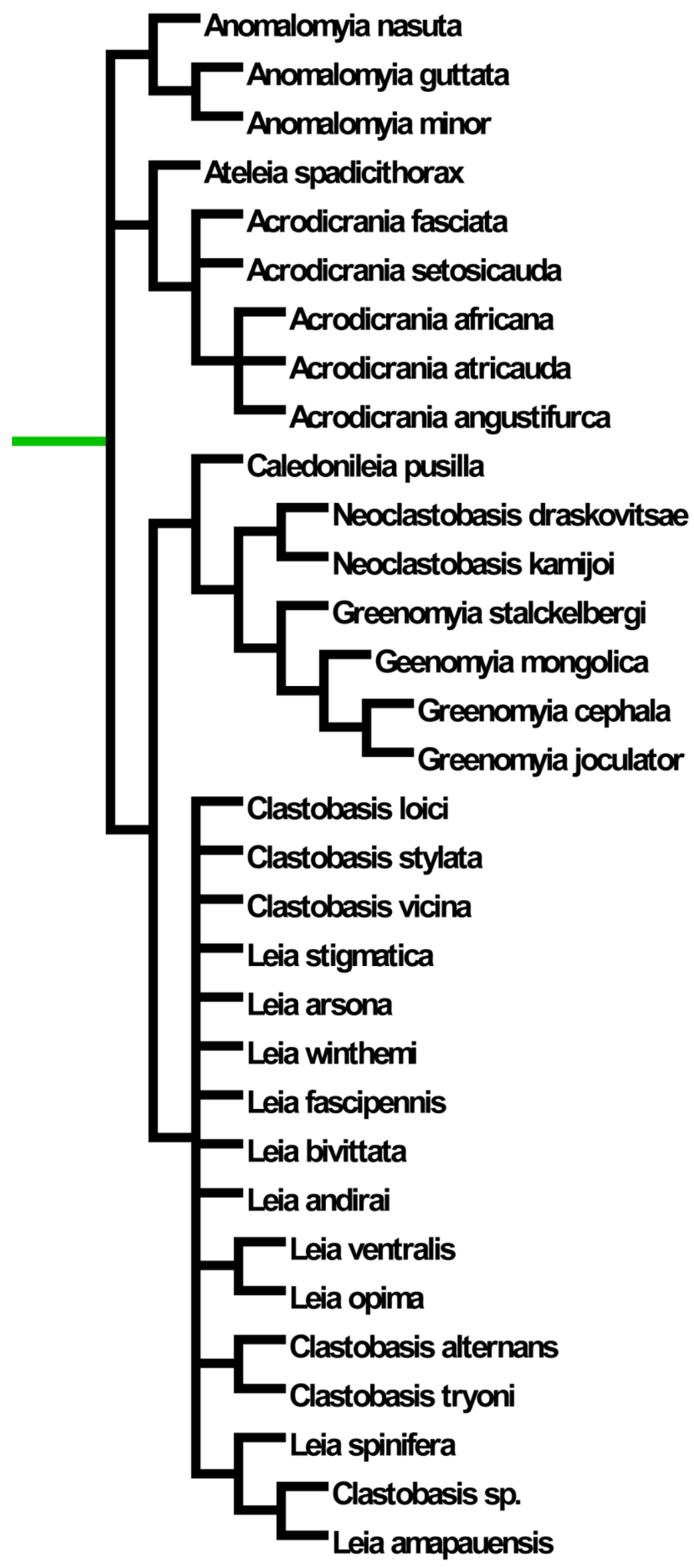

Figura 326 (continuação). Cladograma de consenso estrito para a análise com grupos viventes. 

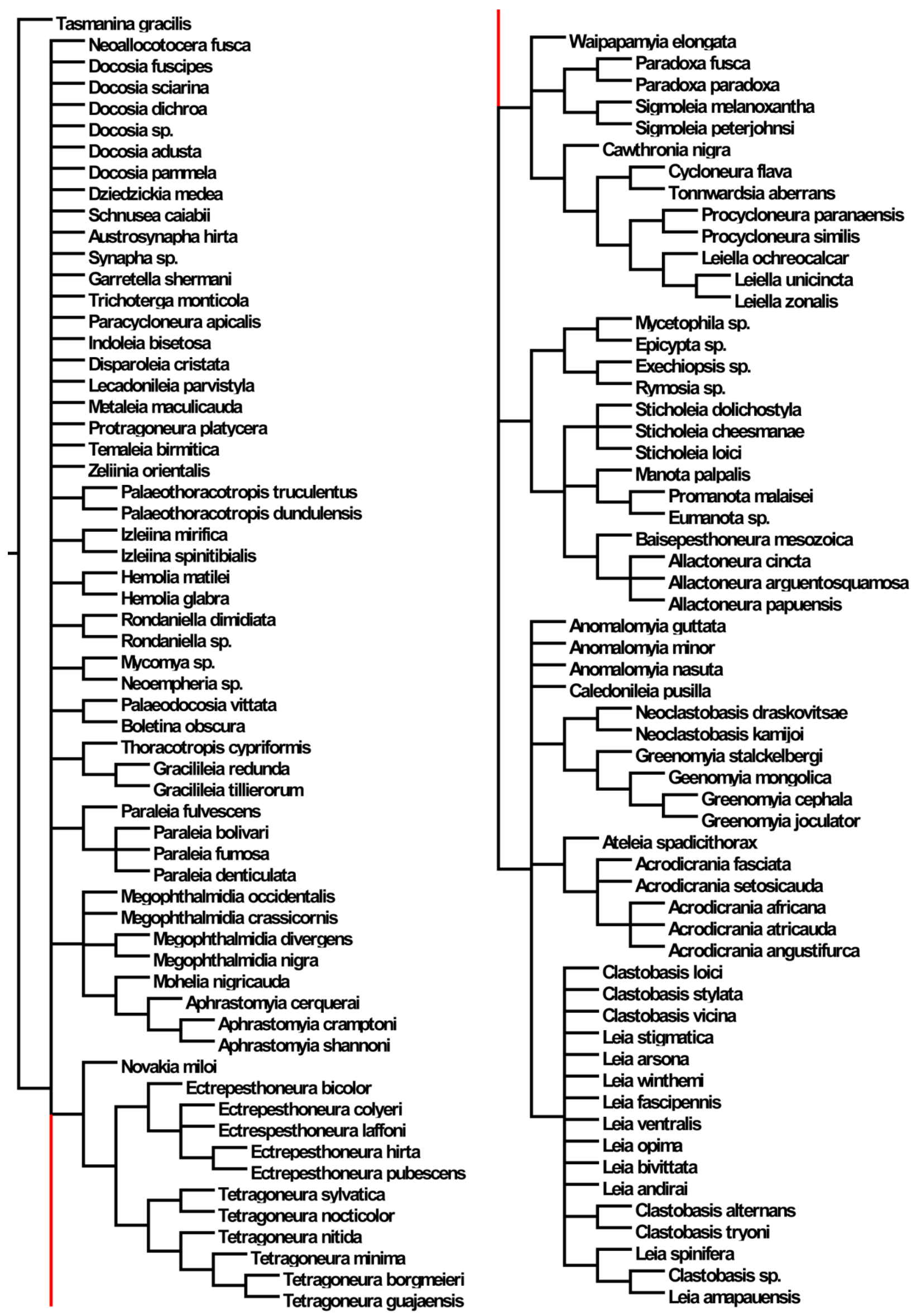

Figura 327. Cladograma de consenso estrito para a análise com grupos viventes e fósseis. 
$\mathbf{A}$

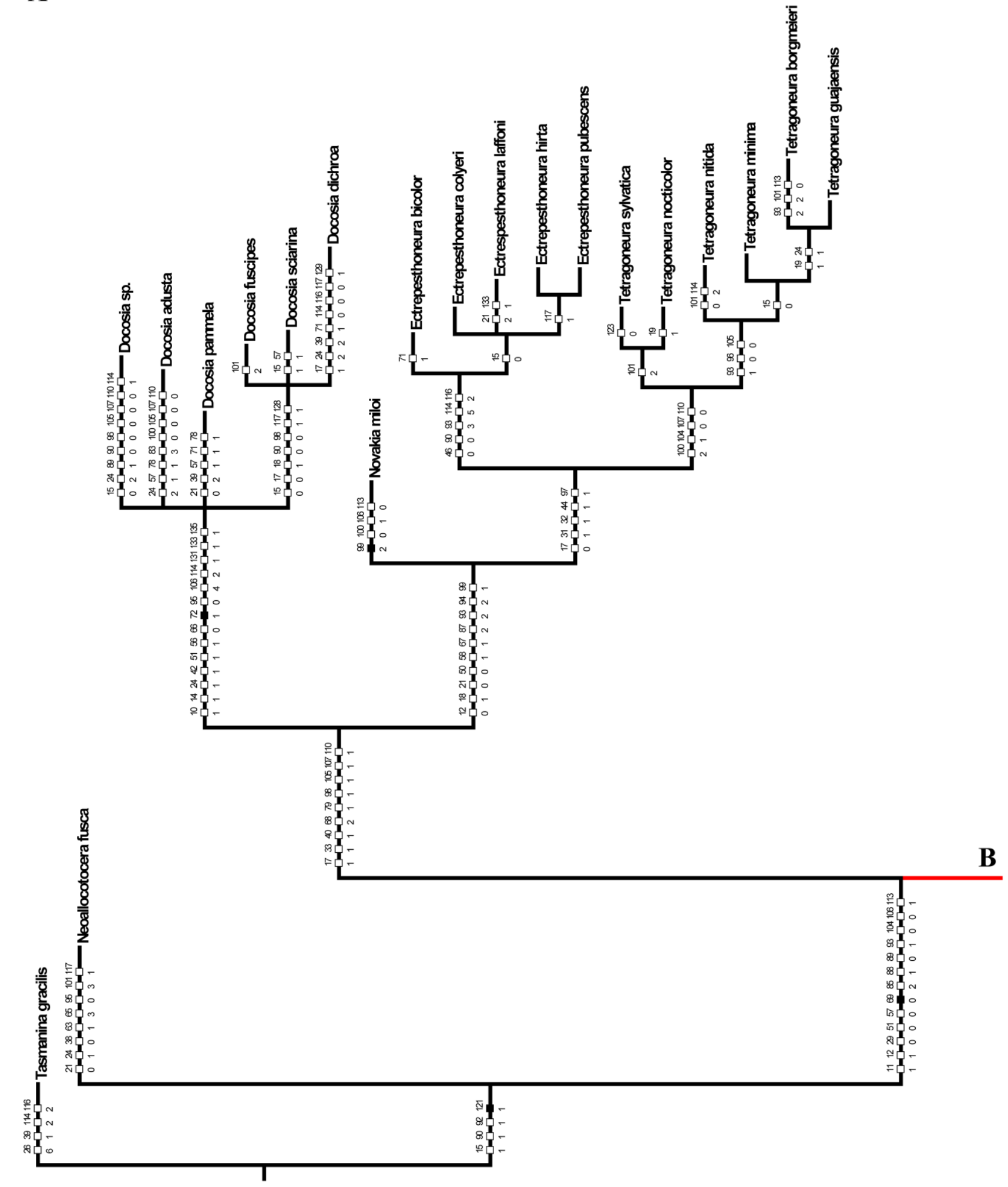

Figura 328 (parte A). Cladograma de consenso estrito para a análise com grupos viventes. Os caracteres foram plotados segundo o modo de otimização ACCTRAN. 
B

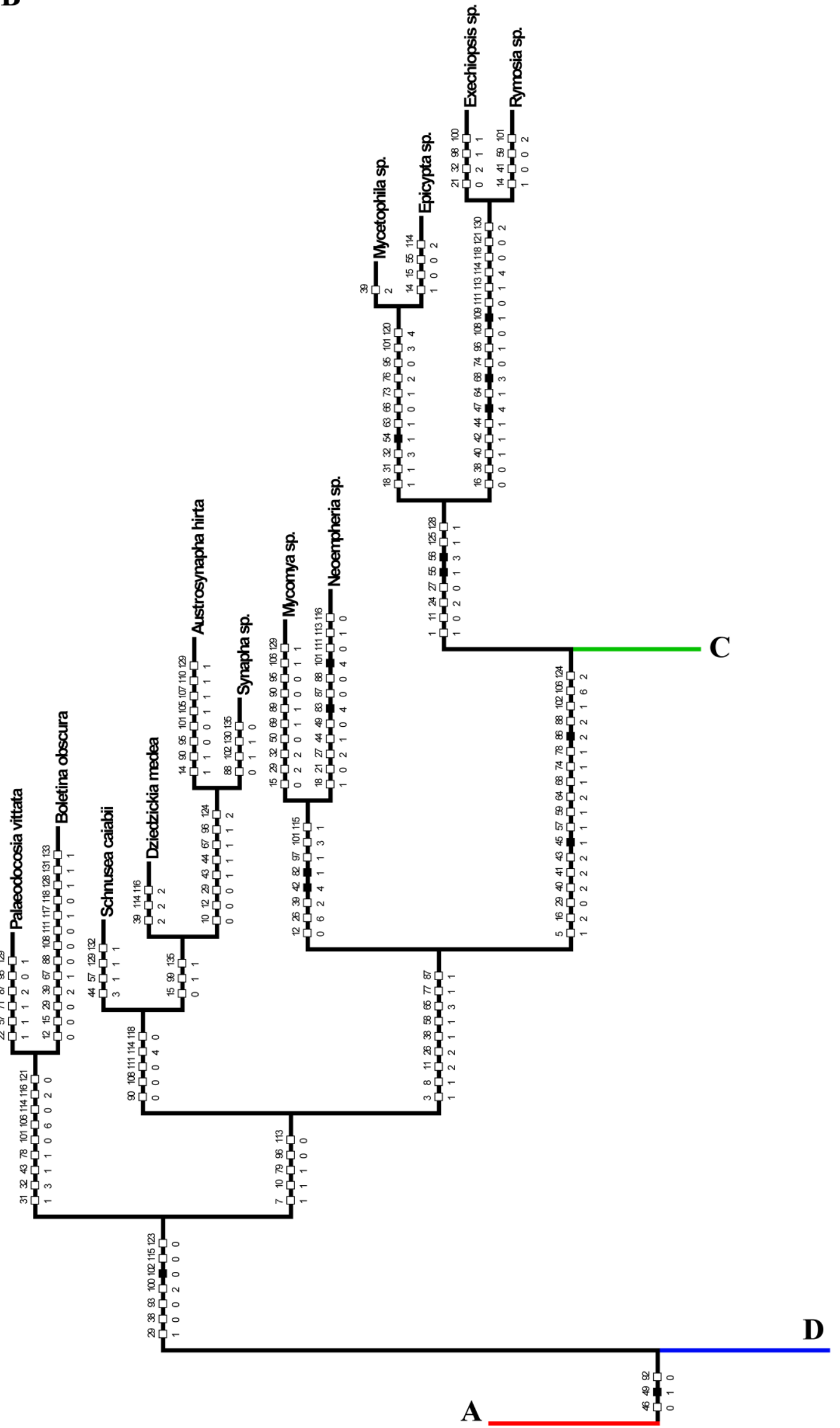

Figura 328 (parte B). Cladograma de consenso estrito para a análise com grupos viventes. Os caracteres foram plotados segundo o modo de otimização ACCTRAN. 


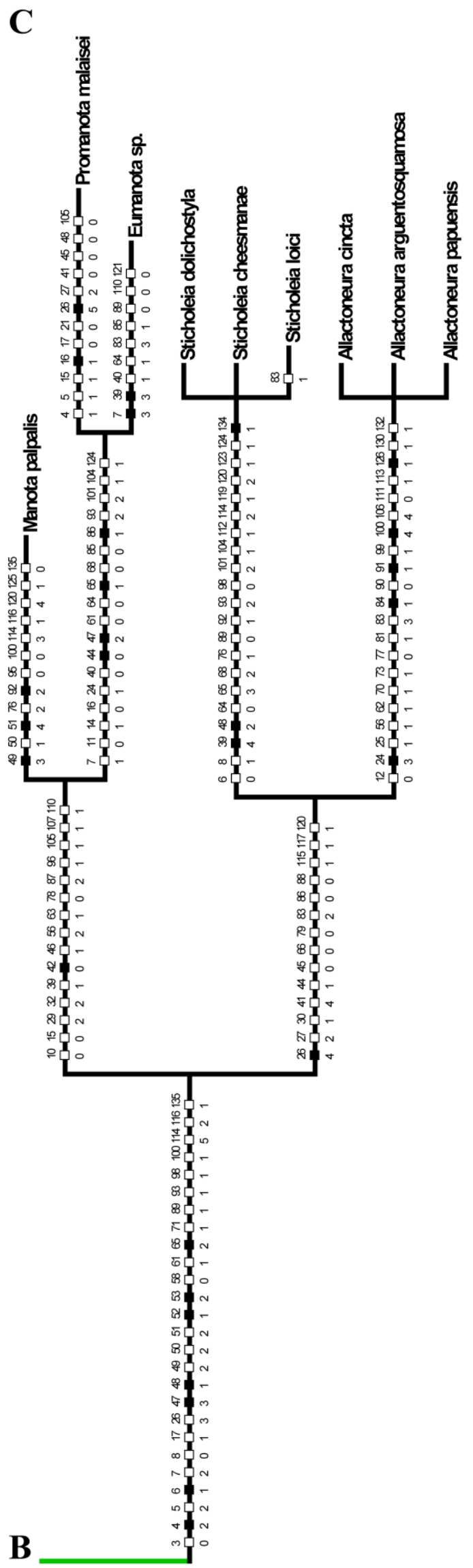

Figura 328 (parte C). Cladograma de consenso estrito para a análise com grupos viventes. Os caracteres foram plotados segundo o modo de otimização ACCTRAN. 
D

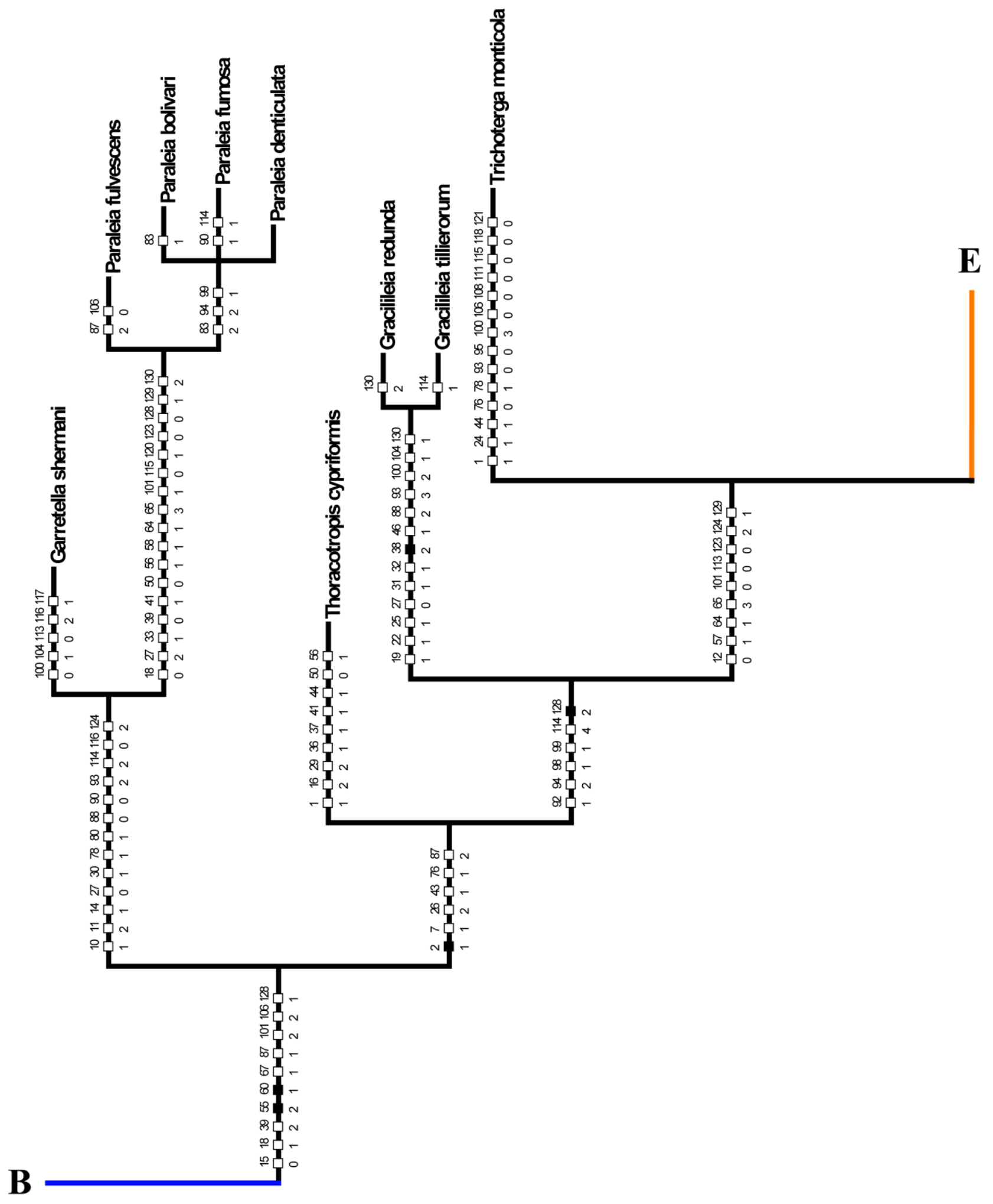

Figura 328 (parte D). Cladograma de consenso estrito para a análise com grupos viventes. Os caracteres foram plotados segundo o modo de otimização ACCTRAN. 
$\mathbf{E}$

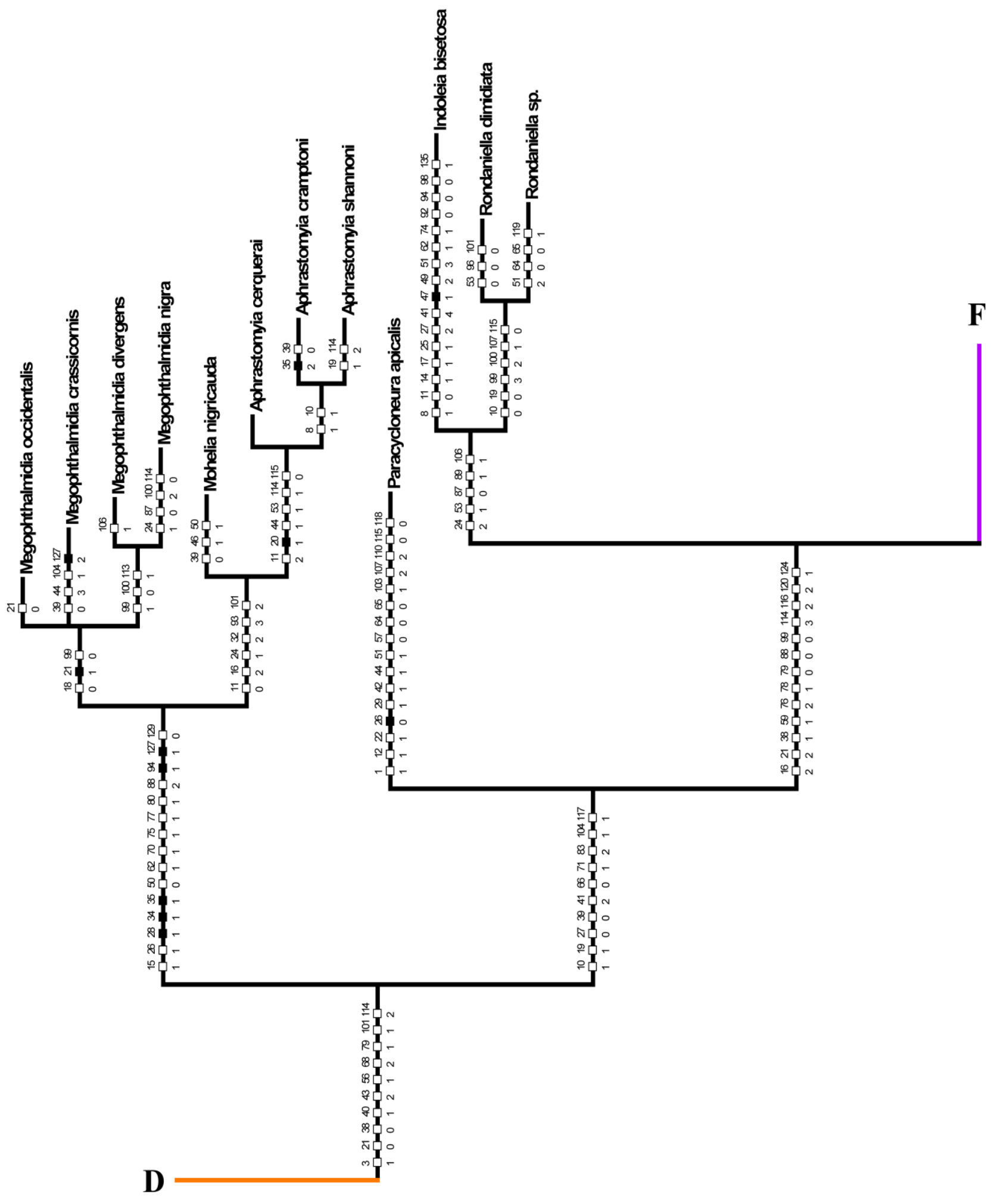

Figura 328 (parte E). Cladograma de consenso estrito para a análise com grupos viventes. Os caracteres foram plotados segundo o modo de otimização ACCTRAN. 


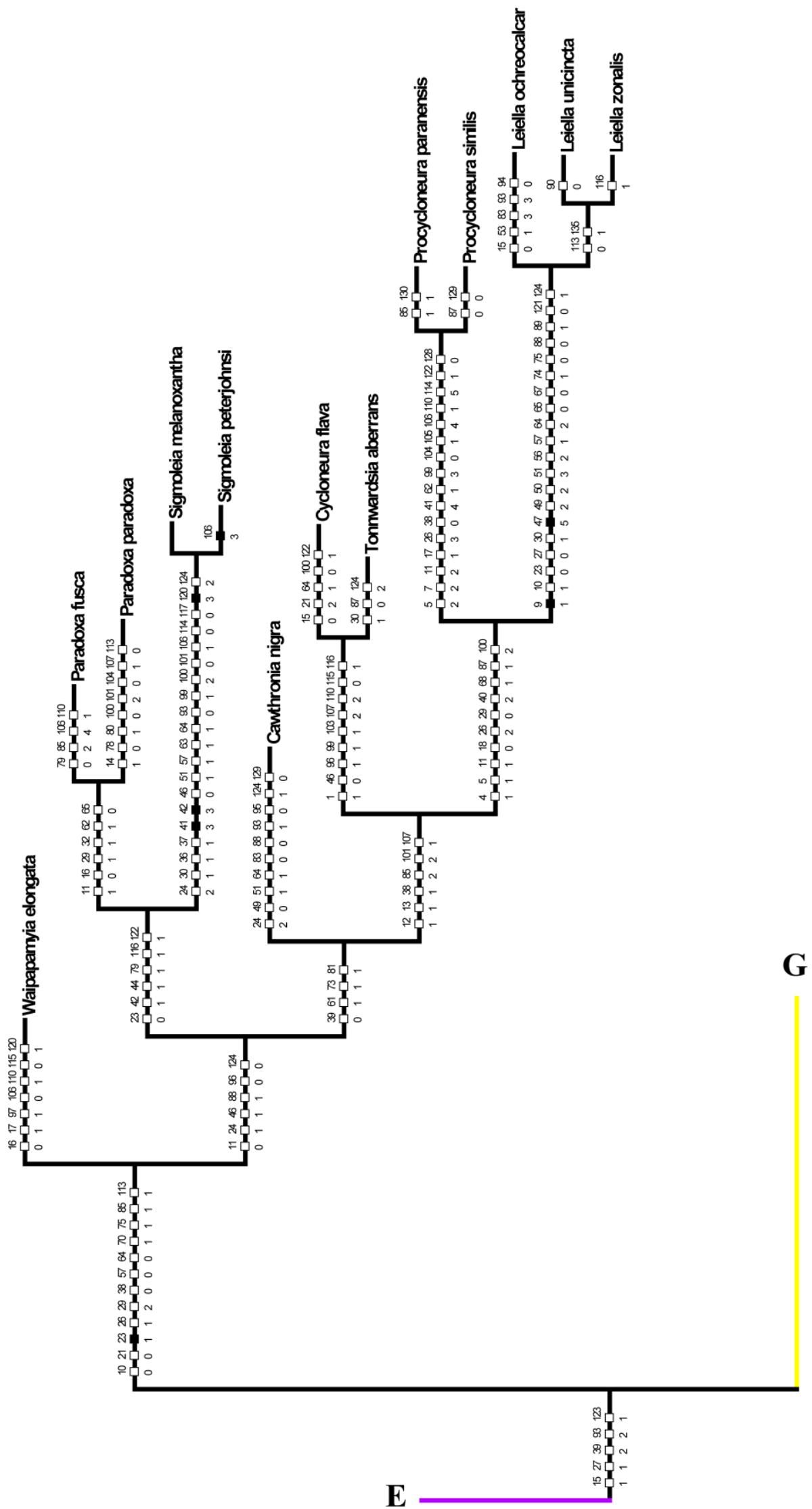

Figura 328 (parte F). Cladograma de consenso estrito para a análise com grupos viventes. Os caracteres foram plotados segundo o modo de otimização ACCTRAN. 


\section{G}

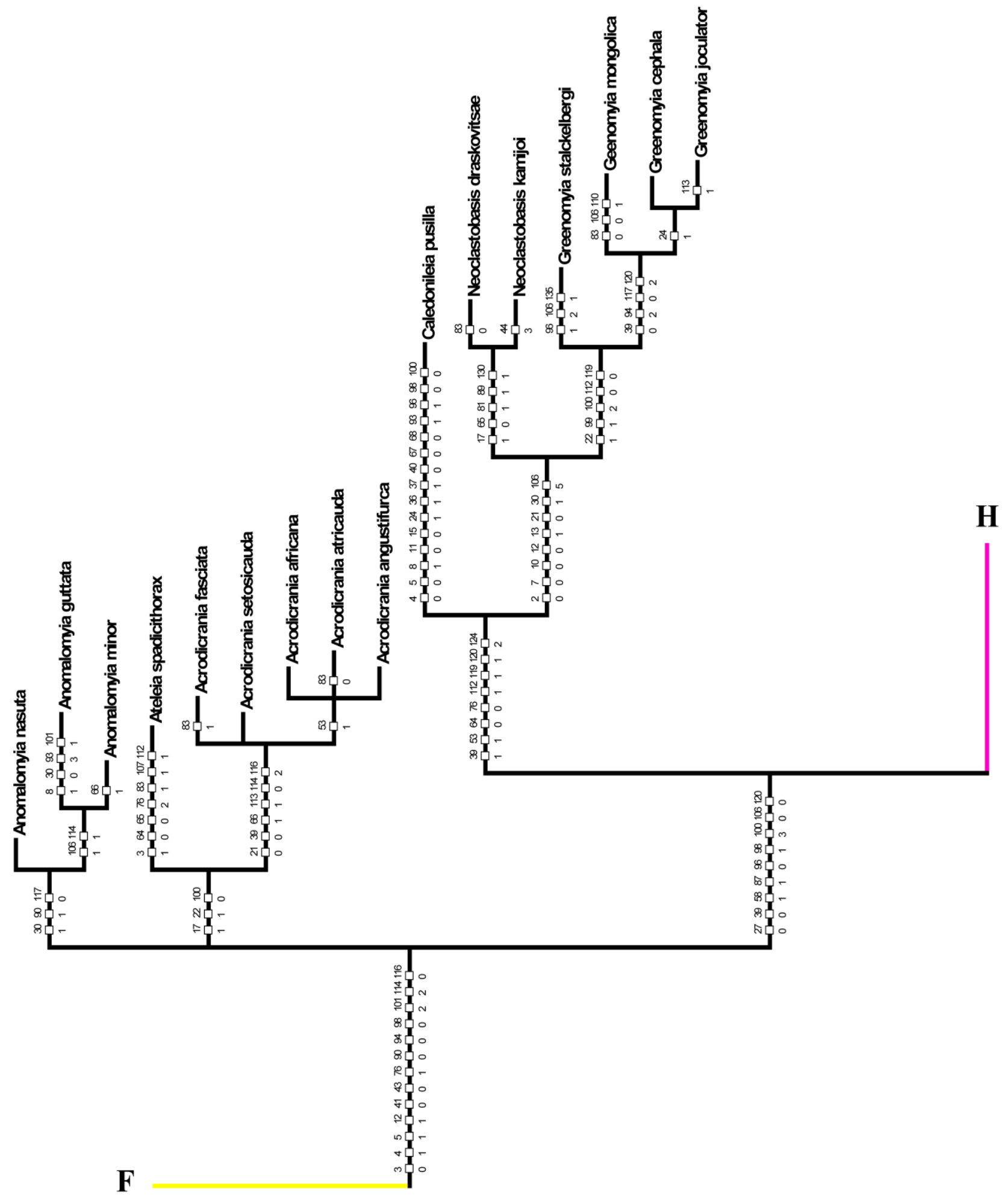

Figura 328 (parte G). Cladograma de consenso estrito para a análise com grupos viventes. Os caracteres foram plotados segundo o modo de otimização ACCTRAN. 


\section{$\mathbf{H}$}

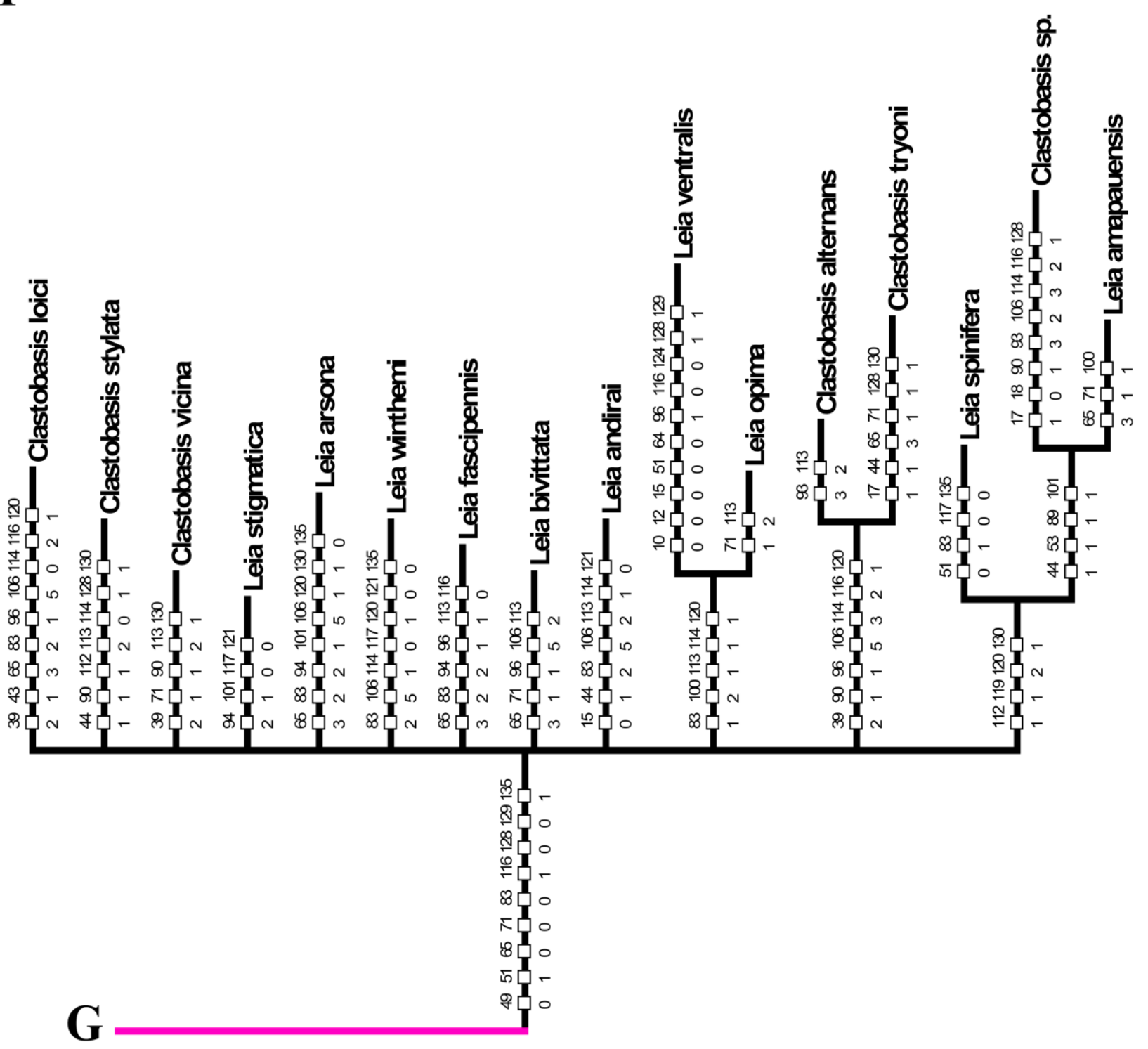

Figura 328 (parte H). Cladograma de consenso estrito para a análise com grupos viventes. Os caracteres foram plotados segundo o modo de otimização ACCTRAN. 


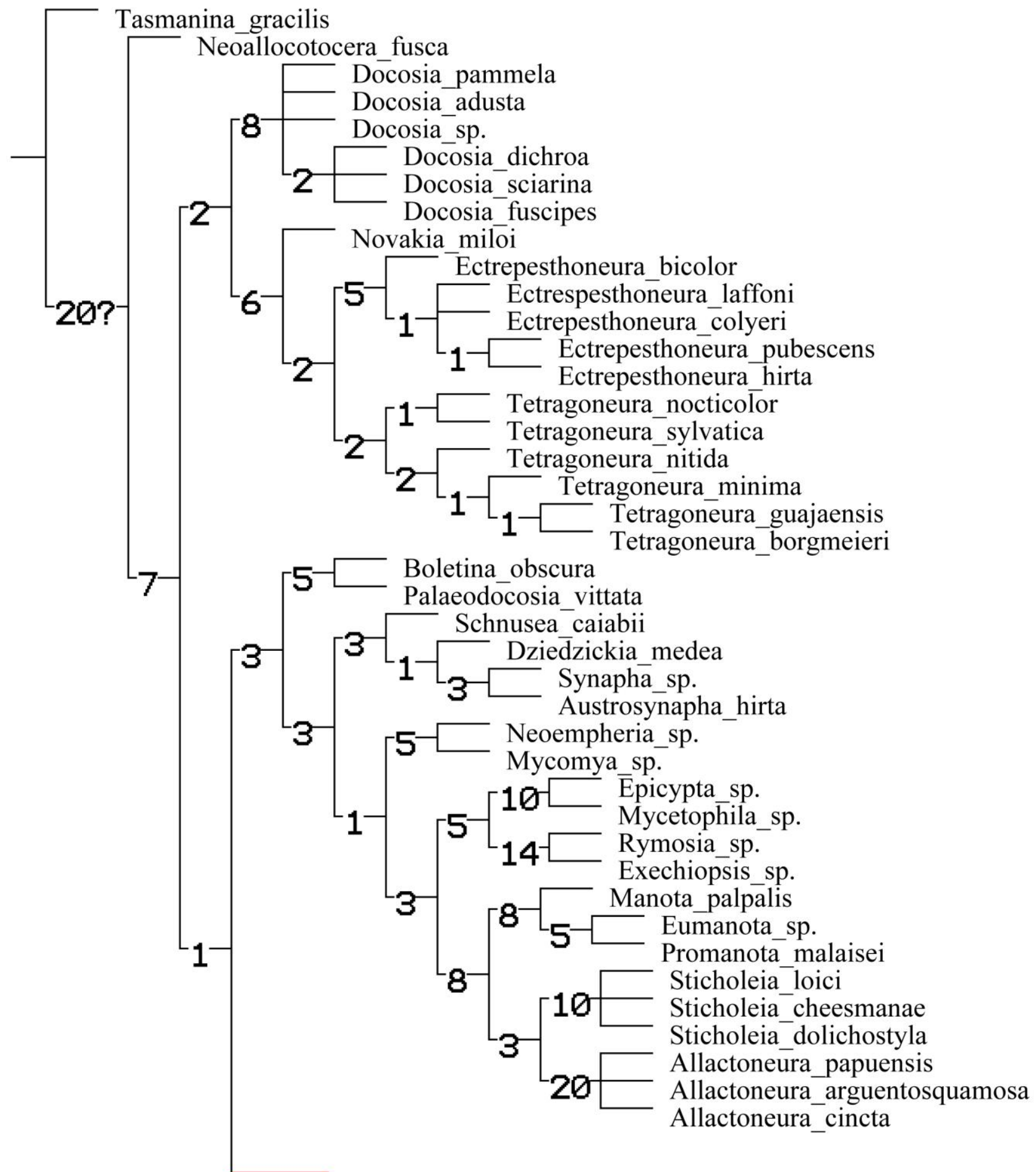

Figura 329. Cladograma de consenso estrito para a análise com grupos viventes com os índices de suporte de Bremer. 


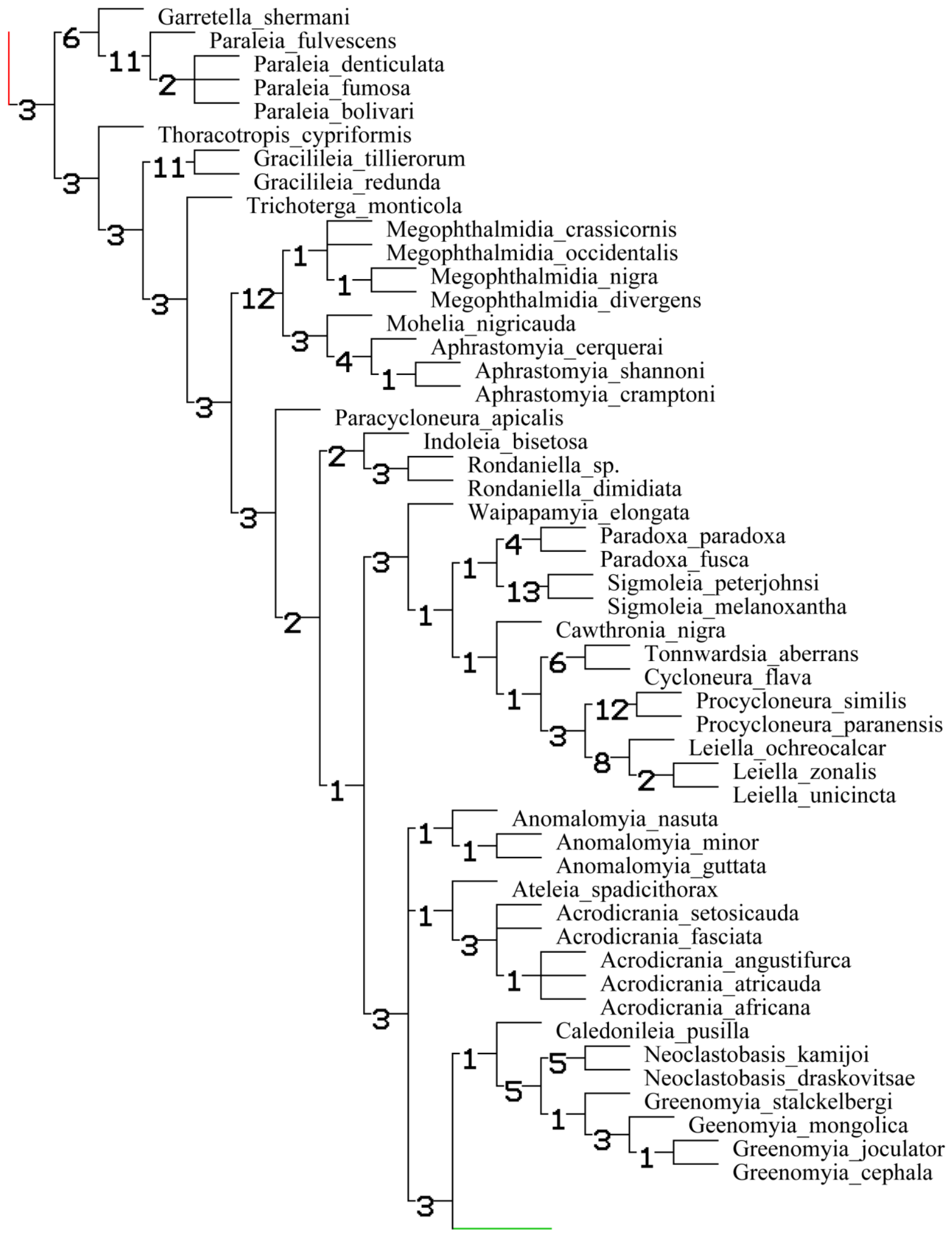

Figura 329 (continuação). Cladograma de consenso estrito para a análise com grupos viventes com os índices de suporte de Bremer. 


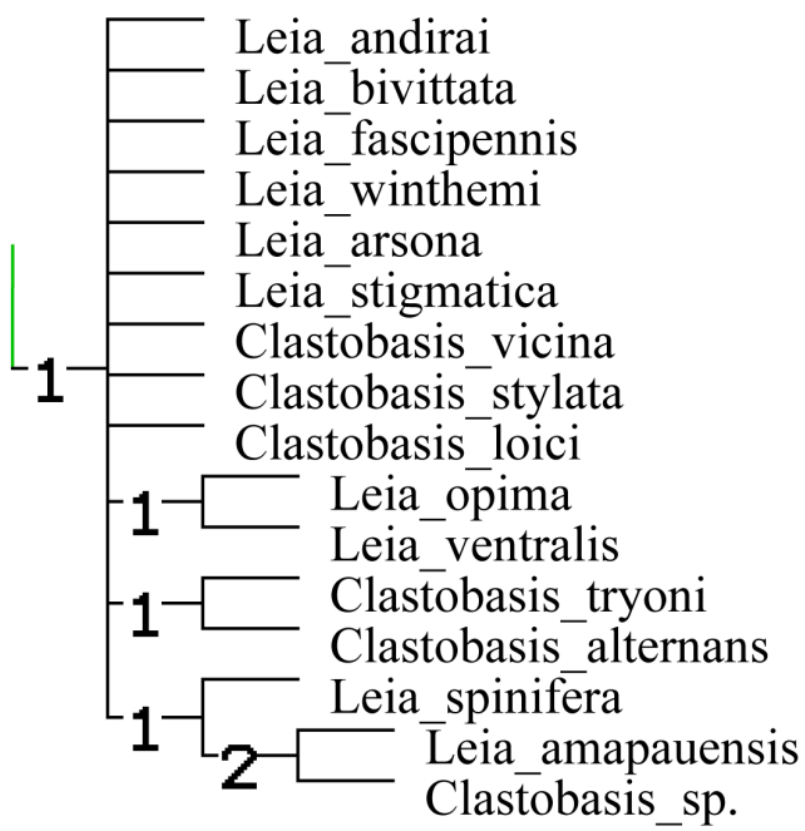

Figura 329 (continuação). Cladograma de consenso estrito para a análise com grupos viventes com os índices de suporte de Bremer.

\section{Leiinae como grupo monofilético e seus principais clados}

A análise realizada (figura 326) aponta um grupo monofilético para Leiinae retirando-se os gêneros Docosia, Ectrepesthoneura, Novakia e Megophthalmidia, posicionando-os em Gnoristinae, e retirando-se Sticholeia, que aparece como grupo-irmão de Allactoneura, de maneira que esse gênero é transferido para Allactoneurinae.

As sinapomorfias de Leiinae (figura 328D) são características torácicas, como o mesepímero em contato com o mesopleurotrocantin, não alcançando a porção ventral do tórax (caráter 55:2), e a presença do mesopleurotrocantin (60:1). A presença de um longa cerda posterior apical no pedicelo (18:1), o catepisterno com uma projeção angulada em que se encaixa o mesepímero $(67: 1)$, costal terminando em $\mathrm{R}_{5}(87: 1)$, r-m longa (mais de quatro vezes o comprimento de Rs) (101:2) e o alongamento de $\mathbf{M}_{1+2}$ (106:2) são características presentes na subfamília, mas presentes também em outros grupos de Mycetophilidaeplesiomorfias.

A característica tradicionalmente entendida como definidora de Leiinae, o deslocamento da base do setor radial (Rs) em direção ao ápice da asa, resultando em um encurtamento evidente de $\mathrm{R}_{1}$ (caráter 92:2) mostrou-se presente na maior parte dos gêneros de Leiinae, mas não é uma sinapomorfia do grupo. 
Apesar do índice de consistência baixo no consenso estrito, o índice de retenção é relativamente alto, o que talvez explique os valores bastante razoáveis para os índices de Bremer suportando uma grande proporção dos clados dentro de Leiinae.

Sobre os clados internos de Leiinae, destaca-se o clado (Garretella+Paraleia) como grupo irmão de todos os outros Leiinae — o clado Thoracotropis ${ }^{+}$(figura 328D).

O gênero Garretella foi erigido por Vockeroth (1980) para Leia shermanni Garrett, que notou diferenças importantes entre essa espécie e as demais do gênero Leia. Paraleia, por sua vez, foi descrito por Tonnoir (1929) para Paraleia fulvescens, da Austrália. Posteriormente, 17 novas espécies neotropicais foram gradualmente adicionadas ao gênero (Edwards, 1933b; Freeman, 1951; Oliveira \& Amorim, 2012a). Nenhum destes autores menciona semelhanças entre Garretella e Paraleia. O estudo morfológico aqui realizado, no entanto, mostra que a morfologia geral de cabeça, tórax e asa desses dois gêneros guarda muitas semelhanças (figuras 8B, 11-12, 92, 154-155), ainda que haja diferenças significativas em relação à terminália masculina (figuras 9B e 206), principalmente no formato e extensão do gonóstilo.

Em Thoracotropis ${ }^{+}$(figura 328D), o posicionamento de Thoracotropis cypriformis, como irmão do restante da subfamília, seguido por Gracilileia e, depois, Trichoterga monticola contraria a hipótese de Tozoni (1998) de que Thoracotropis pertence à Gnoristinae, em um clado que incluiria também Impleta Plassmann e Docosia.

Thoracotropis é um gênero monotípico, endêmico da Região Neotropical, descrito por Freeman (1951) e redescrito por Oliveira et al. (2012). Oliveira e colaboradores reconheceram semelhanças gerais entre as terminálias masculina de Thoracotropis e de Gnoristinae, mas que, se não são suficientes para incluir o gênero em Gnoristinae, ao menos indicam que Thoracotropis não pertence ao grupo mais típico de Leiinae, que inclui, por exemplo, Paradoxa, Sigmoleia, Paracycloneura e Waipapamyia. Além disso, apesar de Thoracotropis possuir uma $\mathrm{R}_{1}$ mais longa que a dos leiíneos típicos, a r-m longa aproximaria o gênero dos membros da subfamília (Oliveira et al., 2012).

O clado Thoracotropis $^{+}$(figura 328D) é suportado pelo deslocamento dorsal do forâmen magno (caráter 2:1), caráter de origem única, além de algumas outras características que sugem mais de uma vez na filogenia. Esse nível ainda precisa de melhor definição. Gracilileia $^{+}$é sustentado pelo gonóstilo bem desenvolvido, ornamentado, com regiões diferenciadas (caráter 128:2), além de algumas outras características. Uma sinapomorfia do gênero Gracilileia é alongamento evidente do terceiro palpômero labial (38:2), clado sustentado por várias outras características. Gracilileia, erigido por Matile (1993), é 
endêmico da Nova Caledônia e compreende seis espécies. Trichoterga, descrito por Tonnoir \& Edwards (1927), é monotípico e endêmico da Nova Zelândia.

O posicionamento desses três gêneros basalmente dentro de Leiinae ainda não foi mencionado na literatura e não parece de todo inesperado, uma vez que a organização geral do corpo é bastante parecida, em termos de plesiomorfias, com a dos Gnoristinae e a venação alar não é tão reduzida quanto observado por Edwards (1925) para o restante dos Leiinae. O restante dos Leiinae, no clado Megophthalmidia ${ }^{++}$(figura 328E), apresenta um encurtamento do tórax e redução do comprimento das pernas (características também presentes em Manotinae e Allactoneurinae), além de diversas outras características que não são únicas desse clado.

O clado formado por Megophthalmidia, Aphrastomyia e Mohelia (figura 328E) havia sido reconhecido por Matile (1978) e Jaschhof \& Kallweit (2004). Para esses autores, Aphrastomyia e Mohelia provavelmente seriam grupos-irmãos e relacionados a Megophthalmidia. Jaschhof \& Kallweit (2009), por outro lado, propuseram que Aphrastomyia e Mohelia fossem removidos de Leiinae e que Megophthalmidia permanecesse no grupo. A análise realizada neste trabalho indica que os três gêneros de fato estão relacionados e que permanecem à Leiinae. Ainda que o índice de Bremer igual a 3 em todos os cinco níveis consecutivos desde a base de Leiinae (figura 329) não seja alto individualmente (Leiinae, Thoracothropis ${ }^{+}, \quad$ Gracilileia $^{+}, \quad$ Trichoterga $^{+}$e Megophthalmidia ${ }^{++}$), há um conjunto de 35 "nested characters" de origem única e de origem múltipla apontando para a relação do grupo Megophthalmidia ${ }^{+}$com os demais Leiinae.

As sinapormorfias do grupo Megophthalmidia ${ }^{+}$(figura 328E) são: clípeo nu (28:1); labro alongado, mais longo que o clípeo (caráter 34:1); peças bucais alongadas formando uma probóscide (35:1); $\mathrm{R}_{1}$ curvada em direção à margem da asa (94:1); e a terminália masculina flexionada (127:1). O gênero Megophthalmidia é suportado pela presença de flagelômeros antenais mais largos que longos (21:1); e Aphrastomyia, pela presença de flagelômeros antenais achatados lateralmente (20:1).

Esse clado é irmão de Paracycloneura ${ }^{+}$(figura 328E), com o restante dos Leiinae mais típicos, do qual se destaca a posição de Paracycloneura apicalis como irmão dos demais gêneros. O grupo-irmão de Paracycloneura é Indoleia ${ }^{++}$(figura 328E), que tem $\left(\right.$ Indoleia+Rondaniella) como grupo-irmão de (Waipapamyia ${ }^{+}+$Anomalomyia $^{*}$ ) (figura 328E-H). Jaschhof \& Kallweit (2009) fizeram uma excelente revisão de um grupo de gêneros de Leiinae, referido como "grupo-Cycloneura". Esse grupo seria composto basicamente por gêneros endêmicos da Nova Zelândia e de outras áreas temperadas do 
Hemisfério Sul, com poucas espécies conhecidas, em que $A_{1}$ está próxima ou fundida a $\mathrm{CuA}$, formando uma célula fechada na região anal da asa, que dá nome ao grupo (Jaschhof \& Kallweit, 2009). O grupo-Cycloneura seria composto por Cawthronia, Cycloneura, Paracycloneura, Paradoxa, Procycloneura, Sigmoleia, Tonnwardsia e Waipapamyia (Jaschhof \& Kallweit, 2009). Além disso, Cycloneura e Tonnwardsia deveriam ser gruposirmãos (Jaschhof \& Kallweit, 2009). Os índices de Bremer dos clados Waipapamyia ${ }^{+}$, Cycloneura $^{+}$e Procycloneura ${ }^{+}$são, respectivamente, 3, 6 e 3 (figura 329), valores bastante razoáveis.

$\mathrm{Na}$ análise aqui realizada, o grupo-Cycloneura da maneira como foi indicado por Jaschhof \& Kallweit (2009), não foi estritamente corroborado. O clado Waipapamyia ${ }^{+}$ (figura 328F), suportado pela presença de um par de cerdas mais longas no último flagelômero antenal (caráter 23:1), engloba a maior parte de seus representantes, com exceção de Paracycloneura, mas inclui também Leiella. O índice de Bremer desse clado é 3 (figura 329). Segundo Jaschhof \& Kallweit (2009), Leiella seria um Leiinae típico, não relacionado ao grupo-Cycloneura, mas irmão de Allactoneura. Neste nível da análise, a inconsistência entre ambas as propostas ainda precisam ser consideradas com atenção. Apesar do número considerável de características de cabeça, tórax e asa que suportam as relações entre Procycloneura e Leiella e Sticholeia e Allactoneura.

O último clado de Leiinae, irmão de Waipapamyia ${ }^{+}$, é Anomalomyia ${ }^{*}$ (figura 328GH). De fato, alguma percepção da ligação entre elementos desse grupo está presente na literatura. Jaschhof \& Kallweit (2009) reconheceram duas linhagens na fauna da Nova Zelândia com base em venação alar, a do gênero Anomalomyia, que seria plesiomórfica, e a do grupo-Cycloneura, que seria apomórfica. Tonnoir \& Edwards (1927) disseram que Anomalomyia seria proximamente relacionado a Acrodicrania, enquanto que Marshall (1896) reconheceu semelhanças entre Anomalomyia, Leia, Ateleia e Acrodicrania. De fato, o clado Anomalomyia* é formado por Anomalomyia, Ateleia, Acrodicrania, Caledonileia, Neoclastobasis, Greenomyia, Leia e Clastobasis, ou seja, o mesmo grupo apontado por Marshall (1896), com alguns outros poucos gêneros.

A relação de grupos-irmãos entre Neoclastobasis e Greenomyia (figura 328G) é condizente com a revisão de Kurina et al. (2011). Em uma revisão das espécies europeias de Greenomyia, eles concluíram que os caracteres utilizados para separar os dois gêneros não são satisfatórios e que há a necessidade de reavaliar o posicionamento de suas espécies em diferentes gêneros. Além disso, os espécimes de Neoclastobasis são muito semelhantes aos de Greenomyia em sua organização corporal geral, com diferenças basicamente na 
terminália masculina (Kurina et al., 2011). Afirmaram ainda que Greenomyia e Neoclastobasis podem ser grupos-irmãos e que um estudo completo de Leiinae seria necessário para definir o posicionamento das espécies desses gêneros ou o estabelecimento de uma sinonímia.

Este estudo corrobora a hipótese de que Greenomyia e Neoclastobasis são grupos irmãos (figura 328G) e seu status genérico por enquanto é mantido, sendo necessária uma revisão de todas as espécies de cada um desses gêneros para decisões taxonômicas. Os caracteres diagnósticos de Neoclastobasis são (figura 328G): presença de densas cerdas na superfície anterior do escapo e pedicelo (caráter 17:1); catepisterno retangular (65:0); esporão tibial da perna III tão longo quanto o primeiro tarsômero (81:1); Sc pubescente (89:1); gonóstilo tão longo quanto o gonocoxito (130:1). Por sua vez, os caracteres diagnósticos de Greenomyia são (figura 328G): primeiro flagelômero antenal mais longo que os demais (caráter 22:1); $\mathrm{R}_{5}$ reta ou quase reta de sua origem até a margem da asa (99:1); r-m transversal (100:2); ápices de $\mathrm{M}_{2}$ e $\mathrm{M}_{4}$ completos, atingindo a margem da asa (112:0 e 119:0, respectivamente).

O posicionamento de Caledonileia como grupo irmão de (Greenomyia+Neoclastobasis) demanda um pouco mais de estudos (figura 328G). Caledonileia foi erigido por Matile (1993) com base em uma espécie da Nova Caledônia. Matile (1993) comentou que Caledonileia compartilha com Sigmoleia e Thoracotropis a presença de apenas dois palpômeros, mas que há diferenças significativas na venação alar entre os três gêneros.

No presente estudo, as características que unem Caledonileia a (Greenomyia+Neoclastobasis) são, em sua maioria, de venação alar (figuras 176-178), bastante plásticas em Mycetophilidae e poderiam levar a interpretações incorretas sobre o posicionamento do gênero (Matile, 1993; Oliveira et al., 2012). O índice de Bremer para esse nível é 1 (figura 329), sugerindo, assim, cautela. O presente estudo baseou-se no exame de um parátipo do MNHN que não está em boas condições de preservação, além da descrição original de Matile (1993).

Os gêneros Leia e Clastobasis correspondem a uma parte importante dos problemas de Leiinae (figura $328 \mathrm{H}$ ). As diferenças entre esses gêneros são sutis e foram relativamente eficazes para a fauna paleártica. Leia é um gênero de distribuição mundial, com mais de 60 espécies descritas para a região Neotropical, enquanto que, estranhamente, Clastobasis não possui representantes neotropicais. 
O estudo de fauna Neotropical de Leia sugere que o gênero não corresponde a um grupo natural, uma vez que parte das espécies neotropicais de Leia se encaixaria na definição de Clastobasis. O táxon terminal Clastobasis sp. é uma espécie neotropical que se encaixa na definição de Clastobasis (segundo a chave de Søli et al., 2000), mas que, na região Neotropical, seria identificado como Leia. Isso reforça a idéia defendida por Tozoni (1998) de que Leia é parafilético nesta região e deve ser revisto e separado em entidades naturais. O cladograma resultante deste estudo filogenético corrobora essa suspeita (figura 328H). Dado o tamanho dos dois gêneros no mundo, no entanto, esse será um trabalho bastante extenso.

As análises com pesagem implícita (figuras 330-332) não mostraram diferenças significativas em relação ao resultado obtido com pesos iguais (figuras 326 e 328A-H), indicando que Leiinae é um grupo monofilético e que seus grandes clados são bem estabelecidos. Há pequenas alterações em relação ao posicionamento de: (1) Caledonileia, que com k=2-5 (figura 330), é grupo-irmão de Thoracotropis e, conforme discutido anteriormente, o posicionamente deste gênero demanda estudos adicionais; (2) Paracycloneura está mais próximo de Megophthalmidia ${ }^{+}$e $\left(\right.$Paradoxa $^{+}+$Waipapamyia $\left.^{+}\right)$nas topologias obtidas com k=2-10 (figuras 331-332), também corroborando a discussão anterior sobre o posicionamento do grupo; (3) com k=15, 20 e 25 (figura 332) há alteração em relação ao cladograma de consenso estrito com pesos iguais no posicionamento de Rondaniella e Indoleia, que estão mais relacionados à Anomalomyia*, formando o clado (Rondaniella (Indoleia $\left(\right.$ Anomalomyia $\left.\left.{ }^{*}\right)\right)$ ).

As alterações mais significativas estão relacionadas aos grupos externos, mas conforme discutido anteriormente, a amostragem utilizada não é suficiente para elucidar as relações entre as outras subfamílias de Mycetophilidae. Com k=1-6 (figura 330), Leiinae é grupo-irmão de Gnoristinae, e com k=7-10 (figura 332) Leiinae é grupo-irmão de (Mycetophilinae (Manotinae+Allactoneurinae)). Além disso, com k=2-10, 15, 20 e 25 (figuras 330-332) o clado (Docosia (Novakia (Ectrepesthoneura+Tetragoneura))) foi recuperado, e sempre não pertencendo à Leiinae. E, em todas as árvores com pesagem implícita a relação entre Mycetophilinae, Manotinae, Sticholeia e Allactoneura foi recuperada (figuras 330-332). 

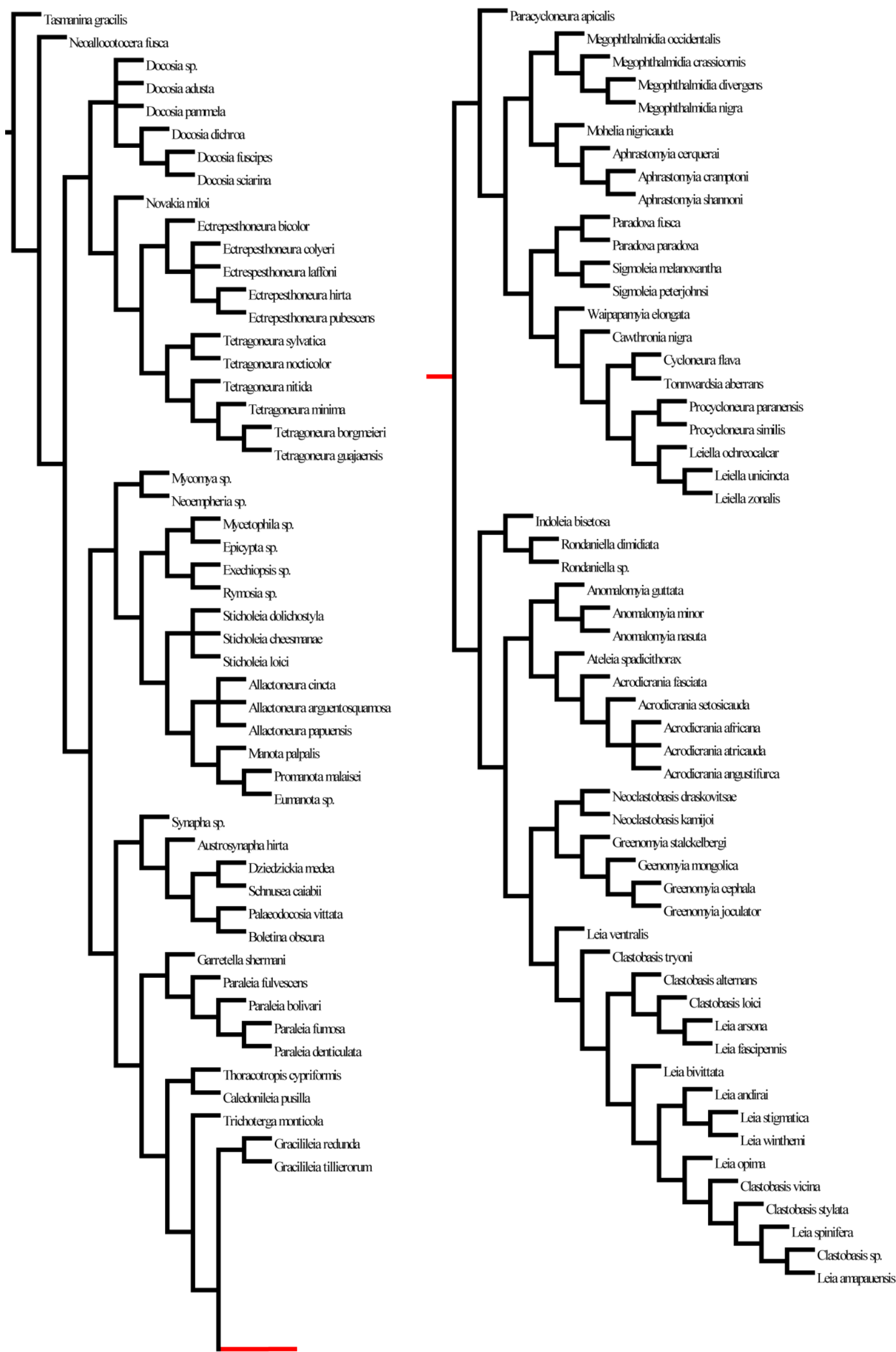

Figura 330. Cladograma para a análise com grupos viventes com pesagem implítica e valor de k=5. 

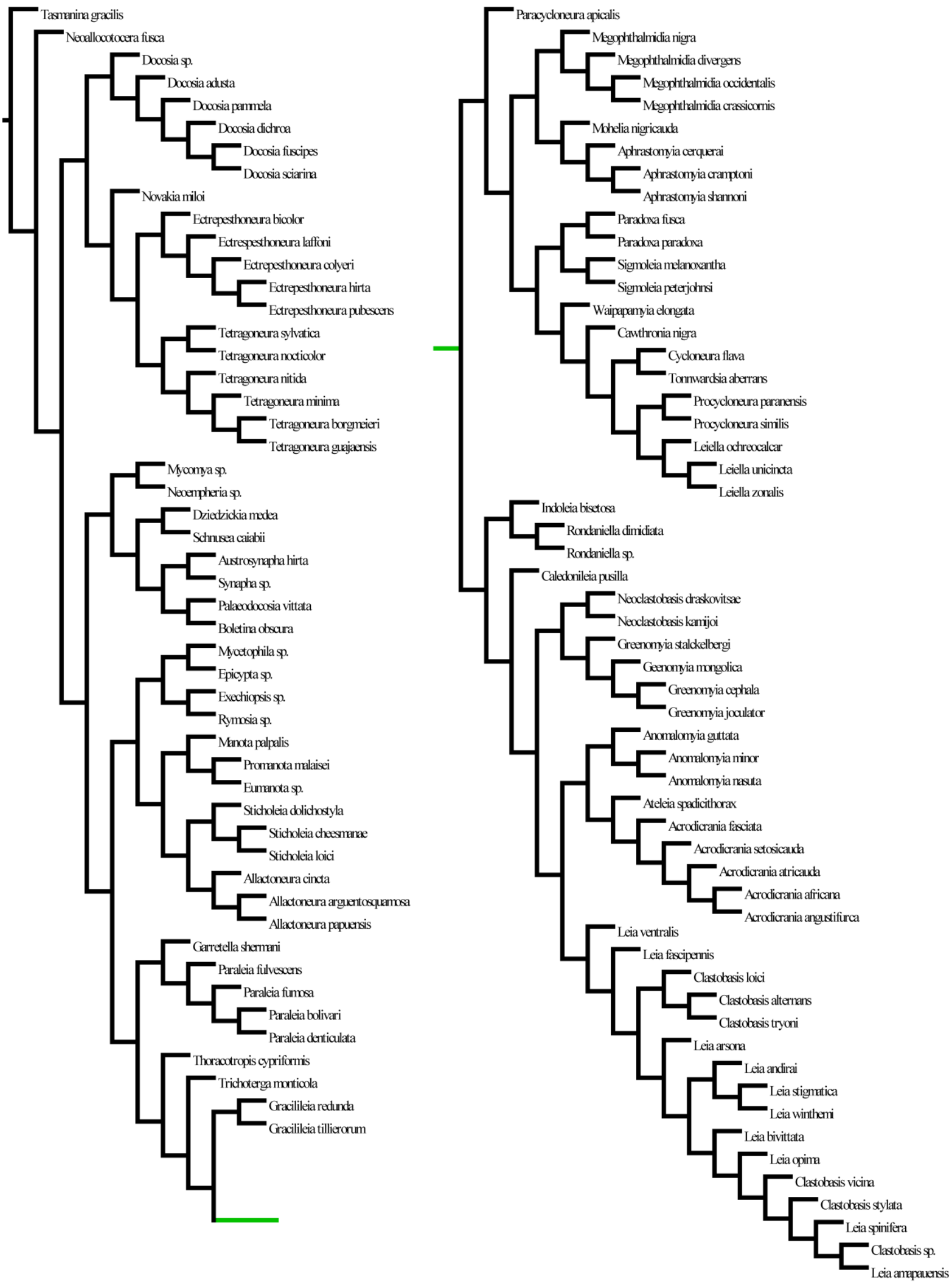

Figura 331. Cladograma para a análise com grupos viventes com pesagem implítica e valor de k=10.

121 


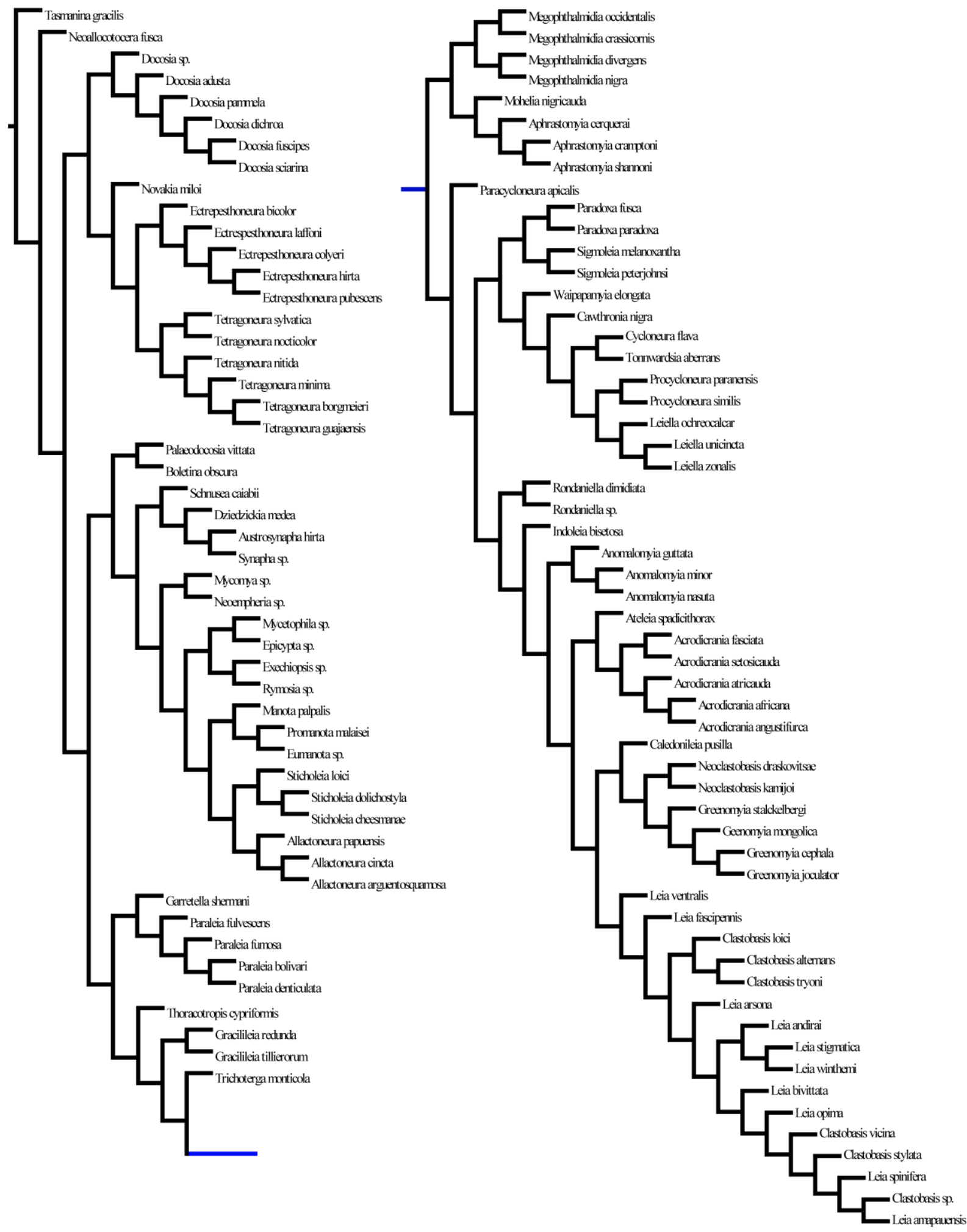

Figura 332. Cladograma para a análise com grupos viventes com pesagem implítica e valor de k=20. 


\section{Fósseis atribuídos a Leiinae}

Os fósseis atribuídos a Leiinae foram descritos por Baxter \& Poinar (1994), Blagoderov (1988a,b, 2000) e Blagoderov \& Grimaldi (2004). Há 54 espécies fósseis divididas em 12 gêneros (Tabela 1), dos quais oito são encontrados em âmbar do Cretáceo.

A análise filogenética utilizou, junto com a diversidade recente do grupo, 13 espécies de 10 gêneros. O cladograma final está apresentado na figura 327. Como pode ser observado, a quantidade de missing entries resulta em falta de resolução para discutir com mais detalhe o relacionamento dos grupos fósseis com os grupos viventes. Uma exceção é Baisepesthoneura que se encaixa em Allactoneurinae.

O gênero Baisepesthoneura foi descrito por Blagoderov (1998a) como possivelmente relacionado ao gênero Ectrepesthoneura. As asas de Baisepesthoneura (figura 301) e Ectrepesthoneura (figura 201) são, de fato, muito semelhantes, divergindo bastante da asa de Allactoneura (figura 183). Assim, a hipótese de relacionamento de Baisepesthoneura com os Allactoneurinae deve ser vista com cautela, possivelmente resultante do excesso de dados faltantes na codificação de Baisepesthoneura.

A comparação entre a análise com fósseis e aquela apenas com grupos viventes indica que, apesar da perda da resolução do cladograma, os clados com suporte de Bremer maior ou igual a 3 (figura 329) estão presentes em ambas as análises (Paraleia, Megophthalmidia ${ }^{+}$, Waipapamyia $^{+}$, Anomalomyia ${ }^{*}$, Neoclastobasis $^{+}$, Novakia $^{+}$, Mycetophilinae $^{+}$), indicando que as características morfológicas que suportam os clados possuem um sinal filogenético significativo.

\section{Docosia, Ectrepesthoneura, Novakia e Tetragoneura como membros de Gnoristinae}

Edwards (1925) comentou sobre as semelhanças entre Tetragoneura e Ectrepesthoneura, mantendo ambos em Leiinae. Väisänen (1986) posicionou os dois gêneros em Gnoristinae, mantendo Docosia dentro de Leiinae. Novakia, por sua vez, já foi posicionado em Sciophilinae (Vockeroth, 1981, 2009) e em Leiinae (Chandler, 1994; Chandler \& Blasco-Zumeta, 2001; Chandler et al., 2005). Segundo Tozoni (1998), Ectrepesthoneura seria irmão de Novakia, ambos relacionando-se a Tetragoneura, Trichoterga, Aphrastomyia, Thoracotropis, Impleta e Docosia.

No presente estudo, Docosia, Ectrepesthoneura, Novakia e Tetragoneura aparecem claramente separados de Leiinae (figuras 326 e 328A). Como a amostragem de gêneros de Gnoristinae neste estudo foi relativamente pequena, o posicionamento desse clado dentro da subfamília ou mesmo a recuperação de um grupo monofilético para Gnoristinae não estão 
em questão. A hipótese de relacionamento ((Docosia)(Novakia (Ectrepesthoneura+Tetragoneura))) corrobora as ideias iniciais de Edwards (1925) e Väisänen (1986) e a exclusão desse grupo dos Leiinae é um dos principais resultados desta análise. A principal característica do clado (figura 328A) é a presença de uma saliência anterior no clípeo (caráter 33:1). Características de tórax e venação alar suportam o clado (Novakia (Ectrepesthoneura+Tetragoneura)), que possui índice de Bremer 6 (figura 329). De fato, as asas desses gêneros são muito semelhantes (figuras 200-202). As características que suportam (Ectrepesthoneura+Tetragoneura) são (figura 328A): ausência de densas cerdas na superfície anterior do escapo e pedicelo (caráter 17:0); margens do clípeo anguladas (31:1); clípeo retangular (32:1); apenas um par de cerdas escutelares (44:1); e presença de $\mathrm{R}_{4}(97: 1)$.

\section{Sticholeia como membro de Allactoneurinae}

Søli (1996) descreveu o gênero Sticholeia, posicionando-o em Leiinae devido à presença de uma subcostal longa, fortes cerdas tibiais e ausência de ocelo mediano. Ressaltou também que Sticholeia, devido à combinação de fortes e recurvadas cerdas atrás dos olhos e arranjo regular das cerdas tibiais, estaria agrupada juntamente com Manotinae em muitas chaves de identificação.

No estudo de Tozoni (1998), Sticholeia é um membro de Leiinae próximo a Leia, Paradoxa, Leiella, Ateleia, Acrodicrania, Rondaniella, entre outros leiines típicos. Jaschhof \& Kallweit (2009) também mantiveram o gênero em Leiinae. Segundo Tozoni (1998), as diferenças no mediotergito de Sticholeia, também vistas em outros leiines, e Allactoneura, são utilizadas para a manutenção do grupo em Leiinae.

No estudo filogenético realizado no presente trabalho, Sticholeia é irmão de Allactoneura (figuras 326 e 328C), sendo sinapomorfia desse clado a face retangular larga (caráter 26:4). Apesar da diferença morfológica no mediotergito de ambos os grupos, há outras características de tórax, cabeça, asa e pernas suficientes para defender o posicionamento de Sticholeia como grupo irmão de Allactoneura. Além disso, a relação (Sticholeia+Allactoneura) foi também obtida por Hippa et al. (2004) em um estudo filogenético de Manotinae (figura 5). Diante do cladograma obtido (figuras 326 e 328C) e das diferenças morfológicas entre Sticholeia e Allactoneura, optou-se por incluir Sticholeia em Allactoneurinae. Ainda que fosse possível, por conta das diferenças morfológicas entre os dois gêneros, criar uma subfamília separada, isso resultaria em mais um táxon ao nível de subfamília contendo apenas um gênero, irmão de outra subfamília pequena. 
Os caracteres diagnósticos de Sticholeia são (figura 328C): último palpômero menor que o penúltimo (caráter 39:4); pronoto predominantemente com cerdas de igual tamanho, mas com algumas mais longas na margem ventral (48:2); cercos extremamente alongados, tão longos quantos as projeções apico-laterais dos gonocoxitos (134:1).

Os caracteres diagnósticos de Allactoneura são (figura 328C): com apenas uma cerda lateral à margem do olho, próxima à base das antenas (24:3); asas dobradas longitudinalmente, como um leque (84:1); setor radial da asa densamente coberto por cerdas (91:1); r-m angulada $90^{\circ}$ medianamente, nua e menos esclerotizada em sua porção ventral (100:4); membrana alar com dobras entre os setores radial/medial, medial/cubital e cubital/anal (126:1).

Os gêneros Sticholeia e Allactoneura foram descritos com base em espécies da região Oriental. As três espécies de Sticholeia conhecidas são da região Oriental, da Indonésia e Papua Nova Guiné, enquanto que a espécie-tipo de Allactoneura-Allactoneura cincta de Meijere-foi descrita para a Indonésia, na região Oriental. Posteriormente, oito novas espécies foram adicionadas Allactoneura, três orientais (Indonésia), três paleárticas (Japão, Rússia e França, uma de fóssil do Oligoceno), uma australasiana (Nova Caledônia) e uma afrotropical (Madagascar).

Em Leiinae, há uma diversidade de gêneros endêmicos da região Australasiana (Austrália e Nova Zelândia), com alguns indícios de ocupação da Papua Nova Guiné (dados não publicados), mas o grupo está mais relacionado a espécies das regiões Neotropical e Afrotropical, com é o caso do clado Waipapamyia ${ }^{+}$.

\section{Sobre a classificação de Mycetophilidae}

A partir do cladograma obtido (figura 326) foram realizadas mudanças relativas à classificação de Mycetophilidae. A lista abaixo resume estas alterações. As subfamílias Sciophilinae, Gnoristinae, Mycetophilinae e Mycomyinae foram pouco amostradas. Elas estão incluídas nesta lista na mesma medida como estão definidas na literatura, ou seja, este estudo não fornece novas evidências consistentes a favor ou contra seu monofiletismo. Tetragoneura, Novakia, Docosia e Ectrepesthoneura são mantidos em Gnoristinae e Sticholeia em Allactoneurinae. Além disso, foi elaborada uma chave de identificação para Leiinae e Allactoneurinae (modificada de Vockeroth, 1981, 2009; Søli et al., 2000). 
MYCETOPHILIDAE

Sciophilinae

Gnoristinae

Mycomyiinae

Mycetophilinae

Manotinae

Manota Williston

Eumanota Tuomikoski

Promanota Tuomikoski

\section{Allactoneurinae}

Allactoneura de Meijere

Sticholeia Søli

\section{Leiinae}

Garretella Vockeroth

Paraleia Tonnoir

Thoracotropis Freeman

Gracilileia Matile

Trichoterga Tonnoir \& Edwards

Megophthalmidia Dziedzicki

Mohelia Matile

Aphrastomyia Coher \& Lane

Paracycloneura Tonnoir \& Edwards

Indoleia Edwards

Rondaniella Johannsen

Waipapamyia Jaschhof \& Kallweit

Paradoxa Marshall

Sigmoleia Tonnoir \& Edwards

Cawthronia Tonnoir \& Edwards

Cycloneura Marshall

Tonnwardsia Jaschhof \& Kallweit

Procycloneura Edwards

Leiella Enderlein

Anomalomyia Hutton

Ateleia Skuse

Acrodicrania Skuse

Caledonileia Matile

Neoclastobasis Ostroverchova

Greenomyia Brunetti

Leia Meigen

Clastobasis Skuse 


\section{Chave de indentificação para Leiinae e Allactoneurinae}

As abreviações que se seguem aos gêneros correspondem a sua distribuição geográfica, sendo: PA, região Paleártica; NE, região Neártica; OR, região Oriental; AF, região Agrotropical; NT, região Neotropical; AU, região Australiana.

1. Mesopleurotrocantin ausente (figuras 120-121); mesepímero em contato com a porção ventral do tórax, paralelo ao catepisterno (figuras 120-121) .................... Allactoneurinae / 2 - mesopleurotrocantin presente (figuras 8B, 95, 109); mesepímero em contato com o mesopleurotrocantin (figuras 8B, 95, 109) Leiinae / 3

2(1). Último palpômero menor que o penúltimo (figura 75); 2 ocelos (figura 75). Asas sem dobras membranosas nos setores radial/medial, medial/cubital e anal (figura 184); asas expandidas, membrana alar distendida (figura 40). Pronoto predominantemente com cerdas de igual tamanho, mas com algumas mais longas na margem ventral (figura 121). Cercos simples, extremamente longos (figura 234A) Sticholeia Søli (AU)

- último palpômero 1,5x o comprimento do penúltimo (p. ex. figuras 69 e 71); 3 ocelos (p. ex. figura 67). Asas com dobras membranosas nos setores radial/medial, medial/cubital e anal (figura 183); asas dobradas longitudinalmente, membrana alar dobrada como um leque (figura 39). Pronoto apenas com cerdas de igual tamanho (figura 120). Cercos bilobados, ovoides (figura 233) Allactoneura de Meijere (PA, OR, AF, AU)

3. Laterotergito nu (figuras 99-103) 4

- laterotergito pubescente (figuras 105-107, 117), geralmente cerdas longas e abundantes, mas algumas vezes curtas e em pequena quantidade, restritas à porção posterior do laterotergito 14

4(3). Peças bucas reduzidas; 2 palpômeros labiais (p. ex. figuras 76 e 78; Oliveira et al., 2012: figura 2). Escudo bilateralmente comprimido com região anterior projetada dorsalmente (figura 13) Thoracotropis Freeman (NT)

- peças bucais desenvolvidas, às vezes pequenas; 5 palpômeros labiais (incluindo o palpígero) (figuras 79-83). Escudo não comprimido bilateralmente (figuras 94-103) 5

5(4). Sc completa, alcançando C (figuras 154-155) 6 
6(5). C terminando em $\mathrm{R}_{5}$ (figura 154); $\mathrm{r}-\mathrm{m}$ mais longa que $\mathrm{R}_{1}$ (figura 154); $\mathrm{CuA}$ sem sinuosidade (figura 154) Garretella Vockeroth (NE)

- C terminando além de $\mathrm{R}_{5}$ (figuras $155-163$ ); $\mathrm{r}-\mathrm{m}$ mais curta ou pouco maior que $\mathrm{R}_{1}$ (figuras 159 e 163); CuA sinuosa (figuras 164-173)

7(6). Ocelos laterais distantes da margem dos olhos por uma distância igual ou menor que seu próprio diâmetro (p. ex. figura 67). $\mathrm{R}-\mathrm{m}$ pouco maior que $\mathrm{R}_{1}$ (figura 155 ); C terminando pouco além de $\mathrm{R}_{5}$ (figura 155); veias do setor radial da asa bem espaçadas entre si, divergentes (figura 155) Paraleia Tonnoir (NT, AU)

- ocelos laterais distantes da margem dos olhos por uma distância maior que seu próprio diâmetro (figura 73). R-m mais curta que $\mathrm{R}_{1}$ (figuras 159, 163-164); C terminando muito além de $\mathrm{R}_{5}$ (figuras 157-162); veias do setor radial da asa próximas entre si, não divergentes (figuras 163-165) 8

8(7). $\mathrm{R}_{4}$ presente (figura 165); forquilhas medial e cubital presentes, $\mathrm{M}_{2}$ e $\mathrm{M}_{4}$ obsoletas basalmente (figura 165) Waipapamyia Jaschhof \& Kallweit (AU)

- $\mathrm{R}_{4}$ ausente (figura 168); forquilhas medial e cubital presentes, mas apenas $\mathrm{M}_{4}$ obsoleta basalmente (figura 168) Cawthronia Tonnoir \& Edwards (AU)

9(5). Forquilha medial ausente (figuras 162, 169-170). 10

- forquilha medial presente (figuras 173-182) 12

10(9). $\mathrm{A}_{1}$ fundida distalmente a CuA (figura 169) Cycloneura Marshall (AU)

- A livre (172-182) .11

11(10). Forquilha cubital bifurcando além de $\mathrm{M}_{1+2}$ (figura 162)

Paracycloneura Tonnoir \& Edwards (AU)

- forquilha cubital bifurcando na base da asa, antes de $\mathrm{M}_{1+2}$ (figura 170); CuA não sinuosa (figura 170) Tonnwardsia Jaschhof \& Kallweit (AU)

12(9). $M_{1}, M_{2}$, e $M_{4}$ com ápice incompleto, não alcançando a margem da asa (figura 157); $\mathrm{A}_{1}$ livre (figura 157) Gracilileia Matile (AU) 
- $\mathrm{M}_{1}, \mathrm{M}_{2}$, e $\mathrm{M}_{4}$ com ápice completo, alcançando a margem da asa (figuras 171-173); $\mathrm{A}_{1}$ fundida distalemente a $\mathrm{CuA}$ (figuras 166 e 171).....

13(12). $\mathrm{M}_{1}$ e $\mathrm{M}_{2}$ obsoletas basalmente (figura 171). Ocelos laterais distantes das margens dos olhos por uma distância igual a seu próprio diâmetro (p. ex. figura 67)

Procycloneura Edwards (NT)

- $\mathrm{M}_{1}$ e $\mathrm{M}_{2}$ completas (figura 166). Ocelos laterais distantes das margens dos olhos por uma distância maior que 2x seu próprio diâmetro (figura 77) Paradoxa Marshall (AF, AU)

14(3). C terminando em $\mathrm{R}_{5}$ (figuras $176-182$ ) .15

- C terminando além de $\mathrm{R}_{5}$ (figuras 173-175) .19

15(14). Ocelos laterais muito próximos ou em contato com a margem dos olhos (figuras 6970); ocelo mediano extremamente reduzido (figuras 69-70). $\mathrm{M}_{1}$ obsoleta basalmente (figura 172) Leiella Enderlein (NT)

- ocelos laterais distantes da margem dos olhos (figura91); ocelo mediano menor ou pouco menor que os ocelos laterais (figura 67). $\mathrm{M}_{1}$ completa (figuras 163, 173, 175-182) .16

16(15). Região ventral da pós-gena tão larga quanto a região dorsal, de forma que a face posterior da cabeça adquira um formato retangular (figuras 33-34); uma cerda pré-ocelar em frente aos ocelos laterais (figura 73); clípeo projetado além da margem ventral da cabeça (figura 91). Fêmur III não achatado ântero-posteriormente (figuras 33-34) 17

- região ventral da pós-gena mais estreita que a região dorsal, de forma que a face posterior da cabeça adquira um formato triangular (figuras 64-65); cerda pré-ocelar ausente (figura 67); clípeo não projetado além da margem ventral da cabeça (figura 72). Fêmur III achatado ântero-posteriormente (figuras 17-18) .18

17(16). Ausência de densas cerdas na superfície anterior do escape e pedicelo (p. ex. figura 76); primeiro flagelômero antenal mais longo que os demais (p. ex. figura 14). Esporão tibial III menos longo que o primeiro tarsômero (figura 34). Sc nua (figura 178); $\mathrm{R}_{5}$ reta ou quase reta de sua origem até a margem da asa (figura 178); r-m transversal (figura 178); ápice de $\mathrm{M}_{2}$ completo, atingindo a margem da asa (figura 178)

Greenomyia Brunetti (PA, NE, OR) 
- presença de densas cerdas na superfície anterior do escape e pedicelo (p. ex. figura 28); primeiro flagelômero antenal do mesmo comprimento dos demais (figura 74). Esporão tibial III mais longo que o primeiro tarsômero (figura 33). Sc pubescente (figura 177); $\mathrm{R}_{5}$ acompanhando a curvatura da asa (figura 177); r-m curvada medianamente (figura 177); ápice de $\mathrm{M}_{2}$ incompleto, não atingindo a margem da asa (figura 177) Neoclastobasis Ostroverchova (PA)

18(16). 2 ou 3 ocelos, sendo que os laterais tocam ou quase tocam a margem dos olhos. Forquilha cubital anter do ápice da Sc (figuras 181-182); sc-r ausente (figura 181-182) Clastobasis Skuse (PA, OR, AF, AU) - 3 ocelos, sendo que os laterais não tocam a margem dos olhos. Forquilha cubital além do ápice da Sc (figuras 179-180); sc-r presente (figuras 179-180)

Leia Meigen (PA, NE. OR. AF, NT, AU)

19(14). Peças bucais reduzidas, apenas dois palpômeros labiais (figuras 76 e 78) 20

- peças bucais desenvolvidas, cinco palpômeros labiais (incluindo o palpígero) (figuras 8183)

20(19). $\mathrm{A}_{1}$ fundida distalmente a $\mathrm{CuA}$ (figura 167); $\mathrm{M}_{1+2}$ do mesmo comprimento da forquilha medial ou mais longa (figura 167); $\mathrm{M}_{1}$ e $\mathrm{M}_{2}$ divergentes (figura 167)

Sigmoleia Tonnoir \& Edwards (AU)

- $A_{1}$ livre (figura 176); $M_{1+2}$ um terço do comprimento da forquilha medial (figura 176); $M_{1}$ e $\mathrm{M}_{2}$ paralelas (figura 176) Caledonileia Matile (AU)

21(19). Peças bucais alongadas, modificadas em probóscide (figuras 64-65). Cerdas tibiais regularmente arranjadas (figuras 148 e 150) .22

- peças bucais como uma labela típica (figuras 77-83). Cerdas tibiais irregularmente arranjadas (figura 149) .24

22(21). Poucas cerdas interocelares; escapo e pedicelo arredondados e do mesmo tamanho (figura 16); ausência de uma longa cerda posterior apical no pedicelo (figura 16); clípeo ovoide. $\mathrm{R}_{1}$ mais longa que r-m (figura159) Megophthalmidia Dziedzicki (PA, NE, NT) 
- muitas ou nenhuma cerdas interocelares; escapo distintamente alongado na base e pedicelo arredondado (figuras 64-65); presença de uma longa cerda posterior apical no pedicelo (figuras 64-65); clípeo triangular. $\mathrm{R}_{1}$ tão longa quanto r-m (figuras 160-161)

23(22). Nenhuma cerda interocelar; flagelômeros antenais achatados lateralmente (figura 64). Um par de cerdas escutelares mais longas. Primeiro setor de $\mathrm{CuA}$ nu (figura 161). Coxa I aproximadamente do mesmo comprimento das coxas II e III (figura 65)

Aphrastomyia Lane \& Coher (NT)

- muitas cerdas interocelares; flagelômeros antenais cilíndricos (figura 17). Dois pares de cerdas escutelares mais longas. Primeiro setor de CuA pubescente (figura 160). Coxa I aproximadamente metade do comprimento das coxas II e III (figura 17)

Mohelia Matile (AF)

24(21). R-m mais curta que $\mathrm{R}_{1}$ (figuras $158,163-164$ )

- r-m mais longa que $\mathrm{R}_{1}$ (figuras 173-175)

25(21). Cabeça encaixada sob a margem do escudo (figura 15); cabeça arredondada; escapo e pedicelo arredondados e do mesmo tamanho; fronte nua. Tórax não deprimido dorsoventralmente (figuras 15 e 95); escudo projetado anteriormente (figuras 15 e 95); escudo com apenas cerdas acrosticais, intra-alares, supra-alares e dorso-centrais (figura 95); um par de cerdas escutelares; laterotergito vertical em relação ao eixo dorso-ventral do tórax (figura 95). Sc livre e nua (figura 158) Trichoterga Tonnoir \& Edwards (AU) - cabeça em frente ao escudo (figuras 20-21); cabeça ovoide; escapo distintamente alongado na base, pedicelo arredondado; fronte completamente pubescente. Tórax moderadamente deprimido dorso-ventralmente (figuras 106-107); escudo não projetado anteriormente (figuras 106-107); escudo somente com cerdas de igual tamanho, com exceção de umas poucas marginais (figuras 20-21); dois pares de cerdas escutelares; laterotergito inclinado/diagonal em relação ao eixo dorso-ventral do tórax (figuras 106-107). Sc terminando em C e pubescente (figuras 163-164) 26

26(25). 2 ocelos; muitas cerdas interocelares; ausência da sutura frontal entre ocelo mediano e a base das antenas (figura 84); presença de densas cerdas na superfície anterior do escapo e pedicelo; face nua. Pronoto retangular estreito (figura 106). $\mathrm{R}_{1}$ alcançando $\mathrm{C}$ no terço apical 
da asa (figura 163); $\mathrm{R}_{1}$ e $\mathrm{r}-\mathrm{m}$ oblíquas/quase horizontais (figura 163); $\mathrm{M}_{1}$ completa (figura 163) Indoleia Edwards (OR, AU)

- 3 ocelos; poucas cerdas interocelares; presença da sutura frontal entre ocelo mediano e a base das antenas; ausência de densas cerdas na superfície anterior do escapo e pedicelo; face pubescente. Pronoto ovoide (figura 107). $\mathrm{R}_{1}$ alcançando $\mathrm{C}$ no terço medial da asa (figura 164); $\mathrm{R}_{1}$ e r-m transversais (figura 164); $\mathrm{M}_{1}$ obsoleta basalmente (figura 164)

Rondaniella Johannsen (PA, OR)

27(24). Cabeça ovoide; ocelos laterais distantes da margem dos olhos por uma distância maior que seu próprio diâmetro. Anepisterno menor que o catepisterno (figura 111); catepisterno retangular (figura 111). $\mathrm{M}_{1}$ obsoleta basalmente (figura 174); ápice de $\mathrm{M}_{2}$ incompleto, não atingindo a margem da asa (figura 174) Ateleia Skuse (AU) - cabeça arredondada; ocelos laterais distantes da margem dos olhos por uma distância menor que seu próprio diâmetro. Anepisterno aproximadamente do mesmo tamanho do catepisterno (figuras 110 e 112); catepisterno quadrado (figuras 110 e 112). $\mathrm{M}_{1}$ completa (figuras 173 e 175); ápice de $\mathrm{M}_{2}$ completo, atingindo a margem da asa (figuras 173 e 175) ...

28(27). Sc-r presente (figura 175); $M_{1}$ e $M_{2}$ divergentes (figura 175); $M_{4}$ obsoleta basalmente (figura 175) Acrodicrania Skuse (OR, AF, AU)

- sc-r ausente (figura 173); $\mathrm{M}_{1}$ e $\mathrm{M}_{2}$ paralelas (figura 173); $\mathrm{M}_{4}$ completa (figura 173) 
O estudo filogenético realizado indica que é possível atribuir a Leiinae um agrupamento monofilético relativamente amplo, caracterizado pela presença do mesopleurotrocantin e do mesepímero sem contato com a região ventral do tórax, terminando no mesopleurotrocantin. As características erigidas por Edwards (1925) não são suficientes para a delimitação do grupo e também estão presentes em membros das outras subfamílias de Mycetophilidae.

Os gêneros Docosia, Novakia, Ectrepesthoneura e Tetragoneura não fazem parte de Leiinae e são alocados provisoriamente em Gnoristinae. Sticholeia também não pertence à Leiinae, sendo grupo-irmão de Allactoneura e, portanto, transferido para Allactoneurinae. A subfamília Allactoneurinae é irmã de Manotinae e ambas relacionadas à Mycetophilinae.

Portanto, Leiinae passa a compreender 27 gêneros viventes. Há três clados maiores dentro de Leiinae, Megophthalmidia ${ }^{+}$, Waipapamyia $^{+}$e Anomalomyia*. Não há caracteres morfológicos que diferenciam Leia de Clastobasis de forma que a separação entre os dois é artificial e uma amostragem mais ampla ao nível de espécie é necessária para inferências mais definitivas. A questão sobre a posição de alguns gêneros, como Thoracothropis, Garretella, Paracycloneura e Caledonileia ainda merece estudos mais detalhados.

A análise realizada com fósseis não foi informativa filogeneticamente. 


\section{REFERÊNCIAS BIBLIOGRÁFICAS}

Amorim, D.S. 1993. A phylogenetic analysis of the basal groups of Bibionomorpha, with a critical examination of the wing vein homology. Revista Brasileira de Biologia, 52(3), 379-399.

Amorim, D.S. 1997. Elementos Básicos de Sistemática Filogenética. Holos Editora, Ribeirão Preto. 276 pp.

Amorim, D.S. 2002. Fundamentos de Sistemática Filogenética. Holos, Editora. Ribeirão Preto. 153 pp.

Amorim, D.S. \& Oliveira, S.S. 2008. Eleven new species of the genus Cluzobra Edwards (Diptera, Mycetophilidae, Sciophilinae) from the Atlantic Forest of Brazil. Zootaxa, $1920,1-28$.

Amorim, D.S., Oliveira, S.S. \& Balbi, M.I.P.A. 2008a. Azana atlantica, n.sp., with reduced mouthparts and two ocelli: first record of Azana for the Neotropical region (Diptera: Mycetophilidae: Sciophilinae). Zootaxa, 1789, 57-65.

Amorim, D.S., Oliveira, S.S. \& Balbi, M.I.P.A. 2008b. First Neotropical species of genus Azana (Diptera: Mycetophilidae: Sciophilinae). Zootaxa, 1937, 67-68.

Amorim, D.S. \& Rindal, E. 2007. A phylogenetic study of the Mycetophiliformia, with creation of the subfamilies Heterotrichinae, Ohakuneinae, and Chiletrichinae for the Rangomaramidae (Diptera, Bibionomorpha). Zootaxa, 1535, 1-92.

Amorim, D.S. \& Silva, V.C. 2002. How far advanced was Diptera evolution in Pangaea? Annales de la Societé Entomologique de France, 38, 177-200.

Baxter, J.E. \& Poinar, G.O. 1994. A new genus and new species of fungus gnats (Diptera: Mycetophilidae) from Dominican amber. Annales de la Société entomologique de France, 30, 93-102.

Bechev, D.N. 2000. World distribution of the genera of fungus gnats (Diptera: Sciaroidea, excluding Sciaridae). Studia dipterologica, 7, 543-552.

Bechev, D.N. \& Pavlova, A.S. 2012. Greenomyia tomovi sp. n. from Bulgaria (Diptera: Mycetophilidae: Leiinae) and a Key to the Palaearctic Species of the Genus. Acta Zoologica Bulgarica, 64(2), 109-111.

Blagoderov, V.A. 1998a. Fungus gnats of the tribes Gnoristini and Leiini (Diptera, Mycetophilidae) from the Early Cretaceous of Transbaikalia. Paleontological Journal, 32(1), 54-59. 
Blagoderov, V.A. 1998b. Fungus gnats (Diptera, Mycetophilidae) from the Lower Cretaceous of Mongolia. Paleontological Jounal, 32(6), 598-604.

Blagoderov, V.A. 2000. New fungus gnats (Diptera: Mycetophilidae) from the Cretaceous and Paleogene of Asia. Paleontological Journal, 34, S355-S359.

Blagoderov, V. \& Grimaldi, D. 2004. Fossil Sciaroidea (Diptera) in Cretaceous ambers, exclusive of Cecidomyiidae, Sciaridae, and Keroplatidae. American Museum Novitates, 3433, 1-76.

Borkent, C.J. \& Wheeler, T.A. No prelo. Phylogeny of the tribe Sciophilini (Diptera: Mycetophilidae: Sciophilinae). Systematic Entomology.

Bremer, K. 1988. The limits of amino acid sequence data in angiosperm phylogenetic reconstruction. Evolution, 42, 795-803.

Bremer, K. 1994. Branch support and tree stability. Cladistics, 10, 295-304.

Brown, B.V. 2005. Malaise Trap Catches and the Crisis in Neotropical Dipterology. American Entomologist, 51(3), 180-183.

Bugledich, E.M.A. 1999. Diptera: Nematocera. In: Wells, A. \& Houston, W.W.K (eds.) Zoological Catalogue of Australia. Vol. 30.1. Melbourne: CSIRO Publishing, Australia xiii 627 pp.

Chandler, P.J. 1980. The European and eastern Nearctic fungus-gnats in the genus Ectrepesthoneura (Mycetophilidae). Systematic Entomology, 5, 27-41.

Chandler, P.J. 1994. The fungus gnats of Israel (Diptera: Sciaroidea, excluding Sciaridae). Israel Journal of Entomology, 28, 1-100.

Chandler, P.J. 2001. Fungus Gnats (Diptera: Sciaroidea) new to Britain. British Journal of Entomology and Natural History, 13, 215-243.

Chandler, P.J. 2004. Fauna Europaea: Mycetophilidae. Fauna Europaea version 1.2. http://www.faunaeur.org Acessado em 29 de abril de 2009.

Chandler, P.J. 2009. The fungus gnats (Diptera: Bolitophilidae, Keroplatidae, Mycetophilidae) of Sardinia, with description of six new species. Zootaxa, 2318, $450-506$.

Chandler, P.J., Bechev, D.N., \& Caspers, N. 2005. The Fungus Gnats (Diptera: Bolitophilidae, Diadocidiidae, Ditomyiidae, Keroplatidae and Mycetophilidae) of Greece, its islands and Cyprus. Studia dipterologica, 12(2), 255-314.

Chandler, P.J. \& Blasco-Zumeta, J. 2001. The fungus gnats (Diptera: Bolitophilidae, Diadocidiidae and Mycetophilidae) of the Monegros region (Zaragoza, Spain) and 
five other new European species of Pyratula Edwards and Sciophila Meigen. Zapateri Revista aragonesa de entomologia, 9, 1-24.

Coher, E.I. 1950. Neotropical Mycomya I (Diptera: Mycetophilidae). Revista de Entomologia, 21, 561-580.

Coher, E.I. 1952. Neotropical Mycomyia II (Diptera: Mycetophilidae). Dusenia, 3, 215-224.

Coots, C., Lambdin, P., Grant, J. \& Rhea, R. 2012. Diversity, Vertical Stratification and CoOccurrence Patterns of the Mycetophilid Community among Eastern Hemlock, Tsuga Canadensis (L.) Carrière, in the Southern Appalachians. Forests, 3, 986-996.

Edwards, F.W. 1925. British fungus-gnats (Diptera, Mycetophilidae). With a revised generic classification of the family. Transactions of the Royal Entomological Society of London, 1924, 505-670.

Edwards, F.W. 1933a. Diptera Nematocera from Mount Kinabalu. Journal of the Federated Malay States Museums, 17, 223-296.

Edwards, F.W. 1933b. New neotropical Mycetophilidae (II). Revista de Entomologia, 3(3), $303-322$.

Evenhuis, N.L. 1994. Catalogue of the fossil flies of the world (Insecta: Diptera). Backhuys, Leiden.

Fitch, W.N. 1971. Toward defining the course of evolution: minimum change for a specified tree topology. Systematic Zoology, 20, 406-416.

Freeman, P. 1951. Diptera of Patagonia and South Chile based mainly on material in the British Museum (Natural History). Part III-Mycetophilidae. London, Br. Mus. (Nat. Hist.). vii \& 138 pp.

Garrett, C.B.D. 1925. Seventy new Diptera - key to the Pseudoleria, Helomyzidae, Tipulidae, Chiromidae, Dixinae, Orphnephilidae, Mycetophilidae. Privately published, Cranbrook. 16 pp.

Goloboff, P.A. 1993. Estimating character weights during tree search. Cladistics, 9, 83-91.

Goloboff, P.A. 1999. Analyzing large data sets in reasonable times: solutions for composite optima. Cladistics, 15, 415-428.

Goloboff, P.A., Farris, J.S. \& Nixon, K.C. 2008. TNT, a free program for phylogenetic analysis. Cladistics, 24, 774-786.

Hackman,W., Lastovka, P., Matile, L. \& Väisanen, R. 1988. Mycetophilidae. 220-328. In:

A. Soós \& L. Papp (eds.). Catalogue of Palaearctic Diptera. Vol. 3. Ceratopogonidae - Mycetophilidae. Elsevier Science Publishers, Amsterdam. The Netherlands and Akadémia Kiadó, Budapest, Hungary. 450 pp. 
Hendel, F. 1936. 26. Ordnung der Pterygogenea (Dreißigste Ordnung der Insecta). Diptera oder Fliegen. In: Kükenthal, W. \& Krumbach, T. (ed.) Handbuch der Zoologie, 4(2), 1729-1998.

Hennig, W. 1955. Das Flügelgeäder der Gattung Allactoneura. Eine Berichtigung (Diptera: Fungivoroidea). Beiträge zur Entomologie, 5(1/2), 127-128.

Hennig, W. 1973. Diptera (Zweiflügler). Handbuch der Zoologie, 4(2) 2/31, 1-337. Walter de Gruyter, Berlin-New York.

Hippa, H., Jaschhof, M. \& Vilkamaa, P. 2004. Phylogeny of the Manotinae, with a review of Eumanota Edwards, Paramanota Tuomikoski and Promanota Tuomikoski (Diptera, Mycetophilidae). Studia dipterologica, 11(2), 405-428.

Huber, F. \& Reis, F.H. 2011. Técnica alternativa para montagem de insetos em lâminas permanentes para visualização em microscopia óptica. EntomoBrasilis, 4(1), 13-19.

Hutson, A.M.; Ackland, D.M. \& Kidd, L.N. 1980. Mycetophilidae (Bolitophilinae, Ditomyiinae, Diadocidiinae, Keroplatinae, Sciophilinae and Manotinae), Diptera, Nematocera. Handbooks for the identifications of British Insects. Vol. IX, Part 3. Royal Entomological Society of London.

Jaschhof, M. \& Kallweit, U. 2004. The genus Aphrastomyia Coher \& Lane, 1949 in Costa Rica (Insecta: Diptera: Mycetophilidae). Faunistische Abhandlungen, 25, 107-123.

Jaschhof, M. \& Kallweit, U. 2009. The Cycloneura Marshall group of genera in New Zealand (Diptera: Mycetophilidae: Leiini). Zootaxa, 2090, 1-39.

Kallweit, U. 1998. Notes on the genus Metanepsia Edwards and its relatives from East Asia (Insecta: Diptera: Mycetophilidae). Reichenbachia, 32, 341-353.

Kerr, P.H. 2007. Revision of the Holarctic genus Novakia Strobl (Diptera: Mycetophilidae). Zootaxa, 1554, 27-40.

Kitching, I.J., Forey, P.L., Humphries, C.J., \& Williams, D.M. 1998. Cladistics: the theory and practice of parcimony analysis. 2nd ed. Systematic association publications 11 .

Kurina, O. 2004. Notes on fungus gnats from the East Mediterranean with description of two new species (Diptera: Sciaroidea excl. Sciaridae). Beiträge zur Entomologie, 54(2), $343-355$.

Kurina, O. 2006. Three new species of Docosia Winnertz (Diptera: Mycetophilidae) from Kazakhstan. Entomologica Fennica, 17, 110-117.

Kurina, O., Hedmark, K., Karström, M. \& Kjaerandsen, J. 2011. Review of the European Greenomyia Brunetti (Diptera, Mycetophilidae) with new descriptions of females. ZooKeys, 77, 31-50. 
Kurina, O. \& Ševčík, J. 2011. Three new species of Docosia Winnertz from central and southern Europe (Diptera: Mycetophilidae). Zootaxa, 2810, 26-36.

Kurina, O. \& Ševčík, J. 2012. Notes on Docosia Winnertz (Diptera: Mycetophilidae), with description of six new species from Central Asia and the first generic record from the Afrotropical region. Zootaxa, 3570, 25-40.

Lane, J. 1959. Insecta Amapaensia - Diptera; Mycetophilidae. Studia Entomologica, 2, 1-4.

Laštovka, P. \& Ševčík, J. A review of the Czech and Slovak species of Docosia Winnertz (Diptera: Mycetophilidae), with atlas of the male and female terminalia. Čas. Slezské muzeum Opava (A), 55, 1-37.

Lee, D.C. \& Bryant, H.N. 1999. A reconsideration of the coding of inapplicable characters: assumptions and problems. Cladistics, 15, 373-378.

Maddison, W.P. 1993. Missing data versus missing characters in phylogenetic analysis. Systematic Biology, 42(4), 576-581.

Marshall, P. 1896. New Zealand Diptera: No. 2.-Mycetophilidae. Transactions of the New Zealand Institute, 28, 250-309.

Matile, L. 1978. Diptères Mycetophilidae de 1'Archipel des Comores. Mémoires du Muséum National d'Histoire Naturelle Paris (Serie A, Zoologie), 109, 247-306.

Matile, L. 1980. Mycetophilidae. Pp. 216-230 In: Crosskey (Ed.): Catalogue of the Diptera of the Afrotropical Region. London.

Matile, L. 1989. Superfamily Sciaroidea. In Catalog of the Diptera of the Australasian and Oceanic Regions. Edited by Evenhuis, N.L. Bishop Museum Press and E. J. Brill. pp. $123-145$.

Matile, L. 1990. Recherches sur la systématique et l'évolution des Keroplatidae (Diptera, Mycetophiloidea). Mémoires du Muséum National d'Histoire Naturelle, 148, 1-682.

Matile, L. 1993. Dipteres Mycetophiloidea de Nouvelle-Caledonie. 5. Mycetophilidae Leiinae et Manotinae. In: L. Matile, J. Najt \& S. Tillier (eds.), Zoologia Neocaledonica, Volume 3. Memoires du Museum National d'Histoire Naturelle, 157, $165-210$.

Nixon, K.C. 1999. The parsimony ratchet, a new method for rapid parsimony analysis. Cladistics, 15, 407-414.

Nixon, K.C. 1999-2004. Winclada (BETA) ver. Asado 1.89. Publicado pelo autor, Ithaca, NY.

Nixon, C.K. \& Carpenter, J.M. 1993. On outgroups. Cladistics, 9, 413-426. 
Økland, B. 1994. Mycetophilidae (Diptera), an insect group vulnerable to forestry practices? A comparison of clearcut, managed and semi-natural spruce forests in southern Norway. Biodiversity and Conservation, 3, 68-85.

Økland, B. 1996. Unlogged forests: important sites for preserving the diversity of mycetophilids (Diptera: Sciaroidea). Biological Conservation, 76, 297-310.

Økland, B., Gotmark, F., Norden, B., Franc, N., Kurina, O. \& Polevoi, A. 2005. Regional diversity of mycetophilids (Diptera: Sciaroidea) in Scandinavian oak-dominated forests. Biological Conservation, 121, 9-20.

Oliveira, S.S. 2009. Dziedzickia Johannsen e Schnusea Edwards (Diptera, Mycetophilidae): diversidade das espécies neotropicais e análise filogenética. Ribeirão Preto, 2009. v + 145p: 47 il.

Oliveira, S.S. 2012. Mycetophilidae (Diptera: Bibionomorpha) type specimens in the Iziko South African Museum, Cape Town. African Entomology, 20(2), 386-389.

Oliveira, S.S. \& Amorim, D.S. Em preparação. Catalogue of the Neotropical Mycetophilidae (Diptera, Bibionomorpha).

Oliveira, S.S. \& Amorim, D.S. 2010a. The genus Phthinia Winnertz (Diptera, Mycetophilidae) in the Neotropical region, with the first records from Brazil. Zootaxa, 2350, 22-34.

Oliveira, S.S. \& Amorim, D.S. 2010b. Four new species of Paratrizygia Tonnoir from the Brazilian Atlantic Forest (Diptera, Mycetophilidae, Sciophilinae). Zootaxa, 2629, 294.

Oliveira, S.S. \& Amorim, D.S. 2010c. Three replacement names for species of the subfamily Leiinae (Diptera, Mycetophilidae). Revista Brasileira de Entomologia, 54(2), 335336.

Oliveira, S.S. \& Amorim, D.S. 2011. Docosia adusta sp. n. (Diptera, Mycetophilidae) from the Colombian Andes: a Holarctic element in northwestern South America. Canadian Entomologist, 143, 688-696.

Oliveira, S.S. \& Amorim, D.S. 2012a. Six new species of Paraleia Tonnoir (Diptera, Mycetophilidae): amphinotic elements at the northern range of the Andes. Zootaxa, $3186,1-24$.

Oliveira, S.S. \& Amorim, D.S. 2012b. Two New Species of Stenophragma Skuse from Western Australia (Diptera, Mycetophilidae, Sciophilinae). Records of the Australian Museum, 64(2), 149-158. 
Oliveira, S.S., Amorim, D.S. \& Blagoderov, V. 2012. Redescription of the enigmatic Thoracotropis cypriformis Freeman (Diptera, Mycetophilidae). Revista Brasileira de Entomologia, 56(4), 458-462.

Oliveira, S.S. \& Muller, B. 2012. The types of Lygistorrhinidae and Mycetophilidae (Diptera: Bibionomorpha) in the KwaZulu-Natal Museum, Pietermaritzburg, South Africa. African Invertebrates, 53(2), 703-714.

Ostroverchova, G.P. 1970. New data on the fauna of fungus-gnats (Diptera, Mycetophilidae) from Siberia. Entomol. Obozr. 49: 452-458. [In Russian] Translation, Entomological Review, 49, 271-274.

Papavero, N. 1978. Mycetophilidae. In: Papavero, N. (ed.), A Catalogue of the Diptera of the Americas South of the United States. Museu de Zoologia, Secretaria da Agricultura do Estado de São Paulo. 78pp.

Pape, T., Blagoderov, V. \& Mostovski, M.B. 2011. Order Diptera Linnaeus, 1758. In: Z.-Q. Zhang, ed. Animal biodiversity: An outline of higher-level classification and survey of taxonomic richness. Zootaxa, 3148, 222-229.

Platnick, N.I., Griswold, C.E. \& Coddington, J.A. 1991. On missing entries in cladistic analysis. Cladistics, 7, 337-343.

Polevoi, A. \& Jakovlev, J. 2011. A review of the European species of the genus Tetragoneura Winnertz (Diptera: Mycetophilidae). Zootaxa, 3062, 1-12.

Rindal, E. \& Søli, G.E.E. 2006. Phylogeny of the subfamily Mycetophilinae (Diptera: Mycetophilidae). Zootaxa, 1302, 43-59.

Rindal, E., Søli, G.E. \& Bachmann, L. 2009a. Molecular phylogeny of the fungus gnat family Mycetophilidae (Diptera, Mycetophiliformia). Systematic Entomology, 34, $524-532$.

Rindal, E., Søli, G.E. \& Bachmann, L. 2009b. On the systematics of the fungus gnat subfamily Mycetophilinae (Diptera): a combined morphological and molecular approach. Journal of Zoological Systematics and Evolutionary Research, 47(3), 227233.

Rindal, E., Søli, G.E.E., Kjærandsen, J. \& Bachmann, L. 2007. Molecular phylogeny of the fungus gnat tribe Exechiini (Mycetophilidae, Diptera). Zoologica Scripta, 36(4), $327-335$.

Santos, C.M.D. \& Falaschi, R.L. 2007. Missing data in phylogenetic analysis: comments on support measures. Darwiniana, 45(Supplement), 25-26. 
Sasakawa, M. \& Tamu, N. 1961. Japanese Fungivoridae (Diptera). III. New or little-known fungus gnats from the Tsushima Islands. The scientific report of Kyoto Prefectural University Human Environment and Agriculture, 13, 68-69.

Sereno, P.C. 2007. Logical basis for morphological characters in phylogenetics. Cladistics, $23,1-23$.

Ševčík, J. 2010. Docosia heikkii sp. nov., the first Oriental record of Docosia (Diptera: Mycetophilidae). Oriental Insects, 44, 91-94.

Ševčík, J. \& Hippa, H. 2010. New species of Chalastonepsia and Pectinepsia gen. nov. (Diptera: Mycetophilidae) from the Oriental and Australasian Regions. Acta Entomologica Musei Nationalis Pragae, 50(2), 595-608.

Ševčík, J. \& Laštovka, P. 2008. Two new European species of Docosia (Diptera: Mycetophilidae). Biologia, 63, 117-119.

Shaw, F.R. \& Shaw, M.M. 1951. Relationship of certain genera of fungus gnats of the family Mycetophilidae. Smithsonian Miscellaneous Collections, 11(3), 1-23.

Siddall, M.E. 2002. Measures of support. In: de Salle, R., Giribet, G. \& Wheeler, W. (eds.), Techinques in Molecular Systematics and Evolution. Birkhäuser Verlag, Switzerland, pp. 81-101.

Søli, G.E.E. 1996. Sticholeia-a new genus of Leiini, with comments on the systematic position of Allactoneura de Meijere (Diptera: Mycetophilidae). Entomologica Scandinavia, 27, 1-10.

Søli, G.E.E. 1997a. The adult morphology of Mycetophilidae (s. str.), with a tentative phylogeny of the family (Diptera, Sciaroidea). Entomologica Scandinavica Supplement, 50, 5-55.

Søli, G.E.E. 1997b. Afrotropical species of Sciophila Meigen (Diptera, Mycetophilidae). Journal of African Zoology, 111, 149-190.

Søli, G.E.E. 2002. New species of Eumanota Edwards, 1933 (Diptera: Mycetophilidae). Annales de la Société entomologique de France, 38(1-2), 45-53.

Søli, G.E.E., Vockeroth, J.R. \& Matile, L. 2000. Families of Sciaroidea. In: L. Papp \& B. Darvas (eds.), Contributions to a Manual of Palaeartic Diptera Appendix (pp. 4992). Science Herald, Budapest.

Strong, E.E. \& Lipscomb, D. 1999. Character coding and inapplicable data. Cladistics, 15, 363-371.

Taber, S.W. 2011. A new species of Docosia Winnertz fungus gnat (Diptera: Mycetophilidae). Southwestern Entomologist, 36(4), 451-462. 
Taber, S.W. 2012. A new Nearctic species of Docosia Winnertz fungus gnat (Diptera: Mycetophilidae), notes on Docosia walpurga Taber and Docosia dichroa Loew, and the identification of females of all three species. Southwestern Entomologist, 37(3), 379-390.

Tonnoir, A.L. 1929. Australian Mycetophilidae. Synopsis of the genera. Proceedings of the Linnean Society of New South Wales, 54, 584-614.

Tonnoir, A.L. \& Edwards, F.W. 1927. New Zealand fungus gnats (Diptera, Mycetophilidae). Transactions of the New Zealand Institute, 57, 747-878.

Tozoni, S.H.S. 1998. Sistemática filogenética dos Mycetophilidae (Diptera: Bibionomorpha). Tese de Doutoramento, Universidade Federal do Paraná, Curitiba. $124 \mathrm{pp}$.

Tuomikoski, R. 1966. Generic taxonomy of the Exechiini (Dipt., Mycetophillidae). Annales Entomologici Fennici, 32, 159-194.

Väisänen, R. 1984. A monograph of the genus Mycomyia Rondani in the Holarctic region (Diptera, Mycetophilidae). Acta Zoologica Fennica, 177, 1-346.

Väisänen, R. 1986. The delimitation of the Gnoristinae: criteria for the classification of recent European genera (Diptera, Mycetophilidae). Annales Zoologici Fennici, 23, 197-206.

Vockeroth, J.R. 1980. New genera and species of Mycetophilidae (Diptera) from the Holarctic region, with notes on other species. Canadian Entomologist, 112, 529-544.

Vockeroth, J.R. 1981. Mycetophilidae. Pp. 223-255. In: McAlpine, J. F.; Peterson, B. V.; Shewell, G. E.; Teskey, H. J.; Vockeroth, J. R. \& Wood, D. M. (eds.), Manual of Nearctic Diptera. Vol. 1. Research Branch Agriculture Canada. Monograph 27. Ottawa, Ontario.

Vockeroth, J.R. 2009. Mycetophilidae. Pp. 267-278. In: B.V. Brown, A. Borkent, J.M. Cumming, D.M. Wood, N.E. Woodley \& M.A. Zumbado (eds.), Manual of Central America Diptera. Vol. 1. National Research Council of Canada, Ottawa. 714 pp.

Walker, F. 1848. List of the specimens of dipterous insects in the collection of the British Museum. Part 1. The Trustees, British Museum (Natural History), London. 1-229.

Walker, A.K. \& Crosby, T.K. 1988. The preparation and curation of insects. New Revised edition. Science Information Publishing Centre, DSIR, information series 163, Wellington, New Zealand. 92 pp.

Wood, D.M. \& Borkent, A. 1989. Phylogeny and classification of the Nematocera. pp. 1333-1370. In: McAlpine, J.F., Peterson, B.V., Shewell, G.E., Teskey, H.J., 
Vockeroth, J.R. \& Wood, D.M. (eds.), Manual of Nearctic Diptera, Vol. 3. Research Branch Agriculture Canada. Monograph 27. Ottawa, Ontario.

Xu, H., Wu, H. \& Yu, X.X. 2003. New Chinese record of the genus Docosia with a description of a new species (Diptera, Mycetophilidae). Acta Zootaxonomica Sinica, $28,343-348$.

Zaitzev, A.I. 1981. Composition and systematic position of the genus Allactoneura de Meijere (Diptera, Mycetophilidae). Entomologicheskoye Obozreniye, 60, 901-913.

Zaitzev, A.I. 1990. On the preimaginal stages of Manota unifurcata Lundst. and the systematical position of the subfamily Manotinae. Biologicheskii Nauki, 1990, 63-71. [in Russian].

Zandler, R.H. 2003. Glycerin Jelly as a Substitute for Hoyer's Solution Mountant. Res Botanica, Missouri Botanical Garden. April, 30. Acessado em janeiro de 2008. http://www.mobot.org/plantscience/ResBot/Meth/GlycerinJelly.htm 
Tabela 2. Matriz de caracteres para as análises realizadas com grupos viventes e fósseis. Estados não observados e dados não aplicáveis codificados como “?” e "-", respectivamente.

Tasmanina_gracilis Neoallocotocera_fusca Docosia fuscipes

Docosia sciarina Docosia dichroa Docosia-sp. Docosia_adusta Docosia pammela Novakia miloi

Ectrepesthoneura colyeri Ectrepesthoneura hirta Ectrepesthoneura_pubescens Ectrepesthoneura_bicolor Ectrespesthoneura laffooni Tetragoneura sylvatica Tetragoneura nitida Tetragoneura minima Tetragoneura_borgmeieri Tetragoneura nocticolor Tetragoneura guajaensis Palaeodocosia vittata Boletina obscura Dziedzickia_medea Schnusea caíabii Austrosynapha_hirta Synapha_sp. Mycomya_sp. Neoempheria_sp. Exechiopsis sp. Rymosia_sp. Mycetophila sp. Epicypta_sp.

Manota palpalis Promanota malaisei Eumanota sp.

Allactoneura cincta

Allactoneura arguentosquamosa Allactoneura_papuensis $\begin{array}{llllllll}1 & 1111111112 & 2222222223 & 3333333334 & 4444444445 & 5555555556 & 6666666667\end{array}$ \begin{tabular}{llllllll}
1234567890 & 1234567890 & 1234567890 & 1234567890 & 1234567890 & 1234567890 & 1234567890 \\
\hline
\end{tabular}

$0000000000 \quad 00000000-0 \quad 2000061020 \quad 0000000110 \quad 0202010001 \quad 1000001000 \quad 0000010010$ $0000000000 \quad 00001000-0 \quad 0001011020 \quad 0000000000 \quad 0202010001 \quad 1000001000 \quad 0010310010$ $0000000001 \quad 1101000100 \quad 2001011000 \quad 0010000101 \quad 0102010001 \quad 1000010000 \quad 0000000200$ $0000000001 \quad 1101100100 \quad 2001011000 \quad 0010000101 \quad 0102010001 \quad 1000011000 \quad 0000000200$ $0000000001 \quad 1101001100 \quad 2002011000 \quad 0010000121 \quad 0102010001-1000010000000000200$ 000000000111010 $0000000001 \quad 11010010-0 \quad 2002011000 \quad 0010000101 \quad 0102010001 \quad 1000010000 \quad 0000000200$ $0000000001 \quad 11011010-0 \quad 2002011000 \quad 0010000101 \quad 0102010001 \quad 1000011000 \quad 0000000200$ $0000000001 \quad 11011010-0 \quad 0001011000 \quad 0010000121 \quad 0102010001 \quad 1000011000 \quad 0000000200$

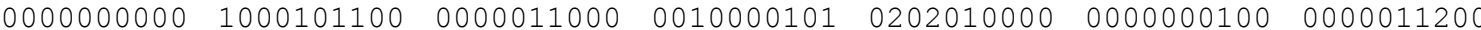
$0000000000 \quad 1000000100 \quad 0000011000 \quad 1110000101 \quad 0201$ $00000000001000000100 \quad 0000011000111000010102010$ $0000000000 \quad 1000000100 \quad 0000011000 \quad 1110000101 \quad 0201000000 \quad 0000000100 \quad 0000011200$ $0000000000 \quad 1000000100 \quad 0000011000 \quad 1110000101 \quad 0201000000 \quad 0000000100 \quad 0000011200$ $0000000000 \quad 1000100100 \quad 0000011000 \quad 1110000101 \quad 0201000000 \quad 0000000100 \quad 0000011200$ $0000000000 \quad 1000000100 \quad 2000011000 \quad 1110000101 \quad 0201000000 \quad 0000000100 \quad 0000011200$ $00000000001000100100 \quad 0000011000 \quad 1110000101 \quad 0201010000 \quad 0000000100 \quad 0000011200$ $0000000001000100100 \quad 0000011000111000010102010100000000000100 \quad 0000011200$ $0000000000 \quad 1000100100 \quad 0000011000 \quad 1110000101 \quad 0201010000 \quad 0000000100 \quad 0000011200$ $0000000000 \quad 1000000100 \quad 0000011000 \quad 1110000101 \quad 0201010000 \quad 0000000100 \quad 0000011200$ $0000000000 \quad 1000000110 \quad 0001011000 \quad 1110000101 \quad 0201010000 \quad 0000000100 \quad 0000011200$ $0000000000 \quad 1000100110 \quad 0000011000 \quad 1110000101 \quad 0201010000 \quad 0000000100 \quad 0000011200$

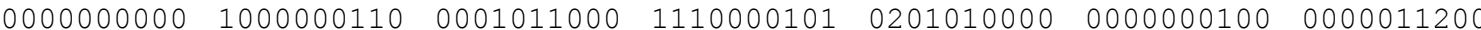
$000000000011001000-0$ 210 $0000000000 \quad 11001000-0 \quad 2100011010 \quad 1300000000 \quad 02120000110000001000 \quad 0000010000$ $0000000000 \quad 10000000-0 \quad 2000011000 \quad 1300000020 \quad 0212000011 \quad 0000000000 \quad 0000011000$ $0000001001 \quad 11000000-0 \quad 2000011010 \quad 0000000020 \quad 02020000110000000000 \quad 0000010000$ $0000001001 \quad 11001000-0 \quad 2000011010 \quad 0000000000 \quad 02030000110000001000 \quad 0000010000$ $0000001000 \quad 10010000-0 \quad 2000011000 \quad 0000000000 \quad 02110000110000000000 \quad 0000011000$ $0000001000-10000000-0 \quad 2000011000 \quad 0000000000 \quad 02110000110000000000 \quad 0000011000$ 00100011-1 20000000-0 $2000061020 \quad 0200000120 \quad 0402000010 \quad 0000000100 \quad 0000310010$ 00100011-1 $2000100100 \quad 0000062010 \quad 0000000120 \quad 0401000001 \quad 0000000100 \quad 0000310000$

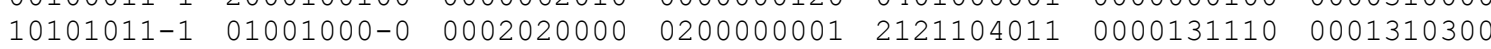

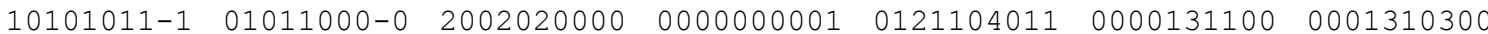
$10101011-1 \quad 0100120100 \quad 2002020000 \quad 1300000122 \quad 22221000110001131110 \quad 0012300100$ 10101011-1 $0101020100 \quad 2002020000 \quad 1300000102 \quad 22221000110001031110 \quad 0012300100$

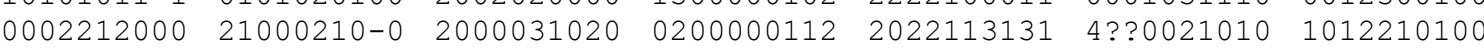

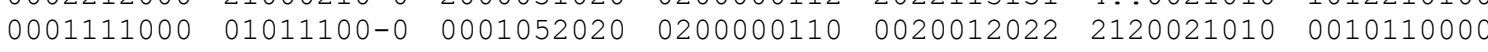
$0002213000 \quad 01010010-0 \quad 2001031020 \quad 0200000131 \quad 2020112122 \quad 2120021010 \quad 0011110000$

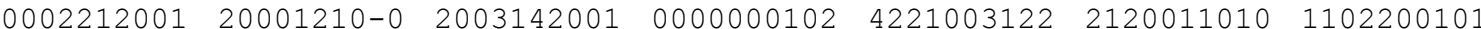
$000221200120001210-0 \quad 2003142001 \quad 0000000102 \quad 4221003122 \quad 21200110101102200101$

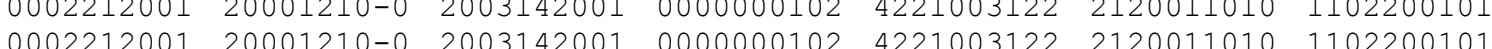


Tabela 2 (Continuação). Matriz de caracteres para as análises realizadas com grupos viventes e fósseis. Estados não observados e dados não aplicáveis codificados como "?" e “-”, respectivamente.

Tasmanina gracilis Neoallocotocera_fusca Docosia_fuscipes Docosia sciarina Docosia dichroa Docosia sp.

Docosia adusta Docosia pammela Novakia miloi

Ectrepesthoneura colyeri Ectrepesthoneura hirta Ectrepesthoneura_pubescens Ectrepesthoneura_bicolor Ectrespesthoneura laffooni Tetragoneura sylvatica Tetragoneura nitida Tetragoneura minima Tetragoneura borgmeieri Tetragoneura nocticolor Tetragoneura guajaensis Palaeodocosia vittata Boletina obscura Dziedzickia medea Schnusea caiabii Austrosynapha hirta Synapha_sp.

Mycomya sp.

Neoempheria sp. Exechiopsis_sp. Rymosia sp. Mycetophila sp. Epicypta sp.

Manota palpalis Promanota malaisei Eumanota_sp.

Allactoneura cincta Allactoneura arquentosquamosa Al lactoneura papuensis $\begin{array}{lllll}1 & 1111111111 & 1111111111 & 1111111111 & 11111\end{array}$ $\begin{array}{lllllllll}7777777778 & 8888888889 & 9999999990 & 0000000001 & 1111111112 & 2222222223 & 33333\end{array}$ \begin{tabular}{llllllll}
1234567890 & 1234567890 & 1234567890 & 1234567890 & 1234567890 & 1234567890 & 12345 \\
\hline
\end{tabular}

$000000000000000000100000110001 \quad 110104010010021201000011000000000 ? ?$

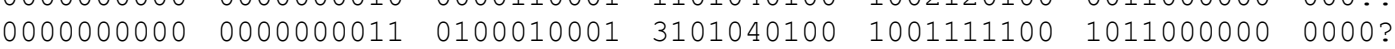

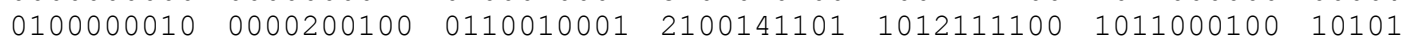
$0100000010 \quad 0000200100 \quad 0110010001 \quad 1100141101 \quad 1012111100 \quad 1011000100 \quad 1010$ ? $1100000010 \quad 0000200100 \quad 0110010001 \quad 1100141101-1010100100-1011000110 \quad 10101$ $1100000010-0000200100 \quad 0110010001 \quad 1100141101-1010100100101100011010101$

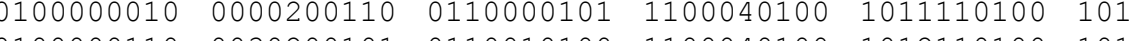
$\begin{array}{lllllllll}0100000110 & 0030200101 & 0110010100 & 1100040100 & 1012110100 & 1011000000 & 10101\end{array}$ $\begin{array}{llllllll}1100000110 & 0000200101 & 0110010101 & 1100141101 & 1012110100 & 1011000000 & 10101\end{array}$

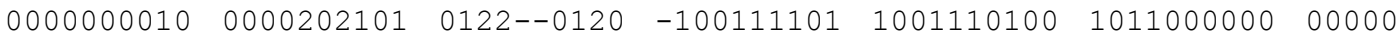

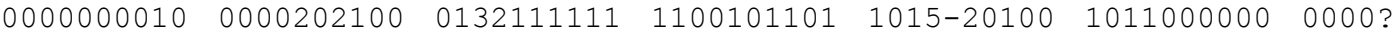
$000000010 \quad 0000202100 \quad 0132111111 \quad 1100101101 \quad 1015-21100-1011000000-0000 ?$

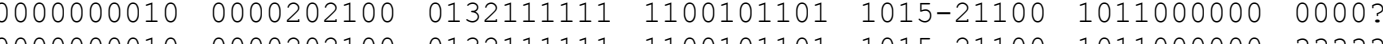
$0000000010 \quad 0000202100 \quad 0132111111 \quad 1100101101 \quad 1015-21100 \quad 1011000000$ ?????

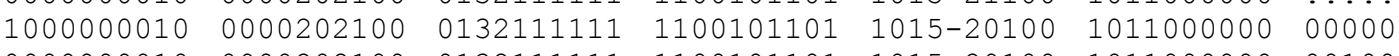
$\begin{array}{llllllll}000000010 & 0000202100 & 0132111111 & 1100101101 & 1015-20100 & 1011000000 & 00100\end{array}$

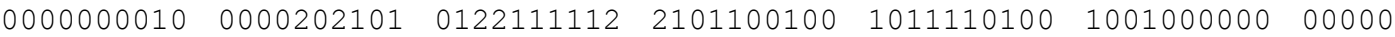

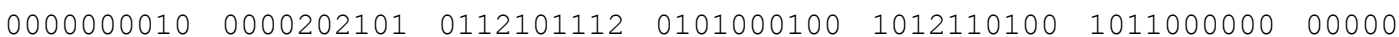

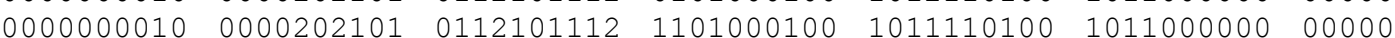

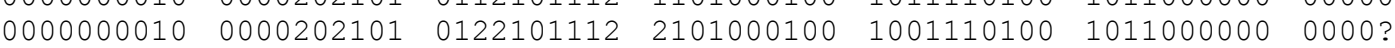

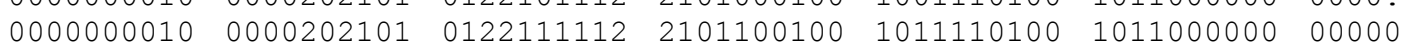
$0000000010 \quad 0000202101 \quad 0112101112 \quad 1101000100 \quad 1011110100 \quad 1011000000 \quad 0000$ ? $\begin{array}{llllllll}1000000100 & 0000202101 & 0000010002 & 0000060100 & 1010020100 & 0001000010 & 00000\end{array}$ $0000000100 \quad 00002000010000110$ $0000000100 \quad 00002000010004$ $0000000010 \quad 0000200100 \quad 0000100012 \quad 1000000000 \quad 0002020000 \quad 1001000000 \quad 00001$ $0000000010 \quad 0000200100 \quad 0000100002 \quad 100---0000 \quad 0004010000 \quad 1001000010 \quad 01000$ $0000000010 \quad 0000200101 \quad 00000100120000101001 \quad 0004010000 \quad 100200001000001$

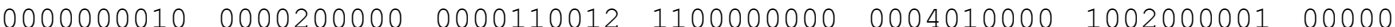
$000001010 \quad 0100201110 \quad 00000010023000010100-1001110100100100001000000$ 020111000000

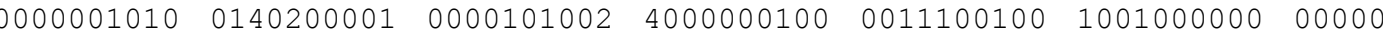
$0000001110 \quad 0000221201 \quad 0000110101 \quad 1100060010 \quad 0014010000 \quad 0002100102 \quad 00000$ $0000001110 \quad 00002212010000110002 \quad 2100060010 \quad 0014010000 \quad 0002100102$ ????0

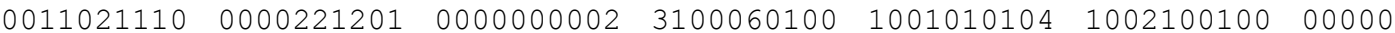
$\begin{array}{lllllllll}0 & 011021110 & 0000221201 & 0000000002 & 3100060100 & 1002010104 & 1002100100 & 00000\end{array}$ $\begin{array}{llllllll}1001021010 & 0000222211 & 0210010100 & 1100161101 & 1003010104 & 1002100000 & 00000\end{array}$

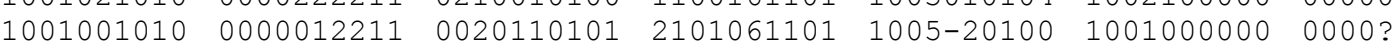
$100100101000301122010020110101 \quad 2101161100 \quad 1005-20100$ 000100???? ????1 $\begin{array}{lllllll}1011000100 & 1031201010 & 1010100114 & 1100040100 & 0015-21101 & 1002010001 & 01001\end{array}$

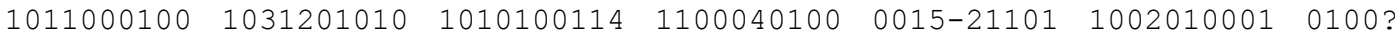

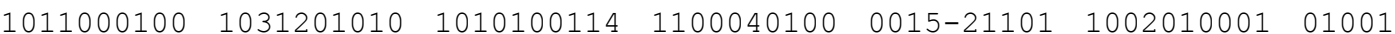


Tabela 2 (Continuação). Matriz de caracteres para as análises realizadas com grupos viventes e fósseis. Estados não observados e dados não aplicáveis codificados como "?" e “"”, respectivamente.

Sticholeia_dolichostyla Sticholeia_cheesmanae Sticholeia loici Garretella shermani Paraleia fulvescens Paraleia bolivari Paraleia_fumosa Paraleia_denticulata Thoracotropis cypriformis Gracilileia redunda Gracilileia_tillierorum Trichoterga_monticola Mohelia_nigricauda Aphrastomyia cramptoni Aphrastomyia shannoni Aphrastomyia_cerquerai Megophthalmidia divergens Megophthalmidia_nigra Megophthalmidia occidentalis Megophthalmidia crassicornis Paracycloneura apicalis Indoleia bisetosa Rondaniēlla_dimidiata Rondaniella_sp.

Waipapamyia elongata Sigmoleia melanoxantha Sigmoleia peterjohnsi Paradoxa fusca Paradoxa paradoxa Cawthronia nigra Cycloneura flava Tonnwardsia aberrans Leiella ochreocalcar Leiella_unicincta Leiella zonalis Procycloneura paranensis Procycloneura similis Ateleia spadicithorax $\begin{array}{llllllll}1 & 1111111112 & 2222222223 & 3333333334 & 4444444445 & 5555555556 & 6666666667\end{array}$ \begin{tabular}{llllllll}
1234567890 & 1234567890 & 1234567890 & 1234567890 & 1234567890 & 1234567890 & 1234567890 \\
\hline
\end{tabular}

00022021-1 21001210-0 2000042001 $00000001424221003222 \quad 21200010101000300200$ 00022021-1 21001210-0 $2000042001 \quad 0000000142 \quad 4221003222 \quad 2120001010 \quad 1000300200$ $00022021-1 \quad 21001210-0 \quad 2000042001 \quad 0000000142 \quad 4221003222 \quad 2120001010 \quad 1000300200$

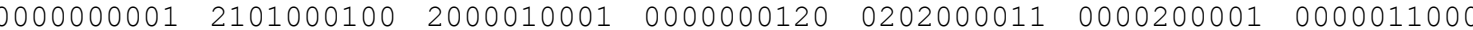
$000000000121010000-0 \quad 2000012001 \quad 0010000100 \quad 120200001000002101010001311000$ $0000000001 \quad 21010000-0 \quad 2000012001 \quad 0010000100 \quad 1202000010 \quad 0000210101 \quad 0001311000$ $0000000001 \quad 21010000-0 \quad 2000012001 \quad 0010000100 \quad 1202000010 \quad 00002101010001311000$ $0000000001 \quad 21010000-0 \quad 2000012001 \quad 0010000100 \quad 1202000010 \quad 0000210101 \quad 0001311000$ $1100001000 \quad 110 ? 020100 \quad 2000021020 \quad 0000011--0 \quad 1 ? 11000010$ 0??0?10?0? 0?0001?000 $\begin{array}{lllllll}0100001000 & 1100000110 & 2100120000 & 1100000220 & 0212010011 & 0 ? 30200001 & 0000011000\end{array}$ $01000010001100000110-2100120000 \quad 1100000220-02120100110000200001$ $\begin{array}{lllllllll}0100001000 & 1100000110 & 2100120000 & 1100000220 & 0212010011 & 0000200001 & 0000011000\end{array}$ $\begin{array}{llllllll}1100001000 & 1000000100 & 2001021000 & 0000000120 & 0211000011 & 0000201001 & 0001311000\end{array}$ $0110001000 \quad 0000120100 \quad 0001011100 \quad 0201100001 \quad 022201001100002110010101311201$ 01100011-1 $2000120101 \quad-001011100 \quad 0201200001 \quad 0221000010 \quad 0010211001 \quad 0101311201$

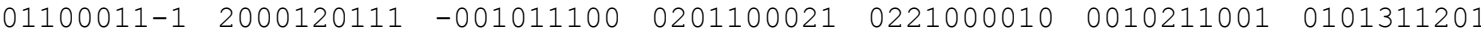
$0110001000-2000120101-001011100-020110$ $0110001000 \quad 10001000-0 \quad 1000011100 \quad 0001100021022200001000002110010101311201$ $0110001000 \quad 10001000-0 \quad 1001011100 \quad 0001100021 \quad 0222000010 \quad 00002110010101311201$

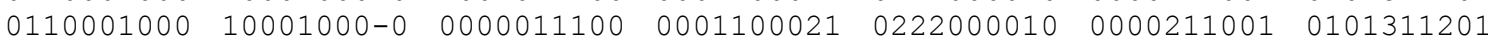
$\begin{array}{llllllll}0110001000 & 10001000-0 & 1000011100 & 0001100001 & 0223000010 & 0000211001 & 0101311201\end{array}$ $\begin{array}{llllllll}1110001001 & 11000003 ? 0 & 0130000010 & 0000000001 & 2121000011 & 1000210001 & 0000001200\end{array}$ $1110001001 \quad 11000003 ? 0013000001000000000012121000011 \quad 1000210001000001200$ 01100011-1 $0001021110 \quad 2002122000 \quad 0000000101 \quad 4222001021 \quad 30102110110101301200$ $0110001000 \quad 1000020100 \quad 2002020000 \quad 0000000101 \quad 222200001100002110110001301200$ 0110001000 1000020??0 $2002020000 \quad 0000000101 \quad 222200001120102110110000001200$

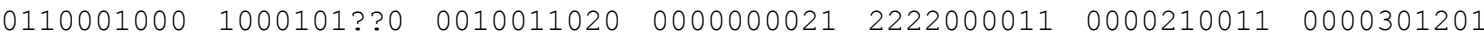
$0110001000 \quad 0000120110 \quad 0002011021 \quad 0000011--1 \quad 3321000011 \quad 10002110110011301201$ $0110001000-0000220110+0002013$ $0110001000 \quad 0000 ? 20110 \quad 0002011$ 0110001000 1000100??0 $0001011010 \quad 0100000021 \quad 212101001100002100110100001201$ $0110001000 \quad 1001100 ? ? 0 \quad 0001011010 \quad 0100000021 \quad 212101001100002100110100001201$ 011?001000 0000120?-0 0012011020 0000000001 2?2?01000? $1000210011 \quad 1001301201$ $\begin{array}{llllllll}1110001000 & 0110020110 & 2011011020 & 0000000101 & 2222000011 & 0000210011 & 1001301201\end{array}$ $11100010000110120110+001101$

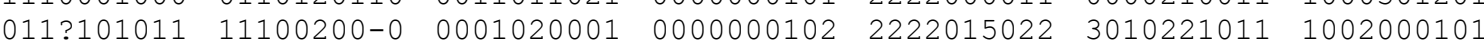

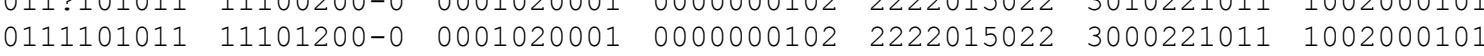
$0111101011 \quad 11101200-0 \quad 0001020001 \quad 0000000102 \quad 2222015022 \quad 3000221011 \quad 1002000101$ $0111202000 \quad 21101210-0 \quad 0011031000 \quad 0000000002 \quad 42220100110000210011 \quad 1100301101$ $0111202000 \quad 21101210-0 \quad 0011031000 \quad 0000000002 \quad 42220100110000210011 \quad 1100301101$ $0111101001 \quad 1100121110 \quad 2100021000 \quad 0000000121 \quad 020200001100002110110000001200$ 
Tabela 2 (Continuação). Matriz de caracteres para as análises realizadas com grupos viventes e fósseis. Estados não observados e dados não aplicáveis codificados como “?” e "-”, respectivamente.

Sticholeia_dolichostyla Sticholeia_cheesmanae Sticholeia loici Garretella shermani Paraleia fulvescens Paraleia bolivari Paraleia_fumosa Paraleia_denticulata Thoracotropis cypriformis Gracilileia redunda Gracilileia tillierorum Trichoterga_monticola Mohelia_nigricauda Aphrastomyia cramptoni Aphrastomyia shannoni Aphrastomyia cerquerai Megophthalmidia divergens Megophthalmidia_nigra Megophthalmidia occidentalis Megophthalmidia crassicornis Paracycloneura apicalis Indoleia bisetosa Rondaniella_dimidiata Rondaniella_sp.

Waipapamyia elongata Sigmoleia melanoxantha Sigmoleia peterjohnsi Paradoxa fusca Paradoxa paradoxa Cawthronia nigra Cycloneura flava Tonnwardsīa aberrans Leiella ochreocalcar Leiella_unicincta Leiella zonalis Procycloneura paranensis Procycloneura similis Ateleia spadicithorax
$1 \quad 1111111111 \quad 1111111111 \quad 1111111111 \quad 11111$ $\begin{array}{lllllllll}7777777778 & 8888888889 & 9999999990 & 0000000001 & 1111111112 & 2222222223 & 33333\end{array}$ \begin{tabular}{llllllll}
1234567890 & 1234567890 & 1234567890 & 1234567890 & 1234567890 & 1234567890 & 12345 \\
\hline
\end{tabular}

$\begin{array}{llllllll}1001011100 & 0020201001 & 0120100001 & 2101060100 & 1102121112 & 1011000000 & 00011\end{array}$

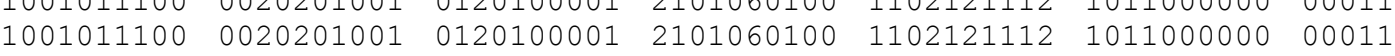
$\begin{array}{lllllll}1001011100 & 0010201001 & 0120100001 & 2101060100 & 1102121112 & 1011000000 & 00011\end{array}$ $\begin{array}{lllllllll}000000101 & 0000201000 & 0020110000 & 2101020100 & 1002121100 & 1012000100 & 00000\end{array}$ $0000000101-0000202000 \quad 0020110001 \quad 1100000100-1012000101100200001200000$ $0000000101 \quad 0010201000 \quad 0022110011 \quad 1100020100 \quad 1012000101 \quad 1002000012 \quad 00000$

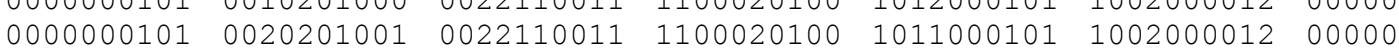
$0000000101 \quad 0020201000 \quad 0022110011 \quad 1100020100 \quad 1012000101 \quad 1002000012 \quad 00000$ 00000?0??? ??00202101 $0010110001 \quad 2100020100 \quad 1011110100$ 101100?100 0000? $0000010000 \quad 0000202201 \quad 0132110112 \quad 2101020100 \quad 1014110100 \quad 1011000202 \quad 00000$ $0000010000 \quad 0000202201 \quad 0132110112 \quad 2101020100 \quad 1011110100 \quad 101100020100000$

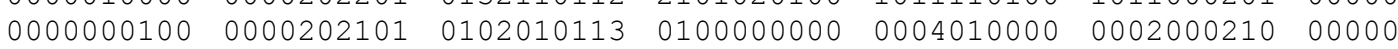
$\begin{array}{lllllllll}0000111011 & 0000202201 & 0131110111 & 2100020100 & 1002110100 & 1002001200 & 00000\end{array}$ $0000111011000020220101311101112100020100 \quad 1001010100 \quad 1002001200$ ????? $0000111011 \quad 00002022010131110111 \quad 2100020100 \quad 1002010100 \quad 1002001200 \quad 0000 ?$ $0001110110000202201 \quad 01311101112100020100 \quad 10010101001002001200$ ????0 $0000111011000020220101311101112100020100 \quad 1001010100 \quad 1002001200$ ????0 $\begin{array}{lllllllll}000111011 & 0000202201 & 0111110110 & 1100010100 & 1012110100 & 1002001200 & 00000\end{array}$

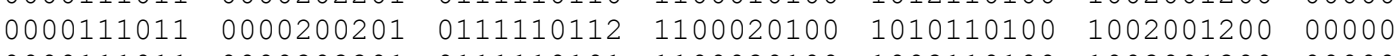
$\begin{array}{llllllll}0000111011 & 0000202201 & 0111110101 & 1100020100 & 1002110100 & 1002001200 & 00000\end{array}$ $000011101100002022010111110101 \quad 1101020100 \quad 1002110100 \quad 1002002200 \quad 0000 ?$ $\begin{array}{llllllll}1000010010 & 0020202101 & 0112110111 & 11110-2-02 & -2-2011000 & 1002000210 & ? 3 ? ? 0\end{array}$ ????0 $\begin{array}{lllllllll}1001020100 & 0020200011 & 0010110001 & 1101010100 & 1003121102 & 1001000210 & 00001\end{array}$ $\begin{array}{llllllll}1000020100 & 0020200011 & 0112100132 & 0101011100 & 1003021102 & 1001000210 & 00000\end{array}$ $1000020100 \quad 00202000110112110132 \quad 1101011100 \quad 1003021112 \quad 1001000210 \quad 0000$ ? $\begin{array}{llllllll}1000120100 & 0020102001 & 0122111101 & 1101000101 & 1013021101 & 1011000210 & 00000\end{array}$ $\begin{array}{lllllll}1000120110 & 0020102101 & 0102100112 & 0101010100 & 1010110103 & 1112000210 & 00000\end{array}$ $1000120110 \quad 0020102101 \quad 010210011201010301001010110103 \quad 1112000210$ ????0 0210 ????0 $1000120100 \quad 0020202101 \quad 0122100101 \quad 1101040101 \quad 1013111102 \quad 1110000210 \quad 00000$

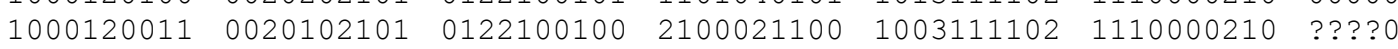
$1 ? 1012010$ ? $1 ? 00102001 \quad 0112000101 \quad 1101020100 \quad 1013121102 \quad 1011000200 \quad 0 ? ? ? 0$ $\begin{array}{lllllll}1010120100 & 1020202101 & 0122110110 & 21110-2-02 & ---3011102 & 1110000210 & 00000\end{array}$ $10101201001020200101012211011121110-2-02--3011102101200021000000$ $1010120100 \quad 1020200101 \quad 0122110111 \quad 21110-2-02 \quad---3011102 \quad 10120$ $\begin{array}{llllllll}1011020100 & 1030201011 & 0130100102 & 2101021100 & 1013121102 & 0011000210 & 00000\end{array}$

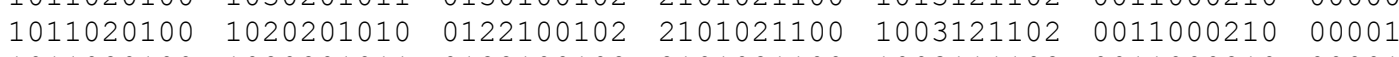
$\begin{array}{llllllll}1011020100 & 1020201011 & 0122100102 & 2101021100 & 1003111102 & 0011000210 & 00001\end{array}$ $\begin{array}{lllllll}1010120100 & 1020101101 & 0122100132 & 2100141101 & 1015-21102 & 1110000011 & 00000\end{array}$ $\begin{array}{llllllll}1010120100 & 1020200101 & 0122100132 & 2100141101 & 1015-21102 & 1110000000 & 0000 ?\end{array}$

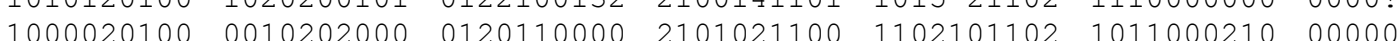


Tabela 2 (Continuação). Matriz de caracteres para as análises realizadas com grupos viventes e fósseis. Estados não observados e dados não aplicáveis codificados como "?" e “"”, respectivamente.

Anomalomyia_guttata Anomalomyia_minor Anomalomyia nasuta Acrodicrania africana Acrodicrania atricauda Acrodicrania angustifurca Acrodicrania_fasciata Acrodicrania setosicauda Caledonileia pusilla Clastobasis alternans Clastobasis loici Clastobasis stylata Clastobasis_vicina Clastobasis tryoni Clastobasis sp. Leia stigmatica Leia arsona Leia_winthemi Leia_fascipennis Leia ventralis Leia opima Leia bivittata Leia_amapaensis Leia spinifera Leia andirai

Neoclastobasis draskovitsae Neoclastobasis kamijoi Greenomyia mongolica Greenomyia_stalckelbergi Greenomyia cephala Greenomyia joculator $\begin{array}{llllllll}1 & 1111111112 & 2222222223 & 3333333334 & 4444444445 & 5555555556 & 6666666667\end{array}$ \begin{tabular}{llllllll}
1234567890 & 1234567890 & 1234567890 & 1234567890 & 1234567890 & 1234567890 & 1234567890 \\
\hline
\end{tabular}

01011011-1 $1100120110 \quad 2000021000 \quad 0000000121020200001100002110110001301200$

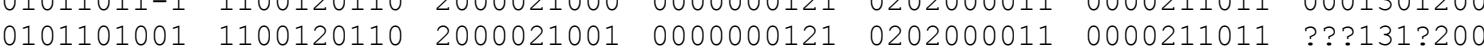
$\begin{array}{llllllll}0101101001 & 1100120110 & 2000021001 & 0000000121 & 0202000011 & 0000211011 & 0001301200\end{array}$ $\begin{array}{llllllll}0101101001 & 1100121110 & 0100021000 & 0000000101 & 0202000011 & 0010211011 & 0001311200\end{array}$ $0101101001-1100121110 \quad 01000210000000000101-0202000011 \quad 00102110110001311200$ $\begin{array}{llllllll}0101101001 & 1100121110 & 0100021000 & 0000000101 & 0202000011 & 0010211011 & 0001311200\end{array}$

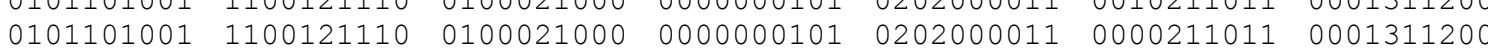
$0101101001 \quad 1100121110 \quad 0100021000 \quad 0000000101020200001100002110110001311200$ 01000011-1 010?020??0 20?1???0?0 $\quad$ ??00011--0 $0 ? 020000110010211111000030000$ ? $\begin{array}{lllllllll}0101101001 & 1100120110 & 2000020000 & 0000000121 & 0202000001 & 1000211111 & 0001001200\end{array}$ $0101101001-11001201102000020000 \quad 0000000121-021200000110002111110001301200$ $0101101001 \quad 1100120110 \quad 2000020000 \quad 0000000121021200$ $0101101001 \quad 1100120 ? ? 0 \quad 2000020000 \quad 0000000101 \quad 0201000001 \quad 10002111110001001200$ $0101101001 \quad 1100120 ? ? 0 \quad 2000020000 \quad 0000000121 \quad 0202000001 \quad 10002111110001001200$ $\begin{array}{llllllll}0101101001 & 1100121110 & 2000020000 & 0000000121 & 0201000001 & 1000211111 & 0001301200\end{array}$

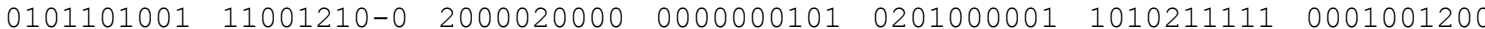
$0101101001 \quad 110012011020000200000000000101 \quad 0202000001 \quad 10002111110001001200$ $\begin{array}{llllllll}0101101001 & 1100120110 & 2000020000 & 0000000101 & 0202000001 & 1000211111 & 0001001200\end{array}$

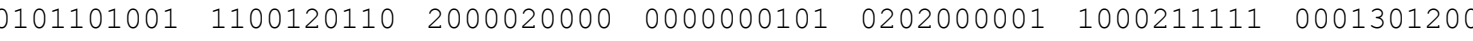
$0101101001 \quad 1100120110 \quad 2000020000 \quad 0000000101 \quad 0202000001 \quad 10002111110001001200$ $0101101001 \quad 1100120110 \quad 2000020000 \quad 0000000101 \quad 0202000001 \quad 10002111110001301200$ $\begin{array}{lllllllll}0101101000 & 1000020110 & 2000020000 & 0000000101 & 0202000001 & 0000211111 & 0000001200\end{array}$ $\begin{array}{lllllllll}0101101001 & 1100120110 & 2000020000 & 0000000101 & 0202000001 & 1000211111 & 0001001200\end{array}$ $01011010011100120110200002000000000001010202000001 \quad 10004$ $0101101001 \quad 1100120110 \quad 2000020000 \quad 0000000101 \quad 0202000001 \quad 10002111110001301200$ $0101101001 \quad 1100120110 \quad 2000020000 \quad 0000000101 \quad 0201000001 \quad 10102111110001301200$

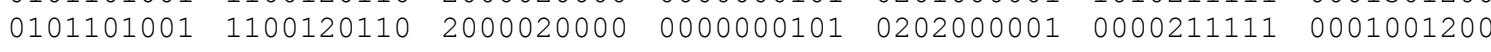
$0101101001 \quad 1100020110 \quad 2000020000 \quad 0000000101 \quad 0201000001 \quad 10002111110001001200$ $0001100000 \quad 1010121110 \quad 0000020001 \quad 0000000111 \quad 020200001100102111110000001200$ 00010211111000001200

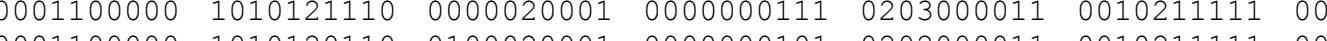
$00011000001010120110 \quad 0100020001 \quad 0000000101 \quad 020200001100102111110000301200$ $0001100000 \quad 1010120110 \quad 0100020001 \quad 0000000111020200001100102111110000301200$ $0001100000 \quad 1010120110 \quad 0101020001 \quad 0000000101 \quad 020200001100102111110000301200$ $0001100000 \quad 10101201 ? 0 \quad 01010200010000000101 \quad 020200001100102111110000301200$ 
Tabela 2 (Continuação). Matriz de caracteres para as análises realizadas com grupos viventes e fósseis. Estados não observados e dados não aplicáveis codificados como "?” e “"”, respectivamente.

Anomalomyia_guttata Anomalomyia_minor Anomalomyia nasuta Acrodicrania africana Acrodicrania atricauda Acrodicrania_angustifurca Acrodicrania fasciata Acrodicrania_setosicauda Caledonileia pusilla Clastobasis alternans Clastobasis loici Clastobasis stylata Clastobasis_vicina Clastobasis tryoni Clastobasis sp. Leia stigmatica Leia arsona Leia winthemi Leia_fascipennis Leia ventralis Leia opima Leia_bivittata Leia_amapaensis Leia spinifera Leia andirai

Neoclastobasis draskovitsae Neoclastobasis kamijoi Greenomyia_mongolica Greenomyia_stalckelbergi Greenomyia cephala Greenomyia joculator
$1 \quad 1111111111 \quad 1111111111 \quad 1111111111 \quad 11111$ $\begin{array}{lllllllll}7777777778 & 8888888889 & 9999999990 & 0000000001 & 1111111112 & 2222222223 & 33333\end{array}$ \begin{tabular}{llllllll}
1234567890 & 1234567890 & 1234567890 & 1234567890 & 1234567890 & 1234567890 & 12345 \\
\hline
\end{tabular}

$1000010100 \quad 00202020010130110001 \quad 1101010100 \quad 1001100102 \quad 101100021000000$ $1000010100 \quad 00202020010120110001 \quad 2101010100 \quad 1001100102$ 1011000210 ???? $1000010100 \quad 0020202001 \quad 0120110001 \quad 2101020100 \quad 1002100102 \quad 1011000210$ ????0

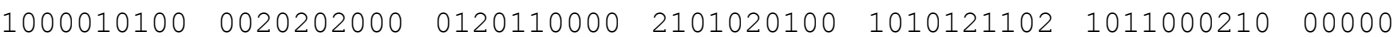

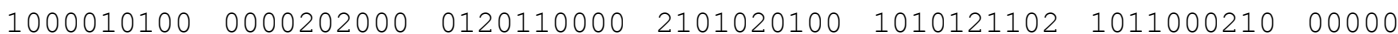

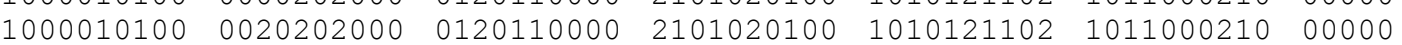

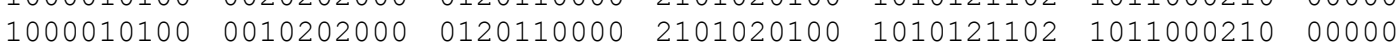
$\begin{array}{lllllll}1000010100 & 0020202000 & 0120110000 & 2101020100 & 1010121102 & 1011000210 & 00000\end{array}$ ?000??010? ?020201000 $0110110000 \quad 2101000100 \quad 1102101111 \quad 1012000210$ ????? $0000010100 \quad 0000201001 \quad 0130110103 \quad 2101050100 \quad 1023121101 \quad 1011000000 \quad 00001$

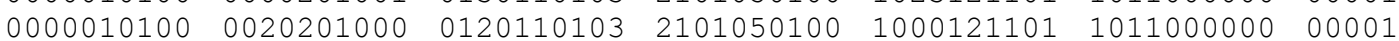
$0000010100 \quad 00002010010120100103 \quad 2101000100 \quad 1120111100$ 1011000101 ?????

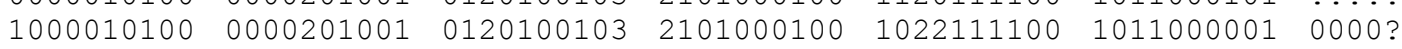
$\begin{array}{llllllll}1000010100 & 0000201001 & 0120110103 & 2101050100 & 1003121101 & 1011000101 & 00001\end{array}$

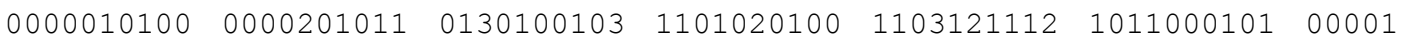
$0000010100 \quad 0000201000 \quad 0122100103 \quad 1101000100 \quad 1002110100 \quad 001100000000001$

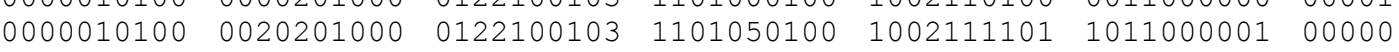
$0000010100 \quad 0020201000 \quad 0120100103 \quad 2101050100 \quad 1001110101 \quad 0011000000$ ????0

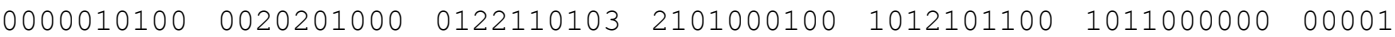

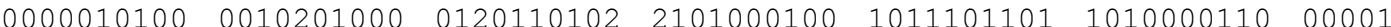
$1000010100 \quad 0010201000 \quad 0120100102 \quad 2101000100 \quad 1021111101 \quad 1011000000$ ????1

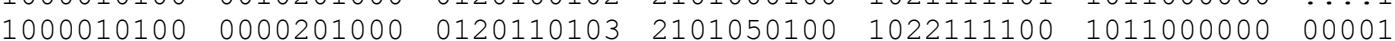

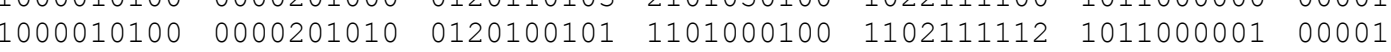
$0000010100 \quad 0010201000 \quad 0120100103 \quad 2101000100 \quad 1102110112 \quad 1011000001 \quad 00000$ $\begin{array}{lllllllll}000010100 & 0020201000 & 0120100103 & 2101050100 & 1021111100 & 0011000000 & 00001\end{array}$ $\begin{array}{llllllll}1000000100 & 1000201010 & 0120100103 & 2101050100 & 1102101111 & 1012000211 & 00000\end{array}$

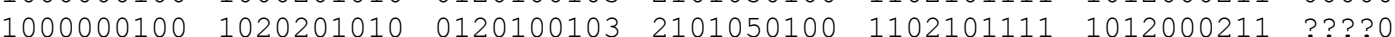

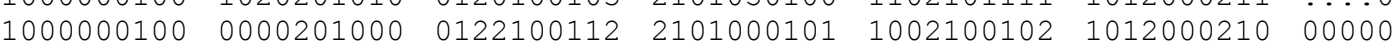

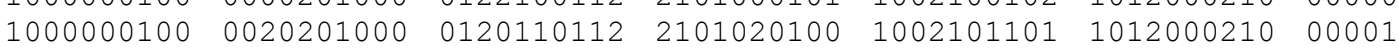

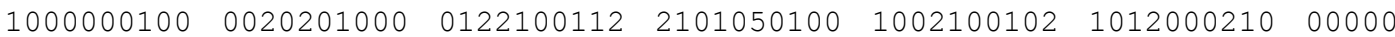
$1000000100 \quad 0020201000 \quad 0122100112 \quad 2101050100 \quad 1012100102 \quad 1012000210 \quad 00000$ 
Tabela 2 (Continuação). Matriz de caracteres para as análises realizadas com grupos viventes e fósseis. Estados não observados e dados não aplicáveis codificados como “?” e “"”, respectivamente.

\section{FÓSSEIS}

Baisepesthoneura mesozoica

Disparoleia cristata

Hemolia matilei

Hemolia glabra

Izleiina mirifica

Izleina-spinitibialis

Lecadonileia parvistyla

Metaleia maculicauda

Palaeothoracotropis truculentus

Palaeothoracotropis dundulensis

Protragoneura platycera

Temaleia birmitica

Zelinia orientalis
$1 \quad 1111111112 \quad 2222222223 \quad 3333333334 \quad 4444444445 \quad 5555555556 \quad 6666666667$ \begin{tabular}{llllllll}
1234567890 & 1234567890 & 1234567890 & 1234567890 & 1234567890 & 1234567890 & 1234567890 \\
\hline
\end{tabular}

\begin{tabular}{|c|c|c|c|c|c|c|}
\hline ????????? & ?? ?? ?? ? ? ? & ?????? & ?? & & & \\
\hline & ?--???0? ?? & 0???? & ??????21-1 & $0 ? 00$ ? 100 ?? & 000 & \\
\hline 001 & ????????? 0 & 0?? & 0??? & 03???0?? & & \\
\hline & ?? ? ? ? ? ? ? ?? & ?? ? ? ??? & ? ? ?? ? ?? & ?? ? 4 ?? ? ? ?? & & \\
\hline ???0?? & ?0??1???? 0 & 0???0? ?0?? & ??????C & 0?020100?1 & 0??? & \\
\hline & ? 0 ? 0 ? 00 ? ? 0 & & & ?2 ?? ? ? ?? & & \\
\hline & ?0 ? ??0 0 ? ? 0 & ?0?? & ?????? $1--1$ & 0 ? 0000 ?? & ??????1 ??? & ???? \\
\hline & ?1 ????0??? & 1?????? & ??????01 ? 1 & 2 ?? ???? & ??? & \\
\hline ?? & ??? ? ?? ? ? ?? & ??????? & ???? ? ?? ? ?? & ?? ?? ? ? ?? & ????? & ? \\
\hline ?? & ?? ? ??? ?? ?? & ?????????? & ???????? ?? & ?????????? & ? ? ??? ?? ?? ? & ???????? \\
\hline 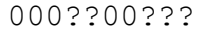 & ????1?0??1 & -??????0?? & ????????? 1 & 0 ?0 ? ?? ? 0 ?? & ? ? ?0 ? ? 000 ? & 00013 ? ?? \\
\hline & ?????? 0 ? ? 0 & 2??????0?? & ??? ? $0020-1$ & 0?03 ?? ???? & ?? ? ?? ?1 ??? & \\
\hline & & & & & & \\
\hline
\end{tabular}

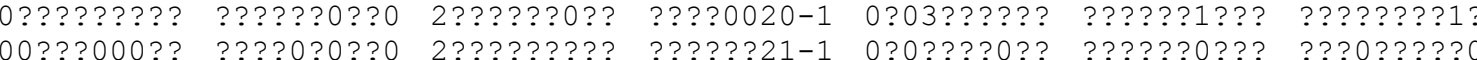

$\begin{array}{llllll}1 & 1111111111 & 1111111111 & 1111111111 & 11111\end{array}$ $\begin{array}{llllllll}7777777778 & 8888888889 & 9999999990 & 0000000001 & 1111111112 & 2222222223 & 33333\end{array}$ \begin{tabular}{llllllll}
1234567890 & 1234567890 & 1234567890 & 1234567890 & 1234567890 & 1234567890 & 12345 \\
\hline
\end{tabular}

\section{FÓSSEIS}

Baisepesthoneura mesozoica

Disparoleia cristata

Hemolia matilei

Hemolia glabra

Izleiina mirifica

Izleina spinitibialis

Lecadonileia parvistyla

Metaleia maculicauda

Palaeothoracotropis truculentus Palaeothoracotropis dundulensis

Protragoneura platycera

Temaleia birmitica

zelinia_orientalis

\begin{tabular}{|c|c|c|c|c|c|c|}
\hline & & & & & & \\
\hline & $0 ? 1$ & 0122110010 & $2 ? 1 ? 1-2--2$ & ---3110100 & ??00? ??? & \\
\hline & ?? 0 ?2 2?02 ? 1 & 0112110102 & $1 ? 0$ ? 050 ? 00 & ?002?10?00 & $10 ? 100 ? 100$ & \\
\hline & ?2?22?1 & 0112110102 & $1 ? 0 ? 050$ ? 00 & $2 ? 10 ? 00$ & & \\
\hline & ??20?1 & & & & & \\
\hline & ?20?1 & & & ---0 & & \\
\hline & $01 ? 1$ & 010 & 11010201 & 11100 & & \\
\hline $10 ?$ & ?? 00 ?? 1011 & 0130100001 & 2100020000 & 002021002 & 0 ???? & ?? \\
\hline ?????? & ??0??? 10 ?0 & 0003110000 & $1 ? 0 ? 000 ? 00$ & $002 ? 20 ? 00$ & 00 ?200???? & ??? \\
\hline & ?? 0 ??? 10 & 0003110000 & $1 ? 0 ? 050 ? 00$ & $002 ? 20 ? 00$ & $00 ? 2$ & $? ?$ \\
\hline & $0 ? 00$ & 0030111001 & $1 ? 0 ? 010$ ? & 00 & 0 & \\
\hline & & & & & & \\
\hline & & & $201 ? 1-2--2$ & & & \\
\hline
\end{tabular}




\section{LISTA DE MATERIAL}

Lista dos espécimes examinados, com informações das etiquetas e instituição depositária. Sempre que foram utilizadas informações provenientes da literatura as respectivas referências bibliográficas foram mencionadas.

A lista está organizada em subfamílias. Dentro de cada subfamília os táxons estão apresentados de acordo com o cladograma obtido (figura 326). Os táxons fósseis estão listados no final.

\section{MYCETOPHILIDAE}

\section{LEIINAE}

Garretella shermanni (Garrett)

- 1ð,, USA, Calif, Lily Pond, Alpine Lk., Marion Co., 1500', Malaise trap, iv-v.1970, D.D. Munroe. Garretella shermanni 1980, Garrett. det. J.R. Vockeroth [ANIC]

- 19, USA, Calif, Lily Pond, Alpine Lk., Marion Co., 1500, Malaise trap, 17-25.v.1971, D.D. Munroe. Garretella shermanni 1980, Garrett. det. J.R. Vockeroth [ANIC]

- 2q, USA, Calif, Lily Pond, Alpine Lk., Marion Co., 1500', Malaise trap, 1725.vi.1971, D.D. Munroe. Oliveira, S.S. det. 2012 [CNC]

- 1ð̊, USA, Calif, Lily Pond, Alpine Lk., 1500', Malaise trap, 22.iv.1971, D.D. Munroe. Oliveira, S.S. det. 2012 [CNC]

- 1ð̊, USA, Calif, Lily Pond, Alpine Lk., Marion Co., 1500’, Malaise trap, 22.iii.1967. Oliveira, S.S. det. 2012 [CNC]

- $1 \hat{\jmath}$, USA, Calif, Lily Pond, Alpine Lk., Marion Co., 1500', Malaise trap, 17.v.1969. Oliveira, S.S. det. 2012 [CNC]

\section{Paraleia fulvescens Tonnoir}

- 1ð, AUSTRALIA, Tasmania, Eaglehawk Neck, 18.xi.1922, A. Tonnoir. HOLOTYPE. Paraleia sp.n. fulvescens A. Tonnoir det. [ANIC]

- 19, AUSTRAliA, Tasmania, St. Patrick R., 30.x.1922, A. Tonnoir. ALLOTYPE. Paraleia fulvescens sp.n. A. Tonnoir det. [ANIC]

- 1ð̄, AUSTRALIA, Tasmania, St. Patrick R., 11.xi.1922, A. Tonnoir. PARATYPE. Paraleia fulvescens A. Tonnoir det. [ANIC] 
- 1ð̄, AUSTRALIA, Tasmania, Burnie, 1.ii.1923, A. Tonnoir. PARATYPE. Paraleia fulvescens sp.n. A. Tonnoir det. [ANIC]

- 1?, AUSTRAliA, Tasmania, Fern Tree, 11.xi.1922, A. Tonnoir. PARATYPE. Paraleia fulvescens sp.n. A. Tonnoir det. [ANIC]

- 10̂, AUSTRALIA, Tasmania, Eaglehawk Neck, 17.xi.1922, A. Tonnoir. PARATYPE. Paraleia fulvescens A. Tonnoir det. [ANIC]

- 19, AUSTRAliA, Tasmania, Eaglehawk Neck, 22.xi.1922, A. Tonnoir. PARATYPE. Paraleia fulvescens A. Tonnoir det. [ANIC]

- 19, AUSTRALIA, Tasmania, Eaglehawk, 18.xi.1922, A. Tonnoir. PARATYPE. Paraleia fulvescens A. Tonnoir det. [ANIC]

- 19, AUSTRALIA, Tasmania, Harz Moutain, 10.x.1922, A. Tonnoir. PARATYPE. Paraleia fulvescens A. Tonnoir det. [ANIC]

- 1?, AUSTRAliA, Tasmania, Barington Tops, ii.1925, SU Zoo Exp. PARATYPE. Paraleia fulvescens n.sp. A. Tonnoir det. [ANIC]

- 19, AUSTRALIA, Tas., Lake St. Clair, Site: SCRE 8, 0434682E 5355692N, 30.ix.1999, Pitfall, Mycetophilidae1. Oliveira, S.S. det. 2011 [AMSA]

- 19, AUSTRALIA, Tas., 4Km E. Rosebery, 41.47S 145.35E, 16.i-1.ii.1983, Malaise ethanol, I.D. Naumann \& J.C. Cardale. Oliveira, S.S. det. 2011 [ANIC]

- $1 \delta^{\Uparrow} 3$, AUSTRALIA, N.S.W., Monga, 19.vii.1962, D.H. Colless. Oliveira, S.S. det. 2011 [ANIC]

- 19, AUSTRALIA, Tas., 14Km SW by S Wilmot, 41.30S 145.05E, 31.i.1983, ex. ethanol, I.D. Naumann \& J.C. Cardale. Oliveira, S.S. det. 2011 [ANIC]

- 1ð, AUSTRALIA, Tas., 12mls. S Deloraine, 2200ft, 5.iii.1963, I.F.B. Common \& M.S. Upton. Oliveira, S.S. det. 2011 [ANIC]

- 1ð̄, AUSTRALIA, Tas., Hellyer Gorge, 14.ii.1963, I.F.B. Common \& M.S. Upton. Oliveira, S.S. det. 2011 [ANIC]

- 2ð, AUSTRALIA, Tas., Nelson R., 42.06S 145.44E, 22.i.1983, ex. ethanol, I.D. Naumann \& J.C. Cardale. Oliveira, S.S. det. 2011 [ANIC]

- 1§,, AUSTRALIA, Vic., Cement Cr., 1800', 25.xii.1965, N. Dobrotworsky. Oliveira, S.S. det. 2011 [ANIC]

Paraleia bolivari Oliveira \& Amorim

- Oliveira \& Amorim (2012) 
Paraleia fumosa Oliveira \& Amorim

- Oliveira \& Amorim (2012)

Paraleia denticulata Oliveira \& Amorim

- Oliveira \& Amorim (2012)

Thoracotropis cypriformis Freeman

- Oliveira et al. (2012)

Gracilileia redunda Matile

- 19, FRANCE, Nouvelle Calédonie, Rivière Bleue, Forêt Trantition, 12-27.v.1989, LBDL-JC-5279. Gracilileia redunda n.sp. q, L. Matile det. 1992 [MNHN]

- 1ð, FRANCE, Nouvelle Calédonie, Rivière Bleue, Parc 7, Alt. 170m, Forêt humide sur pente Plège de Malaise, 13-26.iii.1987, LBL, JC, A \& ST. Gracilileia redunda n.sp. $\lesssim[\mathrm{MNHN}]$

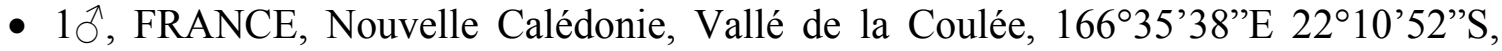
maquis haut, bord rivière s/ périotites, 24.x.1985, Ph. Bouchet. Oliveira, S.S. det. 2011 [ANIC]

Gracilileia tillierorum Matile

- 1ð, FRANCE, Nouvelle Calédonie, Rivière Bleue, Forêt Trans., 24.viii-7.ix.1989, LBDL-JC-526b. Gracilileia tillierorum n.sp. ڤ̊, L. Matile det. 1992 [MNHN]

- 19, FRANCE, Nouvelle Calédonie, Rivière Bleue, Forêt Trans., 24.viii-7.ix.1989, LBDL-JC-526b. Gracilileia tillierorum n.sp. q, L. Matile det. 1992 [MNHN]

Trichoterga monticola Tonnoir \& Edwards

- 1§, NEW ZEALAND, Ohakune, v-vii.1923, T.R. Harris, B.M.1923-419. Trichoterga monticola [MZUSP]

- $1 \mathrm{O}^{\lambda}$, NEW ZEALAND, North Island, Central Plateau, Kaimanawa Forest Park, ex. Malaise trap Notophagus bush, 24-31.i.1971, H.A. Oliver. Oliveira, S.S. det. 2011 [ANIC]

- $1 \AA$, NEW ZEALAND, Whangamea Saddle, Nelson, South Island, Malaise trap, 12 15.v.1970, H.A. Oliver. Oliveira, S.S. det. 2011 [ANIC] 
- $1 \delta^{\Uparrow} 2$ q, NEW ZEALAND, BR Nelson Lakes N.P., Mt. Robert 1100m, 18-23.xii.1983, L. Masner, MT. Oliveira, S.S. det. 2012 [CNC]

Megophthalmidia crassicornis (Curtis)

- 1ð,, NORWAY, EIS 28 AK, Oslo, Bleikøya [N], UTMWG584 32VNM 97504035, 3.vi-15.vii.2008, Malaise trap forest edge, Anders Endrestøl Leg. Megophthalmidia crassicornis (Curtis, 1839) Eirik Rindal det. 2010 [LMED]

- 1ð̂, SLOVAKIA, West Velká Fatra Mts., Mošovce env., 24.vii.1992, Malaise trap, M. Kozánek Leg. Megophthalmidia crassicornis (Curtis, 1839) Jan Ševčik det. 2010 [LMED]

Megophthalmidia divergens Edwards

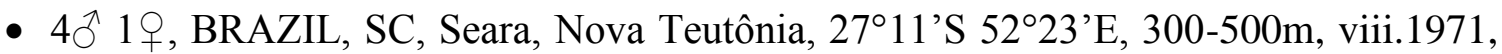
Fritz Plaumann. Oliveira, S.S. det. 2012 [MZUSP]

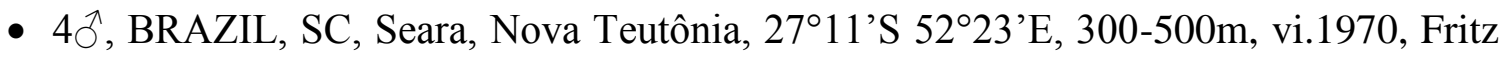
Plaumann. Oliveira, S.S. det. 2012 [MZUSP]

Megophthalmidia nigra Freeman

- $4 \overbrace{}^{\Uparrow}$ \% , CHILE, Estera la Jaula, Curico, i.1964, Notophagus, L.E. Peña Col. Oliveira, S.S. det. 2012 [CNC]

- 1ふ, CHILE, Santiago, Cantillana, 2000m, Cord. De La Costa, xii.1969, L.E. Peña Col. Oliveira, S.S. det. 2012 [MZUSP]

- 1ð, CHILE, Nuble, 40Km E. of San Carlos, xii.1950, Ross \& Michelbacher Leg. Oliveira, S.S. det. 2012 [MZUSP]

Megophthalmidia occidentalis Johhansen

- 1ð̋, USA, Calif., Loop Trail nr Phillipisville, Alt. Hwy. 101, 5.vii.1968, B.V. Peterson. Oliveira, S.S. det. 2012 [CNC]

- 1ð, USA, Calif, Lily Pond, Alpine Lk., Marion Co., 1500', Malaise trap 2, 17 25.v.1971. Oliveira, S.S. det. 2012 [CNC]

- 1ô, CANADA, BC, Victoria, 21.v.1965, at light, D. Evans. Oliveira, S.S. det. 2012 $[\mathrm{CNC}]$ 
- 19, USA, Calif, Lily Pond, Alpine Lk., Marion Co., 1500', Malaise trap, v-vi.1976, D.D. Munroe. Oliveira, S.S. det. 2012 [CNC]

- 1 ㅇ, USA, Calif, Mc Bride Spr. Cpgd., Mt. Shasta, 5200', 20.vii.1968, D.D. Munroe. Oliveira, S.S. det. 2012 [CNC]

Mohelia nigricauda Matile

- $2{ }^{\Uparrow} 11$, , SOUTH AFRICA, Western Cape, Frynbos Estate, Dragonridge, 33³4.092’S $18^{\circ} 47.680$ 'E, 635m, 30.vii-28.ix.2010, S. van Noort, Malaise Trap, DRA09-FYN1M04. Oliveira, S.S. det. 2011 [SAMC]

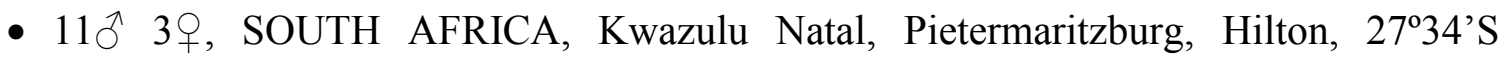
31²17.9’E, 1090m, 1-24.iii.2006, Malaise Trap, M. Mostovski coll. Oliveira, S.S. det. 2011 [NMSA]

- 1ð, ARCH. DES COMORES, Mohéli Djoumadounia, 100-150m, 29.xi.1973, L. Matile Leg. PARATYPE. Mohelia nigricauda n.sp. đ̊ paratype, L. Matile det. 1974 [MNHN]

Aphrastomyia cerquerai Lane

- 1ð̂, BRAZIL, AM, Manaus, Ig. Francês, 12.xii.1957, Col. Elias, N.1299. HOLÓTIPO. Aphrastomyia cerquerai det. John Lane, 1960 [MZUSP]

- 2今̄, BRAZIL, AM, Ipixuna, Rio Liberdade, Estirão da Preta, 07²1'46.7’’S 71'52’07.1’W, 11-15.v.2011, Malaise, J.A. Rafael, J.T. Câmara, R.F. Silva, A. Somavilla, C. Gonçalves Leg. Oliveira, S.S. det. 2012 [INPA]

- $2 \bigcirc^{\Uparrow} 2$, BRAZIL, RO, Porto Velho, 3,2 Km across Rio Madeira from Porto Velho, $8^{\circ} 43.401^{\prime}$ S 63⒌448’'W, Malaise trap 1, 4-14.xii.2011, Amorim, Ament \& Riccardi col. Oliveira, S.S. det. 2012 [MZUSP]

- 1ð̄, BRAZIL, AM, Ipixuna, Rio Gregório, Com. Lago Grande, 07¹0’11.7”S 7049'10.3”W, 18-23.v.2011, Malaise, J.A. Rafael, J.T. Câmara, R.F. Silva, A. Somavilla, C. Gonçalves Leg. Oliveira, S.S. det. 2012 [INPA]

Aphrastomyia cramptoni Coher \& Lane

- 1ð̄, BRAZIL, SP, Salesópolis, Res. Biol. Boracéia, vii.1949, Lane \& Coher col. HOLÓTIPO. Aphrastomyia cramptoni Coher \& Lane, 1949. Aphrastomyia cramptoni det. John Lane, 1952 [MZUSP] 
- 1ð̄, BRAZIL, SP, Salesópolis, Res. Biol. Boracéia, viii.1947, Lane col. PARÁTIPO. Aphrastomyia cramptoni Coher \& Lane, 1949 [MZUSP]

- 1ð̄, BRAZIL, SP, Salesópolis, Res. Biol. Boracéia, Trilha dos Pilões, 23³9’05,8”S 4553'44,6”W, 30.iii-2.iv.2001, Malaise Trilha 4, S.T.P. Amarante \& eq. col. Oliveira, S.S. det. 2012 [MZUSP]

- 1ð̄, BRAZIL, SP, Salesópolis, Res. Biol. Boracéia, Trilha dos Pilões, 2339’02,9’'S 4553’39”W, 30.iii-2.iv.2001, Malaise Trilha 2, S.T.P. Amarante \& eq. col. Oliveira, S.S. det. 2012 [MZUSP]

- 3ð’, BRAZIL, SP, Salesópolis, Res. Biol. Boracéia, Trilha dos Pilões, 23³9’02,9”'S 4553’39’W, 2-5.iv.2001, Malaise Trilha 2, S.T.P. Amarante \& eq. col. Oliveira, S.S. det. 2012 [MZUSP]

- 20, BRAZIL, SP, Salesópolis, Res. Biol. Boracéia, Trilha dos Pilões, 23³9’04,8’'S 4553’41,8’W, 2-5.iv.2001, Malaise Trilha 3, S.T.P. Amarante \& eq. col. Oliveira, S.S. det. 2012 [MZUSP]

- 1ð’, BRAZIL, SP, Salesópolis, Res. Biol. Boracéia, Trilha dos Pilões, 23³9’04,8”S 4553'41,8”W, 30.iii-2.iv.2001, Malaise Trilha 3, S.T.P. Amarante \& eq. col. Oliveira, S.S. det. 2012 [MZUSP]

- 10̄, BRAZIL, SP, Salesópolis, Res. Biol. Boracéia, 23³9’05”S 4553’51”W, 14.xii.2008, Malaise trap forest, Amorim, Falaschi \& Miranda col. Oliveira, S.S. det. 2012 [MZUSP]

- 10̂, BRAZIL, SP, Salesópolis, Res. Biol. Boracéia, Trilha dos Pilões, 2339’05,1”S 4553’51,8’W, 27.ii.2005, 16h00-17h00, Malaise, L.K. Nogueira \& A.P. Aguiar col. Oliveira, S.S. det. 2012 [MZUSP]

Aphrastomyia shannoni Lane

- 19, BRAZIL, AP, Serra do Navio, 29.xi.1957, J. Lane Leg. ALÓTIPO. Aphrastomyia shannoni det. John Lane, 1958 [MZUSP]

- 20, BRAZIL, AM, Ipixuna, Rio Liberdade, Estirão da Preta, 07²1'46.7’'S 7152'07.1'W, 11-15.v.2011, Malaise, J.A. Rafael, J.T. Câmara, R.F. Silva, A. Somavilla, C. Gonçalves Leg. Oliveira, S.S. det. 2012 [INPA]

- 4ð, BRAZIL, RO, Porto Velho, 3,2 Km across Rio Madeira from Porto Velho, $8^{\circ} 43.401^{\prime}$ S 63⒌448’W, Malaise trap 1, 4-14.xii.2011, Amorim, Ament \& Riccardi col. Oliveira, S.S. det. 2012 [MZUSP] 
Paracycloneura apicalis Tonnoir \& Edwards

- 19, NEW ZEALAND, Kanaeranga Vly., 23.i-2.ii.1970, H.A. Oliver. Oliveira, S.S. det. 2011 [ANIC]

- Jaschhof \& Kallweit (2009)

- Tonnoir \& Edwards (1927)

Indoleia bisetosa (Edwards)

- $1 \sigma^{\widehat{1}} 1$, , PAPUA NEW GUINEA, New Britain, Bismarck Isl., Yalom, 1000m. 20.v.1962, Noona Dan Exp. 61-62. Oliveira, S.S. det. 2011 [ANIC]

- 1ð, PAPUA NEW GUINEA, Waitape, Wharton Ra., 19.x.1963, D.K. McAlpine. K305788. Oliveira, S.S. det. 2011 [AMSA]

- 1ð, PAPUA NEW GUINEA, Buri near Sasembata, Popondetta subdist., 31.x.1963, D.K. McAlpine. K305789. Oliveira, S.S. det. 2011 [AMSA]

- 1ठ, PAPUA NEW GUINEA, Wau, 21.vii.1972, B.S. Cheary, Malaise trap $\mathrm{n}^{\circ} 1$. K305784. Oliveira, S.S. det. 2011 [AMSA]

- 1ð̊, PAPUA NEW GUINEA, Wau, 23.ix.1972, B.S. Cheary, Malaise trap $\mathrm{n}^{\circ} 2$. K305786. Oliveira, S.S. det. 2011 [AMSA]

- 1ð, PAPUA NEW GUINEA, Wau, 5.viii.1972, B.S. Cheary, Malaise trap ${ }^{\circ} 1$. K305785. Oliveira, S.S. det. 2011 [AMSA]

- 19, PAPUA NEW GUINEA, Wau, 5.viii.1972, B.S. Cheary, Malaise trap $\mathrm{n}^{\circ} 2$. K305779. Oliveira, S.S. det. 2011 [AMSA]

- 19, PAPUA NEW GUINEA, Wau, 28.vii.1972, B.S. Cheary, Malaise trap ${ }^{\circ} 1$. K305777. Oliveira, S.S. det. 2011 [AMSA]

- 19, PAPUA NEW GUINEA, Wau, 28.vii.1972, B.S. Cheary, Malaise trap $\mathrm{n}^{\circ} 2$. K305778. Oliveira, S.S. det. 2011 [AMSA]

- 19, PAPUA NEW GUINEA, Wau, Marabe District., 1158m, 26.xi.1972, G.A. Holloway. K305782. Oliveira, S.S. det. 2011 [AMSA]

Rondaniella dimidiata (Meigen)

- 19, CANADA, Ont., Ottawa, 27.viii.1992, J.R. Vockeroth. Damp second-growth Acer-Bettulla wood. Oliveira, S.S. det. 2012 [CNC]

- 19, CANADA, Ont., Ottawa, 30.x.1950, J.R. Vockeroth. Oliveira, S.S. det. 2012 $[\mathrm{CNC}]$ 
- 1ठ, CANADA, Ont., Ottawa, 21.ix.1989, J.R. Vockeroth. Swept over barc path in Acer wood. Oliveira, S.S. det. 2012 [CNC]

- 1ð̄, CANADA, Que., Old Chelsea, 9.viii.1961, J.R. Vockeroth. Oliveira, S.S. det. $2012[\mathrm{CNC}]$

- 19, CANADA, NB, Kouchibouguac Nat. Park, 26.vi.1977, J.R. Vockeroth. Code 5381Y. Oliveira, S.S. det. 2012 [CNC]

- 1ð, CANADA, NB, Kouchibouguac Nat. Park, 5.vii.1977, J.R. Vockeroth. Code 5486Z. Oliveira, S.S. det. 2012 [CNC]

- 1ठ̂, SLOVAKIA, centr. Muránska planina Nat. Park, Muráň, Hrdzavá dolina, 28.vi26.vii.2010, Malaise trap, Jan Ševčik Leg. Rondaniella dimidiata (Meigen, 1804) Jan Ševčik det. 2010 [LMED]

Rondaniella sp.

- 1ð, NEPAL, Ktmd., Godavari 6000’, 17.viii.1967, Can. Nepal Exped. Oliveira, S.S. det. $2012[\mathrm{CNC}]$

- 2ð, NEPAL, Ktmd., Pulchauki 6600', 16.viii.1967, Malaise trap, Can. Nepal Exped. Oliveira, S.S. det. 2012 [CNC]

- 13 , NEPAL, Ktmd., Pulchauki 6600', 10.viii.1967, Malaise trap, Can. Nepal Exped. Oliveira, S.S. det. 2012 [CNC]

Waipapamyia elongata Jaschhof \& Kallweit

- $1 \overbrace{}^{\Uparrow} 2$, NEW ZEALAND, N. Island, Pirongia West Road, near Hamilton, 17.xi.1970, Malaise trap, H.A. Oliver. Oliveira, S.S. det. 2011 [ANIC]

- 5ภ, NEW ZEALAND, North Island, Kauaeranga, Vly. Thames, Malaise trap, 2729.xi.1970, H.A. Oliver. Oliveira, S.S. det. 2011 [ANIC]

- 2ð̂, NEW ZEALAND, North Island, Kaimai Ra., ca. 3000ft, ex. Malaise trap, 22.xii.1970, H.A. Oliver. Oliveira, S.S. det. 2011 [ANIC]

- 13 , NEW ZEALAND, North Island, Upp. Kauaeranga, Vly. Thames, Malaise trap, 27-29.xi.1970, H.A. Oliver. Oliveira, S.S. det. 2011 [ANIC]

Paradoxa fusca Marshall

- 1ð, NEW ZEALAND, Campbell I., Tucker Cave, 4m, Malaise trap, 27.xi-1.xii.1961, J.I. Gressit Collector. Paradoxa fusca Marsh $q$ det. 1962, R.A. Harrison [ANIC] 
- 1ð̂, NEW ZEALAND, Campbell I., Tucker Cave, 4m, Malaise trap, 16-18.xii.1961, J.I. Gressit Collector. Paradoxa fusca Marsh §o det. 1962, R.A. Harrison [ANIC]

- 1 ㅇ, NEW ZEALAND, Hongi’s Track, Rotorua, 7.xi.1970, H.A. Oliver, Malaise trap. Oliveira, S.S. det. 2011 [ANIC]

- Jaschhof \& Kallweit (2009)

Paradoxa paradoxa Jaschhof

- 19, SOUTH AFRICA, Natal, 75 Km WSW Estcourt Cathedral Peaks For Stn. 1500m, 7-31.xii.1979, S. \& J. Peck. Oliveira, S.S. det. 2012 [CNC]

- Jaschhof (2006)

- Oliveira \& Muller (2012)

Sigmoleia melanoxantha Tonnoir \& Edwards

- 5ふ⿱㇒, NEW ZEALAND, North Island, Central Plateau, Kaimanawa Forest Park, ex. Malaise trap Notophagus bush, 24-31.i.1971, H.A. Oliver. Oliveira, S.S. det. 2011 [ANIC]

- 19, NEW ZEALAND, North Island, Kauaeranga, Vly. Thames, Malaise trap, 2729.xi.1970, H.A. Oliver. Oliveira, S.S. det. 2011 [ANIC]

- 1ð, NEW ZEALAND, Kanaeranga Vly., 23.i-2.ii.1970, Malaise trap, H.A. Oliver. Oliveira, S.S. det. 2011 [ANIC]

- 1ふ, NEW ZEALAND, Hongi's Track, Rotorua, 7.v.1970, H.A. Oliver, Malaise trap. Oliveira, S.S. det. 2011 [ANIC]

- $1 \delta^{\lambda} 1$, NEW ZEALAND, M.C. Hinewaires, Banks Pen, Malaise trap Quiet Stm., 1.v-10.vii.1994, J.B. Ward. Sigmoleia melanoxantha Edw. §,, L. Matile det. 1997 / Sigmoleia melanoxantha Edw. ㅇ, L. Matile det. 1997 [ANIC]

Sigmoleia peterjohnsi Jaschhof \& Kallweit

- $1 ð$ 2 9 , NEW ZEALAND, Huia, Auckland, 25-26.iv.1970, Malaise trap, H.A. Oliver. Oliveira, S.S. det. 2011 [ANIC]

Cawthronia nigra Tonnoir

- Jaschhof \& Kallweit (2009) 
Cycloneura flava Marshall

- $1{ }^{\Uparrow} 1$ 1 , NEW ZEALAND, Whangamea Saddle, Nelson, South Is., 12-15.v.1970, H.A. Oliver, Malaise trap. Oliveira, S.S. det. 2011 [ANIC]

- 2q, NEW ZEALAND, S. Island, Lower Buller Gorge, Ohikanui Riv. Near Westport, Malaise trap in rain forest, 11-16.xii.1970, H.A. Oliver. Oliveira, S.S. det. 2011 [ANIC]

- 1ふ, NEW ZEALAND, Kanaeranga Vly., 23.i-2.ii.1970, Malaise trap, H.A. Oliver. Oliveira, S.S. det. 2011 [ANIC]

- 1q, NEW ZEALAND, Kanaeranga Vly., 23.i.1970, Malaise trap, H.A. Oliver. Oliveira, S.S. det. 2011 [ANIC]

- 19, NEW ZEALAND, North Island, Central Plateau, Kaimanawa Forest Park, ex. Malaise trap Notophagus bush, 24-31.i.1971, H.A. Oliver. Oliveira, S.S. det. 2011 [ANIC]

- 1q, NEW ZEALAND, Cass., 29.xi.1924, A. Tonnoir. Cycloneura flava Marsh. det. A. Tonnoir 1923 [ANIC]

- 19, NEW ZEALAND, Dun Mt. 3000ft, 5-7.i.1922, A. Tonnoir. Cycloneura flava Marsh. det. A. Tonnoir 1923 [ANIC]

Tonnwardsia aberrans (Tonnoir)

- 2q, NEW ZEALAND, Kanaeranga Vly., 23.i-2.ii.1970, Malaise trap, H.A. Oliver. Oliveira, S.S. det. 2011 [ANIC]

- 10 $\overbrace{}^{\wedge} 19$, NEW ZEALAND, North Island, S.E. National Park, Central Plateau, Malaise trap Notophagus bush, 28.xii.1970-2.i.1971, H.A. Oliver. Oliveira, S.S. det. 2011 [ANIC]

- 19, NEW ZEALAND, North Island, Central Plateau, Kaimanawa Forest Park, ex. Malaise trap Notophagus bush, 24-31.i.1971, H.A. Oliver. Oliveira, S.S. det. 2011 [ANIC]

Procycloneura paranensis Edwards

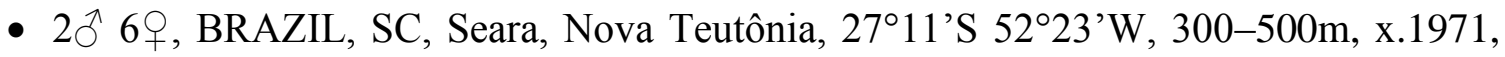
Fritz Plaumann Leg. Oliveira, S.S. det. 2011 [MZUSP]

- 2 ㅇ, BRAZIL, SC, Seara, Nova Teutônia, 27¹1'S 52²3’W, 300-500m, ix.1971, Fritz Plaumann Leg. Oliveira, S.S. det. 2011 [MZUSP] 


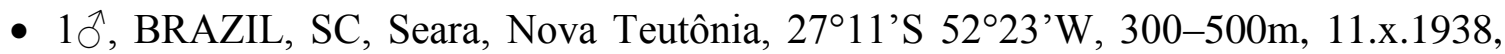
Fritz Plaumann Leg. BMNH(E) \#950074. Oliveira, S.S. det. 2011 [NHM]

- 19, BRAZIL, SC, Palhoça, Massiambu Pequeno, v.1957, E. Neto Leg. Oliveira, S.S. det. 2011 [MZUSP]

- 1, BRAZIL, PA, Ponta Grossa, Vila Velha, Res. IAPAR, Malaise trap, 29.xii.1986, PROFAUPAR. Oliveira, S.S. det. 2011 [MZUSP]

- $1 \AA$, BRAZIL, RJ, Itatiaia, Macieiras, i.1948, D. Andretta Leg. Oliveira, S.S. det. 2011 [MZUSP]

- 1 ภ 3 , , BRAZIL, SP, Campos do Jordão, iv.1957, Antunes. Oliveira, S.S. det. 2011 [MZUSP]

- 19, BRAZIL, SP, Campos do Jordão, xii.1955, J. Lane Leg. Oliveira, S.S. det. 2011 [MZUSP]

- 39, BRAZIL, SP, Cantareira, viii.1945, J. Lane Leg. Oliveira, S.S. det. 2011 [MZUSP]

- 2 + BRAZIL, SP, Cantareira, vii.1945, J. Lane Leg. Oliveira, S.S. det. 2011 [MZUSP]

- 4, BRAZIL, SP, Salesópolis, Reserva Biológica Boracéia, Trilha dos Pilões, 2339’05.1”S 4553’51,8”W, Malaise, 22.ii.2005, L.K. Nogueira \& A.P. Aguiar Leg. Oliveira, S.S. det. 2011 [MZUSP]

- 19, BRAZIL, SP, Jundiaí, Serra do Japi, 28.xii.1992, D.S. Amorim Leg. Oliveira, S.S. det. 2011 [MZUSP]

- 19, BRAZIL, MG, Botelhos, Córrego da Onça, 2140’90”S 46²2’05”W, Varredura, 02-05.xi.2006, D.S. Amorim, R.L. Falaschi \& S.S. Oliveira Leg. Oliveira, S.S. det. 2011 [MZUSP]

- 1, BRAZIL, MG, Botelhos, Córrego da Onça, 2140’90”S 46²2’05”W, Luz mata, 02-05.xi.2006, D.S. Amorim, R.L. Falaschi \& S.S. Oliveira Leg. Oliveira, S.S. det. 2011 [MZUSP]

- 19, BRAZIL, MG, Botelhos, Córrego da Onça, 2140’90”S 46²2’05”W, Luz mata, 15-19.vi.2007, D.S. Amorim, S.S. Oliveira \& R.S. Capellari Leg. Oliveira, S.S. det. 2011 [MZUSP]

- 1, BRAZIL, MG, Botelhos, Córrego da Onça, 2140’90”S 46²2’05”W, Luz mata, 5-20.xi.2006, D.S. Amorim, R.L. Falaschi \& S.S. Oliveira Leg. Oliveira, S.S. det. 2011 [MZUSP] 
Procycloneura similis Freeman

- 1ð̂, CHILE, Cameron, S. Bahia Inutil, T. d. Fuego, Magellanes, 14-17.xi.1960, E. Peña. Oliveira, S.S. det. 2012 [CNC]

- 1ð, CHILE, Estancia Vicina, SE of Cameron, Magellanes, 1-5.xii.1960, E. Peña. Oliveira, S.S. det. 2012 [CNC]

Leiella ochreocalcar Enderlein

- 5, BRAZIL, SC, Seara, Nova Teutônia, $27^{\circ} 11^{\prime}$ S 52²3’'E, 300-500m, vi.1970, Fritz Plaumann. Oliveira, S.S. det. 2012 [MZUSP]

- 19, BRAZIL, SC, Seara, Nova Teutônia, 27¹1'S 52²3’E, 300-500m, vii.1971, Fritz Plaumann. Oliveira, S.S. det. 2012 [MZUSP]

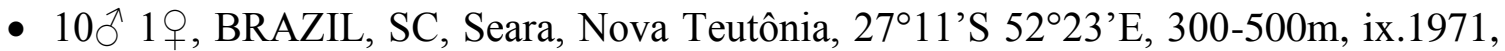
Fritz Plaumann. Oliveira, S.S. det. 2012 [MZUSP]

- 19, BRAZIL, SC, Seara, Nova Teutônia, 27²11'S 52²3’E, 300-500m, vii.1967, Fritz Plaumann. Oliveira, S.S. det. 2012 [MZUSP]

Leiella unicincta Edwards

- 1ð 1q, PARAGUAY, Piyapó, 28-31.xii.1971, L.E. Peña col. Oliveira, S.S. det. 2012 [MZUSP]

- 1Ô, BRAZIL, GO, Corumbá, xi.1945, Barretto col. ALOTIPO. Leiella unicincta det. John Lane, 1949 [MZUSP]

- 19, BRAZIL, SC, Massiambú Pq., v.1957., F. Neto col. Leiella unicincta det. John Lane, 1958 [MZUSP]

- 19, BRAZIL, MT, Poconé, Fr. Valelte, i.1951. Leiella unicincta det. John Lane, 1956 [MZUSP]

- 19, BRAZIL, AM, Ipixuna, Rio Gregório, Com. Lago Grande, 07¹0’11.7’S 7049’10.3”W, 18-20.v.2011, Malaise, J.A. Rafael, J.T. Câmara, R.F. Silva, A. Somavilla, C. Gonçalves Leg. Oliveira, S.S. det. 2012 [INPA]

- 19, BRAZIL, AM, Barcelos, Rio Aracá, Boca Rio Curuduri, 0005’50.2”N 63¹7’22.3”W, 15-19.vi.2010, Malaise, J.A. Rafael, R. Machado, R. Chavichioli, D. Takiya, P. Dias Leg. Oliveira, S.S. det. 2012 [INPA] 
- 19, BRAZIL, AM, Barcelos, Rio Aracá, Com. Bacuquara, 0009’17.5”N 6310'35.2”W, 12-14.vi.2010, Malaise, J.A. Rafael, R. Machado, R. Chavichioli, D. Takiya, P. Dias Leg. Oliveira, S.S. det. 2012 [INPA]

Leiella zonalis Edwards

- 1ठ̂, ARGENTINA, Tucumán, Queb: Cainzo, 18-19.xii.1950, Coll. R. Golbach. Leiella zonalis det. John Lane, 1956 [MZUSP]

- 1ð, ARGENTINA, Tucumán, La Cavera, 23-28.xi.1954, Aczel-Golbach. Oliveira, S.S. det. 2012 [MZUSP]

- 1ð, ARGEnTINA, La Cavera, Dep. Tafi, 23-28.xi.1961, M. Aczel \& R. Golbach. Leiella zonalis det. John Lane, 1953 [MZUSP]

- 1Ỏ, BRAZIL, SP, São Paulo, iii.1955, E. Camera col. Leiella zonalis det. John Lane, 1956 [MZUSP]

- 1ð, ARGENTINA, Santa Fé, Vera, 20.xii.1950, Coll. Duret. Leiella zonalis det. John Lane, 1954 [MZUSP]

- 1ð̂, ARGENTINA, Chaco, Laguna Limpia, 2.xii.1949, Col. Duret. Oliveira, S.S. det. 2012 [MZUSP]

- 19, BRAZIL, RJ, Angra dos Reis, x.1945, L. Trav. Fo col. Leiella zonalis det. John Lane, 1945 [MZUSP]

- 1q, ARGENTINA, Chaco, Colonia Benitez, 1-7.xii.1948, Coll. R. Golbach. Oliveira, S.S. det. 2012 [MZUSP]

- 19, TRINIDAD, U.S. Naval Station, T.H.G. Aitnen. Leiella zonalis det. John Lane, 1956 [MZUSP]

- 1 ㅇ, BRAZIL, GO, Corumbá, xi.1945, Barretto col. Oliveira, S.S. det. 2012 [MZUSP]

- 1q, BRAZIL, SP, São Paulo, ii.1944, Navajas col. Leiella zonalis det. John Lane, 1945 [MZUSP]

- 19, BRAZIL, SP, São Paulo, xi.1924. Leiella zonalis Edw. det. F.W. Edwards, 1931 [MZUSP]

- 19, PARAguAY, Canindeyú, Reserva Natural Bosque, Mbaracayú: Jejuí-mi, Malaise 5, bosque médio, 2-10.iv.1996, A.C.F. Costa Col. Oliveira, S.S. det. 2012 [DZUP] 
Anomalomyia guttata (Hutton)

- 4へ, NEW ZEALAND, Ohakune, 8.iii.1923, A.L. Tonnoir. Anomalomyia guttata (Hutton), det. D.H. Colless [ANIC]

- 2, NEW ZEALAND, Kanaeranga Vly., 23.i.1970, H.A. Oliver, Malaise trap. Oliveira, S.S. det. 2011 [ANIC]

Anomalomyia minor (Marshall)

- 1§̂, NEW ZEALAND, Nelson, 14.xi.1923, A.L. Tonnoir. Anomalomyia minor Mars., A. Tonnoir det. [ANIC]

- 1ð, NEW ZEALAND, Christchurch, 24.xi.1924, A.L. Tonnoir. Anomalomyia minor Mars., A. Tonnoir det. [ANIC]

Anomalomyia nasuta Matile

- 19, FRANCE, Nouvelle Calédonie, Rivière Bleue, Parc. 7, Alt. 170m, 11.viii1.ix.1986, LBDL-JC-AST. Anomalomyia nasuta n.sp. +, L. Matile det. 1991 [MNHN]

- 13 , FRANCE, Nouvelle Calédonie, Rivière Bleue Pardo, Alt. 160m, Forêt humide sur alluvions, 31.1-12.ii.1987, L.B. del., J.C. \& A. et S.T., PARATYPE, Anomalomyia nasuta n.sp., §̊ Paratype, L. Matile det. 1988 [MNHN]

- Matile (1993).

Ateleia spadicithorax Skuse

- 1ठ, AUSTRAliA, N.S.W., Bowral. HOLOTYPE. Atel: spadicithorax § TYPE. F.A.A. Skuse $[\mathrm{ANIC}]$

- 19, AUSTRALIA, N.S.W., 0,5 mi. NW of Bruxner Pk., 16.iv.1970, D.H. Colless. Oliveira, S.S. det. 2011 [ANIC]

- 19, AUSTRALIA, A.C.T., Black Mt., Malaise site 1, 30.i.1980, D.H. Colless. Oliveira, S.S. det. 2011 [ANIC]

- 1ð, AUSTRAliA, A.C.T., Black Mt., Light trap, 23.x.1960, I.F.B. Common. Oliveira, S.S. det. 2011 [ANIC]

- 1ठ઼, AUSTRALIA, A.C.T., Black Mt., Light trap, 28.ii.1963, I.F.B. Common. Oliveira, S.S. det. 2011 [ANIC] 
- 1ठ, AUSTRALIA, N.S.W., 30 mls. S of Singleton, Putty Road, 6.ii.1968, D.H. Colless. Oliveira, S.S. det. 2011 [ANIC]

- 1ð̄, AUSTralia, N.S.W., Colo Heights, Putty Road, 6.ii.1968, D.H. Colless. Oliveira, S.S. det. 2011 [ANIC]

- $1 ð$, AUSTRALIA, A.C.T., Black Mt., xii.1987, M. Irwin, Malaise trap. Oliveira, S.S. det. 2011 [ANIC]

- 1ð, AUSTRALIA, N.S.W., Clyde Mt., East slope., 26.x.1960, D.H. Colless. Oliveira, S.S. det. 2011 [ANIC]

Acrodicrania africana Edwards

- $3 \hat{\jmath} 3$ q, SOUTH AFRICA, Western Cape, Grootvadersbosch Nature Reserve, 3359.030'S 2049.128'E, 340m, 29.iii-23.vii.2010, S. van Noort, Malaise Trap, Afromontane Forest GVB10-FOR1-M03. Oliveira, S.S. det. 2011 [SAMC]

- Oliveira (2012)

Acrodicrania angustifurca Skuse

- 19, AUSTRALIA, N.S.W., Sydney, Mossman's Bay, September, Skuse. HOLOTYPE. A. angustifurca $\odot$ TYPE. F.A.A. Skuse [ANIC]

- 39, AUSTRALIA, Queensland, Lamington NP, Mycetophilidae, Malaise - Ground, $28^{\circ} 13^{\prime}$ S $153^{\circ} 07^{\prime}$ E, R. Kitching, July 1996. Oliveira, S.S. det. 2011 [AMSA]

- 10, AUSTRALIA, N.S.W., Carral SF, 11-16.i.1998, 1055m, 3054'19”'S 152 17 '36”E, Stick trap on E. obliqua, E. Tasker Leg, CC-DP-018-4. Oliveira, S.S. det. 2011 [AMSA]

- 1ð 1q, AUSTRALIA, N.S.W., Carral SF, 3-8.xii.1998, 1055m, 3054’33”S $152^{\circ} 16^{\prime} 28^{\prime \prime}$, Stick trap on E. campanulata, E. Tasker Leg, CC-CR-127-5. Oliveira, S.S. det. 2011 [AMSA]

- 1ð̂, AUSTRAliA, A.C.T., Black Mt., Light trap, 29.viii.1961, I.F.B. Common. Oliveira, S.S. det. 2011 [AMSA]

- 1ð, AUSTRALIA, N.S.W., Macquaire Pass, 9.x.1969, Common \& Upton, Light trap. Oliveira, S.S. det. 2011 [AMSA] 
Acrodicrania atricauda Skuse

- $1 \widehat{\jmath}$, AUSTRALIA, N.S.W., Sydney. HOLOTYPE. Acro: atricauda $\widehat{o}$ TYPE. F.A.A. Skuse [ANIC]

- 19 , AUSTRALIA, N.S.W., Sydney. HOLOTYPE. Acro: atricauda $q$ TYPE. F.A.A. Skuse [ANIC]

- 4, AUSTRALIA, Queensland, Lamington NP, Mycetophilidae M3, Malaise Ground, $28^{\circ} 13^{\prime}$ S $153^{\circ} 07^{\prime}$ E, R. Kitching, January 1995. Oliveira, S.S. det. 2011 [AMSA]

- $1 \delta^{\Uparrow} 1$, AUSTRALIA, Queensland, Lamington NP, Mycetophilidae M1, Malaise Ground, $28^{\circ} 13^{\prime}$ S $153^{\circ} 07^{\prime}$ E, R. Kitching, January 1995. Oliveira, S.S. det. 2011 [AMSA]

- 1ð̊, AUSTRALIA, N.S.W., Clyde Mt., Cabbage Tree Ck. 26.x.1960, D.H. Colless. Oliveira, S.S. det. 2011 [ANIC]

Acrodicrania fasciata Skuse

- 19 , AUSTRALIA, N.S.W, Sydney. HOLOTYPE. Acro: fasciata 9 TYPE. F.A.A. Skuse [ANIC]

- $3 q$, AUSTRALIA, Queensland, Lamington NP, Mycetophilidae, Malaise - Ground, $28^{\circ} 13^{\prime}$ S $153^{\circ} 07^{\prime} \mathrm{E}, \mathrm{R}$. Kitching, July 1996. Oliveira, S.S. det. 2011 [AMSA]

- 1ð̄, AUSTRALIA, N.S.W., Snowy-Thredbo Junction, 8.xi.1961, D.H. Colless. Oliveira, S.S. det. 2011 [ANIC]

Acrodicrania setosicauda Skuse

- 1ðં, AUSTRAliA, N.S.W., Sydney. HOLOTYPE. Acro: setosicauda ô TYPE. F.A.A. Skuse $[$ ANIC]

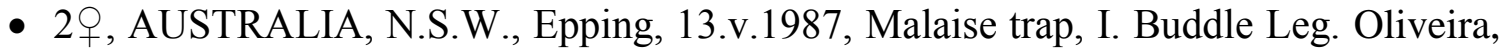
S.S. det. 2011 [AMSA]

- $1 \hat{\jmath}$, AUSTRALIA, Victoria, Buxton, 22.x.1961, D.H. Colless. Oliveira, S.S. det. 2011 [ANIC]

- 10̄, AUSTRALIA, A.C.T., 20.x.1960, D.H. Colless. Oliveira, S.S. det. 2011 [ANIC]

- 19, AUSTRALIA, S.A., Mt. Crawford, State Forest, 6.viii.1968, Colless \& Liepa. Oliveira, S.S. det. 2011 [ANIC] 
Caledonileia pusilla Matile

- 1ठ̂, FRANCE, Nouvelle Calédonie, Haule Rivière Bleue, 250m, Forêt humide, 166³7’24’'E 22³4'40”S, station 243, piège de Malaise, 11.xi.1984, S. Tillier, Ph. Bouchet \& M.P. Triclot. PARATYPE, ふ̋. Caledonileia pusilla n.sp., ふ̊ Paratype, L. Matile det. 1990 [MNHN]

- Matile (1993).

Neoclastobasis draskovitsae Matile

- $1 \delta^{\Uparrow} 1 q$, SLOVAKIA, west Povazkú Inovec Mts., Lúka env., Ihelnik Nat. Res., 27.ix4.x.1999, M. Kozánek Leg., Malaise trap. Neoclastobasis draskovitsae Matile, 1978. Jan Ševčik det. 2010 [LMED]

Neoclastobasis kamijoi (Sasakawa)

- 1ô 1q, SOUTH KOREA, S. Corée-Sanan, 21i (Keumsan), 5-12.vi.1998, P. Tripotin rec. Neoclastobasis kamijoi ${ }_{+}$(Sasak). det. Kurina, O. 2008. / Neoclastobasis kamijoi $\precsim$ (Sasak). det. Kurina, O. 2008 [MNHN]

Greenomyia cephala (Garrett)

- 19, CANADA, B.C., Aspen Grove, 20.vi.1973, H.J. Taskey. Oliveira, S.S. det. 2012 $[\mathrm{CNC}]$

- 19, USA, Colo., Mt. Evans, Echo L. 10,600’, 8.viii.1961, S.M. Clark. Oliveira, S.S. det. 2012 [CNC]

- 19, CANADA, Que., Old Chelsea, 4.vi.1964, J.R. Vockeroth. Oliveira, S.S. det. 2012 $[\mathrm{CNC}]$

- 2ð̄, CANADA, Que., Old Chelsea, 25.v.1964, J.R. Vockeroth. Swept from Pedicularis canadensis L. Oliveira, S.S. det. 2012 [CNC]

- 1ð̃, CANADA, Que., Old Chelsea, 28.v.1963, J.R. Vockeroth. Oliveira, S.S. det. $2012[\mathrm{CNC}]$

Greenomyia joculator (Laffoon)

- 1ð̄, USA, Colo., Doolittle Ranch, Mt. Evans 9,800', 31.vii.1961, C.H. Mann. Slide HCW 7.xii. 1976 n $^{\circ}$ D. Oliveira, S.S. det. 2012 [CNC] 
- 2q, USA, Ore., 9 mi. W. Unity Baker, Co. 4,500', 2.vii.1965, Malaise trap. Oliveira, S.S. det. $2012[\mathrm{CNC}]$

Greenomyia mongolica Laštovka \& Matile

- 1ô 1q, SLOVAKIA, west Povazkú Inovec Mts., Lúka env., 13-20.ix.1999, M. Kozánek Leg., Malaise trap. Greenomyia mongolica Laštovka \& Matile, 1974. Jan Ševčik det. 2010 [LMED]

- Kurina et al. (2011)

Greenomyia stackelbergi Zaitzev

- 20̂, NORWAY, EIS 28 AK, Oslo, Hengsenga, 8.viii-7.ix.2007, UTMWG58432 VNM93414318, Malaise trap [propgly/ethanol], Leg. Anders Endrestor. Greenomyia stackelbergi Zaitzev, 1982. Eirik Rindal det. 2010 [LMED]

- Kurina et al. (2011)

Leia amapaensisi Lane

- 2へ̂, BRAZIL, AP, Serra do Navio, 24.ix.1957, J. Lane Leg. PARÁTIPO [MZUSP]

- 2ð, BRAZIL, AP, Serra do Navio, 24.ix.1957, J. Lane Leg. PARÁTIPO. Leia amapaensis det. John Lane 1957 [MZUSP]

- 1ð, BRAZIL, AP, Serra do Navio, 24.x.1957, J. Lane Leg. [MZUSP]

- 1ð 19, BRAZIL, AM, Barcelos, Rio Padauari, Com. Ararinha, 00³0’18”N 6403’30”W, 5-8.vi.2010, Malaise, R. Machado, P. Dias, J.A. Rafael Leg. Oliveira, S.S. det. 2012 [INPA]

- 19, BRAZIL, AM, Barcelos, Rio Aracá, Com. Bacuquara, 0009’17.5”N 63¹0’35.2’W, 12-14.vi.2010, Malaise, J.A. Rafael, R. Machado, R. Chavichioli, D. Takiya, P. Dias Leg. Oliveira, S.S. det. 2012 [INPA]

- 10̄, BRAZIL, AM, Barcelos, Rio Aracá, Boca Rio Curuduri, 0005'50.2”N 63¹7’22.3”W, 15-19.vi.2010, Malaise, J.A. Rafael, R. Machado, R. Chavichioli, D. Takiya, P. Dias Leg. Oliveira, S.S. det. 2012 [INPA]

Leia andirai Lane

- 19, BRAZIL, SP, Campos do Jordão, xii.1945, J. Lane. HOLÓTIPO. Leia andirai det. John Lane 1945 [MZUSP] 
- $1 \widehat{\jmath}$, BRAZIL, GO, Corumbá, Barretto col. PARÁTIPO [MZUSP]

- 10 , BRAZIL, SP, Santo Amaro, ix.1962. J. Lane col. ALÓTIPO. Desen. Leia andirai det. John Lane 1961 [MZUSP]

- 29, BRAZIL, SP, Morumbi, 1.xi.1949, J. Lane col. PARÁTIPO [MZUSP]

- 29, BRAZIL, SP, Santo Amaro, ix.1962. J. Lane col. [MZUSP]

- 3 , , BRAZIL, SP, Santo Amaro, xi.1960. J. Lane col. Leia andirai det. John Lane 1962 [MZUSP]

- 1, BRAZIL, RJ, Nova Iguaçu, Cascata, v.1960, D. Travassos col. Oliveira, S.S. det. 2012 [MZUSP]

- 2ô, BRAZIL, SP, Santo Amaro, xi.1962. J. Lane col. Leia andirai det. John Lane 1962 [MZUSP]

- 10, BRAZIL, SC, Seara, Nova Teutônia, 27²11'S 52²3’E, 300-500m, 11.vii.1958, Fritz Plaumann. Brit. Mus. 1938-682. Oliveira, S.S. det. 2012 [MZUSP]

- 1ð, ARGENTINA, Buenos Aires, Cap. Fed., 21.x.1950, Em casa, Duret Coll. Leia andirai det. John Lane 1954 [MZUSP]

\section{Leia arsona Hutson}

- 7ô 3ㅁ, SOUTH AFRICA, KwaZulu Natal, Pietermaritzburg, Hilton, 24.xii.200314.i.2004, Malaise trap / garden, M. Mostovski Coll. NMSA-DIP57658. Oliveira, S.S. det. 2011 [NMSA]

- 1ð̊, SOUTH AFRICA, KwaZulu Natal, Pietermaritzburg, Hilton, 1090m, 2734’S 31²17,9’E, 1-24.iii.2006, Malaise trap, M. Mostovski Coll. NMSA-DIP57724. Oliveira, S.S. det. 2011 [NMSA]

- 1ð 1q, SOUTH AFRICA, KwaZulu Natal, Pietermaritzburg, Hilton, 13-23.xi.2003, Malaise trap / garden, M. Mostovski Coll. NMSA-DIP57659. Oliveira, S.S. det. 2011 [NMSA]

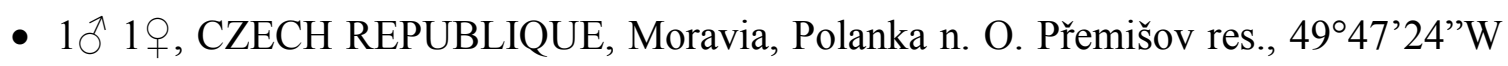
18¹1'23”N, 10.vii.2008, boggy md. ex. Gliceria maxima (B5) emerg. 20.ix-24.x, L. Rohaček Leg. Leia arsona Hutson, 1978, Jan Ševčik det. 2010 [LMED]

- Oliveira \& Muller (2012) 
Leia bivittata Say

- 1ठ̊, CANADA, Ont., Ottawa, 19.vii.1997, Montfort Hosp wood aerial sweep, J.R. Vockeroth. Oliveira, S.S. det. 2012 [CNC]

- 1ð, CANADA, Ont., Ottawa, 12.x.2003, Woods Nepean Sportflex, J.R. Vockeroth. Oliveira, S.S. det. 2012 [CNC]

- 1§, CANADA, Ont., Ottawa, 25.vii.1993, Damp second growth Acer betula wood, J.R. Vockeroth. Oliveira, S.S. det. 2012 [CNC]

- 19, USA, FL., Gainesville, 15-22.iv.1987, Hardwd. For, Malaise trap, Wahl \& Mason. Oliveira, S.S. det. 2012 [CNC]

- 1ð̂, USA, MO, Williamsville, x-xi.1968, J.T. Becker. Oliveira, S.S. det. 2012 [CNC]

Leia fascipennis Meigen

- 1ð, ENGLAND, Alfiston bussex, 22.vi.1942, G.E. Shewell Coll. Oliveira, S.S. det. $2012[\mathrm{CNC}]$

- 29, ENGLAND, Woodstock Oxon, 23.x.1952, J.R. Vockeroth. Oliveira, S.S. det. $2012[\mathrm{CNC}]$

- 1ð, SWEDEN, Vmld. Ekshärad, 22.vii.1960, W.R.M. Mason. Oliveira, S.S. det. 2012 $[\mathrm{CNC}]$

- 19, SWEDEN, Vmld. Ekshärad, 20.vii.1960, W.R.M. Mason. Oliveira, S.S. det. 2012 $[\mathrm{CNC}]$

Leia opima (Loew)

- 1ð̄, CANADA, Manitoba, 2 mi. NE Treesbank, along Souris R., 11.viii.1993, $49^{\circ} 40^{\prime} \mathrm{N} 99^{\circ} 36^{\prime} \mathrm{W}$, Malaise trap, B. Gallaway. Oliveira, S.S. det. 2012 [CNC]

- 1ð̋, USA, NE, Mt. Katahdin, 4.vii.1968, Abol, D.M. Wood. Oliveira, S.S. det. 2012 $[\mathrm{CNC}]$

- 1ふ, CANADA, Ont., Ottawa, 16.vii.1989, Damp second growth Acer betula wood, J.R. Vockeroth. Oliveira, S.S. det. 2012 [CNC]

- 19, CANADA, Ont., Ottawa, 9.vii.1989, Damp second growth Acer betula wood, J.R. Vockeroth. Oliveira, S.S. det. 2012 [CNC]

- 19, CANADA, Ont., Ottawa, 8.vii.2003, Damp second growth Acer betula wood, J.R. Vockeroth. Oliveira, S.S. det. 2012 [CNC] 
Leia spinifera Edwards

- $20^{\wedge} 6$, , BRAZIL, AM, Barcelos, Rio Padauari, Com. Ararinha, 00³0’18’N 6403’30”W, 5-8.vi.2010, Malaise, J.A. Rafael, R. Machado, P. Dias Leg. Oliveira, S.S. det. 2012 [INPA]

- 99, BRAZIL, AM, Barcelos, Rio Aracá, Boca Rio Curuduri, 0005'50.2”N 6317'22.3”W, 15-19.vi.2010, Malaise, J.A. Rafael, R. Machado, R. Chavichioli, D. Takiya, P. Dias Leg. Oliveira, S.S. det. 2012 [INPA]

- 129, BRAZIL, AM, Barcelos, Rio Aracá, Com. Bacuquara, 0009’17.5”N 6310’35.2”W, 12-14.vi.2010, Malaise, J.A. Rafael, R. Machado, R. Chavichioli, D. Takiya, P. Dias Leg. Oliveira, S.S. det. 2012 [INPA]

- 19, BRAZIL, AM, Barcelos, Rio Aracá, Boca Rio Curuduri, 0005’50.2”N 63¹7’22.3”W, 15-19.vi.2010, Suspensa septo amarelo lâmina d'água, J.A. Rafael, R.F. Silva Leg. Oliveira, S.S. det. 2012 [INPA]

Leia stigmatica Edwards

- 3 ふ 2 9 , SOUTH AFRICA, KwaZulu Natal, Natuer Reserve Gudu Forest, 16801730m, 2840.90’S 2855.78’E, 29.i-28.v.2006, Malaise trap, M. Mostovski Coll. NMSA-DIP57656. Oliveira, S.S. det. 2011 [NMSA]

- 1ð, SOUTH AFRICA, KwaZulu Natal, Pietermaritzburg, Hilton, 1090m, 27³4'S 31ำ17,'E, 1-24.iii.2006, Malaise trap, M. Mostovski Coll. NMSA-DIP57724. Oliveira, S.S. det. 2011 [NMSA]

- 1ठ, SOUTH AFRICA, KwaZulu Natal, Pietermaritzburg, Hilton, 4-23.x.2004, Malaise trap / garden, M. Mostovski Coll. NMSA-DIP57651. Oliveira, S.S. det. 2011 [NMSA]

- 1ð, SOUTH AFRICA, Western Cape, Grootvadersbosch Nature Reserve, 340m, 3359.030'S 2049.128'E, 29.iii-23.vii.2010, Malaise trap, Afromontane Forest, S. van Noort, GVB10-FOR1-M03. Oliveira, S.S. det. 2011 [SAMC]

- Oliveira (2012)

Leia ventralis Say

- 1 , , USA, MD, Laurel, 25.vi.1965, Malaise trap. Oliveira, S.S. det. 2012 [CNC]

- 1ð, CANADA, Que., Duncan Lake, Nr. Rupert, 6.vii.1970, J.F. McAlpine. Oliveira, S.S. det. $2012[\mathrm{CNC}]$ 
- 1ð, CANADA, Ont., Black Sturgeon Lake, 19.viii.1963, Emerg. ex. club cop f black spruce. Oliveira, S.S. det. 2012 [CNC]

- 1ð̄, CANADA, Ont., N. Burguess Twp., Lanark Co., 12.vii.1970, D.M. Wood. Oliveira, S.S. det. 2012 [CNC]

Leia winthemi Lehmann

- $3{ }^{\lambda}$ 2q, NORWAY, EIS 38 HES, Kongsvinger, Abborhøgda, 10.vii-06.ix.2003, UTMWGS84 33VUG591746, Karsten Sund Leg. Oliveira, S.S. det. 2012 [LMED]

- 19, CANADA, Ont., Mer Bleu 5 mi. E. Ottawa, 1.vii.1987, Malaise trap B, D.D. Munroe. Oliveira, S.S. det. 2012 [CNC]

- 1§, CANADA, Ont., Ottawa, Iroquois Falls, 21.vi.1987, Populus-Picea wood, rich underground, J.R. Vockeroth. Oliveira, S.S. det. 2012 [CNC]

- 1ð̄, CANADA, Ont., Ottawa, Iroquois Falls, 22.vi.1987, Populus-Picea wood, rich underground, J.R. Vockeroth. Oliveira, S.S. det. 2012 [CNC]

- 1, CANADA, Ont., 7 mi. E. Griffith, 10-16.xi.1983, B.E. Cooper. Oliveira, S.S. det. $2012[\mathrm{CNC}]$

Clastobasis alternans (Winnertz)

- $1 \lesssim 1$ 으, ITALY, South Tyrol, N. Park Stifser Joch, Schmeiz (SW of Prad), 940m, 46³6’42.1N 10³4’35.6E, Malaise, 11-27.vi.2005, Lange \& Ziegler Leg. Clastobasis alternans (Winnertz, 1863), Olavi Kurina det. 2010 [LMED]

Clastobasis loici Chandler

- 2ð, NETHERLANDS, Waarder (Z.H.), 28.vii.1975, C. van Achterberg. Oliveira, S.S. det. 2012 [CNC]

- 1ð, LUXEMBURG, Diekirch, 20.vi.1966, A.W. Steffan. Oliveira, S.S. det. 2012 [CNC]

- 1ð, NETHERLANDS, Nearder (Z.H.), vii.1975, C. van Achterberg. Oliveira, S.S. det. $2012[\mathrm{CNC}]$

- Chandler (2001) 
Clastobasis stylata Matile

- 2ð, FRANCE, New Caledonia, Plage de Poé, 15Km W. Bourail, 15.vii.1995, YPT. Oliveira, S.S. det. 2012 [CNC]

\section{Clastobasis tryoni Skuse}

- 1 , , AUSTRALIA, Brisbane, H. Tryon., Museum, 5.iii.1890, window. Clas. Tryoni $q$ TYPE. F.A.A. Skuse K2319 [AMSA]

- 4, AUSTRALIA, Qld., Repulse Ck. 23Km NE of Bauhinia Downs, 22.iv.1981, at light, D.H. Colless. Oliveira, S.S. det. 2012 [ANIC]

- 1ð, AUSTRALIA, N. Qld., 7-14m W of Herberton, via Watsonville, 1.v.1967, D.H. Colless. Oliveira, S.S. det. 2012 [ANIC]

- 1ð, AUSTRALIA, Qld., nr. Rosewood, Brigalow scrub, 20.xii.1961, R. Lindsay. Oliveira, S.S. det. 2012 [ANIC]

- 1ô, AUSTRALIA, N.T., Cooper Creek, 19Km E by S of Mt. Borradaile, 5.vi.1973, D.H. Colless. Oliveira, S.S. det. 2012 [ANIC]

- 1Ô, AUSTRALIA, N.T., Rimbijá Is., Wessel Islands, 11.01S 136.45E, 18.i.1977, E.D.Edwards. Oliveira, S.S. det. 2012 [ANIC]

Clastobasis vicina Matile

- 1ð̄, FRANCE, New Caledonia, Plage de Poé, 15Km W. Bourail, 15.vii.1995, YPT. Oliveira, S.S. det. 2012 [CNC]

Clastobasis sp.

- 4ð, BRAZIL, RJ, Nova Iguaçu, Reserva Biológica do Tinguá, 22³4’32”S 4326’07,6”W, Malaise Bosque ponto 3, 8-11.iii.2002, S.T.P. Amarante \& eq.col. Oliveira, S.S. det. 2010 [MZUSP]

- 3今, BRAZIL, RJ, Nova Iguaçu, Reserva Biológica do Tinguá, 22³4’27’S 4326'11,4”W, Malaise Bosque ponto 6, 8-11.iii.2002, S.T.P. Amarante \& eq.col. Oliveira, S.S. det. 2010 [MZUSP]

- $1 \delta^{\lambda} 1$, , BRAZIL, RJ, Nova Iguaçu, Reserva Biológica do Tinguá, 22³4’30”S $43^{\circ} 26^{\prime} 07^{\prime \prime} \mathrm{W}$, Malaise Trilha ponto 1, 8-11.iii.2002, S.T.P. Amarante \& eq.col. Oliveira, S.S. det. 2010 [MZUSP] 
- 1ठ 2q, BRAZIL, RJ, Nova Iguaçu, Reserva Biológica do Tinguá, 22³4’28”S 4326'09'W, Malaise Trilha ponto 5, 5-8.iii.2002, S.T.P. Amarante \& eq.col. Oliveira, S.S. det. 2010 [MZUSP]

- $1 \delta^{\lambda} 2$, BRAZIL, RJ, Nova Iguaçu, Reserva Biológica do Tinguá, 22³4’28”S $43^{\circ} 26^{\prime} 10,7^{\prime \prime} \mathrm{W}$, Malaise Bosque ponto 5, 8-11.iii.2002, S.T.P. Amarante \& eq.col. Oliveira, S.S. det. 2010 [MZUSP]

\section{ALLACTONEURINAE}

Allactoneura arguentosquamosa (Enderlein)

- 1ठ̃, MADAGASCAR, Sambirano Lokobe Nosse Bé 6m, 9-23.xi.1957, B. Stuckenberg. Allactoneura arguentosquamosa (Enderlein) det. B. Stuckenberg 1959. Natal Museum, Pietermaritzburg, South Africa [NMSA]

Allactoneura cincta de Meijere

- 19, S. INDIA, Coimbatore, viii.1953, P.S. Nathan. Oliveira, S.S. det. 2012 [CNC]

- $1 \delta^{\lambda} 1$, S. INDIA, Walayar Forests, S. Malabar .000’, x.1952, P.S. Nathan. Oliveira, S.S. det. $2012[\mathrm{CNC}]$

- 1ð, S. INDIA, Ammatti, S. Coorg 3100', x.1952, P.S. Nathan. Oliveira, S.S. det. 2012 $[\mathrm{CNC}]$

- $1 \widehat{\jmath}$, S. INDIA, Cherangode, Niguiri Hills, 3500ft, x.1950, P.S. Nathan. Oliveira, S.S. det. $2012[\mathrm{CNC}]$

Allactoneura papuensis Bechev

- PAPUA NEW GUINEA, Bainyik, 20.xii.1963, D.K. McAlpine. Oliveira, S.S. det.

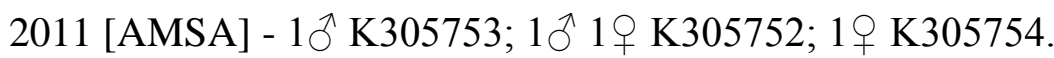

- 1ð̄, PAPUA NEW GUINEA, Bainyik, 17.xii.1963, D.K. McAlpine. K305756. Oliveira, S.S. det. 2011 [AMSA]

- 19, AUSTRALIA, N. Qld., Middle Claudie River, Iron Range, 1.x.1974, G. Daniels. K305761. Oliveira, S.S. det. 2011 [AMSA]

- 19, AUSTRALIA, N. Qld., Middle Claudie River, Iron Range, 28.ix.1974, G. Daniels. K305761. Oliveira, S.S. det. 2011 [AMSA] 
Sticholeia cheesmanae Søli

- 1ठ, AUSTRALIA, Queensland, Claudie R., 5 miles W. Mt. Lamond, 14.i.1972, D.K. McAlpine \& G.A. Holloway. K305801. Oliveira, S.S. det. 2011 [AMSA]

- 19, AUSTRALIA, N. Queensland, Earl Hill, N. of Cairns, 8.v.1967, D.H. Colless [ANIC]

- 1ð, AUSTRALIA, N.T., Baroalba Ck., Springs, 19Km NE by E of Mt. Cahill, 17.xi.1972, D.H. Colless [ANIC]

Sticholeia dolichostyla Søli

- PAPUA NEW GUINEA, Kokoda, 6.i.1964, D.K. McAlpine. Oliveira, S.S. det. 2011 [AMSA] - 3ð K305810; 1ð 1q K305811; 1우 K305814; 1우 K305815; 1 q K305816; 1 ○ K305818.

- 1ð̄, PAPUA NEW GUINEA, Brown R. near Pt. Moresby, 21.x.1963, D.K. McAlpine. K305821. Oliveira, S.S. det. 2011 [AMSA]

- PAPUA NEW GUINEA, Bubia near Lae, 27.xii.1963, D.K. McAlpine. Oliveira, S.S. det. 2011 [AMSA] - 1 q K305817; $1{ }^{\Uparrow} \mathrm{K} 305819$.

- 1ð, PAPUA NEW GUINEA, Bambu R., 8Km. N. Lae, Morabe District, 29.xi.1972, G.A. Holloway. K305813. Oliveira, S.S. det. 2011 [AMSA]

Sticholeia loici Søli

- PAPUA NEW GUINEA, Bainyik, 20.xii.1963, D.K. McAlpine. Oliveira, S.S. det. 2011 [AMSA] - 1ð K305805; 1ð K305806; 1ð K305807.

- PAPUA NEW GUINEA, Apangai near Maprik, 15.xii.1963, D.K. McAlpine. Oliveira, S.S. det. 2011 [AMSA] - 19 K305808; 19 K305809.

- 1ð̋, PAPUA NEW GUINEA, Kuminibus near Maprik, 17.xii.1963, D.K. McAlpine. K305803. Oliveira, S.S. det. 2011 [AMSA]

- 1ð̊, PAPUA NEW GUINEA, Imbia near Maprik, 18.xii.1963, D.K. McAlpine. K305804. Oliveira, S.S. det. 2011 [AMSA]

- 19, PAPUA NEW GUINEA, Oomsis, Lae, 06² $40^{\prime} \mathrm{S} 146^{\circ} 48^{\prime} 0 \mathrm{E}$, Mycetophilidae, Yellow Pan 3, 25.vii.2000, R.L. Kitching. Oliveira, S.S. det. 2011 [AMSA]

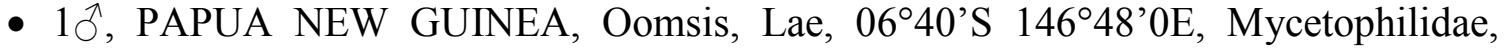
Malaise ground 1, 24.vii.2000, R.L. Kitching. Oliveira, S.S. det. 2011 [AMSA] 


\section{MANOTINAE}

\section{Eumanota sp.}

- 19, PAPUA NEW GUINEA, Oomsis, Lae, 06² 40’S 146²'0E, Mycetophilidae, Malaise ground 1, 26.vii.2000, R.L. Kitching. Oliveira, S.S. det. 2011 [AMSA]

- 19, PAPUA NEW GUINEA, Oomsis, Lae, 06²0’S 14648’0E, Mycetophilidae, Malaise ground 2, 25.vii.2000, R.L. Kitching. Oliveira, S.S. det. 2011 [AMSA]

- Søli (2002).

\section{Promanota malaisei Tuomikoski}

- 1ठ, INDIA, N.E. Burma, Kambaiti, 2000m, 11.v.1934, Malaise. Mus. Zool. Helsinki, Loan nr. D00-171. Mus. Zool. Helsinki Loan no. DIP2011 34 [FMNH]

- 1ð̄, INDIA, N.E. Burma, Kambaiti, 2000m, 4.vi.1934, Malaise. Mus. Zool. Helsinki, Loan nr. D00-173. Mus. Zool. Helsinki Loan no. DIP2011 33 [FMNH]

- 1ð̄, INDIA, N.E. Burma, Kambaiti, 2000m, 4.vi.1934, Malaise. Mus. Zool. Helsinki, Loan nr. D00-172. Mus. Zool. Helsinki Loan no. DIP2011 35 [FMNH]

- $1{ }^{\AA}$, THAILAND, Chiang Mai Doi Inthanon NP, Checkpoint 2, 1700m, 18³1.559’N 98²9.941'E, 29.vi-2.vii.2006, Malaise trap, Y. Areeluck Leg. T44. Promanota malaise Tuom., 1966, det. Jan Ševčik 2011 [LMED]

- Hippa et al. (2004)

Manota palpalis Lane

- 10, BRAZIL, AM, Barcelos, Rio Padauari, Com. Ararinha, 00³0’18”N 6403’30”W, 5-8.vi.2010, Malaise, J.A. Rafael, R. Machado, P. Dias Leg. Oliveira, S.S. det. 2012 [INPA]

- $2{ }^{\Uparrow}$ 19, BRAZIL, AM, Ipixuna, Rio Gregório, Com. Lago Grande, 07¹0’11.7’’S 7049’10.3”W, 18-23.v.2011, Malaise, J.A. Rafael, J.T. Câmara, R.F. Silva, A. Somavilla, C. Gonçalves Leg. Oliveira, S.S. det. 2012 [INPA]

- $1 \delta^{\Uparrow} 1$, , BRAZIL, AM, Ipixuna, Rio Liberdade, Estirão da Preta, 07²1'46.7’'S 7152'07.1'W, 11-15.v.2011, Malaise, J.A. Rafael, J.T. Câmara, R.F. Silva, A. Somavilla, C. Gonçalves Leg. Oliveira, S.S. det. 2012 [INPA] 


\section{MYCETOPHILINAE}

Exechiopsis sp.

- 7ð 1, BRAZIL, AM, Ipixuna, Rio Liberdade, Estirão da Preta, 07²1'46.7’'S 7152'07.1’W, 11-15.v.2011, Malaise, J.A. Rafael, J.T. Câmara, R.F. Silva, A. Somavilla, C. Gonçalves Leg. Oliveira, S.S. det. 2012 [INPA]

Rymosia sp.

- 1ð 2q, BRAZIL, SC, São Bento do Sul, CEPA - Rugendas, Bosque B5, 1619.x.2001, refuge. Oliveira, S.S. det. 2012 [MZUSP]

Epicypta sp.

- 2ð 5q, BRAZIL, SP, Sertãozinho, Res. Biol. Augusto Ruschi, 22.ix-13.x.2010, Malaise fragment 2 (borda), Silva, V.C., Donda, P.F. \& Ignácio, G. Leg. Oliveira, S.S. det. 2011 [MZUSP]

Mycetophila sp.

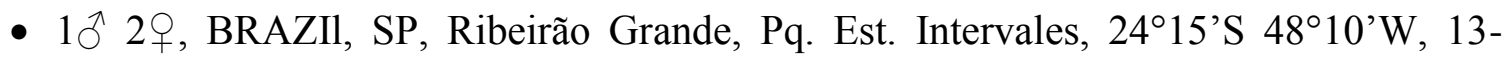
16.xii.2000, Malaise ponto T3, M.T. Tavares \& eq. col. Oliveira, S.S. det. 2011 [MZUSP]

MYCOMYINAE

Neoempheria sp.

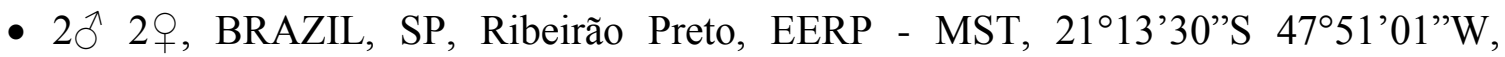
13.iii.2009, em tronco podre, Biffi, G. \& Nascimento, E.A. Col. [LMED]

Mycomya sp.

- $1 \delta^{\Uparrow}$ 6ㅇ, BRAZIl, SC, Urubici, Morro Igreja, 18.viii-5.xii.2005, Malaise, Pinho \& Bizzo Col. Oliveira, S.S. det. 2012 [MZUSP] 


\section{GNORISTINAE}

Synapha sp.

- AUSTRAliA, N.S.W., Warrumbungies, 15.ix.1983, D.K. McAlpine \& B.J. Day. Oliveira, S.S. det. 2011 [AMSA] - 1q K308296; 1 ㅇ K308291; 1ठ K308295; 1ठ K308294; 1 ठ K308768; 1 Љ K308292.

Austrosynapha hirta Tonnoir

- 1q, AUSTRALIA, Tasmania, Burnie, 26.x.1922, A. Tonnoir. HOLOTYPE. Austrosynapha hirta sp.n. A. Tonnoir det. [ANIC]

- 1, AUSTRALIA, Tasmania, Mt. Wellington, 27.xi.1922, A. Tonnoir. PARATYPE. Austrosynpha hirta sp.n. A. Tonnoir det. [ANIC]

- $3 \hat{\jmath}$ 5, AUSTRALIA, Tas., Ewart Ck., 41.58S 145.28E, 16.i-2.ii.1983, Malaise ethanol, I.D. Naumann \& J.C. Cardale. Oliveira, S.S. det. 2011 [ANIC]

Dziedzickia medea Lane

- Oliveira (2009)

Schnusea caiabii Lane

- Oliveira (2009)

Boletina obscura Johhansen

- 1ठ, CANADA, Ont., Ottawa, 27.iv.1955, J.F. McAlpine, Rockcliffe Mc Kay Leg. Oliveira, S.S. det. 2012 [CNC]

- 1ð, CANADA, Que., Old Chelsea, 6.v.1956, at birch sap. J.R. Vockeroth. Oliveira, S.S. det. 2012 [CNC]

- 1ð̄, CANADA, Ont., Marmora, 21.v.1952, J.F. McAlpine. Oliveira, S.S. det. 2012 $[\mathrm{CNC}]$

Palaeodocosia vittata (Coquillett)

- 1ð, CANADA, BC, Squamish, Diamond Head Trail 3500ft., 17.viii.1953, G.J. Spencer. Oliveira, S.S. det. 2012 [CNC]

- 19, CANADA, BC, Squamish, Diamond Head Trail 4000ft., 19.viii.1953, G.J. Spencer. Oliveira, S.S. det. 2012 [CNC] 
- 1ठ, USA, Calif, Lily Pond, Alpine Lk., Marion Co., 1500', Malaise trap, v.1976, D.D. Munroe. Oliveira, S.S. det. 2012 [CNC]

- 1Ô, CANADA, Que., Hull, 10.viii.1965, Malaise trap. Oliveira, S.S. det. 2012 [CNC]

- 1q, CANADA, MB, Fort Churchill, 12.viii.1952, J.G. Chillcott. Ecological data f. E. 21. Oliveira, S.S. det. 2012 [CNC]

Tetragoneura borgmeieri Edwards

- 34ð̋, BRAZIL, SP, Salesópolis, Res. Biol. Boracéia, Trilha dos Pilões, 23³9’02,9”S 4553'39’'W, 2-5.iv.2001, Malaise Trilha 2, S.T.P. Amarante \& eq. col. Oliveira, S.S. det. 2012 [MZUSP]

Tetragoneura guajaensis Lane

- 1ठ̂, BRAZIL, SP, Cantareira, vii.1945, J. Lane col. HOLÓTIPO. Tetragoneura guajaensis det. John Lane 1957 [MZUSP]

- 2ô, BRAZIL, SP, Santo Amaro, vii.1945, J. Lane \& E. Coher col. PARÁTIPO [MZUSP]

- 1Ō, BRAZIL, SP, Morumbi, 1.xi.1949, light, E. Coher col. PARÁTIPO [MZUSP]

- 14ðึ, BRAZIl, SC, Urubici, 5.xii.2004-8.ii.2005, Malaise, Bizzo \& Hugo Leg. Oliveira, S.S. det. 2012 [MZUSP]

Tetragoneura mínima Tonnnoir \& Edwards

- 1ð, NEW ZEALAND, Campbell I., Tucker Cave, 1-50m, 12-17.xii.1961, J.I. Gressit Collector. Tetragoneura minima Tonn. $q$ det. 1962, R.A. Harrison [ANIC]

- 1ð̄, NEW ZEALAND, Campbell I., Mt. Dumas, slope, 20.xii.1961, Sedge, J.I. Gressit Collector. Tetragoneura minima Tonn. ô det. 1962, R.A. Harrison [ANIC]

- 1ð, NEW ZEALAND, Campbell I., Tucker Cave, 4m, 1-3.xii.1961, Malaise trap, J.I. Gressit Collector. Tetragoneura minima Tonn. $\widehat{\sigma}$ det. 1962, R.A. Harrison [ANIC]

- 19, NEW ZEALAND, Campbell I., Courejolles Penin., 200m, 14.xii.1961, Gray headed Mollymamk nests, J.I. Gressit Collector. Tetragoneura minima Tonn. $q$ det. 1962, R.A. Harrison [ANIC]

- 1ふ,, NEW ZEALAND, Campbell I., Tucker Cave, 4m, 16-18.xii.1961, J.I. Gressit Collector. Tetragoneura minima Tonn. ○̊ det. 1962, R.A. Harrison [ANIC] 
- 1ठ, NEW ZEALAND, Campbell I., Tucker Cave, 4m, 18-21.xii.1961, Malaise trap, J.I. Gressit Collector. Tetragoneura minima Tonn. đot. 1962, R.A. Harrison [ANIC]

\section{Tetragoneura nitida Adams}

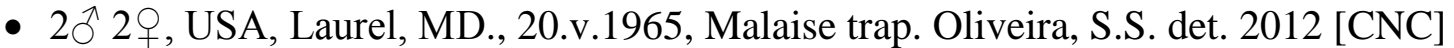

- 1ð̊, USA, NC, Clingman Dome, 6647', 21.v.1965, Great Smoky M.N.P., J.G. Chillcott. Oliveira, S.S. det. 2012 [CNC]

\section{Tetragoneura nocticolor Edwards}

- 54へ̋, BRAZIl, SC, Urubici, 5.xii.2004-8.ii.2005, Malaise, Bizzo \& Hugo Leg. Oliveira, S.S. det. 2012 [MZUSP]

- $80^{\lambda} 3$, BRAZIl, SC, São Francisco do Sul, Vila da Glória, Malaise trilha 5, 1720.x.2001, refugo. Oliveira, S.S. det. 2012 [MZUSP]

\section{Tetragoneura sylvatica (Curtis)}

- 1ð̋, SLOVAKIA, Centr. Polana B.R., 1250m, Lubletovský Vepor N.N.R., 6.ii.2006, Sweeping, Jan Ševčik Leg. Tetragoneura sylvatica (Curtis, 1837) Jan Ševčik det. 2010 [LMED]

- $1 \lesssim$, NETHERLANDS, Waarder (Z.H.), 28.vii.1975, C. van Achterberg. Oliveira, S.S. det. $2012[\mathrm{CNC}]$

- 19, NETHERLANDS, Waarder (Z.H.), vii.1975, C. van Achterberg. Oliveira, S.S. det. $2012[\mathrm{CNC}]$

- 1ð, NETHERLANDS, Steckelheek duin, Rochanjezh, 10.viii.1976, C. van Achterberg. Oliveira, S.S. det. 2012 [CNC]

Ectrepesthoneura bicolor (Coquillett)

- 2へ̂, USA, Laurel, MD., 20.v.1965, Malaise trap. Oliveira, S.S. det. 2012 [CNC]

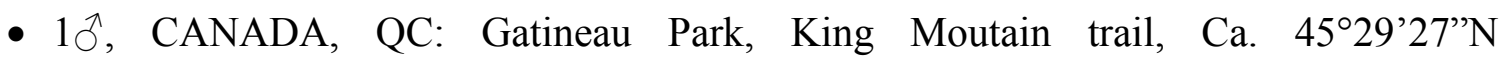
7551'51’W, 13.v.2009, S.E. Brooks. Oliveira, S.S. det. 2012 [CNC]

- 19, CANADA, Ont, Simcoe, 5.vi.1939, G.E. Shewell. Oliveira, S.S. det. 2012 [CNC] 
Ectrepesthoneura colyeri Chandler

- $2{ }^{\lambda}$, SWEDEN, Sm: Ulvsdal. Malaise trap. $\mathrm{N}=58^{\circ} 32^{\prime} ; \mathrm{E}=16^{\circ} 13^{\prime}$, Leg. N. Franc \& Co. 14.v-14.vi.2002. Ectrepesthoneura colyeri Chandler, 1980. Det. O. Kurina 2009 [LMED]

Ectrepesthoneura hirta (Winnertz)

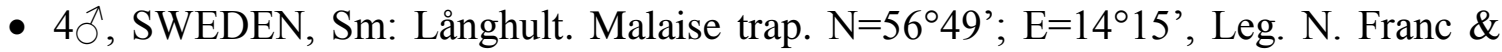
Co. 10.v-10.vi.2004. Ectrepesthoneura hirta (Winnertz, 1846). Det. O. Kurina 2009 [LMED]

Ectrepesthoneura laffooni Chandler

- 2ð, CANADA, Que., Old Chelsea, Summit King Mt. 1150', 11.vii.1965, Malaise trap, Mounted from alcohol. Oliveira, S.S. det. 2012 [CNC]

- 19, CANADA, Que., Old Chelsea, Summit King Mt. 1150', 16.vi.1965, J.R. Vockeroth. Oliveira, S.S. det. 2012 [CNC]

- 19, USA, NIC., Cligman's Dome, 5.viii.1957, W.R. Richards. Oliveira, S.S. det. 2012 $[\mathrm{CNC}]$

- 1ð, CANADA, Ont., 6 mi. W.R. Richmond, 1.vii.1971, J.E.H. Martin. Oliveira, S.S. det. $2012[\mathrm{CNC}]$

Ectrespesthoneura pubescens (Zetterstedt)

- $2{ }^{\lambda}$, SWEDEN, Ög: Fagerhult. Malaise trap. N=58 $4^{\prime} ; \mathrm{E}=15^{\circ} 31^{\prime}$, Leg. N. Franc \& Co. 14.v-14.vi. 2002. Ectrepesthoneura pubescens (Zatterstedt, 1860). Det. O. Kurina 2009 [LMED]

Novakia miloi Kerr

- $4 \widehat{\delta} 8$, USA, CA: Humboldt Co., Humboldt Bay NWR, Lanphere Dunes, MT\#1 (6m), -6masl, 10.vi-18.viii.2008, 4053.488’N 12408.580’W, P.H.Kerr, P.Haggard Leg. CSCA09L111. Mycetophilidae 09D204, Novakia miloi Kerr, 2007. Peter Kerr det. Jul2009 [LMED]

Docosia adusta Oliveira \& Amorim

- Oliveira \& Amorim (2011) 
Docosia dichroa Loew

- 1ठ, CANADA, Que., North Ck., Mt. St. Hilaire, 3-6.v.1982, B.M. Nelson. Oliveira, S.S. det. $2012[\mathrm{CNC}]$

- 1ð, CANADA, Ont., Metcalfe, 12.v.1983, B.E. Cooper. Oliveira, S.S. det. 2012 $[\mathrm{CNC}]$

- 1ð̂, CANADA, Que., Dunkan Lake nr. Rupert, 13.v.1973, J.F. McAlpine. Oliveira, S.S. det. $2012[\mathrm{CNC}]$

- 19, CANADA, Que., Dunkan Lake nr. Rupert, 20.v.1973, J.F. McAlpine. Oliveira, S.S. det. $2012[\mathrm{CNC}]$

- 1ð, CANADA, Que., Old Chelsea, 14.v.1980, J.R. Vockeroth, sweept over bare path in Acer wood. Oliveira, S.S. det. 2012 [CNC]

- 19, CANADA, Que., Old Chelsea, 16.v.1901, J.R. Vockeroth. Oliveira, S.S. det. 2012 [CNC]

- 1q, USA, PA: Sullivan Co., Myoming State For., 5Km NW Laporte, 6.v.1987, J.M. Cumming. Oliveira, S.S. det. 2012 [CNC]

Docosia fuscipes (von Roser)

- $2 \widehat{o}$ CZECH REPUBLIQUE, Silesia Otice near Opava, Otická sopka Nat. Monument, 16.iv.2007, Sweeping veget. Jan Ševčik leg. Docosia fuscipes (von Roser, 1840), Jan Ševčik det. 2010 [LMED]

- Laštovka \& Ševčik (2006)

Docosia pammela Edwards

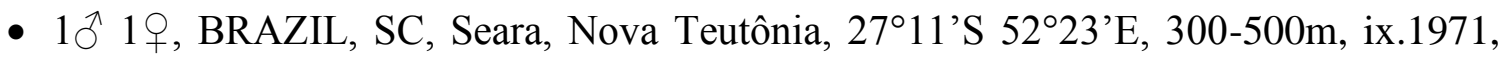
Fritz Plaumann. Oliveira, S.S. det. 2012 [MZUSP]

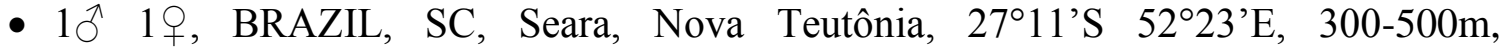
10.vii.1937, Fritz Plaumann. Oliveira, S.S. det. 2012 [MZUSP]

- $1{ }^{\lambda}$, BRAZIL, SC, Seara, Nova Teutônia, 2711'S 52²3’'E, 300-500m, ix.1970, Fritz Plaumann. Oliveira, S.S. det. 2012 [MZUSP]

- 1ठ, BRAZIL, SC, Seara, Nova Teutônia, 27¹1'S 52²3'E, 300-500m, 15.vii.1938, Fritz Plaumann. Oliveira, S.S. det. 2012 [MZUSP] 
Docosia sciarina (Meigen)

- 1Ō, CZECH REPUBLIQUE, Silesia Otice near Opava, Otická sopka Nat. Monument, 16.iv.2007, Sweeping veget. Jan Ševčik leg. Docosia sciarina (Meigen, 1830), Jan Ševčik det. 2010 [LMED]

Docosia sp.

- $2 \widehat{o} 3$ q, USA, Calif., Baldy Mesa 7mi. E. Phelan San Bd' no Co., ii.1981. [CNC]

- 1ð̄, USA, Calif., Baldy Mesa 7mi. E. Phelan San Bd' no Co., 15-30.vi.1982, J.T. Huber $[\mathrm{CNC}]$

\section{SCIOPHILINAE}

Neoallocotocera fusca Tonnoir

- 1ð̂, AUSTRALIA, Tasmania, Cradle Valley, 12.i.1923, A. Tonnoir. HOLOTYPE. Neoallocotocera fusca sp.n. A. Tonnoir det. [ANIC]

- 1?, AUSTRALIA, Victoria, Sassafras, 22.x.1922, A. Tonnoir. PARATYPE. Neoallocotocera fusca? sp.n. A. Tonnoir det. [ANIC]

- 9ð, AUSTRALIA, Tas., 4Km E. Rosebery, 41.47S 145.35E, 16.i-1.ii.1983, Malaise ethanol, I.D. Naumann \& J.C. Cardale. Oliveira, S.S. det. 2011 [ANIC]

Tasmanina gracilis Tonnoir

- 1ð̄, AUSTRAliA, Tasmania, Mount Wellington, 30.xi.1922, A. Tonnoir. HOLOTYPE. Tasmanina gracilis n.sp. A. Tonnoir det. 65. Australian National Insect Collection [ANIC]

- 9ð, AUSTRALIA, Tas., 4Km E. Rosebery, 41.47S 145.35E, 16.i-1.ii.1983, Malaise ethanol, I.D. Naumann \& J.C. Cardale. Oliveira, S.S. det. 2011 [ANIC]

\section{TÁXONS FÓSSEIS}

Baisepesthoneura mesozoica Blagoderov

- Blagoderov (1998a)

Disparoleia cristata Blagoderov \& Grimaldi

- Blagoderov \& Grimaldi (2004) 
Hemolia matilei Blagoderov \& Grimaldi

- Blagoderov \& Grimaldi (2004)

Hemolia glabra Blagoderov \& Grimaldi

- Blagoderov \& Grimaldi (2004)

Izleiina mirifica Blagoderov \& Grimaldi

- Blagoderov \& Grimaldi (2004)

Izleiina spinitibialis Blagoderov \& Grimaldi

- Blagoderov \& Grimaldi (2004)

Lecadonileia parvistyla Blagoderov \& Grimaldi

- Blagoderov \& Grimaldi (2004)

Metaleia maculicauda Baxter \& Poinar

- Baxter \& Poinar (1994)

Palaeothoracotropis truculentus Blagoderov

- Blagoderov (1998a)

Palaeothoracotropis dundulensis Blagoderov

- Blagoderov (1998b)

Protragoneura platycera Blagoderov \& Grimaldi

- Blagoderov \& Grimaldi (2004)

Temaleia birmitica Blagoderov \& Grimaldi

- Blagoderov \& Grimaldi (2004)

Zeliinia orientalis Blagoderov \& Grimaldi

- Blagoderov \& Grimaldi (2004) 
Oliveira, S.S. \& Muller, B. 2012. The types of Lygistorrhinidae and Mycetophilidae (Diptera: Bibionomorpha) in the KwaZulu-Natal Museum, Pietermaritzburg, South Africa. African Invertebrates, 53(2), 703-714.

Oliveira, S.S. 2012. Mycetophilidae (Diptera: Bibionomorpha) type specimens in the Iziko South African Museum, Cape Town. African Entomology, 20(2), 386-389.

Oliveira, S.S. \& Amorim, D.S. 2010. Three replacement names for species of the subfamily Leiinae (Diptera, Mycetophilidae). Revista Brasileira de Entomologia, 54(2), 335336.

Oliveira, S.S. \& Amorim, D.S. 2011. Docosia adusta sp. n. (Diptera, Mycetophilidae) from the Colombian Andes: a Holarctic element in northwestern South America. Canadian Entomologist, 143, 688-696.

Oliveira, S.S. \& Amorim, D.S. 2012. Six new species of Paraleia Tonnoir (Diptera, Mycetophilidae): amphinotic elements at the northern range of the Andes. Zootaxa, $3186,1-24$.

Oliveira, S.S., Amorim, D.S. \& Blagoderov, V. 2012. Redescription of the enigmatic Thoracotropis cypriformis Freeman (Diptera, Mycetophilidae). Revista Brasileira de Entomologia, 56(4), 458-462. 


\title{
The types of Lygistorrhinidae and Mycetophilidae (Diptera: Bibionomorpha) in the KwaZulu-Natal Museum, Pietermaritzburg, South Africa
}

\author{
Sarah Siqueira Oliveira ${ }^{1^{*}}$ and Burgert S. Muller ${ }^{2}$ \\ ${ }^{1}$ Faculdade de Filosofia, Ciências e Letras de Ribeirão Preto - Universidade de São Paulo, Av. \\ Bandeirantes 3900, 14040-901, Ribeirão Preto, SP, Brazil; oliveira.sarahcv@gmail.com \\ ${ }^{2}$ KwaZulu-Natal Museum, P. Bag 9070, Pietermaritzburg, 3200 South Africa, and Department of Zoology \\ \& Entomology, University of the Free State, P.O. Box 339, Bloemfontein, 9300 South Africa; \\ bmuller@nmsa.org.za \\ *Corresponding author
}

\section{ABSTRACT}

An annotated list of the type specimens of Lygistorrhinidae and Mycetophilidae (Diptera: Bibionomorpha) at the KwaZulu-Natal Museum, Pietermaritzburg, South Africa is provided. Information on 54 type specimens, three lygistorrhinids and 51 mycetophilids, with details of labels and actual preservation of the specimens is furnished. Locality data are georeferenced and habitus images of type specimens are provided.

KEY WORDS: Fungus gnats, Lygistorrhinidae, Mycetophilidae, nomenclature, taxonomy, types.

\section{INTRODUCTION}

The Lygistorrhinidae (long-beaked fungus gnats) constitute a small family of Mycetophiliformia (sensu Amorim \& Rindal 2007), which is widely distributed in tropical and subtropical regions. It now contains eight extant genera and about 32 or 33 species (Vockeroth 2009; Pape et al. 2011). The placement of some genera from Cretaceous amber in Lygistorrhinidae is still debatable (Blagoderov \& Grimaldi 2004; Hippa et al. 2005), but the monophyly of the family including only the Recent species has not been questioned (Matile 1997; Grimaldi \& Blagoderov 2001; Hippa \& Vilkamaa 2005).

The fungus gnat family Mycetophilidae s.s. is one of the largest and most diversified families of Bibionomorpha, which fossil record extends back to the Jurassic (Evenhuis 1994; Amorim \& Silva 2002). The family now contains approximately 180 extant genera and almost 4500 species world-wide (Pape et al. 2011). Although the monophyly of the Mycetophilidae is a consensus (Søli 1997; Rindal et al. 2009), a robust phylogeny of this family is still to be provided.

The present paper provides a list of type specimens of Lygistorrhinidae and Mycetophilidae housed in the collection of the KwaZulu-Natal Museum (NMSA, Pietermaritzburg, South Africa), following a recommendation of the International Code of Zoological Nomenclature (ICZN 1999: 72F.4).

\section{MATERIAL AND METHODS}

The list given below is arranged in the alphabetical order of genus and species. Label data are given in double quotation marks, with placement hierarchy (from top to bottom) of the label on the pin or slide being noted in round brackets. In case of handwriting on labels, the handwritten text is reproduced in italics; printed text on labels is reproduced in regular font. For the sake of clarity, additions to some of the original information of labels, such as abbreviated collecting dates and incomplete localities, 
are given in square brackets. All specimen localities were georeferenced following the point-radius method (Wieczorek et al. 2004; Chapman \& Wieczorek 2006), using the MaNIS Georeferencing Calculator April 2011 version (Regents of the University of California 2011).

\author{
TYPE LIST \\ Family Lygistorrhinidae Edwards, 1925 \\ Lygistorrhina sanctaecatharinae Thompson, 1975
}

Fig. 1

Lygistorrhina sanctaecatharinae: Thompson 1975: 442, figs 1-3 (head), figs 4-6 (thorax, head, antenna), figs 7-14 ( $₫ \&$ 9 terminalia). Type locality: United States, Georgia, Liberty County.

Paratypes (NMSA type no. 1866): $3 \hat{\jmath}$ (first two labels are same for all three specimens) (1) printed on white paper: "USA, Georgia: | Liberty Co., St. [Saint] | Catherines Island [31.7106 ${ }^{\circ} \mathrm{N} 81.2624^{\circ} \mathrm{W}$, uncertainty $3.3 \mathrm{~km}$ ] April 24-28, 1972 [24-28.iv.1972]| Thompson \& Picchi"; (2) printed on yellow paper: "PARATYPE | Lygistorrhina | sanctaecatharinae | Thompson 1973”.

Identification: (3) printed on white paper: "NMSA-Dip. 11277"; exemplar glued on a paper triangle; missing parts: none. (3) printed on white paper: "NMSA-Dip. 11308"; exemplar glued on a paper triangle; missing parts: none. (3) printed on white paper: "NMSA-Dip. 11266"; exemplar glued on a paper triangle; missing parts: none.

Distribution: United States (West Virginia, Virginia, North Carolina, Georgia).

Family Mycetophilidae Newman, 1834

Dinempheria enigmata Väisänen, 1994

Fig. 2

Dinempheria enigmata: Väisänen 1994: 14, figs 1-3 (head, thorax, wing); figs 4-9 ( $\precsim$ terminalia). Type locality: South Africa, Mpumalanga.

Holotype (NMSA type no. 2155): $\widehat{\jmath}$ (1) printed on white paper: "S. AFRICA: E. Transvaal [South Africa: Mpumalanga $\mid 9 \mathrm{Km}$ nw. Sabie $2530 \mathrm{BB} \mid$ Bridal Veil Falls $\left[25.0828^{\circ} \mathrm{S} 30.7249^{\circ} \mathrm{E}\right.$, uncertainty $\left.0.75 \mathrm{~km}\right] \mid$ XII 3, 1976. R. Miller [3.xii.1976]"; (2) printed with handwriting on white paper: "Dinempheria §o | enigmata n.sp. | det. R. Väisänen 1992"; (3) printed with handwriting on red paper: "Holotypus $\hat{\delta} \mid$ Dinempheria | enigmata n.sp. | Väisänen"; (4) printed on white paper: "NMSA-Dip. 11312".

Preservation: Exemplar glued on paper triangle, terminalia retained in glycerine, left wing damaged on distal half, abdomen and one leg glued on paper triangle; missing parts: right wing, left leg I, and legs III.

Paratype (NMSA type no. 2155): $q$ (1) printed with handwriting on white paper: "SOUTH AFRICA: Natal [KwaZulu-Natal] $\mid$ Cathedral Peak area [285' S 29¹2'E, uncertainty $2.46 \mathrm{~km}]|2829 \mathrm{Cc} 16-18 . X I I .1977| \mathrm{JGH}$ Londt"; (2) printed with handwriting on white paper: "Dinempheria + | enigmata n.sp. | det. R. Väisänen"; (3) printed on yellow paper: "PARATYPE $ᄋ$ "; (4) printed on white paper: "NMSA-Dip. 11301".

Preservation: Pinned exemplar; missing parts: right legs I and II tarsi, right leg III. Distribution: South Africa (Mpumalanga).

\title{
Dziedzickia peckorum Matile, 1992
}

Fig. 3

Dziedzickia peckorum: Matile 1992: 195, figs 9, 10 (ð terminalia). Type locality: South Africa, KwaZuluNatal, Karkloof range near Mount Alida.

Paratype (NMSA type no. 1952): ठ̊ (1) printed on blue paper: "REP AFR. SUD, NATAL | 75 KM WSW ESTCOURT | CATHEDRAL PEAKS [Cathedral Peak]"; (2) printed on blue paper: "FOR STA. [Forest 


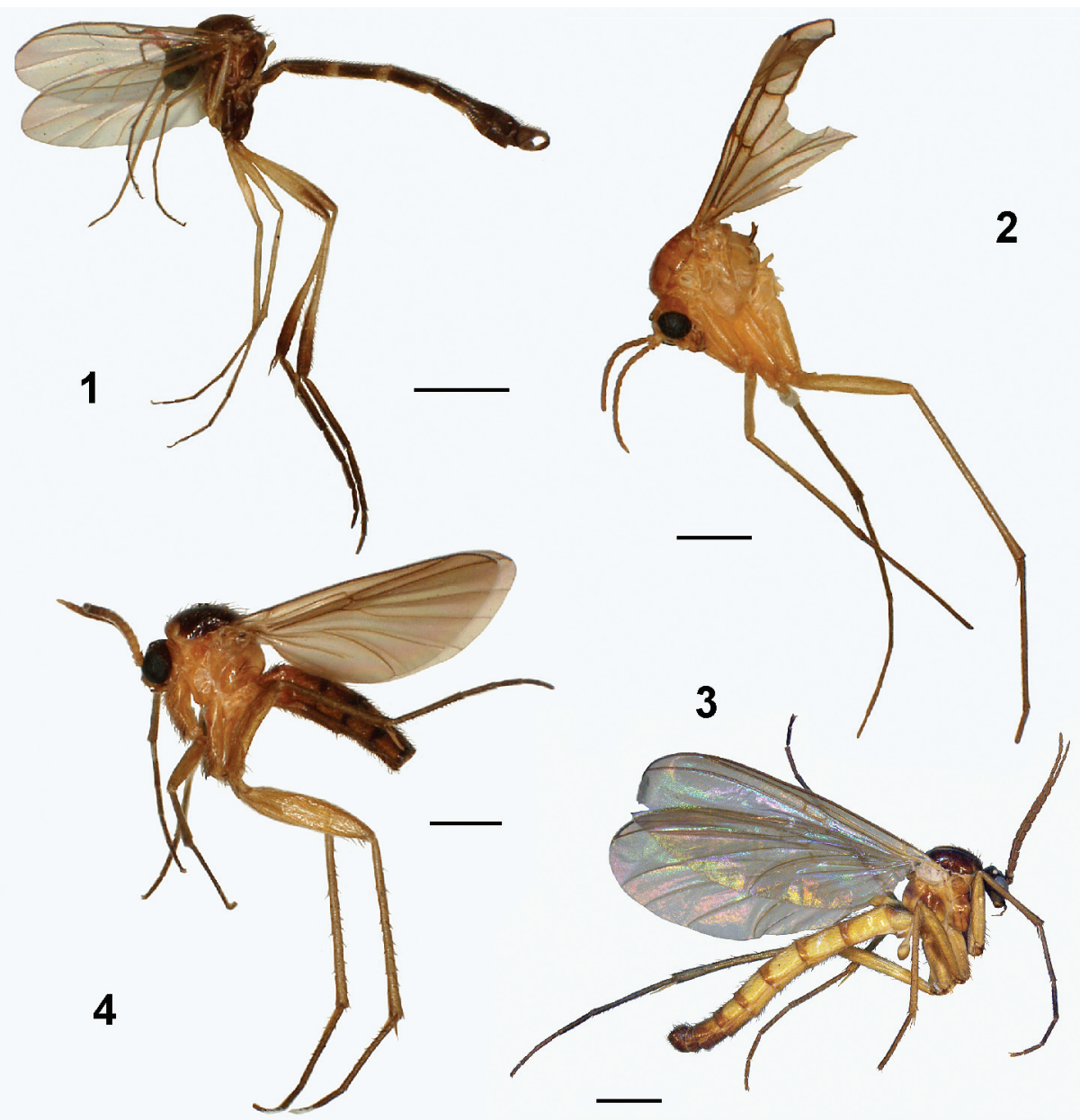

Figs 1-4. (1) Lygistorrhina sanctaecatharinae Thompson, paratype "NMSA-Dip. 11308"; (2) Dinempheria enigmata Väisänen, holotype; (3) Dziedzickia peckorum Matile, paratype "NMSA-DIP 66399”; (4) Dziedzickia stuckenbergorum Matile, holotype. Scale bars $=1 \mathrm{~mm}$.

Station, $29.0333^{\circ} \mathrm{S} 29.2500^{\circ} \mathrm{E}$, uncertainty $0.148 \mathrm{~km}$ ] 1760 M. | 21-31-XII-1979 [21-31.xii.1979] | S. \& J. PECK"; (3) printed on red paper: "PARATYPE"; (4) printed with handwriting: "Dziedzickia $\mid$ peckorum n.sp. | ô paratype | L. Matile det. 1991"; (5) printed on white paper: "NMSA-DIP 66399".

Preservation: Pinned exemplar; missing parts: right leg III, right II tarsi, four terminal segments.

Paratype (NMSA type no. 1952): $q$ (1) printed on blue paper: "REP AFR. SUD, NATAL | 75 KM WSW ESTCOURT | CATHEDRAL PEAKS [Cathedral Peak]"; (2) printed on blue paper: "FOR STA. [Cathedral Peak Forest Station, 29.0333 ${ }^{\circ} \mathrm{S} 29.2500^{\circ}$ E, uncertainty 0.148 km] 1760 M. |21-31-XII-1979 [21-31.xii.1979]| S. \& J. PECK"; (3) printed on red paper: "PARATYPE"; (4) printed with handwriting: "Dziedzickia $\mid$ peckorum n.sp. | o paratype | L. Matile det. 1991"; (5) printed on white paper: "NMSA-DIP 66400".

Preservation: Pinned exemplar; missing parts: legs II.

Distribution: South Africa (KwaZulu-Natal). 


\section{Dziedzickia stuckenbergorum Matile, 1992}

Fig. 4

Dziedzickia stuckenbergorum: Matile 1992: 197, fig. 11 (ठ̂ terminalia). Type locality: South Africa, KwaZuluNatal, Karkloof range near Mount Alida.

Holotype (NMSA type no. 1951): $\widehat{\jmath}$ (1) printed with handwriting on white paper: "19.XI.63 [19.xi.1963] |

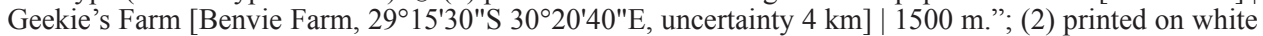
paper: "Karkloof range | nr. Mt Alida [near Mount Alida] | Natal [KwaZulu-Natal], S. Africa [South Africa] | B. \& P. Stuckenberg"; (3) printed on red paper: "HOLOTYPE"; (4) printed with handwriting on white paper: "Dziedzickia | stuckenbergorum $\mid$ n.sp. Oे holotype | L. Matile det. 1991"; (5) printed on white paper: "NMSA-Dip. 11280".

Preservation: Pinned exemplar, terminalia retained in glycerine; missing parts: none.

Distribution: South Africa (KwaZulu-Natal).

\section{Leia arsona Hutson, 1978}

Fig. 5

Leia arsona: Hutson 1978: 123. Type locality: South Africa, Eastern Cape, Grahamstown.

Holotype (NMSA type no. 2149): $\widehat{\partial}$ (1) printed on white paper circle with red edges: "Holo- | type"; (2) printed with handwriting on white paper: "Grahamstown [33.2970 ${ }^{\circ} \mathrm{S} 26.5474^{\circ} \mathrm{E}$, uncertainty $\left.4 \mathrm{~km}\right] \mid$ South Africa | 1-x-1953 [1.x.1953] | B. Stuckenberg"; (3) printed with handwriting on white paper: "HOLOTYPE $\widehat{\jmath} \mid$ Leia $\mid$ arsona Hutson | det. A.M. Hutson, 1977."; (4) printed on white paper: "NMSA-Dip. 11310".

Preservation: Pinned exemplar; missing parts: right leg III.

Paratype (NMSA type no. 2149): $\widehat{\partial}$ (1) printed on white paper circle with yellow edges: "Para- | type"; (2) printed with handwriting on white paper: "Grahamstown $\left[33.2970^{\circ} \mathrm{S} 26.5474^{\circ} \mathrm{E}\right.$, uncertainty $\left.4 \mathrm{~km}\right] \mid$ South Africa $\mid$ 1-x-1953 [1.x.1953]| B. Stuckenberg"; (3) printed with handwriting on white paper: "PARATYPE ○| Leia | arsona Hutson | det. A.M. Hutson, 1977."; (4) printed on white paper: "NMSA-Dip. 11321".

Preservation: Pinned exemplar, abdomen glued on the micropin; missing parts: right leg III.

Paratype (NMSA type no. 2149): ㅇ (1) printed on white paper circle with yellow edges: "Para- | type"; (2) printed with handwriting on white paper: "Grahamstown $\left[33.2970^{\circ} \mathrm{S} 26.5474^{\circ} \mathrm{E}\right.$, uncertainty $\left.4 \mathrm{~km}\right] \mid$ South Africa |24-x-1953 [24.x.1953]|B. Stuckenberg"; (3) printed with handwriting on white paper: "PARATYPE q $\mid$ Leia $\mid$ arsona Hutson | det. A.M. Hutson, 1977."; (4) printed on white paper: "NMSA-Dip. 11311".

Preservation: Pinned exemplar; missing parts: none.

Distribution: South Africa (Eastern Cape), Kenya, Saint Helena. Widely introduced in Europe, in Mediterranean region as well as in New Zealand (Chandler \& Ribeiro 1995; Chandler \& Gatt 2000; Chandler 1994; Toft \& Chandler 2004; Chandler \& Pijnakker 2009; Väisänen 1984).

\section{Manota natalensis Jaschhof \& Mostovski, 2006}

\section{Fig. 6}

Manota natalensis: Jaschhof \& Mostovski 2006: 238, figs 1-3 (o \& $q$ terminalia). Type locality: South Africa, KwaZulu-Natal, Karkloof Nature Reserve.

Holotype (NMSA type no. 1953): $\widehat{\partial}$ (1) printed on white paper: "det. M. JASCHHOF | Manota natalensis | JASCH. \& MOST., male"; (2) printed on red paper circle: "Holo- | type"; (3) printed on white paper: "RSA [South Africa]: KwaZulu-Natal: | Pietermaritzburg, Karkloof Nat. Res. [Karkloof Nature Reserve] | (29.19.1S 30.15.5E) [29 $19.1^{\prime} \mathrm{S} 30^{\circ} 15.5^{\prime} \mathrm{E}$, uncertainty $0.246 \mathrm{~km}$ ]; | 1325m; mistbelt forest; | 24 Nov.-18 Dec. 2005 [24.xi-18.xii.2005]; Malaise trap; | M. MOSTOVSKI, M. \& C. JASCHHOF"; (4) printed on white paper: "NMSA-Dip. 66401".

Preservation: On one slide, with terminalia and right wing separate on the slide; missing parts: three right terminal flagellar segments. 

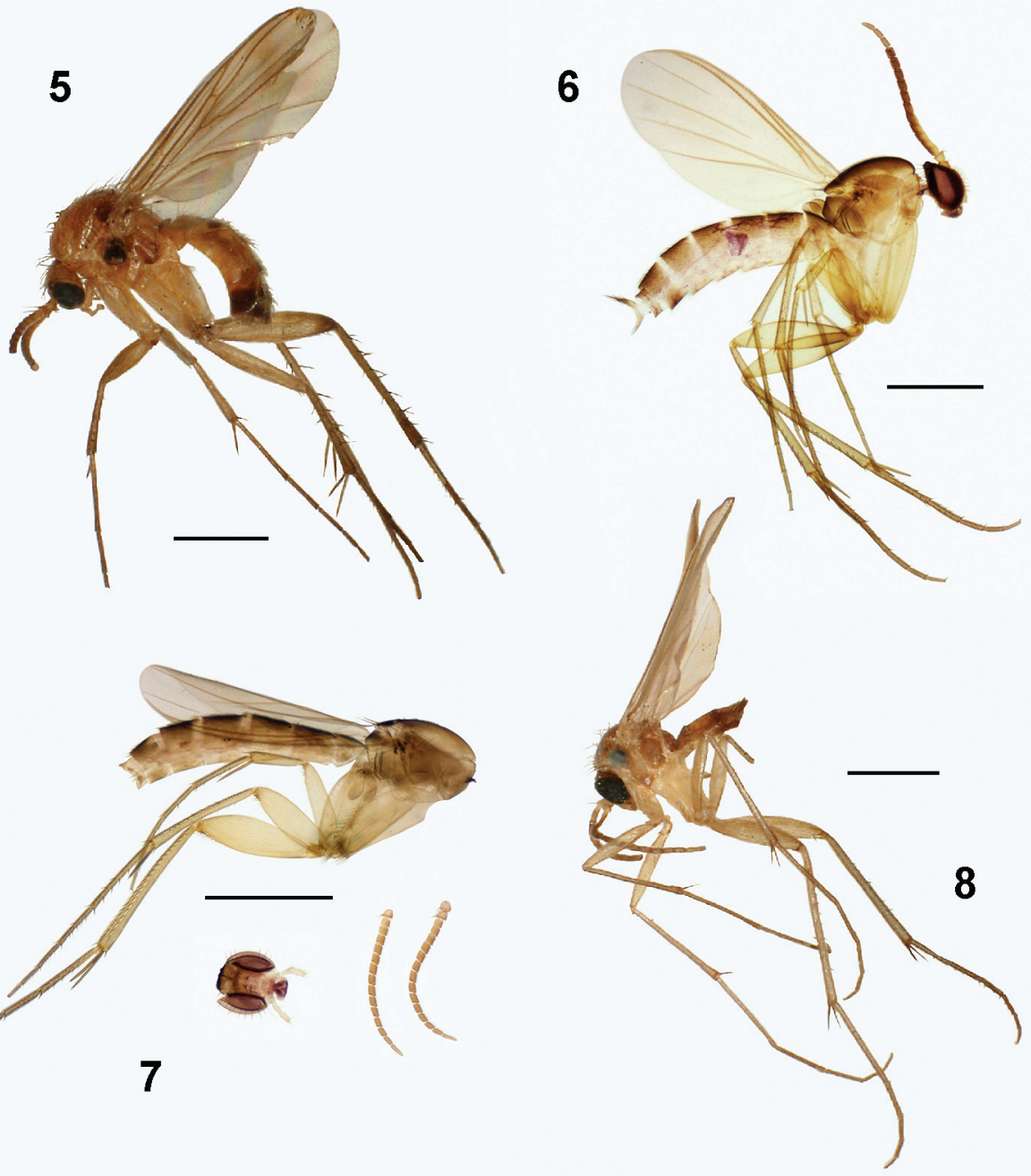

Figs 5-8. (5) Leia arsona Hutson, holotype; (6) Manota natalensis Jaschhof \& Mostovski, holotype; (7) Manota whiteleyi Jaschhof \& Mostovski, holotype; (8) Mycomya edra Väisänen, holotype. Scale bars $=1 \mathrm{~mm}$.

Paratypes (NMSA type no. 1953): 3 (1) printed on white paper: "det. M. JASCHHOF | Manota natalensis | JASCH. \& MOST., male"; (2) printed on yellow paper circle: "Para- | type"; (3) printed on white paper: "RSA [South Africa]: KwaZulu-Natal: | Pietermaritzburg, Karkloof Nat. Res. [Karkloof Nature Reserve] | (29.19.1S 30.15.5E) [29 $19.1^{\prime} \mathrm{S} 30^{\circ} 15.5^{\prime} \mathrm{E}$, uncertainty $0.246 \mathrm{~km}$ ]; | 1325m; mistbelt forest; | 24 Nov.-18 Dec. 2005 [24.xi-18.xii.2005]; Malaise trap; | M. MOSTOVSKI, M. \& C. JASCHHOF".

Identification: (4) printed on white paper: "NMSA-Dip. 66402"; on one slide, with terminalia, left leg II and left wing separate on the slide; missing parts: none. (4) printed on white paper: "NMSA-Dip. 66403"; on one slide, with head, antenna, all right legs, right wing and terminalia separate on the slide; missing parts: none. (4) printed on white paper: "NMSA-Dip. 66404"; on one slide, with terminalia separate on the slide, distal edge of both wings damaged; missing parts: none. 
Paratype (NMSA type no. 1953): ㅇ (1) printed on white paper: "det. M. JASCHHOF | Manota natalensis $\mid$ JASCH. \& MOST., female"; (2) printed on yellow paper circle: "Para- | type"; (3) printed on white paper: "RSA [South Africa]: KwaZulu-Natal: | Pietermaritzburg, Karkloof Nat. Res. [Karkloof Nature Reserve] | (29.19.1S 30.15.5E) [29 $19.1^{\circ} \mathrm{S} 30^{\circ} 15.5^{\prime} \mathrm{E}$, uncertainty $0.246 \mathrm{~km}$ ]; | 1325m; mistbelt forest; | 24 Nov.-18 Dec. 2005 [24.xi-18.xii.2005]; Malaise trap; | M. MOSTOVSKI, M. \& C. JASCHHOF"; (4) printed on white paper: "NMSA-Dip. 66405".

Preservation: On one slide, with left leg I, left antenna, left wing and terminalia separate on the slide; missing parts: none.

Paratypes (NMSA type no. 1953): $3 \hat{\jmath}$ (1) printed on white paper: "det. M. JASCHHOF | Manota natalensis | JASCH, \& MOST., male"; (2) printed on yellow paper circle: "Para- | type"; (3) RSA [South Africa]: KwaZulu-Natal: | Northern Drakensberg, Royal Natal | Nat. [National] Park, Gudu Forest | (28.40.9S $28.55 .8 \mathrm{E}$ ) [28 $40.9^{\prime} \mathrm{S} 28^{\circ} 55.8^{\prime} \mathrm{E}$, uncertainty $\left.0.245 \mathrm{~km}\right] ; 1680-1730 \mathrm{~m}$; old growth indigenous forest; | 28 Nov.-13 Dec. 2005 [28.xi-13.xii.2005]; Malaise trap; | M. MOSTOVSKI, M. \& C. JASCHHOF”.

Identification: (4) printed on white paper: "NMSA-Dip. 66406"; on one slide, with abdomen and both wings separate on the slide; missing parts: none. (4) printed on white paper: "NMSA-Dip. 66407"; on one slide, with head, antennae, both wings and terminalia separate on the slide; missing parts: none. (4) printed on white paper: "NMSA-Dip. 66408"; on one slide, with terminalia separate on the slide; missing parts: none.

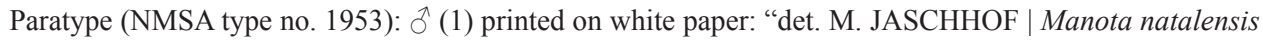
| JASCH. \& MOST., male"; (2) printed on yellow paper circle: "Para- | type"; (3) printed on white paper: "RSA [South Africa]: KwaZulu-Natal: | Central Drakensberg, Cathedral | Peak Nat. Res. [Nature Reserve], Rainbow Gorge | (28.57.6S 29.13.6E) [28 $28^{\circ} 7.6^{\prime} \mathrm{S} 29^{\circ} 13.6^{\prime} \mathrm{E}$, uncertainty $\left.0.246 \mathrm{~km}\right] ; 1500 \mathrm{~m}$; | old-growth indigenous forest; | 3-5 Dec. 2005 [3-5.xii.2005]; Malaise trap; | M. MOSTOVSKI, M. \& C. JASCHHOF". (4) printed on white paper: "NMSA-Dip. 66409".

Preservation: On one slide, with terminalia separate on the slide; missing parts: none.

Distribution: South Africa (KwaZulu-Natal).

\section{Manota whiteleyi Jaschhof \& Mostovski, 2006}

Fig. 7

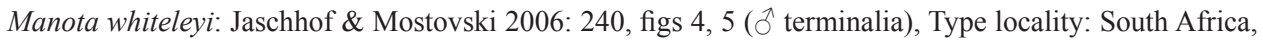
KwaZulu-Natal, Ramsgate.

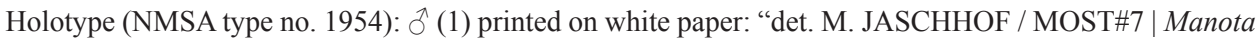
whiteleyi | JASCH. \& MOST., male"; (2) printed on red paper circle: "Holo- | type"; (3) printed on white paper: "RSA [South Africa]: KwaZulu-Natal: | Ramsgate Butterfly Sanctuary | (30.53.3S 30.20.4E) [30 $53.1^{\circ}$ 'S $30^{\circ} 20.4^{\prime} \mathrm{E}$, uncertainty $0.244 \mathrm{~km}$ ]; $\mid 45 \mathrm{~m}$; | indigenous forest patch near | stream; 3-26 Feb 2005 [3-26.ii.2005]; | Malaise trap; M. MOSTOVSKI"; (4) printed on white paper: "NMSA-Dip. 66410".

Preservation: On one slide, with left legs, head and antennae separate on the slide; missing parts: none.

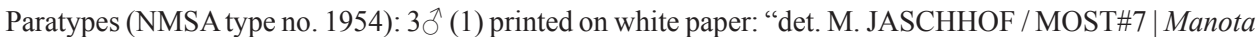
whiteleyi | JASCH. \& MOST., male"; (2) printed on yellow paper circle: "Para- | type"; (3) printed on white paper: "RSA [South Africa]: KwaZulu-Natal: | Ramsgate Butterfly Sanctuary | (30.53.3S 30.20.4E) [30 $30^{\circ} 3.1^{\prime} \mathrm{S} 30^{\circ} 20.4^{\prime} \mathrm{E}$, uncertainty $\left.0.244 \mathrm{~km}\right] ; \mid$ | 45m; | indigenous forest patch near | stream; 3-26 Feb 2005 [3-26.ii.2005]; | Malaise trap; M. MOSTOVSKI".

Identification: (4) printed on white paper: "NMSA-Dip. 66412"; on one slide, with terminalia separate on the slide; missing parts: none. (4) printed on white paper: "NMSADip. 66413"; on one slide, with right wing and terminalia separate on the slide; missing parts: none. (4) printed on white paper: "NMSA-Dip. 66414"; on one slide, with left legs, left wing and terminalia separate on the slide; missing parts: none.

Paratype: + (1) printed on white paper: "det. M. JASCHHOF / MOST\#7 | Manota whiteleyi | JASCH. \& MOST., | female"; (2) printed on yellow paper circle: "Para- | type"; (3) printed on white paper: "RSA 
[South Africa]: KwaZulu-Natal: | Ramsgate Butterfly Sanctuary | (30.53.3S 30.20.4E) [3053.1'S 30²0.4'E, uncertainty $0.244 \mathrm{~km}$ ]; | 45m; | indigenous forest patch near | stream; 3-26 Feb 2005 [3-26.ii.2005]; | Malaise trap; M. MOSTOVSKI"; (4) printed on white paper: "NMSA-Dip. 66415".

Preservation: On one slide, with right wing separate on slide; missing parts: right leg I. Paratype (NMSA type no. 1954): $\delta$ (1) printed on white paper: "det. M. JASCHHOF / MOST\#3 | Manota whiteleyi $\mid$ JASCH. \& MOST., male"; (2) printed on yellow paper circle: "Para- | type"; (3) printed on white paper: "RSA [South Africa]: KwaZulu-Natal: | Ramsgate Butterfly Sanctuary | (30.53.3S 30.20.4E) [3053.1'S $30^{\circ} 20.4^{\prime} \mathrm{E}$, uncertainty $0.244 \mathrm{~km}$ ]; | 45m; | indigenous forest patch near | stream; 9 Jan-2 Feb 2005 [9.i-2. ii.2005]; | Malaise trap; M. MOSTOVSKI"; (4) printed on white paper: "NMSA-Dip. 66411".

Preservation: On one slide, with left legs, left wing and terminalia separate on the slide; missing parts: none.

Distribution: South Africa (KwaZulu-Natal).

\section{Mycomya edra Väisänen, 1994}

Fig. 8

Mycomya edra: Väisänen 1994: 20, figs 28-37 ( 0 \& + terminalia). Type locality: South Africa, KwaZuluNatal, Cathedral Peak.

Holotype (NMSA type no. 2152): ${ }^{\wedge}$ (1) printed with handwriting on white paper: "SOUTH AFRICA: Natal [KwaZulu-Natal] Cathedral Peak area [28 $57^{\circ} \mathrm{S} 29^{\circ} 12^{\prime} \mathrm{E}$, uncertainty $2.46 \mathrm{~km}$ ] $2829 \mathrm{Cc} 16-18 . X I I .1977$ | JGH Londt"; (2) printed with handwriting on white paper: "Mycomya $\widehat{~} \mid$ | edra n.sp. | det. R. Väisänen 1992"; (3) handwritten on red paper: "HOLOTYPE | Mycomya | edra|Väisänen"; (4) printed on white paper: "NMSA-Dip. 11270".

Preservation: Pinned exemplar, terminalia retained in glycerine; missing parts: right leg II tibia and tarsi.

Paratypes (NMSA type no. 2152): 20 (1) printed with handwriting on white paper: "SOUTH AFRICA: Natal | Cathedral Peak area [28 $57^{\circ} \mathrm{S} 29^{\circ} 12^{\prime} \mathrm{E}$, uncertainty $2.46 \mathrm{~km}$ ] 2829Cc 16-18.XII.1977| JGH Londt"; (2) printed with handwriting on white paper: "Mycomya Oे | edra n.sp. | det. R. Väisänen 1992"; (3) printed on yellow paper: "PARATYPE ${ }^{\lambda}$ ".

Identification: (4) printed on white paper: "NMSA-Dip. 11293"; pinned exemplar, terminalia retained in glycerine; missing parts: head, right leg II and legs III. (4) printed on white paper: "NMSA-Dip. 59083"; pinned exemplar, terminalia retained in glycerine; missing parts: right III tarsi and left III.

Paratypes (NMSA type no. 2152): 6 ㅇ (1) printed with handwriting on white paper: "SOUTH AFRICA: Natal [KwaZulu-Natal] Cathedral Peak area [28 $57^{\circ} \mathrm{S} 29^{\circ} 12^{\prime} \mathrm{E}$, uncertainty $2.46 \mathrm{~km}$ ] 2829Cc 16-18.XII.1977 | JGH Londt"; (2) printed with handwriting on white paper: "Mycomya + | edra n.sp. | det. R. Väisänen 1992"; (3) printed on yellow paper: "PARATYPE +".

Identification: (4) printed on white paper: "NMSA-Dip. 59084"; pinned exemplar, terminalia retained in glycerine; missing parts: none. (4) printed on white paper: "NMSADip. 59085"; pinned exemplar; missing parts: right I tarsi 3 to 5, left II tarsi 2 to 5 and left III tibia and tarsi. (4) printed on white paper: "NMSA-Dip. 59086"; pinned exemplar; missing parts: right flagellar segments. (4) printed on white paper: "NMSA-Dip. 59087"; pinned exemplar, terminalia retained in glycerine; missing parts: right legs I and II. (4) printed on white paper: "NMSA-Dip. 59088"; pinned exemplar, terminalia retained in glycerine; missing parts: left flagellar segments, left I and right II and left III tibia and tarsi. (4) printed on white paper: "NMSA-Dip. 59089"; pinned exemplar, terminalia retained in glycerine, abdomen glued to micropin foam; missing parts: apical right flagellar segments and all legs.

Distribution: South Africa (KwaZulu-Natal). 


\section{Mycomya londti Väisänen, 1994}

Fig. 9

Mycomya londti: Väisänen 1994: 18, figs 22-27 (ð̊ terminalia). Type locality: South Africa, KwaZuluNatal, Cathedral Peak.

Holotype (NMSA type no. 2150): $\sigma^{\lambda}$ (1) printed with handwriting on white paper: "SOUTH AFRICA: Natal

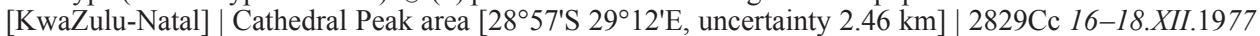
| JGH Londt"; (2) printed with handwriting on white paper: "Mycomya $\widehat{O} \mid$ londti n.sp. | det. R. Väisänen 1992"; (3) handwritten on red paper: "HOLOTYPE | Mycomya| londti |Väisänen"; (4) printed on white paper: "NMSA-Dip. 11340".

Preservation: Pinned exemplar, terminalia retained in glycerine; missing parts: legs I, all other legs have missing tarsi.

Paratype (NMSA type no. 2150): ( (1) printed with handwriting on white paper: "SOUTH AFRICA: Natal [KwaZulu-Natal] | Cathedral Peak area [28 ${ }^{\circ} 57^{\prime} \mathrm{S} 29^{\circ} 12^{\prime} \mathrm{E}$, uncertainty $2.46 \mathrm{~km}$ ] $2829 \mathrm{Cc} 16-18 . X I I .1977$ | JGH Londt"; (2) printed with handwriting on white paper: "Mycomya + $\mid$ londti n.sp. | det. R. Väisänen 1992"; (3) printed on yellow paper: "PARATYPE \%"; (4) printed on white paper: "NMSA-Dip. 11302".

Preservation: Pinned exemplar; missing parts: antenna, right I tibia and tarsi, and right III tarsi.

Distribution: South Africa (KwaZulu-Natal).

\section{Mycomya natalensis Väisänen, 1994}

Fig. 10

Mycomya natalensis: Väisänen 1994: 16, figs 10-19 (ð̊ terminalia). Type locality: South Africa, KwaZuluNatal, Sunwich Port.

Holotype (NMSA type no. 2151): $\widehat{\partial}$ (1) printed on white paper: "Sunwich Port [Sunwich Port, Port Shepstone, $30.6596^{\circ} \mathrm{S} 30.5083^{\circ} \mathrm{E}$, uncertainty $0.8 \mathrm{~km}$ ] | NAT. [KwaZulu-Natal] X.1951"; (2) printed on white paper: "30.35S-30.32E [30 $35^{\circ} \mathrm{S} 30^{\circ} 32^{\prime} \mathrm{E}$, uncertainty $\left.3.44 \mathrm{~km}\right] " ;$ (3) printed with handwriting on white paper: "Mycomya $\widehat{O} \mid$ natalensis n.sp. | det. R. Väisänen 1992"; (4) handwritten on red paper: "HOLOTYPE | Mycomya | natalensis | Väisänen"; (5) printed on white paper: "NMSA-Dip. 11278".

Preservation: Pinned exemplar, terminalia retained in glycerine, left wing damaged distally; missing parts: right leg I and legs II, all remaining legs have missing tarsi 2-4.

Distribution: South Africa (KwaZulu-Natal).

\section{Mycomyiella irwini Väisänen, 1994}

Fig. 11

Mycomyiella irwini: Väisänen 1994: 21, figs 38-42 (ð terminalia). Type locality: South Africa, KwaZuluNatal, Pietermaritzburg.

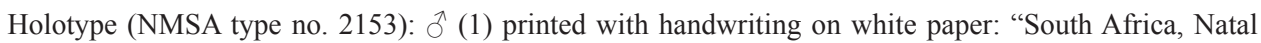
[KwaZulu-Natal] | Pietermaritzburg | Belfort $\left[29.5540^{\circ} \mathrm{S} 30.3823^{\circ} \mathrm{E}\right.$, uncertainty $\left.1.1 \mathrm{~km}\right] 15-\mathrm{V}-73$ [15.v.1973] | ME Irwin; (2930Cb)"; (2) printed with handwriting on white paper: "Mycomyiella | irwini n.sp. $\widehat{O} \mid$ det. R. Väisänen 1992"; (3) handwritten on red paper: "HOLOTYPE | Mycomyiella | irwini |Väisänen"; (4) printed on white paper: "NMSA-Dip. 11258".

Preservation: exemplar glued on paper triangle, terminalia retained in glycerine; missing parts: right legs.

Paratype (NMSA type no. 2153): 0 (1) printed on white paper: "SOUTH AFRICA: NATAL | Cathedral Peak area [28 $57^{\circ} \mathrm{S} 29^{\circ} 12^{\prime} \mathrm{E}$, uncertainty $2.46 \mathrm{~km}$ ] XII.26-27.1977 [26-27.xii.1977]. 2829CC | R.M.Miller. indigenous | for [forest]"; (2) printed with handwriting on white paper: "Mycomyiella ô | irwini n.sp. 1992 | det R. Väisänen"; (3) printed on yellow paper: "PARATYPE O" "; (4) printed on white paper: "NMSA-Dip. $11262 "$.

Preservation: Pinned exemplar, terminalia retained in glycerine; missing parts: all legs. 


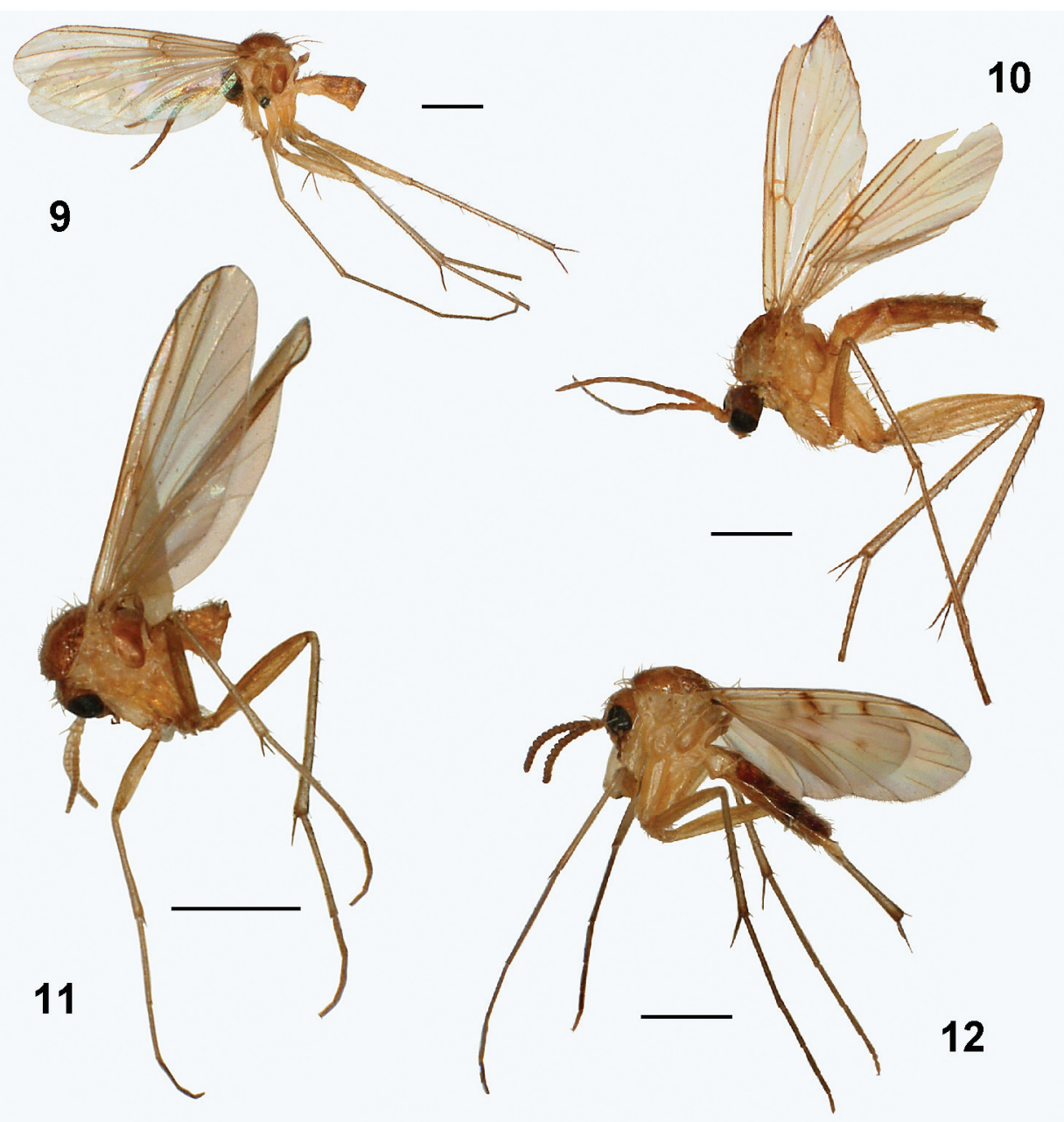

Figs 9-12. (9) Mycomya londti Väisänen, holotype; (10) Mycomya natalensis Väisänen, holotype; (11) Mycomyiella irwini Väisänen, holotype; (12) Neoempheria transvaalensis Väisänen, holotype. Scale bars $=1 \mathrm{~mm}$.

Paratype (NMSA type no. 2153): (1) printed on white paper: "SOUTH AFRICA: NATAL [KwaZuluNatal] | Cathedral Peak area [28 $57^{\prime} \mathrm{S} 29^{\circ} 12^{\prime} \mathrm{E}$, uncertainty $2.46 \mathrm{~km}$ ] | XII.26-27.1977 [26-27.xii.1977]. 2829CC | R.M.Miller. indigenous | for [forest]"; (2) printed with handwriting on white paper: "Mycomyiella

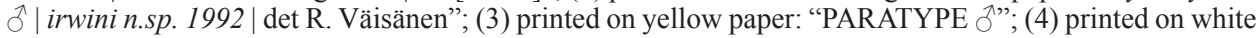
paper: "NMSA-Dip. 59209".

Preservation: Pinned exemplar; missing parts: none.

Paratype (NMSA type no. 2153): 0 (1) printed on white paper: "SOUTH AFRICA: NATAL [KwaZuluNatal] | Cathedral Peak area [28 $57^{\prime} \mathrm{S} 29^{\circ} 12^{\prime} \mathrm{E}$, uncertainty 2.46 km] | XII.26-27.1977 [26-27.xii.1977]. 2829CC | R.M.Miller. indigenous | for [forest]"; (2) printed with handwriting on white paper: "Mycomyiella

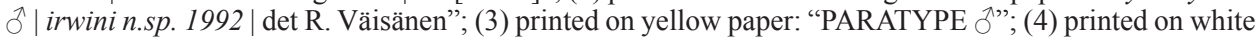
paper: "NMSA-Dip. 59210".

Preservation: Pinned exemplar; missing parts: none.

Distribution: South Africa (KwaZulu-Natal). 


\section{Neoempheria transvaalensis Väisänen, 1994}

Fig. 12

Neoempheria transvaalensis: Väisänen 1994: 22, figs 43-47 (ð terminalia). Type locality: South Africa, Mpumalanga, near Barberton.

Holotype (NMSA type no. 2154): $\widehat{\partial}$ (1) printed on white paper: "STH AFRICA [South Africa]: Transvaal [Mpumalanga] | $8 \mathrm{Km}$ NW Barbeton on | Badplass Rd SE 2530 DD [R38 road, $25.7408^{\circ} \mathrm{S} 30.99923^{\circ} \mathrm{E}$, uncertainty $2 \mathrm{~km}$ ] 6-8.iv.1985 J.Londt | Bushveld long grass"; (2) printed with handwriting on white paper: "Neoempheria $\widehat{~}$ | transvaalensis n.sp. | det. R. Väisänen 1992"; (3) handwritten on red paper: "HOLOTYPE | Neoempheria | transvaalensis | Väisänen"; (4) printed on white paper: "NMSA-Dip. 11319".

Preservation: Pinned exemplar, terminalia retained in glycerine; missing parts: right III, left III tarsi 2-5.

Paratype (NMSA type no. 2154): § (1) printed on white paper: "SOUTH AFRICA 2428CD | Transvaal [Limpopo] Nyl Rivier [River] | $8 \mathrm{Km} \mathrm{SW}$ of Nylstroom [Modimolle, $24.7608^{\circ} \mathrm{S} 28.3502^{\circ} \mathrm{E}$, uncertainty 0.2 km] | 29-31.I.78 [29-31.i.1978] J.Londt | Bushveld near river | Malaise trap coll. "; (2) printed with handwriting on white paper: "Neoempheria ठे | transvaalensis n.sp. | det. R. Väisänen 1992"; (3) printed on yellow paper: "PARATYPE ${ }^{\lambda}$ "; (4) printed on white paper: "NMSA-Dip. 11330".

Preservation: Pinned exemplar, right III and abdomen glued on card; missing parts: right I and legs III.

Distribution: South Africa (Limpopo, Mpumalanga).

\section{Paradoxa paradoxa Jaschhof, 2006}

Fig. 13

Paradoxa paradoxa: Jaschhof 2006: 230, figs 1-9 (ô terminalia and $q$ flagellomeres). Type locality: South Africa, KwaZulu-Natal, Northern Drakensberg, Royal Natal National Park, Gudu Forest.

Holotype (NMSA type no. 1955): $\widehat{\jmath}$ (1) printed on white paper: “det. M. JASCHHOF | Paradoxa paradoxa | JASCHHOF, male"; (2) printed on red paper circle: "Holotype"; (3) printed on white paper: "RSA [South Africa]: KwaZulu-Natal: | Northern Drakensberg; Royal Natal | Nat. [National] Park, Gudu Forest | (28.40.9S 28.55.8E) [28 $40.9^{\prime} \mathrm{S} 28^{\circ} 55.8^{\prime} \mathrm{E}$, uncertainty $0.245 \mathrm{~km}$; $1680-1730 \mathrm{~m}$; | old growth indigenous forest; | 28 Nov.-13 Dec. 2005 [28.xi-13.xii.2005]; Malaise trap;|M. MOSTOVSKI, M. \& C. JASCHHOF"; (4) printed on white paper: "NMSA-Dip. 66416".

Preservation: On one slide, with left legs, left wing and terminalia separate on the slide; missing parts: none.

Paratypes (NMSA type no. 1955): $3 \hat{\jmath}$ (1) printed on white paper: "det. M. JASCHHOF | Paradoxa paradoxa | JASCHHOF, male"; (2) printed on yellow paper circle: "Paratype"; (3) printed on white paper: "RSA [South Africa]: KwaZulu-Natal: | Northern Drakensberg; Royal Natal | Nat. [National] Park, Gudu Forest | (28.40.9S 28.55.8E) [28 $40.9^{\prime} \mathrm{S} 28^{\circ} 55.8^{\prime} \mathrm{E}$, uncertainty $0.245 \mathrm{~km}$ ]; $1680-1730 \mathrm{~m}$; | old growth indigenous forest; | 28 Nov.-13 Dec. 2005 [28.xi-13.xii.2005]; Malaise trap; | M. MOSTOVSKI, M. \& C. JASCHHOF".

Identification: (4) printed on white paper: "NMSA-Dip. 66417"; on one slide, with terminalia, left leg I, both legs II and wings separate on the slide; missing parts: none. (4) printed on white paper: "NMSA-Dip. 66418"; on one slide, with head and terminalia separate on the slide; missing parts: left leg II. (4) printed on white paper: "NMSA-Dip. 66419"; on one slide, with left antenna, left wing and terminalia separate on the slide; missing parts: none.

Paratypes (NMSA type no. 1955): 5 ( (1) printed on white paper: “det. M. JASCHHOF | Paradoxa paradoxa JASCHHOF, male"; (2) printed on yellow paper circle: "Paratype"; (3) printed on white paper: "RSA [South Africa]: KwaZulu-Natal: | Northern Drakensberg; Royal Natal | Nat. [National] Park, Gudu Forest | (28.40.9S 28.55.8E) [28 $40.9^{\prime} \mathrm{S} 28^{\circ} 55.8^{\prime} \mathrm{E}$, uncertainty $0.245 \mathrm{~km}$ ]; $1680-1730 \mathrm{~m}$; | old growth indigenous forest; | 28 Nov.-13 Dec. 2005 [28.xi-13.xii.2005]; Malaise trap; | M. MOSTOVSKI, M. \& C. JASCHHOF”.

Identification: (4) printed on white paper: "NMSA-Dip. 66420"; on one slide; missing parts: none. (4) printed on white paper: "NMSA-Dip. 66421"; on one slide, with ter- 


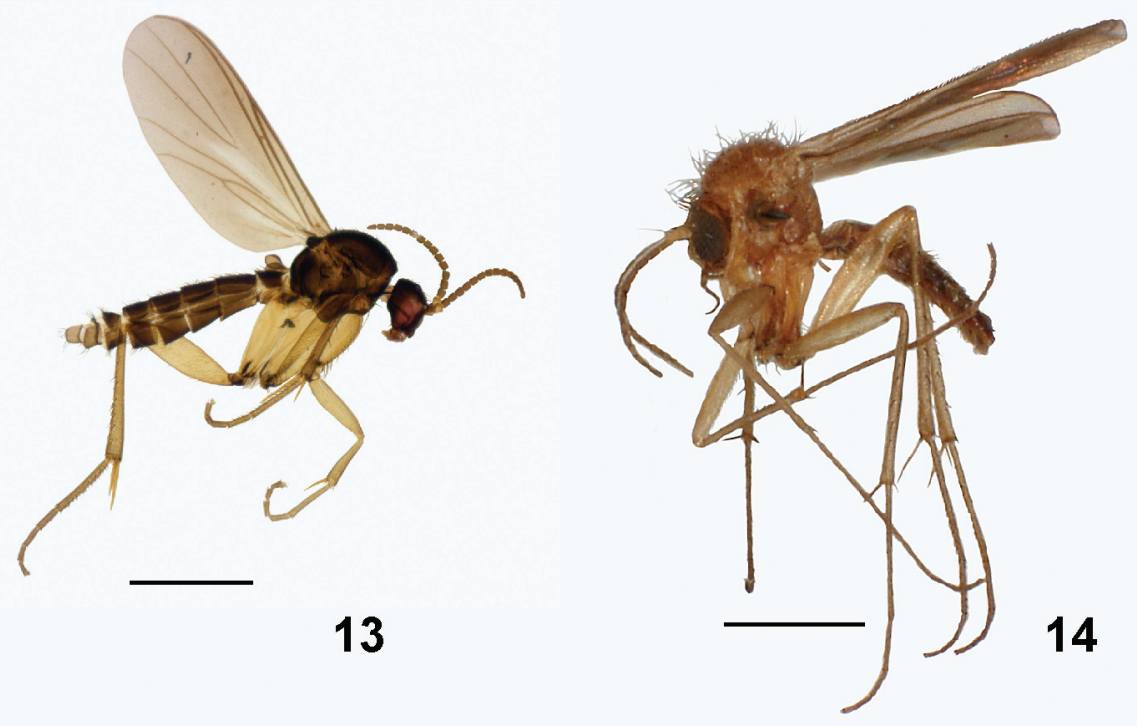

Figs 13, 14. (13) Paradoxa paradoxa Jaschhof, holotype; (14) Sciophila atrigaster Matile, paratype. Scale bars $=1 \mathrm{~mm}$.

minalia separate on the slide; missing parts: right leg III. (4) printed on white paper: "NMSA-Dip. 66422"; on one slide, with left legs, left wing and terminalia separate on the slide; missing parts: none. (4) printed on white paper: "NMSA-Dip. 66423"; on one slide, with right legs, right wing, head and terminalia separate on the slide; missing parts: none. (4) printed on white paper: "NMSA-Dip. 66424"; on one slide, with abdomen, head, terminalia and both wings separate on the slide; missing parts: distal part of right wing missing.

Distribution: South Africa (KwaZulu-Natal).

\section{Sciophila atrigaster Matile, 1979}

Fig. 14

Sciophila atrigaster: Matile 1979: 269, figs 31, 32 (ð terminalia). Type locality: Comoro Islands.

Paratype (NMSA type no. 2129): § (1) printed on white paper: "Madagascar Nord | Montagne d'Ambre [Amber Mountain National Park, $12.5894^{\circ} \mathrm{S} 49.1652^{\circ} \mathrm{E}$, uncertainty $14.8 \mathrm{~km}$ ] $1000 \mathrm{~m}$ | dct Diégo-Suárez | 23.XI-4.XII.57 [23.xi-4.xii.1957] B. Stuckenberg"; (2) printed with handwriting on white paper: "Sciophila | atrigaster n.sp. | o paratype | L. Matile det. 1976"; (3) printed on red paper: "PARATYPE"; (4) printed on white paper: "NMSA-Dip. 11261".

Preservation: Pinned exemplar, terminalia retained in glycerine; missing parts: none.

Distribution: Comoro Islands, Madagascar.

\section{ACKNOWLEDGEMENTS}

The authors are deeply thankful to Peter Chandler (Melksham, UK) for the excellent insights, suggestions and criticisms on an early draft of the manuscript. We also thank Vladimir Blagoderov and an anonymous referee, who provided useful criticisms and suggestions on the manuscript. During the preparation of this paper, the first author received financial support from FAPESP grant 2008/52324-6. 


\section{REFERENCES}

Amorim, D.S. \& Rindal, E. 2007. Phylogeny of the Mycetophiliformia, with proposal of the subfamilies Heterotrichinae, Ohakuneinae, and Chiletrichinae for the Rangomaramidae (Diptera, Bibionomorpha). Zootaxa 1535: 1-92.

Amorim, D.S. \& Silva, V.C. 2002. How far advanced was Diptera evolution in Pangaea? Annales de la Société Entomologique de France 38: 177-200.

Blagoderov, V. \& Grimaldi, D. 2004. Fossil Sciaroidea (Diptera) in Cretaceous ambers, exclusive of Cecidomyiidae, Sciaridae, and Keroplatidae. American Museum Novitates 3433: 1-76.

Chander, P.J. 1994. The fungus gnats of Israel (Diptera: Sciaroidea, excluding Sciaridae). Israel Journal of Entomology 28: 1-100.

Chandler, P. \& Gatt, P. 2000. Fungus Gnats (Diptera: Bolitophilidae, Keroplatidae and Mycetophilidae) from the Maltese islands. Studia dipterologica 7: 69-81.

Chandler, P.J. \& Pijnakker, J. 2009. Tropical fungus gnats established in nurseries in the Netherlands (Diptera: Keroplatidae and Mycetophilidae). British Journal of Entomology and Natural History 22: 81-93.

Chandler, P.J. \& Ribeiro, E. 1995. The Sciaroidea (Diptera) (excluding Sciaridae) of the Atlantic Islands (Canary Islands, Madeira and the Azores). Boletim do Museu Municipal do Funchal (História Natural) Suplemento 3: $1-170$.

Chapman, A.D. \& Wieczorek, J., eds. 2006. Guide to best practices for georeferencing. Copenhagen: Global Biodiversity Information Facility. (http://www.gbif.org/participation/training/resources/gbif-trainingmanuals; accessed 07/2011)

Evenhuis, N.L. 1994. Catalogue of the fossil flies of the World (Insecta: Diptera). Leiden: Backhuys.

Grimaldi, D. \& Blagoderov, V. 2001. A new genus of Lygistorrhinidae from Vietnam (Diptera: Sciaroidea), and phylogenetic relationships in the family. Studia dipterologica 8: 43-67.

Hippa, H., Mattsson, I. \& VilkamaA, P. 2005. New taxa of the Lygistorrhinidae (Diptera: Sciaroidea) and their implications for a phylogenetic analysis of the family. Zootaxa 960: 1-34.

Hippa, H. \& VilkamaA, P. 2005. The genus Sciarotricha gen. n. (Sciaridae) and the phylogeny of recent and fossil Sciaroidea (Diptera). Insect Systematics \& Evolution 36: 121-144.

Hutson, A.M. 1978. An undescribed African species of Leia (Dipt. Mycetophilidae) infesting root-ginger in London. Entomologist's Monthly Magazine 113: 121-124.

ICZN (International Commission on Zoological Nomenclature). 1999. International Code of Zoological Nomenclature. $4^{\text {th }}$ ed. London: International Trust for Zoological Nomenclature.

JASCHHOF, M. 2006. Even more paradoxical: Paradoxa paradoxa sp. n. (Diptera: Mycetophilidae) from South Africa, close relative of the New Zealand Paradoxa fusca Marshall. African Invertebrates 47: 229-235.

JASCHHOF, M. \& Mostovski, M. 2006. First record of Manota (Diptera: Mycetophilidae: Manotinae) from southern Africa, with the description of two new species. African Invertebrates 47: 237-242.

Matile, L. 1979. Diptères Mycetophilidae de l'Archipel des Comores. Mémoires du Muséum National d'Histoire Naturelle, série A, Zoologie 109: 247-306.

1992. Review of the Afrotropical Gnoristinae (Diptera: Mycetophilidae), with descriptions of nine species and first record of Synapha Meigen. Annals of the Natal Museum 33: 189-202.

1997. Phylogeny and evolution of the larval diet in the Sciaroidea (Diptera, Bibionomorpha) since the Mesozoic. In: Grandcolas, Ph., ed., The origin of biodiversity in insects: phylogenetic tests of evolutionary scenarios. Mémoires du Muséum National d'Histoire Naturelle 173: 273-303.

Pape, Th., Blagoderov, V. \& Mostovski, M.B. 2011. Order Diptera Linnaeus, 1758. In: Zhang, Z.-Q., ed., Animal biodiversity: An outline of higher-level classification and survey of taxonomic richness. Zootaxa $\mathbf{3 1 4 8}$ : $222-229$.

Regents of the University of CALIFornia. 2011. MaNIS Georeferencing Calculator April 2011 version. http://manisnet.org/gci2.html (accessed 07/2011).

Rindal, E., Søli, G.E. \& Bachmann, L. 2009. Molecular phylogeny of the fungus gnat family Mycetophilidae (Diptera, Mycetophiliformia). Systematic Entomology 34: 524-532.

SøLI, G.E.E. 1997. The adult morphology of Mycetophilidae (s. str.), with a tentative phylogeny of the family (Diptera, Sciaroidea). Entomologica Scandinavica Supplement 50: 5-55.

Thompson, F.C. 1975. Notes on the genus Lygistorrhina Skuse with the description of the first Nearctic species (Diptera: Mycetophiloidea). Proceedings of the Entomological Society of Washington 77 (4): 434-445.

Toft, R. J. \& Chandler, P. 2004. Three introduced species of Mycetophilidae (Diptera: Sciaroidea) established in New Zealand. New Zealand Entomologist 27: 43-49.

VÄISÄNEN, R. 1984. A monograph of the genus Mycomya Rondani in the Holarctic region (Diptera, Mycetophilidae). Acta zoologica Fennica 177: 1-346.

1994. New Mycomyinae from South Africa (Diptera, Mycetophilidae). Entomologica Fennica 5: 13-26.

Vockeroth, J.R. 2009. Lygistorrhinidae. In: Brown, B., Borkent, A., Cumming, J.M., Wood, D.M., Woodley, N.E. \& Zumbado, M.A., eds, Manual of Central American Diptera. Vol. 1. Ottawa: NRC Research Press, pp. 265-266.

WieczoreK, J., GuO, Q. \& HiJmans, R. 2004. The point-radius method for georeferencing locality descriptions and calculating associated uncertainty. International Journal of Geographical Information Science 18: $745-767$. 


\title{
Mycetophilidae (Diptera: Bibionomorpha) type specimens in the Iziko South African Museum, Cape Town
}

\author{
S.S. Oliveira \\ Faculdade de Filosofia, Ciências e Letras de Ribeirão Preto, Universidade de São Paulo, Avenida Bandeirantes 3900, \\ 14040-901, Ribeirão Preto, SP, Brazil. E-mail: oliveira.sarahcv@gmail.com
}

An annotated list is provided of the type specimens of four species of Mycetophilidae (Diptera: Bibionomorpha) described by Edwards (1925) and placed in the Iziko South African Museum (SAMC), Cape Town, South Africa. The label data and preservation condition of each specimen are provided. The type of Dziedzickia nitida Edwards is formally lost and the lectotypes of Acrodicrania africana and Leia stigmatica are designated below.

The family Mycetophilidae s.s. is one of the largest and most diverse families of Bibionomorpha, with approximately 180 extant genera and more than 4100 species worldwide (Pape et al. 2011). Edwards (1925), in a compilation on Mycetophilidae (s.l., including some Sciaridae and Bibionidae specimens) in the South African Museum, that had been forwarded to him by Dr L. Péringuey, described four new species of Mycetophilidae s.s. of which some of the syntypes are located in the SAMC. Edwards (1925) stated that he had been allowed to retain duplicate specimens in the Natural History Museum (NHM), London, collection evidently including some syntypes of the new species he described.

The present paper provides a list of the type specimens of Mycetophilidae housed in the SAMC collection, with details on their label data and preservation condition. The list is in alphabetical order of genera. Label data are given in single quotation marks; handwritten text is reproduced in italics; completely handwritten and printed labels are reproduced in regular font. Additions and clarifications by the current authors to some of the original information on labels are included within square brackets. Particularly notable information on the types is in bold and underlined. Photographs were taken at the SAMC, Entomology collection, with a Sony Cyber-Shot DSC-W320.

The Mycetophilidae type specimens in the SAMC collection are listed below.

\section{Acrodicrania africana Edwards, Figs 1-2}

Edwards, 1925: 609 (original description). Type locality: South Africa, Western Cape, Cape
Town. Distr. - South Africa (Western Cape, Cape Town). Lectotype $\delta$, NHM (here designated).

Paralectotypes (SAMC) $1 \delta^{\circ}$ and 19: (1) printed on white paper: 'Cape Town | Peringuey | 1915'; (2) printed on white paper with red border: 'Type | H.T.'; (3) printed with handwritten notations on white paper: 'Acrodicrania | africana Edw. [Edwards] | F.W. Edwards | det. 1922'. Preservation: male and female exemplars glued on square of paper (Fig. 1). Missing parts: none.

Remarks. Type listed above with SAMC type number SAM-DIP-A005972.

Comments. Edwards (1925) based his description on two male and one female specimens. As no types were designated, these are syntypes. Notwithstanding, there is a male specimen housed in the NHM (BMNH (E) 254151) with a red cardboard label 'LECTOTYPE Matile, 1970' (V. Blagoderov, pers. comm.), but there is no printed evidence of designation. It is possible that Matile intended to designate it, but did not do so (V. Blagoderov, pers. comm.).

\section{Dziedzickia nitida Edwards, Fig. 3}

Edwards, 1925: 607 (original description). Type locality: South Africa, Western Cape, Cape Town. Distr. - South Africa (Western Cape, Cape Town).

Type: 19 (according to original description): (1) printed with handwritten notations on white paper: 'Cape Town [South Africa] | Lightfoot | Aug 1916 [August]'; (2) printed on white paper with red border: 'Type | H.T.'; (3) printed with handwritten notations on white paper: 'Dziedzickia | nitida, Edw. [Edwards] | F.W. Edwards | det. 1922'. Preservation: type lost (Fig. 3).

Remarks. Type listed above with SAMC type number SAM-DIP-A005970.

\section{Leia stigmatica Edwards, Figs 4-8}

Edwards, 1925: 610 (original description); 611, fig. 3 (male terminalia). Type locality: South Africa, 

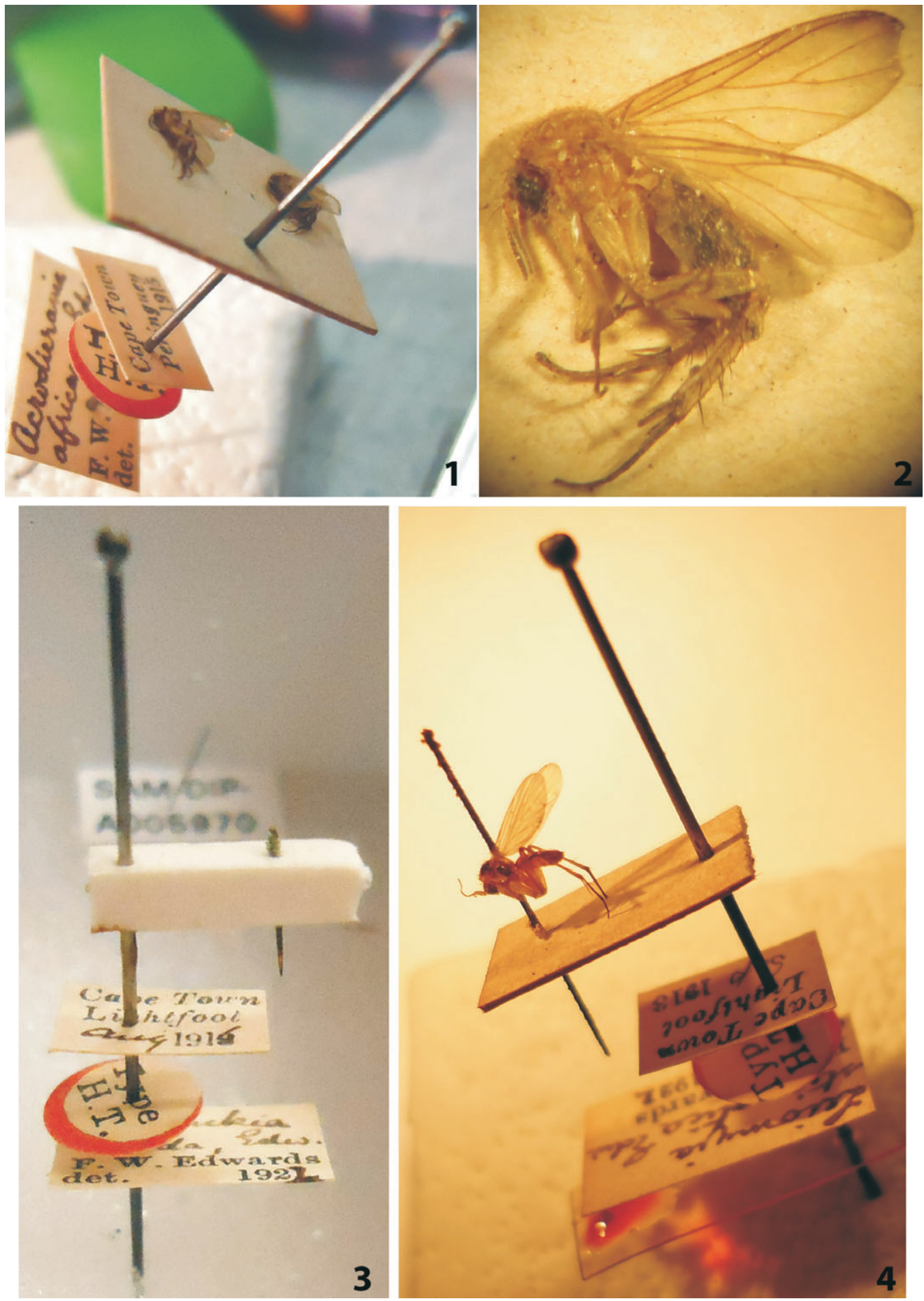

Figs 1-4. Mycetophilidae type specimens housed in the SAMC. 1-2: Acrodicrania africana, 1, male (left) and female (right) paralectotypes, general view; 2, female habitus. 3, Dziedzickia nitida, type lost. 4, Leia stigmatica, male paralectotype, general view. 

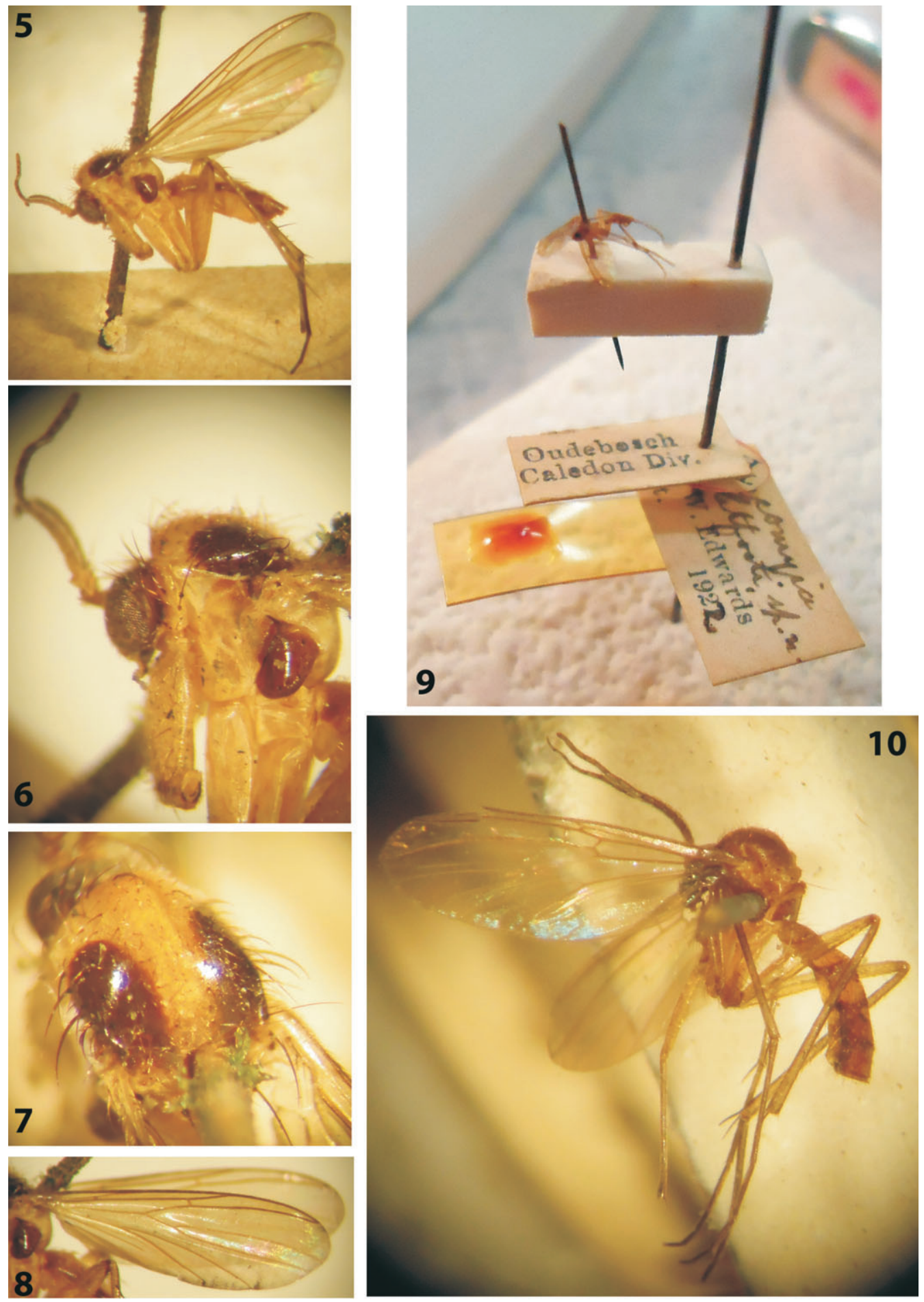

Figs 5-10. Mycetophilidae type specimens housed in the SAMC. 5-8: Leia stigmatica, male paralectotype; 5, habitus; 6, thorax, lateral view; 7, thorax, dorsal view; 8, left wing. 9-10: Mycomya lightfooti, male type; 9, general view; 10 , habitus. 
Western Cape, Cape Town. Distr. - South Africa (Western Cape, Cape Town). Lectotype o, NHM (here designated).

Paralecotype (SAMC) 10ิ: (1) printed on white paper: 'Cape Town | Lightfoot | Sep 1913 [September]'; (2) printed on white paper with red border: 'Type | H.T.'; (3) printed with handwritten notations on white paper: 'Leiomyia | stigmatica Edw. [Edwards] | F.W. Edwards | det. 1922'. Preservation: double-mount pinned exemplar, terminalia in resin on clear plastic film pinned with specimen (Fig. 4). Missing parts: legs I and II.

Remarks. Type listed above with SAMC type number SAM-DIP-A005973.

Comments. Edwards (1925) based his description on two male and three female specimens. As no types were designated these are syntypes. Notwithstanding, there are two specimens housed in the NHM (BMNH (E) 254198). The male specimen has a red cardboard label 'LECTOTYPE Matile, 1970' (V. Blagoderov, pers. comm.). As with Acrodicrania africana, there is no publication with the lectotype designation. The female specimen has a label written by John Chaney (the NHM curator at the time) 'paralectotype', but it seems that he might have put it on after Matile returned the loan (V. Blagoderov, pers. comm.). The remaining two females could not be located.

\section{Mycomya lightfooti Edwards, Figs 9-10}

Edwards, 1925: 608 (original description); 609, fig. 2 (male terminalia). Type locality: South Africa, Western Cape, Oudebosch, Caledon
Division. Distr. - South Africa (Western Cape).

Type 10 (according to original description): (1) printed on white paper: 'Oudebosch | Caledon Div. [Division]'; (2) printed on white paper with red border: 'Type | H.T.'; (3) printed with handwritten notations on white paper: 'Mycomyia | lightfooti sp.n. | F.W. Edwards | det. 1922'. Preservation: double-mount pinned exemplar, terminalia in resin on clear plastic film pinned with specimen (Fig. 9). Missing parts: none.

Remarks. Type listed above with SAMC type number SAM-DIP-A005971.

\section{ACKNOWLEDGEMENTS}

I am most grateful to D. Larsen and S. van Noort for their willing help during my visit to the SAMC collection. V. Blagoderov kindly checked the labels of the NHM specimens. V. Blagoderov, N. Evenhuis and R. Capellari provided advice on the discussion. I am grateful for the financial support from FAPESP grant 2008/52324-6. The manuscript was greatly improved by the comments of the reviewers and the editor.

\section{REFERENCES}

EDWARDS, F.W. 1925. 11. Mycetophilidae and Bibionidae (Diptera) in the collection of the South African Museum. Annals of the South African Museum 19: 601-616.

PAPE, T., BLAGODEROV, V. \& MOSTOVSKI, M.B. 2011. Order Diptera Linnaeus, 1758. In: Zhang, Z-Q. (Ed.) Animal Biodiversity: An Outline of Higher-level Classification and Survey of Taxonomic Richness. Zootaxa 3148: 222-229. 


\title{
Three replacement names for species of the subfamily Leiinae (Diptera, Mycetophilidae)
}

\author{
Sarah Siqueira de Oliveira' ${ }^{1} \&$ Dalton de Souza Amorim ${ }^{1,2}$
}

\begin{abstract}
${ }^{1}$ Universidade de São Paulo, Faculdade de Filosofia, Ciências e Letras de Ribeirão Preto, Departamento de Biologia, Avenida Bandeirantes 3900, 14040-901 Ribeirão Preto-SP, Brazil oliveira.sarahcv@gmail.com ${ }^{2} \mathrm{CNPq}$ Research Fellowship. dsamorim@usp.br
\end{abstract}

\begin{abstract}
Three replacement names for species of the subfamily Leiinae (Diptera, Mycetophilidae). New names are proposed for three cases of homonymy in the Mycetophilidae subfamily Leiinae, one in the genus Docosia Winnerz, one in Leia Meigen, and one in Tetragoneura Winnertz. Docosia garretti nom. nov. is proposed for Docosia setosa Garrett, 1925; Leia walkeri nom. nov. for Leia bimaculata (Walker, 1848); and Tetragoneura sasakawai nom. nov. for Tetragoneura tibialis Sasakawa, 1961. The context of each new name is discussed.
\end{abstract}

KEYWORDS. Docosia; homonymy; Leia; taxonomy; Tetragoneura.

RESUMO. Três novos nomes para espécies da subfamília Leiinae (Diptera, Mycetophilidae). Novos nomes são propostos para três casos de homonímia em Leiinae (Mycetophilidae), um no gênero Docosia Winnerz, um em Leia Meigen e um em Tetragoneura Winnertz. Docosia garretti nom. nov. é proposto para Docosia setosa Garrett, 1925; Leia walkeri nom. nov. para Leia bimaculata (Walker, 1848); Tetragoneura sasakawai nom. nov. para Tetragoneura tibialis Sasakawa, 1961. O contexto de cada nome novo é discutido.

PALAVRAS-CHAVE. Docosia; homonímia; Leia; taxonomia; Tetragoneura.

While revising the literature of the Neotropical Mycetophilidae towards the preparation of an updated catalogue for the family, we came across some species names from different regions in need of replacement in the genera Docosia Winnertz, Leia Meigen and Tetragoneura Winnertz. Here we propose new names for these species, with some additional comments.

\section{Docosia garretti, nom. nov.}

Replacement name for Docosia setosa Garrett, 1925: 12; not Docosia setosa Landrock, 1916: 63. Type-locality: Canada. British Columbia.

Etymology. This species is named after the Canadian dipterist Cecil B. D. Garrett (1882-1979), who contributed to the knowledge of taxonomy of the Mycetophilidae, mainly from the Nearctic.

Comments. Garrett (1925) proposed the name Docosia setosa for a species from British Columbia, Canada. This name was already used by Landrock (1916) for a species described from Czech Republik. In the catalogue of the Nearctic Mycetophilidae, Laffoon (1965) indicated that the name was preoccupied without proposing a replacement name.
Leia walkeri, nom. nov.

Replacement name for Leia bimaculata (Walker 1848: 100); not Leia bimaculata (Meigen 1804: 92). Type-locality: "East Indies".

Etymology. The species is named after the English dipterist Francis Walker (1809-1874). Besides his work on Diptera taxonomy, he also published catalogues of Orthoptera, Neuroptera, Homoptera, Lepidoptera and Hymenoptera.

Comments. The name Mycetophila bimaculata was used by Meigen (1804) for a species from Germany. The same name was proposed later by Walker (1848) for a species from "East Indies", possibly from India. Subsequently both species were moved to Leia. The Oriental catalogue of the Mycetophilidae (Colless \& Liepa 1973) did not recognize the homonymy with Meigen's (1804) species.

\section{Tetragoneura sasakawai, nom. nov.}

Replacement name for Tetragoneura tibialis Sasakawa 1961: 192; not Tetragoneura tibialis Freeman 1951: 86. Type-locality: Ambo-Funayki, Yakushima, Kyushu (Japan). Distr.: Japan.

Etymology. This species is named after the Japanese dipterist Mitsuhiro Sasakawa, who works on different 
dipteran families, especially Agromyzidae and some other acalyptrate groups.

Comments. Sasakawa (1961) proposed the name Tetragoneura tibialis for a species from Japan, not aware that the same name was used earlier by Freeman (1951) for a species described from Argentina (Rio Negro, Bariloche). Hackman et al. (1988) did not recognize that the name was preoccupied.

Further comments

It should also be noted that Fisher (1939: 234) described a species of Leiella under the name Leiella bicolor, which Papavero (1978: 31) mistakenly indicated that had been originally described as a species of Leia. Brunetti (1912: 100) described Leia bicolor from West Bengal, but in fact there is no need of a replacement name in this case.

Another case of homonymy in the Leiinae has already been solved. Leia fasciata Storå (1936: 10), described from the Canary Islands, is a homonym of Leia fasciata Kértesz (Kértesz 1902: 574), described from Peru, also present in Bolivia, Paraguay, Brazil, and Argentina (Papavero 1978). Hackman et al. (1988) did not recognize the homonymy. Later on, Chandler \& Ribeiro (1995) recognized Leia fasciata Storå as identical to Leia arsona Hutson (1978: 123), described from South Africa, St. Helena and Kenya, also present in a London infestation associated to rotting root-ginger. It is worth mentioning that Hutson (1978) pointed to a similarity between Leia arsona Hutson and Leia fasciata Kértesz. It was commented by Hutson (1978: 122) that L. arsona could be a species belonging to "a species-group that is mainly South American". One can not exclude the possibility that $L$. arsona is a Neotropical species later introduced to Africa. Besides, this species has become widely introduced in Europe and the Mediterranean region as well as in New Zealand (Toft \& Chandler 2004).

Acknowledgments. We are grateful to Eirik Rindal for his useful comments to our manuscript and to FAPESP for the financial support (Grants 2003/10.274-9 and 2008/52324-6).

\section{REFERENCES}

Brunetti, E. 1912. Diptera Nematocera (excluding Chironomidae and Culicidae). Fauna of British India (Diptera) 1: 1-581.

Chandler, P. J. \& E. Ribeiro. 1995. The Sciaroidea (Diptera) (excluding Sciaridae) of the Atlantic Islands (Canary Islands, Madeira and the Azores). Boletim do Museu Municipal do Funchal (HistóriaNatural), Suplemento Number 3: 1-170.

Colless, D. H. \& Z. Liepa. 1973. Superfamily Mycetophiloidea, family Mycetophilidae, p. 444-463. In: M. D. Delfinado \& D. E. Hardy (eds.) A catalog of the Diptera of the Oriental Region. Vol. 1. Honolulu, University Press of Hawaii. 618 p.

Fisher, E. G. 1939. Costa Rican Mycetophilidae (Diptera). Transactions of the American Entomological Society 65: 227-236.

Freeman, P. 1951. Diptera of Patagonia and South Chile based mainly on material in the British Museum (Natural History). Part III. Mycetophilidae. London, British Museum (Natural History). vii+138 p.

Garrett, C. B. D. 1925. Seventy new Diptera - key to the Pseudoleria, Helomyzidae, Tipulidae, Chironomidae, Dixinae, Orphnephilidae, Mycetophilidae. Privately published, Cranbrook. 16 p.

Hackman, W.; P. Laštovka; L. Matile \& R. Väisänen. 1988. Mycetophilidae, p. 220-327. In: Á. Soós \& L. Papp. (eds.). Catalogue of Palaearctic Diptera. Volume 3. Amsterdam Elsevier.

Hutson, A. M. 1978. An undescribed african species of Leia (Dipt. Mycetophilidae) infesting root-ginger in London. Entomologist's Monthly Magazine 113: 121-124.

Kertész, K. 1902. Neue Neoglaphyroptera-Arten aus Süd-Amerika. Természetrajzi Füzetek 25: 573-581.

Laffoon, J. L. 1965. Mycetophilidae, p. 196-229. In: A. Stone, C. W. Sabrosky; W. W. Wirth; R. H. Foote \& J. R. Coulson (eds.). A Catalog of the Diptera of America North of Mexico. Washington. Agricultural Research Service. United States Department of Agriculture.

Landrock, K. 1916. Neue mährische Arten der Pilzmückengattung Docosia Winn. Zeitschrift des Mährischen Landesmuseums 15: 59-66.

Meigen, J. W. 1804. Klassifikazion und Beschreibung der europäischen zweiflügeligen Insekten (Diptera Linn.). Erster Band. Abt. I. xxviii + p. 1-152, Abt. II. vi + p. 153-314. Reichard, Braunschweig [= Brunswick].

Papavero, N. 1978. Mycetophilidae, p. 1-78. In: N. Papavero (ed.). A Catalogue of the Diptera of the Americas South of the United States. Museu de Zoologia, Secretaria da Agricultura do Estado de São Paulo, São Paulo.

Sasakawa, M. \& N. Tamu. 1961. Japanese Fungivoridae (Diptera). III. New or little-known fungus gnats from the Tsushima Islands. The scientific report of Kyoto Prefectural University Human Environment and Agriculture 13: 68-69.

Storå, R. 1936. Fam. Mycetophilidae. In: R. Frey: Die Dipterenfauna der Kanarischen Inseln und ihre Probleme. Commentationes biologicae 6: $10-14$.

Toft, R. J. \& P. J. Chandler. 2004. Three introduced species of Mycetophilidae (Diptera: Sciaroidea) established in New Zealand. New Zealand Entomologist 27: 43-49.

Walker, F. 1848. List of the specimens of dipterous insects in the collection of the British Museum. Part 1. London. The Trustees, British Museum (Natural History), 229 p. 


\title{
Docosia adusta sp. nov. (Diptera: Mycetophilidae) from the Colombian Andes: a Holarctic element in northwestern South America
}

\author{
Sarah Siqueira Oliveira, Dalton de Souza Amorim
}

\begin{abstract}
A third Neotropical species of the genus Docosia Winnertz is described from the Colombian Andes. Three males and four females of D. adusta sp. nov. from Cundinamarca, Colombia, collected at $3600 \mathrm{~m}$ elevation were examined. Detailed illustrations of the male and female terminalia are presented and morphological differences in relation to those of other species of the genus are discussed. The relationships between Holarctic and Neotropical species within Docosia are discussed and overlap of circumantarctic, tropical, and Nearctic elements in the northern Andes is considered.
\end{abstract}

\begin{abstract}
Résumé - Nous décrivons une troisième espèce néotropicale du genre Docosia Winnertz des Andes de Colombie à l'examen de trois mâles et quatre femelles de D. adusta sp. nov. de Cundinamarca, Colombie, récoltés à $3600 \mathrm{~m}$. Nous présentons des illustrations détaillées des derniers segments abdominaux du mâle et de la femelle et discutons des différences morphologiques avec les autres espèces du genre. Nous traitons des relations entre les espèces holarctiques et néotropicales au sein de Docosia, en particulier du chevauchement des éléments circumantarctiques, tropicaux et néarctiques dans le nord des Andes.
\end{abstract}

[Traduit par la Rédaction]

\section{Introduction}

Fungus gnats are one of the most species-rich dipteran families, Mycetophilidae (Diptera), in the Neotropical Region. Although the monophyly of Mycetophilidae is a consensus (Søli 1997; Amorim and Rindal 2007; Rindal et al. 2009), a robust phylogeny of this family is still wanting. Seven subfamilies are recognized for Mycetophilidae s.s.: Sciophilinae, Gnoristinae, Mycomyinae, Leiinae, Manotinae, Allactoneurinae, and Mycetophilinae (e.g., Väisänen 1984; Matile 1989; Rindal et al. 2009). However, the monophyly of Sciophilinae, Gnoristinae, and Leiinae is still questionable. Subfamilial rank has been given to the tribe Metanepsiini (Väisänen 1984; Ševčík and Hippa 2010) of Gnoristinae, but this clade would almost certainly make the rest of Gnoristinae paraphyletic (Kallweit 1998).

The present diversity of Leiinae comprises 32 recent genera and almost 550 recent species worldwide. Leiinae are well represented in the fossil record (Evenhuis 1994; Blagoderov and Grimaldi 2004), with 54 species. Particularly noteworthy are 8 genera currently assigned to Leiinae in Cretaceous amber (some of these genera may belong elsewhere). The recurrent discussion about the monophyly of Leiinae (e.g., Søli et al. 2000; Hippa et al. 2005; Jaschhof and Kallweit 2009; Rindal et al. 2009) reflects the problems in establishing subfamily limits. Two characters (short $\mathrm{R}_{1}$ and longitudinal $\mathrm{r}-\mathrm{m}$ ) were used by Edwards (1925) to define Leiinae. These features are indeed met by most leiine genera, but there are

Received 25 January 2011. Accepted 2 March 2011.

S.S. Oliveira, ${ }^{1}$ D. Amorim, Faculdade de Filosofia, Ciências e Letras de Ribeirão Preto, Departamento de Biologia, Universidade de São Paulo, Avenida Bandeirantes 3900, CEP 14040-901, Ribeirão Preto, São Paulo, Brazil

${ }^{1}$ Corresponding author (e-mail: oliveira.sarahcv@gmail.com).

doi: $10.4039 / \mathrm{n} 11-033$ 
a number of exceptions (Jaschhof and Kallweit 2009). The sinuous vein $\mathrm{CuA}$ has more recently been considered a synapomorphy for Leiinae (Baxter and Poinar 1994; Jaschhof and Kallweit 2009), but this actually delimits only a smaller clade, without solving the problem of placing various genera in this clade or Gnoristinae.

Docosia Winnertz is a distinctive genus, possibly close to Tetragoneura Winnertz (Edwards 1925). Väisänen (1986) suggested that Tetragoneura plus Ectrepesthoneura Enderlein should be treated as gnoristines. Docosia has $\mathrm{CuA}$ more or less straight and, even considering that this condition is plesiomophic, it could fit together with Tetragoneura (whatever its placement). Some other features could suggest the placement of the genus in Leiinae, but molecular analysis (Rindal et al. 2009) suggests that Docosia should be assigned to Gnoristinae.

Docosia presently comprises 65 described extant species worldwide of which 46 are Palaearctic (e.g., Chandler et al. 2006; Kurina 2006, 2008; Laštovka and Ševčík 2006; Ševčík 2006b; Ševčík and Laštovka 2008; Xu et al. 2003), 16 are Nearctic (e.g., Garrett 1925; Van Duzee 1928), 1 is Oriental (Ševčík 2010), and 2 are Neotropical (Edwards 1933). Information on the biology of Docosia has been provided mainly through the contributions of Chandler (2010), Ševčík (2006a), and Rulik and Kallweit (2006).

In this paper we describe a new Neotropical species of Docosia from Colombia and compare features shared by this species with the remaining species of the genus. Comments are made on the implications of the relationship of this species with other species of the genus for understanding the biogeography of the Neotropical Region.

\section{Material and methods}

The specimens examined in this study belong to the Diptera collection of the Instituto de Investigación de Recursos Biológicos Alexander von Humboldt (IAvH), Bogotá, Colombia. The holotype and some of the paratypes are deposited in IAvH. One male and one female paratype have been placed in the Diptera collection of the Museu de Zoologia da Universidade de São Paulo (MZUSP).

Head, thorax, wing, and terminalia were drawn after dissection. Soft parts were cleared in $10 \% \mathrm{KOH}$ at $40{ }^{\circ} \mathrm{C}$ for $4-6 \mathrm{~h}$, neutralized in acetic acid, and mounted on permanent slides with Canada balsam. Some specimens were mounted temporarily in glycerin or in jelly with phenol (modified from Zandler 2003) on depression slides. Photographs were taken using a Leica DC camera attached to a Leica MZ16 stereomicroscope and a DM2500 transmission microscope. Photographs were prepared using AutoMontage software and edited with Adobe Photoshop CS. Drawings were prepared using a camera lucida and redrawn using Adobe Illustrator 11.0. Morphological terms follow Søli (1997), except for wing venation, which follows Amorim and Rindal (2007).

\section{Docosia Winnertz}

Docosia Winnertz, 1863: 802.

Type species: Mycetophila sciarina Meigen (Johannsen 1909: 92).

\section{Diagnosis}

Three ocelli, lateral ones close to eye margin. $\mathrm{Sc}$ ending free or in $\mathrm{R} ; \mathrm{R}_{1}$ obviously longer than $\mathrm{r}-\mathrm{m}$; point of furcation of $\mathrm{M}$ very basal in the wing, $\mathrm{r}-\mathrm{m}$ nearly horizontal, $\mathrm{M}_{1+2}$ shorter than r-m. Wing may be darkened, but without markings and without macrotrichia on the membrane. Male cerci with combs of blackish spines. Long apical setae on T9.

\section{Docosia adusta sp. nov.}

(Figs. 1-7)

\section{Diagnosis}

Lateral ocelli not touching eye margin. Laterotergite with a group of 9-12 setae of different lengths on posterior third. Legs and halteres dark. Wing membrane brownish, mainly along anterior margin; Sc without macrotrichia; strong medial and cubital 
Fig. 1. Docosia adusta. Female paratype, habitus. Scale bar $=1 \mathrm{~mm}$.

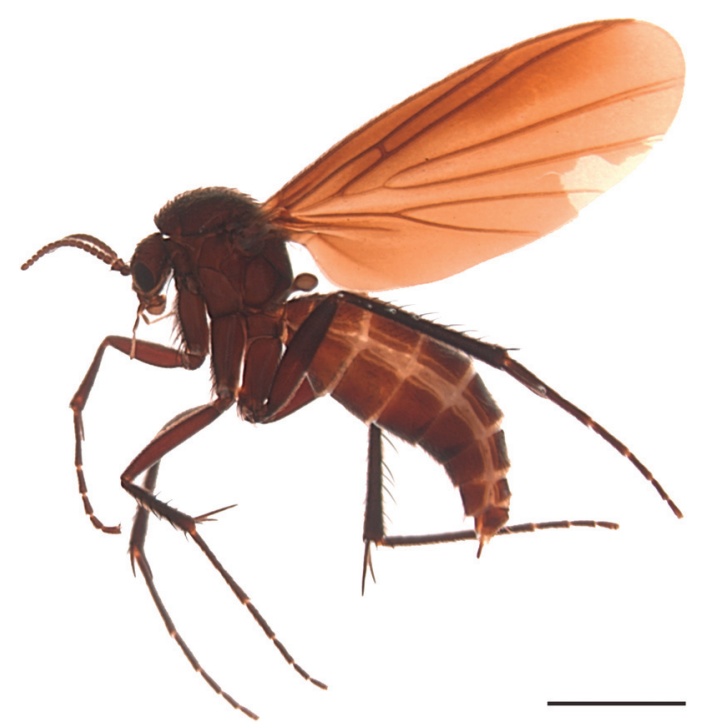

veins. Gonocoxite setose fused to each other ventrally, with a pair of distal mesal extensions, gonocoxal bridge well produced; gonostylus simple, short, with a single apical long seta and 2 small subapical setae; T9 more or less rectangular, longer than wide.

\section{Material examined}

Holotype $₫$ : labelled "COLOMBIA, Cundinamarca, PNN [Parque Nacional Natural] Chingaza Alto de La Bandera, Malaise trap, $04^{\circ} 31^{\prime} \mathrm{N}, 73^{\circ} 45^{\prime} \mathrm{W}, 3,600 \mathrm{~m}$, 15.xi-01.xii.2001, L. Cifluentes leg., M. 2600 [Malaise trap \# 2600]". Paratypes: 2 ô, 4 , same data as holotype.

\section{Description}

Male (Figs. 2, 4-6). Wing length $4.1 \mathrm{~mm}$, wing width $1.7 \mathrm{~mm}$. Head (Fig. 2). Vertex dark brown, with scattered setae. Three ocelli approximately aligned, mid-ocellus smaller than lateral ones, lateral ocelli separated from mid-ocellus by about 2.0 times its width and from eye margin by about its own diameter. Occiput dark brown. Eyes setose. Antennal scape and pedicel quite short, brown, with longer setae dorsally along distal margin; 14 brown flagellomeres, first slightly longer than second, flagellomeres 2-14 same length, almost 1.5 times longer than wide, with scattered setae and a short basal neck. Frons and clypeus brown, covered with short setae; labella light brown, proximal article brown; maxillary palpus brownish, lighter towards apex, five palpomeres, first and second palpomere rounded, apical ones increasingly longer, fourth as long as third, last palpomere 1.5 times penultimate one. Thorax (Fig. 2). Scutum, scutellum, and pleural sclerites dark brown. Pleural membrane brown. Scutum moderately arched, covered with small scattered setae and stronger supra-alar, dorsocentral, and acrostichal setae. Scutellum with eight scutellar bristles, four of them twice length of remaining four, plus many additional setulae. Pronotum with 2 strong setae and some additional setae. Anespisternum with many setulae along posterior margin, katepisternum more or less square ventrally. Mesepimeron not reaching ventral margin of thorax, bare. Laterotergite only slightly projecting, with a group of 9-12 setae of different lengths on posterior third. Mediotergite slightly curved in profile, bare. Metepisternum with five setulae posteriorly. Haltere pedicel brownish, knob light brown, setulae on pedicel, knob more densely setulose. Legs brown. First tarsomere more than twice length of second tarsomere; mid and hind tibiae with long erect darker bristles, in midtibia dorsally and ventrally, in hind tibia more conspicuously dorsally. Tibial spurs 1:2:2, brown, almost 3 times tibial width at apex, internal spurs shorter. Tarsal claws with small basal tooth. Wing. Membrane homogeneously light brown, darker along anterior margin; membrane densely covered with microtrichia in all cells. $\mathrm{R}_{1}, \mathrm{R}_{5}$, and $\mathrm{r}-\mathrm{m}$ with macrotrichia dorsally and ventrally; $\mathrm{M}_{1}, \mathrm{M}_{2}$, $\mathrm{M}_{4}, \mathrm{CuA}$, and $\mathrm{A}_{1}$ with macrotrichia only dorsally. Sc short, ending free, vanishing to apex, without macrotrichia. $\mathrm{C}$ ending much before wing apex, extending about one-sixth of distance between $R_{5}$ and $M_{1}$. First sector of Rs perfectly transverse, devoid of macrotrichia. $\mathrm{R}_{1}$ long, reaching $\mathrm{C}$ on apical third of wing; $\mathrm{R}_{5}$ short, reaching $\mathrm{C}$ quite before wing apex, well sclerotized, slightly sinuous at apex; r-m almost perfectly longitudinal, slightly 
Fig. 2. Docosia adusta. Male paratype, thorax, lateral view (anp, anepisternum; cx I, fore coxa; cx II, midcoxa; cx III, hind coxa; ktp, katepisternum; ltg, laterotergite; mes, metepisternum; mep, mesepimeron; $m t g$, mediotergite; pem, proepimeron; pes, proepisternum; pnt, pronotum; sctl, scutellum). Scale bar $=0.3 \mathrm{~mm}$.

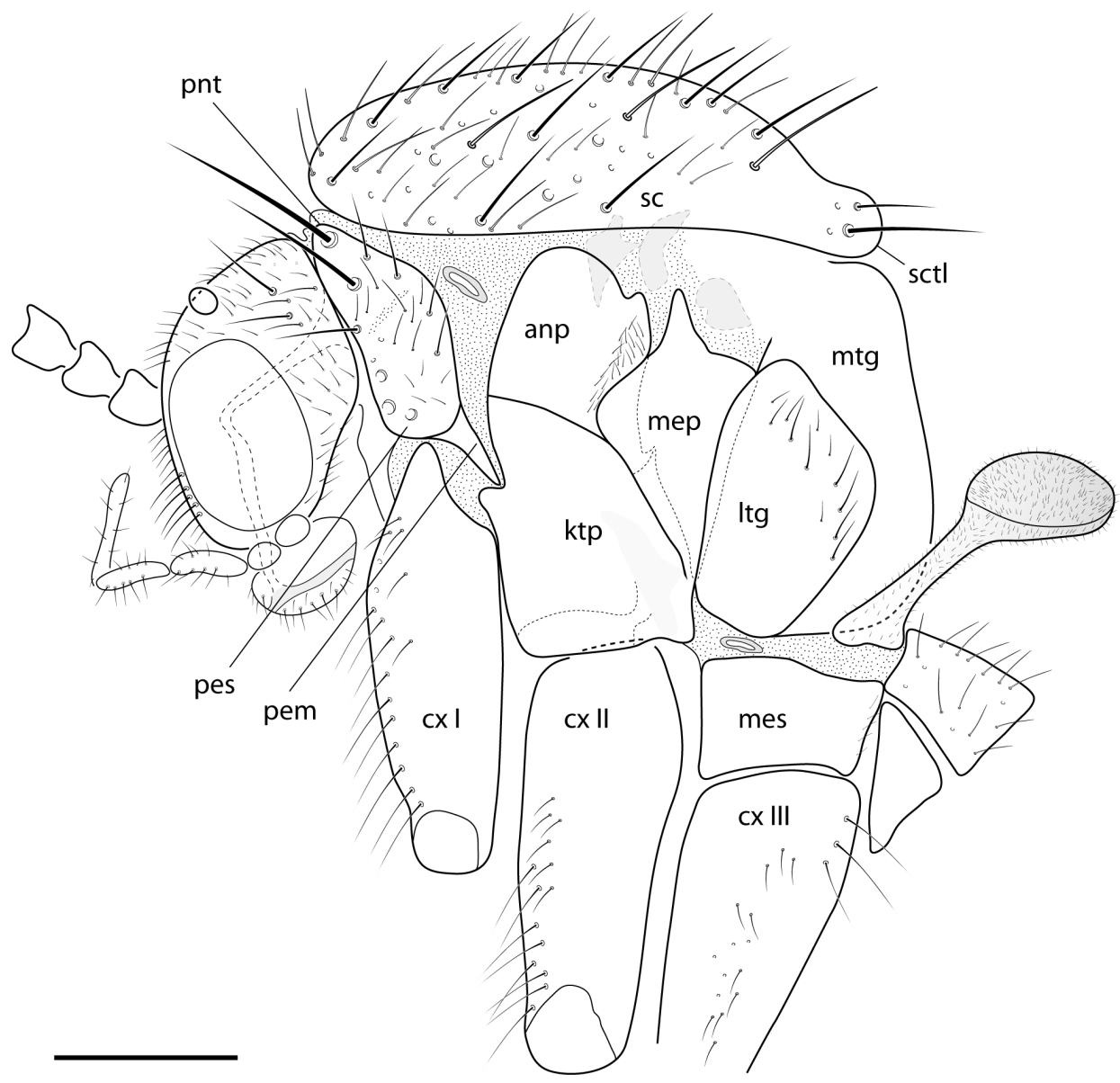

curved at basal end, well sclerotized, more than 4 times length of r-m. $\mathrm{M}_{1+2}$ short, bare, strongly displaced to wing base; medial fork complete, 7 times length of $\mathrm{M}_{1+2}, \mathrm{M}_{1}$ and $\mathrm{M}_{2}$ only slightly divergent towards apex; $\mathrm{M}_{4}$ basally well produced, distally reaching wing margin, $\mathrm{M}_{4}$ and $\mathrm{CuA}$ only slightly divergent along their length; first sector of CuA slightly shorter than second sector of $\mathrm{CuA} . \mathrm{A}_{1}$ incomplete, not produced on apical half. Abdomen. Abdomen brown, setose, lateral margins of tergites and sternites with slender, less sclerotized band. T8 short and wide, S8 longer than wide. Terminalia brown, conspicuous, not particularly elongate. Terminalia (Figs. 4-6). Gonocoxite setose, elongate, fused to each other ventrally, with a pair of distal mesal extensions, gonocoxal bridge well produced; gonostylus short, simple, elongate, slightly curved mesally, with single long apical seta and 2 subapical setae on rounded apex; aedeagus distinctively sclerotized, filiform, trifid basally; T9 more or less rectangular, longer than wide, setose, with four pairs of longer, curved setae on distal margin; cercus very developed, with two rings of distinctively sclerotized spines.

Female (Figs. 1, 3, 7). As in male, except for following features. Wing (Fig. 3). Length $4.4 \mathrm{~mm}$, width $1.7 \mathrm{~mm}$. Head (Fig. 1). Antennal flagellomeres not as elongate as in male, flagellomeres closer to each other. Terminalia 
Fig. 3. Docosia adusta. Female paratype, wing. Scale bar $=0.3 \mathrm{~mm}$.

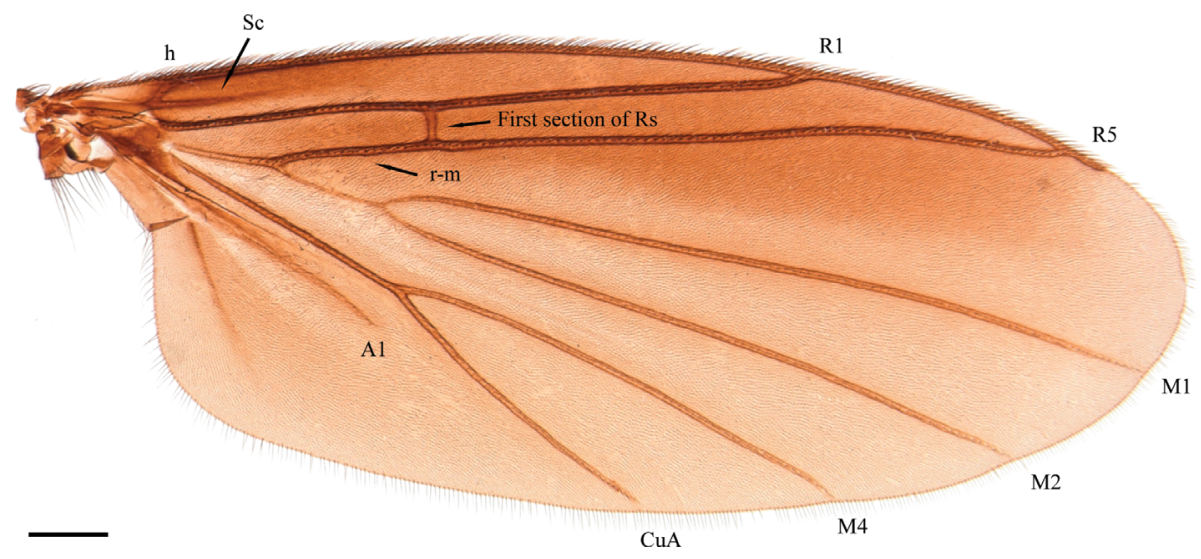

(Fig. 7). Yellowish. S8 weakly sclerotized, with mesal distal projection covered with scattered microtrichia; T8 wide, very short mesally, setae only at lateral margins; S9 (genital fork) weakly sclerotized, wide at anterior end; T9 almost divided in two separate lateral sclerites, with some long setae along distal margin; Ce1 weakly sclerotized, mostly covered by $\mathrm{T} 9, \mathrm{Ce} 2$ more or less cylindrical, weakly sclerotized, devoid of microtrichia, 1 longer seta and 1 shorter seta on basal third and 2 longer subapical setae (one dorsal and one ventral), besides $1-2$ additional short setae.

\section{Etymology}

The species epithet is feminine, derived from the Latin adustus, for "brown", and referring to the brown wing membrane (especially along the anterior margin) and the general body color.

\section{Comments}

The males of this species have the terminalia rotated to some degree. Edwards (1941: 71) considered that the pair of dorsal sclerites in the male terminalia of Docosia gilvipes (Walker) correspond to $\mathrm{T} 9$ divided into two separate plates by a transverse suture. This actually does not seem to be the case in D. adusta sp. nov. The basal sclerites are entirely bare and clearly correspond to the dorsal fusion of lateral extensions of the gonocoxites, resulting in a complete ring anteriorly in the terminalia. This feature is also present in most other species of the gilvipes group (e.g., D. pseudogilvipes Kurina (Kurina 2008, fig. 11)). In the female terminalia the shape of sternite 8 is unusual in relation to that of other genera of Mycetophilidae, in the sense that this sclerite has a single median distal extension, ending acuminate. This is also seen in other species of the genus, like D. gilvipes (Laštovka and Ševčík 2006, fig. 17b). Tergite 9 also has a deep incision distally, which almost divides the plate into two separate lateral sclerites. A single conspicuous cercomere is visible, but this is actually $\mathrm{Ce} 2$, the basal cercomere being weakly sclerotized and partially covered by $\mathrm{T} 9$.

\section{Discussion}

Docosia adusta is different from the two other Neotropical species of the genus, D. pammela Edwards and D. cuzcoensis Edwards, in many respects. The other Neotropical species are small ( $3 \mathrm{~mm}$ long), entirely black, and with the posterior wing veins weakly sclerotized; D. adusta is much larger, dark brown, and with a darkened wing membrane.

A detailed study of the relationships within Docosia is outside the scope of this paper. Nevertheless, it is obvious that D. adusta is not directly connected with the two known Neotropical species. The features shared by D. adusta, D. pammela, and D. cuzcoensis are 
Figs. 4-6. Docosia adusta. Male paratype, terminalia. 4, Lateral view; 5, ventral view, without tergite 9; 6, tergite 9, dorsal view (Ae, aedeagus; Ce, cercus; Dgce, dorsal extension of gonocoxite; Gcap, gonocoxal apodeme; Gcx, gonocoxite; Gs, gonostyle; T, tergite). Scale bar $=0.1 \mathrm{~mm}$.
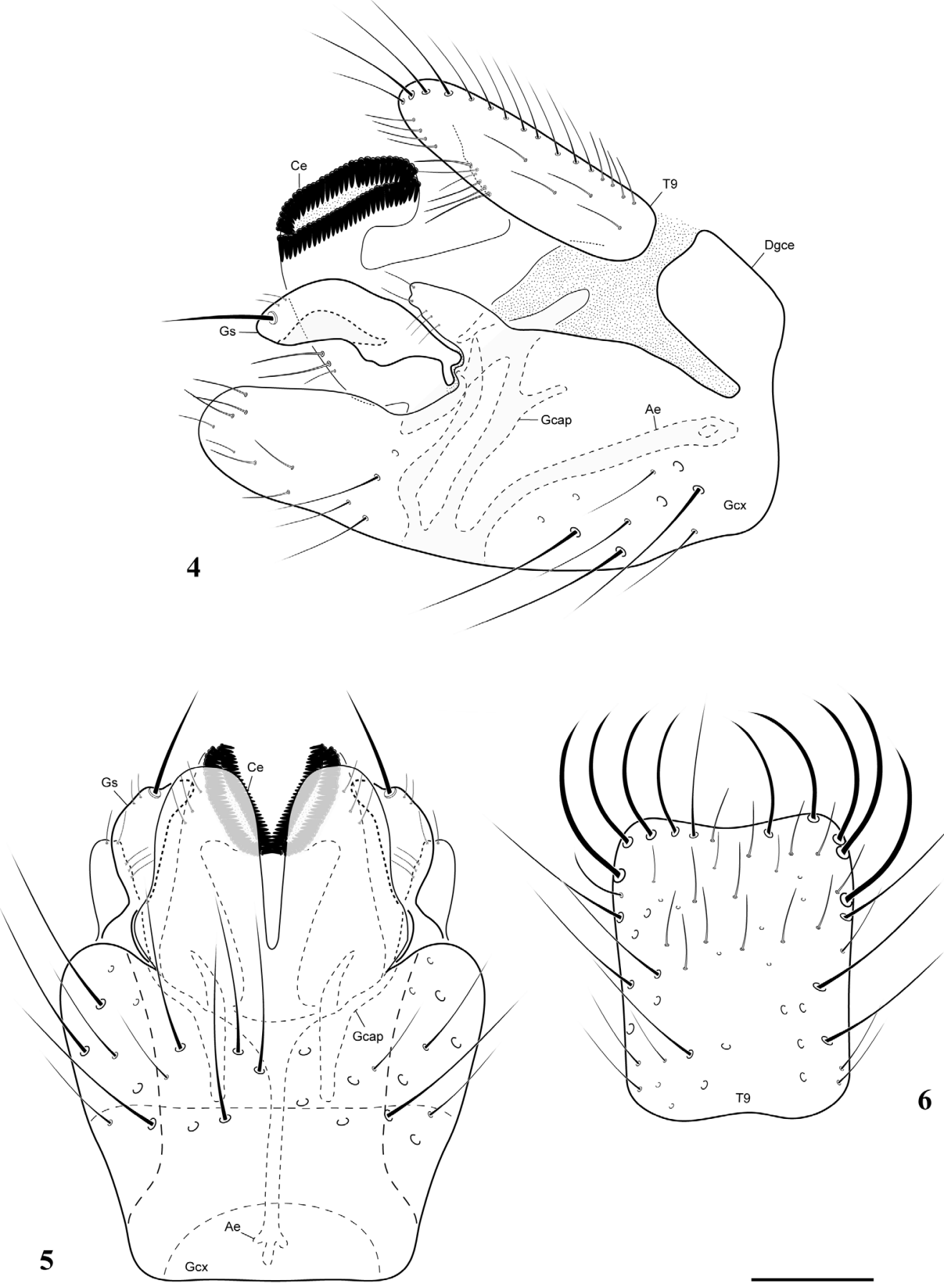
Fig. 7. Docosia adusta. Female paratype, terminalia, laterodorsal view (ce, cercus; S, sternite; T, tergite). Scale bar $=0.1 \mathrm{~mm}$.

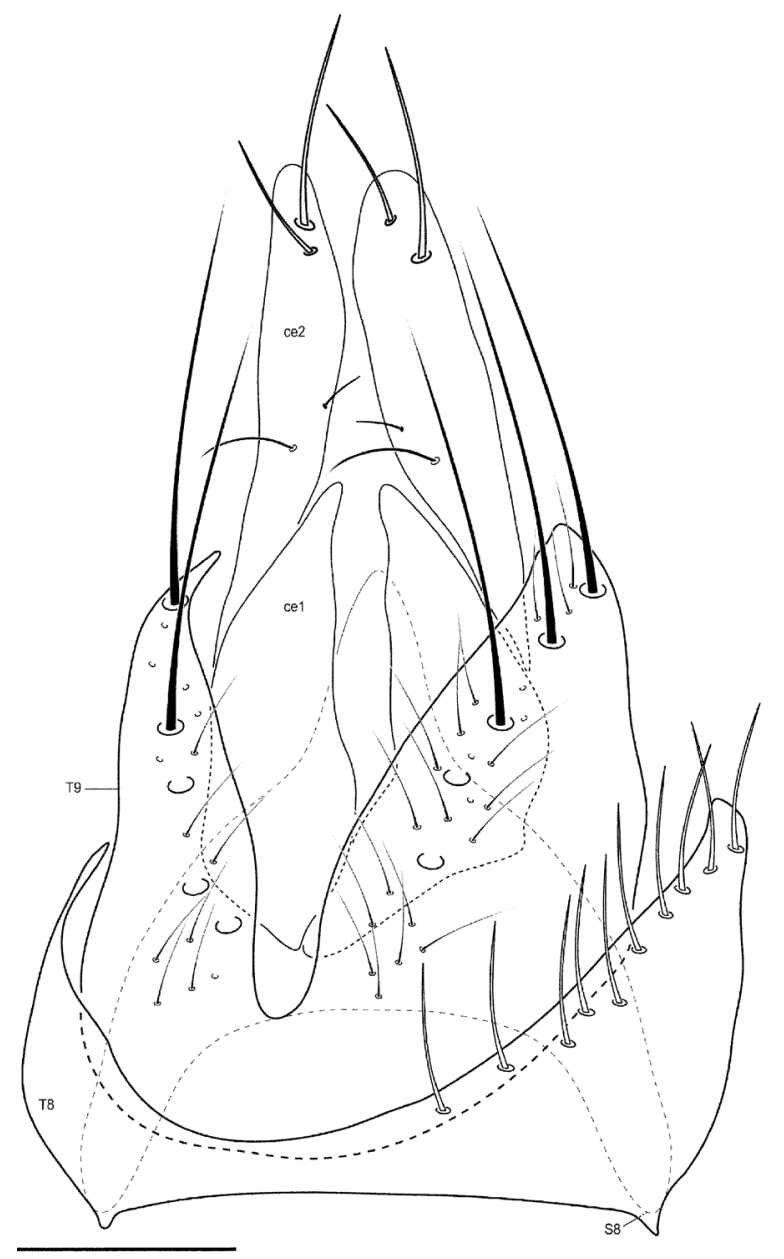

of wider distribution in Docosia and do not correspond to shared exclusive apomorphies. This includes Sc ending free, anespisternum setose, gonocoxites connected to each other dorsally, aedeagus filiform, T9 with some stronger setae along the distal margin, and cerci with rows of black spines.

Docosia adusta seems to be more closely related to the Palaearctic species D. gilvipes and $D$. pseudogilvipes, the morphology of whose male terminalia was carefully described and illustrated by Kurina (2008). A close relationship is suggested by the shape of the cercus with two pairs of rather long rows of spines, the more or less simplified gonostyle, and the distal extension of the syngonocoxite ventrally. From this perspective, D. adusta is considerably different from $D$. carbonaria Edwards, D. cephaloniae Chandler et al., D. chandleri Ševčík and Laštovka, D. enos Chandler, Bechev, and Caspers, D. expectata Laštovka and Ševčík, D. flavicoxa Strobl, D. fumosa Edwards, D. fuscipes (von Roser), D. helveola Chandler, and D. lastovkai Chandler. Laštovka and Ševčík (2006) and Kurina (2008) suggested that $D$. gilvipes could have an isolated position within the genus and could be placed in a separate subgenus or genus (along with D. pseudogilvipes (Kurina 2008)). Some undescribed Nearctic species of Docosia also belong to this group (J. Ševčík, personal communication). 
With reference to a revision of the Palaearctic species of Docosia, Petr Laštovka has commented that relationships within the Nearctic portion of the genus are complex (P.J. Chandler, personal communication). He recognized about 50 species with "interesting phyletic relations" and that there are Nearctic species from the gilvipes group "more numerous than those with $\mathrm{Sc}$ bare and ending in $\mathrm{R}_{1}$ (apart from distinct features of terminalia)".

Independently of the question of the rank of this clade (species group, genus, or subgenus), if the association of D. adusta with this Holarctic group of species within the genus is correct, the presence of this species in Colombia corresponds to a secondary extension of a Nearctic clade to the south, reaching northeastern South America. This pattern is actually not restricted to Docosia within the Mycetophilidae. Two undescribed species of Cordyla Meigen (Mycetophilidae: Mycetophilinae) show this pattern as well, one reported from Costa Rica (Vockeroth 2009), the other reaching Colombia (Oliveira et al. 2007).

The overlap of different biogeographic elements in Colombia is actually even more complex. Besides the presence of elements of Nearctic origin higher in the Andes, close to localities with elements of tropical origin in the Neotropical Region, areas of higher altitude in Colombia also have a number of typical circum-antarctic elements, such as species of Neoaphelomera Miller, Allocotocera Mik, Parvicellula Marshall, Austrosynapha Tonnoir, Paraleia Tonnoir, and Procycloneura Edwards (Oliveira et al. 2007). Further studies of the diversity of Docosia and its phylogenetic connections would contribute to a better understanding of the biogeographic history of the genus and, hence, the biogeographic evolution of the region.

\section{Acknowledgements}

The material used in this study was very kindly made available by Michael Sharkey (National Science Foundation Grant DEB0205982), to whom we are most grateful. Additional information on the project can be found at the web address of the project (http://www.sharkeylab.org/biodiversity/static. php?app $=$ colombia\&page $=$ index). The first author has a graduate fellowship from the Fundação de Amparo à Pesquisa do Estado de São Paulo (Grant 2008/52324-6) and the second author has a fellowship from the Brazilian National Science Research Agency (CNPq). Jan Ševčík helped us with discussions on the Palaearctic Docosia fauna and some advice, and we are grateful to him. Brad Sinclair and two anonymous reviewers helped with an excellent review of the manuscript, with useful suggestions and corrections. The authors sincerely acknowledge J.R. Vockeroth and the general editors of the Manual of Nearctic Diptera for the dedication that resulted in the chapter on the Nearctic Mycetophilidae and the whole manual, respectively. The effort spent in compiling the collective knowledge about Nearctic Diptera has saved countless hours of work by researchers, technicians, and students trying to find scattered primary sources of information worldwide, and prevented an incalculable number of mistakes by those dealing with the complex set of information about each family.

\section{References}

Amorim, D.S., and Rindal, E. 2007. A phylogenetic study of the Mycetophiliformia, with creation of the subfamilies Heterotrichinae, Ohakuneinae, and Chiletrichinae for the Rangomaramidae (Diptera, Bibionomorpha). Zootaxa, 1535: 1-92.

Baxter, J.E., and Poinar, G.O. 1994. A new genus and new species of fungus gnats (Diptera: Mycetophilidae) from Dominican amber. Annales de la Société entomologique de France (N.S.), 30: 93-102.

Blagoderov, V., and Grimaldi, D. 2004. Fossil Sciaroidea (Diptera) in Cretaceous ambers, exclusive of Cecidomyiidae, Sciaridae, and Keroplatidae. American Museum Novitates No. 3433. doi: 10.1206/0003-0082(2004)433 <0001:FSDICA $>2.0 . \mathrm{CO} ; 2$.

Chandler, P.J. (Editor). 2010. A dipterist's handbook. Vol. 15. 2nd ed. The Amateur Entomologists' Society, London, U.K.

Chandler, P.J., Bechev, D.N., and Caspers, N. 2006. The fungus gnats (Diptera: Bolitophilidae, Diadocidiidae, Keroplatidae and Mycetophilidae) of Greece, its islands and Cyprus. Studia Dipterologica, 12: 255-314. 
Edwards, F.W. 1925. British fungus-gnats, with a generic classification of the family. Transactions of the Entomological Society of London, 72: 505-670. doi: 10.1111/j.1365-2311.1925.tb03369.x.

Edwards, F.W. 1933. New Neotropical Mycetophilidae (II). Revista de Entomologia, 3: 303-322.

Edwards, F.W. 1941. Notes on British fungus-gnats (Dipt. Mycetophilidae). Entomologist's Monthly Magazine, 77: 21-33-67-82.

Evenhuis, N.L. 1994. Catalogue of the fossil flies of the world (Insecta: Diptera). Backhuys, Leiden, The Netherlands.

Garrett, C.B.D. 1925. Seventy new Diptera-key to the Pseudoleria Helomyzidae, Tipulidae, Chiromidae, Dixinae, Orphnephilidae, Mycetophilidae. Privately published, Cranbrook, B.C.

Hippa, H., Jaschhof, M., and Vilkamaa, P. 2005. Phylogeny of the Manotinae, with a review of Eumanota Edwards, Paramanota Tuomikoski and Promanota Tuomikoski (Diptera, Mycetophilidae). Studia dipterologica, 11: 405-428.

Jaschhof, M., and Kallweit, U. 2009. The Cycloneura Marshall group of genera in New Zealand (Diptera: Mycetophilidae: Leiini). Zootaxa, 2090: 1-39.

Johannsen, O.A. 1909. Diptera. Fam. Mycetophilidae. In Genera insectorum. Fascicle 93. Edited by P. Wytsman. Brussels, Belgium. pp. 1-141.

Kallweit, U. 1998. Notes on the genus Metanepsia Edwards and its relatives from East Asia (Insecta: Diptera: Mycetophilidae). Reichenbachia, 32: 341-353.

Kurina, O. 2006. Three new species of Docosia Winnertz (Diptera: Mycetophilidae) from Kazakhstan. Entomologica Fennica, 17: 110-117.

Kurina, O. 2008. Diptera Stelviana. 4.3.23 Sciaroidea excl. Sciaridae. Studia dipterologica, Supplement No. 16. pp. 245-293.

Laštovka, P., and Sevčík, J. 2006. A review of the Czech and Slovak species of Docosia Winnertz (Diptera: Mycetophilidae), with atlas of the male and female terminalia. Časopis Slezského Zemského Muzea Opava (A), 55: 1-37.

Matile, L. 1989. Superfamily Sciaroidea. In Catalog of the Diptera of the Australasian and Oceanic Regions. Edited by N.L. Evenhuis. Bishop Museum Press, Honolulu, Hawai'i, and E.J. Brill, Leiden, The Netherlands. pp. 123-145.

Oliveira, S.S., Silva, P.C.A., and Amorim, D.S. 2007. Neotropical, Circum-Antarctic and Nearctic overlap? Mycetophilidae (Diptera) of Colombia and its biogeographic implications. Darwiniana, 45(Supplement): 106-107.

Rindal, E., Søli, G.E.E., and Bachmann, L. 2009. Molecular phylogeny of the fungus gnat family Mycetophilidae (Diptera, Mycetophiliformia). Systematic Entomology, 34: 524-532. doi: 10.1111/j.1365-3113.2009.00474.x.

Rulik, B., and Kallweit, U. 2006. A blackbird's nest as breeding substrate for insects - first record of Docosia fumosa Edwards, 1925 (Diptera:
Mycetophilidae) from Germany. Studia dipterologica, 13: 41-43.

Ševčík, J. 2006a. Diptera associated with fungi in the Czech and Slovak Republics. Casopis Slezského Zemského Muzea Opava (A), 55(supplement 2): 1-84.

Ševčík, J. 2006b. Docosia rohaceki sp.n. and other interesting records of fungus gnats (Diptera: Mycetophilidae) from Polana Biosphere Reserve (central Slovakia). Časopis Slezského Zemského Muzea Opava (A), 55: 131-134.

Ševčík, J. 2010. Docosia heikkii, sp. nov., the first oriental record of Docosia (Diptera: Mycetophilidae). Oriental Insects, 44: 91-94.

Ševčík, J., and Hippa, H. 2010. New species of Chalastonepsia and Pectinepsia gen. nov. (Diptera: Mycetophilidae) from the Oriental and Australasian Regions. Acta Entomologica Musei Nationalis Pragae, 50: 595-608.

Ševčík, J., and Laštovka, P. 2008. Two new European species of Docosia (Diptera: Mycetophilidae). Biologia (Bratislava), 63: 117-119. doi: 10.2478/s11756-008-0010-6.

Søli, G.E.E. 1997. The adult morphology of Mycetophilidae (s. str.), with a tentative phylogeny of the family (Diptera, Sciaroidea). Entomologica Scandinavica, Supplement No. 50. pp. 5-55.

Søli, G.E.E., Vockeroth, J.R., and Matile, L. 2000. Families of Sciaroidea. In Contributions to a manual of Palaearctic Diptera appendix. Edited by L. Papp and B. Darvas. Science Herald, Budapest, Hungary. pp. 49-92.

Väisänen, R. 1984. A monograph of the genus Mycomya Rondani in the Holarctic region (Diptera, Mycetophilidae). Acta Zoologica Fennica, 177: 1-346.

Väisänen, R. 1986. The delimitation of the Gnoristinae: criteria for the classification of recent European genera (Diptera, Mycetophilidae). Annales Zoologici Fennici, 23: 197-206.

Van Duzee, M.C. 1928. New Mycetophilidae taken in California and Alaska. Proceedings of the California Academy of Sciences, 17: 31-65.

Vockeroth, J.R. 2009. 15. Mycetophilidae (fungus gnats). In Diptera of Central America. Vol. 1. Edited by Brown, B., A. Borkent, J.M. Cumming, D.M. Wood, and M.A. Zumbado. NRC Research Press, Ottawa, Ont. pp. 267-278.

Winnertz, J. 1863. Beitrag zu einer Monographie der Pilzmücken. Verhandlung aus zoologisches botanisches Gesellschaft Wien, 7: 11-20.

Xu, H., Wu, H., and Yu, X.X. 2003. New Chinese record of the genus Docosia with a description of a new species (Diptera, Mycetophilidae). Acta Zootaxonomica Sinica, 28: 343-348.

Zandler, R.H. 2003. Glycerin jelly as a substitute for Hoyer's Solution mountant. Res Botanica, Missouri Botanical Garden [online]. Available from http://www.mobot.org/plantscience/ResBot/ Meth/GlycerinJelly.htm [accessed January 2008]. 


\title{
Six new species of Paraleia Tonnoir (Diptera, Mycetophilidae): amphinotic elements at the northern range of the Andes
}

\author{
SARAH SIQUEIRA OLIVEIRA ${ }^{1,3} \&$ DALTON DE SOUZA AMORIM ${ }^{1,2}$ \\ ${ }^{1}$ Departamento de Biologia, Faculdade de Filosofia, Ciências e Letras de Ribeirão Preto, Universidade de São Paulo, Av. Bandei- \\ rantes 3900, 14040-901 Ribeirão Preto SP BRAZIL \\ ${ }^{2}$ E-mail: dsamorim@usp.br, CNPq Research Fellowship, partially developed under FAPESP Grant 2003/10.274-9 \\ ${ }^{3}$ Corresponding author. E-mail: oliveira.sarahcv@gmail.com (FAPESP Grant 2008/52324-6)
}

\begin{abstract}
Paraleia was originally described by Tonnoir for $P$. fulvescens, known from Australia. More recently, eleven Neotropical species were added to the genus - nine of which are from Chile and southern Argentina, one from Bolivia, and one from Peru. This distribution pattern is typical of many mycetophilid genera. Six new Neotropical species of Paraleia from the Andean Colombia and Ecuador are herein described. Male terminalia of $P$. bolivari sp. n., P. denticulata $\mathbf{s p .}$ n., $P$. fumosa sp. n., and $P$. tonnoiri sp. n., as well as female terminalia of $P$. bolivari sp. n., $P$. denticulata sp. n., $P$. fumosa $\mathbf{s p .}$. ., $P$. nidorosa sp. n., $P$. sharkeyi sp. n., and Paraleia sp. are illustrated. High-resolution photos of wings for all species are presented. An identification key for world species of Paraleia is provided.
\end{abstract}

Key words: Paraleia, Mycetophilidae, Diptera, Neotropics, taxonomy

\section{Introduction}

The Mycetophilidae (fungus gnats) contain about 151 extant genera and 4,100 species worldwide (Thompson \& Pape 2011) and there was considerable diversification of the family in the Cretaceous (Blagoderov \& Grimaldi 2004). The known Neotropical diversity of the family is close to 1,000 species now (Thompson \& Pape 2011).

There is a consensus about the monophyly of the Mycetophilidae (Søli 1997, Tozoni 1998, Amorim \& Rindal 2007, Rindal et al. 2009), but a robust phylogeny for the family is still wanting. Most recent classifications of the Mycetophilidae include as subfamilies Sciophilinae, Gnoristinae, Mycomyiinae, Leiinae, Manotinae, Allactoneurinae, and Mycetophilinae (Tuomikoski 1966, Hennig 1973, Väisänen 1984, Matile 1989, Rindal et al. 2009). The "Metanepsiinae", erected by Matile (1971) as a tribe of Gnoristinae, has an uncertain position within the family and is sometimes treated as subfamily (Väisänen 1984, Ševčík \& Hippa 2010). It most certainly constitutes a smaller clade of the Gnoristinae and without a phylogeny of the subfamily it would possibly make the "Gnoristini" paraphyletic (Kallweit 1998).

The delimitation of the Leiinae is still not well established in the literature. Edwards (1925) indicated two features to define the group, a short $R_{1}$ and a rather longitudinal $r-m$. Despite exceptions among the leiine genera, a sinuous $\mathrm{CuA}$ has been also taken as a synapomorphy for the subfamily (Baxter \& Poinar 1994, Jaschhof \& Kallweit 2009). This set of characters, however, corresponds to synapomorphies at different levels, some of them of more inclusive groups. The discussion about the subfamily composition, hence, is recurrent (e.g., Søli 1997, Søli et al. 2000, Hippa et al. 2005, Jaschhof \& Kallweit 2009), suggesting that the monophyly of the Leiinae in a wider sense may be questionable. The delimitation of the group proposed by Edwards (1925), Hackman et al. (1988), Søli (1997), and Kurina (2004) comprises 32 recent genera and almost 550 species. The fossil record assigned to the subfamily is considerably rich, with eight genera in Cretaceous amber and 54 extinct species (Evenhuis 1994, Baxter \& Poinar 1994, Blagoderov 1998, Blagoderov \& Grimaldi 2004).

There is no doubt about the placement of Paraleia within the Leiinae. The genus has the typical displacement of the base of the radial sector to a more distal position in the wing, with a consequent shortening of $\mathrm{R}_{1}$ (Edwards 
1925). In Jaschhof \& Kallweit's (2009) paper on the Cycloneura group of genera in New Zealand, they accept a delimitation of the "Leiini" (= Leiinae, e.g. Chandler 2009) including Leia Meigen, Clastobasis Skuse, Anomalomyia Hutton, Acrodicrania Skuse, Indoleia Edwards, Ateleia Skuse, Leiella Enderlein, and the group of genera around Cycloneura. Despite not making reference to Paraleia, the genus obviously fits in delimitation of the subfamily.

The genus Paraleia was originally described by Tonnoir (1929) for a species from Australia, P. fulvescens Tonnoir. Edwards (1933) published the first records of the genus for the Neotropical region, describing P. caudata, from Bolivia, and P. peruviana, from Peru. Freeman (1951) described four additional species from southern Argentina-P. castanea, P. cinerea, P. falcigera, . funerea (plus a species not formally described, Paraleia sp.) - and Duret (1984) described P. martinici, from Chile. Paraleia nubilipennis (Walker 1837), originally described in Leia, P. nephrodops (Enderlein 1940), described in the genus Selkirkius (synonymized to Paraleia by Freeman 1954), and P. antarctica (Bigot 1888), described as Leia-the former two from Chile, the last from Argentina-also belong in the genus, summing up eleven species.

In this paper, we formally describe six new species of Paraleia plus one additional species only informally referred to, from areas in elevations above 2,000 $\mathrm{m}$ in the Andes of Colombia and Ecuador, increasing the diversity of the genus to 17 formally described species in the world. An identification key for the world species of Paraleia is also furnished.

\section{Material and methods}

The specimens examined in this paper belong to collection of Instituto de Investigación de Recursos Biológicos Alexander von Humboldt (IAvH), Colombia, to the Diptera collection of the Museu de Zoologia da Universidade de São Paulo (MZUSP), Brazil, and to the Diptera collection of the Australian Museum (AMSA), Sydney, Australia. Most of the holotypes and some paratypes are allocated in the IAvH, and one holotype and some paratypes were deposited at the MZUSP collection.

Wings and the terminalia were separated from the rest of the body. The wings are mounted in permanent Canada balsam slide preparations. The terminalia were heated in $\mathrm{KOH}$ solution, neutralized, dehydrated and mounted in permanent Canada balsam slide preparations. Photographs were taken using a Leica DC camera attached to a Leica MZ16 stereomicroscope and a DM2500 Leica compound microscope. Photos were produced using the AutoMontage software. Initial drawings were made using a camera lucida and then redrawn with Adobe Illustrator 11.0. Morphology terminology and wing venation follows Søli (1997) and Amorim \& Rindal (2007). For species with more than one specimen available, measurements in the descriptions correspond to average values.

Some of the males with the terminalia illustrated in this paper have one of the gonostyle represented rotated, so its dorsal face could have its spines properly visualized. Regarding the female terminalia, all the species are very similar in a ventral view. So, one of them is illustrated in this perspective and the other ones in a lateral view, that are more informative and emphasizes the diagnostic features for all species.

Most species are described here from males and females collected together at least in one locality and that fit basically in the same description. One of the species is described based only in males, while two species that do not fit the description of any of the remaining species are described based only in females. The differences in details of the wing, color and details of the female terminalia are enough to justify the description of species based only in females. A group of female specimens that have very similar morphology of the terminalia but some variation in the coloration of the body could be conspecific with one of the species described based only on a male, but the specimens were not collected together, so they are referred here only as "Paraleia sp.".

Abbreviations used are: ae, aedeagus; anp, anepisternum; ce, cercus; ce1, first cercomere of female terminalia; ce2, second cercomere of female terminalia; cxI, fore coxa; cxII, mid coxa; cxIII, hind coxa; gcap, gonocoxal apodeme; gcx, gonocoxite; gs, gonostyle; ktp, katepisternum; ltg; laterotergite; mes, metepisternum; mep, mesepimeron; $\mathrm{mtg}$, mediotergite; par, parameres; pem, proepimeron; pes, proepisternum; pnt, pronotum; S, sternite; sc, scutum; sctl, scutellum; T, tergite. 


\section{Paraleia Tonnoir}

Paraleia Tonnoir, 1929: 611. Type-species, Paraleia fulvescens Tonnoir, by original designation.

Diagnosis. $C$ extending slightly beyond $\mathrm{R}_{5}, \mathrm{R}_{5}$ ending rather close to wing apex; Sc complete, ending at $\mathrm{C}$ on basal third of wing length; $h, S c$, sc-r, Rs and $M_{1+2}$ without macrotrichia, other veins with dorsal macrotrichia; first sector of Rs transverse or almost transverse; $r-m$ long, almost longitudinal, aligned with second sector of $R_{5}$, this $r-m / R_{5}$ system pretty much separated from $\mathrm{R}_{1}$. Medial and cubital forks complete, CuA slightly concave, $\mathrm{A}_{1}$ absent on distal third. Laterotergite and mediotergite bare. Gonocoxite with an extension distal to the base of gonostyle, the inner face typically with numerous short spines; gonostyle elongated, with combs of short spines and a long, preapical spine. Paraleia is unequivocally separated from its closeby relatives in the Leiinae-e.g., Leia, Leiella, Indoleia, Clastobasis, Rondaniella Johannsen, Neoclastobasis Ostroverchova, and Greenomyia Brunetti-by the r$\mathrm{m} / \mathrm{R}_{5}$ complex largely displaced from the anterior margin, actually a uniquely derived feature of the genus. The distal projection of the gonocoxite, posterior to the insertion of the gonostyles, bearing a number of spines, sometimes forming combs, also present in the gonostyle, is also a very distinctive of the species of Paraleia.

\section{Identification key to world species of Paraleia}

1. Body entirely yellow, no brownish areas (Australia) $\ldots \ldots \ldots \ldots \ldots \ldots \ldots \ldots \ldots \ldots \ldots \ldots \ldots$ f f $\ldots \ldots$. $\ldots \ldots$. $\ldots \ldots$ Tonnoir

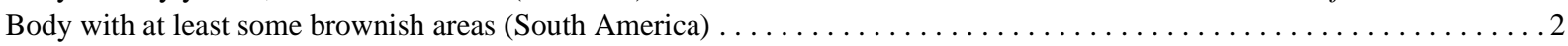

2(1). Scutum and most pleural sclerites of thorax predominantly yellow, brownish areas, if present, restricted to longitudinal bands

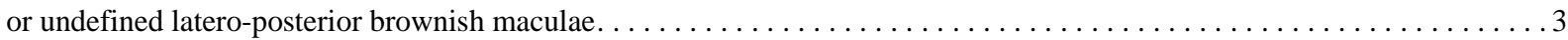
Thorax entirely or predominantly brown, yellow areas restricted in extension, generally to the anterior corners or as longitudi-

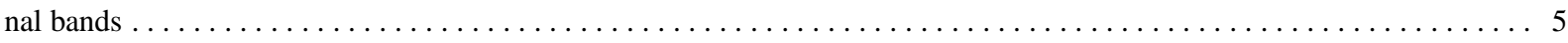

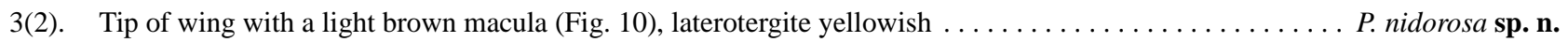

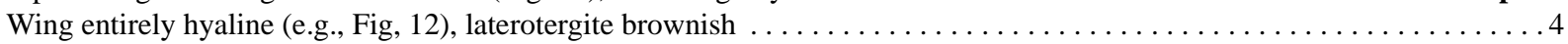

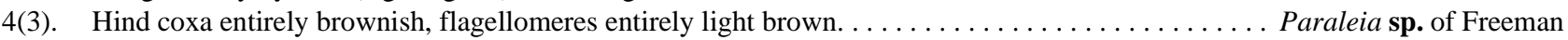
Hind coxa yellow with a brown distal spot, flagellomeres $1-3$ yellow at base $\ldots \ldots \ldots \ldots \ldots$ Paraleia $\mathbf{s p .}$ of this paper

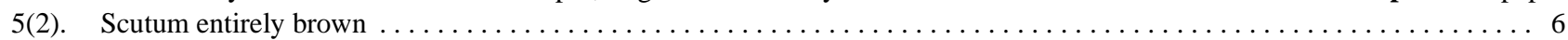

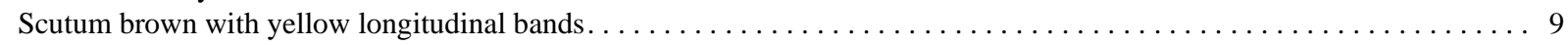

6(5). Wing membrane not entirely hyaline, with a faint area close to tip of $\mathrm{R}_{5} \ldots \ldots \ldots \ldots \ldots \ldots \ldots \ldots$ caudata Freeman

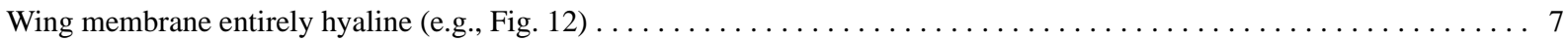

7(6). Gonostyle with few long apical setae, distally with angle of about $90^{\circ}$ (Freeman 1951: fig. 147) ...... P. cinerea Freeman Gonostyle without a group of long apical setae, gradually curved distally $\ldots \ldots \ldots \ldots \ldots \ldots \ldots \ldots \ldots \ldots$

8(7). Gonostyle more or less slender, with no inner indentation midway to apex (Freeman 1951: fig. 148) . . P. falcigera Freeman Gonostyle wider at basal 2/3, with an inner indentation midway to apex (Duret 1984: fig. 8) . . . . . . P. martinici Duret

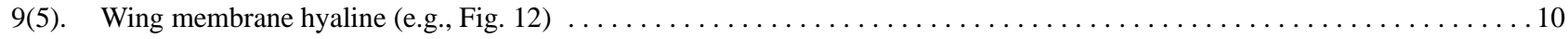

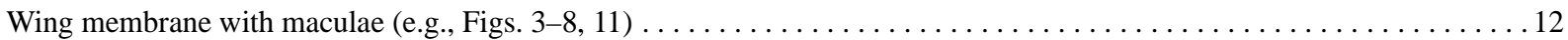

10(9). Gonocoxite dorsal projection as long as the gonostyle with a number of small denticulate spines and one evident elongated

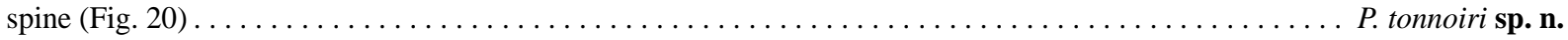
Gonocoxite dorsal projection shorter than the gonostyle, with small denticulate spines, but no elongated spine . . . . . 11

11(10). Denticulate spines along the dorsal margin of the gonocoxite dorsal projection (Freeman 1951: fig. 150) $\ldots \ldots \ldots \ldots \ldots$

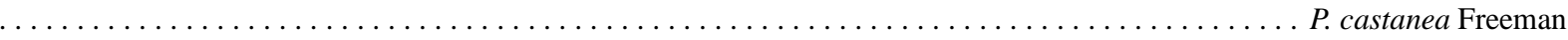
Denticulate spines scattered along the apex of the gonocoxite dorsal projection (Freeman 1951: fig. 149) .

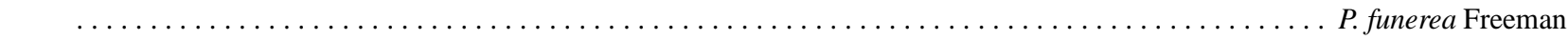

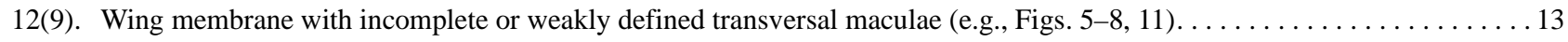
Wing membrane with three well defined transversal brownish maculae (e.g., Figs. 3-4) $\ldots \ldots \ldots \ldots \ldots \ldots \ldots$

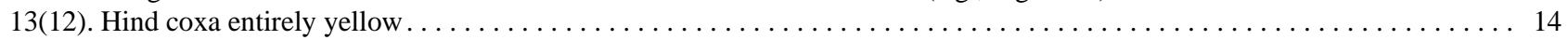

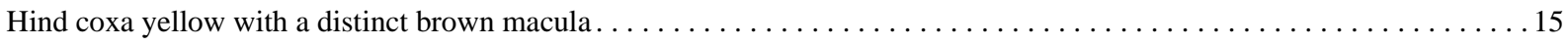

14(13). Wing maculae very weak across medial veins and at anal cell; CuA not sinuous (Figs. 5, 6) . . . . . . . . P. fumosa sp. n. Wing maculae more distinct across medial veins, stronger on the first section of Rs and apex of $\mathrm{R}_{5}$, and at anal cell; $\mathrm{CuA}$

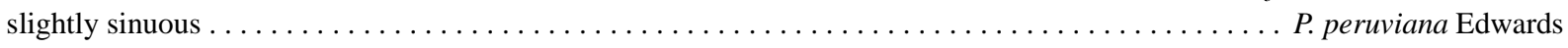

15(13). Wing membrane inconspicuous maculated at the first section of Rs and at the wing apex (Figs. 7, 8). Female sternite 8 wide,

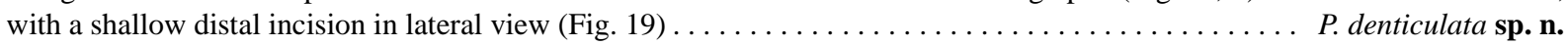
Wing membrane stronger maculated just after the first section of Rs, apex of $\mathrm{R}_{5}$, and around base of cubital fork (Fig. 11). Female sternite 8 slender, with a deep distal incision in lateral view (Fig. 22) . . . . . . . . . . . P. sharkeyi sp. n.

16(12). Wing with two marks along line of $r-m+R_{5}$ (Freeman 1951: fig. 306). Male gonostyle with an external crest before apex bear-

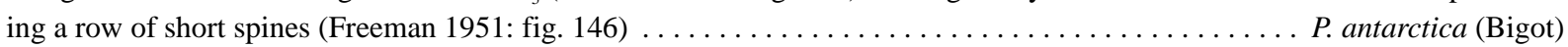


Wing with three marks along line of $r-m+R_{5}$ (e.g., Figs. 3-4). No external crest on male gonostyle $\ldots \ldots \ldots \ldots \ldots 17$

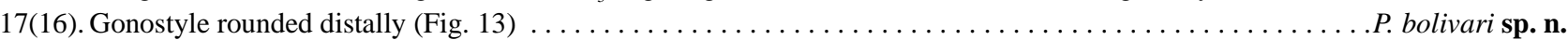

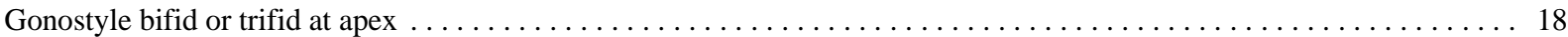

18(17). Gonostyle bifid at apex (Freeman 1951: fig. 145, Freeman 1954: fig. a). . . . . . . . . . . . . . . . P. nubilipennis (Walker)

Gonostyle trifid at apex (Freeman 1954: fig. c) ........................... nephrodops (Enderlein)

\section{Paraleia bolivari, sp. n.}

(Figs. 2-4, 13-15)

Diagnosis. Three ocelli. Three dark brown maculae across the wing. Gonostyle round apically, with a row of short spines on distal half, and a long spine at apex. Female sternite 8 round apically, with a fringe of brown setae.

Material examined. Holotype $\lambda$, COLOMBIA, State of Cundinamarca, PNN Chingaza, Bosque Palacio,

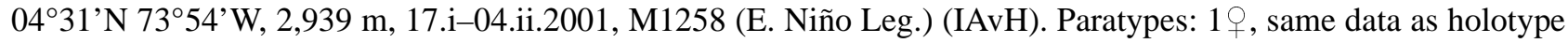
$(\mathrm{IAvH}) ; 1$ \% , COLOMBIA, State of Cundinamarca, PNN Alto de la Bandera, $04^{\circ} 31^{\prime} \mathrm{N} 73^{\circ} 45^{\prime} \mathrm{W}, 3,660 \mathrm{~m}, 04$ 16.ii.2001, M1261 (L. Cifuentes Leg.) (MZUSP).

Description. Male. Head (Fig. 2). Vertex brown, with scattered, whitish, longer bristles. Mid ocellus smaller, lateral ocelli close to but not touching eye margin. Frons light brown, covered with setulae, clypeus light yellow; labella yellow; maxillary palpus whitish yellow, five palpomeres, last palpomere almost twice length of penultimate, first two palpomeres short. Scape shorter than pedicel, both yellow, first flagellomere light brown on distal half, lighter on basal half, second and third flagellomeres brown, with basal fourth lighter, remaining flagellomeres brown. Thorax (Fig. 2). Pronotum yellowish-brown, with five strong yellow setae, dorsal three stronger, ventral two shorter. Scutum basically brown, dark yellow on anterior corners, above wings, and long dorso-centrals, covered with short scattered setae, stronger dorso-centrals and supra-alars. Scutellum yellow, with four scutellar bristles. Proepisternum light-brown, proepimeron slightly darker, bare. Meso and metapleura brown, entirely bare. Haltere whitish, setose. Fore leg with coxa whitish-yellow, trochanter brown, femur light yellow, except for a brown ventro-basal macula, tibia and tarsus light brown; mid and hind coxae light yellow, with a brown mesal macula, mid femur light yellow, darker ventrally, hind femur light yellow, brown at apical fifth, mid and hind tibiae and tarsi light brown, darker to apex. Tibial spurs 1:2:2, brown, spurs almost twice tibial diameter at apex. Some few dark apical setae on fore tibia, mid and hind tibiae with long, strong, black setae. Wing (Fig. 3). Length, $4.9 \mathrm{~mm}$, width, $1.6 \mathrm{~mm}$. Membrane without macrotrichia, light yellowish brown, darker brown bands at basal third, mid and apex of wing, darker at base of Rs; sc-r present, close to apex of Sc; $C$ extending slightly beyond $\mathrm{R}_{5}$ apex, almost reaching wing tip; Sc complete, reaching $\mathrm{C}$ at wing basal third. $\mathrm{R}_{1}$ less than twice $\mathrm{r}-\mathrm{m}$ length, reaching $\mathrm{C}$ at distal third of wing; Rs almost vertical; $\mathrm{R}_{5}$ reaching $\mathrm{C}$ close to the wing tip, almost straight; $\mathrm{r}-\mathrm{m}$ almost longitudinal, about seven times length of base of Rs. $M_{1+2}$ slightly shorter than $r-m ; M_{1}$ and $M_{2}$ more than twice length of $M_{1+2}$; $\mathrm{CuA}$ depressed midway to apex; $\mathrm{A}_{1}$ incomplete on distal third. $\mathrm{M}_{1}, \mathrm{M}_{2}, \mathrm{M}_{4}$, apical third of second sector of $\mathrm{CuA}$ and $A_{1}$ distally with macrotrichia. Abdomen. Tergites 1-6 brown, tergites 2 and 3 lighter; sternites 1-6 whitish yellow mesally, brownish laterally; segment 7 brown, with numerous yellowish setulae. Terminalia yellowish. Terminalia (Fig. 13). Gonocoxite yellowish with brown margins, with extensions distally to the base of the gonostyle, rounded distally, with many short spines at ventral surface; gonostyle long, round distally, with a row of short spines, and a single, long spine at apex; aedeagus thin, long, bifid at distal half; parameres well developed, more sclerotized at apex, involving the aedeagus; cercus covered with setulae; tergite 9 weakly sclerotized, round apically.

Female. As males, except as follows. Wing (Fig. 4). Length, $4.4 \mathrm{~mm}$, width, $1.5 \mathrm{~mm}$. Brown maculae slightly lighter. Vertex lighter ventrally. Mid and hind coxae and femora darker. Abdominal tergites brown, with lateral margins lighter. Terminalia (Figs. 14-15). Terminalia yellowish-brown, distal margin of sternite 8 round, with a fringe of brown setae; cercus longer than rest of terminalia, basal cercomere longer than apical one.

Etymology. This species is named after Simon Bolivar (1783-1830), born in Venezuela and responsible for the independence of Bolivia, Ecuador, Peru, Colombia, Venezuela, and Panama.

Comments. One of the P. bolivari sp. n. females has the wing maculae lighter than the others, but the shape of sternite 8 is similar, so they are considered here as conspecific. The wing pattern in this species is quite similar to that of $P$. denticulata $\mathbf{s p .} \mathbf{n}$. and $P$. sharkeyi sp. $\mathbf{n}$. regarding the disposition of the maculae on the wing membrane, but it is stronger and more conspicuous than in that from the other species, especially on the first section of Rs. The 
presence of a long gonostyle, with a row of short spines and a single long apical one (Fig. 13) also differentiate $P$. bolivari sp. n. from P. denticulata sp. n., where the gonostyle shows an irregular row of short spines, as well as a single subapical one (Fig. 18). In the female terminalia, the distal margin of the sternite 8 is very particular in each one of these species: round with a fringe of brown setae in P. bolivari sp. n. (Figs. 14, 15); wide with a distal incision, brown and long setae in P. denticulata sp. n. (Fig. 19); and with a deep lateral incision, quite strongly setose in $P$. sharkeyi sp. n. (Fig. 22).

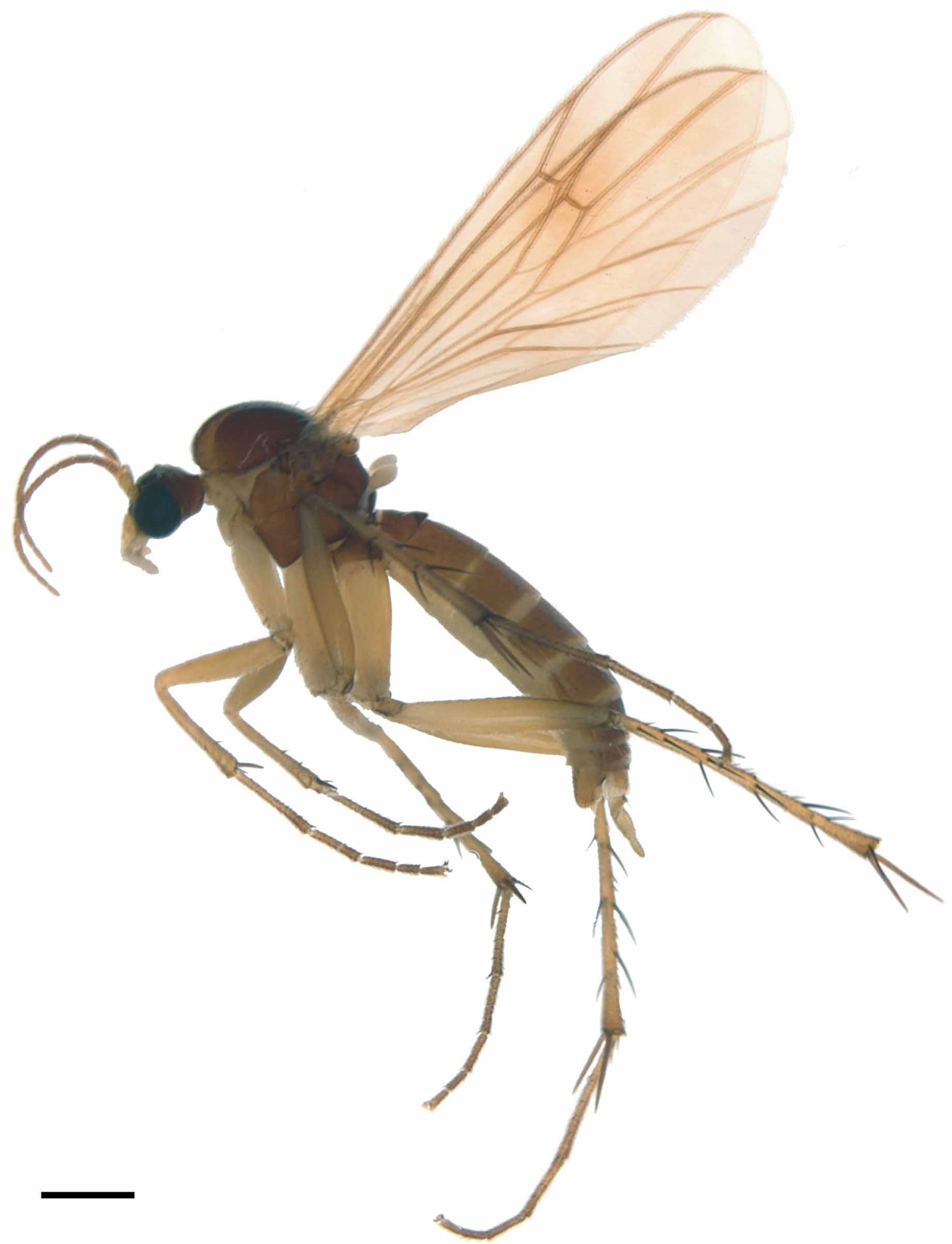

FIGURE 1. Habitus. Female paratype of Paraleia fumosa sp. n., lateral view. Scale $1 \mathrm{~mm}$. 


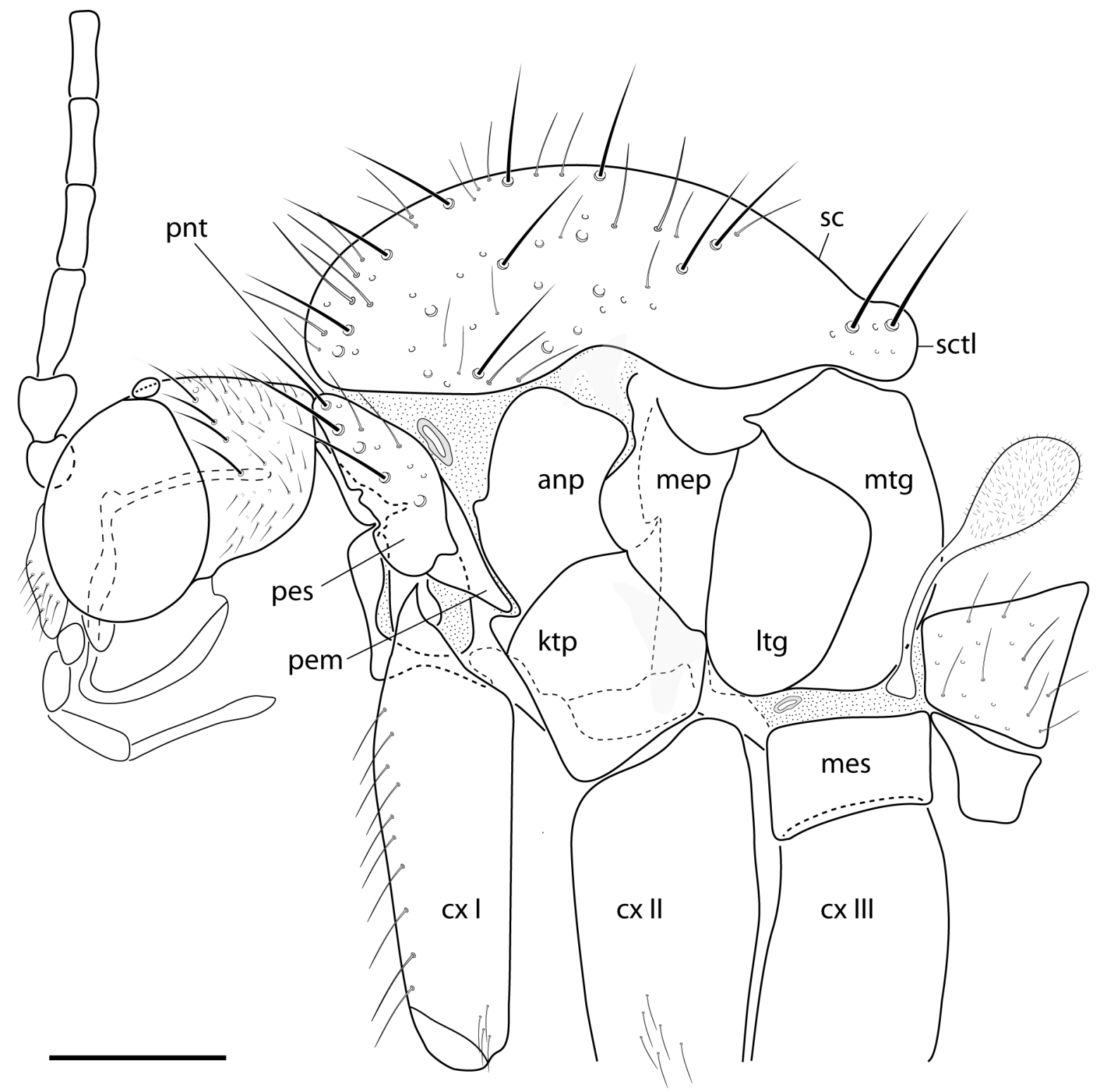

FIGURE 2. Lateral view of head, thorax and first abdominal segment. Male paratype of Paraleia bolivari sp. n. Scale $1 \mathrm{~mm}$.

\section{Paraleia fumosa, sp. n.}

(Figs. 1, 5-6, 16-17)

Diagnosis. Two ocelli. Wings brown maculae rather inconspicuous, $\mathrm{R}_{5}$ straight. Gonostyle folded distally, with a single spine at apex and a subapical row of spines, gonocoxite projection distal to base of gonostyle with a distal and a ventral rows of spines.

Material examined. Holotype ${ }^{\lambda}$, ECUADOR, E. Papallacta (Quito/Baeza), 2,900 m, 12-15.i.1971 (L.E. Peña Col.) (MZUSP). Paratypes: $10^{\top} 2$ q COLOMBIA, State of Huilla, PNN Cueva de los Guácharos, Mun. Acevedo, $01^{\circ} 37^{\prime} \mathrm{N} 76^{\circ} 06^{\prime} \mathrm{W}, 2,150 \mathrm{~m}, 15-19 . v i .2003$, M3787 (J. Lopes leg.) (IAvH).

Description. Male. Head. Vertex brown, with scattered, whitish, longer bristles. Two ocelli close to but not touching eye margin, mid ocellus absent. Frons light brown, covered with setulae, clypeus light yellow; labella yellow, maxillary palpus whitish yellow, five palpomeres, last palpomere as long as penultimate, first two palpomeres short. Scape and pedicel of equal length, yellow, first flagellomere yellow on basal half, remaining flagellomeres brown. Thorax. Pronotum yellow, with four strong bristles. Scutum brown, yellow on anterior corners until the middle of scutum, as an anterior-posterior line. Scutellum yellow, four scutellar bristles. Mediotergite and lateral 

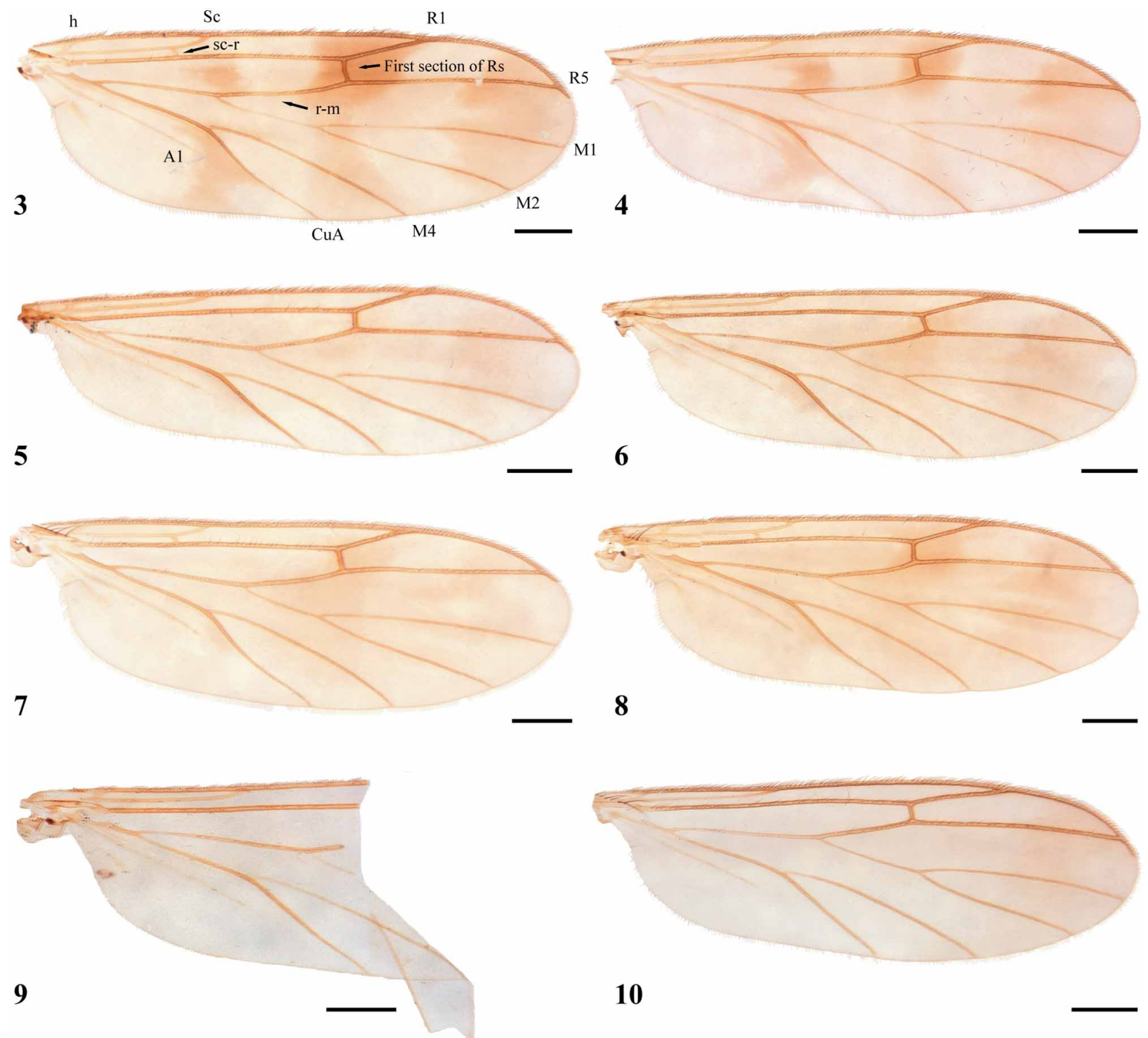

9

10
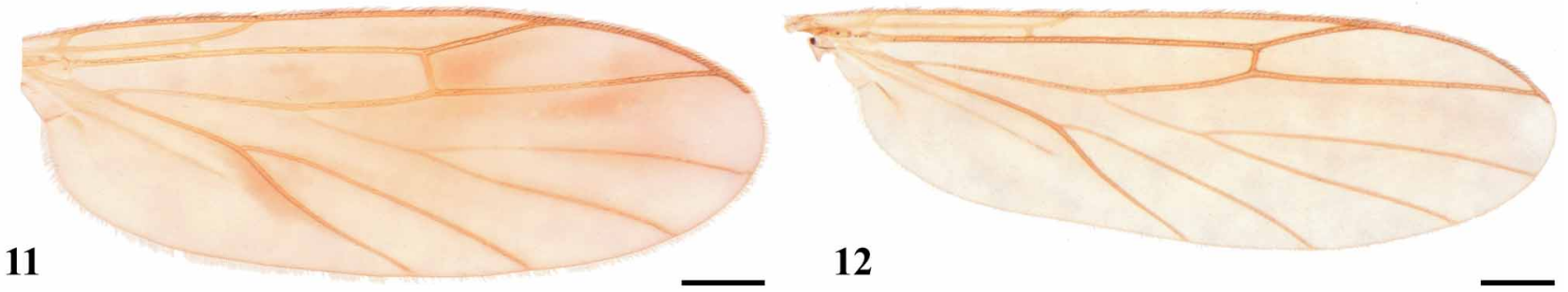

FIGURES 3-12. Wings of Paraleia. 3. Paraleia bolivari sp. n., male paratype. 4. Paraleia bolivari sp. n., female paratype. 5. Paraleia fumosa sp. n., male paratype. 6. Paraleia fumosa sp. n., female paratype. 7. Paraleia denticulata $\mathbf{s p .}$ n., male paratype. 8. Paraleia denticulata sp. n., female paratype. 9. Paraleia tonnoiri sp. n., male holotype. 10. Paraleia nidorosa sp. n., female holotype. 11. Paraleia sharkeyi sp. n., female paratype. 12. Paraleia sp., female paratype. Scale $0.5 \mathrm{~mm}$. 


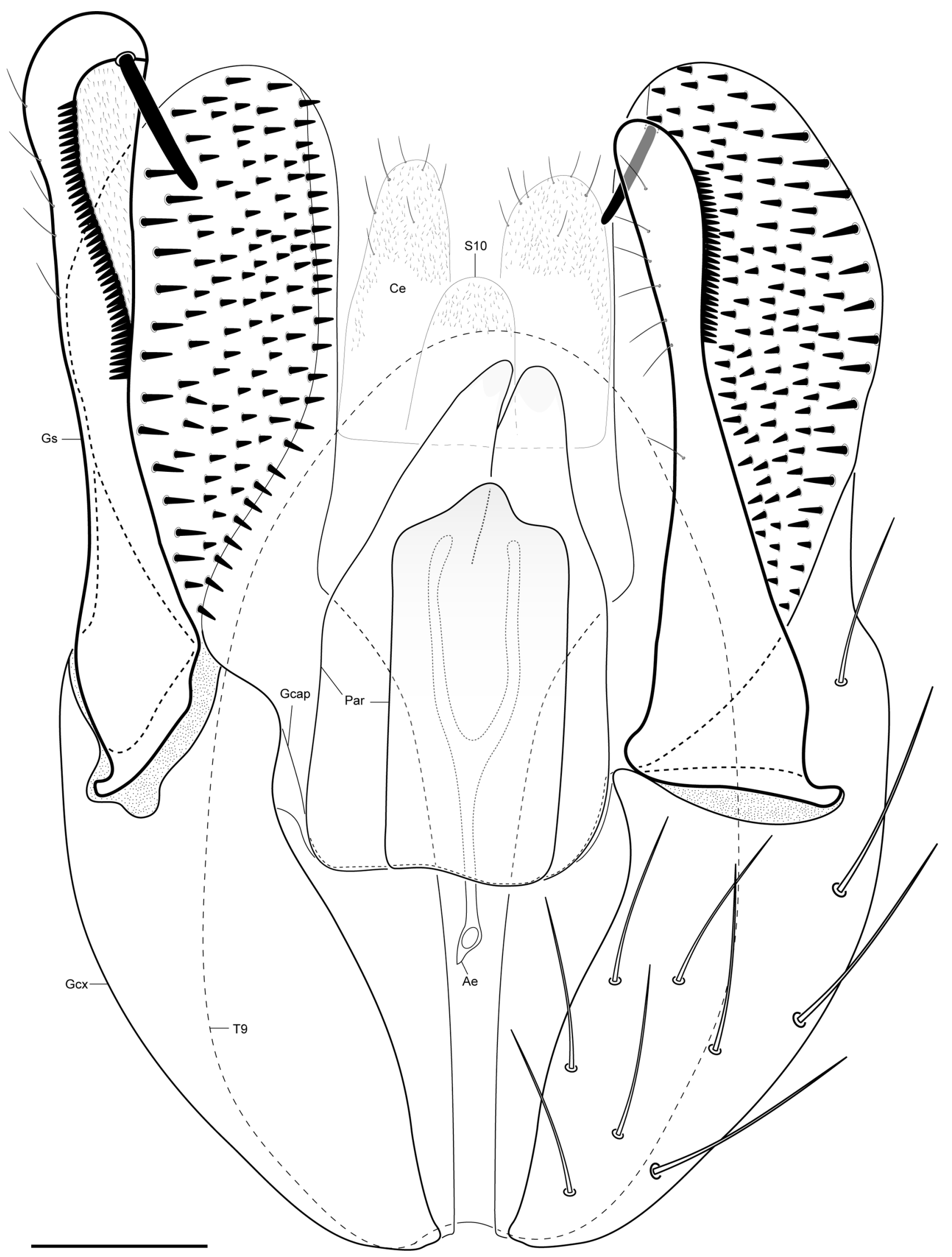

FIGURE 13. Male terminalia of Paraleia bolivari sp. n., ventral view. Paratype. Scale $0.1 \mathrm{~mm}$. 


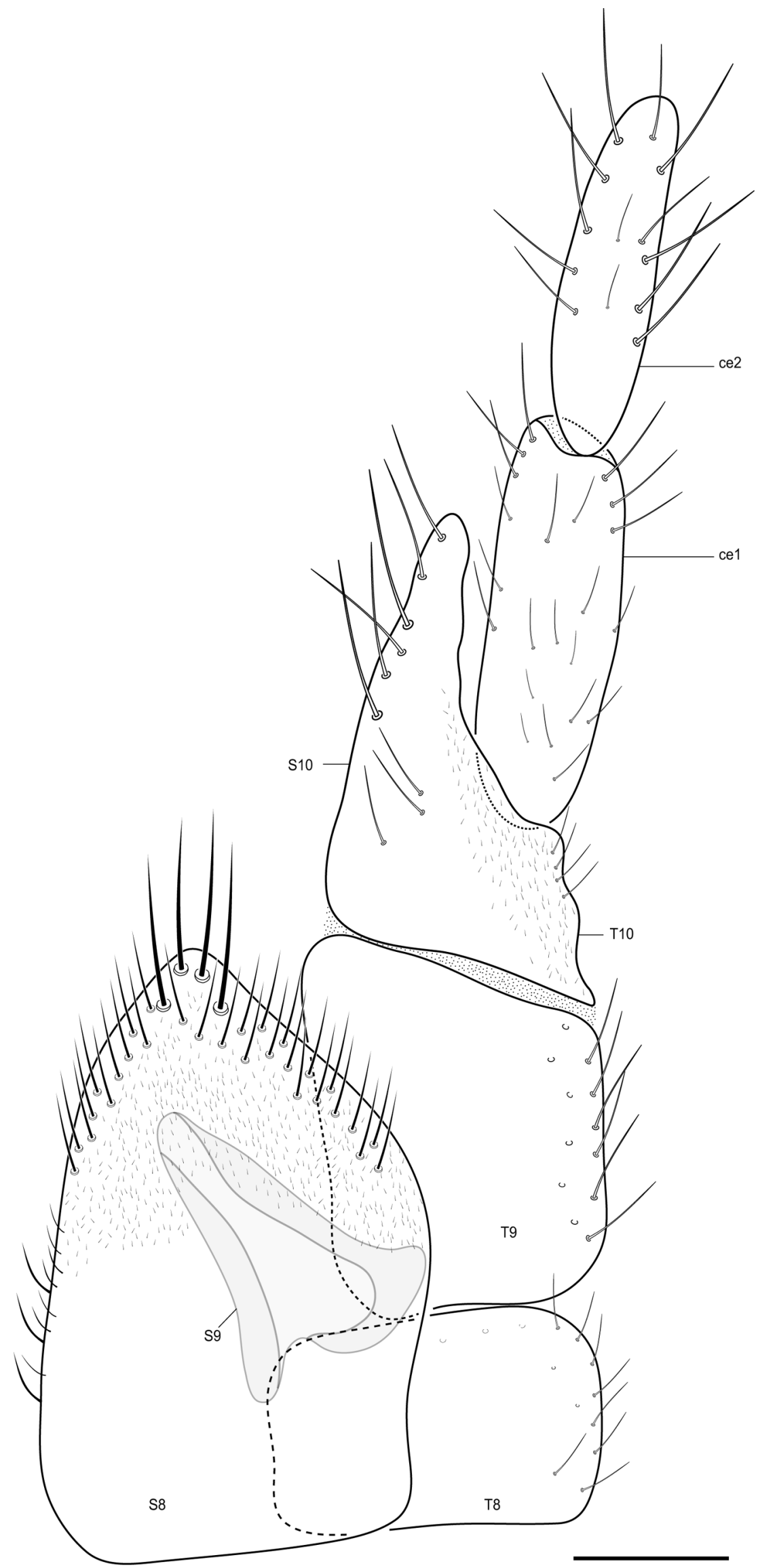

FIGURE 14. Female terminalia of Paraleia bolivari sp. n., lateral view. Paratype. Scale $0.1 \mathrm{~mm}$. 


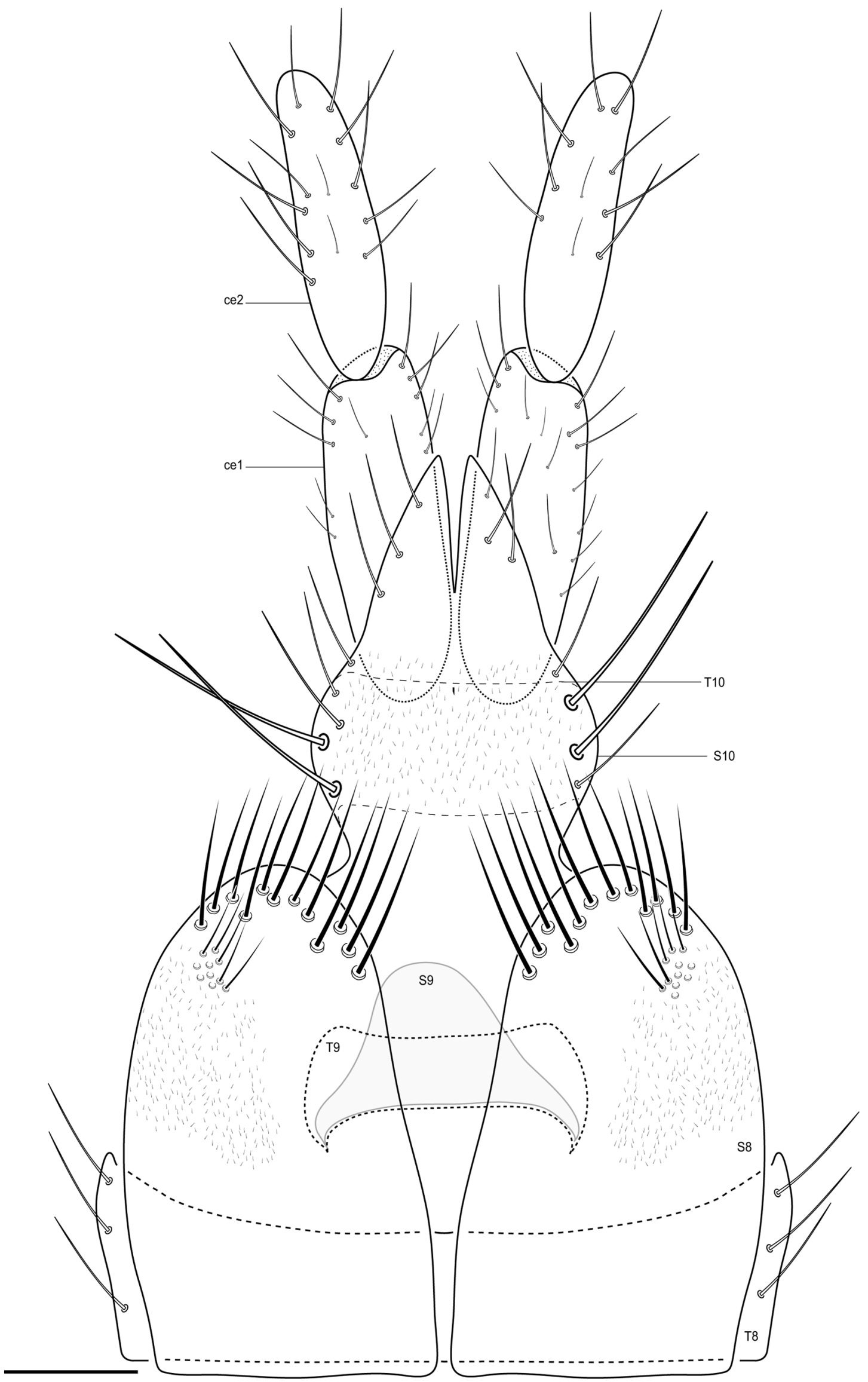

FIGURE 15. Female terminalia of Paraleia bolivari sp. n., ventral view. Paratype. Scale $0.1 \mathrm{~mm}$. 


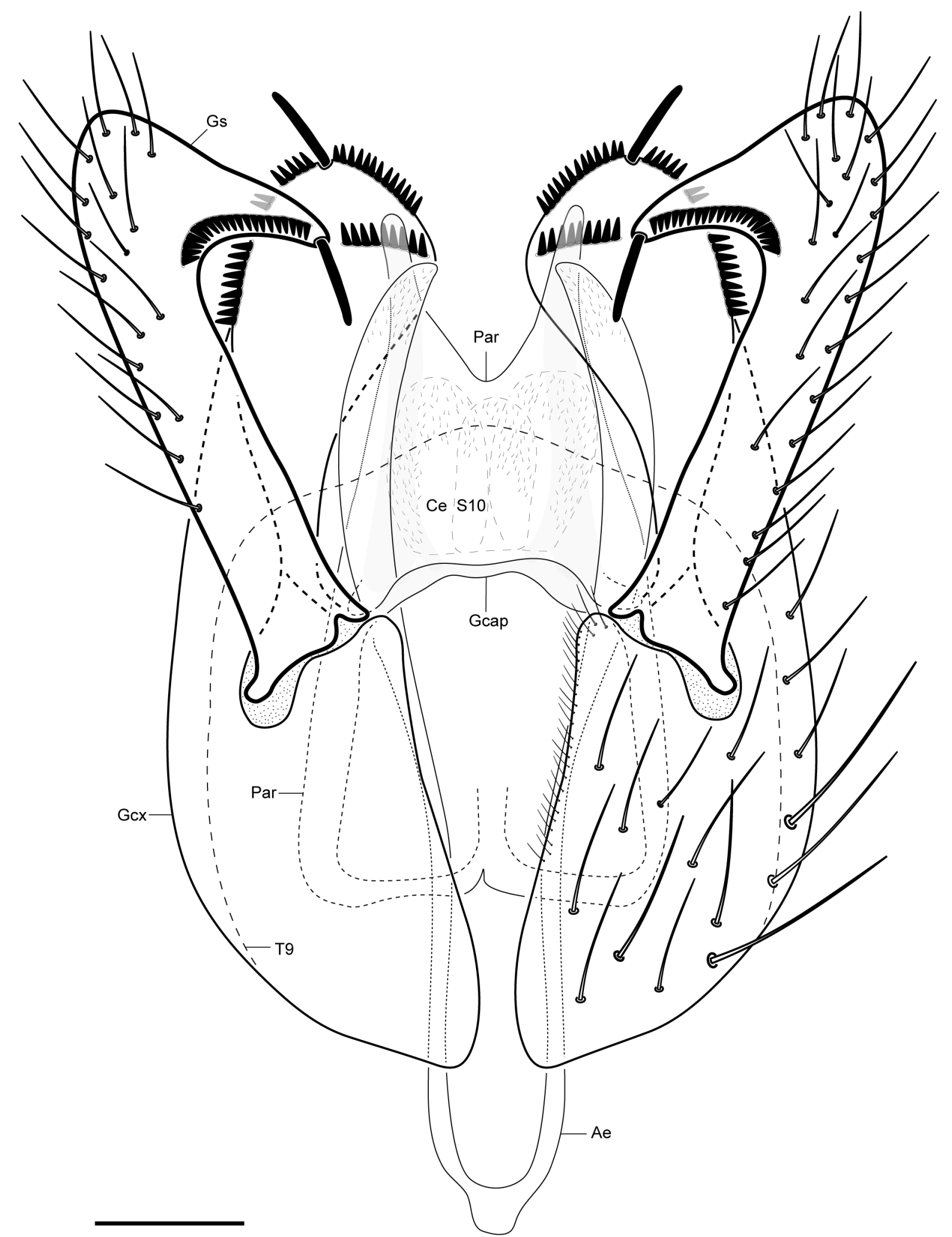

FIGURE 16. Male terminalia of Paraleia fumosa sp. n., ventral view. Holotype. Scale $0.1 \mathrm{~mm}$.

sclerites bare, brown. Pleural membranae yellow, bare. Haltere whitish, knob slightly brownish, setose. Legs yellow. Tibial spurs 1:2:2, spurs almost twice width of tibial apex. Some few dark apical setae on fore tibia, mid and hind tibiae with long, strong, black setae. Wing (Fig. 5). Length, $4.2 \mathrm{~mm}$, width, $1.2 \mathrm{~mm}$. Membrane without macrotrichia, translucent, brown maculae rather inconspicuous across mid and apex of wing, a slightly darker area just posterior to $A_{1}$. Sc-r present, not strongly sclerotized; $C$ extending slightly beyond $R_{5}$ apex; Sc complete, reaching 
$C$ on distal third of wing. $R_{1}$ shorter than $r-m$ length, reaching $C$ at distal third of wing; Rs transverse; $R_{5}$ straight, reaching $C$ close to wing apex; $r-m$ almost longitudinal, about seven times Rs length. $M_{1+2}$ shorter than $r-m$ length; $\mathrm{M}_{1}$ and $\mathrm{M}_{2}$ more than twice length of $\mathrm{M}_{1+2} ; \mathrm{CuA}$ slightly depressed midway to apex; $\mathrm{A}_{1}$ incomplete on distal third. $\mathrm{M}_{1}, \mathrm{M}_{2}, \mathrm{M}_{4}$, second sector of $\mathrm{CuA}$ and $\mathrm{A}_{1}$ setose. Abdomen. Abdomen pubescent. Tergites 1-7 brown, tergites 2-4 with a yellowish distal band; sternites 1-4 yellow, sternite 5 yellow on the basal half, brownish distally, sternites 67 brown. Terminalia yellowish on basal half, brownish apically. Terminalia (Fig. 16). Gonocoxite yellow, with brown margins, extending beyond base of gonostyle, with a row of short spines along distal margin, an additional transverse row of short spines ventrally, and one long spine at apex; gonostyle long, with a distal fold inwards, a row of short spines ventrally close to apex and a single, long spine at apex; aedeagus thin, long, bifid since its base, with small setulae apically; parameres well developed, more sclerotized apically, involving the aedeagus; cercus covered with setulae; tergite 9 less sclerotized, short mesal projection along distal margin.

Female (Fig. 1). As male, except as follows. Wing (Fig. 6). Length, $4.6 \mathrm{~mm}$, width, $1.4 \mathrm{~mm}$. R-m six times length of Rs first sector. Abdominal tergites 2-5 with apical yellow band; sternites 1-6 yellow, lateral margins brownish, sternite 7 brownish. Terminalia (Fig. 17). Terminalia brownish, distal margin of sternite 8 rounded, with a fringe of brown, long setae; cercus almost as long as rest of terminalia, basal cercomere longer than apical one.

Etymology. The specific epithet is Latin adjective fumosus, meaning smoky, in reference to the weakly defined, light wing maculae.

Comments. The holotype wing has the base of vein $M_{1}$ nearly separated from $M_{1+2}$, but is otherwise identical to the females. $R_{5}$ in all specimens analyzed is particularly straight. The general body coloration of this species is quite similar to P. peruviana Edwards, known from Mamara, Peru. In the Edwards original description of P. peruviana there are no illustrations of male and female terminalias, but it is possible at this moment to note some differences in the wing maculation. In P. fumosa sp. n., the wing membrane shows very weak maculae across medial veins and at anal cell (Figs. 5, 6) and the $\mathrm{CuA}$ is not sinuous. On the other hand, in P. peruviana the wing membrane is maculated at the medial veins; stronger on the first section of $\mathrm{Rs}$, apex of $\mathrm{R}_{5}$, and anal cell; and the $\mathrm{CuA}$ is slightly sinuous.

\section{Paraleia denticulata, sp. $\mathbf{n}$.}

(Figs. 7-8, 18-19)

Diagnosis. Three ocelli. Wing with a pair of pretty well defined brown maculae at the mid and apex of the wing, plus a weaker marking distal to $\mathrm{A}_{1}$. Gonostyle widening to the apex, inner surface with a distal row of short spines and a long apical spine, gonocoxite projection distal to the base of gonostyle with an irregular row of short spines and scattered short apical spines. Female sternite 8 with apical border mesally depressed laterally, with short spines distally.

Material examined. Holotype $\overbrace{}^{\lambda}$, COLOMBIA, State of Cundinamarca, PNN Sumapaz Bocatoma, Cerro El Zapato, $04^{\circ} 14^{\prime} \mathrm{N} 74^{\circ} 12^{\prime} \mathrm{W}, 3,560 \mathrm{~m}, 06-20 . x i .2002$, M3444 (A. Patiño Leg.) (IAvH). Paratypes $2 \hat{0}^{\wedge}$ same data as holotype (IAvH); $1 \overbrace{}^{\Uparrow}$ idem, but 18.xi-04.xii.2002, M3443 (MZUSP); $4 \overbrace{}^{\Uparrow} 2$ idem, but 02-17.i.2003, M3442 (IAvH/MZUSP).

Description. Male. Head. Vertex brown, with scattered, whitish long bristles. Mesal ocellus small, lateral ocelli close to but not touching eye margin. Frons and clypeus light brown, covered with setulae; labella yellow; maxillary palpus whitish yellow, with five palpomeres, last palpomere almost twice length of penultimate, first two palpomeres short. Scape and pedicel of similar lenght, yellow, first flagellomere lighter on the basal third, second and third flagellomeres brown with lighter basal fourth, remaining flagellomeres brown. Thorax. Pronotum yellow, with five strong yellow setae, four of them stronger dorsally and one smaller ventrally. Scutum brown, dark yellow on anterior corners, above base of wing, and along dorso-centrals; scutum covered with scattered short setae, stronger dorso-centrals and supra-alars. Scutellum yellow, brownish at margins, with four scutellar bristles. Pleural sclerites brown, bare. Pleural membranae yellowish. Haltere whitish, setose. Legs yellow, mid and hind coxae with a brown mesal macula. Tibial spurs 1:2:2, brown, spurs almost twice tibia diameter at apex. Some few dark apical setae on fore tibia, mid and hind tibiae with long, strong black setae. Wing (Fig. 7). Length, $4.5 \mathrm{~mm}$, width, $1.5 \mathrm{~mm}$. Membrane without macrotrichia, yellowish, with one brownish macula across mid of wing and an additional, less well defined mark close to apex, a third inconspicuous mark posterior to $\mathrm{A}_{1}$. C extending slightly 


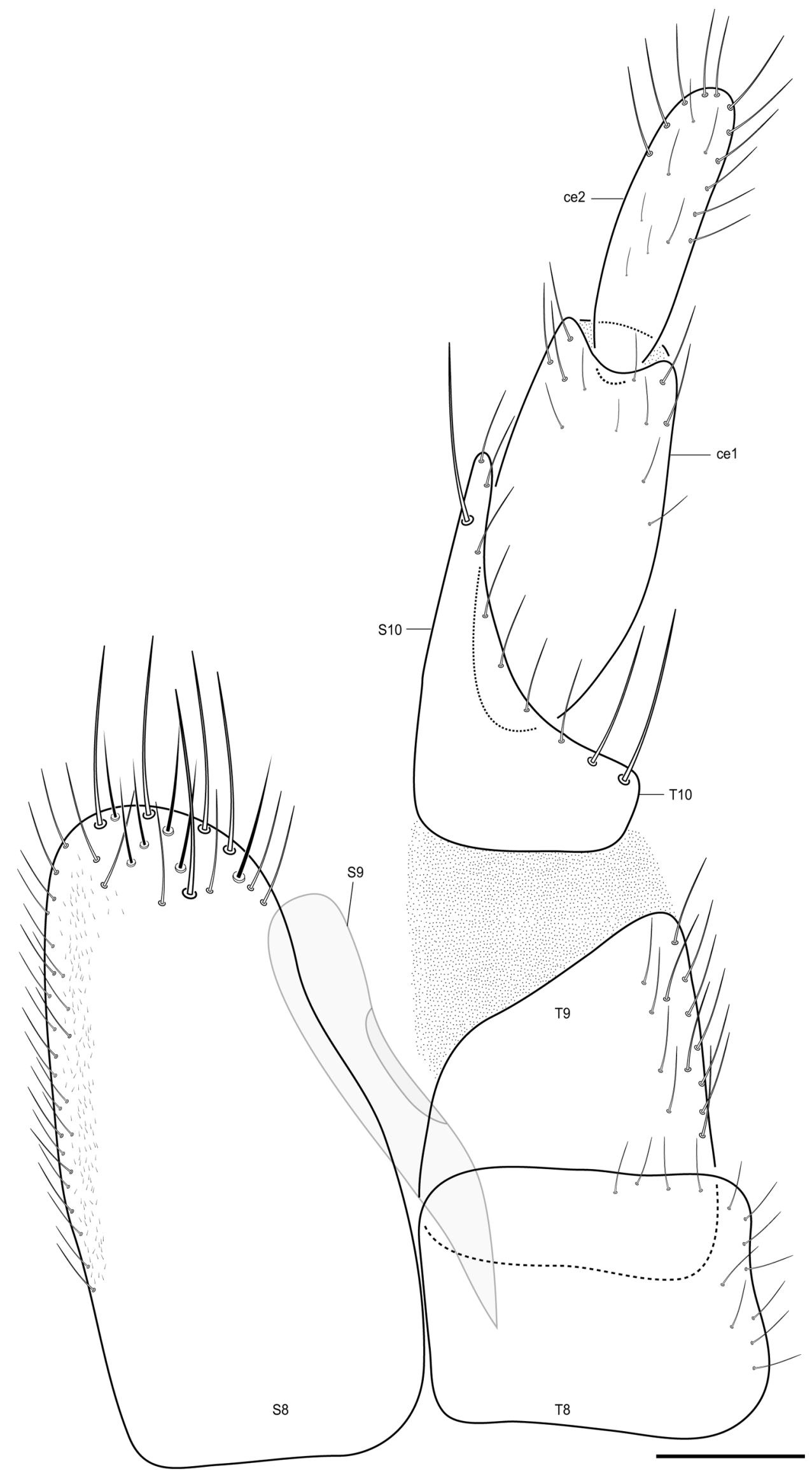

FIGURE 17. Female terminalia of Paraleia fumosa $\mathbf{s p . ~ n . , ~ l a t e r a l ~ v i e w . ~ P a r a t y p e . ~ S c a l e ~} 0.1 \mathrm{~mm}$. 


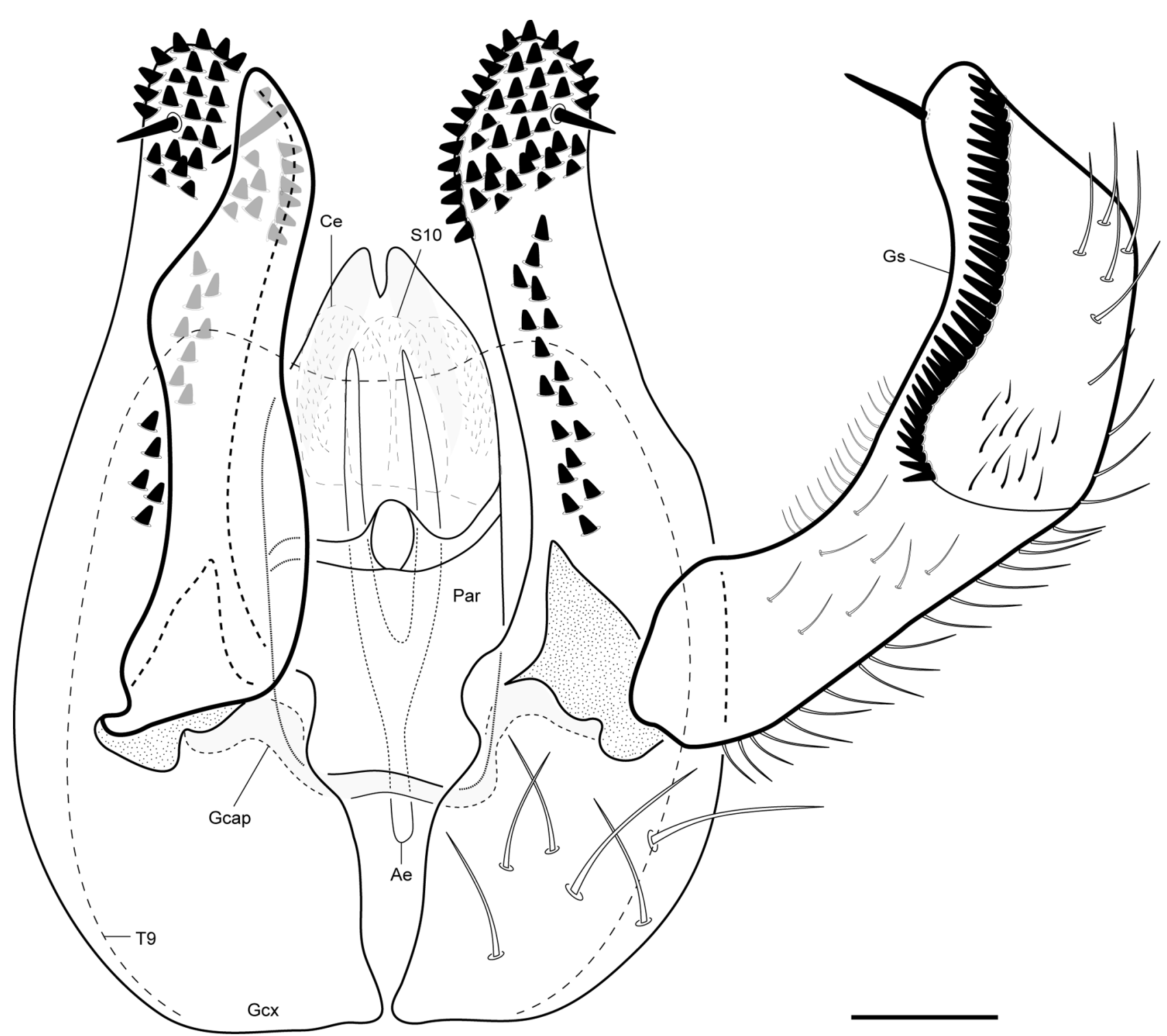

FIGURE 18. Male terminalia of Paraleia denticulata $\mathbf{s p . ~ n . , ~ v e n t r a l ~ v i e w . ~ P a r a t y p e . ~ S c a l e ~} 0.1 \mathrm{~mm}$.

beyond $\mathrm{R}_{5}$ apex; sc-r present; Sc complete, ending in $\mathrm{C}$ at wing basal third. $\mathrm{R}_{1}$ less than twice $\mathrm{r}-\mathrm{m}$ length, reaching $\mathrm{C}$ at distal third of wing; Rs nearly transverse; $\mathrm{R}_{5}$ reaching $\mathrm{C}$ close to wing tip, nearly straight; $r-m$ almost longitudinal, about six times length of first sector of Rs. $M_{1+2}$ shorter than r-m length; $M_{1}$ and $M_{2}$ twice length of $M_{1+2} ; C u A$ depressed midway to apex. $\mathrm{M}_{1}, \mathrm{M}_{2}, \mathrm{M}_{4}$, second sector of $\mathrm{CuA}$ setose and $\mathrm{A}_{1}$ setose. Abdomen. Abdomen covered with numerous yellowish setulae. Tergites 1-7 brown, tergites 2-4 lighter than remaining; sternites 1-4, whitish yellow mesally, brownish laterally; sternites 5-6, brownish; sternite 7, brown. Terminalia yellowish basally, brownish apically, tergite 9 yellow, with a brown mesal, transverse band. Terminalia (Fig. 18). Gonocoxite extension distal to base of gonostyle with an irregular row of short spines along basal two thirds, scattered short spines at apex, as well as a single, subapical spine; gonostyle long widening to the apex, inner surface with a row of short spines along distal margin, besides a long, subapical spine; aedeagus thin, bifid at distal two thirds; parameres well developed, more sclerotized at apex, involving aedeagus; cercus covered with setulae; tergite 9 weakly sclerotized, with a shallow mesal depression at distal margin.

Female. As male, except as follows. Wing (Fig. 8). Length, $4.6 \mathrm{~mm}$, width, $1.6 \mathrm{~mm}$. Wing maculae slightly less conspicuous. All coxae with a brown mesal maculae. Abdominal tergites $2-4$ brown with a light transverse, distal stripe. Terminalia (Fig. 19). Terminalia yellow, sternite 8 wide, distal margin wide, with a distal incision, with some brown, long setae along distal margin, and some short spines at laterals; cercus almost as long as rest of terminalia, basal cercomere longer than apical one. 


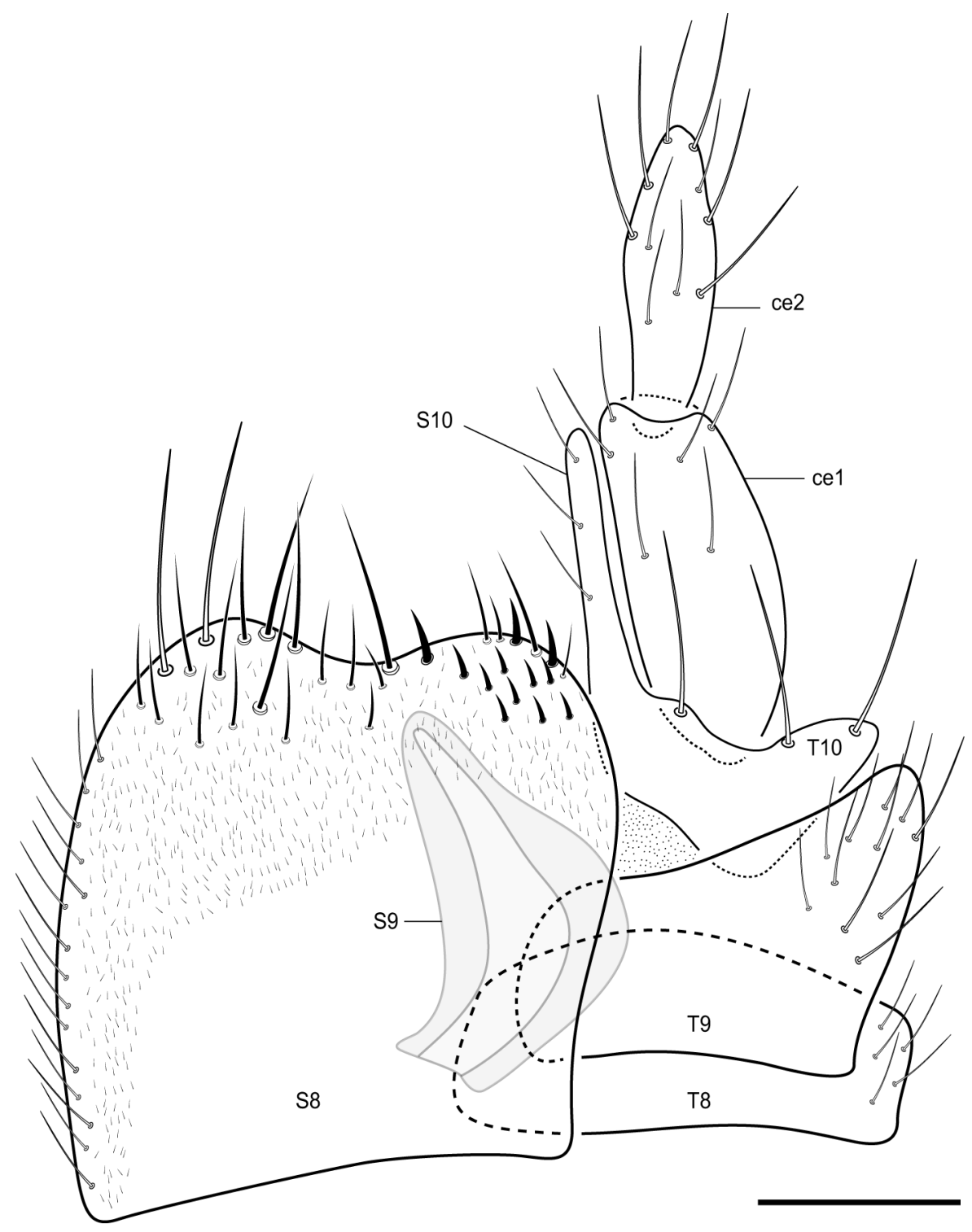

FIGURE 19. Female terminalia of Paraleia denticulata sp. n., lateral view. Paratype. Scale $0.1 \mathrm{~mm}$.

Etymology. The specific epithet is Latin adjective denticulatus, meaning bearing small teeth, in reference to the short spines at apex of gonocoxite projection.

Comments. Some specimens have a more inconspicuous maculae and $A_{1}$ weaker. The male gonocoxite and gonostyle of this species are in somewhat similar to those P. bolivari sp. n. Paraleia denticulata sp. n. has a single subapical spine at gonocoxite apex and a gonostyle widening to the apex, with an irregular row of short spines, as well as a single subapical one (Fig. 18). On the other hand, P. bolivari sp. n. doesn't have the subapical spine at gonocoxite apex and shows a long gonostyle, with a row of short spines and a single long apical one (Fig. 13).

\section{Paraleia tonnoiri, sp. n.}

(Figs. 9, 20)

Diagnosis. Two ocelli. Wings without clear markings. Gonocoxite distal extension with an irregular row of short spines on distal two thirds at inner surface, two regular, parallel, longitudinal rows of short spines near apex, short spines distributed around the apex, and a long subapical spine. Gonostyle long, pointed at apex, with a longitudinal row of short spines at distal fourth, two short rows of spines and a long, subapical spine. 


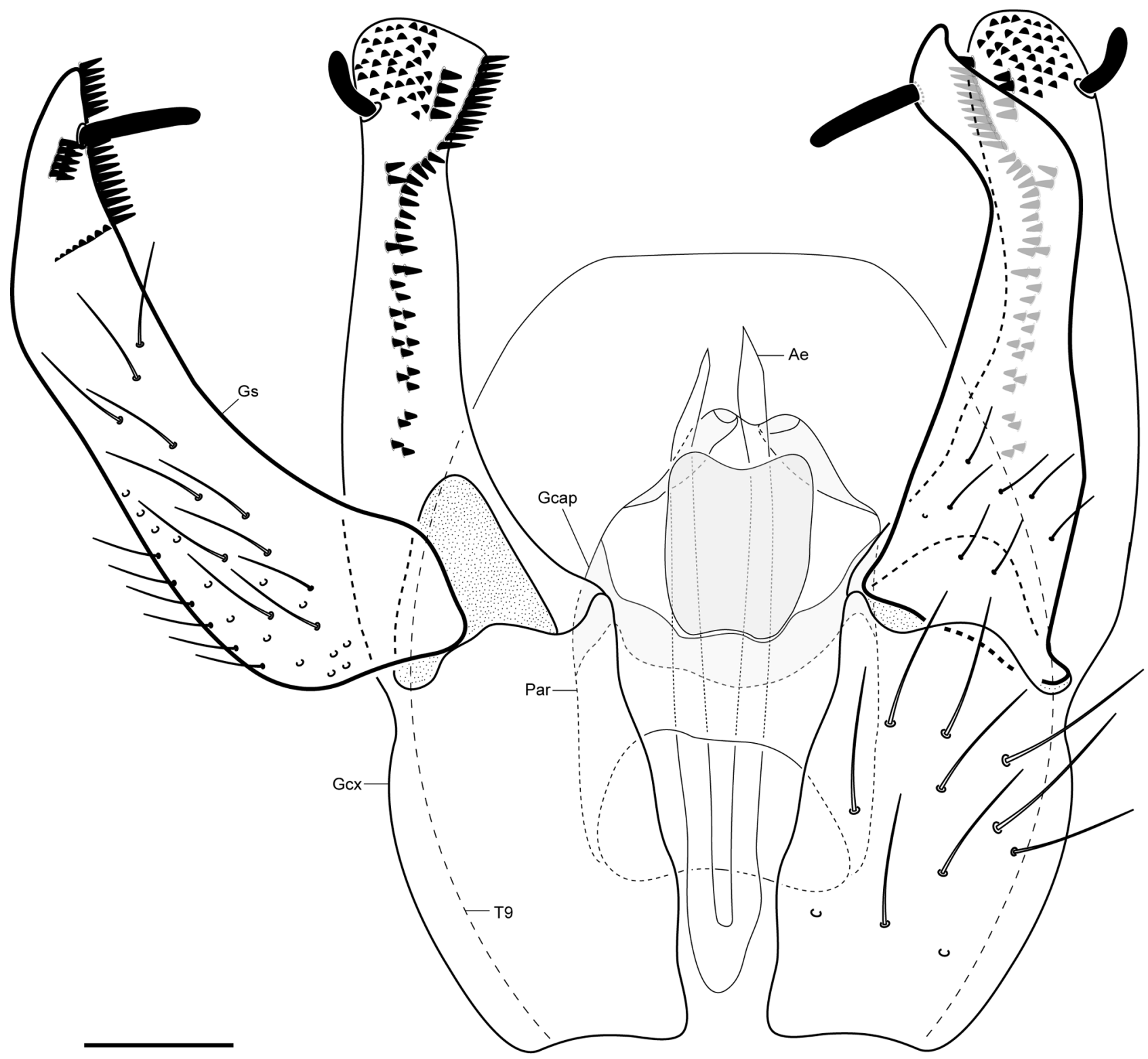

FIGURE 20. Male terminalia of Paraleia tonnoiri sp. n., ventral view. Holotype. Scale 0.1 mm.

Material examined. Holotype $\hat{\sigma}$, COLOMBIA, State of Magdalena, PNN Santa Marta, San Lorenzo, $10^{\circ} 48^{\prime} \mathrm{N} 73^{\circ} 39^{\prime} \mathrm{W}, 2,500 \mathrm{~m}, 15-30 . i .2001$, M1186 (J. Cantillo Leg.) (IAvH).

Description. Male. Head. Vertex brown, with scattered, whitish, longer bristles. Two ocelli close to, but not touching eye margin, mid ocellus absent. Frons and clypeus light brown, with scattered setulae; labella yellow, maxillary palpus whitish yellow, five palpomeres, last palpomere almost twice length of penultimate, first two palpomeres short. Scape and pedicel of equal length, yellow, first flagellomere yellow at basal half, light brown distally, second and third flagellomeres light brown, with basal fourth lighter, distal flagellomeres light brown (flagellomeres 9-14 missing). Thorax. Pronotum yellow, with five strong bristles, three anterior and two mesal. Scutum light brown, two narrow yellow bands beginning on anterior corners and joining in the median region of scutum. Scutellum yellow, four scutellar bristles. Mediotergite and lateral sclerites light brown, bare. Pleural membranae yellow. Haltere whitish, setose. Legs yellow. Tibial spurs 1:2:2, spurs almost twice width of tibia apex. Mid and hind tibiae with long and strong setae. Wing (Fig. 9). Width, $2.4 \mathrm{~mm}$. Membrane without macrotrichia, yellowish, no clear markings. Sc complete, ending in C; sc-r absent; CuA slightly curved midway to apex; $\mathrm{A}_{1}$ weakly sclerotized, absent on distal third. $\mathrm{M}_{4}$, second sector of $\mathrm{CuA}$ and $\mathrm{A}_{1}$ setose. Abdomen. Abdomen pubescent. Tergite 1 light brown, tergites 2-6 light brown with a distal yellow band, tergite 7 yellow. Sternites yellow, sternites 6 and 7 with brownish spots. Terminalia (Fig. 20). Terminalia yellow, gonostyle and gonocoxite with brownish distal mar- 
gin. Gonocoxite distal extension with an irregular row of short spines on distal two thirds at inner surface, two regular, parallel, rows of short spines near apex, and additional short spines around the apex, besides a long subapical spine. Gonostyle long, pointed apically, with a longitudinal row of short spines at distal fourth on inner surface, two short transversal rows of spines, and a long, subapical spine; aedeagus thin, entirely bifid; parameres well developed, more sclerotized at apex, involving aedeagus; cercus not visualized; tergite 9 weakly sclerotized, straight at distal margin.

Female. Unknown.

Etymology. The specific epithet is formed after the Belgian entomologist André Léon Tonnoir (1885-1940), who described a large number of species and genera of Mycetophilidae from Australia and New Zealand region, including the first known species of Paraleia.

Comments. One of the wings of the only specimen known is entirely missing and the other wing has the distal part missing. The aedeagus is bifid from its base to the apex, the presence of only two ocelli and the regular rows of short spines at the apex of gonostyle clearly approximate this species to $P$. fumosa $\mathbf{s p}$. n. However the gonocoxite distal extension and wing maculation are very particular in each of these species. The gonocoxites of $P$. tonnoiri sp. n. show an irregular longitudinal row of short spines at their inner surface and one apical spine longer and curved (Fig. 20); the wing membrane seems do not have maculation (Fig. 9). In $P$. fumosa sp. n. the gonocoxites have a row of short spines along distal margin, with one very long; an additional transverse row of short spines ventrally (Fig. 16); the wing membrane shows maculae brown close to the wing apex and just posterior to $A_{1}$ (Figs. 5, 6).

\section{Paraleia nidorosa, sp. n.}

(Figs. 10, 21)

Diagnosis. Three ocelli. Wing with a brown macula apically. Female sternite 8 rounded apically, a little depressed at inner margin dorsally, with long setae apically.

Material examined. Holotype + , COLOMBIA, State of Huilla, PNN Cueva de los Guácharos, Mun. Acevedo, $01^{\circ} 37^{\prime} \mathrm{N} 76^{\circ} 06^{\prime} \mathrm{W}, 2150$ m, 15-19.xi.2003, M3788 (J. Lopes Leg.) (IAvH).

Description. Male. Unknown.

Female. Head. Vertex brownish, with scattered bristles. Three ocelli, mid ocellus small, lateral ones close to but not touching eye margin. Frons and clypeus yellow, covered with short setulae; labella yellow; maxillary palpus whitish yellow, five palpomeres, last palpomere almost twice length of penultimate, first two palpomeres short. Scape and pedicel subequal, yellow, with setulae; flagellomeres 1-4 with basal half yellow, distal half light brown, remaining flagellomeres light brown. Thorax. Thorax predominantly yellow. Pronotum yellow, with three strong bristles near posterior margin. Scutum yellow, with three longitudinal brownish bands, mesal band with a yellow narrow line anteriorly. Scutellum yellow, with four scutellar bristles. Mediotergite brownish, bare, remaining pleural sclerites yellow, bare, pleural membrane yellowish. Haltere with brownish knob and whitish pedicel, setose. Legs yellow, mid and hind tibiae with long, strong black setae. Tibial spurs 1:2:2, spur length almost twice tibial width at apex. Wing (Fig. 10). Length, $4.0 \mathrm{~mm}$, width, $1.3 \mathrm{~mm}$. Membrane without macrotrichia, translucent, with a light brown, rather indefinite macula close to wing apex. $\mathrm{C}$ extending slightly beyond $\mathrm{R}_{5}$ apex; $\mathrm{Sc}$ complete, reaching $\mathrm{C}$ at wing basal third; sc-r absent; $\mathrm{R}_{1}$ about as long as $\mathrm{r}-\mathrm{m}$, reaching $\mathrm{C}$ beyond distal third of wing; first sector of Rs transverse; $R_{5}$ reaching $C$ close to wing tip, with a very gentle curve on distal half; $r-m$ almost longitudinal, about six times length of first sector of Rs. $M_{1+2}$ longer than r-m length; $M_{1}$ and $M_{2}$ almost twice $M_{1+2}$ length; $\mathrm{CuA}$ nearly straight along its entire length. $\mathrm{M}_{1}$ and $\mathrm{M}_{2}$ with setae, $\mathrm{M}_{4}$, second sector of $\mathrm{CuA}$ and $\mathrm{A}_{1}$ apically with macrotrichia. Abdomen. Abdomen pubescent, covered with setulae. Tergites 1-7 brown. Sternites 1-3 yellow, sternites 4-6 yellow with brownish lateral margins, sternite 7 brownish; distal margin of sternite 8 rounded. Terminalia (Fig. 21). Terminalia brownish, gonapophysis 8 rounded distally, not wide; cercus length subequal to that of rest of terminalia, basal cercomere longer than apical one.

Etymology. The specific epithet is Latin adjective nidorosus, meaning steam, in reference to the apical inconspicuous macula in the wing membrane.

Comments. Considering the other female species described here, differences in the wings and shape of the sternite 8 are enough to erect $P$. nidorosa $\mathbf{s p .} \mathbf{n}$. as a new species despite missing the male specimen. Paraleia nidorosa sp. n. shows the wing membrane with only a brown macula rather indefinite close to wing apex (Fig. 10) and 
a female sternite 8 rounded apically, little depressed at inner dorsal margin, with long setae apically (Fig. 21). Paraleia bolivari sp. n., P. fumosa sp. n., P. denticulata sp. n., and P. sharkeyi sp. n., besides the macula on the wing apex, show wing membrane patterned in other regions (Figs. 4, 6, 8, 11) and Paraleia sp. has the wing hyaline (Fig. 12). The distal margin of sternite 8 of P. bolivari sp. n. is round with fringe of setae, not depressed at inner dorsal margin (Figs. 14, 15); in P. fumosa sp. n. it is rounded with a fringe of long setae (Fig. 17); in P. denticulata sp. n. it is wide with a distal incision, brown and long setae (Fig. 19); in P. sharkeyi sp. n. (Fig. 22) it has a deep lateral incision and is quite strongly setose; in Paraleia $\mathbf{s p .}$ is pointed with black setulae along its distal margin.

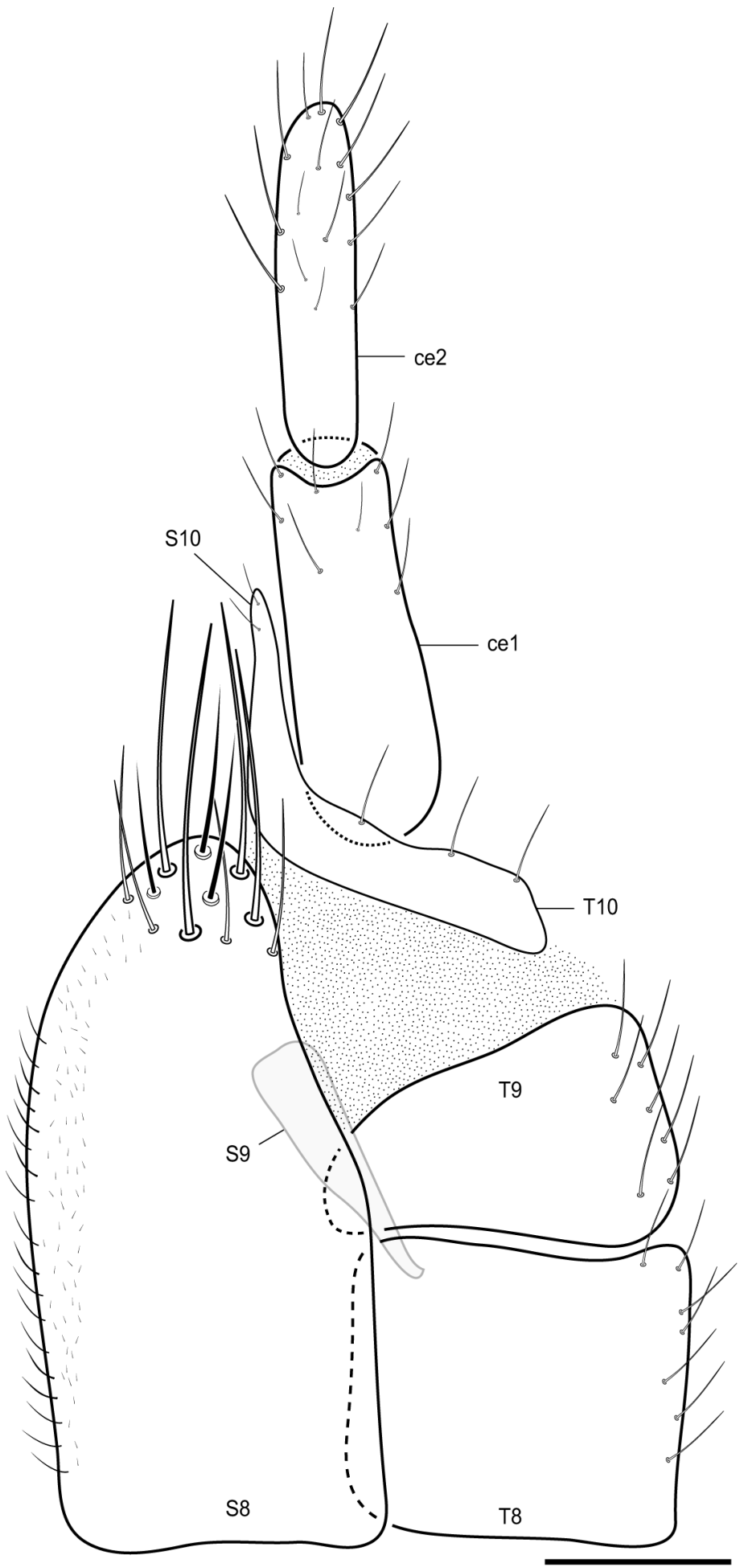

FIGURE 21. Female terminalia of Paraleia nidorosa sp. n., lateral view. Holotype. Scale $0.1 \mathrm{~mm}$. 


\section{Paraleia sharkeyi, sp. n.}

(Figs. 11, 22)

Diagnosis. Three ocelli. Wing with brown, undefined markings. Female sternite 8 distal border with deep lateral incisions at each side, quite strongly setose.

Material examined. Holotype ${ }_{+}$, COLOMBIA, State of Cundinamarca, PNN Chingaza, Alto de La Bandera, $04^{\circ} 31^{\prime} \mathrm{N} 73^{\circ} 45^{\prime} \mathrm{W}, 3,660 \mathrm{~m}, 04-10 . v .2002$, M3218 (A. Garcia Leg.) (IAvH). Paratype. 1 \% , same data as holotype, 15.xi-01.xii.2001, M2600 (L. Cifuentes Leg.) (MZUSP).

Description. Male. Unknown.

Female. Head. Vertex brown, with scattered, whitish, longer bristles. Mesal ocellus small, lateral ocelli close to but not touching eye margin. Frons and clypeus brown, with scattered setulae; labella yellow; maxillary palpus whitish yellow, five palpomeres, length of last palpomere almost twice the penultimate, first two palpomeres short. Scape and pedicel subequal in length, yellow, apical half of first flagellomere light brown, basal half lighter, second and third flagellomeres brown with lighter basal fourth, remaining flagellomeres brown. Thorax. Pronotum yellow, with four strong yellow setae, three stronger, dorsally, one smaller, ventrally. Scutum brown, dark yellow on anterior corner, above wings, along line of dorso-centrals. Scutum with short scattered setae, stronger dorso-centrals, and supra-alars. Scutellum yellow, with four scutellar bristles. Pleural sclerites brown, bare. Pleural membranae brown. Haltere whitish, setose. Legs yellow, mid and hind coxae with a brown mesal macula. Tibial spurs 1:2:2, brown, spurs almost twice width of tibial apex. Some few dark apical setae on fore tibia, mid and hind tibiae with long, strong black setae. Wing (Fig. 11). Length, $4.5 \mathrm{~mm}$, width, $1.6 \mathrm{~mm}$. Membrane with few macrotrichia scattered on anal cell, brown rather undefined transverse markings at basal third, around base of cubital fork, mid of wing, distal to first sector of Rs and base of medial fork, and across distal third of $\mathrm{R}_{5}$, besides an inconspicuous macula anteriorly to $\mathrm{r}-\mathrm{m}$. $\mathrm{C}$ extending considerably beyond apex of $\mathrm{R}_{5}$; Sc complete, ending in $\mathrm{C}$ at wing basal third; sc-r present. $\mathrm{R}_{1}$ clearly shorter than $\mathrm{r}-\mathrm{m}$, reaching $\mathrm{C}$ at distal third of wing; $\mathrm{Rs}$ almost transverse; $\mathrm{R}_{5}$ relatively short, reaching $\mathrm{C}$ before level of $\mathrm{M}_{1} ; \mathrm{r}-\mathrm{m}$ almost longitudinal, about seven times length of first sector of Rs. $\mathrm{M}_{1+2}$ almost as long as $r-m$ length; length of $M_{1}$ and $M_{2}$ more than twice $M_{1+2}$ length; CuA clearly depressed midway to apex. $\mathrm{M}_{1}$ and $\mathrm{M}_{2}$, apical half of $\mathrm{M}_{4}$ and second sector of $\mathrm{CuA}$ setose, $\mathrm{A}_{1}$ bare. Abdomen. Abdominal tergites brown, sternites light brown. Terminalia (Fig. 22). Terminalia yellow. Distal border of the sternite 8 with deep lateral incisions at each side, quite strongly setose; cercus longer than rest of terminalia, basal cercomere longer than apical one.

Etymology. This species is named after the American entomologist Michael Sharkey.

Comments. There is some minor variation at wing maculation between the specimens of the type series. This species is very similar morphologically to $P$. bolivari, sp. n. and $P$. denticulata $\mathbf{s p . ~ n . , ~ w i t h ~ d i f f e r e n c e s ~ i n ~ t h e ~ w i n g ~}$ maculation and in the shape of sternite 8. Paraleia sharkeyi $\mathbf{s p .} \mathbf{n}$. has stronger maculae on wing membrane just after the first section of Rs, apex of $\mathrm{R}_{5}$, and around base of cubital fork (Fig. 11), and sternite 8 with a deep lateral incision, which is quite strongly setose (Fig. 22). Paraleia bolivari sp. n. has the wing membrane strongly at the first section of Rs, at wing apex, at base and apex of cubital fork (Figs. 5, 6), and a sternite 8 round with fringe of setae (Figs. 14, 15); in P. denticulata sp. n. the wing membrane is inconspicuous maculated at the first section of Rs and at the wing apex (Figs. 7, 8), and the sternite 8 is wide with a distal incision, brown and long setae (Fig. 19).

\section{Paraleia sp.}

(Figs. 12, 23)

Diagnosis. Two ocelli. Wing nearly translucent. Female sternite 8 pointed, with some black setulae along distal margin.

Material examined. 19 , COLOMBIA, State of Cundinamarca, PNN Chingaza, Bosque Palacio, $04^{\circ} 31^{\prime} \mathrm{N}$ 735'' W, 2,939 m, 17.i-04.ii.2001, M1258 (E. Niño Leg.) (IAvH). 1 + State of Boyacá, SFF Iguaque, Cabana Mammaramos, $05^{\circ} 25^{\prime} \mathrm{N} 73^{\circ} 27^{\prime} \mathrm{W}, 2,855 \mathrm{~m}, 23 . v-08 . v i .2000$, M146 (P. Reina Leg.) (IAvH). 2 q State of Huilla, PNN Curva de los Guácharos, Mun. Acevedo, 01³7’N 7606’W, 2,150 m, 15-19.vi.2003, M3787 (J. Lopes Leg.) (MZUSP). 


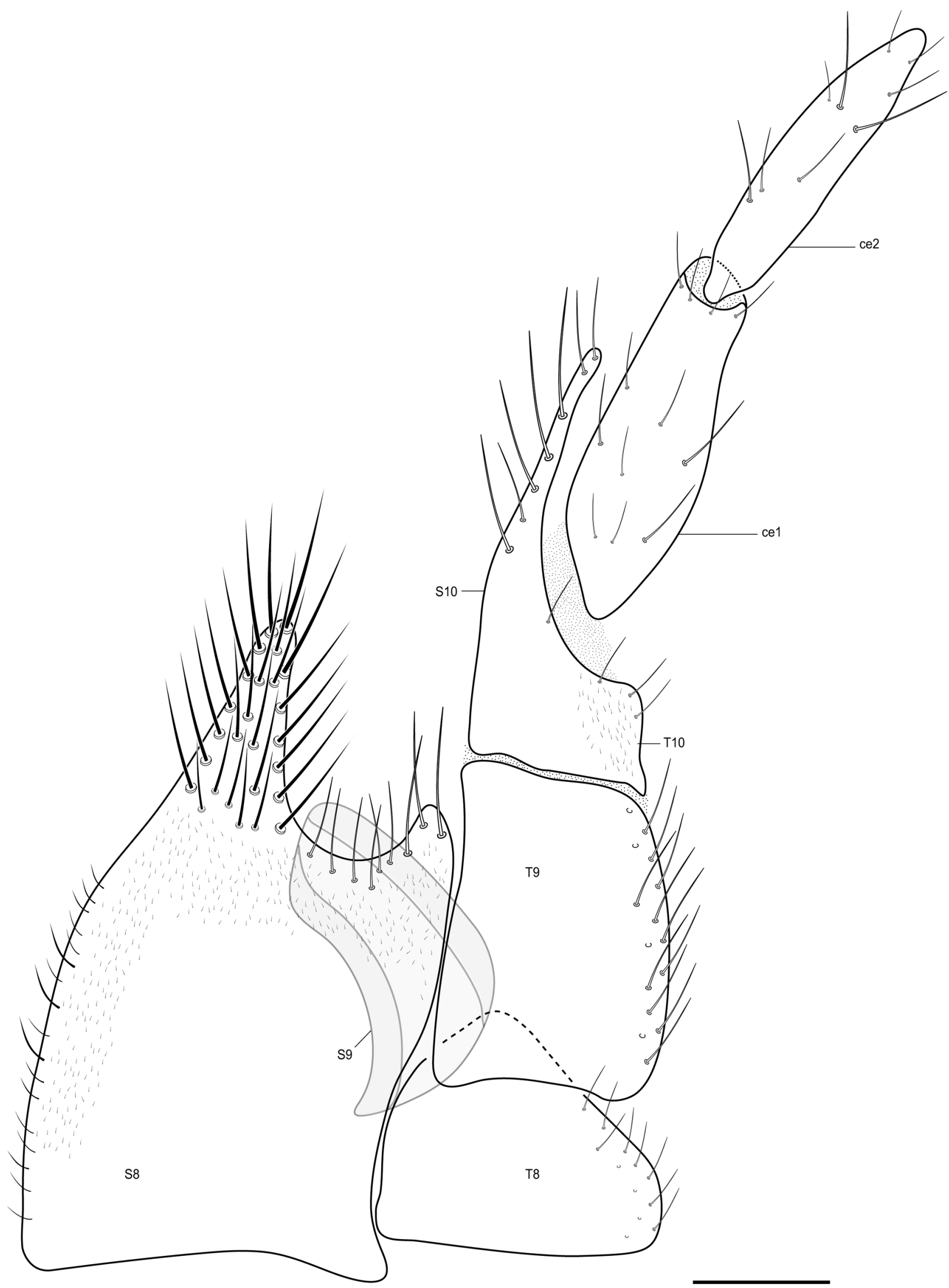

FIGURE 22. Female terminalia of Paraleia sharkeyi sp. n., lateral view. Paratype. Scale $0.1 \mathrm{~mm}$. 


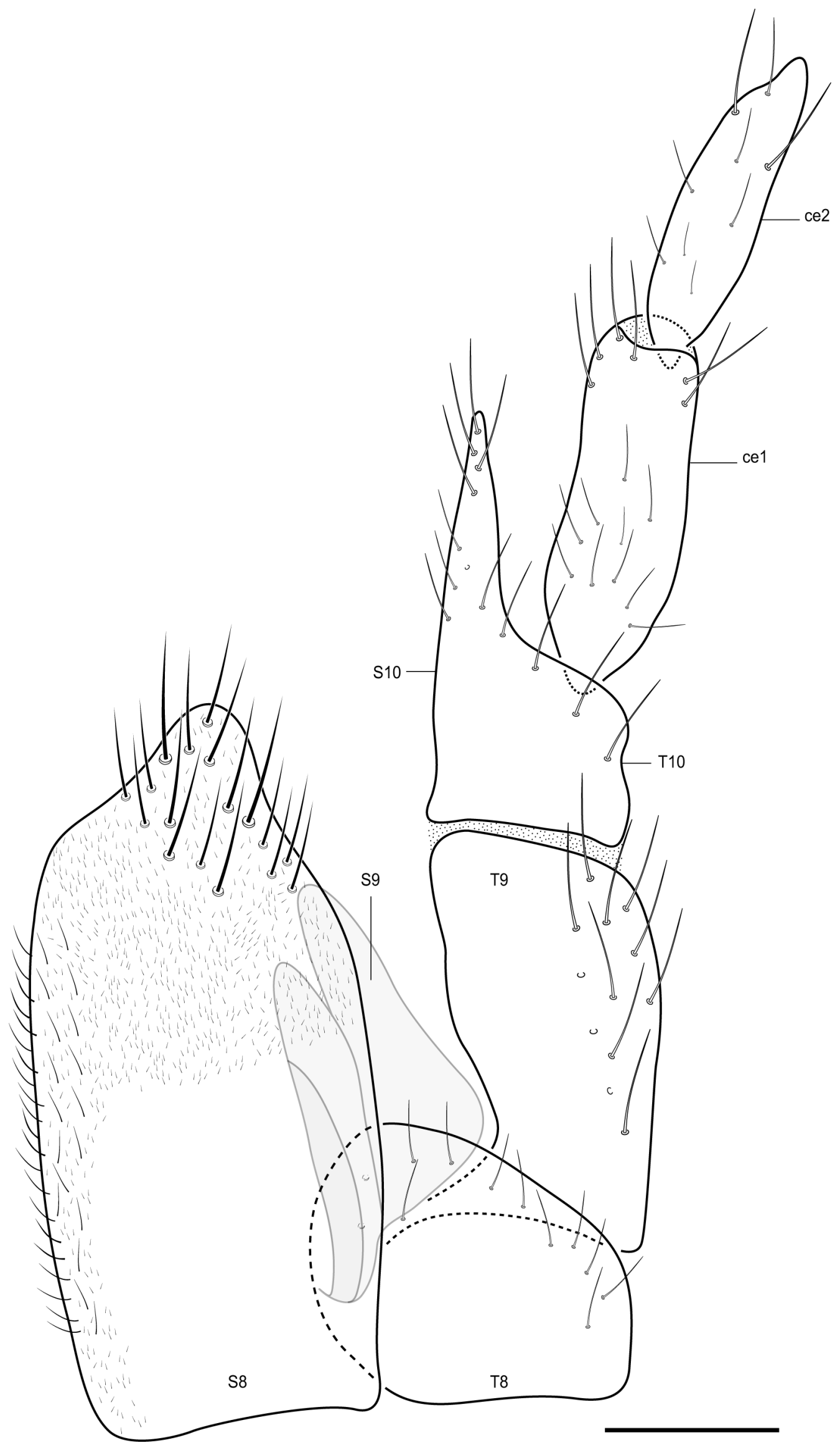

FIGURE 23. Female terminalia of Paraleia sp., lateral view. Paratype. Scale $0.1 \mathrm{~mm}$. 
Description. Female. Head. Vertex lighter ventrally, with scattered, whitish, longer bristles. Two ocelli close to but not touching eye margin, mid ocellus absent. Frons light brown, covered with scattered setulae, clypeus light yellow; labella yellow; maxillary palpus whitish yellow, five palpomeres, last palpomere length almost twice penultimate, first two palpomeres short. Scape smaller than pedicel, both yellow, apical half of first flagellomere light brown, basal half lighter, second and third flagellomeres brown with lighter basal fourth, remaining flagellomeres brown. Thorax. Pronotum yellowish-brown, five strong yellow setae, three stronger, dorsally, and two smaller, ventrally. Scutum dark yellow, with a small, undefined latero-posterior brown macula. Scutellum yellow mesally, brownish at margins, with four scutellar bristles. Antepronotum and proepisternum light yellow, bare. Pleural sclerites brown, bare, katepisternum, mesepimeron and laterotergite each with a yellowish mesal macula, metepisternum light yellow. Legs light yellow, darker to apex, hind coxa with a brown mesal macula. Tibial spurs 1:2:2, brown, spurs almost twice width of tibial apex. Some few dark apical setae on fore tibia, mid and hind tibiae with long, strong, black setae. Haltere whitish, setose. Wing (Fig. 12). Length, $4.8 \mathrm{~mm}$, width, $1.7 \mathrm{~mm}$. Membrane without macrotrichia, hyaline. $\mathrm{C}$ extending slightly beyond $\mathrm{R}_{5}$; Sc complete, reaching $\mathrm{C}$ at basal third of wing; sc-r present. $R_{1}$ pretty shorter than $r-m$ length, reaching $C$ beyond distal third of wing; first sector of Rs almost transverse, directed basalwards distally; $\mathrm{R}_{5}$ reaching $\mathrm{C}$ close to wing tip; r-m almost longitudinal, about five times length of first sector of Rs. $M_{1+2}$ obviously shorter than r-m length; medial fork long, $M_{1}$ and $M_{2}$ more than twice length of $\mathrm{M}_{1+2}$; CuA slightly depressed midway to apex. $\mathrm{M}_{1}$ and $\mathrm{M}_{2}, \mathrm{M}_{4}$, second sector of $\mathrm{CuA}$ and $\mathrm{A}_{1}$ setose. Abdomen. Abdominal tergites 1-7 brown, with a whitish band at distal margin, and yellow brown lateral bands on tergites 27. Sternites almost entirely whitish yellow, with slender, irregular brown bands laterally. Terminalia (Fig. 23). Terminalia yellow. Sternite 8 pointed, with some black setulae along the distal margin; cercus almost longer than rest of terminalia, basal cercomere longer than apical one.

Comments. In most of the Paraleia species studied here, there is not much color variation between males and females, but there are a few exceptions. The female specimens included here as Paraleia $\mathbf{s p . ~ s h o w ~ s o m e ~ v a r i a t i o n ~}$ concerning the presence of a brown spot basally at the hind coxa (which is missing in some specimens), and yellowish spots may be present or absent on the brownish anepisternum and katepisternum. Interestingly, all these females have identical female terminalia, suggesting that, despite some variation in coloration, these specimens may be conspecific. These females, on the other hand, are similar to the male of $P$. tonnoiri sp. $\mathbf{n}$. for most details of the morphology, including the number of ocelli, but were collected in different localities in Colombia. In $P$. tonnoiri sp. n. the coloration of the scutum is brown with two narrow yellow bands joining posteriorly, a feature present in one of the specimens of Paraleia sp., less evident in the remaining females. At this stage, the fact that the distal part of the wing is missing in P. tonnoiri sp. n. and that there are no males collected together with the females included here under Paraleia sp. makes it advisable not to propose a separate species name for these latter specimens.

\section{Taxonomic and biogeographical considerations}

The presence of Paraleia in Colombian Andes is particularly noteworthy-it constitutes the northern most occurrence of a taxon with amphinotic distribution (sensu Matile 1990), i.e., present only in Australia and South America. This is not a common pattern, but also happens, e.g., with the Leiinae genus Procycloneura (Oliveira et al. 2007).

The wide $\mathrm{r} 5$ cell, with displacement of the $\mathrm{R}_{5}-\mathrm{r}-\mathrm{m}$ system of veins away from the anterior margin, is unique in Leiinae and gives a characteristic aspect to the wing venation of Paraleia, strongly suggesting that the genus is monophyletic. All new species show this feature, as well as the remaining diagnostic characters. Long spines apically at the gonostyle and subapically at the gonocoxite distal extension are shared by $P$. fulvescens and most of the Neotropical species, but combs of shorter spines in the gonostyles are present only in Neotropical clade of the genus. The evolution of the wing maculation, on the other hand, is not easy to interpret throughout the evolution of the subfamily or even within the genus. In the only known Australian species of the genus, Paraleia fulvescens, a typical maculation pattern is absent and there is only a darkening of the membrane along the anterior margin. Some of the Neotropical species miss a clear maculation pattern in the wing (e.g., P. martinici Duret, $P$. falcigera Freeman, $P$. funerea Freeman, P. castanea Freeman, and Paraleia sp. from this paper), but the presence of maculae in most of the genera in the subfamily suggests that this could represent a secondary loss. 
The presence in Colombia and Ecuador of species with both obvious wing patterns and no maculation at allas it is also observed in Chile- suggests that there are species in the northern range of Paraleia belonging to different clades within the genus.

The opening of the southern Atlantic Ocean, breaking up Gondwana, began in early Cretaceous, 145 mya (Raven \& Axelrod 1974), while New Zealand, Australia and South America were connected until Late Cretaceous, 70 mya (McCarthy 2003, 2005). The final disruption between Australia and South America occurred only in the second half of the Cenozoic, about 35 mya (McLoughlin 2001), meaning that there has been a lasting connection between Australia and South America with Antarctica since the Cretaceous to the mid Cenozoic. This explains why amphinotic distributions are a widespread biogeographical pattern — and, hence, originated through vicariance, not transoceanic dispersal — but with an age of disruption not compatible with the initial division of Gondwana (Amorim et al. 2009).

Indeed, in a study on colletid bees (Hymenoptera, Colletidae), molecular divergence between clades with amphinotic distribution point to a mid Oligocene disjunction, 33-35 mya (Almeida et al. in press). This is pattern is remarkably similar to what found in Paraleia. In fact, there may be a group of leiine and sciophiline genera that compose a clade within each of these subfamilies that have, as in the case of the colletid bees, multiple lineages each with amphinotic distribution, with representatives in South America and Australia.

The first cladogenesis in the genus, therefore, with the separation of the Australian and South American components, hence, would have been in the Late Eocene-Early Oligocene, at a time when the Andean cordillera was already formed in the south. The presence of Paraleia species in the northern extreme of the Andes with both patterned and non-patterned wing membrane suggests that early events in the evolution of the genus, whatever the topology, resulted in clades that extended to the north together with the uplift of the northern half of the Andes itself.

\section{Acknowledgements}

The material used in this study was very kindly made available by Michael Sharkey (NSF Grant DEB-0205982) and Carlos José Einicker Lamas (MZUSP), to whom we are most thankful. Additional information on the Michael project can be found in the web address of the project (http://www.sharkeylab.org/biodiversity/ static.php?app=colombia\&page=index). SSO benefited from FAPESP (grant 2008/52324-6) and a Geddes Post Graduate Award 2010-2011 from the Australian Museum, while DSA has a fellowship from CNPq (314371/20095). Special thanks to Dan Bickel, Dave Britton, and Jacqueline Ressel, of the Australian Museum, Sydney, Australia, for be very helpful and careful during the time expended in the AMSA. We also deeply thank Maria Isabel Proti de Andrade Balbii, for help us amiably with malaise traps samples and slides preparations. The authors express sincere thanks to Peter Kerr, Vladimir Blagoderov, Jevgeni Jakovlev, and one anonymous referee for very nice criticisms and suggestions to the manuscript.

\section{References}

Almeida, E.A.B., Pie, M.R, Brady, S.G. \& Danforth, B.N. Biogeography and diversification of colletid bees (Hymenoptera: Colletidae): emerging patterns from the southern end of the world. Journal of biogeography DOI: 10.1111/j.13652699.2011.02624.x (in press).

Amorim, D.S. \& Rindal, E. (2007) A phylogenetic study of the Mycetophiliformia, with creation of the subfamilies Heterotrichinae, Ohakuneinae, and Chiletrichinae for the Rangomaramidae (Diptera, Bibionomorpha). Zootaxa, 1535, 1-92.

Amorim, D.S. Santos, C.M.D. \& Oliveira, S.S. (2009) Allochronic taxa as an alternative model to explain circumantarctic disjunctions. Systematic Entomology, 34(1), 2-9.

Baxter, J.E. \& Poinar, G.O. (1994) A new genus and new species of fungus gnats (Diptera: Mycetophilidae) from Dominican amber. Annales de la Société entomologique de France (N.S.), 30(1), 93-102.

Bigot, J.M.F. (1888) Diptères. Pp. 1-45, pls. 1-4. In: Ministères de la Marine et de l'Instruction Publique, Mission Scientifique du Cap Horn, 1882-1883, 6 (Zool., 2). Paris, '1891'.

Blagoderov, V.A. (1998) Fungus Gnats (Diptera, Mycetophilidae) from the Lower Cretaceous of Mongolia. Paleontological Journal, 32(6), 53-59.

Blagoderov, V. \& Grimaldi, D. (2004) Fossil Sciaroidea (Diptera) in Cretaceous ambers, exclusive of Cecidomyiidae, Sciaridae, and Keroplatidae. American Museum Novitates, 3433, 1-76. 
Chandler, P.J. (2009) The fungus gnats (Diptera: Bolitophilidae, Keroplatidae, Mycetophilidae) of Sardinia, with description of six new species. Zootaxa, 2318, 450-506.

Duret, J.P. (1984) Los micetofilídeos del Archipielago Cabo de Hornos. The Mycetophilidae of Cape Horn Archipelago. Anales des Instituto de la Patagonia, Série Ciencias Naturales, 15, 37-50, 9 figs.

Edwards, F.W. (1925) British fungus-gnats, with a generic classification of the family. Transactions of the Entomological Society of London, 1924, 505-670, 13 pls.

Edwards, F.W. (1933) New neotropical Mycetophilidae (II). Revista de Entomologia, 3(3), 303-322.

Enderlein, G. (1940) Die Dipterenfauna der Juan-Fernandez-Inseln und der Oster-Inseln. Pp 643-680, pls. 49. In: Skottsberg, Natural History of the Juan Fernandez Island and Easter Island, (Zool.) 3. Uppsala.

Evenhuis, N.L. (1994) Catalogue of the fossil flies of the world (Insecta: Diptera). Backhuys, Leiden.

Freeman, P. (1951) Diptera of Patagonia and South Chile based mainly on material in the British Museum (Natural History). Part III-Mycetophilidae. London, British Museum Natural History. vii \& 138 pp.

Freeman, P. (1954) [1953] Los insectos de las Islas Juan Fernandez. 13. Mycetophilidae, Sciaridae, Cecidomyiidae and Scatopsidae (Diptera). Revista Chilena de Entomología, Santiago 3, 23-40, 3 pls.

Hackman, W., Lastovka, P., Matile, L. \& Väisanen, R. (1988) Mycetophilidae. Pp. 220-328. In: A. Soós \& L. Papp (eds.). Catalogue of Palaearctic Diptera. Vol. 3. Ceratopogonidae - Mycetophilidae. Elsevier Science Publishers, Amsterdam. The Netherlands and Akadémia Kiadó, Budapest, Hungary. 450 pp.

Hennig, W. (1973) Ordnung Diptera (Zweiflügler). Handbuch der Zoologie, Berlin, 4, 1-337.

Hippa, H., Jaschhof, M. \& Vilkamaa, P. (2005) Phylogeny of the Manotinae, with a review of Eumanota Edwards, Paramanota Tuomikoski and Promanota Tuomikoski (Diptera, Mycetophilidae). Studia dipterologica, 11(2), 405-428.

Jaschhof, M. \& Kallweit, U. (2009) The Cycloneura Marshall group of genera in New Zealand (Diptera: Mycetophilidae: Leiini). Zootaxa, 2090, 1-39.

Kallweit, U. (1998) Notes on the genus Metanepsia Edwards and its relatives from East Asia (Insecta: Diptera: Mycetophilidae). Reichenbachia, 32, 341-353.

Kurina, O. (2004) Notes on fungus gnats from the East Mediterranean with description of two new species (Diptera: Sciaroidea excl. Sciaridae). Beiträge zur Entomologie, 54(2), 343-355.

McCarthy, D. (2003) The Trans-Pacific zipper effect: disjunct sister taxa and matching geological outlines that link the Pacific margins. Journal of Biogeography, 30, 1545-1561.

McCarthy, D. (2005) Biogeographical and geological evidence for a smaller, completely-enclosed Pacific Basin in the Late Cretaceous. Journal of Biogeography, 32, 2161-2177.

McLoughlin, S. (2001) The breakup history of Gondwana and its impact on pre-Cenozoic floristic provincialism. Australian Journal of Botany, 49, 271-300.

Matile, L. (1971) Une nouvelle tribu de Mycetophilidae: les Metanepsiini (Dipt.). Bulletin de la Société Entomologique de France, 76, 91-97.

Matile, L. (1989) Superfamily Sciaroidea. Pp. 123-145. In: N.L. Evenhuis (ed.), Catalog of the Diptera of the Australasian and Oceanian Regions. Honolulu \& Leiden.

Matile, L. (1990) Recherches sur la systématique et l'evolution des Keroplatidae (Diptera, Mycetophiloidea). Mémoir du Museum National d'Histoire Naturelle, 148, 1-682.

Oliveira, S.S., Silva, P.C.A. \& Amorim, D.S. (2007) Neotropical, Circum-Antarctic and Nearctic overlap? Mycetophilidae (Diptera) of Colombia and its biogeographic implications. Darwiniana, 45(Supplement), 106-107.

Raven, P.H. \& Axelrod, D.J. (1974) Angiosperm biogeography and past continental movements. Annals of the Missouri Botanical Garden, 61(3), 539-673.

Rindal, E., Søli, G.E.E. \& Bachmann, L. (2009) Molecular phylogeny of the fungus gnat family Mycetophilidae (Diptera, Mycetophiliformia). Systematic Entomology, 34, 524-532.

Ševčík, J. \& Hippa, H. (2010) New species of Chalastonepsia and Pectinepsia gen. nov. (Diptera: Mycetophilidae) from the Oriental and Australasian Regions. Acta Entomologica Musei Nationalis Pragae, 50(2), 595-608.

Søli, G.E.E. (1997) The adult morphology of Mycetophilidae (s. str.), with a tentative phylogeny of the family (Diptera, Sciaroidea). Entomologica Scandinavica Supplement, 50, 5-55.

Søli, G.E.E., Vockeroth, J.R. \& Matile, L. (2000) Families of Sciaroidea. In: L. Papp \& B. Darvas (eds.), Contributions to a Manual of Palaeartic Diptera Appendix (pp. 49-92). Science Herald, Budapest.

Thompson, F.C. \& Pape, T. (2011) Systema Dipterorum. The Biosystematic Database of World Diptera. Available at http:// www.diptera.org/index.php, acessed Nov 08, 2011.

Tonnoir, A.L. (1929) Australian Mycetophilidae. Synopsis of the genera. Proceedings of the Linnean Society of New South Wales, 54, 584-614.

Tozoni, S.H.S. (1998) Sistemática filogenética dos Mycetophilidae (Diptera: Bibionomorpha). Tese de Doutoramento, Universidade Federal do Paraná, Curitiba.

Tuomikoski, R. (1966) Generic taxonomy of the Exechiini (Dipt., Mycetophillidae). Annales Entomologici Fennici, $32,159-194$.

Väisänen, R. (1984) A monograph of the genus Mycomya Rondani in the Holarctic region (Diptera, Mycetophilidae). Acta Zoologica Fennica, 177, 1-346.

Walker, F. (1837) Descriptions, etc. of the Diptera. Pp. 331-359. In: Descriptions, etc. of the Insects collected by Captain P.P., King, R.N., F.R.S., in the Survey of the Straits of Magellan. In: Curtis, J., Haliday, A.H., and Walker, F. Transactions of the Linnean Society of London, 17, 315-359. 


\title{
Redescription of the enigmatic Thoracotropis cypriformis Freeman (Diptera, Mycetophilidae)
}

\author{
Sarah Siqueira Oliveira ${ }^{1,3}$, Dalton de Souza Amorim ${ }^{1} \&$ Vladimir Blagoderov $^{2}$
}

\begin{abstract}
'Departamento de Biologia, Faculdade de Filosofia, Ciências e Letras de Ribeirão Preto, Universidade de São Paulo, Av. Bandeirantes 3900, 14040-901 Ribeirão Preto-SP, Brazil. oliveira.sarahcv@gmail.com,dsamorim@usp.br

2Department of Entomology, Natural History Museum, Cromwell Road, London SW7 5BD, United Kingdom. vblago@gmail.com

${ }^{3}$ Corresponding author.
\end{abstract}

\begin{abstract}
Redescription of the enigmatic Thoracotropis cypriformis Freeman (Diptera, Mycetophilidae). The Chilean species Thoracotropis cypriformis, type species of the monotypic genus Thoracotropis, is redescribed based on the only known specimen, the holotype. Habitus, head, wing venation, and male terminalia are illustrated. Comments are made on the diagnostic features of the genus and on its position in the subfamily to which it is usually assigned, the Leiinae.
\end{abstract}

KEYWORDS. Mycetophilidae; redescription; taxonomy; Thoracotropis.

RESUMO. [Redescrição do enigmático gênero Thoracotropis cypriformis Freeman (Diptera, Mycetophilidae)]. A espécie chilena Thoracotropis cypriformis, espécie-tipo do gênero monotípico Thoracotropis, é redescrita com base no único exemplar conhecido, o holótipo. Habitus, cabeça, venação alar e terminália do macho são ilustrados. Comentários são feitos sobre as características diagnósticas do gênero e sua posição na subfamília na qual ele é normalmente incluído, Leiinae.

PALAVRAS-CHAVE. Mycetophilidae; redescrição; taxonomia; Thoracotropis.

Thoracotropis Freeman, 1951 was described based on a single species from Chile - T. cypriformis - known from a single male specimen. The genus can be separated from other mycetophilids based on the reduced mouth parts, with two segmented palpus, and a some curious thoracic traits, as the mesonotum laterally compressed, quite strongly arched.

Freeman (1951) included the genus in the Mycetophilidae “Leiini” (= Leiinae; e.g., Väisänen 1984; Matile 1993; Chandler 2009), a tribe encompassing 32 recent genera and almost 560 species worldwide (Edwards 1925; Hackman et al. 1988; Søli 1997; Kurina 2004; Oliveira \& Amorim 2012). Thoracotropis has $\mathrm{R}_{1}$ length less than twice r-m length (hence, longer than in other leiines and shorter than in other gnoristines) and a rather longitudinal $\mathrm{r}-\mathrm{m}$, two features used by Edwards (1925) to delimit Leiinae. A sinuous $\mathrm{CuA}$ (i.e., $\mathrm{CuA}_{2}$ of Vockeroth 2009) has been also taken more recently as diagnostic for the subfamily (Baxter \& Poinar 1994; Jaschhof \& Kallweit 2009). In a recent discussion about the limits of the Leiinae (Jaschhof \& Kallweit 2009) Thoracotropis was considered a leiine genus with a sinuous $\mathrm{CuA}$. A detailed reexamination of the holotype of T. cypriformis, however, revealed that $\mathrm{CuA}$ is neither sinuous nor even slightly sinuous (Fig. 6), raising some doubts about its inclusion in the subfamily or at least in a higher clade of the Leiinae.

Indeed, not all genera of Leiinae have the features proposed to be diagnostic for the subfamily. Actually, there is a recurrent discussion about the composition of the subfamily (e.g., Väisänen 1986; Søli 1997; Søli et al. 2000; Hippa et al. 2005; Jaschhof \& Kallweit 2009). The problem of the mono- phyly of the Leiinae in a wider sense is being addressed in a phylogenetic study of the Leiinae (Oliveira \& Amorim, unpublished data). The purpose of this paper is to redescribe the holotype of Thoracotropis cypriformis, kept in the collection of the Natural History Museum, London (NHM) and to consider the problem of its inclusion in the Leiinae.

\section{METHODS}

Photographs were taken in the Sackler Biodiversity Imaging Lab at the Natural History Museum, London with a Zeiss SV11 stereomicroscope and Zeiss Axioskop coupled with Cannon EOS 450D camera. Extended depth of field images were obtained using Helicon Focus v. 5.2 software. The illustration of the male terminalia was prepared with the help of a camera lucida and the Adobe Illustrator CS software.

Morphological terms follow Søli (1997) and Amorim \& Rindal (2007). Abbreviations used are: ae, aedeagus; ce, cercus; gcap, gonocoxal apodeme; dorsal proj, gonostyle dorsal projection: gcx, gonocoxite; gs, gonostyle; par, parameres; par proj, paramere projection; ventral proj, gonostyle ventral projection.

\section{Thoracotropis Freeman 1951}

Thoracotropis Freeman, 1951: 81. Type-species, T. cypriformis Freeman (orig. des.).

Diagnosis. Three ocelli, lateral ones almost touching eye margins. Mouthparts reduced, palpus two segmented. 
Mesonotum laterally compressed, dorsally arched. Laterotergite bare. Medial fork complete, $\mathrm{r}-\mathrm{m}$ almost longitudinal, $\mathrm{M}_{4}$ and $\mathrm{CuA}$ not sinuous. Male gonostylus digitiform, flattened, main body with an inner-apically bare tooth and a dorsal, well developed bare hook projecting meso-caudally at its distal third. Parameres with a pair of very long, thin, curved processes projecting well beyond apex of the terminalia.

Species included. Only the type-species of the genus is known.

\section{Thoracotropis cypriformis Freeman, 1951}

(Figs. 1-10)

Thoracotropis cypriformis Freeman, 1951: 81, figs. 156 (ơ terminalia), 292 (wing). Type-locality: Chile, Chiloé, Ancud. Holotype o", NHM.

Labels. The labels of the holotype are: "Thoracotropis / cypriformis [hw] / Freeman. / HOLOTYPE" [printed on a red label]" // [male terminalia on a microslide attached to a pinned plastic stripe]" // "HOLO- / TYPE" [printed in black on a rounded label with red border]" // "Ancud / 1719.xii.1926." // "S. Chile: / Llanquihue Prov. / F. \& M. Edwards / B.M. 1927-63." // "BMNH(E) \# / \# 254350".

Redescription of the holotype. Male (habitus, Fig. 1). Head (Figs. 2-4). Predominantly yellowish; brownish on postgena and occiput. Three ocelli, lateral ones almost touching eye margins, median ocellus smaller than lateral ones. Mouthparts reduced; palpus yellowish, two segmented, basal palpomere large, wide, distal palpomere short, about half the length of the basal one. Face and clypeus yellow, pubescent. Antennae yellow, scape and pedicel pretty short, flagellomeres cylindrical, longer than wider, close to each other, first flagellomere slightly shorter than second one. Thorax (Figs. 4-5). Scutum with a light yellow stripe anteriorly continuing along paraalars, two brownish bands along the dorsocentrals and two short brown bands above wings; laterally compressed, arched, bearing dense rows of acrostichals, dorsocentrals, and slightly stronger supra-alars and prescutellars. Scutellum brown, with one pair of long scutellar bristles and several pairs of shorter setae medially. Mediotergite yellowish, with thin brown medial line, bare, curved in profile. Pleural sclerites dark brown, except for yellow dorsal margin of mesepimeron and laterotergite. Pleural membrane light brown. Pronotum with two long and five shorter setae. Anepisternum and katepisternum bare, katepisternum twice as high as anepisternum, bluntly pointed ventrally. Mesepimeron not reaching ventral margin of thorax, bare. Laterotergite bare. Haltere pedicel yellowish, knob light brownish. Legs light yellow, except for tibiae and tarsi brownish, mid coxae dark brown basely and brown hind coxa on basal two thirds. Tibiae with short bristles. Tibial spurs 1:2:2, brownish, almost twice the length of tibial apex width, inner spur of hind tibia only slightly longer than outer one. Wing (Fig. 6). Membrane translucent, dense and regularly covered with microtrichia. $R_{1}, R_{5}$ and all posterior veins except $M_{1+2}$ with dorsal macrotrichia. Sc very short, ending free, $\mathrm{sc}-\mathrm{r}$ absent. $\mathrm{R}_{5}$ ending before wing apex, $\mathrm{C}$ extending about half the distance between $R_{5}$ and $M_{1}$. First sector of Rs perfectly transverse, short, devoid of setae. $\mathrm{R}_{1} 1.9 \mathrm{X}$ the length of $\mathrm{r}-\mathrm{m}$, reaching $\mathrm{C}$ at apical third of wing; $\mathrm{R}_{4}$ absent; $\mathrm{R}_{5}$ gently curved anteriorly on distal half, reaching $\mathrm{C}$ almost at level of apex of $\mathrm{M}_{1} ; \mathrm{r}-\mathrm{m}$ long, only slightly oblique, well sclerotized. $\mathrm{M}_{1+2}$ length about $0.6 \mathrm{X}$ median fork length; $\mathrm{M}_{1}$ and $\mathrm{M}_{2}$ slightly divergent, complete. First sector of $\mathrm{CuA} 1.2 \mathrm{X}$ longer than second sector, cubital fork at level of origin of $\mathrm{M}_{1+2}$, second sector gently curved along its length, not sinuous. $\mathrm{A}_{1}$ quite weakly sclerotized, not produced on distal half. Abdomen (Fig. 1). Slender, covered with long, yellow setae, T1 dark brown, T2-T6 brown, with a wide anterior yellow band not reaching the margins laterally, T7-T8 brown with a basal band yellow; S1 brown, S2-S6 dark brown, yellow mesally; S7S8 light brown, with yellowish mesal band (Freeman 1951: 82). Terminalia (Figs. 7-10). Gonocoxites setose, not too elongate, extending mesally, but with a deep median suture, with no distal extension beyond level of insertion of gonostyles. Gonostyles digitiform, flattened, main body with setae spread basally, setulose apically, with an inner apically bare tooth, a dorsal, well developed bare hook projecting meso-caudally at its distal third. Gonocoxal apodeme well developed; parameres well developed, involving the aedeagus, with a rounded apex setulose apically, with a pair of very long, thin, curved processes projecting well beyond apex of the terminalia; aedeagus bifid at apex. Cercus membranous and setose. T9 fairly narrow.

Comments. Information about T9 follows the original description of Freeman (1951: 82). The male terminalia mounting, however, is in a pretty bad state. The dorsal part of the terminalia was removed, so details on the epandrium cannot be properly verified.

\section{DISCUSSION}

The original position of Thoracotropis as a member of the Leiinae was more recently corroborated by Jaschhof \& Kallweit (2009), even though there is not a phylogenetic analysis of the group. In Tozoni's (1998) phylogenetic study of the Mycetophilidae, she suggests that Thoracotropis would belong to the subfamily Gnoristinae, and fit in a clade with Impleta Plassmann and Docosia Winnertz. However, she also highlighted the need for a wider sampling of the Gnoristinae and the Leiinae to properly recover this part of the phylogeny of the family. Freeman (1951) actually mentioned the similarities between Thoracotropis and Docosia and the dissimilarities between Thoracotropis and the other Leiinae. Søli (1997) and Rindal et al. (2009) did not include the genus in their wider phylogenetic studies of the family.

A better placement of Thoracotropis in the system of the Mycetophilidae is obviously dependent on the solution of the problem of the monophyly of Leiinae and its delimitation. There is still no agreement in the literature about the limits of the subfamily (Väisänen 1986; Søli 1997; Søli et al. 2000; Hippa et al. 2005; Jaschhof \& Kallweit 2009) and 


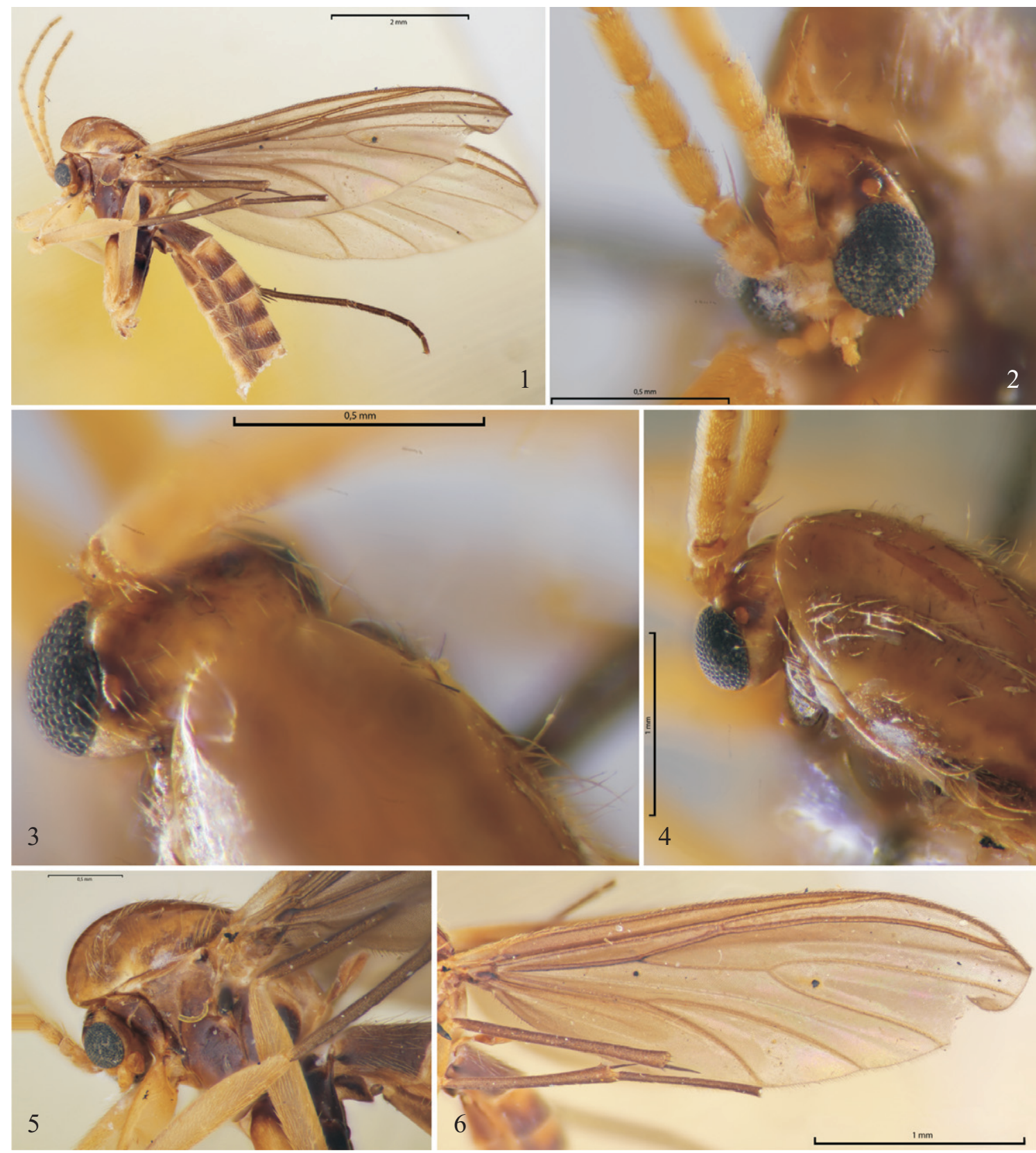

Figs. 1-6. Thoracotropis cypriformis Freeman, holotype: 1, habitus, lateral view; 2, head, frontal view; 3, head, dorsal view; 4, head and thorax, dorsal view; 5 , thorax, lateral view; 6 , left wing.

only a phylogenetic analysis considering all putative leiine genera, manotines, gnoristines, and other outgroups could render a reliable solution. This study is still not available and the redescription of this genus is a way of providing information towards a better understanding of the subfamily.

In the original description of the genus, Freeman (1951: 81) mistakenly refers to only two ocelli. This feature varies among the Leiinae genera, so this may have led to misleading conclusions about the position of the genus. The mesonotum strongly arched and produced anteriorly is distinctive of the genus. The shape of the mesonotum is variable in the Mycetophilidae, but a mesonotum produced anteriorly is present in Sceptonia Winnertz and Epicypta Winnertz (Søli 1997) as well, so it is not informative enough whether or not to place the genus in Leiinae.

The Thoracotropis male terminalia is remarkable because of the long, thin paramere projections. The general structure of the male terminalia, with a narrow T9, digitiform gonostyle, and absence of spines in the gonocoxite, is plesiomorphic in mycetophilids and, in this sense, is more similar to the male terminalia of some Neotropical Dziedzickia Johannsen (Oliveira 2009) and Tetragoneura Winnertz (Freeman 1951) than to typical Leiinae genera, as Paraleia Tonnoir (Oliveira \& Amorim 2012), Paradoxa Marshall, Sigmoleia Tonnoir \& 

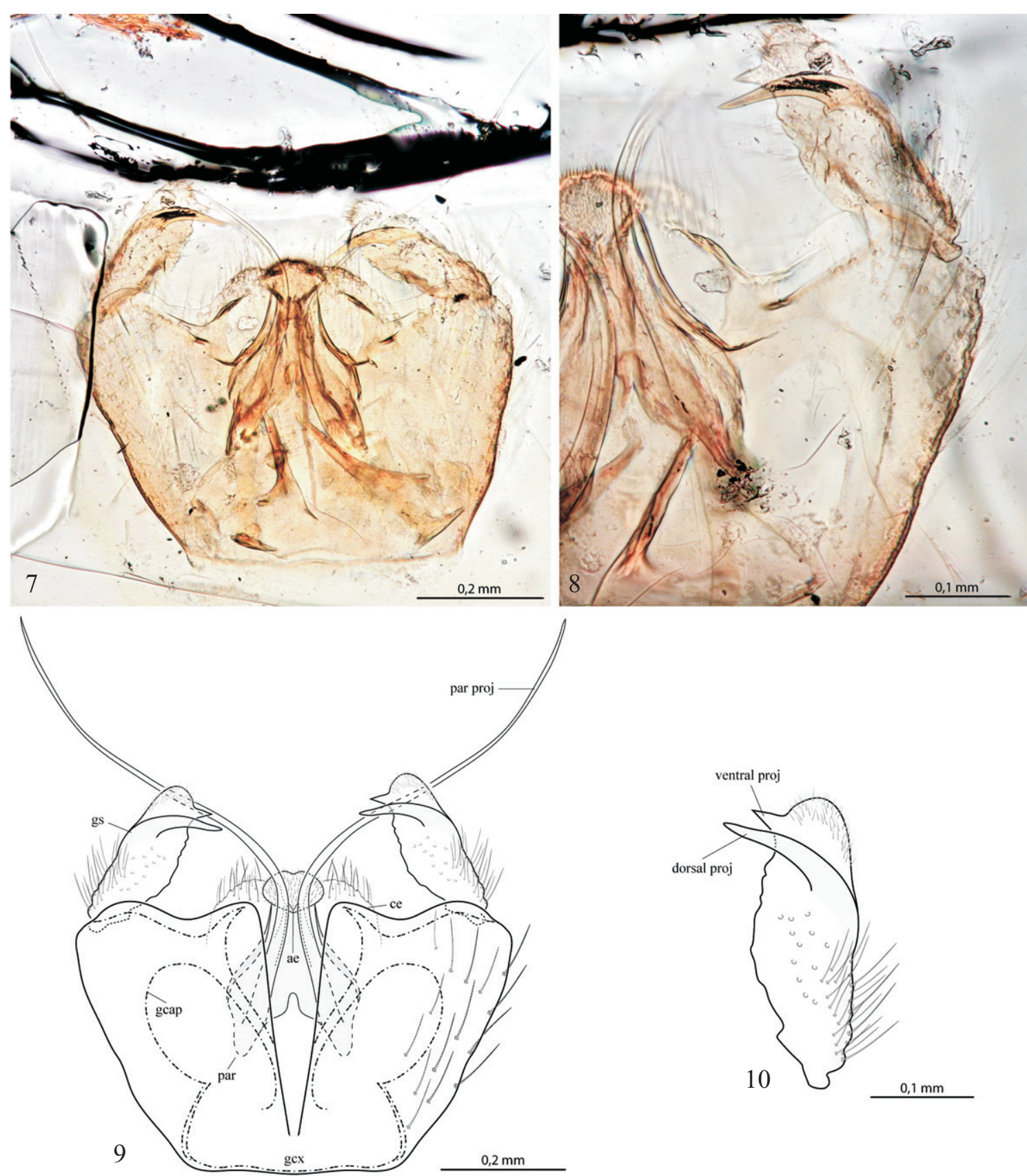

Figs. 7-10. Thoracotropis cypriformis Freeman, holotype. Male terminalia. 7. Dorsal view. 8. Detail of the parameres, parameres projections, and gonostyle, dorsal view. 9. Dorsal view. 10. Detailed of the gonostyle projections, dorsal view.

Edwards, Paracycloneura Tonnoir \& Edwards, Waipapamyia Jaschhof \& Kallweit (Jaschhof \& Kallweit 2009). If these features are not enough to include Thoracotropis in the gnoristines, they at least show that the genus does not belong to the core group of genera of leiines.

Wing features can also contribute to this discussion. Most leiines have $\mathrm{R}_{1}$ typically short, as well as a sinuous $\mathrm{CuA}$. Genera assigned to the subfamily with long $\mathrm{R}_{1}$ and $\mathrm{CuA}$ not sinuous (or not even slightly sinuous) include, among others, Aphrastomyia Coher \& Lane, Docosia, Ectrepesthoneura Enderlein, Megophthalmidia Dziedzicki, Novakia Strobl,
Tetragoneura or, to a lesser extent, Rondaniella Johannsen and Trichoterga Tonnoir \& Edwards. Despite its inclusion as Leiinae by Jaschhof \& Kallweit (2009), Thoracotropis has $\mathrm{R}_{1}$ much longer than typical leiines. The extension of $\mathrm{r}-\mathrm{m}$, on the other hand, a condition also seen in most leiines, is much longer in Thoracotropis than in typical gnoristines, what could suggests a position closer to the leiines.

It is worth noting that Matile (1993), while describing Caledonileia Matile, commented that this genus shares with other genera of Leiinae, Thoracotropis and Sigmoleia, the presence of only two palpomeres. Nevertheless, he noted that the 
wings of Sigmoleia and Caledonileia are considerably different and that the number of ocelli is not the same in these two genera, the former with three, the latter with two. Matile (1993) also stressed that the wings of Thoracotropis and Caledonileia are relatively close and that both these two genera have two ocelli-information, as commented above, that was mistaken in Freeman's (1951) original description. Additionally, these three genera also share the loss of sc-r, a feature he recognized that is recurrent in the Mycetophilidae (Matile 1990), and could be misleading about the position of the genus.

Matile's (1993) conclusion is that an inference about the position of these genera would be premature before a phylogeny of the Leiinae. We hold here this position. A robust answer about the position of Thoracotropis is strictly dependent on recovering the Mycetophilidae phylogeny, defining the limits of the subfamilies. The problem of the monophyly of the Leiinae is being addressed in a phylogenetic study of the group (Oliveira \& Amorim, unpublished data) but the detailed redescription here of the genus, including photos and illustrations, corrects some mistakes in its original description, a necessary step towards the solution of the problem of the position of this genus.

\section{ACKNOWLEDGEMENTS}

We are deeply thankful to Erica McAlister for the access to the holotype. SSO has a FAPESP PhD fellowship (Grant \# 2008/52324-6); DSA has a research fellowship from the Brazilian National Science Research Agency, CNPq. The manuscript was benefited from the corrections of two anonymous referees and the editor Márcia Souto Couri. Thanks to all of them.

\section{REFERENCES}

Amorim, D. S. \& E. Rindal. 2007. A phylogenetic study of the Mycetophiliformia, with creation of the subfamilies Heterotrichinae, Ohakuneinae, and Chiletrichinae for the Rangomaramidae (Diptera, Bibionomorpha). Zootaxa 1535: 1-92.

Baxter, J. E. \& G. O. Poinar. 1994. A new genus and new species of fungus gnats (Diptera: Mycetophilidae) from Dominican amber. Annales de la Société entomologique de France 30: 93-102.

Chandler, P. J. 2009. The fungus gnats (Diptera: Bolitophilidae, Keroplatidae, Mycetophilidae) of Sardinia, with description of six new species. Zootaxa 2318: 450-506.

Edwards, F. W. 1925. British fungus-gnats (Diptera, Mycetophilidae). With a revised generic classification of the family. Transactions of the Entomological Society of London 1924: 505-670.
Freeman, P. 1951. Diptera of Patagonia and South Chile based mainly on material in the British Museum (Natural History). Part IIIMycetophilidae. London, British Museum (Natural History), vii+138 p.

Hackman, W.; P. Laštovka; L. Matile \& R. Väisanen. 1988. Mycetophilidae, p. 220-327. In: Á. Soós \& L. Papp (eds.). Catalogue of Palaearctic Diptera. Vol. 3. Ceratopogonidae - Mycetophilidae. Budapest, Akadémiai Kiadó, 448 p.

Hippa, H.; M. Jaschhof \& P. Vilkamaa. 2005. Phylogeny of the Manotinae, with a review of Eumanota Edwards, Paramanota Tuomikoski and Promanota Tuomikoski (Diptera, Mycetophilidae). Studia dipterologica 11: $405-428$.

Jaschhof, M. \& U. Kallweit. 2009. The Cycloneura Marshall group of genera in New Zealand (Diptera: Mycetophilidae: Leiini). Zootaxa 2090: 139.

Kurina, O. 2004. Notes on fungus gnats from the East Mediterranean with description of two new species (Diptera: Sciaroidea excl. Sciaridae). Beiträge zur Entomologie 54: 343-355.

Matile, L. 1990. Recherches sur la systématique et l'évolution des Keroplatidae (Diptera, Mycetophiloidea). Mémoires du Muséum National d'Histoire Naturelle 148: 1-682.

Matile, L. 1993. Dipteres Mycetophiloidea de Nouvelle-Caledonie. 5. Mycetophilidae Leiinae et Manotinae. In: L. Matile, J. Najt \& S. Tillier (eds.), Zoologia Neocaledonica, Volume 3. Memoires du Museum National d'Histoire Naturelle 157: 165-210.

Oliveira, S. S. 2009. Dziedzickia Johannsen e Schnusea Edwards (Diptera, Mycetophilidae): diversidade das espécies neotropicais e análise filogenética. Dissertação de mestrado. Ribeirão Preto, Universidade de São Paulo, v+145 p.

Oliveira, S. S. \& D. S. Amorim. 2012. Six new species of Paraleia Tonnoir (Diptera, Mycetophilidae): amphinotic elements at the northern range of the Andes. Zootaxa 3186: 1-24.

Rindal, E.; G. E. E. Søli \& L. Bachmann. 2009. Molecular phylogeny of the fungus gnat family Mycetophilidae (Diptera, Mycetophiliformia). Systematic Entomology 34: 524-532.

Søli, G. E. E. 1997. The adult morphology of Mycetophilidae (s. str.), with a tentative phylogeny of the family (Diptera, Sciaroidea). Entomologica Scandinavica Supplement 50: 5-55.

Søli, G. E. E.; J. R. Vockeroth \& L. Matile. 2000. A.4. Families of Sciaroidea, p. 50-92. In: L. Papp \& B. Darvas (eds.). Contributions to a Manual of Palaearctic (with Special Reference to Flies of Economic Importance). Appendix. Science Herald, Budapest. 604 p.

Tozoni, S. H. S. 1998. Sistemática filogenética dos Mycetophilidae (Diptera: Bibionomorpha). Tese de Doutorado, Curitiba, Universidade Federal do Paraná, p. 124.

Väisänen, R. 1984. A monograph of the genus Mycomya Rondani in the Holarctic region (Diptera, Mycetophilidae). Acta Zoologica Fennica 177: 1-346.

Väisänen, R. 1986. The delimitation of the Gnoristinae: criteria for the classification of recent European genera (Diptera, Mycetophilidae). Annales Zoologici Fennici 23: 197-206.

Vockeroth, J. R. 2009. Mycetophilidae (fungus gnats), p. 267-278. In: B. V. Brown; A. Borkent; J. M. Cumming; D. M. Wood; N. E. Woodley \& M. A. Zumbado (eds.), Manual of Central America Diptera. Vol. 1, Ottawa, National Research Council of Canada, 714 p. 